\title{
Culture and Diversity in the United States
}

So Many Ways to Be American

\section{Jack David Eller}

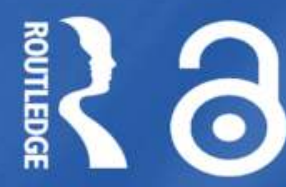




\section{Culture and Diversity in the United States}

“This comprehensive textbook provides a nuanced, sophisticated discussion of diversity, covering key concepts and historical context. It is excellent as a primary resource-very user-friendly with extensive use of demographics and liberal in-text citations. Particularly notable is the chapter on age, which is so often absent in textbooks. Desperately needed and highly recommended!"

Juliana McDonald, University of Kentucky, USA

Knowledge of and sensitivity toward diversity is an essential skill in the contemporary United States and the wider world. This book addresses the standard topics of race, ethnicity, class and gender but goes much further by engaging seriously with issues of language, religion, age, health and disability, and region and geography. It also considers the intersections between and the diversities within these categories. Eller presents students with an unprecedented combination of history, conceptual analysis, discussion of academic literature, and up-to-date statistics. The book includes a range of illustrations, figures and tables, text boxes, a glossary of key terms, and a comprehensive bibliography. Additional resources are provided via a companion website, www.routledge.com/cw/eller.

Jack David Eller is Associate Professor (Emeritus) of Anthropology at the Community College of Denver, USA. An experienced teacher, his publications include the major introductory textbook Cultural Anthropology: Global Forces, Local Lives (second edition, 2012), also available from Routledge. 
$\because$ Taylor \& Francis

Taylor \& Francis Group

http://taylorandfrancis.com 


\title{
Culture and Diversity in the United States
}

So Many Ways to Be American

\author{
Jack David Eller
}


First published 2015

by Routledge

2 Park Square, Milton Park, Abingdon, Oxon OX14 4RN

and by Routledge

52 Vanderbilt Avenue, New York, NY 10017

Routledge is an imprint of the Taylor \& Francis Group, an informa business

(C) 2015 Jack David Eller

The right of Jack David Eller to be identified as author of this work has been asserted by him in accordance with sections 77 and 78 of the Copyright, Designs and Patents Act 1988.

With the exception of Chapter 3, no part of this book may be reprinted or reproduced or utilised in any form or by any electronic, mechanical, or other means, now known or hereafter invented, including photocopying and recording, or in any information storage or retrieval system, without permission in writing from the publishers.

Chapter 3 of this book is available for free in PDF format as Open Access from the individual product page at www.routledge.com. It has been made available under a Creative Commons Attribution-Non Commercial-No Derivatives 4.0 license.

Trademark notice: Product or corporate names may be trademarks or registered trademarks, and are used only for identification and explanation without intent to infringe.

British Library Cataloguing-in-Publication Data

A catalogue record for this book is available from the British Library

Library of Congress Cataloging-in-Publication Data

Eller, Jack David, 1959-

Culture and diversity in the United States : so many ways to be American / Jack David Eller.

pages $\mathrm{cm}$

Includes bibliographical references.

1. Cultural pluralism-United States. 2. Multiculturalism-United States. 3. National characteristics, American. 4. United States-Ethnic relations. 5.

United States-Race relations. I. Title.

E184.A1E397 2015

305.800973 -dc23

2014042667

ISBN: 978-1-138-82668-7 (hbk)

ISBN: 978-1-138-82669-4 (pbk)

ISBN: 978-1-315-73912-0 (ebk)

Typeset in Sabon

by Swales \& Willis Ltd, Exeter, Devon, UK 


\section{Contents}

List of Images vi

List of Boxes, Figures and Tables ix

About This Book xii

1 Thinking about Diversity 1

2 Inter-Group Relations and the History of Diversity in the US 17

3 Race and Racial Thinking 36

4 Ethnicity: Beyond the Race Binary 62

5 Class $\quad 89$

6 Sex and Gender: Male and Female 111

7 Sex and Gender: Beyond the Gender Binary 137

8 Language 163

9 Religion 191

10 Age 218

11 Health and (Dis)ability 249

12 Region and Geography: The Spatial Distribution of Diversity 275

Glossary $\quad 311$

Bibliography $\quad 319$

Index 336 


\section{Images}

2.1 Portrait of a Native American man in Euro-American attire rather than traditional dress, c.1860s (Courtesy of the Library of Congress, Prints and Photographs Division)

2.2 "Landing of the Pilgrims at Plymouth" (Courtesy of the Library of Congress, Prints and Photographs Division)

2.3 Immigrants arriving at Ellis Island, New York Harbor, c.1904 (Courtesy of the Library of Congress, Prints and Photographs Division)

3.1 Slave sale in Charleston, South Carolina (Courtesy of the Library of Congress, Prints and Photographs Division)

3.2 The "Great Migration" to the North-Chicago, 1918 (Courtesy of Chicago History Museum/Getty Images)

3.3 Black Panther rally, Lincoln Memorial, 1970 (Courtesy of the Library of Congress, Prints and Photographs Division)

$3.4 \mathrm{Ku}$ Klux Klan parade held in Washington, DC, c.1926 (Courtesy of the Library of Congress, Prints and Photographs Division)

4.1 American Indian Movement sign and tipi in front of the Washington Monument during the "Longest Walk" in 1978, held to support tribal sovereignty and bring attention to anti-Indian legislation (Courtesy of the Library of Congress, Prints and Photographs Division)

4.2 US immigration officer watching cars entering El Paso, Texas, from Ciudad Juárez in Mexico, c.1964 (Courtesy of the Library of Congress, Prints and Photographs Division)

4.3 Entrance to Chinatown, San Francisco (Courtesy of Jeff Whyte/Shutterstock.com)

4.4 A Syrian restaurant in New York, 1910s (Courtesy of the Bain Collection, Library of Congress, Prints and Photographs Division)

5.1 A 1930s poster for the Works Progress Administration encouraging laborers to work for America (Courtesy of the Library of Congress, Prints and Photographs Division)

5.2 A homeless man sleeps on the streets in New York (Courtesy of ChameleonsEye/Shutterstock.com)

5.3 A Ferrari parked outside high-end stores on LA's Rodeo Drive (Photo by David McNew/Thinkstock by Getty Images) 
6.1 Suffrage campaign in New Jersey c.1915 (Courtesy of the Library of Congress, Prints and Photographs Division)

6.2 Two flappers doing the Charleston with US Capitol in background, 1920s (Courtesy of the Library of Congress, Prints and Photographs Division)

6.3 Yahoo CEO Marissa Mayer speaks onstage at the FORTUNE Most Powerful Women Summit, 2013 (Courtesy of Paul Morigi/Getty Images for FORTUNE)

6.4 Boy Scouts (Courtesy of the Bain Collection, Library of Congress, Prints and Photographs Division)

6.5 Contest at Muscle Beach in California, which dates back to the 1930s (Courtesy of the Jon B. Lovelace Collection of California Photographs in Carol M. Highsmith's America Project, Library of Congress, Prints and Photographs Division)

7.1 We-Wa, a Zuni "two-spirit" (Courtesy of the US National Archives and Records Administration, ID 523798)

7.2 A group outside the boarded-up Stonewall Inn, 1969 (Courtesy of Fred W. McDarrah/Getty Images)

7.3 Same-sex parents, Utah (Courtesy of George Frey/Getty Images)

7.4 Night of a Thousand Gowns, 2013 (Courtesy of Astrid Stawiarz/Getty Images)

8.1 Class at Carlisle Indian School, c.1901 (Courtesy of the Frances Benjamin Johnston Collection, Library of Congress, Prints and Photographs Division)

8.2 Arab American women sit in a classroom during a course in English as a Second Language at the Arab American Association of New York office in Bay Ridge, Brooklyn (Courtesy of Robert Nickelsberg/Getty Images)

8.3 Example of Mock Spanish (Courtesy of Jill Johnson/Fort Worth Star-Telegram/MCT via Getty Images)

9.1 Evangelical congregation in Boston (Courtesy of Melanie Stetson Freeman/The Christian Science Monitor via Getty Images)

9.2 George Whitefield, eighteenth-century illustration (Courtesy of the Library of Congress, Prints and Photographs Division)

9.3 A Jewish man on the subway in New York City (Courtesy of Andrey Bayda/Shutterstock.com)

9.4 Atheist billboard, New York City (Courtesy of Richard Levine/Alamy) 216

10.1 “Childhood's Happy Hours," illustration c.1873 (Courtesy of the Library of Congress, Prints and Photographs Division)

10.2 Teenagers dressed for their high school prom (Courtesy of Digital Vision/Thinkstock by Getty Images)

10.3 Retired couple, Florida (Courtesy of Edward Fielding/Shutterstock.com)

11.1 Obesity is on the rise in the United States (Courtesy of Jakub Cejpek/Shutterstock.com)

11.2 Paramedics attend to a man in Colorado (Courtesy of John Moore/Thinkstock by Getty Images) 
viii List of Images

11.3 The Deaf and Dumb Institute in Columbus, Ohio, c.1904 (Courtesy of the Library of Congress, Prints and Photographs Division)

12.1 2012 Presidential Election: Voters at polling station in Ventura County, California (Courtesy of American Spirit/Shutterstock.com) 276

12.2 SoHo lofts (Courtesy of the Carol M. Highsmith Archive, Library of Congress, Prints and Photographs Division)

12.3 Detroit, c.1910 (Courtesy of the Library of Congress, Prints and Photographs Division)

12.4 Pruitt-Igoe housing project being demolished, 1972 (Courtesy of Lee Balterman/The LIFE Images Collection/Getty Images) 


\section{Boxes, Figures and Tables}

\section{Boxes}

1.1 Barack Obama: Black, White, Both, or Neither 8

1.2 Erving Goffman on Stigma 14

2.1 Measuring "Social Distance" 25

2.2 The Visa System in the US 32

3.1 "Double-Consciousness" among African Americans 45

3.2 Critical Race Theory 53

4.1 Sherman Alexie on the Reservation 71

4.2 Diversity within Shi'ism in America 84

5.1 Surviving in a Poor Black Neighborhood: Carol Stack's All Our Kin 102

5.2 The New Rich: David Brooks on the "Bobos" 107

6.1 Women's Bodies and Morals in Early-Twentieth-Century America 117

6.2 Every Woman is Beautiful (or Better Be) 131

7.1 The "Two-Spirit" in Native American Culture 144

7.2 The Transvestite "Scenes" of New York 159

8.1 Basil Bernstein and the Two Codes of English 169

8.2 Language Assimilation: The Indian Boarding School 177

9.1 "Civil Religion" and Religious Legitimacy in the US 195

9.2 The Twelve Religious Tribes of America 213

10.1 Is Childhood Disappearing? 235

10.2 Numbering the Days in an Elderly Community 245

11.1 A Social Scientist Learns the Sick Role: Robert Murphy's Body

11.2 Is Deafness a Disability or a Culture? 270

12.1 A Case Study in Domination and Succession: Downtown Lofts 281

12.2 The Rise and Fall of an American Place: Pruitt-Igoe 304

\section{Figures}

2.1 US total and foreign-born population, 1850-2008 31

2.2 Foreign-born population as percentage of state population, $2010 \quad 32$

3.12010 Census questions on Hispanic origin and race 49

3.2 Number of sentenced prisoners (State and Federal) by race and
Hispanic origin, 2000-2009 
3.3 Rate of sentenced prisoners (State and Federal) per 100,000 population by race and Hispanic origin, 2000-2009

4.1 American Indian and Alaska Native as percentage of county population, 2010

4.2 Largest ancestries in the US by county, 2000

5.1 Median household income by race and Hispanic origin, 1967 to 2011

6.1 2010 Census questions on sex and age 112

6.2 The components of sex/gender 114

6.3 US population pyramid, 2000 and $2010 \quad 119$

$\begin{array}{ll}6.4 & \text { Sex ratio by county, } 2010 \\ 7.120\end{array}$

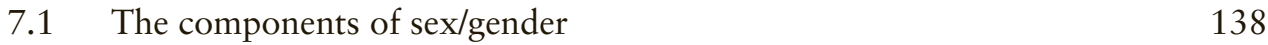

7.2 Fluid-continuum model of sexual orientation 148

8.1 2011 American Community Survey questions on language 172

8.2 Geographical distribution of population speaking a language other than English at home, 2009

$\begin{array}{lll}8.3 & \text { The Cherokee Syllabary } & 176\end{array}$

9.1 Estimated Jewish population in the US by county, 2011208

10.1 US population pyramid: 2010 and $2000 \quad 221$

10.2a US population pyramid: 2000 (actual) 222

10.2b US population pyramid: 2025 (projected) 222

10.2c US population pyramid: 2050 (projected) 223

10.3 Population pyramid for Italy: 2025 (projected) 223

10.4 Population pyramid for Mexico: 2025 (projected) 224

10.5 Age distribution and median age in US, 1960-2010 231

10.6 Median age by state, $2010 \quad 232$

10.7a Percentage of population age 65 and over by state, 2010243

$10.7 \mathrm{~b}$ Percentage of population age 65 and over by county, $2010 \quad 244$

11.1 Age-adjusted death rate by state, $2010 \quad 260$

11.2 Life expectancy at birth by race and Hispanic origin 262

11.3 Rates of primary and secondary syphilis by race/ethnicity
and sex, 2010

11.4 Rates of gonorrhea by race/ethnicity and sex, $2010 \quad 265$

12.1 Electoral College results for 2012 Presidential Election by state 275

12.2 The spatial distribution of health: Tuberculosis rate (per 100,000 $\begin{array}{ll}\text { population) by state, } 2009 & 279\end{array}$

12.3 Population density by county, $2010 \quad 288$

12.4 Sex ratio (males to females) by county, $2010 \quad 289$

12.5 Regions and sub-regions in the United States 290

12.6 Garreau's nine nations of North America 292

12.7 Lieske's eleven subcultural regions of the United States 293

12.8 Rate of net migration (per 100,000 population) by metropolitan
and micropolitan statistical area, 2010 to 2011

12.9 Reasons for moving, 1999 to $2013 \quad 296$

12.10 Black or African American population as a percentage of
county population, 2010

12.11 Hispanic or Latino population as a percentage of total
population by county, 2010 
12.12 Median household income by county, 2012

12.13 Percentage of population living in poverty by county, 2012

\section{Tables}

2.1 US immigration totals by decade, 1820-1969 28

2.2 Foreign-born population by region of birth, $2010 \quad 31$

3.1 Lynching victims by race and region, 1889-1918 43

3.2 US population by race and Hispanic origin, $2010 \quad 50$

3.3 Imprisonment rate (State and Federal) of males by race, 2011

4.1 Race or ethnicity in the US?, 2010

4.2 Largest American Indian and Alaska Native tribal groupings, $2010 \quad 71$

4.3 Hispanic American population by country of origin, $2010 \quad 74$

4.4 Asian American population by country of origin, 2010 77

4.5 Top ten countries of origin for foreign-born American population, 1990-2008

4.6 Population of Arab Americans by country of origin (of those claiming a single Arab ancestry), $2000 \quad 82$

4.7 Fifteen largest national ancestries in the US, $2000 \quad 85$

5.1 GNP per capita for ten richest and ten poorest countries 93

5.2 Distribution of household money income by quintile, 2011

5.3 Household income by selected social characteristics, 201197

8.1 Most commonly spoken non-English languages in the US, $2009 \quad 173$

8.2 Language spoken at home other than English and English-speaking ability, $2007 \quad 174$

8.3 Most commonly spoken Native North American languages 179

9.1 The Christian population of the US 197

9.2 The non-Christian population of the US 197

9.3 Political style and party identification by religion 213

10.1 Infant mortality, 2013 estimated 220

$\begin{array}{ll}10.2 & \text { Life expectancy, } 2013 \text { estimated } 220\end{array}$

10.3 American population by various age increments and sex 230

10.4 American population by various age increments and race/ethnicity, in thousands

10.5 Comparison between seven twentieth-century generations 247

11.1 Top five causes of death by age, $2010 \quad 259$

11.2 Top ten causes of death by race and ethnicity, 2010263

11.3 Healthy weight, obesity, and Grade 3 obesity by gender, race/ethnicity, and poverty level (age 20 to 74 ) as percentage of population, 1988 to $2010 \quad 267$

11.4 Disabled Americans by type and severity of disability, $2010 \quad 271$

12.1 Mobility of American population by distance moved, 2012 to $2013 \quad 294$

12.2 Crime rates by region, 2011 


\section{About This Book}

People are different ... and there is much to learn from our differences. Because there are so many human possibilities worth exploring, we neither expect nor desire that every person or every society should converge on a single mode of life.

(Appiah 2006: xv)

The United States is self-conscious of, usually proud of, but occasionally ambivalent about its diversity. It knows that it is an immigrant society, and one of its greatest monuments proclaims its welcome to anyone yearning to breathe free, even as it struggles with present-day immigration and perceived threats to its economy and culture.

Because diversity is such an obvious and important issue, there are many courses and textbooks on the subject. Most focus on the "big three" topics of race/ethnicity, class, and gender, which are certainly worthy of attention. However, the United States, like all societies, contains many more dimensions of diversity than those three (or four), and at least two of those major topics-class and gender-are not exclusively related to immigration.

This new text examines additional angles of American diversity, including sexuality, religion, language, age and generation, health and (dis)ability, and geography and region. A few other books mention some of these subjects, but none offer the combination of statistical data, conceptual analysis, historical background, crosscultural comparison, and classic and contemporary literature found in these pages. Further, not only the social construction of diversity categories but also the interaction of social and physical characteristics-the socialization of the physical and the physicalization of the social-are among its main themes. The text also describes the diversity within diversity categories, for example the differences within the category "Hispanic Americans" between Mexican Americans, Cuban Americans, and Puerto Ricans or within the category "nonheterosexuals" between gay men, lesbian women, and bisexuals. Finally and quite uniquely, there is a sustained focus on "intersectionality" or how the various categories of diversity interact with each other and are distributed across the American landscape to create an indefinite array of distinct social positions and experiences.

The first chapter presents some new ways to think about diversity, challenging the very notion of "categories" and suggesting a more fluid and composite quality to identity. The second chapter, building on Fredrik Barth's famous inquiry into groups 
and boundaries, discusses the variety of boundaries and relations between groups as well as the plural forms of multiculturalism (or, in some instances, anti-multiculturalism). At that point, the reader is ready for an odyssey through all of the most important variables of American diversity past and present. Nor do the chapters only concentrate on the "marginal" groups or categories in the United States; for instance, in the presentation on "class," not only "the poor" or "the lower class" receive attention but also "the rich" and "the middle class." Likewise, the section on gender regards masculinity every bit as socially constructed as femininity, the chapter on ethnicity does not forget the "white ethnics," and the discussion on age includes "childhood," "adolescence," and "middle age" along with old age.

Each chapter opens with a short vignette and a question. It then proceeds through conceptual investigation, identifying the key categories and plotting their historical invention and change in the United States while contrasting them to other societies. Each chapter provides statistical information in narrative and tabular (and often map) form, features two boxes for deeper discussion, and includes several short boxed "diversity facts." The text is followed by a comprehensive glossary.

The approach is distinctly interdisciplinary, drawing from sociology and anthropology, psychology and history, political science, legal studies, and academic and popular literature. Much of the data come from the US Census, but other sources include the Centers for Disease Control, the Pew Research Center, the Barna Group, the American Religious Identification Survey, the Anti-Defamation League, the Arab American National Museum, and many more. Where there are contrasting and even contradictory perspectives on groups and categories, those perspectives are allowed to stand, as part of the tapestry of American diversity.

An awareness of and sensitivity to diversity in American society is a valid academic exercise, but it is also a matter of great practical importance. In 1994 the Office of Special Education Programs in the United States declared that one of its "strategic targets" was "valuing and addressing diversity" which would contribute to "equitable outcomes" and "the identification and provision of services that are responsive to issues of race, culture, gender, and social and economic status." And government has not been alone in appreciating the benefits of what is often called "cultural competence," or the ability to interact successfully with people of diverse race, ethnicity, gender, class, religion, language, (dis)ability, and region. Many corporations have heeded the call of diversity: "Recruiting, retaining, and promoting diverse employees are critical to a corporation's success in this evolving marketplace," according to Marcus Robinson, Charles Pfeffer, and Joan Buccigrossi's 2003 "Business Case for Inclusion and Engagement," not to mention serving such diverse customers and clients as women, gays and lesbians, the elderly, and people with disabilities. Some professions, like social work, actually develop and promote their own standards of cultural competence, and most professions grasp the importance of diversity in their work.

In the end, as Kwame Anthony Appiah stated in the opening quotation, it is simply interesting to realize how different Americans and "the American experience" can be and how much we can learn from this realization. Among the most valuable lessons to be learned is each one of us is diverse-is a "minority" in multiple ways-and that the same respect we demand for ourselves is owed to others. 
xiv About This Book

\section{Companion Website}

Additional resources to accompany the book are available at: www.routledge.com/ cw/eller.

This includes:

- Glossary flashcards.

- Full color maps, including additional linguistic maps not included in the book.

- Annotated suggestions for further reading.

- Links to useful web resources.

- Links to relevant audio-visual material.

- $\quad$ Test questions (multiple choice and true or false). 


\section{Thinking About Diversity}

What is an American? According to the 2010 Census:

63.7 percent White non-Hispanic, 12.6 percent Black, 16.3 percent Hispanic, 4.8 percent Asian, 0.9 percent Native American, 0.2 percent Native Hawaiian/Pacific Islander

97.1 percent mono-racial, 2.9 percent two or more races

50.8 percent female, 49.2 percent male

24 percent under age 18, 63 percent age 18 to 64, 13 percent age 65 or over

15 percent living in poverty

78.4 percent Christian, 1.7 percent Jewish, 0.7 percent Buddhist, 0.6 percent Muslim, 0.4 percent Hindu, 16.1 percent no religion ${ }^{1}$

18 percent residing in Northeast, 21.7 percent residing in Midwest, 37.1 percent residing in South, 23.3 percent residing in West

18.7 percent physically disabled (including 3.3 percent visually impaired and 3.1 percent hearing impaired), 20 percent mentally ill ${ }^{2}$

80 percent English-speaking, 12.4 percent Spanish-speaking, 0.9 percent Chinesespeaking, 0.5 percent Tagalog-speaking, 0.4 percent Vietnamese-speaking

What then is an American? Even worse, what is a "normal" American or an "average" American? Is there any such thing?

In some ways, you are like all other individuals.

In some ways, you are like no other individuals.

In some ways, you are like some other individuals but unlike others.

Humans are a polymorphic species-that is, we come in many forms. As a species, humanity is less polymorphic than some (there is much greater physical variety among dogs than among humans, for example: imagine if humans occurred in a comparable range of shapes, sizes, and colors) but more polymorphic than others. And in addition 


\section{Thinking About Diversity}

to the physical diversity of humans is the "cultural" or learned behavioral diversity, which often makes even physically similar humans exotic and incomprehensibleand sometimes intolerable-to one another.

The characteristics that all human individuals share unite us as a species. The characteristics that no human individual shares with any other (if there are any such) make each person unique. The characteristics that some human individuals share with some other humans divide us into varied and often ranked groups and categories, for instance "societies" or "peoples" or "nations." This diversity of traits not only affects our identity and our life-quality and life-chances but more than occasionally pits us against each other as members of rival collectivities and communities.

The question of "universal" and "unique" qualities is a valid one and a subject for other studies. This book, however, focuses on the partially and differentially shared qualities, the ones that (perhaps ironically) unite us differentially-that is, join or have the potential to join us with some people but not others. This is especially critical in the society called the United States of America, among the people known as Americans, who are fantastically, dazzlingly, some would say unmanageably diverse. While Americans claim to be, or at least aspire to be, one nation-to bridge or meld differences, to blend the many into one (an early motto of the United States was e pluribus unum, "out of many, one")—the American people contain incredible and often unmeldable diversity. In other words, differences will not and cannot go away, nor will they likely cease to make a difference: women are not men, the old are not young, the poor are not rich, the white are not black, the Christian are not Muslim, and so on. No doubt there are things that American women and men share, or American rich and poor, or American whites and blacks, or American Christians and Muslims-or American able-bodied and disabled or American urbanites and rural-dwellers, ad infinitum. However, the group differences are there too, they are real, and in some instances they are crucial.

\section{Diversity: Cultural and Physical}

Charles Darwin's most fundamental and most important insight was that diversity is natural and even necessary or beneficial in any population. Before his time, and commonly enough since, the idea has reigned that there is a single basic typeperhaps imaginary, perhaps real-that characterizes a group or population. One of the most obvious and odd instances of such thinking happens in the question of "race" (Chapter 3), where, for instance, the "white" or "Caucasian" race has sometimes literally been imagined as possessing blond hair and blue eyes, while many "whites" (myself included) are not blond or blue-eyed. The "blond beast" view of Caucasian race identity emphasizes an extreme or ideal trait set but by no means actually describes all the members of the category. The reality is a range of differing traits.

In this idealist perspective (or what some have called essentialism), one point on the spectrum of population traits is the ideal or essential point, inherently and immutably separated from all others. White Americans would thus have some essential quality of "whiteness" that is manifested in physiological traits like blue eyes and blond hair. In such a view, difference-within the group and certainly between groups-is not so much diversity as deviance, inferiority, or even evil. However, what Darwin showed is that variety within a population and between populations is the rule rather than the 
exception: there is always a range of traits in any group, and no single point along that range is the "real" or "normal" one. In a critical sense, the reality is diversity.

Commonly when people hear the word "diversity" or "difference" they think automatically of "culture." To be sure, Americans and all human groups differ culturally. "Culture" is an important and powerful term in contemporary scholarship and politics; not only do academic disciplines like anthropology and sociology discuss it, but an entire field of "cultural studies" has emerged recently to investigate it. Even more, the general public has embraced the term, and political groups and movements often form around culture for the purposes of defending or promoting culture, especially but not exclusively "ethnic" group and movements.

Culture is thus a significant concept for understanding group characteristics. We can think of culture as the learned and shared ways of thinking, feeling, and acting within a group, particularly the kind of group that we call a society. Culture is acquired through social interaction, not innate or inborn. Certainly the capacity to acquire culture depends on the natural/physical characteristics of human beings, including the human brain. But no particular culture is programmed into all or any human brains: it is untrue that Americans are born to speak English or Mexicans Spanish or Russians Russian. Through the process of enculturation, namely life-long interaction with other competent members of a group, an individual can acquire any culture to which s/he is exposed. An individual can even learn aspects of a second or third culture; if not, then anthropology and sociology, indeed any intercultural communication, would be impossible, since these disciplines entail learning about someone else's culture.

Further, culture is shared or distributed among a collectivity of humans. Obviously, something cannot be learned unless there is someone else to learn it from. When an infant enters the world, s/he lacks cultural knowledge and skill, but other people in the environment "have" it or "do" it. As the child grows, s/he acquires cultural competence through observation and practice. However, while it is accurate and important to say that culture is shared, it need not be and generally is not shared evenly or universally within the group. Some individuals will have access to certain aspects of the group's cultural heritage but not other aspects. The group may have different cultural expectations for different kinds of members (e.g. male or female, young or old, tall or short, rich or poor, etc.). And some individuals may become "experts" or "professionals" in particular areas of culture while other individuals possess only "amateur" or rudimentary knowledge or skill or no knowledge/skill at all.

So, as with physical traits, there will be a range or distribution of culture within a group or society. In an English-speaking society, there are those who speak English differently from each other (based, for instance, on region or class or age or education), not to mention those who speak other minority languages; in a Christiandominant society, there are those who hold different beliefs and interpretations about Christianity (based, for instance, on sect or denomination or liberal/fundamentalist orientation or upbringing or interest), not to mention those who belong to other minority religions or no religion at all.

Culture should thus be seen as integrated or composed of multiple parts in complex interrelation. A culture is not a single monolithic "thing" but a system of (more or less) connected elements or functions. Anthropologists commonly envision the main areas of culture as economics, politics, kinship, and religion, while sociologists add a fifth in the form of education. Each of these systems actually consists of a number of 
subsystems or institutions (for instance, kinship includes elements of marriage, residence, and descent). Additionally, cultural factors and practices like language and gender permeate the various systems and institutions. The integrated quality of culture demands a holistic approach to culture, noting the influence of each part on every other part. We cannot hope to understand any aspect of culture in isolation, nor can we expect to add or subtract or modify one aspect without consequences for other aspects.

Sociology in particular has a number of useful ways for conceiving the internal complexity of culture and the group that bears it. Any society contains a variety of "positions," each of which is deemed a status. For example, American society includes the status of "teacher" and "student," or of "husband" and "wife," or formerly of "slave" and "master" (notice that statuses tend to occur in pairs or sets, since they are nodes in social relationships). Different behaviors-and often different kinds and degrees of social knowledge, even of personality traits-are expected of occupants of different statuses: each status then is associated with a particular social role. In every society, even the smallest and simplest, therefore, it is not only common but necessary that individuals occupy varying social statuses and perform varying social roles; there is no actual or even imaginable society in which every individual knows and does exactly the same things.

Beyond the basic and unavoidable variation within any group, there is always the possibility of serious and sometimes intentional exception, even resistance, to social norms and expectations. There really is, for instance, such a thing as deviance (although what is "deviant" will depend on the norms of the society and of the moment: slavery is deviant in America today but was normal and legal in the past). Deviance can be individual or collective: social scientists often regard gangs as deviant groups. People can also band together on the basis of interests or values to form a subculture, with its own (sometimes minor, sometimes major) deviations from mainstream culture; examples might include Goth culture or skateboard culture or "vampire" culture in the United States. People might actually organize to oppose aspects of mainstream culture, constituting a counterculture like the "hippie" lifestyle of the 1960s. And, of course, groups might be specifically designed to change certain aspects of the dominant culture, often taking the form of a social movement such as religious fundamentalism (Chapter 9), the civil rights movement (Chapter 3), the gay and lesbian rights movement (Chapter 7), the disabled rights movement (Chapter 11), and many others.

Two last things must be said about culture. First, all social scientists insist that culture is symbolic or embodied in symbols. A symbol is anything (word, object, image, gesture, etc.) that "stands for" or "represents" something-something, that is, that conveys information or meaning other than itself. As the anthropologist Clifford Geertz expressed it, symbols are "tangible formulations of notions, abstractions from experience fixed in perceptible forms, concrete embodiments of ideas, attitudes, judgments, longings, or beliefs" (1973: 91). The key words here are "attitudes" and "judgments," although it is also necessary to situate these attitudes and judgments in relation to individual and collective "beliefs" (things that are held as true) and "longings" (things that are held as valuable and desirable). In every human group and society, actions, objects, words, styles, and even physical traits potentially have more social significance than their mere existence suggests. Humans are inveterate classifiers and valuers, passing judgment on and adding associations to cultural and physical phenomena, holding them up (and frequently enough smashing them) against their 
beliefs and longings. We must, and we will later in this chapter and throughout this book, keep an eye on the symbolic social meaning and value of human differences, not merely on the differences themselves.

Second, culture circulates. The diverse and distributed elements of a culture do not necessarily stay "in their place." Sociology and anthropology have conventionally conceived of a society as a collectivity of humans who tend to interact and intermarry among themselves, who occupy a territory, and who share a common identity and a worldview or culture. But societies are not always-and in today's world are increasingly not at all-discrete entities. With migration and forced resettlement of populations, members of a society may be and often are strewn across the globe, living in circumstances from refugee status to diaspora or dispersion from their homeland while retaining memories of and attachments to that home. Even more, with modern communication and transportation technologies, bits of culture become detached from particular places and groups and flow across social boundaries, potentially and actually to the entire world. As part of the process known as globalization, cultural items travel and mix and blend in interesting and unprecedented ways, such that it often becomes impossible, if not futile to identify some bit of culture as belonging exclusively to this group or that group. As a result, individuals in far-flung locations are increasingly similar to each other in certain cultural ways, even as they retain their "own" cultures and re-interpret the "foreign" cultures they meet in their own way.

In other words, we can no longer maintain the simple notion that $a$ society has $a$ culture. Culture is neither spatially/geographically homogeneous nor contained: there are differences within groups and similarities between groups. Culture and the identities and interests that go with it are increasingly translocal, referring to more than one place. Ultimately, it may be possible or sensible to speak of "American society" (and then again it may not), but it is ever more difficult to speak of a single "American culture" as something that unites all Americans and sets them apart from all non-Americans.

\section{The Diversity of Diversity}

Whatever "American culture" may be, it is apparent that there is considerable, occasionally extreme, cultural and physical variation among Americans. It might be fair to say that diversity is the nature of America. Most treatments of diversity, unsurprisingly, tend to focus on a few dimensions of diversity, especially race, ethnicity, class, and gender. These are, to be sure, real and important aspects of human, and American, variety, but they are hardly the full extent of it.

Americans, like all humans, are not only diverse but diverse in diverse ways; in other words, there are multiple simultaneous variables of diversity. Each American individual can be identified simultaneously by

- race

- ethnicity and/or ancestry

- class and occupation

- gender

- language

- religion

- $\quad$ age or generational category 
- $\quad$ health and (dis)ability

- geographic/regional location.

Thus, each individual represents a particular intersection of manifold social characteristics and statuses, that is, occupies a particular set of statuses. One of these multifarious statuses may be the key one for any given individual or in any given society or social situation-what sociologists call a master status - which most strongly determines his/ her social identity and social opportunities. I myself am a white, middle-class, male, English-speaking, middle-aged, suburban, married, normally-abled college professor, although I am not sure which of these qualities I would consider my master status: one person with my status set might take white as his master status, while another might take male and another English-speaking. Of course, in some societies it is more clearly dictated which statuses have most significance, as with the black/white racial distinction during America's slavery period.

We can think of each of these major terms (race, gender, class, etc.) as a statusdomain, consisting of a socially-available and salient system of alternatives or specific statuses. That is to say, in America, for instance, there is a specific and limited number of "races" to be, "classes" to be, "genders" to be, languages to speak, religions to follow, and so on (sometimes as few as two but often many more). However, these possible statuses are not necessarily mutually exclusive: one individual can belong to or descend from two or more races, speak two or more languages, work two or more jobs, perhaps even observe two or more religions. Thus, we cannot always situate an individual unambiguously in one and only one status in each of these status-domains.

Furthermore, an individual is not an entirely consistent or immutable social actor. Social scientists stress that any society is comprised of numerous socially-defined situations or contexts or "frames." In each frame, different behaviors are appropriate, and different statuses are highlighted. For example, I am a college teacher, but I am not always in the situation of teaching college courses; sometimes I am in the situation of being a guest at a party, or of being a husband, or of being a friend, and so on. When I am occupying the "teaching frame" and performing the role of teacher, I comport myself in certain ways in terms of dress, speech style, even posture and body language. At a party or interacting with my wife, I dress and speak and pose differently. If a person were to cross his or her frame-specific behaviors-say, act like a spouse toward students or like a teacher toward a spouse-the social inappropriateness would be palpable and serious. So each individual in a society must be a master of multiple social scenes and styles, knowing when and how to perform them. Some scholars go so far as to assert that the individual or the "self" is not a singularity but a plurality-that, in the words of the psychologist Paul Bloom, "within each brain, different selves are continually popping in and out of existence. They have different desires, and they fight for control-bargaining with, deceiving, and plotting against one another" (2008: 92). Whether this is entirely true, the point is that diversity is a much more complex and diverse matter than many people perceive.

\section{Categories, Continuums, and Composites}

The multiplicity of variables involved in the description of any particular human, American or otherwise (his/her race, gender, language, class, and so on), together 
with the very real possibility of occupying two or more "positions" for any specific variable (mixed race, bilingual, etc.) while inhabiting varying circumstances or social frames, makes the division of people into simple groups and types quite unlikely. If diversity is one reality in human and American existence, then ambiguity or multiplicity may be another.

It is a habit of American culture, and generally of Western civilization, to classify things, to try to assign phenomena to classes or categories. As a technical term, sociology uses the word category to refer to a set of humans who share some specified characteristic, physical (like blond hair) or social (like occupation), whether or not the members of the category identify themselves as such or interact with each as such; in fact, ordinarily people in a category do not engage in significant interaction with others on the basis of category membership. In this sense, a category is a passive or potential group but not a functional one.

Human beings certainly can be sorted into categories, some meaningful, some not. But the practice of categorizing the variables of human diversity, especially in American experience, tends to have an additional and problematic quality. In what we will call categorial thinking, the idea is that humans (or anything else) can be divided into a finite set of discrete and non-overlapping categories, sometimes as few as two, without exception or with nothing in between. A category then is like a box or slot or bucket into which individuals can be placed; the most concrete expression of this line of thinking is categories in a census, in which the person must select one of the available alternatives. The clearest example is gender, where most Americans would insist that there are obviously two genders, male and female, and that every individual falls unambiguously into one or the other. Race is another such categorial domain: there are two, or three, or four, or however many distinct races, and a person belongs in or to one of them. Likewise with age, Americans tend to divide the life-cycle into divergent age categories (infancy, childhood, adolescence, adulthood, middle age, etc.) and age cohorts into separate and even named categories (baby boomer, generation $\mathrm{X}$, and such).

There are two glaring problems with categorial thinking. First, in many statusdomains, it is not even certain how many categorial options there are. Gender seems fairly simple at two (although, as we will see below and in Chapters 6 and 7, matters are not nearly so simple), but race is obviously trickier. How many races are there? Some race systems have included as few as two alternatives, some as many as eight or nine. In other areas, the entire practice of creating categories becomes a muddle: how many classes, ages, religions, languages, or geographic regions are there? And what are the criteria and cut-offs, that is, what makes someone "an adult" as opposed to "a minor" or "middle class" as opposed to "upper class"?

Second, as we have already indicated, these alleged categories are not mutually exclusive: a person can be bi/multiracial, bi/multilingual, bisexual, bi/multi-religious, and so on. We could create new categories for these "exceptions," but how many categories would we need now and how meaningful would they be? We could establish a single category for "biracial" people, or we could establish several categories for "white-black" and "white-Asian" and "black-Asian" and "Asian-Native American" (not to mention people of three or four or more races). The "black" golfer Tiger Woods famously coined a new term for himself, Cablinasian (Caucasian, black, Indian/Native American, and Asian) to express his blended racial origins. Or we 
could, as some have done in American history, regard these bi- and multiracial people as exceptions, as corruptions, as "half-breeds" and "mixed-bloods," products of miscegenation or bad race mixing.

\section{Box 1.1 Barack Obama: Black, White, Both, or Neither}

The United States recently elected its first black president—or did it? According to Jesse Washington (2008), a journalist with the Associated Press, many Americans insist that Obama is "actually not black." Writes Washington:

"Debate over whether to call this son of a white Kansan and a black Kenyan biracial, African American, mixed-race, half-and-half, multiracial—or, in Obama's own words, a 'mutt'-has reached a crescendo since Obama's election shattered assumptions about race.

"Obama has said, 'I identify as African-American-that's how I'm treated and that's how I'm viewed. I'm proud of it.' In other words, the world gave Obama no choice but to be black, and he was happy to oblige.

"Intermarriage and the decline of racism are dissolving ancient definitions. The candidate Obama, in achieving what many thought impossible, was treated differently from previous black generations. And many white and mixed-race people now view President-elect Obama as something other than black.

"So what now for racial categories born of a time when those from far-off lands were property rather than people, or enemy instead of family?

“'They're falling apart,' said Marty Favor, a Dartmouth professor of African and African-American studies and author of the book Authentic Blackness...

"'We are in a transitional period' regarding these labels, [John] McWhorter [of the Manhattan Institute's Center for Race and Ethnicity] said. 'I think that in only twenty years, the notion that there are white people and there are black people and anyone in between has some explaining to do and an identity to come up with, that will all seem very old-fashioned.'”

An alternative to categorial thinking, one that provides for more degrees of diversity, is the concept of a continuum. In the continuum approach, diversity is "analog" rather than "digital," falling along a range of gradual variation instead of a finite set of strict distinctions. Along the continuum are positions "in between" familiar and supposedly absolute statuses like "black" and "white"; it would even be possible to be neither black nor white but "nearer" black than white or white than black.

While continuum thinking does open greater freedom in conceiving human diversity, it also poses its own challenges. The main problem is trying to place statuses relative to each other, especially trying to decide what goes between what; indeed, continuum thinking can lead to its own absurdities. As we will note in Chapter 3, Johann Friedrich Blumenbach in the eighteenth century proposed a continuum of races with white at the center and with black and Asian at opposite ends of the spectrum; other races then were intermediate between these key nodes-Native Americans between Caucasians and Asians, and Malayans between Caucasians and Africans. This analysis is not only ridiculous; it is literally without sense. 
While there might be a certain utility in viewing the life-cycle or class differences as a continuum which we can divide into multiple stages or levels (but still, which ones, how many, and at what points on the spectrum?), there is much less benefit and meaning in trying to impose this attitude on status-domains like gender or language or religion or health and (dis)ability or geography/region. If we reinterpret homosexuality, for instance, as a distinct gender, does it go between male and female, and does that have any meaning whatsoever? Should male homosexuality and female lesbianism be on the same location or separate locations? How would languages or religions fit on a spectrum at all? And while there might be a shading from "urban" to "suburban" to "rural," is there an order in which to arrange North, South, Midwest, and West-if those are the relevant variables in the first place (see Chapter 12)?

I want to propose a third way of organizing difference, beyond the categorial and continuum approaches. Let us call it the compositional model. As a number of scholars have discovered about a wide assortment of subjects, phenomena which we are accustomed to viewing as unitary are really a composite of plural elements or bits or building blocks. The human brain is a perfect illustration of this composite phenomenon: the brain is not a single homogeneous organ but a combination of many different specialized regions and sub-organs, each with its own (although not completely unalterable) function. One part of the cortex seems to control speech, and in fact the speech center(s) actually control separable activities, like speech comprehension and speech production (i.e., actually moving the lips and tongue). Other parts specialize in vision or muscle activity or abstract thought. Set within the brain are tissues like the amygdala and the hypothalamus and the hippocampus, regulating emotion, body temperature/hunger/thirst/sleep, and memory, respectively. Even lower areas like the cerebellum and brain stem control basic body functions like breathing and heartbeat.

In the social and psychological realm, a classic illustration of compositional thinking is Howard Gardner's research on intelligence. Typically, we imagine intelligence to be a single universal ability or skill, which you either have or you don't, which applies to every aspect of your behavior, and which can be quantified through intelligence tests. In his influential 1983 book Frames of Mind Gardner argued that intelligence is not a single but a plural capacity, that there are multiple "intelligences" that can be quite independent of each other. Intelligence thus is really a bundle of different intelligences, seven in his initial analysis (linguistic, musical, logico-mathematical, spatial, bodily-kinesthetic, interpersonal, and intrapersonal) to which he added two more in later versions (naturalist and existentialist). As experience all too clearly shows, a person might be gifted in music or language but quite hopeless in dance or social relationships, so treating intelligence as a single "thing" misses and mismeasures it totally.

Compositional thinking can be easily and profitably applied to diversity and statusdomains as well. Let us take race as an example. At the outset we stated that humanity is a polymorphous species, coming in many different forms. Some of these forms have been dubbed races. However, a race is not a single homogeneous "thing" but rather a constellation of traits, including skin color, hair color and texture, facial features (of which there are several, like eye and nose shape), and others. On the basis of what geneticists call the law of independent assortment, each of these traits can be transmitted and inherited independently: an individual or group could have dark skin but straight wavy hair-as some Australian Aboriginal populations actually do. Further, each trait is really a spectrum of traits, that is, each type is actually polytypic: humans do not really come in just two colors, black and white, and skin color runs along a 
spectrum of shades and gradations. The genetic basis for this fact is that such major physical characteristics are ultimately the product of more than one gene (i.e., polygenetic), and these various genes can interact in numerous ways to generate an array of physical appearances.

We are accustomed to thinking of a race as a particular bundle of physical features (light skin, straight hair, and narrow nose, for instance), but this is ultimately nothing more than a particular historical agglomeration of discrete traits; a different history might have resulted in the agglomeration of dark skin, straight hair, and narrow nose. Because human populations, especially at great distances from each other, were formerly relatively isolated and thus genetically "closed" (that is, could not interbreed), each population tended to converge on a "type" which was nothing but a particular compound of inherited qualities. But once far-flung populations began to mix genetically, these compounds that we call "races" were able to dissolve into their constituent parts and re-assemble in new mixtures, giving us Americans with dark skin and narrow noses.

The same process occurs in all domains of diversity. A language like English is a composite of many linguistic sources-Latin and Greek, Germanic languages, Native American, African, Asian, and many others. Words, phrases, styles, and such can pass into English from other languages and out of English into other languages. Religions are composite entities, drawing from many different springs: Christianity is certainly a blend of Judaic beliefs, Greco-Roman ideas, pre-Christian/pagan practices, and many other streams. Once formed, Christianity could meet and mix with other traditions, producing Mexican curanderas or spirit-healers, Haitian voodoo priests and priestesses, Brazilian candomblé, and the like. Elements from other religions (like Islam or Buddhism) can flow into Christianity and vice versa, as well as elements from non-religious sources like science, psychology, and popular culture. This is what we mean when we say that culture circulates: not only do complexes like a religion or a race move as a whole, but the individual constituent parts of such cultural "molecules" dissociate in their constituent "atoms" and travel independently of each other, re-combining in novel and unprecedented compounds that defy previously existing concepts and categories.

Even gender can be deconstructed into more basic components (see Chapter 7). While one variable in gender is the gendered body (specifically, the genitals), other variables include sexual preference, sexual identity, sex roles, sexual expression, and so on, each of which can vary independently. So, from the most "physical" to the most "cultural" areas of human existence, diversity is complicated, transient, and mutable, producing ever-new-and-shifting forms.

Finally but crucially, like any chemical compound in the bloodstream, statusdomains can and do interact in unpredictable but socially significant ways. Kimberlé Crenshaw $(1989 ; 1991)$ is credited with the influential term "intersectionality" for this overlooked effect. A legal scholar, Crenshaw used the term intersectionality to critique "the tendency to treat race and gender as mutually exclusive categories of experience and analysis" (1989: 139). In particular, when the experiences and legal issues of black women were considered through the lens of race, then the gender angle was lost, and when they were considered through the lens of gender, the race dimension was ignored. Crenshaw insisted that "black woman" was an integral intersection of race and gender that demanded treatment as an integrated whole. Legally and socially, since both black and female are statuses of subordination, Crenshaw argued that "minority women suffer from the effects of multiple subordination, coupled with institutional expectations based on inappropriate nonintersectional contexts" (1991: 1251). 
As Leslie McCall recently reminded us, there is no reason why intersectionality should be restricted to race and gender, since it refers more generally to "the relationships among multiple dimensions and modalities of social relations and subject formations" (2005: 1771). That is, intersectionality is not specific to race and gender: important intersections occur between class and language, between sexuality and politics, between religion and region, and so on. More, intersectionality is not inherently binary: three or more status-domains can and do intersect, making the experience and social/legal issues of, say, older non-white rural Christian homosexual men unique. Ultimately, as McCall recognizes, the intracategorical complexity of social experience (that is, not all women or white people or English-speakers or Southerners are the same) has an anticategorical effect, rendering "suspect both the process of categorization itself and any research that is based on such categorization" (2005: 1777) and potentially dissolving them altogether.

\section{Culturizing the Physical}

We have now seen that Americans and all other humans are not only diverse but diverse in diverse and intersecting ways - that each individual is a matrix of diversity variables (race, gender, language, etc.), that each diversity variable or status-domain has a finite set of potential "slots" or values (e.g., for race, "white" and "black" and "Hispanic" and "Asian" and "Native American" or some such list), and that each slot or value is less a discrete category than a composite of lower-level elements which can be separated and recombined in ways that confound the standard categorial divisions. We have also seen that this array of diversity can take both cultural and physical forms.

However, like other simple dichotomies, the cultural/physical split is not easily defended. First, it should be noted that sociologists and anthropologists typically distinguish statuses into "ascribed" and "achieved." An ascribed status is one that the individual is born with or that naturally develops over time (the latter would include aging: one is not born elderly, but if one lives long enough one will become elderly, without any effort to age and against any effort not to age), while an achieved status is one that the individual must exert some effort to acquire during his/her lifetime. Among ascribed statuses, most researchers would reckon gender, race, age, ancestry, family name, and in societies that have such a concept, nobility or royalty. Achieved statuses usually include education, profession, and marital status, among others. Two things are immediately clear about this distinction. One is that ascribed/achieved does not superimpose perfectly on physical/cultural. Gender, race, and age may be physical (although, as we will argue below, not exclusively physical), but family name and aristocratic standing are not; on the other hand, education and marital status are cultural but other statuses that are more often acquired than ascribed, like vision- or hearing-impairment (which are usually the result of illness or injury) or for that matter a "ripped" physique, are very physical. The other is that some statuses straddle the line between ascribed and achieved: wealth/class can be inherited or earned, and a family name can be transmitted by birth or acquired by marriage.

In short, not every ascribed status is "natural," nor is every achieved status "learned," and some fall in between or in both. This raises the much bigger and more profound point that "physical" and "cultural" are not incommensurable categories, certainly not opposites, but rather merely two modes that can and generally do interact. That is to say, one of the most important effects of society is to make the physical or natural 


\section{Thinking About Diversity}

"cultural" too, to culturize the physical/natural and, to some extent, physicalize and naturalize the cultural (Sahlins 1976). This is why social scientists assert that both social and physical qualities are ultimately socially constructed. There are a number of crucial ways in which this process operates:

1 The cultural selection of significant physical traits

Every human being has a vast assortment of physical attributes, including skin color and nose shape not to mention foot size and blood type. In any society, some of these traits and not others are singled out for cultural interest and elaboration. In the United States, skin color is a particular preoccupation, while in other societies it may be of little or no interest. Some people in America attach some significance to the month in which a person is born (their zodiac or astrological sign); on the other hand, Chinese society traditionally placed the emphasis on the year in which a person was born (the Year of the Dog, the Year of the Monkey, and so on). Most Americans do not think that there is any serious social meaning to a person's blood type, but there is a school of thought in Japanese society that blood type is tied to other psychological and social qualities. At the same time, Japanese society made (and to some degree still makes) a distinction between "normal" Japanese people and burakumin or inferior/low-caste people, despite the fact that there is no clearly discernible physical difference between them. In other words, no society can or does attend equally to every physical characteristic of its members, and different societies choose different ones to attend to.

2 The cultural definition and/or classification of physical traits

After determining which attributes have cultural importance, a society establishes its own definitions and categories for those attributes. Two good examples are gender and race. American society emphasizes certain overt anatomical qualities, which are defined as "racial" qualities, and propounds a race classification system, in which a certain number of named race categories exist and into which all individuals must or should fit (although, as we observed above, this sort of categorization does not always succeed). In the strongest cases, each "type" or category is believed to possess its own unique and immutable "essence," that which sets it permanently and irreconcilably apart from all other types or categories. Mixing of such types/categories is often seen as undesirable, unnatural, and even impossible. Of course, other societies define and classify race differently (if at all). Brazil is a famous case of a loose and analog race system. The country likes to fancy itself a "racial democracy," a place where the frequent blending of the races "made the line between Black and White imprecise" (Daniel 2005: 89), and race categories "displayed fluid racial markers, such that Blackness and Whiteness represented merely polar extremes on a continuum" (91). Accordingly, Brazilian race thinking includes many more fine distinctions of color and other physical features than American race thinking does: the Brazilian Institute of Geography and Statistics found that people used an incredible 134 different color terms to describe themselves and others, including alva (pure white), alva-escura (off-white or dark white), esbranquecimento (mostly white), acastanhada (cashew- or caramelcolored), trigueira (wheat-colored), amarelo (yellow), verde (greenish), roxa (purplish), preta (black), queimada (burnt), quase-negra (almost Negro), pretinha 
(light black), meio-preta (mid-Negro), mulatinha (lighter-skinned white-Negro), and of course mulatta (mixed white and black).

Gender is an even more edifying case, since it seems self-evident to most Americans that there are two genders, male and female. It also seems self-evident that this binary gender system is purely physical: examine the bodies, or more narrowly the genitals, of individuals and their gender is certain. However, readers might be surprised to learn that not all societies share this perspective. Some societies maintain that there are three or four or more genders: according to one study, the Bugis of Indonesia identify five different genders (Davies 2007). The hijras of India are regarded by their society as neither men nor women, who achieve their full gender neutrality by castration (Nanda 1999). In other societies, gender is also believed to be an achievement, not an automatic ascription. The Sambia of New Guinea traditionally felt that a boy would not "naturally" grow into a man but required the cultural intervention of adult men in the form of rituals and specific sexual behaviors (Herdt 1987); similar notions lie behind the initiation rites in many cultures. Finally, in some Native American societies it was held that gender was not settled at birth but could change during one's life and that gender was not a merely physical, but also a spiritual, status, such that males were men because they possessed a masculine spirit, females were women because they possessed a feminine spirit, and a third gender (popularly known as the berdache) was both because they possessed two spirits (e.g. Roscoe 1998).

3 The cultural sources of or contributors to physical traits

While certain attributes are indisputably physical, this fact does not mean that they are without social/cultural precursors. For instance, one of the most noted contemporary physical trends among Americans is the increasing rate of obesity, which is beyond doubt a physical condition. However, it is also widely noted that aspects of the American way of life contribute to this epidemic - habits like sitting at work or at home, a high-calorie and high-fat diet, and stress and eating as a response to stress. In some instances, one physical status appears to relate to other physical statuses (another case of intersectionality): African Americans suffer from different distributions and rates of diseases than whites. In other instances, a cultural status appears to relate to a physical status: the poor or non-English speakers or urban residents, etc., have statistically different physical characteristics and outcomes (e.g. health) than the rich or English speakers or suburban and rural residents. There is, it can be concluded, a significant association between cultural variables and physical variables.

4 The cultural meaning and value-and consequences-of physical traits

Perhaps most critically, physical/natural characteristics (and not only these characteristics) are assigned differential meaning and value in a society. We are talking here, for example, of the relation between race and racism, or between sex and sexism, or between age and ageism, or for that matter between appearance or beauty and "lookism." In any society, at least some status differences also become status hierarchies, in which one status alternative is more desirable than or superior to another alternative. In the United States, it is difficult to deny that white status has conferred social advantages over black status, and there are those today who continue to claim that the white race is superior to all other races (see Chapter 3). Likewise, males have enjoyed and largely still enjoy cultural dominance over females, 
and "non-ordinary" males and females often remain on the margins of the status system (see Chapter 7). The elderly (and, some would insist, the very young) suffer certain social disadvantages, as do non-English speakers, non-Christians, the disabled, and other "minority" or subordinated groups and statuses.

The point here is that diversity frequently translates into inequality. The spoils of society, from wealth to power to prestige, are often distributed unevenly on the basis of physical-and also cultural-differences. Difference is then often implicated in a system of stereotypes, prejudices, and discrimination (see Chapter 2). In the worst cases, particular statuses have the effect of stigmas. A stigma, according to the sociologist Erving Goffman, is "an attribute that is deeply discrediting," one "that makes [its bearer] different from others in the category of persons available for him to be, and of a less desirable kind-in the extreme a person who is quite thoroughly bad, or dangerous, or weak" (1963: 3).

\section{Box 1.2 Erving Goffman on Stigma}

"Society establishes the means of categorizing persons and the complement of attributes felt to be ordinary and natural for members of each of these categories. Social settings establish the categories of persons likely to be encountered there. The routines of social intercourse in established settings allow us to deal with anticipated others without special attention or thought" (2). A person whose attributes fall outside the ordinary, natural, and desirable has a stigma and "is thus reduced in our minds from a whole and usual person to a tainted, discounted one .... [The stigma] is also called a failing, a shortcoming, a handicap ... . The term stigma, then, will be used to refer to an attribute that is deeply discrediting, but it should be seen that a language of relationships, not attributes, is really needed. An attribute that stigmatizes one type of possessor can confirm the usualness of another, and therefore is neither creditable nor discreditable as a thing in itself" (3). "Three grossly different types of stigma may be mentioned. First there are abominations of the body-the various physical deformities. Next there are blemishes of individual character perceived as weak will, domineering or unnatural passions, treacherous and rigid beliefs, and dishonesty, these being inferred from a known record of, for example, mental disorder, imprisonment, addiction, alcoholism, homosexuality, unemployment, suicidal attempts, and radical political behavior. Finally there are the tribal stigma of race, nation, and religion, these being stigma that can be transmitted through lineages and equally contaminate all members of a family" (4). "The attitudes we normals have toward a person with a stigma, and the actions we take in regard to them, are well known .... By definition, of course, we believe the person with a stigma is not quite human. On this assumption we effectively, if often unthinkingly, reduce his life chances. We construct a stigma-theory, an ideology to explain his inferiority and account for the danger he represents, sometimes rationalizing an animosity based on other differences, such as those of social class. We use specific stigma terms such as cripple, bastard, moron in our daily discourse . . . W We tend to impute a wide range of imperfections on the basis of the original one" (5). 
In short, the classification and categorization of human diversity is not a neutral or idle activity but a crucial form of social action and social judgment, evaluating people against some social standard as better or worse, more or less deserving, higher- or lower-quality individuals and groups. The consequences of this judging and ranking process can be quite real, from segregated neighborhoods to differential access to the products and institutions of society to uniquely oppressive institutions like slavery to shortened life-spans for some to inter-group conflict and violent deaths.

5 The cultural organization and institutionalization of physical traits

Individuals possess attributes, which they share with some other individuals. These traits may not necessarily be the basis for any special form of social organization. However, in many cases, shared physical qualities are employed by their possessors to build communities, institutions, and cultures. One such use of shared characteristics would be the creation of self-help organizations and political parties. The National Association for the Advancement of Colored People (NAACP), the National Council on Disability, and the American Association of Retired Persons (AARP) were designed to represent particular status constituencies, and institutions like Gallaudet University or the American Athletic Association of the Deaf, the National Theater of the Deaf, and the Special Olympics serve members of specific status communities. Attribute-groups may also construct their own neighborhoods, literature, music, food and clothing styles, linguistic habits, signs and symbols, and so on. Some of these activities may be for purely pleasurable and recreational purposes, but others are intentionally advanced as means to promote the interest and identity of the membershipto increase its visibility in the mainstream society, to compete for resources and to fight for rights, and to enhance the self-image and the collective mobilization of the group, in fact in some cases to transform a category into a group.

Finally, it should go without saying that all five of these processes apply not only to physical characteristics but to cultural ones as well. It is just especially important to stress that physical traits often have social/cultural sources and social/cultural consequences. But, to be sure, cultural and social characteristics are selected by any particular society for attention and elaboration; for some people in the United States, the language you speak, the religion you practice, or the region you inhabit is highly significant. Also, each society provides its own classification of social/cultural qualities - the languages it recognizes, the religions it includes, the ethnic groups it understands, the regional and other geographic locales it comprises, and so on. Third, social/cultural attributes have other social/cultural (and sometimes physical/natural) underpinnings and contributing factors: poverty, for example, is closely related to race and gender and region and household composition, as religion is statistically associated with political party affiliation and voting habits. As indicated by the concept of intersectionality, disparate social statuses are not utterly independent but do tend to come (within the limits of the compositional approach) in recognizable "bundles" or "packages"- some of which are merely statistical (like health consequences for different races) and some of which are seen as normative by the members of the group (those that people of a certain status "should engage in"). 


\section{Thinking About Diversity}

Like physical traits, social/cultural characteristics are also graded and judged: some languages (or accents or speech styles) or religions or regions may be deemed superior to others, and social advantages and disadvantages may attach to them. And socio-cultural characteristics can be and often are the basis of organization and institutionalization, from ethnic clubs and parties to religious congregations to mutual-interest societies to group-rights associations like the American Indian Movement and the Gay Liberation Front, the Gay and Lesbian Alliance against Defamation (GLAAD), and the AIDS Coalition to Unleash Power (ACT UP), among a universe of others.

\section{Conclusion}

Humanity is a diverse species. We are diverse along a number of dimensions, both physical/inherited and cultural/learned, all of which interact in unique ways in each society, producing a complex field of socially constructed characteristics. Each particular variable or status-domain (like race or language) includes a set of possible alternatives or values (like white/black/etc. or English/Spanish/etc.) which are conventionally seen as mutually exclusive categories but which are in actuality composites of multiple traits which themselves consist of independently transmissible and creatively mixable sub-traits. In the contemporary world, too many individuals break the old familiar category boundaries for these boundaries to be viable any longer.

Whether ascribed or achieved, physical or cultural, the array of attributes presented by a society is always selectively picked and elaborated, defined and classified. Potentially any and all attributes provide a basis or explanation for other attributes, and all of these differences are arranged into a hierarchical distribution of valued and meaningful characteristics—some more valuable and meaningful than others. Consequently, individuals and communities that notice their shared qualities-and the shared consequences of their qualities-may gather themselves into communities, subcultures, institutions, and organizations to act as groups within the wider society. All of this leads to the observation that not only is there diversity in the human world but that there are diverse systems of diversity across societies, and the United States represents one such system of diversity.

\section{Notes}

1 The US Census does not collect data on religion. Source of this data is the Pew Religious Landscape Survey, 2008

2 Source of mental illness data is Substance Abuse and Mental Health Services Administration 


\section{Inter-Group Relations and the History of Diversity in the US}

E pluribus unum-out of many, one. It is an American motto, an American creed, perhaps an American project.

The United States is a society of immigrants, which means a society of people from different societies. Yet in 1915, then-President Woodrow Wilson stated that "America does not consist of groups. A man who thinks of himself as belonging to a particular national group in America has not yet become an American".

Is it possible to be a "byphenated American"-an African-American, an ItalianAmerican, a Muslim-American-and still be an American? Is it possible not to be a byphenated American? Is there any such thing as just a plain American?

American society, like all societies but maybe more so than most, is a complex system of groups, categories, cultures, and institutions. It is not a single homogeneous mass or a "majority" with an assortment of divergent "minorities." Everyone is a minority in some way or another. This raises the question of how the United States became such a plural society, which is roughly the question of immigration and settlement in the new nation. However, the point is not merely to examine the qualities of the various social sources that compose the contemporary United States but to consider the relationships between these groups. Whatever the precise attributes of specific "kinds" of Americans that make up the American tapestry or "melting pot," it is the dense and often tense interrelations between these kinds that have most thoroughly defined the history and conditions of life of the US.

\section{The Structure of Inter-Group Relations}

We have already discovered that humans, including Americans, are polymorphic and that they tend to congregate (and/or be congregated) with other humans of their own "kind." This inevitably creates more or less identifiable categories and groups in particular relations with each other-economic, political, marital, even geographic relations. The human story is basically a story of the dealings of different "types" of humans, and when those "types" are cast within the same overarching social system, the issue is more profound.

The "types" that are categorized and grouped in any society vary from sex/gender ones to age/generational ones to physical/racial ones to cultural/ethnic ones, among others, as noted in the previous chapter. In the present chapter we will be focusing on racial 
and ethnic - to be still more precise, international or multi-geographic or translocalgroups and identities, although the lessons gleaned from the investigation of these two major but hardly exhaustive groups are generally applicable to other sorts of groups as well. These lessons are also widely applicable outside the US too, of course.

\section{The Temper-or Distemper-of Groups}

A great number of social observers have commented on the nature of human groups, both internal (the processes within groups) and external (the processes between groups). Much of this commentary has not been heartening. One of the earliest analyses of group dynamics, Gustave Le Bon's 1896 study, The Crowd: A Study of the Popular Mind, paints an unusually alarming picture. Whether groups and crowds bring out something dormant in individuals or develop their own unique collective tendencies, they display a shared pattern of thought and behavior that he christened "the mental unity of crowds" (1-2), which is "a singularly inferior mentality" (ix). Among the qualities of the group mentality are:

- “a sentiment of invincible power which allows [the member] to yield to instincts which, had he been alone, he would have perforce kept under restraint" (10);

- "irresistible impetuosity" (12), such that members attempt things they otherwise would not;

- "impulsiveness, irritability, incapacity to reason, the absence of judgment and of the critical spirit, the exaggeration of the sentiments" (17);

- “a state of expectant attention" (22);

- "dictatorialness and intolerance" (39) and a common certainty in the group's cause and goodness.

From Sigmund Freud, who quoted Le Bon extensively in his own 1921 treatise on group psychology, to Elias Canetti's more recent (1963) study of groups and power, there has been a consistent sense that groups and crowds tend to seek to minimize internal differences, to maximize differences from other groups, and to be prone to destructive behavior. Canetti noted that a group or crowd "particularly likes destroying houses and objects: breaking objects like window panes, mirrors, pictures, and crockery .... The noise is a promise of the reinforcements the crowd hopes for, and a happy omen for deeds to come" (1963: 19). Howard Bloom (1995) went so far as to opine that a group, especially a society, is virtually a separate organism from the individuals who compose it - a sort of superorganism with its special, and dangerous, traits.

The social psychologist Gordon Allport distilled much of this research down to one key concept: prejudice. In his book The Nature of Prejudice he defined the concept as "an avertive or hostile attitude toward a person who belongs to a group, simply because he belongs to that group, and is therefore presumed to have the objective qualities ascribed to the group" (1979: 7). Prejudice is based on two even more fundamental social processes-the tendency to categorize and generalize and the tendency for groups to distance themselves from each other. Categorization, Allport wrote, is absolutely intrinsic to human life; it simplifies social existence by organizing differences into "large classes and clusters to guide daily adjustments," assimilating "as 
much as possible to the cluster" (20). This simplification and generalization "enables us quickly to identify related objects [and people]," binding them into a category that "saturates all that it contains with the same ideational and emotional flavor" (21). Two worrisome features of categorization are that the "knowledge" on which it is based need not be (and often is not) accurate and that, once formed, the categories and judgments can be "stubborn and resist change" (23). Such a stubborn and (frequently) erroneous idea about another group is what we call a stereotype.

As for the second general process, "human groups tend to stay apart" (19). The fact that humans tend to divide themselves into groups increases the likelihood of false knowledge and gross overgeneralization of others. At the same time, false knowledge, gross overgeneralization, and the resultant prejudice (i.e., judging prior to actual experience or information) tend to facilitate the group divisions. Categorization and (usually negative) prejudgment build boundaries around groups, which are defended against assault, literal and figurative. When evidence contrary to the preconceptions about another group is encountered, it is either ignored completely or "perfunctorily acknowledged" and then overlooked (23); Allport called this behavior "re-fencing," since it allows group boundaries to be repaired and preserved. This prejudice also works to enhance identification with and loyalty to one's own group: interactions with out-group members are minimized, those out-group members are often demonized, and devotion to the interests and institutions and ideals and identity of the in-group is emphasized. As Freud and others have mentioned, the role of the "leader" cannot be stressed enough in this regard.

Unfortunately but not unexpectedly, negative attitudes can lead to negative actions. One of Allport's “milder” forms of disadvantageous behavior was discrimination, by which he meant "any conduct based on a distinction made on grounds of natural or social categories, which have no relation either to individual capacities or merits, or to the concrete behavior of the individual person" (52). To be more nuanced here, all humans do and must differentiate between things or people when real and relevant differences exist-that is, we really should make distinctions between food and nonfood or between a qualified physician and an unqualified one. However, discrimination becomes a social problem when we discriminate not between but against, and when those distinctions are not based on any real or relevant criteria. The most common form of socially inappropriate and socially pernicious discrimination is on the basis of group membership — of race, of sex, of age, of language, of religion, of ethnic background, etc. The assumption is, first, that the traits of the "other group" are inferior to our own and, second, that all members of the "other group" share those traits.

When not only groups and group prejudices and discrimination but group competition exist, the negative consequences can be more extreme. These consequences can include conflict and open violence. Prejudice and discrimination escalate into inter-group violence, Allport posited, when the following conditions have been met:

- "There has been a long period of categorical prejudgement."

- "There has been a long period of verbal complaint against the victimized minority."

- "There has been growing discrimination."

- "There has been some outside strain upon members of the in-group. They have for a long time suffered from economic privation, a sense of low-status, irritation due to political developments_-such as wartime restrictions or fear of unemployment." 
- "People have grown tired of their own inhibitions, and are reaching a state of explosion."

- "Organized movements have attracted these disconnected individuals. They join the Nazi party, the Ku Klux Klan, or Black Shirts. Or a less formal organizationa mob-may serve their purpose in case no formal organization exists."

- "From such a formal or informal social organization the individual derives courage and support [as Le Bon and Canetti suggested]. He sees that his irritation and his wrath are socially sanctioned. His impulses to violence are justified by the standards of his group-or so he thinks."

- "Some precipitating event occurs ... . The incident may be wholly imaginary, or it may be exaggerated by rumor" (57-8).

Finally, Allport noted that "When violence actually breaks out, the operation of 'social facilitation' becomes important in sustaining the destructive activity. To see other equally excited persons in a condition of mob frenzy augments one's own level of excitement and behavior" (58).

\section{The Diversity of Group Relations}

It is neither claimed nor implied in this discussion that all groups are bad or that all group differences lead to condemnation and violence. In fact, like groups themselves, the relationships between groups are quite diverse. There are many kinds of intergroup relations, and what is more, within any particular society groups $\mathrm{X}$ and $\mathrm{Y}$ may be in one relationship while groups $\mathrm{X}$ and $\mathrm{Z}$ are in another. And these relations can most certainly change over time.

Numerous social scientists have offered typologies of inter-group relations. George Simpson and Milton Yinger (1972), for instance, gave a six-component analysis which will be useful to orient our presentation, while providing opportunities for modification and elaboration. In their system, the six forms of group interaction included pluralism, assimilation, legal protection of minorities, population transfer, continued subjugation, and extermination.

\section{Pluralism}

Pluralism is the coexistence in the same country or society of groups with distinct cultural or other characteristics, in relative peace and without extensive loss or blending of characteristics. Rather than adopting a foreign or dominant culture, each group retains (at least some of its) distinct appearance, behaviors, or values. Naturally, there is more than one version of pluralism. In one situation, a society might (warmly or grudgingly) welcome group differences within its midst, and the members of various groups might interact (more or less) freely and continuously without any condemnation of-occasionally with some celebration of-their differences. This can take the form of "multiculturalism," to which we will return below. In another situation, the coexistence of plural groups might include or depend on the functional or geographic separation of the groups. Indeed, the first scholar to use the term, J. S. Furnivall (1956) had precisely this arrangement in mind. 
Furnivall, who was writing specifically about late-colonial Southeast Asia, proposed a notion of "plural society" not based on seamless social integration but exactly the opposite: a system of "separate racial [and ethnic] sections," each with its own culture or language or religion, etc. which "mix but do not combine" (30-4). They live side-by-side in the same society but do not integrate socially, politically, or economically. Society, if the word even applies, is atomized into groups pursuing their goals and interests almost oblivious of each other. Ultimately, his plural society was a purely functional, nakedly economic fact: based on what he called "the process of the survival of the cheapest," economic and market forces act "to eliminate all non-economic values," leaving nothing but practical material interest and relations to bind various groups; little in the way of shared beliefs or values is achieved or sought (299). The relationships between constituent groups are utilitarian, each group filling a particular niche in the broader social system but otherwise having fairly little to do with each other. By this standard, Furnivall did not regard the United States as a plural society at all but merely as a society with some plural features.

We could further distinguish between different kinds of pluralism. There is cultural pluralism, in which disparate groups maintain something of their unique historical cultures (language, religion, food or clothing style, and so on) while integrating within the institutions of the society; they might, that is to say, share common workplaces, neighborhoods, special interest clubs, and political parties where their non-shared cultural attributes are not expressed or do not matter. On the other hand, groups might live in a system of structural pluralism, in which they may occupy different sites in the social structure-different classes, occupations, neighborhoods, and institutions-on the basis of their cultural differences or even in the absence of any appreciable cultural differences.

\section{Assimilation}

One very familiar form of group interaction-sometimes viewed as the classic or ideal/ preferred form in the American society-is assimilation. Assimilation refers to the circumstance in which multiple "groups" may initially exist in a society but lose some or all of their unique group characteristics, and some or all of their groupness, by virtue of living in the society. Ordinarily, the various constituent groups (often arriving in the society through immigration) over time adopt many of the qualities of some other group, which can be regarded as the dominant group in the society. In the United States, one such dimension of dominance is the English language, and newly arriving groups, families, and individuals have been encouraged and in some cases compelled to learn English; certainly, fluency in English confers social advantages in terms of functioning in the mainstream of the society.

Assimilation can be further analyzed into its cultural, structural, and sometimes physical/racial aspects. Cultural assimilation stresses the adoption of behaviors, attitudes, and values of the dominant group in society-in the US, speaking English, wearing Western-style clothing, living in Western-style housing, embracing mainstream American gender roles, perhaps converting to Christianity.

In structural assimilation, groups are integrated into the institutions of the mainstream society (workplaces, neighborhoods, and so forth) whether or not they drop their non-American behaviors and values; here, one might see men in mainstream 


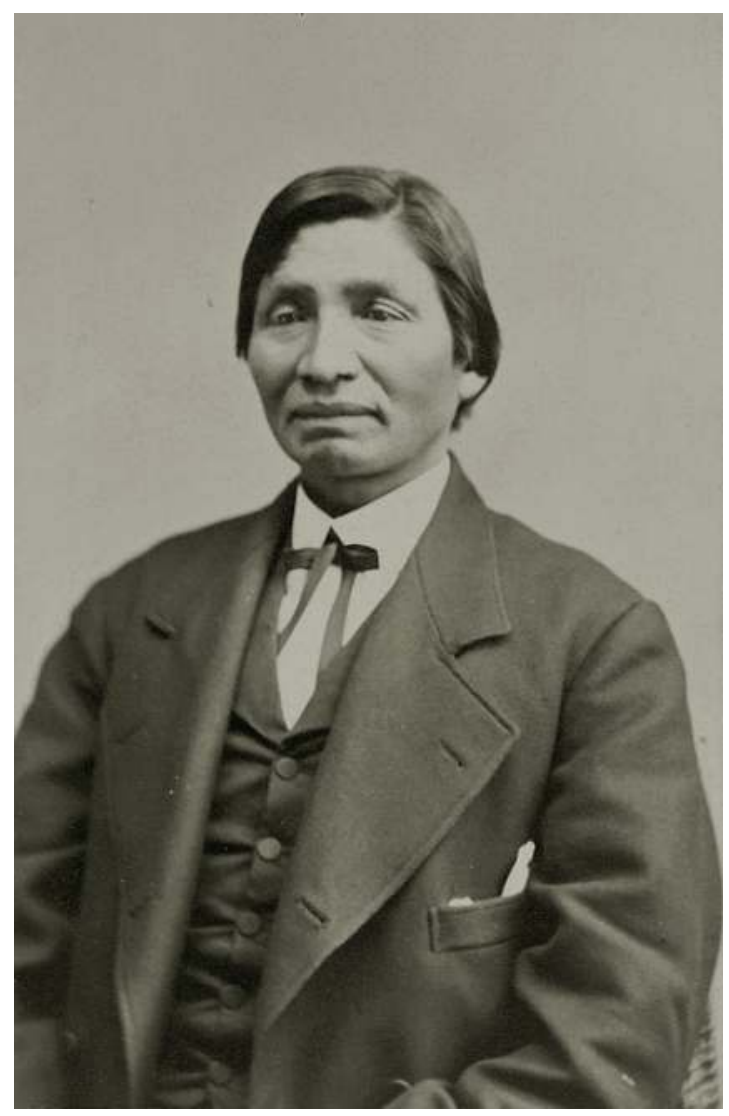

Image 2.1 Portrait of a Native American man in Euro-American attire rather than traditional dress, c.1860s.

(Courtesy of the Library of Congress, Prints and Photographs Division)

offices wearing turbans or women in mainstream shopping areas donning saris or veils. Physical or racial assimilation would entail the actual dilution of biological characteristics by way of intermarriage so as to produce children with more of the dominant physical features than their parents.

Assimilation, then, while often seen as a generous offer from the dominant element in a society, may in reality be a mechanism to perpetuate the attributes of that element-and to perpetuate the privileges of that element. Non-dominant groups could easily find the offer or expectation of assimilation to be coercive and discriminatory.

\section{Legal Protection of Minorities}

In societies that recognize the existence of numerical minorities and/or groups with historical and contemporary social/cultural disadvantages, the dominant group or the government of the society might take steps to guarantee the lives and rights of 
the disadvantaged groups. The reservation system in the United States was, in part, intended as a sort of protection for surviving (but defeated) Native populations: as one illustration, the 1794 Treaty of Canandaigua with the Iroquois nation acknowledged Iroquois rights to certain territory and further promised that "the United States will never claim the same, nor disturb them or either of the Six Nations, nor their Indian friends residing thereon and united with them, in the free use and enjoyment thereof: but the said reservations shall remain theirs, until they choose to sell the same to the people of the United States, who have the right to purchase" (see Chapter 4).

There are a number of other ways to ensure rights and protections for subordinated minorities, especially since the US does not recognize collective territorial rights for any group other than Native Americans. One procedure is to enshrine minority rights into law. Subsequent to the abolition of slavery with the Thirteenth Amendment to the US Constitution in 1865, the Fourteenth Amendment (ratified three years later) guaranteed citizenship to "all persons born or naturalized in the United States" and prohibited the federal and state governments from making any law "which shall abridge the privileges or immunities of citizens" or "deny to any person within its jurisdiction the equal protection of the laws." The Fifteenth Amendment in 1870 then secured the right to vote without regard to "race, color, or previous condition of servitude," which was, like the previous amendments, aimed specifically at recently emancipated blacks (but did not yet extend to women; see Chapter 6). Since these paper assurances did not prevent discrimination in the form of segregation and "Jim Crow" laws in parts of the country, the 1964 Civil Rights Act in the United States (like the similar 1965 Race Relations Act in England) was designed to enforce those earlier promises and was followed by many other measures to attempt to establish equality between groups and to reduce or eliminate the prejudice and animosity against disadvantaged groups.

In other societies, formal power-sharing arrangements have been adopted to provide for political participation by all groups. In countries like Belgium, Lebanon, and the former Yugoslavia, confederation, that is, a form of government that creates a relatively weak union between relatively sovereign distinct local cultural groups, has been adopted. In Yugoslavia, several "nationalities" were given their own ethnic republics (Slovenia, Croatia, Serbia, Bosnia-Hercegovina, etc.) which cooperated in the central government. However, the repeated civil wars in Lebanon and the fragmentation of Yugoslavia into independent ethnic states underline the limitation of this political solution.

\section{Population transfer}

One way to make peace between groups is to separate them; therefore, one approach to group relations is a policy or practice of physically moving groups from one location to another, ostensibly to reduce tensions and hostilities. It can be in the interest of subordinated groups to shift to another location, but it can also be in the interest of the dominant group. For instance, while in a sense the reservation system was intended to protect Native Americans, in another more powerful sense it was designed to eliminate Indians from Euro-American areas (and perhaps to eliminate them altogether). The most egregious case is the "removal" of Native peoples from parts of the Southeast in 1830, who were forced to resettle in "Indian country" (present-day Oklahoma)which clearly did not remain Indian country very long. Particularly, in the United States 
(as in Canada and Australia, which also have their "reserve" systems), Native peoples were often transferred to regions far from their traditional homelands, frequently impossibly small or harsh regions.

Population transfer has occurred around the globe, commonly as a corollary to territorial partition. With partition an area is divided between two or more cultural or political groups, as with the division of Palestine into Jewish and Arab regions, the split of colonial India into the modern states of India and Pakistan, or the political cleaving of Korea, Vietnam, or Germany. Since ethnic populations are typically geographically mixed, these partitions tended to leave significant numbers of people on the "wrong side" of the ethnic boundary, leading to (especially in the India/ Pakistan case) massive shifts of people moving to "their side" of the border. In yet other situations, population transfer can be part of the domination project of one group: in the former Soviet Union, ethnic Russians were encouraged to settle in non-Russian areas (like the Baltic republics of Lithuania, Latvia, and Estonia or the central Asian republics such as Kazakhstan) to promote the integration of those territories into the dominant society, even as non-Russian groups were sometimes dispersed throughout the country to dilute their political and cultural strength.

\section{Continued Subjugation}

In still other instances, the dominant group may have no inclination to change the subordinate position of other groups in the society or country. In such cases, discriminatory practices and institutions, such as segregated neighborhoods, ghetto or slum living conditions, and even slavery, may persist. Sometimes, these practices and institutions may actually become more formalized through regulations that legalize inequality and oppression. The loose but formal system of segregation in the United States, buttressed by Supreme Court decisions that legalized "separate but equal" institutions (which were never actually equal), was a good example. The classic case, of course, was South Africa, with its elaborate system of apartheid. Meaning "apartness" in Afrikaans (the language of local whites), apartheid became a legal reality after 1948 and the ascension of the Nationalist Party to power. With it came official registration of the South African "races" into "white," "Asian," “colored," and "African." Race labels were applied without regard to cultural assimilation: "coloreds," for instance, were generally fully Westernized and Christian like whites but were still legally and structurally set apart. Of course, the four race-categories were carefully separated and ranked in terms of wealth, power, and status, with the whites dominating in all three realms; each race had an explicitly defined set of rights and restrictions, with strong sanctions against race fraternization and intermarriage. Black Africans were at the bottom of the system, with coloreds second only to whites in most regards, and Asians (mostly Asian Indians) subjected to more limitations than the coloreds, although generally economically better off. The black African majority (over two-thirds at the height of apartheid) was largely relegated to slums or to nominal "homeland" areas.

Other societies and governments have achieved various levels of separation and discrimination. In modern Turkey, the ethnic Kurds have sometimes been subjected to denial of their language, their land, and even their very identity, the argument being made that Kurds are not a distinct group at all but nothing more than "eastern Turks.” By many estimates, the Chinese subjugate the Tibetans in the political-military 
occupation of that region, and indigenous people throughout the world are victims of greater or lesser, more or less formal, relations of subjugation and exploitation.

\section{Extermination}

As Nazi Germany expressed and epitomized, the "final solution" to racial and ethnic "problems" is the eradication of disfavored groups. The most overt form of population elimination is genocide, defined by Article II of the 1948 United Nations Genocide Convention as "acts committed with intent to destroy, in whole or in part, a national, ethnical, racial, or religious group, as such: (a) Killing members of the group; (b) Causing serious bodily or mental harm to members of the group; (c) Deliberately inflicting on the group conditions of life calculated to bring about its physical destruction in whole or in part; (d) Imposing measures intended to prevent births within the group; (e) Forcibly transferring children of the group to another group." Many such genocides have been recorded in recent history: the best known is, of course, the Nazi extermination of Jews during the 1940s, but others include the eradication of Armenians by Turkey, of Hottentots by Dutch settlers in South Africa, of Aboriginals by Euro-Australians, and of Native Americans by Euro-Americans.

An alternative to genocide, one that leaves human beings alive but deprives them of their cultural uniqueness and identity, is known as ethnocide and is sometimes called "cultural genocide." There are many "humane" and legally acceptable ways to destroy a people without destroying people. Separation of children from families through forced adoption, banning of cultural practices and symbols (including language, religion, clothing and hair styles, songs and stories, and so on), forced assimilation through mandatory education (especially and ideally boarding schools, which again separate children from parents) - these are a few of the techniques of cultural erasure.

Short of the all-out extermination of groups is the outbreak and persistence of ethnic conflict, that is, violence between social/cultural groups. Ethnic conflict actually covers a vast array of hostile and destructive relations and actions, such as pogroms, antiSemitism, fascism, racial violence, race riots, policing in racially/ethnically mixed settings, slavery, colonialism, third-world revolutions, separatism, irredentism, xenophobia and anti-immigrant violence, "ethnic unmixing," force migrations, refugee flows, religious violence, terrorism, paramilitary formations, state violence, and cultural humiliation (Brubaker and Laitin 1998: 429).

\section{Box 2.1 Measuring “Social Distance”}

Social scientists have naturally experimented with ways to quantify the relations between various groups and categories within a society. One influential concept is social distance, the degree to which groups are willing or unwilling to mingle and interact. First proposed by Emory Bogardus (1933), it exists in multiple versions, all of which preserve the basic notion of surveying people's attitudes toward sharing social space with others unlike themselves. A typical social distance scale asks a series of increasingly exclusionary questions in reference to 
(continued)

some list of social/cultural groups; the test can be adapted to include any particular groups or number of groups. The test generally takes the form of:

How do you feel about members of the following group (whichever groups are chosen for comparison)?

1 I would accept them as members of my family by marriage.

2 I would accept them as friends or peers in my club.

3 I would accept them as neighbors on my street.

4 I would accept them as co-workers at my job.

5 I would accept them as citizens of my country.

6 I would accept them as visitors to my country.

7 I would prohibit them from my country.

Obviously, groups that scored a large percentage of positive answers on the first two or three questions would have achieved a high degree of integration into the society (i.e. minimal social distance between test-subject and other groups). Groups that received many negative answers on the final two or three questions would suffer from maximum social distance, the test-subject wanting to keep them as far away from him/herself as possible.

\section{How the US Became Culturally Diverse: A Short History of Diversity and Cultural Policy}

Every society is diverse in multiple intersecting ways, containing a mixture of individuals of different genders, ages, heights and weights, beauty, talent, occupation, frequently wealth or class, and so on. To these universal dimensions of human diversity, the US-not uniquely in the world, but more so than many societies and countries-adds virtually every other dimension of human diversity, such as nationality/ethnicity, race, language, and religion. This is primarily so because the United States is, as it always claims and often proudly proclaims, a society of immigrants: people have come from all parts of the world to live in America, sometimes as citizens, sometimes as temporary workers. Therefore, if not every kind of individual and culture then a very great sample of the multiplicity of individuals and cultures can be found in the pot we call the United States.

The North American continent was culturally diverse long before the Europeans arrived. Estimates are difficult to make and notoriously imprecise, but probably hundreds of distinct Native societies numbering some millions of members occupied the territory that would become the United States of America. Each group had its own language, religion, traditions, and other distinguishing markers. Spanish explorers were the first Westerners to touch the future US, exploring in the southeast and southwest; French travelers visited the northeast (including Canada) and the Mississippi River region (leaving their imprint on the city of New Orleans and the state of Louisiana). But it was the British who would make the deepest mark on North America and the society that would eventually be the US. 


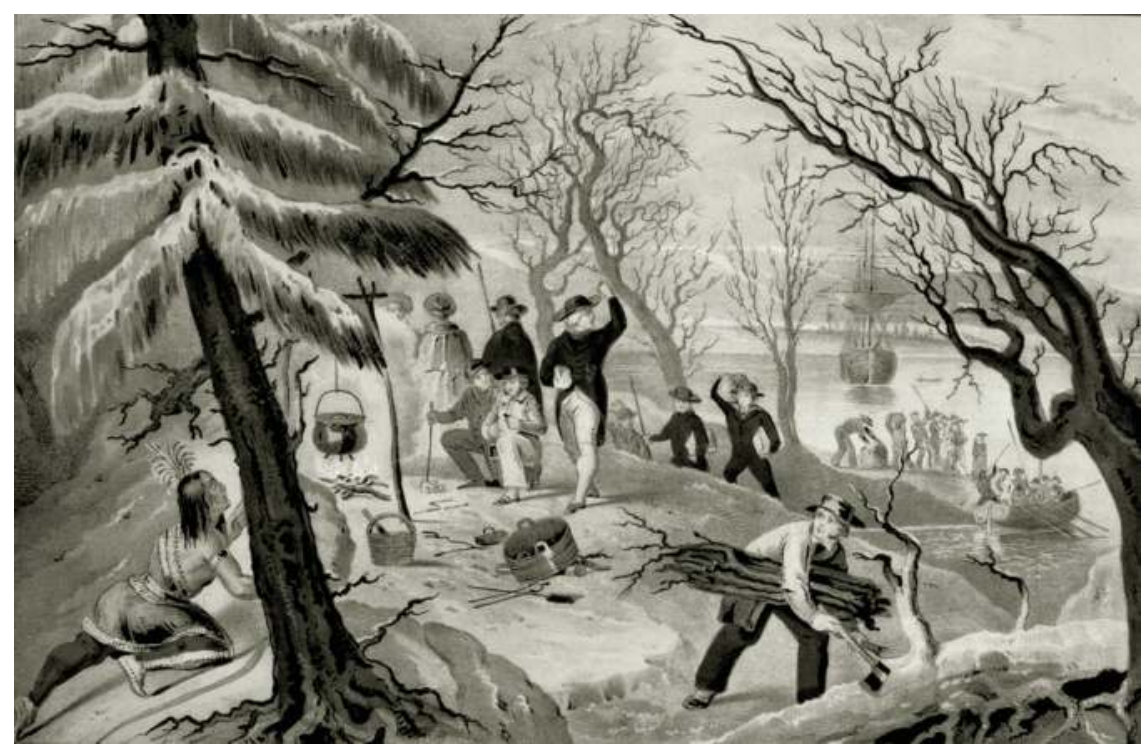

Image 2.2 "Landing of the Pilgrims at Plymouth".

(Courtesy of the Library of Congress, Prints and Photographs Division)

The earliest successful British settlements in what they regarded as the "new world" were Jamestown (1607) in future Virginia and Plymouth (1620) in future Massachusetts. In these first decades of occupation, the British were not alone: French, Spanish, and Dutch colonies were also founded (the most important Dutch regions being New Holland, which would become New York after British conquest, and the interior of present-day Pennsylvania where many "Pennsylvania Dutch" communities still reside). German and other settlers also came to the continent. And to be sure, Africans began to step ashore almost as soon as the British: the first Africans, twenty of them, arrived at Jamestown in 1619-but, like millions of their compatriots to come, involuntarily, although not quite yet as slaves (see Chapter 3).

Immigration to America was rapid: by 1700 there were some 250,000 people living in the east-coast colonies, approximately 10 percent African and almost all of the rest English (Native peoples were already being displaced or destroyed). By the time of the American Revolution in 1776, the population of the thirteen colonies had grown to 2.5 million, of which 50 percent were English and 20 percent were African. However, the African population was not distributed evenly throughout the colonies: in Virginia they composed 40 percent of the population and in South Carolina 60 percent. Most of the remaining settlers during the 1700s were German and Irish, contributing around 10 percent each to the national total.

Thus, it is clear that the new independent United States was going to be a society characterized as overwhelmingly European and white, Protestant, and English-speaking. "American" essentially meant an offshoot of English society, which inherited a disapproval of non-English-speakers and of non-Protestants (which basically meant Catholics; non-Christians were almost unthinkable). Full independence 
under the Constitution brought two relevant legal practices-the first census and the first definition and policy of citizenship and naturalization (the process by which subsequent immigrants could become citizens). The 1790 Census counted 3.9 million Americans, and the first naturalization law stipulated that "free [non-slave] white persons" residing in the country for two years were qualified to be citizens; a second naturalization act in 1795 stiffened the residence requirement to five years.

As we will see, times of political and economic turmoil tend to make immigration and naturalization more difficult and exclusionary. For instance, in 1798 the young government passed the Alien and Sedition Acts, which raised the residence requirement to fourteen years (that is, one would have had to be living in the US before 1784, prior to the adoption of the Constitution). Non-citizens were classified as aliens and compelled to register with the government; the President could order them to leave at any time, and in the event of war he could confine male aliens over the age of 14 .

Nonetheless, as tensions reduced and opportunities grew, immigration increased. During the first decades of the nineteenth century, most of the new arrivals continued to be European, especially Irish. The ten years from 1820 to 1829 saw more than 128,000 immigrants arrive, the 1830 s over 538,000, and the 1840 s almost 1.5 million.

A major alteration in American population patterns began in the 1840s, with the arrival of new kinds of cultural diversity in the country. This diversity came from three sources. One was still European but now southern and eastern European, including Italians, Poles, and Russians. A second source was Asian: especially with the construction of the intercontinental railroad and the discovery of gold in California (1848), Chinese and then Japanese and other Asian groups began to disembark on the west coast. A third, different in yet another way from the first two, was the "influx" of Hispanics, primarily from Mexico. In this case, however, the process was not so much immigration as annexation, the integration of new territory (usually someone else's territory) into an already existing society. Some Mexicans had previously been absorbed by the US in its 1819 acquisition of Florida (first settled by the Spanish in 1565). Texas had declared its independence from Mexico (which itself had become

Table 2.1 US immigration totals by decade, 1820-1969

\begin{tabular}{lc}
\hline Decade & Immigrants \\
\hline $1820-9$ & 128,502 \\
$1830-9$ & 538,381 \\
$1840-9$ & $1,427,337$ \\
$1850-9$ & $2,814,554$ \\
$1860-9$ & $2,081,261$ \\
$1870-9$ & $2,742,287$ \\
$1880-9$ & $5,248,568$ \\
$1890-9$ & $3,694,294$ \\
$1900-9$ & $8,202,388$ \\
$1910-19$ & $6,347,380$ \\
$1920-9$ & $4,295,510$ \\
$1930-9$ & 699,375 \\
$1940-9$ & 856,608 \\
$1950-9$ & $2,499,268$ \\
$1960-9$ & $3,213,749$ \\
\hline
\end{tabular}

Source: US Department of Justice. Immigration and Naturalization Service Annual Report, 1969 
independent from Spain in 1820) in 1835, leading to the famous 1836 Battle of the Alamo, a fort garrisoned by a number of illustrious American figures; after a brief stint as a sovereign country, Texas was annexed to the US in 1845. The war that followed between the United States and Mexico (1846-8) was a disaster for Mexico, leading to the cession of almost one-third of its land to the US, including most of the southwest of present-day America and some 80,000 resident Mexicans, who suddenly and involuntarily became "Mexican-Americans" (see Chapter 4).

As Table 2.1 shows, the late nineteenth century and the early twentieth century was a boom era for immigration into the US: in the forty years from 1880 to 1920 , almost 24 million foreigners moved into the country, 80 percent of them from south and east Europe. By 1914 and the outbreak of World War One, 5 million Germans, 4.5 million Italians, 2.5 million Poles, and 2 million Russians had settled in America, not to mention 700,000 Asians (over half Chinese and almost half Japanese), just short of 1 million Latinos, and 2 million Jews. In the first decade of the twentieth century alone, more than 8 million immigrants arrived, including over 2 million from Austria-Hungary, 2 million from Italy, 1.6 million from Russia, and the first significant Muslim influx from Turkey and Syria. In fact, during the half-century between 1860 and 1920, the US population was consistently 12-14 percent foreign-born (i.e., first-generation immigrants).

For many American nativists, white and predominantly Anglo-Saxon, Englishspeaking, and Protestant, this was all too much. President Theodore Roosevelt himself

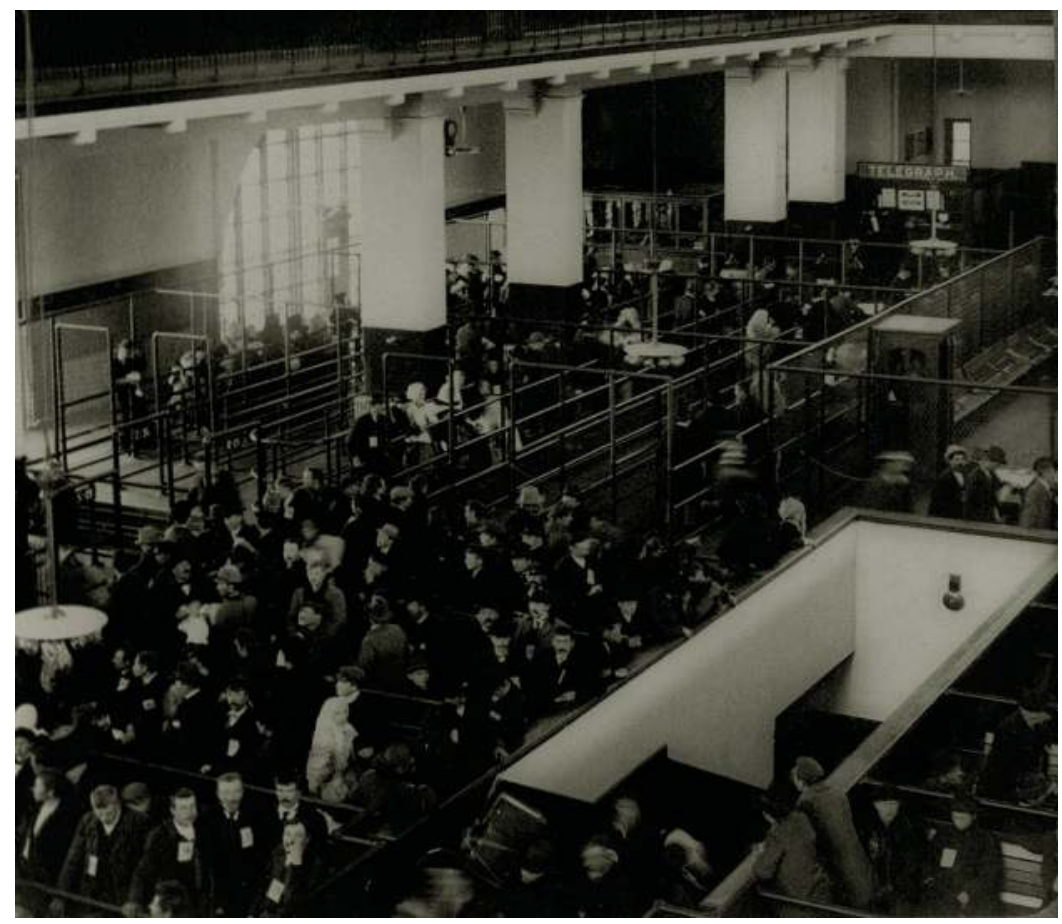

Image 2.3 Immigrants arriving at Ellis Island, New York Harbor, c.1904.

(Courtesy of the Library of Congress, Prints and Photographs Division) 
opined that this "tangle of squabbling nationalities" was a danger to American society, "the one certain way of bringing the nation to ruin." Already in 1882 the country had taken the step, for the first time in its history, of prohibiting one particular nationality from crossing its borders: the Chinese Exclusion Act banned the immigration of any additional people from China and set the stage for a dramatic drop in the resident Chinese population (see Chapter 4). In the older and eastern parts of the country, cities especially had become ethnic enclaves, with places like Chicago and Boston comprised of 75 percent first-generation immigrants, especially Polish and Irish, respectively. Not only were these groups not fully assimilating, "melting" into the American pot as was expected or imagined, but some were going so far as organizing their own ethnic institutions like the Sons of Italy or the Knights of Columbus; in some cases, they were even seizing municipal political offices.

After World War One, the US enacted a series of immigration reform laws, beginning with the National Origins Act in 1924. This Act set quotas for total immigration and for immigration per nationality. The limit for total immigration was 150,000 per year (one-fifth of the pre-war level), but the limit for each foreign nationality was pegged to its percentage of the already existing white population in America; in other words, large groups like English and German had high quotas, but smaller groups like Italians, Poles, and Russians had lower quotas. By definition, non-white groups like Asians were not permitted at all. The effect, indeed the intent, of the law was to slow immigration overall and, more specifically and significantly, to "freeze" the existing composition of the American population, so that it would not become more southern/ eastern European or Hispanic or Asian. If anything, some hoped that these non-WASP nationalities would emigrate back to their homelands.

A major revision to immigration policy occurred in 1965, with the simply named Immigration Act, which eliminated national-origin quotas. Instead, a total immigration cap of 290,000 per year was set, with limits per country (no more than 20,000) and per region $(120,000$ from the Western hemisphere and 170,000 from the rest of the world). Preferences were established for family members of previous immigrants, for skilled or professional workers, and, most interestingly, for refugees; this was, after all, the middle of the Cold War, and the US especially welcomed refugees from communist countries including Vietnam, where the US was engaged in a war, as well as from Cuba and other Iron Curtain states. These realities drove the immigration totals well beyond the official quotas between 1976 and 1985, with an average 546,000 immigrants/year. In 1980 alone, 800,000 arrived, a substantial percentage from Asia (Philippines and Vietnam) and of course Latin America, particularly Mexico.

According to the US Census, in 201039.9 million first-generation or foreign-born immigrants were living in the United States, comprising 12.9 percent of the country's population.

These new Americans were not evenly distributed throughout the country, nor were they distributed identically to the native-born population. In fact, more than half of all foreign-born residents lived in just four states-California, New York, Texas, and Florida. California had the highest percentage of foreign-born residents (27 percent) while West Virginia had the lowest (1 percent).

In aggregate, compared to native-born Americans, they also: 


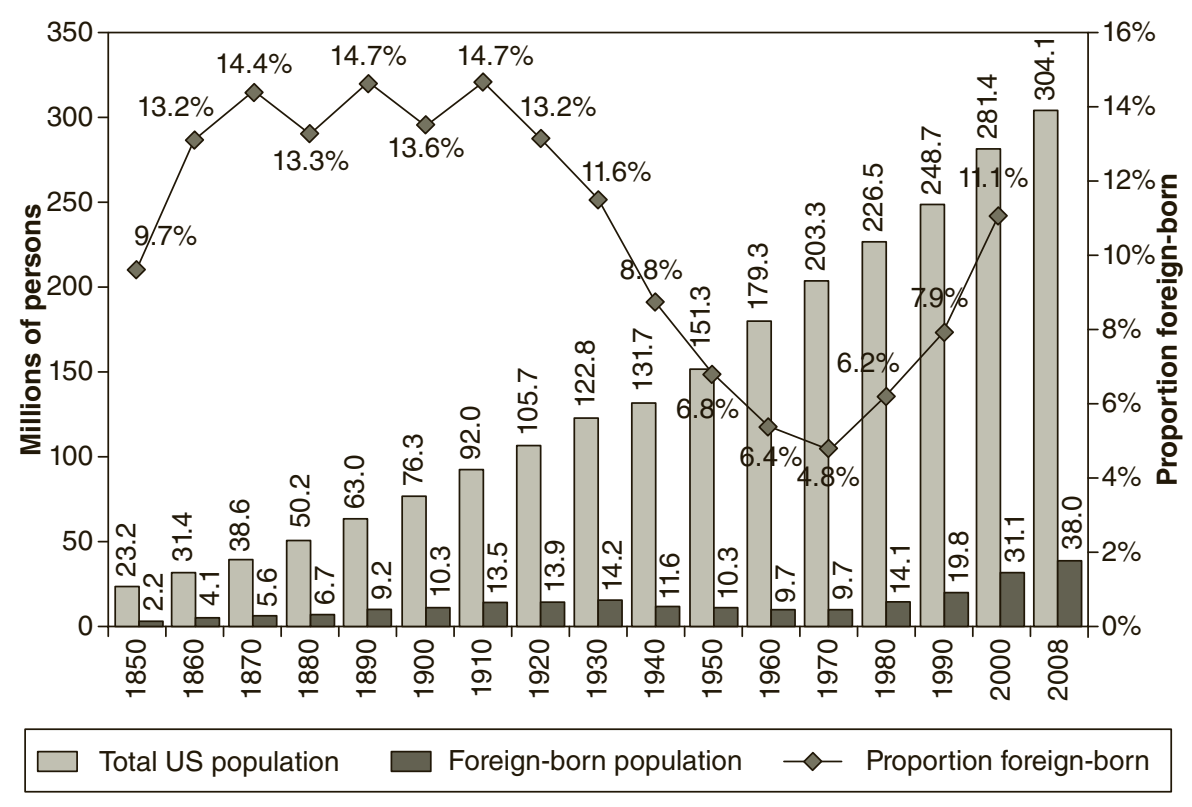

Figure 2.1 US total and foreign-born population, 1850-2008.

Source: Congressional Research Service. The U.S. Foreign-Born Population: Trends and Selected Characteristics, 2011

Table 2.2 Foreign-born population by region of birth, 2010

\begin{tabular}{lc}
\hline Region & Percent of foreign-born population \\
\hline Latin America & 53.1 \\
Central America & 36.9 \\
South America & 6.8 \\
Caribbean & 9.3 \\
Asia & 28.2 \\
Europe & 12.1 \\
Africa & 4.0 \\
Other regions & 2.5 \\
\hline
\end{tabular}

Source: US Census Bureau. American Community Survey Report: The Foreign-Born Population in the United States, 2010

- were more likely to be adults age 18 to 44 (50 percent versus 35 percent) but less likely to be children under age 18 (7.1 percent versus 26.5 percent);

- were more likely to be married (58 percent versus 47 percent);

- had higher fertility rates (70 births per 1,000 women versus 52 ) and lived in larger households (3.4 persons per household versus 2.5 ); 


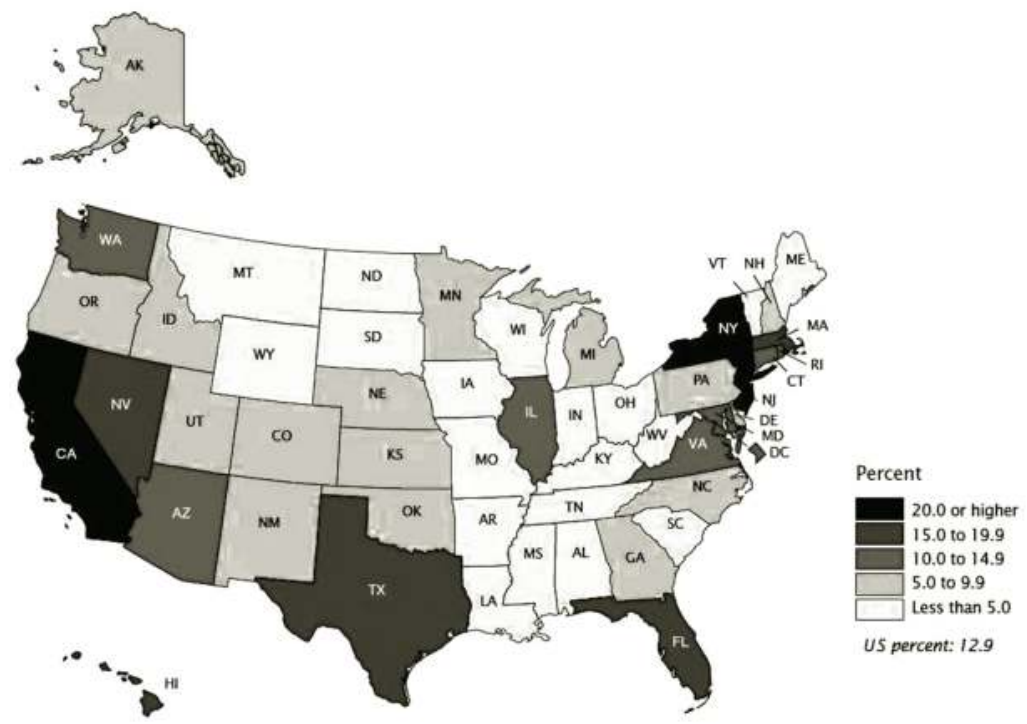

Figure 2.2 Foreign-born population as percentage of state population, 2010.

Source: US Census Bureau. American Community Survey Report: The Foreign-Born Population in the United States, 2010

Note: The full colour version of this map can be found on the companion website, www.routledge. com/cw/eller.

- were more likely to have less than a high school education (31.7 percent versus 11 percent) but roughly equally likely to have a college degree or higher education (27 percent versus 28.4 percent);

- more likely to live in poverty (19 percent versus 15 percent).

Significantly, education and income varied dramatically depending on the place of origin of the foreign-born residents: 48.5 percent of Asians and 40.3 percent of Africans had a bachelor's degree or higher, while only 18.5 percent of Caribbeans and 5.3 percent of Mexicans had achieved that level of education.

\section{Box 2.2 The Visa System in the US}

Like all modern state societies, the United States sets conditions for entry into the country, distinct from the requirements for citizenship in the country. The standard procedure for granting admittance into a modern state is the issuance of a visa, and the specific types of visas depend on the nature and duration of the stay in the country. There are many classes of visas in the US. Class B visas include B-1 for business visitors and B-2 for tourists. Class C-1 is a transit visa for people merely passing through en route to other destinations. Class F-1 is a student visa. Class $\mathrm{P}$ pertains directly to athletes or entertainers, while Class $\mathrm{R}-1$ applies to 
religious visits. The most relevant visa types for most temporary residents (those not seeking citizenship) are the "work visas" in the $\mathrm{H}$ class. The $\mathrm{H}-1 \mathrm{~B}$ visa allows college-educated professionals in "specialty occupations" to work in the country for up to three years, with possible extension up to six years; at the time of researching this book, a maximum of $65,000 \mathrm{H}-1 \mathrm{~B}$ visas were granted each year to doctors and nurses, computer specialists, engineers, scientists, financial analysts, architects, and lawyers. An $\mathrm{H}-2 \mathrm{~B}$ visa, on the other hand, grants short-term residence to skilled and unskilled laborers such as seasonal non-agricultural workers; a quota of 66,000 per year is set. Finally, permanent resident status can be achieved by acquisition of a "Green Card," of which some 55,000 are granted annually through the Diversity Immigrant Visa Program, also known as the Green Card Lottery. Green Cards are most commonly distributed on the basis of marriage to an American citizen or of relatives who are already US citizens by birth or naturalization.

\section{The Struggle for Culture: Multiculturalism and Identity Politics}

Given the dazzling diversity of national and cultural origin in the contemporary United States, it is predictable that culture would become an issue, even a sore spot, in American society. In fact, during the 1990s the term "culture wars" was frequently used, in both the political sense (as between "conservatives" and "liberals") and the ethnic-cultural sense (as between the mainstream, essentially white English-speaking Christian/Protestant, group and all other ethnic and racial groups). It is the latter sense we want to address here, in the social-cultural movement known as multiculturalism.

Multiculturalism arose out of the perception and the criticism that American society, not exclusively but especially the educational system, is highly "Eurocentric," focusing on the perspectives - the history, the literature, the values, etc.—of the white majority at the expense of the various non-white minorities. As Bernice Johnson Reagan stated it in an article called "Battle Stancing," intellectual and cultural attention is lavished on the European or European-derived elements of America while "the rest of us are pushed to the periphery, occupying the restricted category of 'other'" (1993: 71). The monocultural focus of traditional American society allows the dominant group to "maintain its stance of superiority by controlling the public resources intended for nurturing and disseminating cultural values" (p. 71). Accordingly, multiculturalists have complained that "American culture" has tended to mean white culture or Western culture, that "American literature" has tended to mean white literature or Western literature, that "American history" or "American music" has tended to mean white/Western literature or music, etc., while all other sources or subcultures in the US have been marginalized as "folk traditions" or "mythology" if not ignored altogether.

Multiculturalism, then, has generally demanded an acknowledgement of, a respect for, sometimes even a celebration of the multiple streams of American culture and society. One particular form that this demand has taken is the inclusion in the curriculum of schools and the broader "canon" (the official or unofficial list of "what counts" as literature or history or music and so on) of non-mainstream materials-of black, of Hispanic, of Native American, of Asian, sometimes also of female or of gay and lesbian or of disabled, etc., perspectives and achievements. This is imperative, they argue, not only for the self-esteem of these groups (who otherwise become invisible in the mainstream society) but for an honest assessment of the plurality of America's 
cultural past and present and for a more sophisticated understanding of how culture and society work in the late twentieth and early twenty-first centuries.

All multiculturalists agree that the multiplicity of America should somehow be recognized and that this recognition should lead to attitudinal and institutional changes. However, as in every other facet of human existence, multiculturalism is itself multiple and diverse. Kincheloe and Steinberg (2001), for instance, identified four different versions of multiculturalism, which they called liberal, pluralist, leftessentialist, and critical.

1 Liberal multiculturalism holds "that individuals from diverse race, class and gender groups share a natural equality and common humanity" (2001: 10). It emphasizes the sameness or unity that underlies group differences, adopting the stance there is only one race, the buman race. This form of multiculturalism thus promotes the commonalities of humanity over the differences.

2 Pluralist multiculturalism, which Kincheloe and Steinberg regarded as the predominant version, asserts that the diversity of humans is more significant than their sameness. Differences should be studied, protected, and even celebrated. It calls for a kind of "multicultural literacy" (16), e.g. adding other groups and voices to the canon, based on principles like inclusiveness and cultural pride.

3 Left-essentialist multiculturalism goes further, taking seriously the notion that there is something essentially and irreconcilably different about each particular group (its "essence"). It emphasizes concepts of "authenticity," "origins," and absolute unchangeable "identity." It can become exclusivist and even separatist, representing not an transcendence of Eurocentrism but the institutionalization of one or more alternatives centrisms (like Afrocentrism).The Afrocentrist professor of Harlem's City College, Leonard Jeffries, represented this position when he taught that dark-skinned people were "sun people," with more positive qualities than the white-skinned "ice people" who are "individualistic," "competitive," and "exploitative."

4 Critical multiculturalism, finally, more subtly and accurately views culture and identity as an ongoing process of self/group construction and self/group knowing. It also understands self and group in relation to large-scale social factors and relations, especially power. In the struggle for power, culture is an "ideology," and even multiculturalism is an ideology, produced and perpetuated by our linguistic, behavioral, and institutional practices (23-4).

To these four approaches, they added a fifth which they called conservative multiculturalism but which, as "the efforts to assimilate everyone who is capable of assimilation to a white, middle-class standard" (4), is actually monoculturalism: it recognizes that there are cultural differences now, but it aims to reduce, submerge, or erase these differences in the cause of a single unified culture-but a culture that is dominated by one privileged group above others. It might even rightly be dubbed anti-multiculturalism, and it bases its position on a number of claims. First, it sees multiculturalism as a movement and cultural diversity as a fact of American life to be dangerously divisive, to threaten the "disuniting of America" (Schlesinger 1992). Lawrence Auster has gone so far as to call it the "end of American civilization" (1994: 61). A society requires a 
common culture, proponents insist, and existing American culture (with its European, white, English-speaking, Christian roots) is that culture.

At its worst, monoculturalists accuse multiculturalists and representatives of various non-dominant groups of using culture and identity for political purposes, of playing a kind of identity politics. Rising originally out of activism on behalf of the disabled community (see Anspach 1979), identity politics grew into a philosophy "that identity itself-its elaboration, expression, or affirmation-is and should be a fundamental focus of political work" (Kauffman 1990: 67). In some cases, more than a mere recognition of a collective culture or identity, identity politics is "the recognition of a collective hurt" (Gitlin 1995: 147) which cannot be healed in any way other than collectively-and in contrast or even opposition to those who caused the hurt. Such an attitude, monoculturalists warn, can turn group differences into group enmity, into a wallowing in the cultural past and not simply demands for inclusion but "spirited assertions of the supremacy of one's own culture" (Parens 1994: 173).

Finally, some monoculturalists resist multiculturalism with the argument that it trendy, producing low-quality work that screams for undeserved attention. Thinkers like Dinesh D'Souza and Allan Bloom have argued that the American curriculum and canon include "dead white male" writers like Shakespeare and Plato not because those sources are white and male but because they are the best, which is why they have survived the centuries and still command respect today. Multiculturalism, D'Souza and Bloom countered, insists that non-white or female or gay/lesbian or non-Western materials be forced into the curriculum for no other reason than that they are nonwhite, female, gay/lesbian, or non-Western. There is no regard, monoculturalists assert, for quality, and the overall effect is to make disadvantaged groups feel better but to "dumb down" the level of education and literacy in American society. That is why monoculturalists write books with titles like Illiberal Education (D' Souza 1991) and The Closing of the American Mind (Bloom 1987). Culture should be color-blind and diversity-indifferent, they say-without realizing that the standard set for culture is set by their culture to the advantage of their culture.

\section{Conclusion}

Groups and categories of people exist in America, of many different kinds, with many different qualities, and-more importantly—in many different relations to each other. The relationships between groups are to a greater or lesser extent independent of the actual trait-differences between members of the groups, and these relationships can range from tolerant and mutually inclusive to separatist to hostile and violent.

"Cultural" or "ethnic" diversity is not the only dimension of diversity in the US, but it is a major and much-heralded dimension. The United States, as a new society and country, has received a steady but ever-changing stream of settlers over its history, bringing variety in race, language, religion, and every other conceivable characteristic and habit. The result has been, is, and seems likely to remain a pluralistic, multicultural society that may have a dominant culture and a (distant and questionable) future as an assimilated "melting pot" of peoples into something distinctly and universally "American" but for now and the near-future is an arena of struggling and evolving identity- and interest-groups, vying to define American society-and defining it in the process of vying for it, perhaps defining it as a place where people vie for culture. 


\section{Race and Racial Thinking}

Alexis de Tocqueville, that early and observant chronicler of American society, noted in 1830 that its inhabitants "are not, as in Europe, shoots of the same stock. It is obvious that there are three naturally distinct, one might almost say hostile, races. Education, law, origin, and external features too have raised almost insurmountable barriers between them; chance has brought them together on the same soil, but they have mixed without combining, and each follows a separate destiny. Among these widely different people, the first that attracts attention, and the first in enlightenment, power, and happiness, is the white man, the European, man par excellence, below him come the Negro and the Indian. These two unlucky races have neither birth, physique, language, nor mores in common; only their misfortunes are alike. Both occupy an equally inferior position in the land where they dwell; both suffer the effects of tyranny, and, though their afflictions are different, they have the same people to blame for them" (1969: 316-17).

How can the concept-and the history - of race in the US be reconciled with the American ideals of equality, liberty, and justice? Does "race" necessarily lead to "racism"? Can the US be a race-conscious society and, at the same time, a society of equality? And can the US ever cease to be a race-conscious society?

One of the defining practices and institutions of the United States, slavery, has been called "the peculiar institution"-peculiar perhaps because it was so contrary to the founding principles of the new democracy (not, certainly, because it was unusual in the world). To be sure, America was a slave society for a longer period of time than it has been without slavery, abolishing the practice only 150 years ago. If slavery is the peculiar institution in American history and society, then its underlying concept, race, must be the peculiar concept in American thought and experience. As we will see, not all societies have possessed quite the race concept prevalent in the US, nor have they used their race concept to quite the same ends. Race is, almost certainly, a, if not the, central and inescapable problem in American experience and consciousness.

If de Tocqueville is correct that the early US was the home of three races, then we will postpone the discussion of the other "unlucky race," the Native Americans, until the next chapter. In the present chapter, we will focus on black and white groups and relations, finding, first, that "white" is as much (or as little) a race as "black" and, second, that there is and long has been significant diversity within each of these groups or categories just as between them. 


\section{Race, Race Categories, and Race Ideology in the United States}

Race is an inevitable part of American discourse; hardly any discussion of history, class, politics, or contemporary social problems fails to raise the issue. Race is even present in discussions of "color-blind society" or "post-racial America," of how race supposedly does not matter anymore. Yet, despite the omnipresence of race in American experience, there is a wide (although not quite complete) consensus that race is not a natural, objective, "real" thing at all. Rather, as Audrey Smedley has written in her major analysis of race in North America, the "reality of race" resides in "a set of beliefs and attitudes about human differences, not the differences themselves" (1999: xi). Franz Boas, one of the founders of modern anthropology, critiqued the race concept even more strenuously, arguing first that there "is little clarity in regard to the term 'race'" (1928: 19), since people use it to refer to everything from the English race or the French race to the white or black race to the human race. Second, he insisted that the races as we think of them are a product of admixture from many different population sources; in other words, there "are not pure racial types. We do not know how much their descendants may vary from themselves and what their ancestry may have been" (22-3). Third, he discovered that racial traits, although physical, were not fixed and immutable but rather appeared to change over time; the defining features of a race only seemed stable as long as populations remained apart and environmental (including the social environment) conditions remained the same.

The most devastating attack on the race concept came from Ashley Montagu who, in his book Man's Most Dangerous Myth: The Fallacy of Race, concluded that "Such a conception of 'race' has no basis in scientific fact or in any other kind of demonstrable fact. It is a pure myth, and it is the tragic myth of our tragic era" (1945: 8). He pressed the point that race was less a physical fact than a social relationship, "a term for a social problem which is created by special types of social condition and by such special conditions alone. In terms of social relations so-called 'race problems' are, in the modern world, essentially of the nature of caste problems" (67). The physical characteristics ascribed to a race "are merely the pegs upon which culturally generated hostilities are made to hang” (66).

Manning Nash has helpfully redirected our attention away from the details of race characteristics and categories to the matter of racial thinking itself, to what he calls the "ideology of race." While questioning the natural, factual side of race, he continued to recognize the social importance and efficacy of race ideology, understood as

a system of ideas which interprets and defines the meanings of racial differences, real or imagined, in terms of some system of cultural values. The ideology of race is always normative: it ranks differences as better or worse, superior or inferior, desirable or undesirable, and as modifiable or unmodifiable. Like all ideologies, the ideology of race implies a call to action; it embodies a political and social program; it is a demand that something be done.

Smedley has gone so far as to identify five key components of the ideology of race in the US. These include the notions that: 


\section{Race and Racial Thinking}

1 a race is an "exclusive and discrete biological" entity;

2 races are fundamentally unequal, and the relations between races are necessarily hierarchical (some are "better" than others);

3 "the outer physical characteristics" of races are "but surface manifestations of inner realities [such as] behavioral, intellectual, temperamental, moral, and other qualities";

4 all of the qualities of a race are "natural" and genetically inherited-and inherited as a single indivisible bundle;

5 therefore, the differences and hierarchies between races are immutable, "fixed and unalterable, [and] could never be bridged or transcended" (1999: 28).

In other words, races are believed to be categorial, in the sense we discussed in Chapter 1: the categories of "white" or "black" or whatever are taken as absolute, mutually exclusive, and exhaustive. These categories are thus seen as real, permanent, and (at least ideally) unmixable; they are also inevitably ranked in relation to (i.e., superior or inferior to) each other. Most crucially, the traits of a race are thought to include psychological, cultural, and even "moral" ones, which are also "fixed and unalterable": some races are simply smarter or dumber, or more prone to crime or vice or delinquency.

Finally, as Nash proposed three decades earlier, a system of thought like American racial ideology is likely to develop in certain social contexts. Specifically, an ideology of race tends to coalesce when there is a conflict between two or more groups that are distinguishable in physical terms; when there is a division of labor based on this distinction that results in the "subordination or systematic deprivation of one group"; when the subordinate group resists its subordination; and interestingly when there is dissent within the dominant group over the "prevailing facts of disprivilege" (288). Under such conditions, racial thinking serves not only to subjugate the "lower race" but to help the "dominant race" justify to itself its advantages and privileges. Racial thinking is, then, a way of naturalizing social or cultural differences: the subordinate group is subordinated because of its inferior racial attributes. If Nash is correct, the appearance and elaboration of a race system would be caused by the social inequalities which it explains, legitimates, and perpetuates rather than be a cause of those inequalities.

\section{A History of Race in the US}

As de Tocqueville reminds us, from the moment that Europeans stepped on North American soil, there was racial diversity on the continent (Europeans and Native Americans). However, when most Americans think of race, they think in terms of "black" and "white." In the previous chapter we mentioned that Africans were also in America within a decade of the first permanent English settlements, the initial twenty arriving at Jamestown in 1619. Leon Higginbotham (1978), in his major study of race in colonial America, claimed that these unlucky souls were brought to Virginia involuntarily but not exactly as slaves; instead, they were treated, he determined, more or less as additions to the already existing social class into which whites had often been pressedthat of indentured servant. Although both were a form of compulsory labor, the status of indentured servant differed from the status of slave in two critical ways: in duration (indenture often consisted of a limited term of service) and in degradation (indentured 
servants were not deprived of all rights nor regarded as the property of their masters). And, consequentially, indentured servitude was not a status reserved solely for Africans; many Scottish and Irish laborers came to the colonies in the same boat, as it were.

\section{Africans and Slavery}

The traffic in African laborers grew steadily over the decades, as did the strictness of their servitude. In the 1650 s over one thousand reached colonial America, mostly Virginia. The 1660 s brought twice as many $(2,377)$, and by the 1690 s the slave trade had escalated to more than 6,600. At its peak (1730s), greater than 60,000 Africans disembarked in the future US, almost half destined for Virginia and most of the rest headed for Georgia and the Carolinas. The slave trade declined fairly steadily after that, to 14,000 in the 1790 s, although there was a brief spike to 73,000 in the years from 1801 to 1810 , then only 91 in the 1820 s. Officially the importation of slaves was outlawed in 1808, although slavery still continued and as many as tens of thousands of new slaves may have been imported illegally. All in all, between 400,000 and 600,000 living Africans arrived on American soil during the era of the slave trade (many more died during the Atlantic passage), some 90 percent from coastal West Africa and interior West-Central Africa. By most reckonings, the traffic in Africans to the British colonies constituted 5-6 percent of the total trade, much greater numbers destined for Brazil (38 percent), Spanish America (17 percent), and French America (13 percent).

As this physically distinct population grew, the institution of slavery gradually solidified: "By the later part of the seventeenth century," Higginbotham found, "slavery would be defined as a lifetime and hereditary form of servitude" (1978: 25). Virginia imposed lifetime servitude on Africans in 1640, although as late as 1669 it was still conceivable for an African to be a freeman or even to have power over whites (30). Further, an act of the Virginia legislature in 1669 decriminalized the killing of a slave who dared to escape from or even resist his/her white master. Between 1680 and 1682 an explicit "slave code" emerged in Virginia,

expressing a mixture of fear, greed, and prejudice, [which] simply reduced the privileges and rights of blacks. [The whites] rationalized their actions on the ground of security, without religious or moral qualm whatsoever. . . And just as often, they probably made no effort at all to find a rationale; they simply dehumanized those who were black because of the color of their skins and because blacks were largely powerless to prevent it.

It was only around this time (1690s) that Africans began to arrive in South Carolina in large numbers, and by 1708 blacks actually outnumbered whites in the colony. Perhaps because of this demographic reality, or perhaps because of Virginia's prior experience, South Carolina "started with a relatively definitive legal structure on slavery based on a fierce determination to use slavery wherever it was profitable" (152). The colony of Georgia, chartered in 1732, at first seemed poised to avert the worst of the new slave system, but "with the writing and passage of slave codes of 1755 , 1765, and 1770, Georgia quickly became as strict as any other American colony in the prohibitions on freedom enforced against enslaved blacks" (217). 
Despite the noble assertion in the 1776 Declaration of Independence that all men were created equal, slavery persisted during and after the American Revolution. In the first US Census in 1790, 697,681 slaves were counted, among the 757,000 blacks in the country or 19 percent of the nation's population of nearly 4 million. (The slave population rose to $3,950,546$ by 1860 , on the eve of the Civil War.) In that first census, Virginia still claimed almost half of slaves (over 300,000), with Maryland and North and South Carolina each containing over 100,000. Despite these noteworthy numbers, slavery was by and large a small-scale enterprise: 50 percent of slave owners possessed less than five slaves at a time, and almost three-quarters owned less than ten. It was the rare rich white landholder who mastered more than a dozen-like George Washington, who claimed 188 on his property in 1782 .

As mentioned, the slave trade was banned in 1808 but the peculiar institution of slavery persisted. Notwithstanding a growing abolition movement (to end slavery altogether), many white Americans could not or would not foresee the end of the practice. For many, slave labor was an absolute necessity for the economy of the expanding society, especially after the introduction of the cotton gin in 1793 and the increased profitability of farm production; at least, they+ maintained, freedom should come slowly, and owners should be compensated for their losses. More than a few accepted the natural inferiority of the black person and the impossibility of his/her emancipation. And some positively lauded the institution as a blessing: as reported by Waldrep and Bellesiles, one "moderate" newspaper in Atlanta stated, "We regard every man in our midst an enemy to the institutions of the South, who does not boldly declare that he believes African slavery to be a social, moral, and political blessing" (2006: 146). Either way, the feelings over slavery were white-hot, leading to difficult "compromises" like the 1820 agreement to admit Missouri into the Union as a slave state in exchange

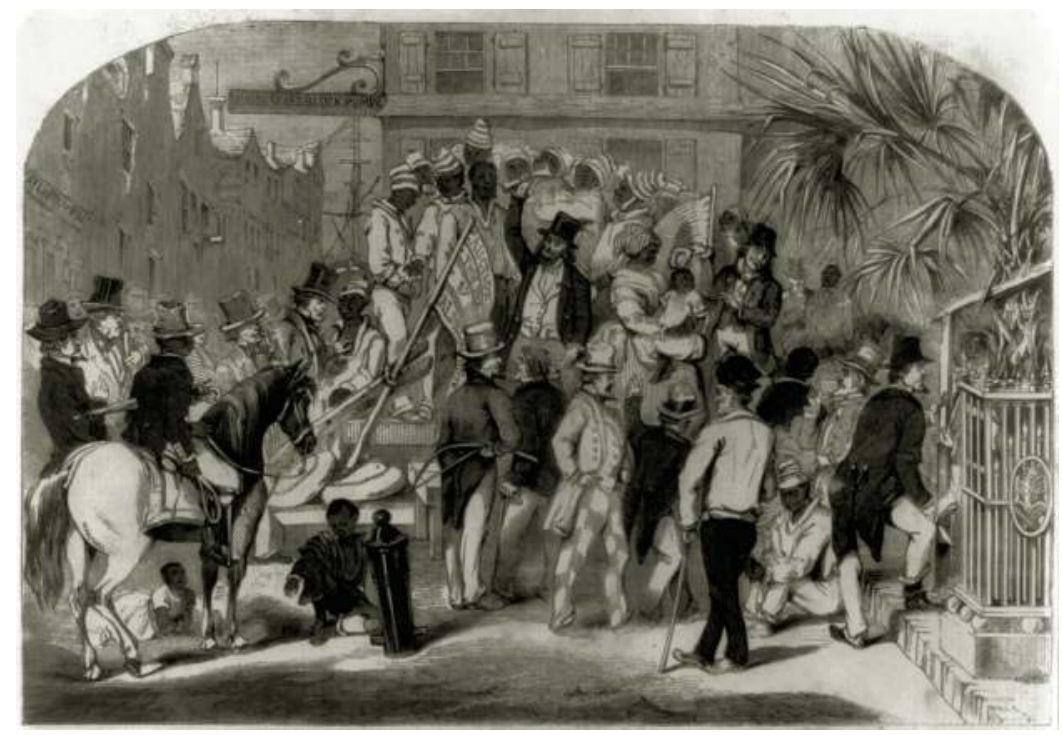

Image 3.1 Slave sale in Charleston, South Carolina.

(Courtesy of the Library of Congress, Prints and Photographs Division) 
for Maine as a non-slave state. The so-called Missouri Compromise was repealed in 1854 with the Kansas-Nebraska Act, which provided for popular determination as to whether any new states would be slave-owning or not. This led, not unpredictably, to confrontations and violence between proponents and opponents of slavery, in which people were assaulted or killed and the entire city of Lawrence, Kansas was burned in 1856. In fact, one pro-slavery advocate named Benjamin Stringfellow actually urged his side to "mark every scoundrel ... that is the least tainted with free-soilism or abolitionism, and exterminate him.... I advise you, one and all, to enter every election district in Kansas ... and vote at the point of the bowie-knife and the revolver" (quoted in Waldrep and Bellesiles 2006: 144).

\section{Diversity Fact:}

The distribution of Africans in the early United States varied dramatically by region. In 1790 there were 657,000 black slaves in the South and only 40,000 in the North. However, not all blacks in the South were enslaved: there were also 32,457 free blacks in the South (and 27,000 in the North, or more than one-third of the Northern black population). Virginia alone held 41 percent of the black slave total, and New England held virtually none. In 1860 the entire Northeast had altogether 18 black slaves and 156,000 free blacks, while the South had 3.8 million slaves, representing 34.5 percent of the region's people. Virginia had the largest number of slaves (more than 472,000), but South Carolina had the largest state percentage of slaves (57.2 percent).

\section{From Emancipation to Segregation}

In 1860 African slavery was a well-entrenched institution. There were approximately 4 million slaves in the US, more than 3.5 million in the South and almost half a million in the border states. The total number of slave owners was around 385,000, including nearly one-third of all households in the South and close to one-half of all households in South Carolina and Mississippi. In the Dred Scott case of 1857 (Scott $v$ Sanford), the Supreme Court had already upheld the legality of slavery, declared that blacks were not qualified to be US citizens, and ruled that the federal government did not have the authority to ban slavery in states. As is generally known, the American Civil War was fought partly over slavery, or more broadly over states' rights, that is, whether each state could make its own laws on slavery and other issues or whether the federal government could impose standard laws on all states. In the midst of the Civil War (1861-5), Abraham Lincoln issued his Emancipation Proclamation on January 1, 1863. Of course, the Proclamation had little effect until the war was won and slavery was officially abolished by the Thirteenth Amendment to the Constitution (ratified December 6, 1865), which stipulated simply that "Neither slavery nor involuntary servitude, except as a punishment for crime whereof the party shall have been duly convicted, shall exist within the United States, or any place subject to their jurisdiction." This was followed by the Fourteenth Amendment (1868), which granted that "All persons born or naturalized in the United States," including former slaves, were 
citizens with all the "privileges and immunities" proper to a citizen, and the Fifteenth (1870), which legally secured the right to vote regardless of "race, color, or previous condition of servitude."

And so it would seem that America's race problem was solved. Instead, of course, immediately the practical and the legal/political status of African Americans did not change much at all. Most freed slaves, with little other option, continued to labor on Southern farms, now as "sharecroppers" instead of slaves; however, their economic wealth and political power did not advance much, if at all. Additionally, the military occupation of the South by the federal government (known as Reconstruction) turned many white Southerners against the reforms imposed from outside. Even the Civil Rights Act of 1875, which ostensibly granted equal rights to African Americans in public accommodations and access to court, had little impact and was soon reversed (see below). And to be sure, generations of racist attitudes were not going to be altered suddenly with the stroke of a pen.

In 1877 Reconstruction ended, federal troops were withdrawn from the South, and national efforts to guarantee black rights were curtailed. From that moment, new legal restrictions were enacted in Southern states to re-establish much of the privilege of whites that had been lost in the Civil War. These laws, known popularly as "Jim Crow" laws, formed the basis of the system of segregation for nearly a century. In 1881, for instance, public transportation (railroad cars) was segregated in Tennessee, then in other Southern states. In 1883 the Civil Rights Act was negated, ruled unconstitutional by the Supreme Court. This unleashed a new set of initiatives to constrain freed slaves, including poll taxes and literacy tests to disqualify them from voting. In many locations, separate (and substandard) schools, hospitals, restaurants or dining areas, bathrooms, old-age homes, prisons, neighborhoods, and (in Louisiana) ticketbooths at the circus were established, essentially creating two parallel societies, one white and one black. Obviously, intermarriage or "miscegenation" was prohibited in several states. All of this was sanctioned again by the Supreme Court in 1896 with its Plessy $v$ Ferguson decision, ruling that "separate but equal" facilities and accommodations for different races were legal.

The renewed oppression of Africans did not take the form merely of legal restrictions, though; in multiple instances, it took the form of true violence. Lynching was one of the principal coercive means of keeping the freed blacks in their place. Lynching, a kind of vigilante justice in which gangs of men would seize and typically kill and/ or burn a victim, was an old tradition in the US, and one not reserved exclusively for blacks; rather, it was applied to undesirables of all sorts, from horse thieves to drunks to the poor and indigent. However, according to one major study of the practice (National Association for the Advancement of Colored People 1919), of the 3,224 people lynched in the period from 1889 to $1918,78.2$ percent were black and 21.8 percent were white. Whites were actually the majority of victims in most parts of the country, but in the South over 80 percent were black.

In addition to individual lynchings, there were also sporadic and destructive race riots, a number in the years immediately after the Civil War: New Orleans, Louisiana (1866, 1868, and 1874), Memphis, Tennessee (1866), Meridian, Mississippi (1870), Vicksburg, Mississippi (1874), and Yazoo City, Mississippi (1875). Another wave of rioting occurred in the late 1800s and early 1900s, in places like Lake City, North Carolina (1898), Wilmington, North Carolina (1898), Greenwood County, 
Table 3.1 Lynching victims by race and region, 1889-1918

\begin{tabular}{lcccc}
\hline Region & Total white & $\begin{array}{l}\text { Percent } \\
\text { white }\end{array}$ & Total black & $\begin{array}{l}\text { Percent } \\
\text { black }\end{array}$ \\
\hline All of US & 702 & 21.8 & 2,522 & 78.2 \\
New England & 118 & 54.4 & 101 & 45.6 \\
Mid-Atlantic & 4 & 50 & 4 & 50 \\
East North Central & 33 & 53.1 & 30 & 46.9 \\
West North Central & 80 & 54.7 & 67 & 45.3 \\
South Atlantic & 78 & 9.1 & 784 & 90.9 \\
East Central South & 134 & 13.3 & 880 & 86.7 \\
West Central South & 213 & 21.7 & 745 & 78.3 \\
Mountain West & 114 & 92.3 & 12 & 7.7 \\
Pacific West & 43 & 93.5 & 3 & 6.5 \\
Alaska and Unknown & 15 & 100 & 0 & 0 \\
\hline
\end{tabular}

Source: NAACP. Thirty Years of Lynching in the United States 1889-1918

South Carolina (1898), New Orleans (1900), New York City (1900), Wilmington, Delaware (1903), Springfield, Ohio (1904), Atlanta (1906), Greenburg, Indiana (1906), Brownsville, Texas (1906) and Springfield, Illinois (1908). Some of the worst riots happened in the aftermath of World War I, as in Philadelphia (1917), Houston (1917), Washington DC (1919), Chicago (1919), Omaha (1919), Charleston, South Carolina (1919), Longview, Texas (1919), and perhaps most notoriously Tulsa, Oklahoma (1921), where up to 76 people were killed during the destruction of a thirty-squareblock predominantly black area of north Tulsa. Some observers even maintained that whites used airplanes to bomb the neighborhood.

The late 1800 s and early 1900 s was also, not surprisingly, the era of "scientific racism" and of eugenics, the empirical and quantitative study of "racial differences" to explain and justify racial inequality as well as the attempt to control and "breed out" unwanted physical traits. In the name of anthropometry, for instance, efforts were undertaken to measure and compare bodily features like head size and shape, face shape and angle, and length of limbs in order to determine the "superior" and the "primitive" characteristics of humanity. Of course, these scientists found what they wanted to find: that Africans had smaller brains, less desirable cranial and facial shapes, and more "primitive" anatomy than whites. As Haller noted in his study of scientific racism, the consistently low ranking of Africans proved to the contemporary racists that the black race bore "a far closer relationship to the ape" than did any other race (1971: 34), which "relegated the Negro to the bottom of the scale of race development" (49-50). More than a few influential figures of the day, like Edward Drinker Cope, insisted that the "inferior character of the Negro mind in the scale of evolution made him unfit for American citizenship" (198), while Nathaniel Southgate Shaler went so far as to excuse lynching as a legitimate form of race self-defense (184-5).

It will be noted above that some of the race riots of the last century occurred in Northern cities like Philadelphia and New York. This is because arguably the single most significant change in African American demographics since the introduction of slavery was the migration of a great many Southern blacks to the North a generation or two after the Civil War. In what is sometimes dubbed the Great Migration, almost 5 million African Americans moved northward in the first half of the twentieth century, 
most to large cities like Chicago, Cleveland, Detroit, Pittsburgh, and New York. This, naturally, shifted the demographics of the North and of urban areas in historically important ways, driving many white people out of city centers and into (generally racially segregated) suburban neighborhoods (what is known as "white flight") and creating black-majority and predominantly poor downtown districts characterized by ghetto or slum conditions (see Chapter 12). (Interestingly, the last couple of decades have witnessed a noteworthy migration of African Americans back to Southern cities like Atlanta.)

As happens in all situations of migration and urbanization, African Americans in the early twentieth century began to become more conscious of their status as a disadvantaged population and to organize and mobilize on that basis. One of the key and most enduring institutions established in this period was the National Association for the Advancement of Colored People (NAACP), founded on February 12, 1909 (Lincoln's birthday) as an organization to promote the legal and civil rights of blacks. One of the leading figures in the formation and early activity of the NAACP was William Edward Burghardt Du Bois, better known as W. E. B. Du Bois. An effective activist and an accomplished sociologist, Du Bois not only spearheaded the drive for black equality but also studied and wrote about the social and psychological plight of Africans in America. His best-known work is The Souls of Black Folk (1903), in which he identified the duality, the otherness, not only in American society, riven as it was by racial difference and unrest, but in the African American personality and soul specifically.

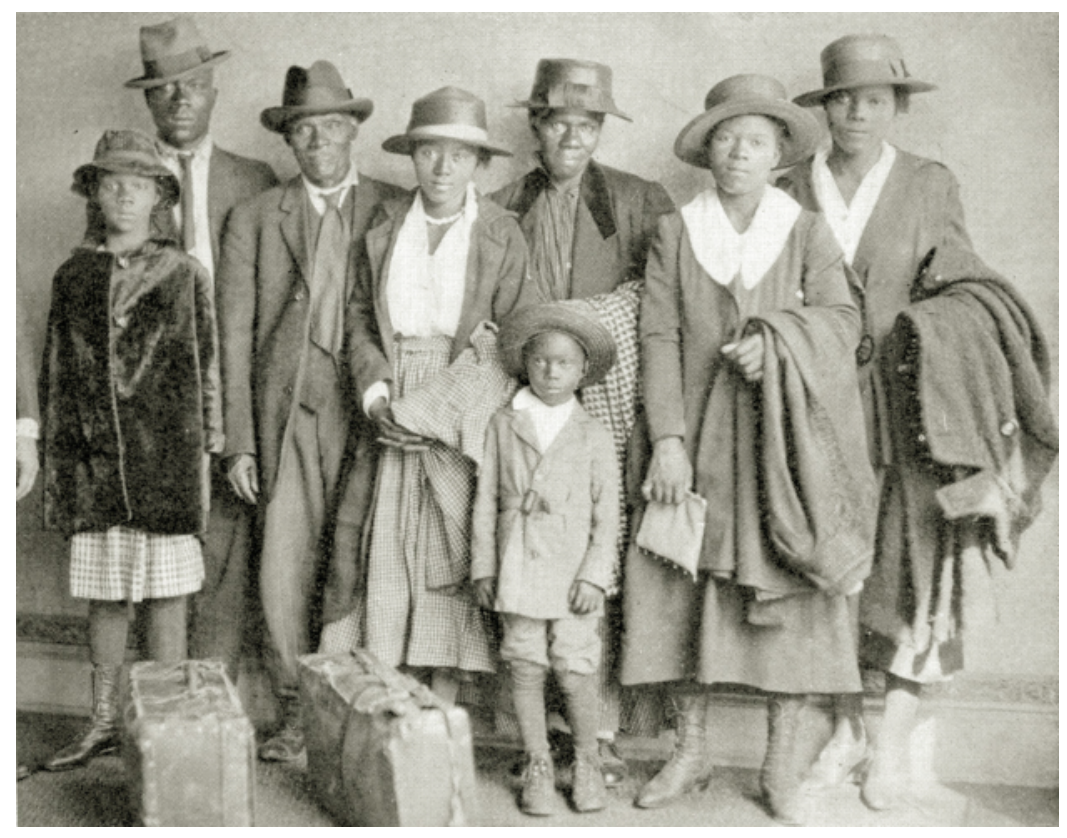

Image 3.2 The "Great Migration" to the North—Chicago, 1918.

(Courtesy of Chicago History Museum/Getty Images) 


\section{Box 3.1 “Double-Consciousness” among African Americans}

According to Du Bois, Africans in the US suffered an almost insurmountable problem-their own double-consciousness as Americans and yet non-Americans, as an indelible part of American society and yet not really a part of American society at all. In The Souls of Black Folk he wrote:

the Negro is a sort of seventh son, born with a veil, and gifted with second-sight in this American world-a world which yields him no true self-consciousness, but only lets him see himself through the revelation of the other world. It is a peculiar sensation, this double-consciousness, this sense of always looking at one's self through the eyes of others, of measuring one's soul by the tape of a world that looks on in amused contempt and pity. One ever feels his twoness-an American, a Negro; two souls, two thoughts, two unreconciled strivings; two warring ideals in one dark body, whose dogged strength alone keeps it from being torn asunder.... The history of the American Negro is the history of this strife-this longing to attain self-conscious manhood, to merge his double self into a better and truer self. In this merging he wishes neither of the older selves to be lost. He would not Africanize America, for America has too much to teach the world and Africa. He would not bleach his Negro soul in a flood of white Americanism, for he knows that Negro blood has a message for the world. He simply wishes to make it possible for a man to be both a Negro and an American, without being cursed and spit upon by his fellows, without having the doors of Opportunity closed roughly in his face.

(2006: 9)

\section{Integration or Separatism?}

This internal duality was reflected in the diversity of African American attitudes and initiatives, in the first years of the twentieth century and beyond, especially in the split between "integrationists" and "separatists." Du Bois (and later Martin Luther King) was an integrationist, who aspired and worked for a single united America in which, as King put it, white children and black children would be equally welcome and individuals would be judged by their character and not by their skin color. However, not all blacks in America shared this same vision and goal.

In Du Bois' own time, the main rival to the integrationist activities of the NAACP was Marcus Garvey and the "Back to Africa” movement. Arising around 1920, Garvey and his some 3 million followers concluded that the white majority would never accept blacks as equals and that blacks should stop trying to gain white acceptance. Instead, black Americans should develop self-reliance and racial pride (what would, decades later, be expressed as "black is beautiful"). Blacks should voluntarily separate themselves from white American society, creating their own institutions and exercising their own power. But, since this goal seemed impossible on the North American continent, Garvey advocated a return to Africa, where blacks could once again be "at 
home" and, thus, resolve once and for all their double-consciousness by rejecting their American consciousness and embracing their African identity.

In the 1930s, a still more radical version of African separatism emerged, this time associated not with the land of Africa as much as with the religion of Islam. Its leaders, like Elijah Muhammad, argued that Islam was the true religion and identity of Africans and that Christianity was a white religion forced upon blacks by slaveryone dimension of the deculturation of Africans in America, that is, the suppression of their true selves. Hence came the Nation of Islam or, as its full name suggests, the Lost Found Nation of Islam in the Wilderness of North America. During the 1950s the Nation of Islam gained members and attention under the guidance of Malcolm X, who disdained "white culture" including Christianity and English (or "slave") names, referring black identity back to Islam and Africa (where there had, in fact, been powerful Islamic societies in central Africa prior to slavery). In the 1950s and 1960s many prominent African Americans took Islamic names, most famously the championship boxer Cassius Clay, who became Muhammad Ali. Some black separatists went so far as to demand their own racial territory in the US as well as reparations for the damage done to them by slavery; after all, they argued, it was their labor that had built this country, and they had never received anything in return. Malcolm X was killed in 1965, and in recent years Louis Farrakhan has been the face of the Nation of Islam.

Meanwhile, the integrationist side strived for inclusion and justice in mainstream American society. Its crowning achievement was the 1954 Brown $v$ Board of Education of Topeka, Kansas Supreme Court decision, which ruled, after nearly a century of legal segregation, that "separate but equal" facilities were unconstitutional. The NAACP had argued the case against official segregation, and now the federal government was empowered to begin the dismantling of Jim Crow laws and the system of racial discrimination pervading American society. However, a court ruling does not automatically change the law, let alone human attitudes. Inspired by the decision, and for the purpose of directly challenging segregation laws, the "civil rights" movement got underway in 1955 when Rosa Parks of Montgomery, Alabama intentionally refused to give her bus seat to a white person. Her action sparked a boycott by blacks of the bus system and other white businesses and led to the formation of the Southern Christian Leadership Council (SCLC) in 1957, led by Dr. Martin Luther King, Jr. King advocated a unique form of action, based on Mahatma Gandhi's policy of nonviolence in resistance to British colonialism in India. Civil disobedience, that is, deliberately breaking unjust laws, coupled with nonviolent resistance (for example, sit-down strikes and peaceful demonstrations, with no attempt to avoid arrest), allowed the civil rights activists to claim the moral high ground as Americans watched menacing white authorities attack peaceful crowds with dogs and water hoses.

The racial integrationist movement always focused its efforts on law and institutions, especially schools. Jim Crow had called for separate schools and colleges, but Brown $v$ Board of Education banned them. Accordingly, President Eisenhower ordered federal troops into Little Rock, Arkansas to enforce school desegregation, while Governor George Wallace of Alabama stood on the steps of the University of Alabama to prevent black students from entering and to promote "segregation now and forever." In 1963, 200,000 marchers gathered in Washington, DC to demand their civil rights, and in 1964 the Civil Rights Act provided for equality of all citizens 
in voting, education, public accommodations, and federally funded programs. A further Act in 1968 ensured equality in access to housing and real estate.

Despite these gains, or perhaps because of them, the separatist and even militant side of black activism continued to expand. After 1965 the Student Nonviolent Coordinating Committee (SNCC) became a leading voice in the "black power" movement. Personalities like Stokely Carmichael echoed Marcus Garvey's and Malcolm X's earlier calls for autonomous black action and the preservation of the African American community and culture, that is, non-assimilation. With the slogan "Black is beautiful," the movement sought to empower African Americans to solve their own social, political, and economic problems through control of their own institutions like schools, businesses, and government. Rioting also broke out again, in 1964 in the Los Angeles neighborhood of Watts and after Martin Luther King's assassination in 1968. Finally, the Black Panthers, formed to prosecute an aggressive program of civil rights and social justice, expressed in their "Ten Point Plan":

1 "We want freedom, we want power to determine the destiny of our black and oppressed communities.

2 "We want full employment for our people.

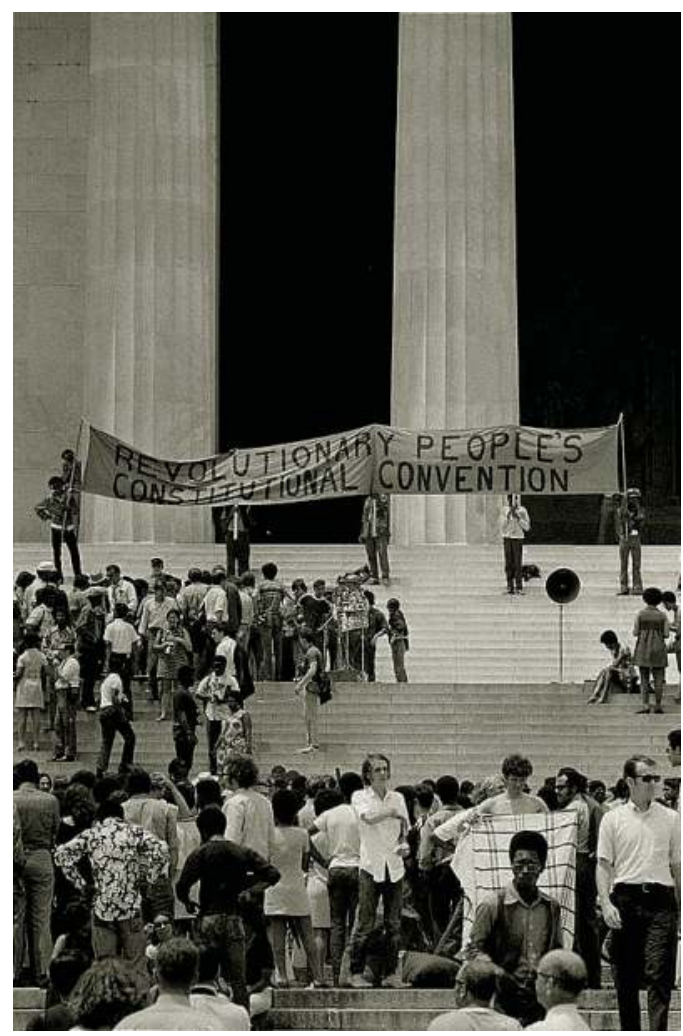

Image 3.3 Black Panther rally, Lincoln Memorial, 1970.

(Courtesy of the Library of Congress, Prints and Photographs Division) 
3 "We want an end to the robbery by the capitalists of our black and oppressed communities.

4 "We want decent housing, fit for the shelter of human beings.

5 "We want decent education for our people that exposes the true nature of this decadent American society. We want education that teaches us our true history and our role in the present-day society.

6 "We want completely free health care for all black and oppressed people.

7 "We want an immediate end to police brutality and murder of black people, other people of color, all oppressed people inside the United States.

8 "We want an immediate end to all wars of aggression.

9 "We want freedom for all black and oppressed people now held in US federal, state, country, city, and military prisons and jails. We want trials by a jury of peers for all persons charged with so-called crimes under the laws of this country.

10 "We want land, bread, housing, education, clothing, justice, peace, and people's community control of modern technology."

\section{Race in Contemporary American Society}

Not only the racial composition but the racial thinking and the very racial categories of the US have changed over time. In the Census of 1850, for instance, "color" was polled, and three options were available (white, black, and "mulatto" or mixed); theoretically, then, only two actual races were officially recognized. The 1880 Census introduced more categories: white, black, mulatto, Chinese, and Indian (Native American). The most recent census, conducted in 2010, took a very different approach, asking respondents first to identify as "Spanish/Hispanic/Latino" or not and then to select a race from a remarkably longer list of alternatives or to write in "some other race" (see Figure 3.1). The principal race categories employed were "White," "Black or African American," "American Indian and Alaska Native," "Asian," "Native Hawaiian and Other Pacific Islander," and "Some Other Race," defined as follows:

- White "refers to a person having origins in any of the original peoples of Europe, the Middle East, or North Africa. It includes people who indicated their race(s) as 'White' or reported entries such as Irish, German, Italian, Lebanese, Arab, Moroccan, or Caucasian."

- Black or African American "refers to people having origins in any of the Black racial groups of Africa. It includes people who indicated their race(s) as 'Black, African Am., or Negro,' or reported entries such as African American, Kenyan, Nigerian, or Haitian."

- American Indian and Alaska Native "refers to a person having origins in any of the original peoples of North and South America (including Central America) and who maintains tribal affiliation or community attachment. This category includes people who indicated their race(s) as 'American Indian or Alaska Native' or reported their enrolled or principal tribe, such as Navajo, Blackfeet, Inupiat, Yup'ik, or Central American Indian groups or South American Indian groups.”

- Asian "refers to a person having origins in any of the original peoples of the Far East, Southeast Asia, or the Indian subcontinent, including, for example, Cambodia, China, India, Japan, Korea, Malaysia, Pakistan, the Philippine Islands, 
Thailand, and Vietnam. It includes people who indicated their race(s) as 'Asian' or reported entries such as 'Asian Indian,' 'Chinese,' 'Filipino,' 'Korean,' 'Japanese,' 'Vietnamese,' and 'Other Asian' or provided other detailed Asian responses.”

- Native Hawaiian and Other Pacific Islander "refers to a person having origins in any of the original peoples of Hawaii, Guam, Samoa, or other Pacific Islands. It includes people who indicated their race(s) as 'Pacific Islander' or reported entries such as 'Native Hawaiian,' 'Guamanian or Chamorro,' 'Samoan,' and 'Other Pacific Islander' or provided other detailed Pacific Islander responses.”

- Some Other Race finally "includes all other responses not included in the White, Black or African American, American Indian or Alaska Native, Asian, and Native Hawaiian or Other Pacific Islander race categories described above. Respondents reporting entries such as multiracial, mixed, interracial, or a Hispanic or Latino group (for example, Mexican, Puerto Rican, Cuban, or Spanish) in response to the race question are included in this category."

By these standards and definitions, the racial composition of the US was as reported in Table 3.2.

\section{Is this person of Hispanic, Latino, or Spanish origin?}

No, not of Hispanic, Latino, or Spanish origin

Yes, Mexican, Mexican Am., Chicano

Yes, Puerto Rican

Yes, Cuban

Yes, another Hispanic, Latino, or Spanish origin - Print origin, for example, Argentinean, Colombian, Dominican, Nicaraguan, Salvadoran, Spaniard, and so on. Z

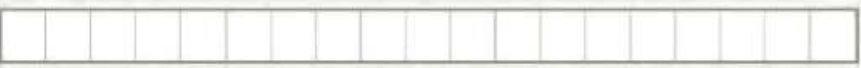

6. What is this person's race? Mark $X$ one or more boxes.

White

Black, African Am., or Negro

American Indian or Alaska Native - Print name of enrolled or principal tribe.

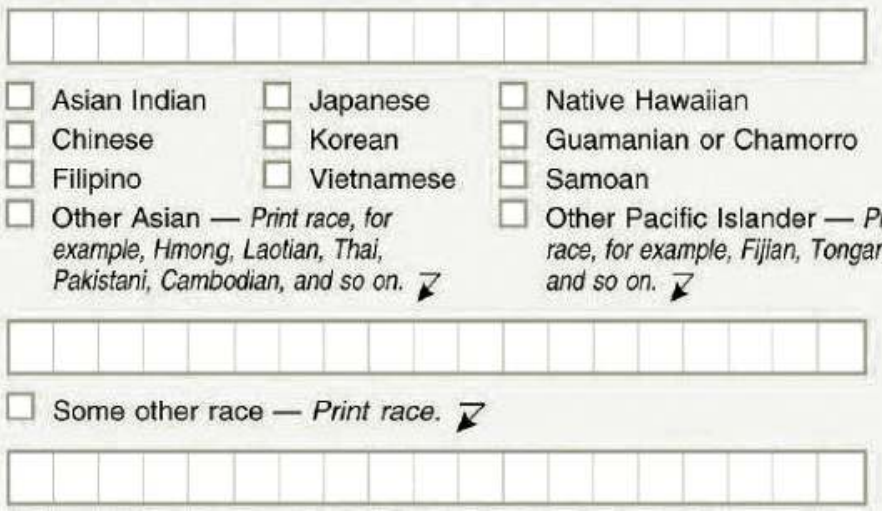

Figure 3.1 2010 Census questions on Hispanic origin and race. 
Table 3.2 US population by race and Hispanic origin, 2010

\begin{tabular}{lrc}
\hline Race & Number & $\begin{array}{c}\text { Percent of } \\
\text { population }\end{array}$ \\
\hline Total population & $308,745,538$ & 100 \\
One race & $299,736,465$ & 97.1 \\
White & $223,553,265$ & 72.4 \\
Black or African American & $38,929,319$ & 12.6 \\
American Indian and Alaska Native & $2,932,248$ & 0.9 \\
Asian & $14,674,252$ & 4.8 \\
Native Hawaiian and Other Pacific Islander & 540,013 & 0.2 \\
Some other race & $19,107,368$ & 6.2 \\
Two or more races & $9,009,073$ & 2.9 \\
Hispanic or Latino & $50,477,594$ & 16.3 \\
\hline
\end{tabular}

Source: US Census Bureau. 2010 Census Brief: Overview of Race and Hispanic Origin

In 2000, for the first time in American history, the Hispanic population outnumbered the African American population-a potentially significant development (see Chapter 4). Also, of those who self-identified with more than one race, the most common combinations were "White and Black/African American" (1,834,212), "White and Some Other Race" (1,740,924), "White and Asian" $(1,623,234)$, and "White and American Indian/Alaska Native" (1,432,309). Finally, to make matters maximally complicated, 676,469 people identified as three races, 57,875 as four races, 8,619 as five races, and 792 as six races. The utility of America's trusty race categories suddenly appears to be in question.

\section{Desegregation and Affirmative Action}

Political initiatives like the 1964 Civil Rights Act, as epochal and well-intentioned as they are, do not automatically change social realities; they merely provide the basis for changing them. These realities included individual and institutional discrimination against non-whites in housing, education, and employment. Even before the Civil Rights Act, President John F. Kennedy had issued Executive Order 10925, instructing those businesses that received government contracts to "take affirmative action to ensure that applicants are employed, and that employees are treated during employment, without regard to their race, creed, color, or national origin." The order also created an agency, the Committee on Equal Employment Opportunity. Hence the policy known as affirmative action was born.

The philosophy of affirmative action was premised on the historical and informal disadvantages that prevented non-whites from achieving equality, even when the formal barriers had been removed. As President Lyndon Johnson explained in 1965,

You do not take a person who for years has been hobbled by chains and liberate him, bring him up to the starting line of a race and then say, "You're free to compete with all the others," and still justly believe that you have been completely fair. Thus it is not enough just to open the gates of opportunity. All our citizens must have the ability to walk through those gates. 
So, proactive steps were to be taken to correct past injustices. The two main arenas of these steps were in jobs and education. In late 1971 the Department of Labor (Revised Order No. 4) mandated that all its contractors develop "an acceptable affirmative action program" to determine where they were "deficient in the utilization of minority groups and women" and to establish "goals and timetables to which the contractor's good faith efforts must be directed to correct the deficiencies." These goals were conceived not as "rigid and inflexible quotas" but as "targets reasonably attainable" through "good faith efforts." Eventually, affirmative action was imposed on or adopted by other employers besides federal contractors.

The other main area of desegregation was the school system. Part of the problem of school segregation was explicit exclusion and class inequality (e.g., the inability of non-whites to enter elite colleges), while another problem was residential separation. At the primary and secondary school level, access to schools in the US is basically local: students attend their local neighborhood school. However, if different groups live in segregated neighborhoods with unequal educational facilities, equal-opportunity laws will not alter that fact. Short of shifting people to new neighborhoods, the best solution seemed to be to shift the students to new schools. So began the era of busing. In 1970 a federal court ruled that North Carolina should achieve racial integration by using buses to move black students to white schools and vice versa. In 1971 the Supreme Court heard the case of Swann $v$ Charlotte-Mecklenburg Board of Education and decided to allow mandatory busing to integrate segregated schools. School systems around the country (Richmond, Virginia 1971, Boston 1974, Wilmington, Delaware 1976, Los Angeles 1978, to name a few) voluntarily or under order devised busing programs, often with great protest by parents who objected to their children being shipped so far from home and/or to inferior facilities. Often the effect of mandatory busing was not racial integration but the flight of white students to private, parochial, or suburban schools.

Meanwhile, colleges were adopting their own affirmative action policies in regard to admission. The University of California was among the colleges that considered race as an issue in evaluating applicants, and in 1978 the Supreme Court (Regents of the University of California $v$ Bakke) ruled that it was indeed acceptable to use race as one factor in selecting candidates for admission; however, it ruled against an actual quota system that reserved eighteen places specifically for minority students. In 1998 the same university ended its affirmative action efforts for undergraduate admissions, resulting in a 61 percent decline in admissions for African American, Latino, and Native American students at UC-Berkeley and a 36 percent drop at UCLA.

Naturally, there were those who objected to mandatory desegregation, affirmative action, and race-conscious hiring and admissions, and not only those who were racists. Some argued that, by the 1990s or 2000s, it was unnecessary, since minorities had achieved reasonable equality. Others argued that it was unfair, that it took jobs or college seats from equally or more qualified white applicants; many called it "reverse discrimination." And others argued that it was fundamentally un-American, that employment or education was to be achieved on the basis of individual merit, not group membership and entitlement. Two court cases against the University of Michigan in 2003 resulted in a split decision: Grutter $v$ Bollinger approved of the university's narrow use of race in admission to its law school in the interest of studentbody diversity, but Gratz $v$ Bollinger rejected an explicit system that awarded points toward undergraduate admission for race and ethnicity. 


\section{Race and Racial Thinking}

By the late 1990s electoral efforts were also being launched to stop affirmative action. One prominent case was Proposition 209 on California's 1996 ballot, a constitutional amendment mandating that the state would "not discriminate against or grant preferential treatment to any individual or group on the basis of race, sex, color, ethnicity, or national origin in the operation of public employment, public education, or public contracting." One of the strongest supporters of the measure was Ward Connerly, a prominent black figure. The proposition passed with 54 percent of the vote, was challenged but upheld in court, and spawned a series of subsequent efforts in other states from Washington to Texas, Michigan, and Florida. Clearly, the debate and struggle over racial equality and racial access to wealth and status in the US is far from over.

\section{Diversity Fact:}

The effects of prohibiting affirmative action or race-based admissions in colleges have been mixed by race, by state, and by institution. There was almost always a drop in minority enrollment immediately after such bans: for instance, at the University of California-Berkeley, Hispanic enrollment peaked in 1990 at 23 percent and African American enrollment at 8 percent in 1997, but by 2011 those groups constituted only 11 percent and 2 percent of the student body, respectively. At the University of Texas, Hispanic enrollment dipped slightly from 16 percent to 13 percent at the 1997 ban but rose to a high of 23 percent in 2010, and African American enrollment rose modestly from 3 percent to 5 percent over the same period. At Florida State University, Hispanic enrollment rose while African American enrollment fell, and at the University of Michigan, Hispanic enrollment was roughly flat while African American enrollment declined by almost half.

\section{The Achievement Gap}

Despite the real and significant fact that non-whites have made observable advances in American society, a number of troubling inequalities still remain. As we will discuss more fully in Chapter 5, most non-white groups continue to linger behind whites in wealth and to surpass whites in poverty. For instance, since 1980 the median income for black households has consistently hovered around 60 percent of median income for white households (in 2011, \$32,229 compared to \$55,214); Hispanic households tend to fare better than black ones $(\$ 38,624)$, while Asian American households have outperformed all others $(\$ 65,129)$. And while the poverty rate for whites was 12.8 percent in 2011, it was 27.6 percent for blacks, and 25.3 percent for Hispanics (but only 12.3 percent for Asian Americans).

One of the most concerning and confusing differences between white Americans and minority groups like African Americans and Hispanics is the disparity in academic success between the two groups, which is often called the achievement gap. Black and Hispanic students tend to lag behind their white counterparts in high school performance, high school graduation rates, and college attendance and graduation. For example, according to the 2000 Census, out of every 100 white children who entered kindergarten, 91 would graduate from high school, 62 would attend college, 
and 30 would earn a bachelor's degree by age 24; the same 100 black kindergarteners would produce only 87 high school graduates, 54 college students, and 16 bachelor's degrees. For Hispanics it was a bleak 62, 29, and 6, respectively.

The gap shows up in the early years of education. The National Assessment of Educational Progress for 2003 (Donahue et al. 2005) indicated that more white fourthgraders (39 percent) achieved proficiency in reading than their black (12 percent) or Hispanic (14 percent) peers-none of which, by the way, are very impressive percentages. By age 17, African American and Latino students were doing math and reading at the level of 13-year-old white students. SAT scores in 2006 for white test-takers averaged 1,063, but only 863 for blacks, 919 for Hispanics, and 981 for Native Americans, but 1,088 for Asian Americans. The Schott Foundation for Public Education found that high school graduation rates for African Americans, especially males, fell behind their white counterparts in every state in the country in 2003/4, in all but three cases by double digits (Alaska, Rhode Island, and Arizona), and by as much as 40 percent in Illinois and 47 percent in Wisconsin (Holzman 2006: 2). In 2008, 9.9 percent of African American school-age youths had dropped out of school—and an alarming 18.3 percent of Hispanic youths-compared to 4.8 percent of whites and 4.4 percent of Asians. The problem is so serious, and so persistent (no major gains have occurred since 1980), that Harvard University has actually formed an Achievement Gap Initiative.

The explanations offered for the achievement gap vary. In the case of Hispanics, one obvious potential issue is language; the standard use of English as the language of instruction represents a type of institutional discrimination against non-English speakers. This is the justification for bilingual programs in American schools (see Chapter 8). Language cannot quite be the culprit in the case of African Americans, nor does it seem to deter Asian Americans on the whole. Another explanation that is sometimes given is the relevance of the curriculum: non-white students who are taught a Eurocentric curriculum, it is argued, might not see themselves and their group in the material and might suffer disinterest or, worse, a blow to their self-esteem. A third variable that cannot be overlooked is class. Since, as noted already and explored further in Chapter 5 , non-whites tend to be poorer than whites, this economic disadvantage could translate into an academic disadvantage. This is no doubt a concern, but Richard Rothstein (2004) finds that the gap still exists when family income is corrected for; that is, black and white children perform unequally even when those children come from households of similar class and income. No matter what the source, the achievement gap-and underachievement by any element of society-is a major problem that should worry all Americans.

\section{Box 3.2 Critical Race Theory}

"Today, while all manners of civil rights laws and precedents are in place, the protection they provide is diluted by lax enforcement, by the establishment of difficult-to-meet standards of proof, and worst of all, by the increasing irrelevance of antidiscrimination laws to race related disadvantages, now as likely to be a result of social class as of color"-so wrote Derrick Bell (1987: 5), a legal scholar like Kimberlé Crenshaw who noted the persistent legal inequalities faced 
(continued)

by African Americans and the intersectionality of multiple variables of disadvantage. Bell's books And We Are Not Saved: The Elusive Quest for Racial Justice (from which the above sentence is taken) and Faces at the Bottom of the Well: The Permanence of Racism (1992) were the impetus behind what became known as "critical race theory." Critical Race Theory or CRT, according to Rollock and Gillborn (2011), is a movement and "a body of scholarship steeped in radical activism that seeks to explore and challenge the prevalence of racial inequality in society. It is based on the understanding that race and racism are the product of social thought and power relations; CRT theorists endeavor to expose the way in which racial inequality is maintained through the operation of structures and assumptions that appear normal and unremarkable." Born at a time when and out of a sense that the civil rights movement had stalled and perhaps failed (as the discussion above suggests), Bell and others came to conclude that racism could not be countered by legislative or judicial action, since it was spawned by a deeper mindset, "an experientially limited bundle of presuppositions, received wisdom, and shared cultural understanding that persons in the majority" - that is, white persons-bring to discussions of race" (cummings 2012: 55). As Gary L. Williams put it in a recent issue of the journal Myriad dedicated to it, CRT insists "that we are not a colorblind society: that justice is not blind and that scales of justice are not balanced. Additionally, CRT validates voices and experiences of those who are victims of the 'isms' and other forms of subordination, especially at the institutional level" (2011: 2). From the institutional side, CRT maintains "that racism is endemic in US society, deeply ingrained legally, culturally, and even psychologically" and thus "that laws to remedy racial inequality are often undermined before they can be fully implemented" (4). Interestingly and significantly, since the experiences of African Americans transcend the available categories and "isms"-that there is no "singular truth or reality" of race in America-CRT often resorts to unconventional writing styles, such as storytelling or "counter-narrative" which "may be semi-autobiographical or allegorical in nature" and which presents the "voices of people of color" (Rollock and Gillborn 2011) rather than claiming to arrive at the final truth of race and American society.

\section{Race and the Criminal Justice System}

Among the many dimensions of American society in which race makes a difference is the law. It is often observed that African Americans comprise more than their share of Americans in trouble with the law. A watch-dog group, the Sentencing Project, has defined this glaring racial disparity in the criminal justice system as the situation in which "the proportion of a racial/ethnic group within the control of the system is greater than the proportion of such groups in the general population" (2000: 2). As Table 3.3 and Figures 3.2 and 3.3 clearly illustrate, African Americans, who number only one-sixth of the white population, comprise as many prison inmates as whites, and therefore a much higher incarceration rate, and have done so for many years. 
Table 3.3 Imprisonment rate (State and Federal) of males by race, 2011

\begin{tabular}{lc}
\hline Race & Rate (per 100,000 population) \\
\hline Total & 492 \\
White male & 478 \\
Black male & 3,023 \\
Hispanic male & 1,238 \\
\hline
\end{tabular}

Source: Bureau of Justice Statistics, US Department of Justice. Bulletin: Prisoners in 2011

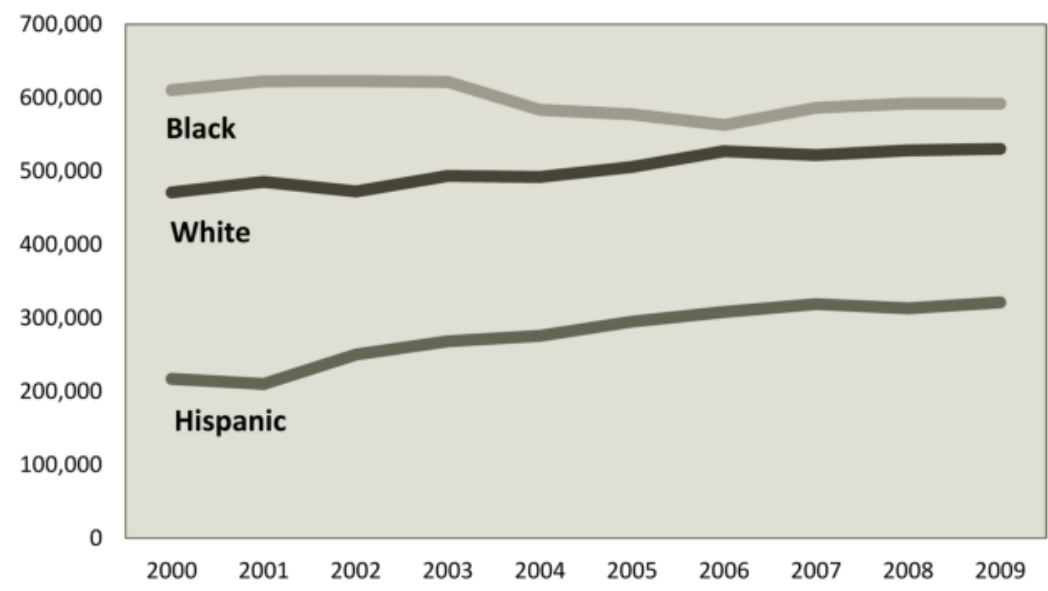

Figure 3.2 Number of sentenced prisoners (State and Federal) by race and Hispanic origin, 2000-2009.

Source: Bureau of Justice Statistics, US Department of Justice. Bulletin: Prisoners in 2009

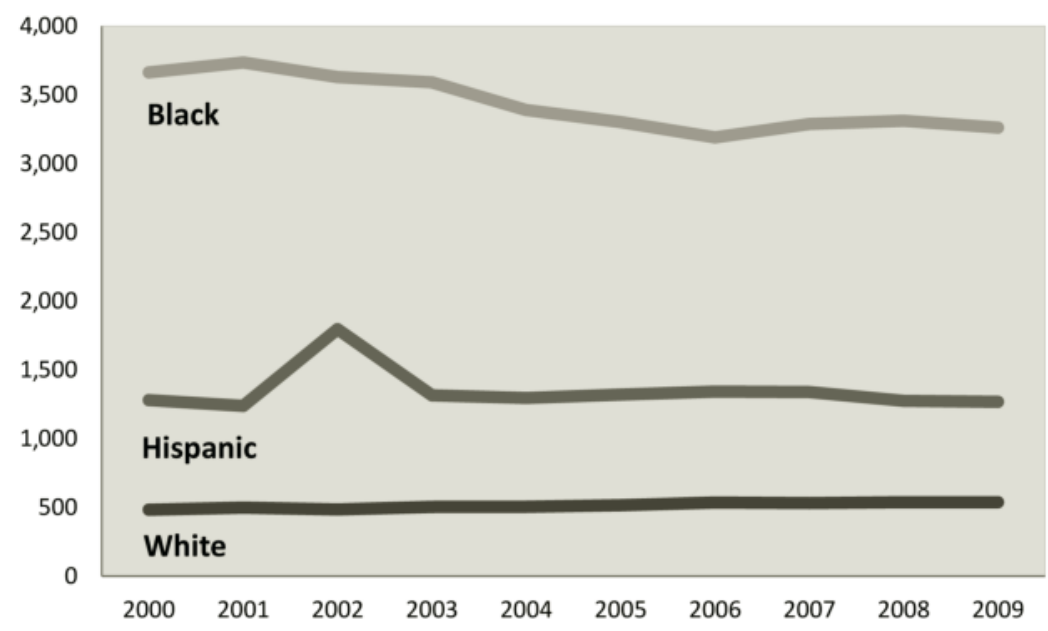

Figure 3.3 Rate of sentenced prisoners (State and Federal) per 100,000 population by race and Hispanic origin, 2000-2009.

Source: Bureau of Justice Statistics, US Department of Justice. Bulletin: Prisoners in 2009 
As the Bureau of Justice Statistics summarizes, blacks were six times as likely to be in prison as whites, and nearly three times as likely as Hispanics. Back in 1990 it was calculated that almost one-quarter of all young black males (under age 30) were "under supervision" by the criminal justice system in some way (in prison, on parole, on probation, etc.), and this trend has continued. In 2004 one-quarter of adult black men were under supervision in Texas, and in 2005 the Justice Policy Institute reported that 52 percent of young black men in Baltimore were in the criminal justice system. The Drug Policy Alliance Network (2009) found that African Americans amounted to 13 percent of the nation's drug users but 35 percent of its arrests for drug possession, 55 percent of its drug convictions, and 74 percent of its prison population on drug charges. Most seriously, blacks are more likely to receive the harshest correctional sentence, death, than whites or any other group: while the death-row population has risen dramatically since 1970 (from less than 1,000 to over 3,000), blacks make up almost half of that amount.

Ironically perhaps, African Americans are not only more likely to be the perpetrators of crime but also the victims of crime. The National Crime Victimization Survey (NCVS) of 2011 found that blacks, both male and female, were victimized at higher rates than whites in nearly every type of crime, for instance 26.4 per 1,000 for violent crimes versus 21.5 per 1,000 of whites (although Native Americans led both groups with 45.4 per 1,000). Black women suffered almost three times the rate of rape compared to white women. According to the NCVS, race was by far the greatest basis for hate crimes.

\section{New African Immigrants}

One of the most underappreciated yet most remarkable developments in African American demographics in recent years has been the upsurge in new immigrants from Africa. When most Americans think of “African American," they think of an ancestry of slavery in the United States going back generations. However, according to the Population Reference Bureau (http://www.prb.org), the foreign-born black population of the US increased from less than 1 percent of all US blacks in 1980 to 8 percent in 2005-threatening to change the very meaning of the term "African American."

Prior to 1980, black immigration to the US was, as Sam Roberts of the New York Times (2006) phrases it, a trickle, but by the turn of the twenty-first century more blacks were arriving annually from Africa and other black regions than during the heights of the slave trade. During the 1980 s, over 700,000 came to the country, in the 1990s almost 900,000, and from 2000 to 2005 another 656,000. According to a report by Capps, McCabe, and Fix (2011), in 2009 the total number of African immigrants living in the US was 1.5 million, representing about 4 percent of all immigrants; however, they also note that only 74 percent of those African immigrants identified themselves as black, since other races also inhabit the African continent.

\section{Diversity Fact:}

During the period from 2008 to 2009 , more than 1 million new black African immigrants stepped ashore, of whom 201,000 originated in Nigeria, 143,000 in Ethiopia, 110,000 in Ghana, and 68,000 in Kenya. Interestingly, not all immigrants 
from Africa were black; in fact, only 74 percent were, others being white or Arab. And not all black immigrants were from Africa: in 2008-9, more than half of all black immigrants ( 1.7 million) arrived from countries in the Caribbean region, especially Jamaica and Haiti.

In every case, these new groups brought with them not only racial differences from the white American majority but cultural and linguistic differences from both white and black Americans. The new African Americans (and Caribbean-African Americans) tend to settle in five states (New York, Texas, California, Florida, and Illinois) and to concentrate in cities, with almost two-thirds of Caribbean black immigrants living in New York City or Miami. For some reason an unexpectedly large number have ended up in Minneapolis-St. Paul, Minnesota (African-born blacks comprised 15.4 percent of the entire black population of the twin cities, according to the 2000 Census), including the Nuer (pastoralists of Sudan) described by Jon Holtzman (2000) in his ethnography of these refugees from Sudanese political violence.

With the exception of the Nuer and other similar tribal groups, the new black immigrants bring more "human capital," as Capps, McCabe, and Fix put it, to their new homelands than most new arrivals. Almost half (46 percent) of all black immigrants, and over one-fifth (21 percent) of black African immigrants already speak English, and only 2-3 percent speak no English. They also tend to come with high education and good job skills: black immigrants bring almost the same percentage (16 percent) of college degrees as the native-born population, and black Africans specifically actually have a greater percentage (23 percent). Remarkably, 15 percent of black African immigrants possess a graduate or professional degree, compared to 10 percent of the native-born population. As a group they have higher rates of employment than the general population, though they are often employed in relatively low-paying jobs. The same problem has been noted for black African immigrants to Canada, where African degrees and professional experience are not always recognized, language accents are disfavored, and racial discrimination often occurs (Creese 2011). Finally, African immigrants, who often identified by tribe or region or language or country back in Africa, are often surprised and confused to find themselves assigned to the "black" category along with people whom they consider very different from themselves.

\section{Biracial and Multiracial America}

As mentioned above, some 2.9 percent of Americans identified themselves as belonging to two or more races in the last census. While this is a small number, it is larger than the percentage of Americans who are Mormon or Jewish (1.3 percent each) and is almost certainly a growing trend, so it deserves our attention.

The structure of the 2010 Census, with its six official race categories and multiple race possibilities, allowed for dozens of combinations of two or more races. Of these combinations, thirteen had more than 100,000 members. The four largest combinations accounted for the vast majority of biracial and multiracial citizens, approximately 6.5 million individuals. As already stated, the single largest mixed-race group was 
"White and Black" (1.8 million or 20.4 percent of all mixed-race Americans), followed by "White and Some Other Race" (1.7 million or 19.3 percent), "White and Asian" (1.6 million or 18 percent), and "White and American Indian/Native Alaskan" (1.4 million or 15.9 percent). Interestingly but sensibly, the bi/multiracial groups were much younger than the general population, indicating the novelty of interracial marriage and interracial children. Because of their youth, and because of the increasing acceptability of interracial marriage, we can expect to see a continuing growth in the two-or-more-races categories as these young people marry and have children themselves. Very generally speaking, bi/multiracial people tend to be lower in wealth and status than the general population, but this varied widely by particular race combination.

We can say confidently that the diversity of race in America is becoming more so daily and that the standard historical race categories seem destined to lose much if not most of their meaning and value in the years ahead.

\section{The White Supremacist Movement}

The Census predicts that by 2050 the white population of the US will decline to 72 percent from its 2000 level of 81 percent, of which a mere 50.1 percent will be white and non-Hispanic; at the same time, the black population will rise to 14.6 percent and the Hispanic population to a historic 24.4 percent. Clearly, this will not only challenge the traditional dualistic concept of race in the country, with "white" and "black" as only two categories, but it will also seriously challenge white domination. Obviously, not everyone in America will approve of this change.

White citizens who take their whiteness seriously, and especially who perceive their white group threatened by political, economic, or social forces, have repeatedly organized themselves "in defense of" their white race. The best-known example is undoubtedly the Ku Klux Klan, formed in the aftermath of the Civil War, allegedly in Tennessee in late 1865 or early 1866. While perhaps started as a prankish club for former Confederate soldiers, it quickly evolved into a terrorist organization, an expression of the vigilante tradition so deep in American culture. According to an observer of the time, Lewis Merrill,

Beyond doubt the object of the organization ... is to terrify the negroes [sic] into obeying the whites in voting and to compel them to stay away from the polls. The more active and intelligent of the negroes who have influence with their own color and who advise them are to be driven away or killed, and such white men as affiliate with the negroes politically are to be handled the same way.

(quoted in Wade 1987: 97)

By 1871 the Klan had become such a problem that President Ulysses Grant had to order a military suppression of the group.

The KKK was revived in the early 1900s, when immigration was at its highest level and when World War I broke out, both adding to the hostility toward and suspicion of foreigners who were not proper whites. Consequentially, a fateful mixture of white racism, American nationalism, and Christianity shaped the new Klan-a combination that would shape many later movements as well. A Klan document of the era proclaimed: 
Only native born American citizens who believe in the tenets of the Christian religion and owe no allegiance of any degree or nature to any foreign Government, nation, political institution, sect, people, or person are eligible [which excluded Catholics].... We avow the distinction between races of mankind as same has been decreed by the Creator, and we shall ever be true to the faithful maintenance of White Supremacy and will strenuously oppose any compromise thereof in any and all things.

So, clearly, the ideology of the Klan had expanded from anti-black to anti-all-thingsnot-WASP, including ethnic whites and non-Christians.

A third incarnation of the Klan arose in the 1960s, in reaction to the civil rights movement. Black residences and churches were fire-bombed, and civil rights activists were

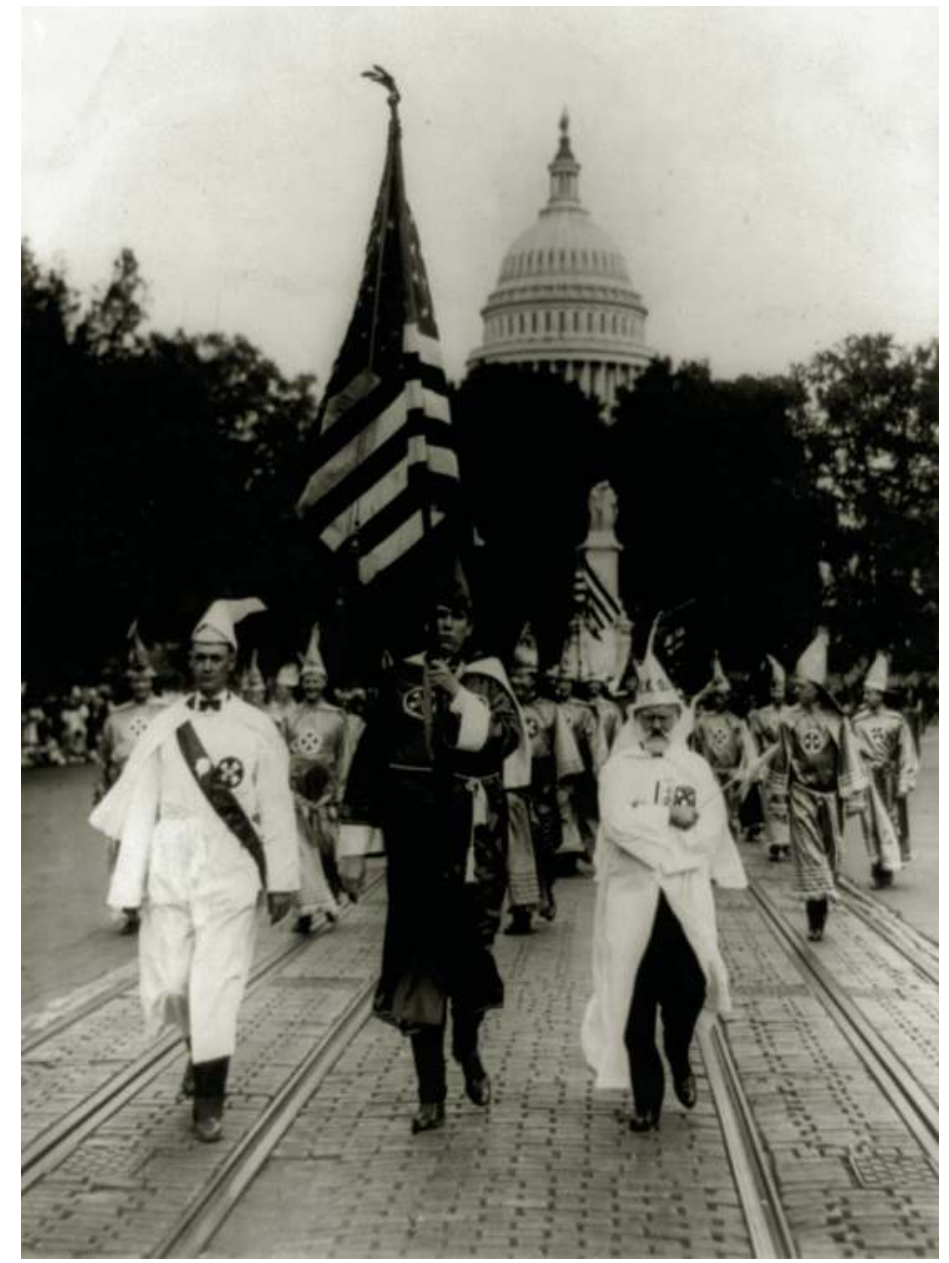

Image 3.4 Ku Klux Klan parade held in Washington, DC, c.1926.

(Courtesy of the Library of Congress, Prints and Photographs Division) 
attacked. When three such activists-James Chaney, Andrew Goodman, and Michael Schwerner-were found dead, the Klan came under withering criticism and investigation from the FBI and institutions like Klanwatch (an arm of the Southern Poverty Law Center), and it began to fade. By this time, though, other groups were emerging to take up the struggle for white supremacy. Some of them were inspired by Nazism, some by militant Christianity (especially Christian Identity and Anglo-Israelism), and some by both. Christian Identity is a movement that asserts that the white race is the true Christian nation: Kingdom Ministry, a major proponent of the position, explained on its website (now inactive) that "We believe the White, Anglo-Saxon, Germanic and kindred people to be God's true, literal Children of Israel. Only this race fulfills every detail of Biblical Prophecy and World History concerning Israel and continues in these latter days to be heirs and possessors of the Covenants, Prophecies, Promises, and Blessings of YHVH God made to Israel.” Anglo-Israelism is an extension and refinement of Christian Identity, arguing again that not the entire white race but only the English (or American) branch of the white race is the true Israel, God's true people; all non-whites, and all non-English whites, are inferior and godless.

Other and more virulent organizations like the Posse Comitatus, Aryan Nations, and White Aryan Resistance (with the acronym WAR), emerged over time, with similar philosophies and greater propensities for violence; often their enemies were less blacks than Jews and communists. James Wickstrom, a figure in these formative movements, wrote that "Yahweh our father is at work setting the stage for the final act against the Christ-murdering Jews and their father, Satan" (quoted in Stern 1996: 50). The Aryan Nations goes further, stating:

We believe in the preservation of our Race, individually and collectively, as a people as demanded and directed by Yahweh (Aryan Nations members do not call the supreme being God because God is dog spelled backwards).... We believe that Adam, man of Genesis, is the placing of the White Race upon this earth. Not all races descend from Adam. Adam is the father of the White Race only. ... We believe that the Cananite [sic] Jew is the natural enemy of our Aryan (White) Race. .. . The Jew is like a destroying virus that attacks our racial body to destroy our Aryan culture and the purity of our Race.

(quoted in Snow 1999: 2)

Finally, the White Aryan Resistance, on their website (www.resist.com), take the battle not only to America's racial diversity but to its cultural and ethnic diversity too, its very immigrant origins, complaining that America

is not a real nation. This is a bastard nation, with almost no roots, where millions of non-Whites can claim only one generation on the land. That land usually being the asphalted big metropolis.... The metropolises being the gaping anal cavities of a sick and dying nation [sic]. To those unclean places flock the worst of all races. Only the most degenerate of the White race struggle to stay on top of the maggot pile in such unnatural settings.

Obviously, while such groups encompass and represent only a small portion of the white population of the US, they are a significant factor in the society and express a long- and deeply-held view by many. 


\section{Conclusion}

Race is a potent and recurrent mode of thinking in the United States. Although the specifics (the number, the traits, the relations) of race have varied over time, racial thinking in the US has consistently emphasized certain key physical characteristics distinguishing supposedly distinct and closed groups which also determine other nonphysical qualities like intelligence or moral character. The ideology of race has been categorial, hierarchical, and, until recently, largely binary.

The central race issue throughout American history has been black/white relations, and there is some reason to conclude that the negative status of Africans in America is at least to an extent a product of slavery rather than a cause of slavery. It is certainly true that black status declined precipitously in the 1700s and 1800s, as slavery institutionalized. After slavery was abolished, new forms of inequality were invented (segregation and Jim Crow laws), which were sanctioned for decades by governments and courts. African Americans themselves demonstrated some ambivalence over whether to strive for integration and equality with whites or not, but the civil rights movement initiated a process of inclusion and racial justice that is not quite completely fulfilled today.

Race continues to make a difference in the United States, whether or not races are "real" or "natural" categories. Differences and inequalities in wealth and class, in education, and in legal treatment persist, and other differences-in health, religion, language, etc.-will be explored in later chapters. Despite the efforts of prejudiced, anti-immigrant, and even racial supremacist individuals and groups, America continues and promises to become a more racially diverse and a more racially mixed society, challenging the old binary and categorial ideology of race. 


\section{Ethnicity \\ Beyond the Race Binary}

In 2007, the Lakota nation of Native Americans (better known to many as the Sioux) issued a letter to the United States government. Essentially the letter was a declaration of independence. Because of ongoing "gross violations" of treaties by the US, as well as dreadful living conditions on the Lakota reservations-where 97 percent of the people lived in poverty, one-third of homes had no running water, substance abuse was rampant, disease rates were five to eight times higher than the US average, and life expectancy for men was only 44 years-the Lakota basically broke off relations with the American government and declared itself a sovereign nation, the Republic of Lakotah. The territory of this new republic covered more than half of Nebraska, half of South Dakota, and large areas of North Dakota, Montana, and Wyoming. Much of their land had been acquired in the first place by the United States through the famous "Louisiana Purchase," but the Lakota affirmed that they had "never had knowledge of, nor gave consent to, the sale of their national territory." The American government has never formally acknowledged the Lakota letter, let alone responded to it.

Many racial and cultural groups live within the boundaries of the United States, but not all of them became "American" voluntarily and not all of them are happy about it. What rights do racial and cultural groups have in a modern society like the US? Why are the experiences of groups so disparate and unequal? And what can and should a society do when one group expresses its sincere desire to leave?

As discussed in the previous chapter, America has always been self-conscious of its cultural and racial diversity, and de Tocqueville stressed that the new country was explicitly composed of at least three quite different groups-Europeans, Africans, and Native peoples. Since the coming of Europeans and the founding of the independent United States, many more peoples from many more continents and cultures have arrived. Not all of these peoples have been of a different "race" from the English, Dutch, and German early settlers, and not all of them have thought of themselves as a "race."

While race has been and continues to be a key concept in American thought, in recent decades another term, ethnicity, has become popular and important. Often Americans use the words interchangeably, but they are not quite synonymous. Race refers to a category system based on socially significant physical differences. Ethnicity, which may or may not have a physical component, is a set of categories based on cultural, historical, geographical, or other "identity" differences. 


\section{The Concept of Ethnicity and Ethnic Groups}

The idea of ethnicity was not invented in the United States, nor was it heard there until the twentieth century. The ancient Greek historian Herodotus used the word ethnos to distinguish the various peoples he encountered on his travels, but at that time the term had a very vague meaning, referring to "a people" or "a nation" or "a cultural group" without consistently identifying the nature of the difference or identity. According to Julian Huxley and A. C. Haddon, who revived the term, Herodotus' ethnos "is at times a tribe, at times a political unit, at times a larger grouping, and in using the word he guards himself against treating either type of unit as necessarily or even probably of common descent" (1935: 31). Nevertheless, because of the jaded nature of the concept of "race," Huxley and Haddon advocated the use of "ethnic group" instead of "race."

Social theorists have tried to define ethnicity or ethnic group in such a way as to make the idea concrete and useful. Perhaps the most important and influential attempt came from one of the founding fathers of sociology, Max Weber, who in 1922 characterized ethnic groups as "those human groups that entertain a subjective belief in their common descent because of similarities of physical type or of customs or both, or because of memories of colonization and migration; conversely, it does not matter whether or not an objective blood relationship exists" (1968: 389). R.A. Schermerhorn thought of an ethnic group as "a collectivity within a larger society having real or putative common ancestry, memories of a shared historical past, and a cultural focus on one or more symbolic elements defined as the epitome of their peoplehood.... A necessary component is some consciousness of kind among members of the group" (1970: 12). Milton Yinger, who collaborated with George Simpson to describe various group relations (see Chapter 2), defined it as "a segment of a larger society whose members are thought, by themselves or others, to have a common origin and to share important segments of a common culture and who, in addition, participate in shared activities in which the common origin and culture are significant ingredients" (1994: 3). Finally, the well-known sociologist of nationalism Anthony Smith called it "a type of cultural collectivity, one that emphasizes the role of myths of descent and historical memories, and that is recognized by one or more cultural differences like religion, customs, language, or institutions" (1991: 20).

While these definitions are not identical, they share a number of themes. First, an ethnic group is necessarily one social element in a mixed or multicultural society; where there is no diversity in a society, there is no ethnicity. Second, while as mentioned an ethnic group may have distinct physical traits, the more important matter is its "customs" (for Weber), its "historical past" and "cultural focus" (for Schermerhorn), its "common origin," "common culture," and "shared activities" (for Yinger), or its "myths of descent and historical memories" (for Smith). Even more crucially, the group must have "some consciousness" of its identity and its uniqueness; in other words, cultural difference alone is not enough to constitute an ethnic group. For instance, in Northern Ireland, Catholics and Protestants may think of themselves, more or less, as ethnic groups, but American Catholics and Protestants do not. We can say, then, that there is no one-to-one correspondence between the amount of cultural difference and the degree of ethnicity.

When does a cultural difference become an "ethnic" difference"? There is no simple answer, but the key is when that cultural difference makes a difference. That is to say, 
we may think of ethnicity as the "subjective symbolic or emblematic use of any aspect of culture" by members of a group "in order to differentiate themselves from other groups" (DeVos 1975: 16). Thus, it is not the cultural difference itself but the subjective and symbolic meaning of that difference, in a culturally mixed society, that is the issue. But the question remains as to why people would symbolically use their culture or what they use it for. The answer lies in the fact that ethnicity appears when the benefits and burdens of society are unevenly distributed between groups. When people notice that wealth, power, land, education, housing, jobs, and other social resources are unequally shared because of differences in culture or place of origin, then those people may organize, compete, and even fight along those cultural/historical lines. In short, they rally around their culture or history and begin to identify as a group.

\section{Bed, Blood, and Cult}

Some of the similarities and differences between race and ethnicity can be seen in Manning Nash's (1989) analysis of ethnicity, in which he identified the three major components of "bed, blood, and cult." There is, in some cases and to some extent, a biological or genetic component: an ethnic group may value endogamy (marrying within the group), so that the members are more or less biologically related. In other words, social rules about who may share a bed can result in real blood relationships. However, blood/biological relations are often more imaginary or ideological than factual; the group may think of itself as a big family or descent group, whether or not it is true. Here is the power of "cult," by which Nash meant not only religion but all of the cultural factors (the beliefs and values, the shared stories and myths) that unite the group. Orlando Patterson explicitly stated that certain aspects of its culture have "the functions of ... rituals for the group - the ways in which they are used to maintain group cohesiveness, to sustain and enhance identity, and to establish social networks and communicative patterns" (1975: 305). We should stress the effects of creating and perpetuating a social memory and social self-consciousness through the practice of cultural habits (for instance, using a language or eating certain foods) and storytelling, as well as events like holidays or marches, not to mention violence.

To Nash's three variables we should add a fourth that is more contentious in some countries than in the US, although, as we will see below, it also appears in the American context. That is the issue of "soil" or "land," a group's special territory. All people, of course, need a place to live, but some places are more valuable symbolically, places where our ancestors resided, where our forefathers and foremothers died, or where great things occurred (wars were fought or religious leaders taught).

\section{Ethnic Culture or Ethnic Boundary?}

As we have stated, there is no one-to-one correspondence between culture and ethnicity. No group, for example, uses all of its culture in formulating its ethnicity; it picks and chooses between its cultural "raw materials" to construct its identity, often changing its choices over time. Further, no group is culturally different from its surrounding groups in every conceivable way; there are common cultural traits as well as distinguishing ones. Both Northern Irish Catholics and Protestants, after all, are Christians, and both Iraqi Sunnis and Shi'ites speak Arabic. 
For these reasons, social scientists have shifted their attention away from the cultural particulars of ethnic groups (what we might call their "contents") and toward the boundaries-and therefore the relationships-between them. One of the most influential statements on this topic was Fredrik Barth's Ethnic Groups and Boundaries. Rejecting the simplistic notion that there really are discrete "aggregates of people who essentially share a common culture" (1969: 9) which can be identified by a list of cultural items (a specific language, religion, history, name, territory, and such), Barth insisted that the essence of ethnicity and ethnic groups is "the ethnic boundary that defines the group, not the cultural stuff that it encloses" (15). This change of focus allows us to see that ethnicity is a form of social organization, not some fact of timeless and immutable cultural difference. It therefore compels us to analyze the processes by which groups construct and preserve boundaries over time, even while individual members or cultural traits within the boundary may vary over time. In some cases, ethnic groups come into or go out of existence, and of course the relationships between groups can fall anywhere on the spectrum from pluralism and coexistence to subjugation and extermination, as discussed in Chapter 2. And these relationships can and do also alter through the years.

\section{Ethnicity in the United States}

As mentioned, Americans often use the terms "race" and "ethnicity" interchangeably, but social scientists make a crucial distinction between them. For example, even in the US Census, "Hispanic" is not a race but a stand-alone category; this is appropriate, because there are white Hispanics and black Hispanics and Native Hispanics and every combination thereof. Further, while "black" or "African American" is offered as a race, there are clearly very real ethnic differences within the black-race category: as discussed in the previous chapter, African Americans who descend from eighteenthand nineteenth-century slaves are culturally quite different from new African immigrants arriving in the twentieth and twenty-first centuries, and these new African immigrants bring considerable ethnic differences between them (language, nationality, religion, etc.). Finally, the race category "Asian" includes a dramatic amount of cultural difference, from Chinese to Japanese to Asian Indians and Vietnamese, and

Table 4.1 Race or ethnicity in the US?, 2010

\begin{tabular}{lrc}
\hline Racelethnic category & Number & Percent \\
\hline Total population & $308,745,538$ & 100 \\
One Race & $299,736,465$ & 97.1 \\
White & $223,553,265$ & 72.4 \\
Black or African American & $38,929,319$ & 12.6 \\
American Indian and Alaska Native & $2,932,248$ & 0.9 \\
Asian & $14,674,252$ & 4.8 \\
Native Hawaiian and Other Pacific Islander & 540,013 & 0.2 \\
Some Other Race & $19,107,368$ & 6.2 \\
Two or More Races & $9,009,073$ & 2.9 \\
Hispanic or Latino & $50,477,594$ & 16.3 \\
\hline
\end{tabular}

Source: US Census Bureau. 2010 Census Brief: Overview of Race and Hispanic Origin 
so on. Additionally, there are populations where neither the race nor the ethnic label seems quite to apply, like Native Americans or Arabs. Of course, people over time may eventually come to think of themselves in ethnic terms, but there is no requirement that they do so, and when they do it is the product of a complex social process.

\section{Native Americans}

It is perhaps fitting to begin our journey with Native Americans, who were the first peoples on the American continent, long before the Europeans, Africans, or others. However, no one ever called themselves "Native Americans" or "American Indians" until much later in history. Before the arrival of foreigners, there were probably some three hundred distinct social/national groups (often dubbed, quite inaccurately, "tribes") numbering millions of members. Groups varied in their languages, religions, economies, and political systems, not to mention food and clothing; some were allies, some were enemies.

The contact experience of Native Americans varied dramatically depending on the specific time and place of contact, as well as whether that contact was with Spanish, Dutch, French, or English settlers. While there were, of course, some peaceful interactions and even intermarriage, the relationships between Native peoples and immigrants tended to fall roughly into three types. One was assimilation, especially in such cultural domains as language and religion. Inevitably a certain amount of cultural diffusion occurred (in both directions, by the way), but much of this assimilation work was undertaken by missionaries. In Spanish colonial territories Catholic missions were established in the early 1500s, and the English royal charter for a colony in Virginia in 1606 explicitly commended

the Furtherance of so noble a Work, which may, by the Providence of Almighty God, hereafter tend to the Glory of his Divine Majesty, in propagating of Christian Religion to such People, as yet live in Darkness and miserable Ignorance of the true Knowledge and Worship of God, and may in time bring the Infidels and Savages, living in those parts, to human Civility, and to a settled and quiet Government.

(Thorpe 1909)

In early New England, a noteworthy form of assimilation was the "praying town," promoted from 1646 to 1675, into which Native peoples of Massachusetts were gathered to be Christianized. During its time, fourteen praying towns were supported by the white settlers. Through the years, many Native societies voluntarily assimilated, like the Cherokee who eventually developed their own written language and even publishing business; some actually owned African slaves, but their adoption of European ways did not prevent them from being banished from their land (see below). The other great institution of assimilation besides the mission, however, was the school, especially the boarding school (which was often run by a religious organization). The most famous and prototypical boarding school was the Carlisle Indian Industrial School, founded by Captain Richard Henry Pratt in 1879. Based on his experience as a soldier and prison warden, he created a school for Native children that was very much a barracks or a jail, where Native language, religion, food, and customs were forbidden. During its short history (it ceased to be an Indian industrial school in 1918), it 
processed almost 12,000 Native children from 140 different societies, and it provided a model for 26 government schools and 450 church-run schools.

The second main relationship between Native peoples and foreign settlers was forced relocation. In many cases, Eastern peoples moved westward voluntarily, to escape the creeping invasion of the continent. In other instances, though, entire societies were uprooted and transplanted to "Indian territory." The most famous and disreputable example is the "Trail of Tears" following the 1830 Indian Removal Act, which compelled the Cherokee, the Chickasaw, the Choctaw, the Creek, and the Seminole to leave their lands east of the Mississippi River and resettle in what would later become Oklahoma. In the Northeast, members of Iroquois tribes like the Seneca were dislocated after siding with the British in the Revolutionary War; some Seneca were transferred to Oklahoma and Missouri. Later and much farther west, after Kit Carson's campaign to destroy the Navajo in 1863, some 8,500 surviving Navajo were forced onto their own trail of tears, walking four hundred miles in the middle of winter, which they remember today as "The Long Walk."

The third relationship, which often preceded the two already mentioned, was conflict and often attempted or successful extermination. Some experts estimate that 90 percent of Native Americans were wiped out by war, malnutrition, and disease, and infectious diseases often reached them before white people did, sweeping ahead of the invasion. Violent clashes occurred throughout American history and American territory, from the so-called King Philip's War in New England in 1675-6 (which helped end the praying town institution), to the rebellion of chief Pontiac in Pennsylvania in 1763, to the Native participation in the "French and Indian" war of 1756-63 and the Revolutionary War. The period after the Civil War is best known as the era of "Indian wars," as the reunited US expanded inexorably westward. General George Custer was decisively defeated in 1876 in the Battle of Little Bighorn in Montana, and the last "battle" in the Plains wars happened in 1890, when soldiers massacred peaceful practitioners of the Ghost Dance at Wounded Knee, South Dakota. Along the way, many renowned Native leaders emerged, from Sitting Bull and Crazy Horse to Geronimo and Chief Joseph.

One unique relationship between Native societies and the American government is the treaty relationship, continuing an earlier practice of the British colonial administration (in America as well as in Canada and New Zealand, but interestingly not in Australia). This is important because a treaty is a formal political contract between two sovereign entities. Sovereignty means political independence and self-rule, therefore British and American treaties recognized Native independence, national existence, and territorial rights. In fact, the whole point of a treaty was usually to extinguish Native territorial rights and "legally" transfer those rights to the US government and white settlers, holding a small part of Native land in "reserve" for the indigenous people, hence a "reservation." It is critical to understand that the land transfer and the reservation it often created was not a grant of land to the Natives but a grant of land from the Natives.

This formal legal relationship meant that Native Americans were not "Americans" at all through this period; they were citizens of their own foreign nations, often of enemy nations, and not American citizens. The significance of this fact is that Native Americans not only have distinct and at least at one time intact cultures but that they have collective legal rights and identities unlike any other groups in the United States. For this reason, they have been subjected to more legislation than any other 
group, from the Removal Act of 1830 to, for instance, the 1887 Dawes (or General Allotment) Act, which divided reservations into lots, assigned those lots to Native individuals or families, and then opened up "excess" land to white settlement and ownership. A federal Bureau of Indian Affairs was set up in 1824, at first (not surprisingly) under the War Department and later under the Department of the Interior.

While Native sovereignty is still to some extent recognized and contested, as Native societies became more fully integrated into American society that sovereignty has been diminished. Officially, Native groups are "dependent sovereign nations" or "domestic dependent nations," American and yet not American, and their sovereignty can be extinguished by the US government. In 1924, Native Americans were offered US citizenship, and in 1934 the Indian Reorganization Act permitted groups to write their own tribal constitutions and form their own tribal governments. However, the US used its power over its domestic dependent nations in the 1950 s to "terminate" many tribes as official entities. House Concurrent Resolution 108 in 1953 began the policy of "termination" by withdrawing federal recognition of tribal identity, first of the Menominee and Klamath and then dozens of other tribes. Termination was part of the wider assimilation policy, to break up reservations, urbanize Native peoples, and end federal financial support (even when such support was guaranteed in a treaty).

Since the late 1960s, the trend has been toward greater Native rights, starting with the 1968 American Indian Civil Rights Act which ended termination, returned some political authority back to tribes, and actually allowed terminated tribes to recover their official status. In 1975 the Indian Self-Determination Act gave Native groups even more power to operate their own institutions such as schools, hospitals, and businesses, and the Native American Graves Protection and Repatriation Act (NAGPRA) of 1990 went so far as to give Native groups control over artifacts and human remains held by museums, libraries, universities, or laboratories. These rights did not come without some struggle, of course. Urban Indians in the 1950s and 1960s became politically active, on the model of the civil rights movement. One key organization was the American Indian Movement (AIM), which used confrontational actions like marches and sit-ins to protest the oppression of Native peoples. In 1969 AIM members occupied Alcatraz Island in California, and in 1972 they marched to Washington, DC in the "Trail of Broken Treaties." An uprising on the Pine Ridge reservation in South Dakota, near the site of the 1890 Wounded Knee massacre, led in 1973 to the largest military conflict on American soil since the Civil War, as American troops clashed with Native activists for ten weeks.

Today, Native Americans compose a very small portion of the American population and control very little of its land. The 2010 Census counted 2.9 million people who identify as "American Indian or Alaska Native," along with another 2.3 million who claimed that identity in combination with at least one other race/ethnicity; those numbers constitute 0.9 percent and 0.7 percent of the American population, respectively. Interestingly, however, the Native population grew at twice the general American rate between 2000 and 2010 (18 percent versus 9.7 percent). It is important to distinguish this self-identification with the way in which the US government and the tribes themselves determine membership, which depends upon inclusion on an official list or "roll." Officially, only individuals who are registered on a tribal roll are legally considered "Indian" and thereby entitled to rights as Indians. 


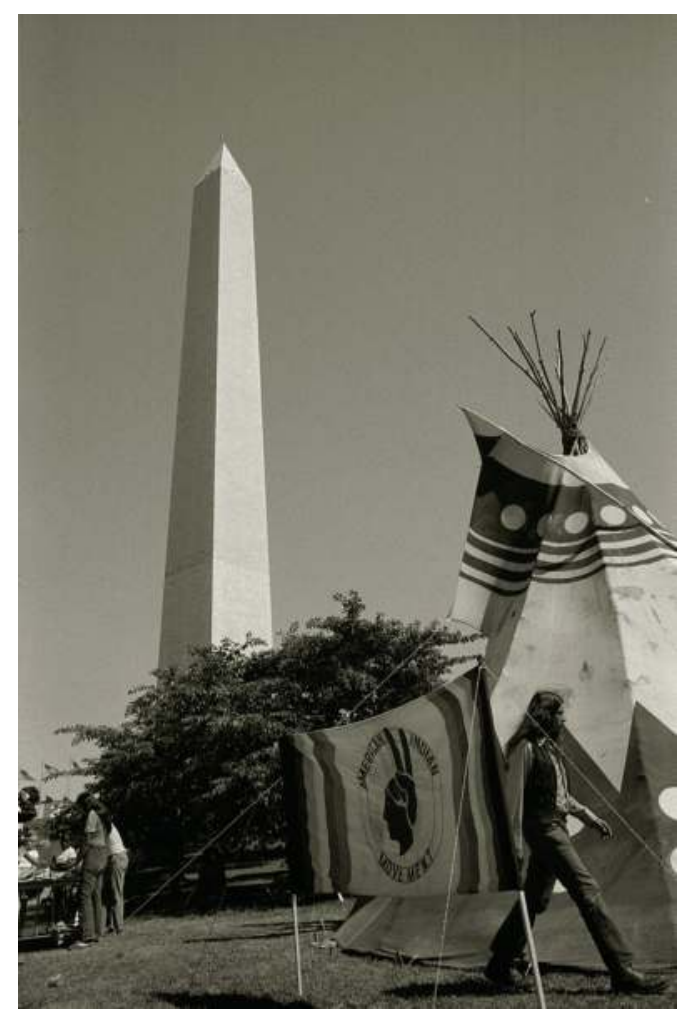

Image 4.1 American Indian Movement sign and tipi in front of the Washington Monument during the "Longest Walk" in 1978, held to support tribal sovereignty and bring attention to anti-Indian legislation.

(Courtesy of the Library of Congress, Prints and Photographs Division)

(The National Archives maintains information on Indian Census Rolls; see http:// www.archives.gov/research/census/native-americans/1885-1940.html). Understandably, this procedure can embroil individuals and families in disputes about who is "really an Indian" and who is not.

Not surprisingly, the largest number of Native Americans live in the West, according to the 2010 US Census: 2.1 million occupy that region, one-third of them in California alone, while 1.3 million inhabit the South, 879,000 the Midwest, and only 505,000 the Northeast. Oklahoma holds a large concentration of Native peoples, as does Alaska, North and South Dakota, Montana and Washington, and especially Arizona and New Mexico, where the vast Hopi-Navajo reservation is situated.

As mentioned before, many Native peoples reject the notion of "race" or "ethnicity," preferring to regard themselves as members of venerable and sovereign societies. As of 2012, the Bureau of Indian Affairs officially recognized 566 "tribal entities" (see http://www.bia.gov/cs/groups/public/documents/text/idc-041248.pdf for the current list), with the largest groups according to the 2010 US Census listed below in Table 4.2. 


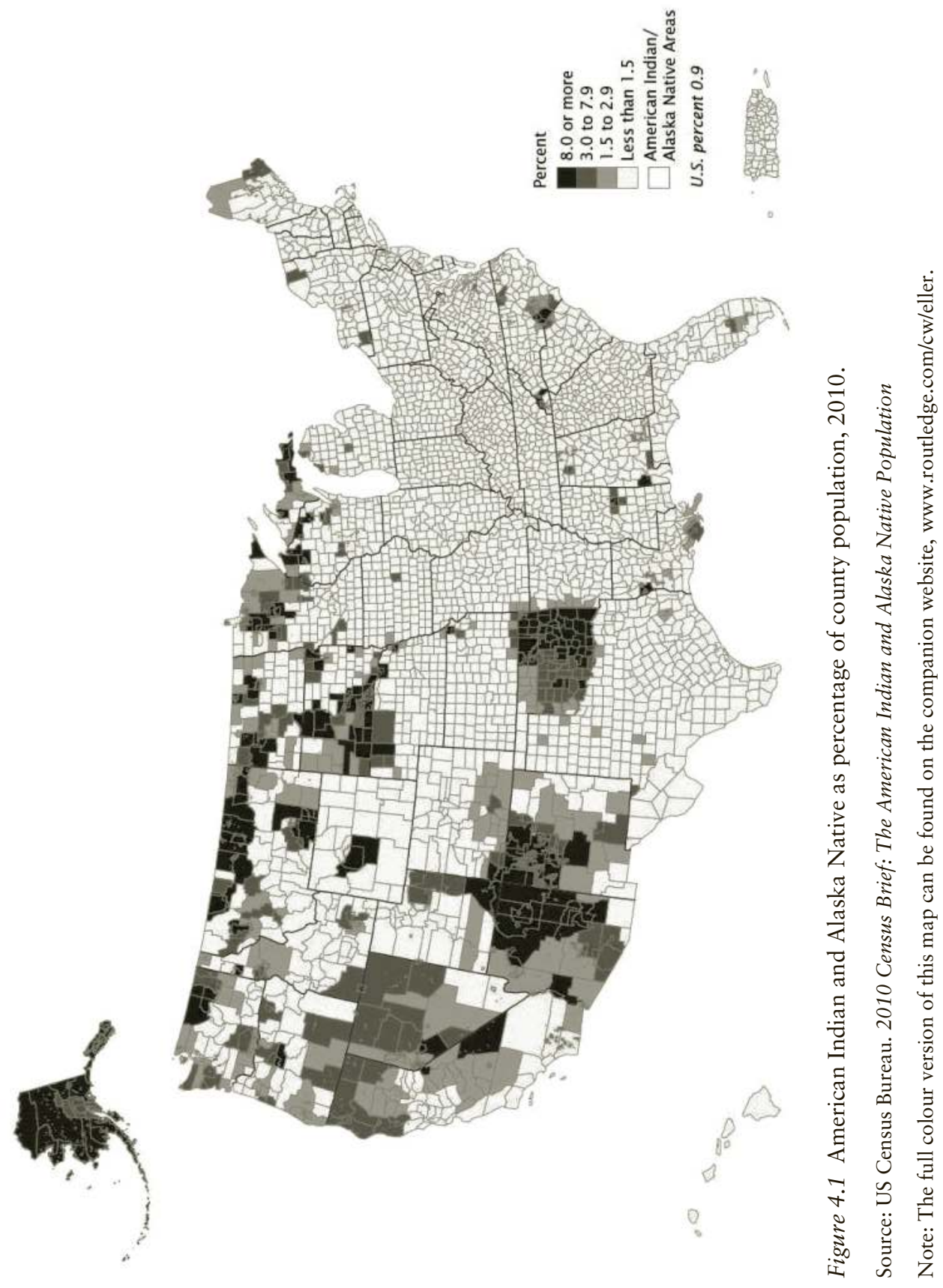


Table 4.2 Largest American Indian and Alaska Native tribal groupings, 2010

\begin{tabular}{lc}
\hline Group & Population \\
\hline Navajo & 286,731 \\
Cherokee & 284,247 \\
Mexican American Indian & 121,221 \\
Chippewa & 112,757 \\
Sioux & 112,176 \\
Choctaw & 103,910 \\
Apache & 63,193 \\
Lumbee & 62,306 \\
\hline
\end{tabular}

Source: US Census Bureau. 2010 Census Brief: The American Indian and Alaska Native Population

Native peoples in the United States continue to suffer from lower standards of living than the American average or, by many measures, any other race/ethnic group. For instance, the poverty rate for American Indians and Alaska Natives in 2011 was 27 percent, the highest of any race/ethnicity; in some places like Rapid City, South Dakota, that rate is 51 percent, and Native peoples in nine states had poverty rates of 30 percent. As a result, Native peoples experience many social and health consequences, such as shorter life expectancy (on average six years less), notably higher rates of diseases like tuberculosis and diabetes, significant substance abuse problems, and twice the rate of violence of African Americans and two-and-a-half times the rate of white Americans. Many of these problems are concentrated on reservations, but it is important to remember that two-thirds of Native peoples today do not live on reservations but rather in urban and suburban areas (additionally, the Census found that most people-a full 77 percent-living on Indian land were not Native peoples).

\section{Box 4.1 Sherman Alexie on the Reservation}

Sherman Alexie is one of a number of accomplished Native American writers who have described life on the contemporary reservation. One of his most dramatic accounts was given in his 1994 novel The Lone Ranger and Tonto Fistfight in Heaven, which is a funny, bittersweet, and angry collection of memories and commentaries about reservation life. The following excerpt is from pages $149-53$.

"Imagine Crazy Horse invented the atom bomb in 1876 and detonated it over Washington, D.C. Would the urban Indians still be sprawled around the one-room apartment in the cable television reservation? Imagine a loaf of bread could feed the entire tribe. Didn't you know Jesus Christ was a Spokane Indian? Imagine Columbus landed in 1492 and some tribe or another drowned him in the ocean. Would Lester Falls Apart still be shoplifting in the 7-11? ...

"Survival = Anger X Imagination. Imagination is the only weapon on the reservation. 
(continued)

“The reservation doesn't sing anymore but the songs still hang in the air. Every molecule waits for a drumbeat; every element dreams lyrics. Today I am walking between water, two parts hydrogen, one part oxygen, and the energy expelled is named Forgiveness....

"What do you believe in? Does every Indian depend on Hollywood for a twentieth-century vision?

"Listen: when I was young, living on the reservation, eating potatoes every day of my life, I imagined the potatoes grew larger, filled my stomach, reversed the emptiness. My sisters saved up a few quarters and bought food coloring. For weeks we ate red potatoes, green potatoes, blue potatoes. In the dark, 'The Tonight Show' on the television, my father and I telling stories about the food we wanted most. We imagined oranges, Pepsi-Cola, chocolate, deer jerky. We imagined the salt on our skin could change the world.

"July 4th and all is hell. Adrian, I am waiting for someone to tell the truth. ... But, Adrian, it's the same old story, whispered past the same false teeth. How can we imagine a new language when the language of the enemy keeps our dismembered tongues tied to his belt? How can we imagine a new alphabet when the old jumps off billboards down into our stomachs? There are so many possibilities in the reservation 7-11, so many methods of survival. Imagine every Skin on the reservation is the new lead guitarist for the Rolling Stones, on the cover of a rock-and-roll magazine. Imagine forgiveness is sold 2 for 1 . Imagine every Indian is a video game with braids. . . .

Do you believe laughter can save us? All I know is that I count coyotes to help me sleep. Didn't you know? Imagination is the politics of dreams; imagination turns every word into a bottle rocket. Adrian, imagine every day is Independence Day and save us from traveling the river changed; save us from hitchhiking the long road home. Imagine an escape. Imagine that your own shadow on the wall is a perfect door. Imagine a song stronger than penicillin. Imagine a spring with water that mends broken bones. Imagine a drum which wraps itself around your heart. Imagine a story that puts wood in the fireplace."

However, there also positive developments for Native peoples in America. A number of tribes have found financial success through treaty and sovereignty exemptions that allow them to operate casinos even in states that prohibit gambling. Many tribes also operate other lucrative businesses: the Seminole nation recently purchased the Planet Hollywood restaurant and hotel chain. Native Americans have trained as professionals, including constitutional lawyers to defend their peoples' rights, and produced highly-regarded scholars like Vine Deloria. Through tourism and arts and the establishment of tribe-run museums, they have increasingly taken ownership of their history and culture and declared their intention to survive and to revive their languages and religions. A few Native groups have gone so far as to issue their own tribal passports, an ultimate act of sovereignty. 


\section{Diversity Fact:}

A fascinating case of the controversy over Native American identity arose in 1996, when a skull and some bones were discovered on the banks of the Columbia River in Washington State. Named "Kennewick Man," some scientists concluded that the remains were those of an ancient Caucasian, in the Americas millennia before European colonization. The local Umatilla and other tribes claimed the man as their own ancestor and demanded his return under the provisions of NAGPRA. In 2005 the US Congress considered an amendment to NAGPRA to redefine "Native American" as any individual who "is or was indigenous to the United States," which would have made Kennewick Man a Native American, whatever his biology and ancestry.

\section{Hispanic Americans}

Currently, a very large number of Hispanics or Latinos/Latinas come to the United States: since the 1990s, half of all immigrants have originated from Latin America and approximately 30 percent from Mexico alone. It is essential to realize three things, however. First, it has not always been this way: prior to the 1940s, Latin America provided less than 10 percent of immigrants to the US, and as recently as 1970 Mexicans represented only 8 percent of the foreign-born American population. Second, originally Hispanics did not so much come to the United States as the United States came to them: during its expansion, the US purchased, annexed, or conquered large areas with Hispanic inhabitants, such as Florida, California, and Texas. Third, like "Native American," "Hispanic" or "Latino/a" is a relatively new term and identity; no one was Hispanic or Latino/a until long after the arrival of the Spanish in the Western hemisphere.

As already mentioned, "Hispanic" is a very diverse category, and even in the US Census it is not a "race" category. Rather, Hispanics can be and are white, black, Native, Asian (Peru's former president Alberto Fujimori was of Japanese descent), or-and usually-some combination of these race groups. Hispanic Americans also hail from a wide assortment of countries, mostly Mexico but also every Central and South American and Caribbean nation. Therefore they are quite culturally and economically diverse; the only thing that they presumably have in common is the Spanish language or, since not all Hispanic Americans speak Spanish, an ancestry from a Spanish-speaking country or a country with a history of Spanish-influenced culture and language. As Table 4.3 shows, the vast majority of Hispanic Americans trace back to three areas-Mexico, Puerto Rico, and Cuba-each with a clearly distinct culture and history. We will thus focus primarily on those three populations.

Mexico has a long and complicated history with the United States. Prior to Spanish conquest, the Aztecs or Mexicas dominated the heartland of what would become Spanish Mexico. Spanish people, language, and religion (Catholicism) spread through Central America, as well as parts of what would eventually be the United States: the Spanish reached Florida in 1565 and New Mexico in 1581, later settling the towns 
74 Ethnicity: Beyond the Race Binary

Table 4.3 Hispanic American population by country of origin, 2010

\begin{tabular}{lrc}
\hline Country of origin & Number & Percent \\
\hline All Hispanic & $50,477,594$ & 100 \\
Mexico & $31,798,258$ & 63 \\
Puerto Rico & $4,623,716$ & 9.2 \\
Cuba & $1,785,547$ & 3.5 \\
El Salvador & $1,648,968$ & 3.3 \\
Dominican Republic & $1,414,703$ & 2.8 \\
Guatemala & $1,044,209$ & 2.1 \\
Colombia & 908,734 & 1.8 \\
Spain & 635,253 & 1.3 \\
Honduras & 633,401 & 1.3 \\
\hline
\end{tabular}

Source: US Census Bureau. 2010 Census Brief: The Hispanic Population

of San Diego (1769) and San Francisco (1776) on the west coast of California. Of course, many Native peoples inhabited those lands before the Spanish, and a racially and culturally mixed population (sometimes referred to as mestizo) arose from their interactions.

The first substantial Hispanic territory to come under American control was Florida, which had been given to England by Spain in 1763 and briefly became the Republic of West Florida in 1810. After claiming parts of the future state, the US purchased the peninsula from Spain in 1819. Mexico's independence from Spain in 1821 provided a new opportunity for Americans, who were allowed to enter and settle in the vast territory of Texas. By 1830 there were 20-30,000 US citizens living in Texas, who engineered the secession of Texas from Mexico in 1835 (as the sovereign Lone Star Republic), which led to the celebrated but misunderstood Battle of the Alamo in 1836. The United States annexed Texas in 1845, sparking a war with Mexico (1846-8) that ended with a crushing Mexican defeat, the occupation of Mexico City by American troops, and the seizure of almost half of Mexico's land, including some 80,000 Mexican people. In the process, the first sizable population of "Mexican Americans" was created, not from Mexican immigration but as a result of American expansion. This means that Mexican Americans have been in some parts of the United States longer than white Americans. During the Mexican-American war, settlers in California also declared their independence (as the California Republic); the region was claimed and occupied by the US Army in 1847 and granted statehood in 1850, after gold was discovered in 1849 .

So far, most "Mexican Americans" had become Americans involuntarily, but this did not exempt them from discrimination and violence in their new country. According to Luis Angel Toro, "The Anglos who poured into Texas and the rest of the Southwest brought their apparatus of racial terror, developed to hold the African American people in bondage, to the newly conquered territories. Mexicans became frequent victims of beatings and lynching" (1995: 1247). The fact that the lynching rate of Mexicans in the American Southwest was 473 per 100,000 during the two decades after the loss that territory led many refugees from the violence to dub the American democracy a linchocracia (lynch-ocracy).

When Mexican immigration into the US began in earnest in the 1920s, it encountered racist opposition from many white Americans, like the unnamed Congressman 
who characterized Mexicans as a "blend of low-grade Spaniard, peonized Indian, and negro slave" and the 1925 Department of Labor report that evaluated 90 percent of Latin Americans as "of Indian blood and therefore inferior to whites" (Toro 1995: 1427). Mass deportations during the Great Depression prompted some Latinos to found the League of United Latin American Citizens in Texas in 1930, which describes itself on its website (http://lulac.org) today as "the largest Latino civil rights and advocacy group in the United States.”

As recently as 1970 Mexico was only the fourth-largest source of immigrants (behind Italy, Germany, and Canada), but this did not stop the US from enacting "Operation Wetback" in the 1950s to arrest and deport Mexicans. Nevertheless, by 1980 and since, Mexico has been the leading origin-point of immigrants to the United States, due to internal and international conditions, and, according to the Migration Policy Institute, 11.4 million Mexico-born people lived in the US in 2008. Some 70 percent of Mexican immigrants lived in four American states, and over half lived in just ten American cities. Significantly, almost one-third of all Mexican immigrants in the US arrived after the year 2000. More than half of foreign-born Mexican Americans did not have a high school diploma, and nearly 40 percent of the men worked in jobs like construction and transportation (Terrazas 2010).

The second-largest contingent of Hispanic Americans originates from Puerto Rico, which has a very different history and relation with the United States. Spain first colonized the island during Columbus' second voyage in 1493, decimating the Native population while intermarrying with it and also introducing Africans as early as 1513. Like the Philippines and other territories (see below), Puerto Rico was acquired by the United States during the 1898 Spanish-American War. It has been, therefore, an official American possession for almost a century, since the Jones Act of 1917, which

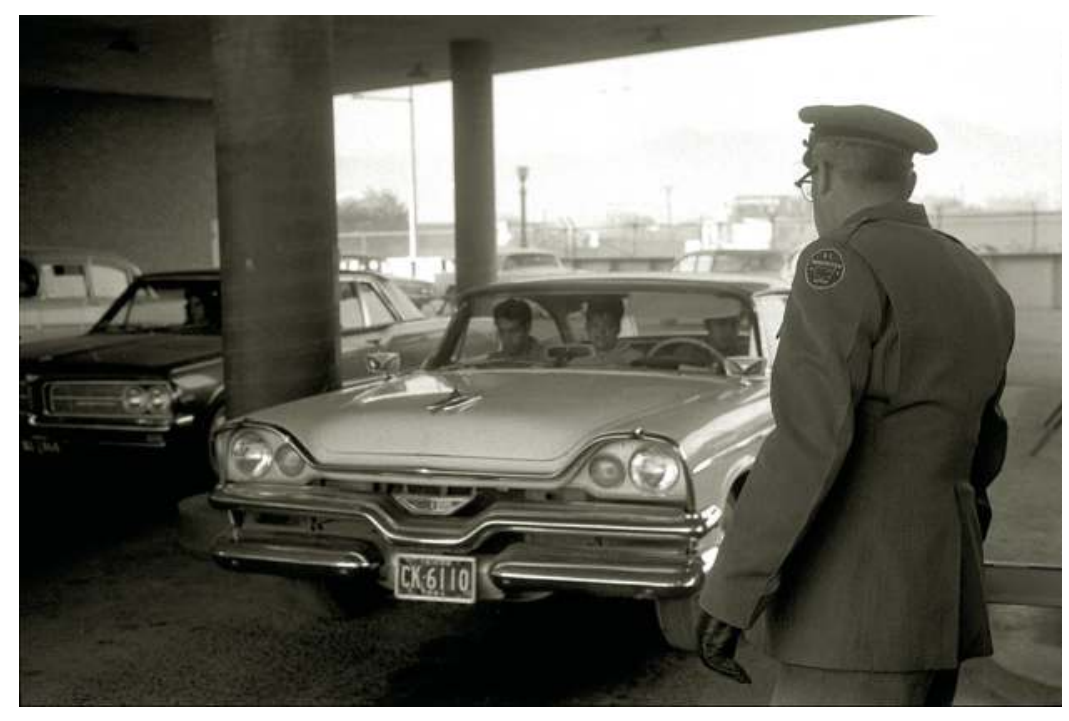

Image 4.2 US immigration officer watching cars entering El Paso, Texas, from Ciudad Juárez in Mexico, c.1964.

(Courtesy of the Library of Congress, Prints and Photographs Division) 
offered its residents limited US citizenship. After World War II, large-scale migration of Puerto Ricans to the American mainland began, most settling in New York City, which is still the center of Puerto Rican immigration and culture in the US. By 1950, fully one-fifth of the population of the island had moved to mainland America, mostly because of the poverty of the island. By 1990 there were over two-thirds as many Puerto Ricans living in the continental United States (2.7 million) as remained on Puerto Rico (3.7 million).

\section{Diversity Fact:}

According to the report "We the People: Hispanics in the United States," based on the 2000 Census, Puerto Ricans were second among Hispanic Americans only to Mexicans in youth (33.6 percent of Puerto Ricans were under age 18, compared to 37.1 percent of Mexicans and 25.6 percent of the total US population). Puerto Ricans were the least likely of all Hispanic groups to be married (only 42.3 percent, compared to a national rate of 54.4 percent) and the most likely to live in female-headed households (26.2 percent). They also had lower median family income $(\$ 32,791)$ than any Hispanic nationality except Dominicans $(\$ 28,729)$. By comparison, Mexican median family income was $\$ 33,516$ and Cuban an impressive $\$ 42,824$.

The third-largest Hispanic American community is the Cubans. Cuba too was one of Spain's first colonies, where Native peoples were massacred by the encroaching conquerors and Africans were imported as laborers. Cuba was another prize for the United States from the Spanish-American War, but the US relinquished authority to a Cuban government in 1902, which remained a friend of its northern neighbor until the Communist revolution of 1959 put Fidel Castro in power. As a consequence, emigration from the island exploded after 1960, as middle-class professionals escaped the island and sought refuge as political exiles, mostly in southern Florida, the closest point to their lost home. By 1980 there were over 800,000 Cubans living in the United States, two-thirds of them in the vicinity of Miami, Florida. Parts of south Florida had become a virtual Cuban subculture of refugees hoping to return to reclaim their island. However, as time passed and that outcome became less likely, a new wave of poorer Cuban emigrants hit the shores of Florida, including the "boat people" who tried to cross the short strait between Cuba and Florida on anything that would float. The result was two quite different generations of Cuban Americans, the first highly educated and successful, the second much less so.

On average, Cubans are the most successful Hispanic American community, with higher household income and higher levels of education: in 2000, only Hispanics from Spain (29.9 percent) had a larger percentage of college degrees than Cubans (21.2 percent), and therefore Cubans experienced lower rates of poverty (14.6 percent) than Mexicans (23.5 percent) or Puerto Ricans (25.8 percent). Cuban Americans were much older than any other Hispanic American group (median age of 40.3 years, compared to 27.7 years for Puerto Ricans and 24.4 years for Mexicans), but interestingly 
less likely than the other two nationalities to speak English, which, along with their concentration in south Florida, explains much of their creation of parallel neighborhoods and businesses.

Because of their very different histories, cultures, and identities, the various Hispanic American groups have not always shared a common name or a common cause. Not all identify first, if at all, as "Hispanic"; some prefer the name of their country of origin, and some, like people of Mexican descent who have grown up in America, use terms like "Chicano/a." At the same time, the US government and society has increasingly recognized common Hispanic issues, related less to race or ethnicity than to language. In 1968 the Bilingual Education Act offered Spanish-speaking students instruction in their own language, and in 1975 the Voting Rights Act (passed in 1965) was amended to protect "persons of Spanish heritage" from discrimination neither as a race nor an ethnic group but as a "language minority" (see Chapter 8). In recent years, illegal or undocumented immigration has become a major concern for many Americans, and in 2013 a major new immigration bill was before the US Congress.

\section{Asian Americans}

While Native Americans share the characteristic of descending from the original populations of the American continent, and while Hispanics share the characteristic of descending from Spanish-speaking populations of the Americas, Asian Americans share only the fact that they or their ancestors lived somewhere on the vast continent of Asia (or the islands lying off its coast). This ensures that the cultural (linguistic, religious, historical, educational) and even racial diversity within the imprecise category of "Asian" will be truly extraordinary. As Table 4.4 depicts, Asian Americans come from a wide array of countries and societies that are in no way culturally or racially homogenous. Indeed, according to a Pew study, only 19 percent of Asian Americans prefer to call themselves "Asian Americans," 62 percent preferring to specify their country of origin (that is, "Chinese Americans" or "Vietnamese Americans").

Table 4.4 Asian American population by country of origin (for respondents who indicated only one Asian origin), 2010

\begin{tabular}{lrc}
\hline Country of origin & Number & Percent \\
\hline All Asian & $14,674,252$ & 100 \\
China & $3,535,382$ & 22.8 \\
India & $2,918,807$ & 19.4 \\
Philippines & $2,649,973$ & 17.4 \\
Vietnam & $1,632,717$ & 10.6 \\
South Korea & $1,463,474$ & 9.7 \\
Japan & 841,824 & 5.2 \\
Pakistan & 382,994 & 2.6 \\
Cambodia & 255,497 & 1.7 \\
Hmong* & 252,323 & 1.7 \\
Laos & 209,646 & 1.4 \\
\hline
\end{tabular}

Source: US Census Bureau. 2010 Census Brief: The Asian Population

*Hmong is a cultural group that straddles China, Vietnam, Laos, and Thailand 
Table 4.5 Top ten countries of origin for foreign-born American population, 1990-2008

\begin{tabular}{lll}
\hline 1990 & 2000 & 2008 \\
\hline 1. Mexico & 1. Mexico & 1. Mexico \\
2. China & 2. China & 2. China \\
3. Philippines & 3. Philippines & 3. Philippines \\
4. Canada & 4. India & 4. India \\
5. Cuba & 5. Cuba & 5. Vietnam \\
6. Germany & 6. Vietnam & 6. El Salvador \\
7. United Kingdom & 7. El Salvador & 7. Korea \\
8. Italy & 8. Korea & 8. Cuba \\
9. Korea & 9. Dominican Republic & 9. Canada \\
10. Vietnam & 10. Canada & 10. Dominican Republic \\
\hline
\end{tabular}

Source: Congressional Research Service, The US Foreign-Born Population: Trends and Selected Characteristics, 2011

Over the past twenty or thirty years, along with Spanish-speaking countries, Asian countries have become the main sources of immigrants to the United States, as illustrated in Table 4.5. In fact, by 2008, only one non-Hispanic or non-Asian country was on the list of the top ten sources for immigrants, namely Canada.

It is impossible to give equal or even adequate coverage to all of the Asian populations in America today, so a few remarks about the predominant groups will have to suffice.

Chinese immigrants were the first Asians to arrive in the US in significant numbers. There are records of Chinese agricultural laborers in the Hawaiian sugar cane fields in the 1830s, long before those islands became American possessions. However, the major influx of Chinese occurred after 1848, with the discovery of gold in California: 52,000 Chinese arrived in 1852, many of them working on the western railroads that would connect the far-flung parts of the new country. According to a recent report from the Pew Research Center (2010b), by 1870 Chinese settlers comprised 9 percent of the population of California and 25 percent of its workforce. The vast majority were young men, usually coming to the Americas as temporary workers to earn money to send back to their families in China. Many arrived on what was known as the "credit ticket system," in which poor men would borrow money for the passage to America from a sponsor, who would provide housing and jobs and subtract the debt from the workers' pay.

As radically non-Western people competing for American jobs, the Chinese encountered considerable discrimination and hostility. Already in 1854, the California Supreme Court (People v Hall) ruled that Chinese witnesses could not testify in court because they were "inferior and . . . incapable of progress or intellectual development beyond a certain point." There were also acts of violence, especially after the railroads were completed and work was scarcer: in 1871 there was massacre of 19 Chinese in Los Angeles, in 1877 an anti-Chinese riot in Chico, California, and in 1887 a two-day confrontation in Snake River, Oregon that left 31 Chinese miners dead. Disapproval of Chinese immigrants became so intense that the US did something unprecedented in its history-pass a law banning immigrants from one specific country. The 1882 Chinese Exclusion Act curtailed the flow of Chinese into the US; as a result, many returned to their land of origin, and (without Chinese women to marry and prohibited from marrying white women) the population dwindled. In 1910 there were only 70,000 Chinese living in the United States, a figure which declined to 60,000 by 1940 . 
During the Second World War, with China as an ally, the Exclusion Act was repealed, and, as in Cuba, the Communist takeover in 1949 led to a flood of refugees into America: by 1960 135,000 Chinese men and 101,000 women inhabited the US. The Chinese Communist government restricted emigration, although some Chinese were willing and able to pay thousands of dollars to a professional smuggler (known as a "snakehead") to escape. In 1994 Peter Kwong reported that traffickers were charging on average $\$ 33,000$ and that, in a repeat of the credit ticket system, "the snakeheads simply make the debtors their virtual slaves. During the day, the victims work at restaurants that have been linked to organized crime. At night, after they are brought back to prisonlike dorms, they hand over all their money and are locked up until the next day" (1994: 425).

Despite the fact that in 2008 China was still the second-largest source of immigrants to the US, because of China's economic growth the outflow of Chinese has slowed from 87,000 in 2006 to 71,000 in 2010. In fact, the distinctive "Chinatowns" that exist in cities like San Francisco and New York have shrunk both in population and in area, signaling a shift in the demographics, spatial structure, and lifestyle in major American cities (see Chapter 12). And "if China continues to boom, Chinatowns will lose their reason for being, as vital ports of entry for working class immigrants. These workers will have better things to do than come to America" (Tsui 2011: 18).

The early wave of Asian immigrants also included Japanese, who were first brought to Hawaii in 1868 as contract laborers. After the Chinese Exclusion Act took effect, American employers turned to Japanese workers to provide cheap, expendable labor, and by the time Hawaii was annexed by the US there were over 25,000 Japanese living on the island (compared to less than 6,000 Chinese). Social change and industrialization pushed more Japanese people off their land and out of their country after 1900, so much

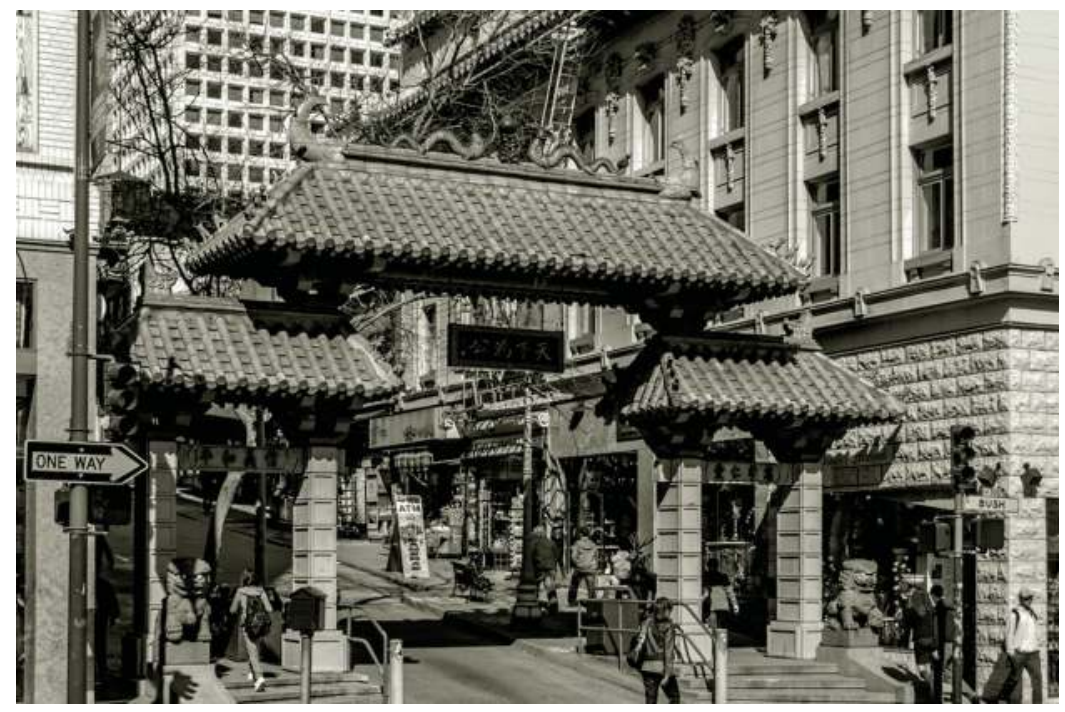

Image 4.3 Entrance to Chinatown, San Francisco.

(Courtesy of Jeff Whyte/Shutterstock.com) 
so that in 1908 the US and Japan entered into a "Gentleman's Agreement" to restrict immigration into the United States to non-farm workers and families of previous immigrants. Many of the "wives" of already settled Japanese men were so-called "picture brides" whose marriages were arranged between the homeland and the new land.

The 1924 Oriental Exclusion Act, part of the Immigration Act (see Chapter 2), set discriminatory quotas for all Asian countries, with a limit of less than two hundred Japanese per year. But the greatest indignity suffered by Japanese Americans was their mass arrest during World War II. Despite the fact that two-thirds of Japanese Americans in 1942 were US-born, more than 100,000 were rounded up and held in detention camps out of suspicion of their loyalty to Japan. In 1989 President George $\mathrm{H}$. W. Bush signed an order granting reparations of $\$ 20,000$ to each survivor of the internment camps.

There are records of Asian Indians in the United States as far back as 1820, but the first real contingent from India, some 6,000, arrived between 1904 and 1911, again as farm laborers. Remarkably, according to the Pew Research Center study, American law originally categorized them as Caucasians, eligible to marry whites; however, in 1923 the Supreme Court ruled that Asian Indians were non-white and therefore not able to become American citizens or intermarry with white Americans (2010b: 44). Immigration from India was blocked after 1917 and resumed only around 1965, when many well-educated and English-speaking professionals were sought by American employers. Because recent Indian immigrants have tended to be highly skilled, often in computer and technology fields, their average household income $(\$ 88,000)$ is actually dramatically higher than other Asian Americans $(\$ 66,000)$ or the American average $(\$ 49,800)$. Fewer (9 percent) live in poverty. Asian Indians are also very internally diverse, bringing many languages, religions, and racial features.

Filipinos are different from other Asian groups in that the Philippines was, like Cuba and Puerto Rico, an American territory for a time after the Spanish-American War (1898). The Philippines had been a Spanish colony for centuries, giving Filipinos a distinct Spanish flavor to their culture (in some ways, they are a Hispanic society as well as an Asian one!). Thus, Filipino culture is a blend of indigenous, Spanish, and American. After the repressive American conquest of the islands, Filipinos were free from the restrictions on other Asian nationalities and were much sought for their labor: by 1920 there were 20,000 living in Hawaii and 5,600 on the American mainland. In 1946, after a decade of political transition and World War II, the Philippines became independent, and immigration picked up substantially after 1960, with more than 25,000 arriving in the year 1970 alone. With their history of American contact, many (78 percent) of Filipino Americans claim proficiency in English, and a mere 6 percent live in poverty. American military bases in the Philippines have contributed to many marriages between American men and Filipino women, and for years the Philippines was famous as a source of "mail order brides" as well as a destination for sex tourism.

Koreans, like all other Asian nationalities, began their American odyssey as laborers in the west, especially Hawaii, where the first group of 93 arrived in 1903. When Japan annexed Korea in 1920, emigration was curtailed, but after America's war in Korea (1950-3) it recommenced: by 1970 there were 70,000 Koreans in the US, and by 1980 that number had risen to 355,000 . As the Pew report notes, Koreans "have the highest self-employment rate" of Asian American populations (2010b: 51), because many 
Koreans come from urban middle class parts of Korea and start small businesses in the US. Many Koreans are also already Christians before they depart from Korea.

Finally for our purposes, Vietnamese people who left their homeland did not initially travel to the United States, since Vietnam was a French colony. It was American participation in the war in Vietnam during the 1960s and 1970s that opened a pipeline between the two countries, through which approximately 20,000 immigrants passed during the war and then 135,000 in 1975 with the fall of South Vietnam to the Communist North. This first wave, as the Pew study indicates, was relatively urban and educated, like the refugees from Cuba. However, the second wave starting in 1978 tended to be rural, poor, and less educated, especially the "boat people" who fled across the ocean. Some 200,000 boat people took to sea, most held in camps in the US until they could be settled or returned to Vietnam. Not surprisingly, then, more than 90 percent of Vietnamese Americans are relative newcomers, arriving only after 1970, and 84 percent of Vietnamese American adults were born in Vietnam. Their Englishlanguage skills are not as developed as some other Asian groups (41 percent English proficient), and their median household incomes are lower than other Asian groups $(\$ 53,400$ versus $\$ 66,000)$ but still higher than the US average.

As these overall statistics indicate, Asian Americans have been particularly successful in the United States, despite discrimination and exclusion, leading many observers to consider them the "model minority." As a model minority, they have on average higher incomes, better education and jobs, more stable families, and other characteristics desirable to Americans and widely associated with success in America. Of course, there is wide internal variation, and there are exceptions (like Asian criminal gangs).

\section{Diversity Fact:}

Some noteworthy "model minority” traits of Asian Americans include:

- 49 percent possess a college degree or higher;

- Median household income of $\$ 66,000$;

- 11.9 percent poverty rate;

- 14 percent employed in science or engineering careers (versus 5 percent of general US population), including 28 percent of Asian Indians;

- 80 percent of children live with two married parents (versus 63 percent of general US population), including 92 percent of Asian Indians;

- 52 percent describe their financial circumstances as good or excellent (versus 35 percent of general US population);

- 88 percent view themselves as equally or more successful than other racial and ethnic minorities.

\section{Arab Americans}

If Asian Americans challenge and complicate our conventional notions of race and ethnicity, then Arab Americans render them essentially useless. Note, for instance, that 


\section{Ethnicity: Beyond the Race Binary}

there is no category in the US Census for "Arab Americans": by the labels and definitions available, Arabs would be classified as "white" (see Chapter 3 for definitions of race categories, which explicitly list "Arab" as one subtype of white/Caucasian). However, most Americans probably do not regard Arabs as white, nor do most Arabs identify as such. But "Arab" is not a race in any standard race-classification scheme, nor is it a nationality or an "ethnicity"; indeed, the English/American race/ethnic system does not quite have a place for it. Further, not all Arabs are Muslims, even in "Arab countries," and not all Muslims are Arabs (Turks, Iranians, Indonesians, and many Africans are Muslims but not Arabs). Historically, "Arab" has referred to someone who speaks the Arabic language and traces ancestry to one of countries in the Arab region of the world (which is a somewhat circular definition), including the Middle East and North Africa. These various countries bring much cultural diversity to the category "Arab American."

According to the Arab American Institute (http://www.aaiusa.org/) and its reading of the more recent American Community Survey, 1.9 million people of Arab descent live in the United States, representing 0.5 percent of the total US population. Of those, 26 percent originated from Lebanon, 10 percent from Egypt, 8 percent from Syria, 6 percent from Somalia (who would not be considered racially Arab), 5 percent each from Iraq, Palestine, and Morocco, 5 percent calling themselves Assyrian or Chaldean, 3 percent from Jordan, and 15 percent calling themselves Arab without specifying a country. Perhaps most remarkably of all, data suggest that 63 percent of Arab Americans are Christian and only 24 percent are Muslim, with 13 percent identifying as some other or no religion.

As mentioned in Chapter 9's presentation on Islam, there have been Arabs in the Americas almost as long as there have been Europeans; an Arab slave named Zammouri from Morocco is regarded as the first Arab (and the first African) in North America, arriving in 1528 (Arab American National Museum n.d.: 3). Arab voluntary immigration took off during the great era of immigration to the United States, from 1880 to 1920: by 1924 around 200,000 Arabs were documented in the country, and two of them, Najeeb and Ibrahim Arbeelys (second-generation Syrian Americans), opened the first Arabic newspaper, The Star of America, in 1892. As with other newly arrived populations, the majority were men, specifically Christian men from the struggling Ottoman Empire.

Table 4.6 Population of Arab Americans by country of origin (of those claiming a single Arab ancestry), 2000

\begin{tabular}{lrl}
\hline Country & Number & Percent of US population \\
\hline Total & 850,027 & 0.30 \\
Lebanon & 244,525 & 0.09 \\
Egypt & 123,489 & 0.04 \\
Syria & 75,517 & 0.03 \\
Palestine & 61,691 & 0.02 \\
Jordan & 36,352 & 0.01 \\
Morocco & 30,352 & 0.01 \\
Iraq & 29,429 & 0.01 \\
"Arab" unspecified & 167,166 & 0.06 \\
\hline
\end{tabular}

Source: US Census Bureau. Census 2000 Special Report: We the People of Arab Ancestry in the United States 


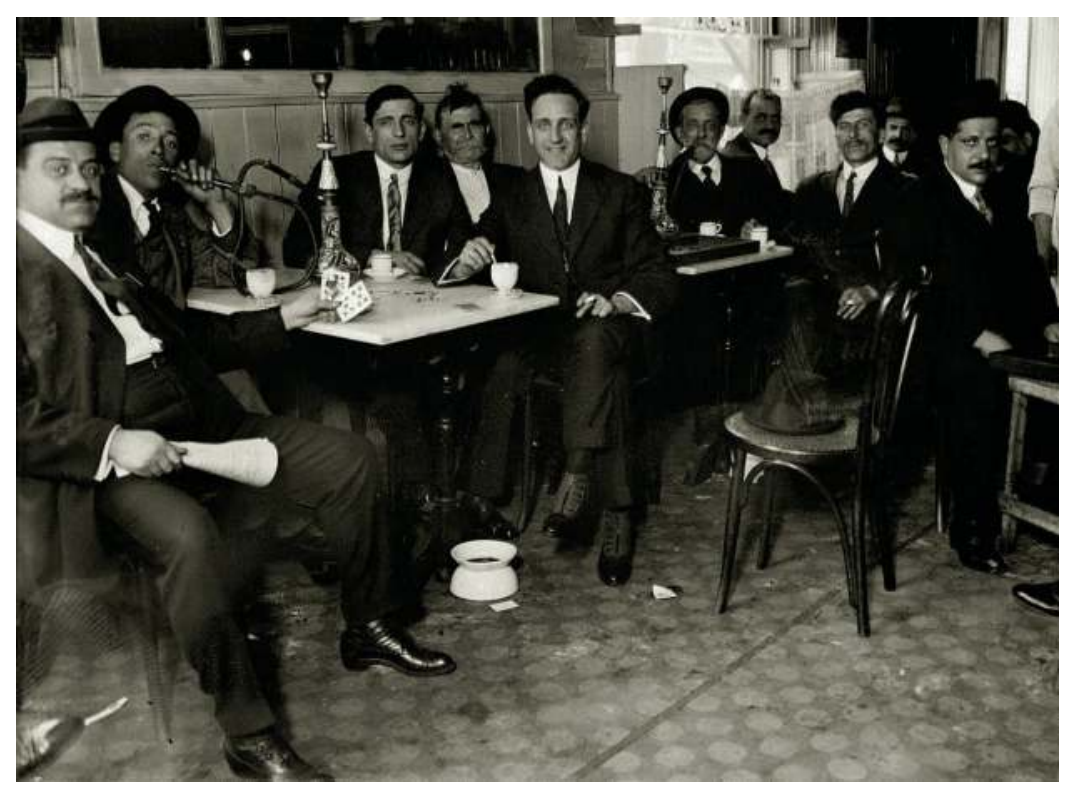

Image 4.4 A Syrian restaurant in New York, 1910s.

(Courtesy of the Bain Collection, Library of Congress, Prints and Photographs Division)

The Immigration Act of 1924 had the same chilling effect on Arabs as on other "nonwhite" nationalities, and Arab immigration did not really recover until the 1950s. Like Asian Indians, many Arabs of this wave of immigrants were educated and technically skilled, although the arrivals also included low-skill Yemenis as well as Palestinians seeking refuge after the Arab-Israeli wars. The Arab American National Museum also claims that these mid-twentieth-century settlers were "much more secular and had a strong sense of a broader Arab identity" compared to earlier migrants (11). Since the 1960s, Arabs have flowed to America from a variety of regional conflicts, including the Lebanese civil war and the two Gulf wars, all of which have generated a steady stream of refugees and expatriates.

According to the Arab American Institute, Arab Americans are on average well educated, 89 percent possessing at least a high school diploma and 45 percent holding a bachelor's or higher college degree. The median income for Arab American households between 2006 and 2010 (\$56,433) was actually slightly higher than the national average $(\$ 51,914)$, although the range varied greatly from Lebanese $(\$ 67,264)$ to Iraqi $(\$ 32,075)$. Arab Americans were also more likely to live in married-couple family units than the general population (55.7 percent versus 49.5 percent). Thus, economically, Arab Americans are relatively well integrated into American society.

The terrorist attacks of September 11, 2001 have, of course, left a bad taste in the mouths of many Americans toward Arabs, and immediately after that event and until today, prejudice and even violence against Arabs (and other Muslims or assumedMuslims) has occurred. A new term, Islamophobia, has even been coined to name this dread and fear of Muslims (who, again, are often equated with Arabs). More 
seriously, according to the Southern Law Poverty Center, hate crimes against Arabs tripled between 2000 and 2008. In fact, in the first nine weeks after 9/11 more than seven hundred attacks against Arabs or presumed-Arabs took place (including some murders), with 165 more violent incidents in the first ten months of 2002 (Ibish 2003: 7). One great (although apparently unjustified) concern among many non-Arab Americans is the threat of the imposition of Muslim or shari'a law on American society, despite the fact that some Jewish sects have arbitration processes in the US, especially over family law, that effectively "are acting as rabbinical courts” (Hanshaw 2010: 188).

\section{Box 4.2 Diversity within Shi'ism in America}

As noted, the majority of Arabs in the United States are apparently Christians, not Muslims. Even so, within that Muslim minority are more divisions, most obviously between Sunnis and Shi'ites. The doctrinal differences between the two groups need not concern us here, but estimates of the number of Shi'ites in the US range between 780,000 and 2 million, making them 10-30 percent of the total Muslim population. Again, not all Muslims in America are Arabs; many, if not most are Asian Indians, Southeast and Central Asians (e.g. Indonesians and Pakistanis), and even native-born African Americans and white Americans. Further, in a rare study of Shi'ism in America, Liyakat Nathani Takim finds that there is not a single unified "Shi'ite Muslim" identity or community but rather that Shi'ites "have tended to fragment along ethnic lines and remain loyal to customs fermented in home states" (2009: 57). That is, Iraqi Shi'ites or Syrian Shi'ites or Egyptian Shi'ites, etc., manage their own mosques, maintain their own practices, and follow their own leaders. There is often little interaction between national groups: "there are few interethnic marriages, and few Shi' is have friends outside their own ethnic background" (59). Interestingly, by contrast, "Sunni mosques are more ethnically diverse than Shi'a centers" (60). In other words, Arab and Muslim Americans possess a variety of different and competing identities and affiliations, and not Arab nor Muslims nor (or especially) small minorities like Shi'ite Muslim Arabs can be viewed as uniform categories or groups.

\section{"White Ethnics"}

Long before African Americans or Native Americans or Hispanics, etc., were ethnic, some white groups were ethnic. Not only does "white" cover a wide range of national and ethnic variation, but it has not always been clear who is white and who is not: ironically, Asian Indians were first classified as "white" and later became "non-white," while, if we follow Noel Ignatiev (1995), Irish were first classified as "non-white" and later became "white."

As de Tocqueville noticed, and as continues to be true today, the central drama in American society is race-the alleged binary between white and non-white (originally meaning African and Native). However, "white" has not always been a single simple category, and it has certainly not always equated simply to "European." For example, 
in 1899, William Ripley wrote a treatise arguing that "there is no single European or white race of men" (1899: 103) but rather three European races, namely Teutonic, Alpine, and Mediterranean. The Teutonic race (since the term "ethnicity" was not in current use) included particularly the Anglo-Saxon peoples, that is, the peoples of England and Germany, and when eighteenth- and nineteenth-century Americans talked about "white people," they primarily meant Anglo-Saxon people.

In fact, for most early Americans, there were probably more than three kinds of Europeans, including also Celtic and Slavic ones. Significantly, the first wave of AngloSaxon settlers, who were also overwhelmingly Protestant, set themselves up as the real or original (even "native") Americans, such that later waves of European immigrants (Irish, Italian, Polish, Jewish, and many others) "were sometimes thought of as 'races' or 'subraces'-people possessing innate or inborn characteristics and capabilities that affected their fitness for American citizenship" (Fredrickson 2001: 23). Most of these new Americans stepped ashore in the late 1800s and early 1900s, and they were subjected to considerable discrimination, stereotyping, and segregation for decades. They were widely believed to bring an inferior biology, personality, and morality (mental deficiency, criminality, drunkenness and vice, and Catholicism) to the United States. They often settled in ethnic/national neighborhoods like the Italian district of Boston described by Herbert Gans in 1962, where they frequently lived as "urban villagers," perpetuating the culture and identity not even of their mother country but of their particular mother region or village. Gans called this a "peer group society" where individuals were deeply enmeshed in their local social structure (not only "ethnic" group but also age and sex groups) and did not interact much with other ethnicities or the wider city, let alone the US as a whole. They were expected to assimilate (to "melt into") American society, but they were often disliked and resented, and their loyalty to their adopted country was often questioned.

In the case of Gans' Italian Americans, their "ethnic" peer-group society was not really broken until the second or third generation, and then sometimes only when

Table 4.7 Fifteen largest national ancestries in the US, 2000

\begin{tabular}{llc}
\hline Ancestry & Number (in millions) & Percent of total population \\
\hline German & 42.8 & 15.2 \\
Irish & 30.5 & 10.8 \\
African & 24.9 & 8.8 \\
English & 24.5 & 8.7 \\
American & 20.2 & 7.2 \\
Mexican & 18.4 & 6.5 \\
Italian & 15.6 & 5.6 \\
Polish & 9.0 & 3.2 \\
French & 8.3 & 3.0 \\
Native American & 7.9 & 2.8 \\
Scottish & 4.9 & 1.7 \\
Dutch & 4.5 & 1.6 \\
Norwegian & 4.5 & 1.6 \\
Scotch-Irish & 4.3 & 1.5 \\
Swedish & 4.0 & 1.4 \\
\hline
\end{tabular}

Source: US Census Bureau. 2000 Census Brief: Ancestry 
city leaders literally demolished their neighborhoods, forcing them to dissolve into the American mainstream. By the mid-twentieth century, most non-Anglo-Saxon Europeans had been sufficiently assimilated, structurally and culturally, to declare the "melting pot" ideal successful for them. This meant two things, as Fredrickson and other observers like David Roediger (2005) have posited. First, the non-AngloSaxon Europeans lost much of their cultural distinctiveness, especially their languages. Second, in exchange for their cultural loss, they made a racial gain: they were welcomed into the "white" race, so that the differences within the white race became less salient than the differences between white and other races.

Interestingly, just as the melting pot had presumably done its work, researchers in the 1960s and 1970s documented the persistence of "white ethnics," beginning perhaps with Nathan Glazer and Daniel Patrick Moynihan's (1963) Beyond the Melting Pot. While their case studies of New York included blacks and Puerto Ricans, they also featured Jews, Italians, and Irish and found that these ethnicities were not completely assimilated and that ethnicity served symbolic, psychological, and real social functions. Many other studies followed, some celebrating the "unmeltable ethnics" like Michael Novak's (1972) The Rise of the Unmeltable Ethnics and others worrying about their stubborn refusal to assimilate. Andrew Greeley (1971) asked rhetorically, "Why can't they be like us?" insisting that real cultural differences remained. As recently as 1990 Richard Alba found a weak but lingering white ethnicity: in spite, or perhaps because, of the fact that actual cultural differences had diminished, and that social distance had narrowed (in other words, "white ethnics" freely intermarried and moved out of ethnic enclaves), many former white ethnics-especially, he suggested, the more educated ones-still took interest and pride in their ethnicity, if only within the family and in symbolic ways (like eating certain "ethnic" foods or visiting the old country). Most importantly, former white ethnics developed a new shared identity, a single white "ethnicity" of European American "based on ancestry from anywhere on the European continent" (1990: 293) and, more, on a shared narrative of immigration and struggle for acceptance which became the "prototypical American experience, against which non-European minorities ... are pressured to measure themselves" (316). One powerful consequence is that this new "European-American identity provides a way for whites to mobilize themselves, bridging what were once their own ethnic divisions, in opposition to the challenges of non-European groups" (316). If so, then white ethnic openness could contribute to white racial closure.

\section{Conclusion}

While the story of America is often seen as the meeting of three races (European, African, and Native), America has always been home to much more historical, cultural, and national diversity than just three groups. In the past century, the concept of ethnicity has emerged to make sense of this diversity and the persistence of their identity differences. Although race and ethnicity in the US are often confused or conflated, they do not refer to the same kinds of differences.

At least officially, a set of ethnic categories is available to Americans, but many of these are quite new; they mask a tremendous amount of variation within the categories (in terms of pre-immigration culture as well as of post-immigration 

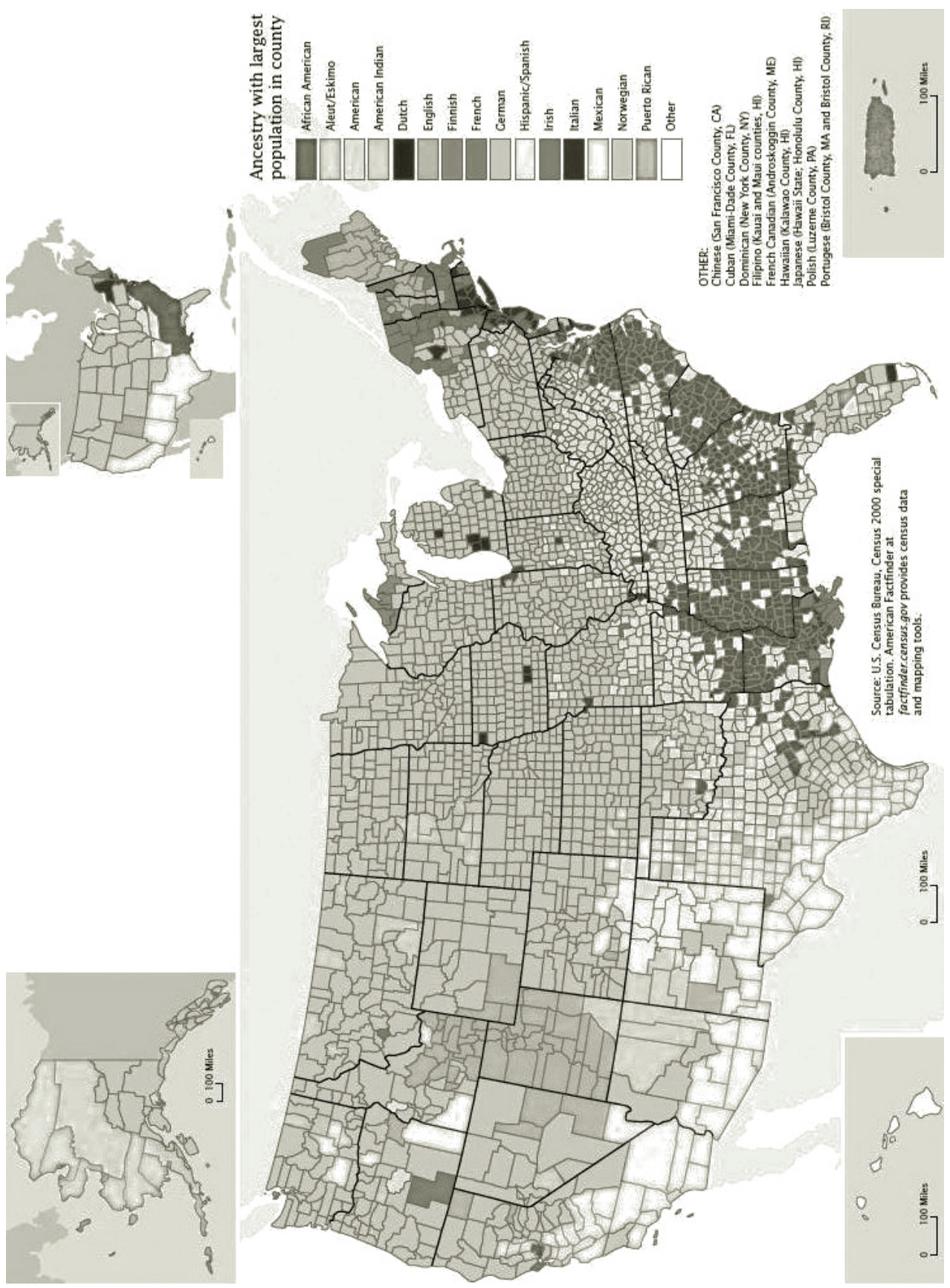

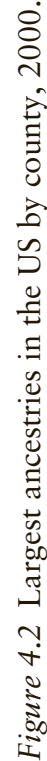

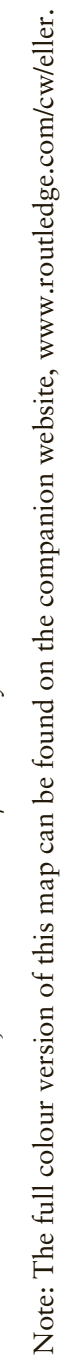




\section{Ethnicity: Beyond the Race Binary}

experience), and they are not unproblematically accepted by the people they are meant to describe. Perhaps most importantly but mostly imperceptibly, white/ European Americans are also "ethnic," and the general invisibility of "white ethnicity" tends to make white Americans seem more uniform than they actually are and to make whites seem like the "real" or "natural" Americans, unmarked by culture, while everyone else (non-white and non-European) is "ethnic" with a "culture" that needs assimilating. 


\section{Class}

Although people of diverse races and ethnicities had been attracted to the United States for decades prior, the term "American Dream" was reportedly first used by historian James Truslow Adams in 1931, at a time (the Great Depression) when that dream seemed particularly unattainable for many. According to Lawrence Samuel's cultural history of the so-called American Dream, it has always been a vague and fragmented idea, associated with "familiar tropes" like "continually rising expectations..., the entrepreneurial spirit, the sacredness of home, the seductiveness of wealth, the pressure to succeed, our perverse fascination with 'hope' and 'change,' and the belief that 'anything is possible"” (2012: 5). No doubt it has meant different things to different people, but among other basic meanings it has idealized upward mobility, the hope and possibility of a better life in the future. While the American Dream is premised on the "inherent right to be restricted by no barriers" (14), many Americans have been continuingly restricted by variables of race, ethnicity, gender, language, religion, health, and more. And, of course, the upward movement of the individual depends on larger social forces and changes, like jobs and wages, the price of housing and food and healthcare, and the global economy. The dream of being a self-sufficient farmer on one's own land has almost completely vanished, as most of us bear the burden of "working for someone else" (45). And oil shocks, housing bubbles, bank failures, and recessions have made it harder to "get ahead" or even keep what you have. The American Dream seems increasingly out of reach, but then it always did: "Constantly coming and going, the American Dream seemed to almost always reside in the past or to loom in the future, rarely ever existing in the here and now" (197).

Is there an "American Dream" that differs from the dreams of other countries? Is the American Dream purely an economic ideal, and, if so, why are Americans so preoccupied with their economic position, especially in a supposedly "classless" society? And what are we to think about the data that show that economic inequality is increasing in America, making the dream more elusive for more Americans?

In the conventional study of society and diversity, class is one of the big three or four dimensions of difference (along with race/ethnicity and gender). In fact, in some theories class is the defining issue of society; it is class more than anything else that determines, or should determine, the individual's place in society. This is particularly odd for the United States, which likes to imagine itself an egalitarian society, where everyone is equal—or at least free to try. However, while Americans are not as classconscious as some societies, there still are real and effective differences in wealth and 
income between individuals, families, and social groups that impact their quality of life and their power in society.

Unlike race (or gender; see Chapter 6), there is no inherent physical component to class. A person may be "born into" money-that is, born from rich parents-but class is not a physical or natural characteristic of the individual. Class may be partly assigned on the basis of physical characteristics (such as race), and it may certainly have physical consequences (for example, on health or life expectancy), though. Not all societies have a concept of class at all, and not all societies that do have the concept have the same concept. Even more important, class is intimately related to other social variables like race, gender, and education, and it is more conspicuously tied to macrosocial institutions like "the economy" than the other category-systems described in this book. Thus, we cannot begin to understand class without some reference to the structure of occupations, historical conditions of employment and unemployment, and even economic forces outside of the United States, including the cost and availability of oil, the industrialization of China, and the financial stability of European countries.

\section{The Social Concept of Class}

In the most general sense, a "class" is nothing more than a category in a classification scheme, and the criteria of classification can be anything. In familiar social practice, "class" tends to refer to some economic criterion, which is necessarily quantitative and hierarchical (for instance, how much money you have). Class then is a cross-culturally common although not quite universal way of dividing society into distinct and unequal categories; it is both a cause and an effect of social stratification, the "layering" of society into "higher" and "lower" levels. The precise number of levels or classes varies between societies, as do the principles for assigning individuals to specific classes and the social consequences of class differences. While we tend to think of class as a predominantly "economic" question, it also has many other social meanings and implications.

Not all societies have made class distinctions. In early hunting and gathering societies, there were no serious or enduring economic differences between individuals or groups, so class was not an issue. (Such societies often made other distinctions, for instance between male and female, young and old, and various kinship groups, but these did not amount to "class" in the familiar sense.) At least as important as the mere existence of classes is the relationship between classes, especially the question of social mobility or whether one can change his/her class position. Social scientists call classes "closed" when there is little or no expectation of social mobility, that is, when one's class status is settled early and permanently; one's class position is thus typically determined by ascribed and immutable qualities. The Hindu caste system is the often-mentioned example of a closed class arrangement, in which a person's caste membership is determined at birth (or before birth, by previous lives) and unchangeable. Hindu castes also combine multiple social functions and meanings, not only economic but also political and even spiritual. In Western societies, the classes of "royalty" and "commoner" were also essentially closed, although the United States does not recognize such categories.

By contrast, the US maintains an ideal of “open" classes, in which a person may or should establish his/her own class position. In an open-class system, one's position is not determined by ascribed or innate qualities but is negotiable on the basis of 
achieved traits like education or profession. Individuals or groups who are poor and low now are welcome to strive to become rich and high later. In fact, social mobility, in the form of joining the "middle class," is one of the measures of assimilation for race and ethnic groups in the United States: if they have reached the middle class in occupation, neighborhood, and cultural values, then they have "made it" and are truly Americans.

\section{Social Theories of Class}

Class was one of the first areas of concentration in the social sciences. Karl Marx, for instance, made class the center of his analysis of the past, present, and future of society. Writing in the mid-1800s, Marx argued that the most fundamental aspect of any society was the kind of work that people did, that is, "labor" or how a society produced the goods and services that it needed. This very practical, material aspect of human life could be identified as a "mode of production" (e.g., hunting, farming, industry, and so on). More significantly, each mode of production created certain relationships between people and groups (or "relations of production"). These relationships included who did what kind of work, who owned the resources, who made the decisions, and who controlled the wealth that was produced. Finally, these fundamental social realities generated ideas and institutions that seem to be independent of economy and class but are not; this "ideology" as Marx called it includes arts, religion, philosophies, the media, and the educational system. Any particular historical society could be understood as a "social formation" composed of these productive and ideological constituents.

There are three additional crucial elements to the Marxian analysis of class. First, Marx believed that class was the single most influential status or identity that a person occupied; other statuses or identities, such as nationality or ethnicity or religion, were either insignificant or literally false. Thus, individuals should overcome their "false consciousness" and become conscious of themselves as a class. Second, while there may have been societies in the past with more classes, Marx asserted that modern, industrial society had condensed class categories down to two: there were those who owned the "means of production" (land, factories, etc.), whom he called "bourgeoisie," and those who owned nothing and sold their labor for money, whom he called the "proletarians." In his scheme, one was either an owner who exploited laborers or a laborer who got exploited as a "wage slave." Third, the dominant class (in this case, the bourgeoisie) not only benefited from the wealth but also defined the relations and ideology of society, and it was in their interests to keep society steady and unchanging, to reproduce the current and unequal relationships between the classes. They used everything from military power to education and religion to justify and perpetuate their advantage.

Émile Durkheim also made socio-economic differences central to his theory of society. For him, the key to modern society was the division of labor: modern, industrial, urban society featured many different jobs to perform and therefore a specialization of labor. Unlike pre-modern societies, in which he believed families or villages were self-sufficient, modern industrial people were dependent on each other (some people were farmers, some were factory workers, some were doctors or teachers, and so forth). Thus the division of labor was the glue that held urban society together; large numbers of comparative strangers were integrated by mutual need. Moreover, since some jobs required more talent and training, and since some individuals had more 
education or skill, the qualified individuals who held those more demanding jobs would necessarily and rightfully acquire more money and rise to a higher class. And society would prepare individuals and groups to occupy their differentiated positions, making the differences natural and acceptable to their holders.

Durkheim conceived of class as being more complex, and more positive, than Marx did, but it was Max Weber who elaborated most effectively on the class concept. In his famous Economy and Society he defined class explicitly as

(1) a number of people [who] have in common a specific causal component of their life chances, insofar as (2) this component is represented exclusively by economic interests in the possession of goods and opportunities for income, and

(3) is represented under the conditions of the commodity or labor markets. This is "class situation."

(1968: 927)

Weber was clear that a class is not necessarily or usually an actual concrete group but rather a shared social "situation." What was important about a class was that its members shared common "life chances," which we can think of as the possibility and likelihood of living in a certain kind of house, eating certain kinds of food, wearing certain kinds of clothing, and generally living a certain kind of life.

Weber also recognized much more diversity in class positions than Marx. To start, he insisted that class was not the only source of identity or determinant of life chances; there were also "status groups" that varied in honor and respectability more than in economic circumstances and wealth, as well as "parties" that varied in social and political interest and power. Even more, one's class position was a function of multiple variables, not just Marx's single relationship to the means of production. Weber identified three independent variables-wealth, power, and prestige-which allowed for a number of combinations and a subtle gradient of class instead of a stark binary. This allowed him and us to re-introduce non-economic social dimensions like race, ethnicity, gender, age, and such. Finally, in keeping with his focus on meaning, Weber confirmed that there is a subjective quality to class, that it depends at least in part on how the individual thinks about class and experiences his/her class status and identity.

\section{Social Study of Class}

These relatively abstract approaches to class do not settle the questions of how many classes there are, what separates one class from another, and which class(es) we should focus our attention on. Income, for instance, is a continuous "analog" variable, not a discrete "digital" one; there is no sharp, obvious cut-off that distinguishes one class from another. It is common practice to speak of "lower class," "middle class," and "upper class," but these are blunt and arbitrary terms. For instance, the US Census does not have an official definition for these terms, and while there is an official measure of poverty (see below), "lower class" does not exactly equal "poor." Additionally, most people would make distinctions within the "middle class," say, between the "lower-middle" and the "upper-middle." Nevertheless, such language does not name real objective economic distinctions, nor does it capture the subjective experience of individual members. 
Some of the technical measures of economic standing within and between countries include gross national product, the quintile division, and the Gini index or coefficient. Gross national product refers to the total value of all the goods and services produced in a country (the gross domestic product) plus the income earned by citizens from investments in other countries. Representing this data "per capita" (that is, divided by the population) provides a means to compare the average wealth per person between countries. As Table 5.1 shows, the global income/wealth disparities are extreme.

Indeed, an eye-opening website called The Global Rich List (http://www.globalrichlist. com) allows you to find your position in the global distribution of wealth. For example, in mid-2015, a person earning \$53,960 (the American GNP per capita) is in the top 0.25 percent of the world's incomes, among the 15,000,000 richest people in the world.

To be sure, not everyone in America earns \$53,960; the wealth of a modern society is inevitably unequally distributed. Representing a country's wealth by quintile is one informative way to indicate the inequalities. A quintile is one-fifth or 20 percent of the country's population or households; in other words, the first or highest quintile separates out the top 20 percent, the second quintile the next 20 percent, and so on. Table 5.2 depicts the five American quintiles in terms of range of income and share of total national income; each quintile consists of 24,217,000 households.

It is plain to see that the lower quintiles possess lower incomes and a smaller share of America's wealth, which is the definition of income inequality. The richest 20 percent

Table 5.1 GNP per capita for ten richest and ten poorest countries

\begin{tabular}{lclc}
\hline Richest countries & GNP per capita & Poorest countries & GNP per capita \\
\hline Qatar & 123,860 & Democratic Republic of Congo & 680 \\
Singapore & 76,850 & Malawi & 760 \\
Norway & 66,520 & Liberia & 790 \\
United States & 53,960 & Burundi & 820 \\
Saudi Arabia & 53,780 & Niger & 910 \\
Sweden & 44,660 & Mozambique & 1,040 \\
Germany & 44,540 & Guinea & 1,160 \\
Denmark & 44,440 & Eritrea & 1,180 \\
Austria & 43,810 & Togo & 1,180 \\
Netherlands & 43,210 & Guinea-Bissau & 1,240 \\
\hline
\end{tabular}

Source: World Bank, 2013

Note: The World Bank calculates gross national income as purchasing power parity in international dollars

Table 5.2 Distribution of household money income by quintile, 2011

\begin{tabular}{lll}
\hline Quintile & Range of income & Share of total household income (percent) \\
\hline First & $\$ 101,583$ or more & 51.5 \\
Second & $\$ 62,435$ to $\$ 101,582$ & 23 \\
Third & $\$ 38,521$ to $\$ 62,434$ & 14.3 \\
Fourth & $\$ 20,263$ to $\$ 38,520$ & 8.4 \\
Fifth & Up to $\$ 20,262$ & 3.2 \\
\hline
\end{tabular}

Source: US Census Bureau. Current Population Report: Income, Poverty, and Health Insurance Coverage in the United States, 2011 
of households control sixteen times the wealth of the poorest 20 percent of households; the top 5 percent of households alone control almost a quarter of all of America's wealth.

The Gini index is a single coefficient that represents income inequality: the Gini index number ranges from zero to one, with zero meaning perfect income equality and one meaning perfect inequality (a single individual or household owns all wealth). In short, the higher the coefficient, the greater the inequality. Between the years 2006 and 2010, the Gini index for the United States was 0.467 , indicating a high degree of inequality, and all indicators point to an increase in wealth inequality over recent decades (see below). However, America's economic inequality is unequally distributed, both geographically and socially. For example, the South has the most unequal distribution: almost one-third of counties in the South were among those with the highest Gini indices. On the other hand, the Midwest had only 8 percent of counties among the most income-unequal in America, and the West had 26 percent of counties among the most income-equal in the nation. Finally, wealth inequality varied by race: in 2011 the national Gini index was 0.477 , income was slightly more equally distributed among whites (0.469), Hispanics (0.458), and Asians (0.467) than among blacks (0.502). That is to say, not only did African Americans have lower incomes on average, but there was greater disparity among African Americans.

It is worth noting that economists make a distinction between wages, income, and wealth. Wages are the pay that a person receives for labor, often as an hourly rate. Income refers to all sources of money including both earned (wages) and unearned; the latter includes sources like interest, dividends, and capital gains. Wealth (also known as net worth) then means the total value of a person's or household's possessions, including land, houses, businesses, stocks, and such. Not surprisingly, poorer individuals and households depend most on wages and own the least in terms of wealth; indeed, the very poorest actually have negative wealth, since they owe more money than they earn. A report from the Economic Policy Institute (Allegretto 2011) finds that more households (26.9 percent) in the lowest quintile have high debt burdens than the national average (14.7 percent) or than the top quintile (around 6 percent). In 2007, the top 5 percent of households owned 69 percent of the stock, 76 percent of the other financial assets, and 59 percent of the country's total worth, while the bottom 95 percent owned less than a third of stock, less than a quarter of financial assets, and only 41 percent of America's wealth.

One last point: for not surprising reasons, most of the attention of social scientists and policymakers has been directed at the poor rather than the other classes of society. One reason, naturally, is that scholars and politicians have shared the attitude that the poor are a "problem" and therefore that they must be "solved"; the rich or at least middle class seemed like less of a pressing issue. Since poverty has disproportionately fallen on racial and ethnic minorities, the focus on poverty has also permitted researchers to explore these other social variables and the relations between them. A second reason, though, is that it is more difficult to study the rich; their workplaces and homes are harder to access (they literally have guards and gates), and they are better able to shield their economic circumstances and their activities from view.

\section{Class in the United States}

The problem, one might say the irony, of studying class in America is that, according to many Americans, it does not exist. That keen observer Alexis de Tocqueville had 
claimed in 1830 that America lacked classes, that the people were one big agrarian middle class, and that although there were rich and poor these groups did not crystallize into classes. More than a century later, anthropologist Walter Goldschmidt insisted that "American society presents the enigma that despite great differentials in wealth, prestige and power, there are no clearly marked social classes” (1950: 483). Almost exactly between these two writers, James Bryce in 1899 had asserted that there "is no rank in America, that is to say, no external and recognized stamp, marking a man as entitled to any special privileges, or to deference or respect from others. . . . The total absence of rank and universal acceptance of equality do not, however, prevent the existence of grades and distinctions which, though they find no tangible expression, are sometimes as sharply drawn as in Europe" (quoted in Goldschmidt 1950: 483).

This should sound contradictory: as Goldschmidt himself commented incredulously, "Great differentials in wealth, sharply drawn distinction in status, but no classes" (483). Indeed, Americans do not tend to think of themselves in class terms, and it is almost impolite to discuss class. At worst, talk of class is sometimes condemned as engaging in "class warfare." At best, class violates American sensibilities about what Katherine Newman (1988) called "meritocratic individualism." Meritocracy is a system in which people ideally have what they deserve. In a true meritocracy, those individuals with talent who make an effort earn their just rewards; there are surely inequalities, since individuals bring unequal talent and effort to the task, but the results are fair, and individuals always have the opportunity to improve their lot. But there are no pre-determined social levels, and success or failure is private, not collective.

Yet, as Goldschmidt went on to say, "virtually every social scientist who has attacked the problem of the American social organization has asserted a class system" (483). Anthropologist Sherry Ortner called class a "hidden" category-system in America; she proposed that “class exists in America but cannot be talked about, that it is 'hidden,' that there is no language for it, but that it is 'displaced' or 'spoken through' other languages of social difference-race, ethnicity and gender" (1998: 8). Not only did she respond that race and ethnicity "have been the dominant discourses of social difference" (2), obscuring the reality of class, but that Americans literally understand the discourse of race/ethnicity better than talk of class:

I have recently been interviewing people about class . . , and when I introduce the term "class," informants immediately ask what I mean by that. But when I mention race or ethnicity, "everybody knows" what those things mean or refer to in the "real world." These self-explanatory categories, moreover, seem to carry with them a whole social theory.

There are two good bits of evidence to support the idea of the invisibility, even the inappropriateness, of class-talk in America. The first is that there is no agreement whatsoever on how many classes there are. Goldschmidt himself offered four-the elite (old money with an aristocratic attitude), the middle class, the working or laboring class (roughly Marx's proletarians), and the lower class (characterized by work without hope of advancement). In an influential study/manual in 1949, Warner, Mekker and Fells added two more classes, to make six-the upper upper class (old money), the lower upper class (new rich people like Bill Gates), the upper middle class 
(high-earning professionals like doctors), the lower middle class (lower-earning professionals), the upper lower class (manual laborers or "blue-collar workers"), and the lower lower class (the unemployed and the working poor). Much more recently, Paul Fussell (1983) went so far as to identify nine classes:

- The super-rich or "top out-of-sight," who are so wealthy that they are literally beyond the sight of ordinary Americans;

- The "upper class" who are born into wealth;

- The "upper middle class" (or perhaps more accurately the lower upper class), professionals with high educations and high salaries;

- The "middle class" who are "white collar" employees or self-employed;

- The "high prole" who, as skilled craftsmen and artisans, may actually earn more than some middle- or upper-middle-class individuals but are characterized by comparatively "low-brow" attitudes and behaviors;

- The "mid prole" who hold lower-paying and lower-status jobs (Fussell gives the example of bus drivers);

- The "low prole" who perform unskilled labor; they are sometimes poor despite having jobs;

- The "destitute" who are poor and often homeless;

- The "bottom out-of-sight" who are so poor that they too are invisible to most people; some of them are in prison or other institutions.

The imprecision and disagreement about class categories and their membership highlight the subjective quality of class. Warner et al. stressed this fact, claiming that class had more to do with shared attitudes than with objective indicators like money (which is what, for example, separates Fussell's high proles from the middle and upper classes). In the same year, psychologist Richard Centers agreed that class is highly if not essentially subjective, that "a class is no more nor less than what people collectively think it is. It is a psychological structure," not an objective fact, and therefore "classes demand social definitions. That is, they must be defined by the people collectively" (1949: 78). Centers believed that occupation was the most important marker of class for Americans.

The second and related bit of evidence for the vagueness of class in America is that most Americans do not really understand their own class system. The vast majority of Americans think they are middle class, and "the middle class" is a kind of icon of American society. However, David Francis (2012) recently concluded that "many Americans aren't aware of which one of these categories they fall into. Many believe they are better or worse off than they actually are, and have misconceptions about how other classes live."

\section{Diversity Fact:}

According to a Pew Research Center study, the number of Americans who assert that there are strong or very strong conflicts between the rich and poor increased significantly between 2009 and 2011, from 47 percent to 66 percent. Among African Americans, the perception of rich/poor conflict was higher ( 74 percent) 
in 2011 than among whites (65 percent), but whites marked a greater increase over those two years (22 percentage points). In both years, Democrats were more inclined to note a class conflict (from 55 percent to 73 percent) than Republicans (38 percent to 55 percent).

\section{Some Economic Facts in America}

While class ultimately remains slippery and subjective, there are some statistical facts that depict the economic distributions and disparities in American society. For example, median household income in 2011 was \$50,054, a 1.5 percent drop from 2010 and 8.9 percent lower than 2007 (the year before the recent recession). However, household income varied along a number of social dimensions, as shown in Table 5.3.

Clearly, many social variables are correlated with income in the United States, race and ethnicity key among them, as illustrated in Figure 5.1.

Another valuable indicator is poverty, which, unlike class, does have a formal designation in the US. The poverty line is stipulated by the government in terms of family size, which for 2015 was

- $\$ 11,770$ for a family of one

- $\$ 15,930$ for a family of two

- $\$ 20,090$ for a family of three

- $\$ 24,250$ for a family of four

For each additional family member, the poverty line increases by approximately $\$ 4,000$. On that basis, a family of the appropriate size earning less money than the

Table 5.3 Household income by selected social characteristics, 2011

\begin{tabular}{lc}
\hline Type of household & Median income (\$) \\
\hline All households & 50,054 \\
Married couple & 74,130 \\
Female householder, no husband present & 33,637 \\
Male householder, no wife present & 49,567 \\
White & 52,214 \\
Black & 32,229 \\
Asian & 65,129 \\
Hispanic & 38,624 \\
Householder under age 65 & 55,640 \\
Householder age 65 or older & 33,118 \\
Householder with disability & 25,420 \\
Region-Northeast & 53,864 \\
Region-Midwest & 48,722 \\
Region-South & 46,899 \\
Region-West & 52,376 \\
\hline
\end{tabular}

Source: US Census Bureau. Current Population Report: Income, Poverty, and Health Insurance Coverage in the United States, 2011 


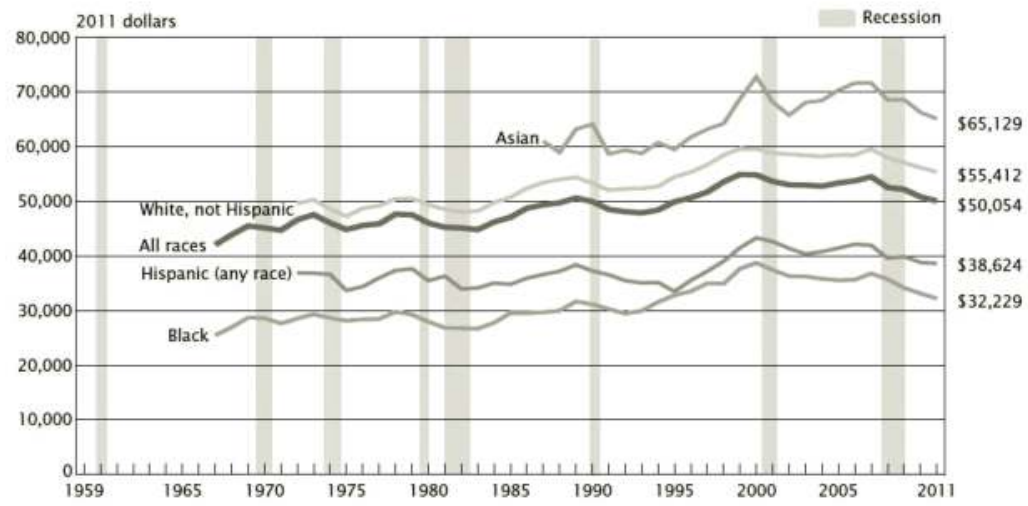

Figure 5.1 Median household income by race and Hispanic origin, 1967 to 2011.

Source: US Census Bureau. Current Population Report: Income, Poverty, and Health Insurance Coverage in the United States, 2011

poverty line is officially living "in poverty" and "poor." By these standards, 46.2 million or 15 percent of Americans were poor in 2011; for specific race and ethnic groups, the rate varied, from 9.8 percent for non-Hispanic whites to 27.6 percent for blacks, with Asians (12.3 percent) and Hispanics (25.3 percent) in between. Poverty is more prevalent among children (21.9 percent) than among working-age adults (13.7 percent) or the elderly (8.7 percent), and it is higher in the South (16 percent) than in the West (15.8 percent), Midwest (13.1 percent), or Northeast (13.1 percent).

\section{A Short History of Class in America}

In the New Testament (Matthew 26:11, New International Version), Jesus is quoted as saying, "The poor you will always have with you." Surely America has always had its poor, even during early colonial days, although the society has not always been charitable toward them. Americans often forget that the poor, particularly those in debt, were typically put in prison; the colony of Georgia was originally founded in the first place as a destination for debtors from England. The practice of incarcerating the poor and indebted did not begin to disappear until the 1830 s.

Based on its Protestant/Puritan morality, which valued hard work, modesty, frugality, and individualism, the poor were not necessarily treated equally. There was a major distinction between "the deserving poor" and "the undeserving poor," and only the former were entitled to any pity or assistance. The deserving poor were those who were poor through no fault of their own, like orphans, widows, or the disabled or elderly; even for them, the solution to their plight was often servitude or sentencing to an almshouse. The undeserving poor were seen to be victims of their own character flaws or sins, including drunkenness or idleness; rather than receiving help, they were typically branded as vagrants or criminals and punished or given "discipline" in the form of hard labor and Bible study.

During those years, America's most inhumane and caste-like practice continued, namely, slavery. Race and class/caste became virtually superimposed in slave states in the South, where a class consciousness formed that could still be identified by John 
Dollard in his 1937 Caste and Class in a Southern Town. Significantly, the mid-1800s was also an era of economic dislocation for many white citizens, who found themselves transformed from yeoman farmers (the stuff of the original American Dream) into wage laborers. This wage labor, while greatly needed, was not necessarily respected: one Southern newspaper, the Charleston Mercury, featured an item around the time of the outbreak of the Civil War affirming that "Slavery is the natural and normal condition of the laboring man ... and the Northern states will yet have to introduce it. The theory of a free society is a delusion" (quoted in Boyer and Morais 1975: 13). In reaction, many citizens resisted the encroachment of big business and the railroads on their land, and corporations and the government collaborated to quash labor unrest and, for a long time, the organization of labor into unions.

There were, in the early decades of the United States, few if any institutions to serve the poor and virtually no government-provided institutions or services; aid to the poor was considered to be an individual or church matter. However, industrialization and urbanization, large-scale immigration, and economic booms and busts revealed a poverty problem of proportions that could not be ignored. The "poorhouses" of an earlier era, publicly supported residential sites where destitute people were forced to live, slowly gave way to "outdoor relief," the supposedly cheaper alternative of providing poor people with a small stipend to live in their own homes-a step toward the familiar "welfare" approach. In 1889 Jane Addams and Ellen Gates Starr founded the famous Hull House in Chicago as a "settlement house" for new immigrants. But the disaster of the Great Depression changed everything.

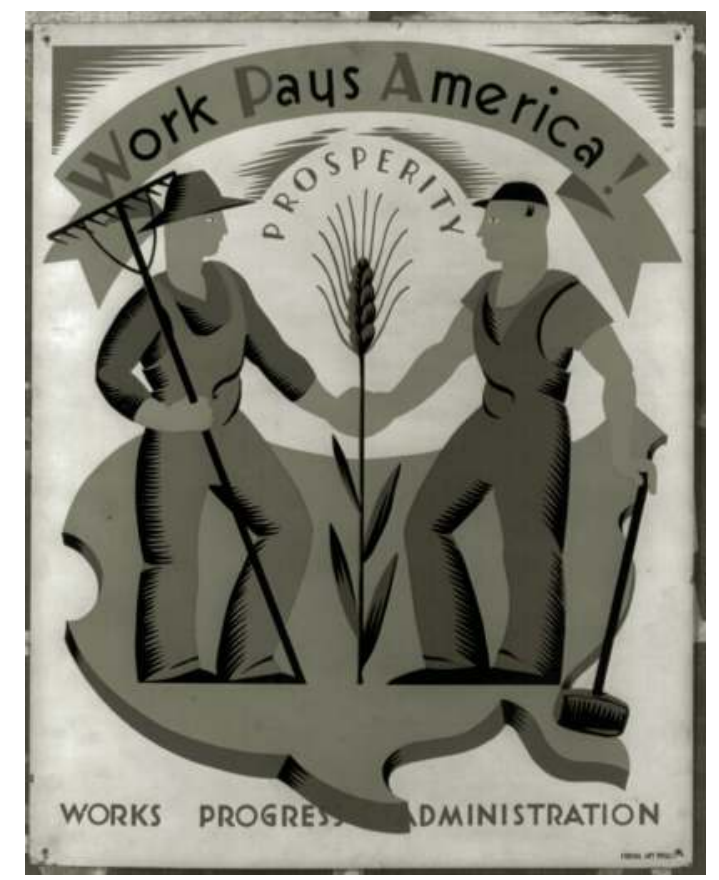

Image 5.1 A 1930s poster for the Works Progress Administration encouraging laborers to work for America.

(Courtesy of the Library of Congress, Prints and Photographs Division) 
In 1929 a stock market crash and a run on banks led to a long and deep crisis. After four years of dawdling, the government, under the newly-elected president, Franklin Roosevelt, began to implement planks of what would become the modern welfare system. The Social Security Act of 1935 guaranteed support for the elderly, widows, the disabled, and poor families in the form of Aid to Families with Dependent Children (AFDC). Also, a federal minimum wage was set in 1938 (at 25 cents an hour or about $\$ 4$ in 2012 dollars); the minimum wage would grow to a high in 1968, at the peak of the welfare state, of $\$ 10.51$ in 2012 dollars, and settle at the current rate of \$7.25. Many other work programs were also created during the 1930 s, many of them shortterm.

\section{Diversity Fact:}

While the federal minimum wage in 2015 was $\$ 7.25$ for most workers, for those who can expect tips from their services (like waiters and waitresses), the Fair Labor Standards Act established a minimum wage of \$2.13, on the assumption that tips would provide the difference. That is, tips were expected to produce two-thirds of the supposed minimum income. Meanwhile, most states in the Union have minimum wage rates equal to or higher than the federal standard, but a few-all in the South—have state minimum wages lower than the federal rate.

Social Security and AFDC would not prove to be short-term, though, and by 1960 3.1 million people were receiving AFDC; this figure ballooned to 6.1 million in 1969, 10.8 million in 1975, and a staggering 50 million in 1996. Along the way, new programs were added, particularly healthcare in the form of Medicare (for the elderly) and Medicaid (for the poor) in 1965 (most recently, the Affordable Care Act of 2010, sometimes known as "Obamacare," extended healthcare coverage and subsidies to more Americans). In fact, the 1960s was a decade of official "war on poverty," with additional initiatives such as Head Start for young children and a Cabinet-level Department of Housing and Urban Development.

By the 1980s "welfare" was coming under increasing criticism for not only failing to solve the problem of poverty but actually making it worse. The cause according to many was that welfare handouts discouraged individual initiative: if free money was coming, why work at all? In short, it fostered dependency. Worse, it was believed that welfare encouraged bad behaviors, like divorce or out-of-wedlock pregnancy; one of the most widely cited villains of the anti-welfare movement was the supposed "welfare queen" who had children just to collect bigger checks. In response, in 1996 Congress passed the Personal Responsibility and Work Opportunity Reconciliation Act, which stated explicitly that the existing "welfare system contradicts fundamental values that ought to be encouraged and rewarded: work, family, personal responsibility, and self-sufficiency." In a social climate that favored "workfare" over welfare-that is, in which public assistance was intended to be temporary (and certainly not multigenerational) and merely a transition to employment-the old AFDC was discontinued and replaced by Temporary Assistance for Needy Families 
(TANF), a means test was applied to potential recipients, under-age mothers were required to live with their parents or another adult guardian, and the term of assistance was set to no more than five years.

Surely enough, the welfare rolls decreased by 50 percent between 1994 and 1999. However, the rate of poverty did not decrease equivalently and in fact has risen in recent years. Simply cutting poor people off from assistance programs does not automatically eliminate poverty.

\section{The Poor in America}

As mentioned, much social-scientific attention has been directed at the poor, in an effort to explain or diagnose and then solve the "problem" of poverty. This can be seen as a major advance over the attitude that blames the plight of the poor on their own alleged mental or moral failings. This social-reform motivation has yielded some results: poverty rates dropped from 22.4 percent in 1959 (prior to the "war on poverty") to a low of 11.1 percent in 1973 . However, at that point the gains against poverty stalled, and for the past forty years the rate has stubbornly hung around the low- to mid-teens, recently rising to 15 percent, its highest level since 1993.

One enduring explanation for persistent poverty has been the "culture of poverty." A phrase most associated with Oscar Lewis, the culture of poverty first appeared in his 1959 Five Families: Mexican Case Studies in the Culture of Poverty. In his follow-up study, The Children of Sanchez: Autobiography of a Mexican Family, Lewis elaborated on the concept, stating that it had both economic and social/psychological patterns. The common economic traits of the culture of poverty were

the constant struggle for survival, unemployment and underemployment, low wages, a miscellany of unskilled occupations, child labor, the absence of savings, a chronic shortage of cash, the absence of food reserves in the home, the pattern of frequent buying of small quantities of food many times a day as the need arises, the pawning of personal goods, borrowing from local money lenders at usurious rates of interest, spontaneous informal credit devices organized by neighbors, and the use of second-hand clothing and furniture.

(1961: xxvi)

More importantly in terms of lifestyle and life chances, Lewis offered these social and psychological features of the culture of poverty:

living in crowded quarters, a lack of privacy, gregariousness, a high incidence of alcoholism, frequent resort to violence in the settlement of quarrels, frequent use of physical violence in the training of children, wife beating, early initiation into sex, free unions or consensual marriages, a relatively high incidence of the abandonment of mothers and children, a trend toward mother-centered families and a much greater knowledge of maternal relatives, the predominance of the nuclear family, a strong predisposition to authoritarianism, and a great emphasis upon family solidarity - an ideal only rarely achieved. Other traits include a strong present time orientation with relatively little ability to defer gratification and plan for the future, a sense of resignation and fatalism based upon the realities of their 
difficult life situation, a belief in male superiority which reaches its crystallization in machismo or the cult of masculinity, a corresponding martyr complex among women, and, finally, a high tolerance for psychological pathology of all sorts.

(xxvi-xxvii)

Not surprisingly, many observers considered this profile of the poor insulting, and denounced it for blaming the victims for their own problems. However, Lewis explained that his cultural concept was meant to counter the widespread sociological and popular view that poor people had no culture at all or that they lived in a state of cultural breakdown. A good example of this competing perspective is found in Blackways of Kent (1955), in which Hylan Garnet Lewis (no relation to Oscar) attributed the poverty of Southern African Americans partially to the broken black family, with its fatherlessness and its single-motherhood. But the classic statement on the American black culture of poverty came in Daniel Patrick Moynihan's 1965 The Negro Family, subtitled The Case for National Action. He sounded an urgent alarm that the "fundamental problem" for the future of African Americans "is that of family structure. The evidence-not final, but powerfully persuasive-is that the Negro family in the urban ghettos is crumbling. ... So long as this situation persists, the cycle of poverty and disadvantage will continue to repeat itself" (5). Acknowledging the destructive effects of slavery, segregation, recent urbanization, and lingering poverty, Moynihan nevertheless bemoaned the "reversal" of male and female roles in the black family and the resulting delinquency and crime. He concluded that the urban black family was pathological and that "the tangle of pathology is tightening."

Such worries led profitably to a series of field studies of poor, often minority, neighborhoods, including Elliott Lebow's 1968 Tally's Corner, Gerald Suttle's 1968 The Social Order of the Slum, and Ulf Hannerz's 1969 Soulside: Inquiries into Ghetto Culture and Community. However, particularly noteworthy was Carol Stack's All Our Kin: Strategies for Survival in a Black Community (1974), which argued strongly that the lifeways of the poor were not deviant but rather adaptive (see Box 5.1).

\section{Box 5.1 Surviving in a Poor Black Neighborhood: Carol Stack’s All Our Kin}

Actually living in a poor black community and interacting with the femalecentered households criticized by Moynihan and both Lewises, Carol Stack first and foremost urged that we cannot use the conventional concept of family-the isolated, household-bounded, nuclear husband-and-wife unit-as the standard for understanding and judging all kinship systems. This ideal nuclear, selfsufficient, and male-headed family was a white middle-class structure, not suited to all social conditions. Instead, she found that poor urban black families relied on a network of individuals and households for a range of needs, from food and money to child care. A family in her sense, then, was "the smallest, organized, durable network of kin and non-kin who interact daily, providing domestic needs of children and assuring their survival" (1974: 31). In the poor neighborhood, "family" was not restricted either to "household" or to "kin." Shared residence was not the key to family, as multiple residences might share family responsibilities; therefore, not all of the functions that might occur in one white middle-class 
"family" were performed in a single black household. Children did not necessarily live with their mother or father, and their residence often shifted over time. Nor was "family" or family obligation determined solely by blood relations. For instance, the women of Stack's neighborhood did "not expect a single person, the natural mother, to carry out by herself all of the behavior patterns which 'motherhood' entails" (83). Even more, a person's status as "kin" was based more on their participation in exchange relations than on biology. Therefore, mere biological fatherhood did not make a man a "father" either; only if he-and his female kin-participated in raising the child did full social fatherhood result. And, of course, there were many factors that intervened in that relationship, both for the man and the woman. The fact that men's employment was unstable, that their incomes were low, that forming a separate household with a man tended to strain cross-household exchange networks, and that co-residence and marriage could jeopardize welfare payments all conspired to make male-female relationships and marriages risky: "Kin regard any marriage as both a risk to the woman and her children and as a threat to the durability of the kin group" (117).

In a word, the research of Stack and others suggested that the poor (often black) family was not so much a pathology as an adaptation, and a not-unreasonable adaptation at that. And this fits with Oscar Lewis' intention for introducing the culture of poverty concept, which underscored the fact that poverty "is not only a state of economic deprivation, of disorganization, or of the absence of something. It is also something positive in the sense that it has a structure, a rationale, and defense mechanisms without which the poor could hardly carry on. In short, it is a way of life, remarkably stable and persistent, passed down from generation to generation along family lines" (1961: xxiv).

Of course, as Oscar Lewis also acknowledged, not all poor people come from or enter into the culture of poverty. Poverty has a number of causes and effects, although, as David Shipler recently explained, "Poverty is a peculiar thing: a cause whose effects then cause the original cause, or an effect whose causes are caused by the effect" (2004: 53). This is what we call the cycle of poverty. According to Kathiann Kowalski's (2003) research on poverty, there are many contributors to the situation, including illness and injury (many people are thrust suddenly into poverty when they get sick or hurt), substance abuse, mental illness, old age, single motherhood, and certainly unemployment. These factors can interact too: she tells us that 85-90 percent of the severely mentally ill are unemployed. More perversely, many poor people actually have jobs, but those jobs are low-paying and/or temporary or part-time.

These "working poor" earn money but not enough to pull themselves or their families out of poverty. After all, at the minimum wage of $\$ 7.25$ an hour, a full-time employee stands to earn $\$ 15,080$ per year before taxes, which would fall below the poverty line for a family of two, let alone a family with several children. We could assume that such a job also would provide little in the way of benefits like healthcare or paid vacation. And if the wage earner is a single mother, then the cost of childcare must be factored in-which is why many working-poor women depend on a network of kin to survive.

Barbara Ehrenreich conducted some in-person research on the experience of the minimum-wage worker and the working poor, published in her Nickle and Dimed 


\section{Class}

(2002). She actually took a number of different low-paying jobs like house cleaner, retail clerk, and waitress. She found that it was difficult to get by on the wages offered for such work; it was often necessary to share housing with one or more other adults. The work was also physically difficult, involving strenuous or repetitive activity, with little time for rest or eating; such jobs leave the worker exhausted and undernourished. Unable to afford their own vehicles, low-wage workers often spend great amounts of time walking or commuting to jobs, making their workday even longer. And the work itself is seldom intellectually stimulating or personally rewarding-yet it is work that needs to get done. These conditions help explain Shipler's observation that the working poor tend to have little or no savings (making them vulnerable to one catastrophic event in life or simply to a temporary illness, injury, or inability to work), to have little or no time to attend to their health, to live unhealthy lifestyles like poor diets, and to suffer depression and feelings of helplessness and hopelessness.

At the extreme of poverty are the homeless. According to a 2012 report from the Homelessness Research Institute, 633,782 people were homeless in America, making for a rate of 200 per 100,000 of population. The majority were living in emergency shelters or transitional housing, although fully 38 percent were literally homeless, living in cars, abandoned buildings, or out on the street. While the majority of the homeless $(394,379)$ were adult individuals, more than one-third $(239,403)$ were families with children; after all, if a parent is homeless, so is his/her child. Additionally, more than 62,000 of America's homeless were military veterans. Every category of the homeless had decreased at least slightly from the previous year, except sadly for families with children. And while homelessness had declined in some states, it had increased in others-by 14 percent in Missouri and North Dakota and by an astonishing 75 percent in Wyoming. Simultaneously, national spending for public assistance on a per capita basis dropped by nearly 3 percent.

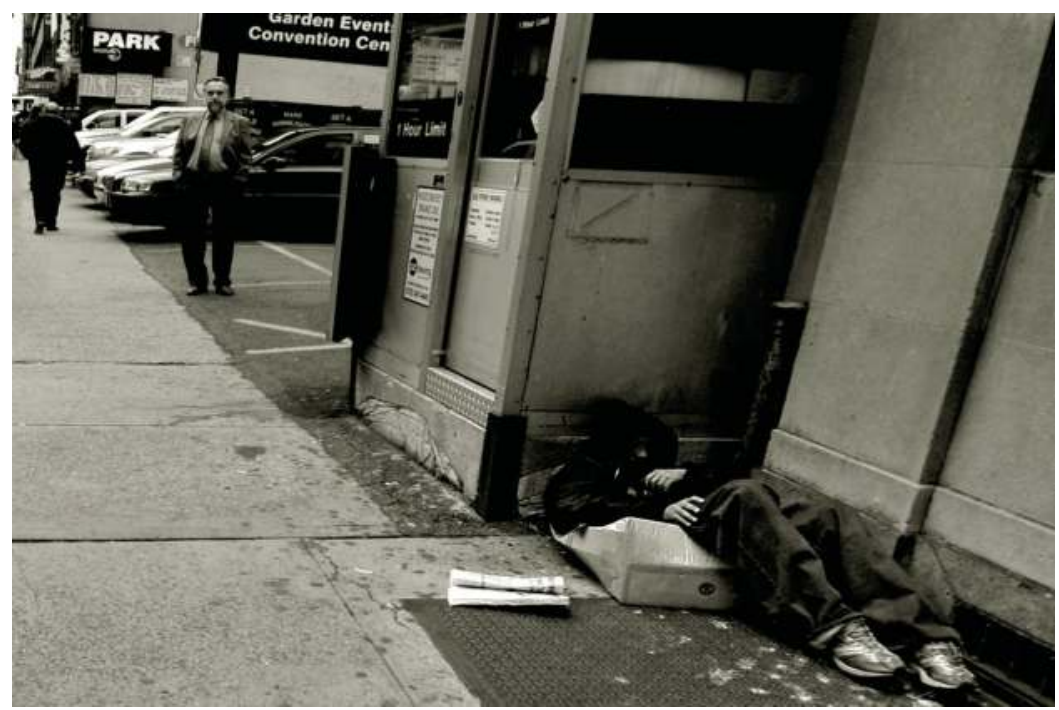

Image 5.2 A homeless man sleeps on the streets in New York.

(Courtesy of ChameleonsEye/Shutterstock.com) 
Homelessness, like the wider class system, is not a single experience. Some individuals and families occupy shelters, often sleeping there while holding jobs. Some beg on street corners and busy intersections. Others, like the street vendors described by Mitchell Duneier (1999), try to make a living in a "sidewalk society." These people who set up tables on Sixth Avenue in New York City and sell whatever they can often think of themselves as small business folk rather than "street people, and they organize their own little society with roles like "table watcher," "mover," "storage provider," and "place holder" (who sleeps on the street to reserve the table-seller's spot for the next day), taking advantage of local resources like public bathrooms and sinks, cheap or free food, and supplies of sellable items they find in the trash.

\section{The Rich in America}

If the general sense is that the poor are a problem to understand and solve, then the rich require neither understanding (don't we all know exactly what "rich" is?) nor solving (aren't the rich doing fine?). However, at least since Laura Nader's (1972) essay "Up the Anthropologist: Perspectives Gained From Studying Up," social scientists have understood that the rich are just as much deserving of our attention as the poor. The poor or even the middle class is not the only class, any more than black is the only race or female is the only gender; the rich are part of a more comprehensive class system. Even more, the rich define and construct that system more than the poor do; it has been suggested that poverty itself is less a matter of the poor than of the rich, since poverty is about how wealth is distributed, and the rich dominate that distribution.

Nader was, of course, not the first thinker to ponder the lifestyles of the rich or the impact of the rich on society. Marx himself stressed that the dominant class (in his time, the bourgeoisie) controlled the means of production but also the relations and ideas of society: one of his main maxims was that the dominant beliefs and values of a society are those of the dominant class of society. However, one of the first social thinkers to expound on the social habits and social influence of the rich in America was Thorstein Veblen, the son of Norwegian immigrants. His groundbreaking 1899 Theory of the Leisure Class: An Economic Study of Institutions introduced the concept of conspicuous consumption. Precisely because, as de Tocqueville, Goldschmidt, and others had noted, Americans lacked obvious markers of social station but yet diverged profoundly in wealth, Veblen claimed that consumption was the primary American means to display one's social status; that is, goods and services (a Rolls Royce or a live-in maid) were "status symbols" or indicators of one's status. (Of course, "status" in this sense need not refer only to high status; certain symbols mark one's low status, such as having an old beat-up car or eating cat food.) There are two things in particular that the privileged classes can enjoy and flaunt-ostentatious goods and "conspicuous leisure." The rich and privileged can obviously buy and use more, better, and more flamboyant goods and services. But they also display their freedom from ordinary labor with their conspicuous use of their time. They travel and vacation; they play tennis and golf in the middle of the day; they go on adventures like around-the-world voyages or rides in spacecraft. At least as importantly, Veblen believed that the "leisure class" served as the arbiters of taste and style in society. The lower classes watched and emulated the upper class, getting their image of proper behavior from the latter. Upper-class 


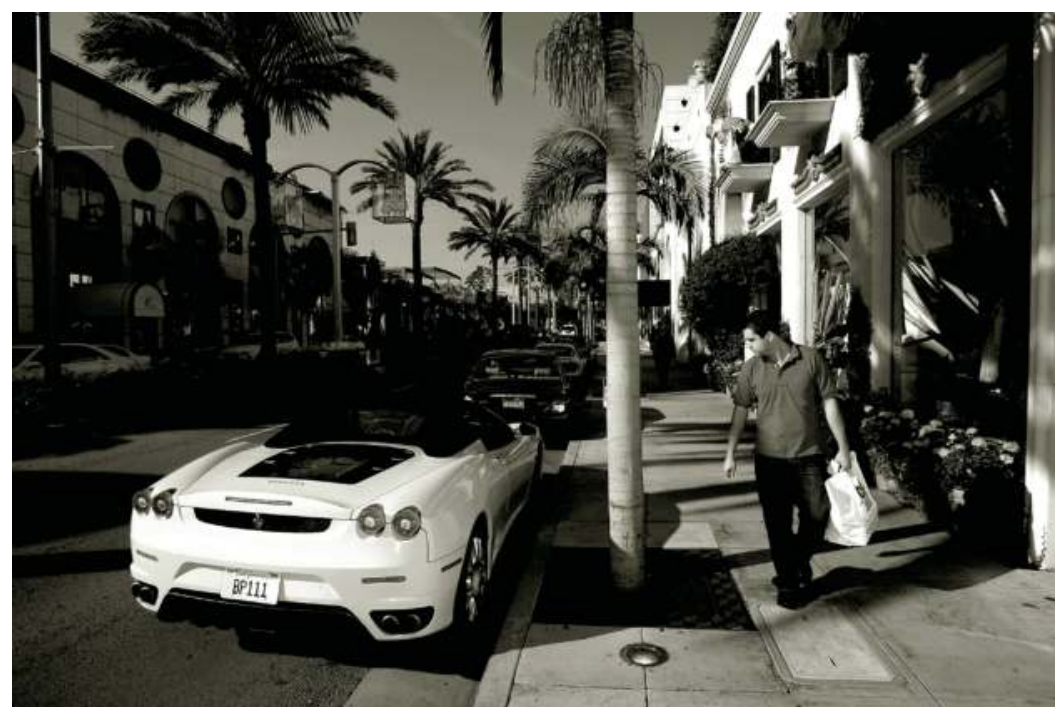

Image 5.3 A Ferrari parked outside high-end stores on LA's Rodeo Drive.

(Photo by David McNew/Thinkstock by Getty Images)

speech patterns (accent, grammar, etc.) were elevated as superior and sophisticated; upper-class trends in clothing, food, music, art, and so forth were assumed to be the epitome of fashion.

But more crucial than their trend-setting quality is the actual power exercised by the upper class. Sociologist C. Wright Mills wrote about their multiple ways of projecting power over society in his renowned The Power Elite, whom he described as

men [and also women] whose positions enable them to transcend the ordinary environments of ordinary men and women; they are in positions to make decisions having major consequences. . . . For they are in command of the major hierarchies and organizations of modern society. They rule the big corporations. They run the machinery of the state and claim its prerogatives. They direct the military establishment. They occupy the strategic command posts of the social structure, in which are now centered the effective means of the power and the wealth and the celebrity which they enjoy.

In today's world we would probably also add the "celebrities" themselves, movie and music stars and people who are simply famous for being famous.

Not only do these three (or four) American types enjoy cultural and political power, but they are also deeply socially enmeshed: business leaders become government officials and vice versa, while military and business are mutually dependent, and government and military often and ideally coincide (the American president, a civilian, is also the military commander-in-chief). Even more, the elites tend to know 
each other, to live in the same neighborhoods, to vacation together, to sit on corporate boards and charitable foundations together, even to intermarry. Many of them have been friends since college or before: Thomas Dye (2002) has calculated that 54 percent of top business leaders and 42 percent of the highest government officials in the United States attended just twelve prestigious universities such as Yale, Harvard, Stanford, and Princeton.

At their extreme, the rich constitute a "global elite" who have more in common with each other internationally than with the little people in their own societies and countries. Chrystia Freeland (2011) has characterized them as "a new super-elite that consists, to a notable degree, of . . . hardworking, highly educated, jet-setting meritocrats who feel that they are the deserving winners of a tough, worldwide economic competition-and many of them, as a result, have an ambivalent attitude toward those of us who didn't succeed so spectacularly." Even more importantly and problematically, "they are becoming a transglobal community of peers who have more in common with one another than with their countrymen back home. Whether they maintain primary residences in New York or Hong Kong, Moscow or Mumbai, today's super-rich are increasingly a nation unto themselves," traveling the international conference circuit from the World Economic Forum to the Aspen Ideas Festival to Google's Zeitgeist event, shaping the world society.

Even if they are not super-rich and out-of-sight for the average American, research indicates that the people in the higher classes are different, objectively and subjectively. According to a Pew Research Center report (Parker 2012), individuals in higher classes are more likely to have a college degree, to be married, to be homeowners, and to be non-Hispanic. They are also more likely to be in good health and to be immune from problems like paying their bills or losing their jobs. They are much more likely to be Republicans (63 percent of the rich are Republicans compared to 23 percent of the middle class and 3 percent of the poor). Subjectively, the rich are more likely to feel financially secure, satisfied with their job, and happy with their overall lives. They experience less stress, and they enjoy a certain admiration from the general society, which tends to see them as more intelligent and hardworking than the average American.

\section{Box 5.2 The New Rich: David Brooks on the "Bobos"}

Being rich is not what it used to be in America, at least for the new rich. According to David Brooks, the young professional category of rich people do not act or want to act like Donald Trump or a nineteenth-century robber-baron. For one thing, contrary to Veblen, almost all Americans today enjoy some of the fruits of leisure, and not only are more members of society participating in the lifestyle of the leisure class but that class is also comporting itself differently from the past. Brooks offered the term "Bobos" for this new upper class, a contraction of "bourgeois" and "bohemian." The Bobos, he declared, "define our age. They are the new establishment. Their hybrid culture is the atmosphere we breathe. Their status codes now govern social life. Their moral codes give structure to our personal lives" (2000: 11). The two main differences between the Bobos as 
(continued)

the new elite and past elites are the education levels and the occupations of the Bobos, which are closely related. Bobos are highly educated, and many of their habits are formed at prestigious institutions like Harvard, Yale, and Princeton. They are also members of information professions-doctors, lawyers, scholars, computer programmers, and the like. This new elite establishment "is a large, amorphous group of meritocrats who share a consciousness and who unselfconsciously reshape institutions to accord with their values" (44). The key to the bohemian quality of their bourgeois lifestyle is the mixture of affluence with the sensibility of "a free-spirit rebel" (42). While they are clearly well-to-do, they do not value ostentation, viewing the old style of wealth, with its top hats and gold gilt, as tacky and snobbish. However, they happily display their prestige and sophistication by consuming designer brands of clothing and coffee, "allnatural" foods, and gym memberships, and generally partaking of "utilitarian pleasure." They also collect and consume experiences, whether "cultural tourism" or spiritual quests, and show off their youthful and athletic physiques.

\section{The Endangered Middle Class}

As we have noted, the majority, or at least the largest single group of Americans, consider themselves "middle class"; in the research described above, 49 percent categorized themselves as middle class, while 32 percent called themselves lowermiddle or lower class and 17 percent upper middle or upper class. More importantly, for decades America has proudly regarded itself as a middle-class society, with a not only strong but dominant middle class. In Marxian terms, the ideal attitudes and values of American society have been the attitudes and values of the American middle class.

Much analysis describes significant negative changes for the much-vaunted middle class. Income inequality is growing in the United States. Another Pew study (Pew Social \& Demographic Trends 2012) finds that middle-class incomes have dropped by 25 percent (in 2011 dollars) over the past decade, and a huge majority ( 85 percent) admit that it is harder now to maintain their middle-class way of life. The Pew study actually calls the first ten years of the twenty-first century "the lost decade" for middle America. Not only does the middle class earn less of the country's income than at the heyday of the middle class forty years ago (down to 45 percent from 62 percent), while the upper class has increased its share over the same period (up to 46 percent from 29 percent), but the middle class has also actually shrunk demographically during those years, from 61 percent of the population to 51 percent. These changes can literally be observed on the ground: housing has become more segregated over recent decades, as more neighborhoods have become majority lower-income or majority higher-income, reflecting a decline in the middle-class neighborhoods.

There are many reasons why the middle class is endangered, some having to do with structural changes in the macro-economy. Manufacturing jobs, long the foundation of the middle class, have disappeared from America: a recent article claimed that sixty years ago one-third of Americans held a manufacturing job while only 10 percent presently do (Derek Thompson 2013), and often the remaining jobs offer lower pay, fewer 
benefits, and less security. Outsourcing of manufacturing and global competition has pushed wages down, while the cost of housing and healthcare has continued to rise. The recession of 2008 hit the middle class hard, costing many Americans their jobs, their savings, and their homes; as happens with most recessions, employment has been the last area to recover, while Wall Street has enjoyed great profits largely through what has been dubbed a "jobless recovery." Technology has made many jobs obsolete, pushing people into lower-paying sectors like retail and service, but Thompson warns that those jobs too are in peril, as technology replaces many tasks formerly performed by humans and as online commerce reduces the need for human salespeople.

\section{Diversity Fact:}

According to a policy study released by the Hamilton Project in late 2013 (http:// www.brookings.edu/research/reports/2013/12/12-facts-lower-middle-class), the "middle class" is very diverse, including a stratum that the report calls the "lowermiddle-class" comprised of families that earn between $\$ 15,000$ and $\$ 60,000$ per year. "Though not officially poor," the paper concludes, "these families experience limited economic security; one major setback in income could push them into poverty." Almost one-third of such families receive federal or state income support, yet perversely they are hit with the highest marginal income tax rates.

Consequently, another pillar of the middle class, economic mobility, has become shakier as well. While a study conducted by Pew Charitable Trusts (2012) finds that half of Americans surpassed their parents' wealth at the same age, this means that the other half did not. Further, while the ideal is mobility, the reality is less mobility than we dream of: 66 percent of people raised in the bottom quintile remained in the bottom or next-to-bottom quintile, and 43 percent did not move from the bottom. This social immobility was even more pronounced for black Americans, 53 percent of whom grew up and stayed in the bottom of the income distribution, compared to 33 percent of whites. Education is another significant variable: among those raised in the bottom quintile, 47 percent without a college degree remained there but only 10 percent with such a degree. However, while about a third (35 percent) of all Americans enjoyed upward mobility, half as many (16 percent) suffered from downward mobility, dropping one or more quintiles. The study concludes that " 20 percent of Americans are 'falling despite the rising tide'-they make more money than their parents did, but have actually fallen to a lower rung of the income ladder. Another 29 percent have higher family incomes but are at the same place on the income ladder as their parents were" (2012: 9).

The social effects of declining mobility, the shrinking middle class, and wider economic changes, especially on young people, have been described and predicted. Younger Americans are waiting longer before getting married and have altered their buying patterns, purchasing fewer cars and homes. In fact, more than a few have continued to live in their parents' homes, despite completing college, having a job, or even getting married. And many economists and other social scientists expect that 
there will be a long-term, maybe permanent impact on the lives of individuals emerging into the job market in the years after the recent recession: they will take lower-paying jobs, or have to wait to find a job at all, putting their career and income-earning history behind schedule, from which they may never fully recover. The class and lifestyle of the next generation will be different from those of past and future generations.

\section{Conclusion}

Americans dislike the idea of class, given their egalitarian ideology, but deep and growing differences in income and standard of living exist in the country. Nevertheless, most Americans continue to believe in the "American Dream" that, no matter where you start in the stratification system, with hard work you can improve your station and rise from rags to riches. The facts show, however, that while it is possible it is not very likely (only 4 percent of Americans move from the lowest quintile to the highest in their lifetime).

Even more than the race, ethnic, and gender category-systems, the class system in America is vague and subjective. There is no agreement among scholars or the general public about the number of classes or the criteria and cut-offs of classes. But even without clear and firm lines, the "lifestyles of the rich and famous" are different from those of the middle or lower classes, and all of the classes-not just the poor-are worthy of social-scientific attention. Unlike race or ethnicity or gender, there is a fair chance that any one American may occupy most or all of the class levels during his or her lifetime. 


\section{Sex and Gender \\ Male and Female}

Everyone in America knows that blue is for boys and pink is for girls; girls' toys and clothes abound in pink, and what right-minded parents would dress their baby boy in pink? Yet, according to Jo Paoletti, "Sexual 'color coding' in the form of pink or blue clothing for infants was not common in this country until the 1920s; before that time male and female infants were dressed in identical white dresses" (1987: 136-7). She further explained that before the twentieth century gender differences in children's clothing "were delayed" until the children were five or six years old; from ages two to five or six, both sexes wore shifts that "bore a strong resemblance to women's dress of the period" (138). The crucial fact was that "it was not considered important to differentiate boys and girls at such an early age" (139). In fact, some social critics actually thought it was bad to introduce gender distinctions and gender awareness at a tender age: Paoletti quotes a 1910 article by the prominent feminist sociologist and writer Charlotte Perkins Gilman, who insisted that the "most conspicuous evil here is in the premature and unnatural differentiation in sex in the dress of little children. . . A little child should never be forced to think of this distinction," which might threaten their natural innocence (142). The practice of associating a particular sex of infant with a particular color was not really established until around 1920, but even then the sexappropriate colors were reversed: a 1918 item in Ladies Home Journal taught parents that the "generally accepted rule is pink for the boys, and blue for the girls. The reason is that pink, being a more decided and stronger color, is more suitable for the boy, while blue, which is more delicate and dainty, is prettier for the girl" (Frevele 2011).

Blue-for-boys and pink-for-girls seems so obvious and natural to contemporary Americans, but if those taken-for-granted color associations are cultural inventionsand recent ones at that-what other aspects of our gender system may be recent and arbitrary social constructions? And is it absolutely necessary-and desirable-that boys be associated with strength while girls are associated with looks?

As vague, contested, and uncomfortable for Americans as class is, sex or gender seems clear, natural, and familiar; note, for instance, that there are no personal pronouns to indicate a person's class, but English-speakers have no choice but to specify a person's sex or gender (that is, "he" or "she," "his" or "her"). In other words, if Ortner was correct that we do not want to and often cannot talk about class, we cannot avoid talking about sex or gender.

The American sex/gender system is, thus, quite unlike the class system; individuals tend not to know where they are in the class system, and they are (ideally) free to change their position, but individuals (ideally) know exactly where they are in the sex/gender 


\section{Sex and Gender: Male and Female}

system and are not free to change (there is no standard notion of "gender mobility"). In this sense, sex/gender is more like race in the United States: both are supposedly ascribed statuses, and both are if not binary then at least digital, that is, there are a few explicit categories to which people can be assigned (white, black, Asian, etc. or male and female). Sex/gender is like race in another fundamental way: both build social categories out of physical differences.

At the same time, sex/gender and race are different in two dramatic ways. First, while American culture and official instruments recognize racial diversity, neither culture nor official measures tend to recognize sex/gender diversity. As a case in point, in the US Census, an individual can select any or all race categories, but it is virtually inconceivable that one person could select both sexes/genders, and there are no third options beyond male and female.

Second, as the awkward terminology "sex/gender" indicates, there are two discourses of sex and gender running simultaneously but not quite overlapping in American society, and these two systems are not equivalent, for example, to the race/ethnicity distinction.

In this chapter and the next, we will explore the sex/gender category-system(s), discovering how sex/gender diversity is related to differences in bodies, sexualities, identities, and other issues. The present chapter will focus on the conventional binary of male-versus-female, while the seventh chapter will turn to the question of "alternative" or "third" (or fourth or more) genders and sexualities. Both presentations will consider how American society “culturizes" real differences between bodies or the sexual behaviors that people engage in with those bodies. Finally, just as discussions of race tend to concentrate on "minority" races as if the dominant race is not a race too, discussions of sex/gender often concentrate on the "minority" sex/gender (that is, women) as if the dominant sex/gender is not a sex/gender too. Therefore, in the present chapter we will also talk about men and masculinity, which are every bit as socially constructed as women and femininity.

\section{Sex/Gender, Sex/Gender Categories, and Sex/Gender Ideology in the US}

Some people perhaps find it odd to think of race as categories and ideology, but many, if not most Americans find it almost unthinkable to regard sex/gender as categories and ideology. However, it is not ridiculous to assert that sex/gender is every bit as

\section{What is this person's sex? Mark $X$ ONE box.}

Male $\square$ Female

4. What is this person's age and what is this person's date of birth? Please report babies as age 0 when the child is less than 1 year old. Print numbers in boxes.

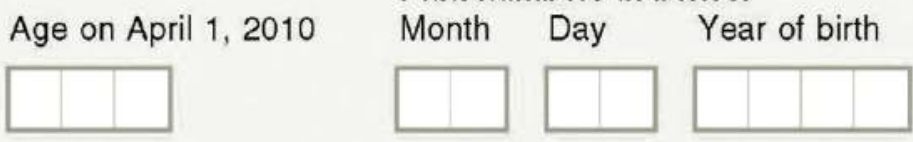

Figure 6.1 2010 Census questions on sex and age. 
much a product of "sex/gender thinking" as race is of "racial thinking." In their book Gendering Bodies Sara Crawley, Lara Foley, and Constance Shehan go so far as to proclaim that "gender does not exist (in nature)" although "it is real (in terms of real consequences, including various structural inequalities, physical violence, etc.”) (2008: 4). They are not denying that there are physical sexual differences between humans, any more than that there are differences in skin color, but they are asserting that societies turn these physical sexual differences into sex/gender categories with various social meaning and value; certainly they understand that the consequences of sex/ gender are quite real, just as are the consequences of race.

Let us start with this problematic language of "sex" and "gender." Often, the two terms are used interchangeably. However, it was a significant advance in the socialscientific perspective on sex/gender to distinguish the two concepts. In her study of gender diversity (to which we will return in Chapter 7), Serena Nanda defined sex as "the biologically differentiated status of male or female. It includes anatomic sex, particularly the genitals, and also secondary invisible characteristics such as genes and hormones" (2000: 2). Gender, on the other hand, is defined as "the social, cultural, and psychological constructions that are imposed upon the biological differences on sex" (2). For instance, certain genitalia assign a person to the sex "female," but it is a social and cultural practice to dress that person in pink or to encourage her to wear makeup or be a nurse (or not to have a job at all). There is obviously no connection between female genitalia and pink clothes, lipstick, or any particular occupation (or lack thereof), and the same is true for male genitalia and its standard cultural associations.

However, Nanda and others also realized immediately that the simplistic distinction between sex and gender led to an intolerable dichotomy: "biological sex ... was viewed as 'natural' and universal, and gender ... was viewed as culturally learned and variable." Instead, Nanda rightly stressed that sex and gender, biology and culture, are thoroughly intermixed: "biological sex is also an idea mediated only through culture" (2). Or, as Crawley, Foley, and Shehan put it, "social messages and physical ('natural') bodies are inextricably inseparable. There is no physical body separate from social practices (which originate from gendered messages). There is no social experience separable from physical bodies" (2008: 1$)$. Two examples should suffice to make the point: when a woman grows her hair long or has a bone surgically removed so she can wear narrow shoes or throws up her meals so she can stay thin, or when a man undergoes a circumcision, then culture has been literally inscribed (written on or into) their body, and their body has become a cultural production and message.

\section{The Composite Nature of Sex/Gender}

In the first chapter we explained the composite nature of most or all social phenomena. Sex/gender is a particularly clear instance of the multiple elements that form categories through their composition. For Americans, sex/gender tends to refer to, indeed to be defined by, anatomical traits, even by one single anatomical trait-the genitals. Therefore, Americans think that they can determine a person's sex at the moment of birth or even before. Notice, though, as Nanda did above, that a person's sex includes other anatomical or physical characteristics, such as hip shape, facial hair, the "Adam's apple," and internal differences in chromosomes and body chemistry. In a word, the physical side of sex/gender is composite on its own. 


\section{Sex and Gender: Male and Female}

Beyond the body, there are many other elements or building blocks that constitute gender. A critical one is sexual preference, what kind of person the individual is sexually attracted to. In the United States and other Western/Christian countries, the assumption is that there are two sexual preferences (for men or for women) and that individuals with male bodies (assigned to the "male" sex or gender) desire women while those with female bodies (assigned to the "female" sex or gender) desire men; for most of American history, any other combination was considered deviant, and at times actually criminal or pathological. In fact, sexual preference is not automatically determined by one's own body; further, there are more possibilities for sexual preference than "man" or "woman," such as both, neither, or something much more particular (e.g. men with tattoos, women with blonde hair).

In addition to physical features and sexual preference, sex/gender contains an element of gender identity-which gender an individual identifies with or feels like. An individual may have a male body but identify with or feel like a woman, sometimes inducing a "sex change operation" (see Chapter 7). Furthermore, sex/gender includes gender personality, the emotional, cognitive, and other traits associated with sex/gender (e.g. the stereotypes that women are more emotional or that men are more aggressive). We can also distinguish gender display, the presentation of gender in terms of clothing, speech patterns, hair styles, and even how individuals stand or walk. Finally, sex/gender entails a system of gender roles, the expected behaviors for various sexes/genders, such as that males should perform certain jobs or like cars and sports while females should perform other jobs (or, in some societies, not work outside of or even leave the house) or like romantic comedy movies.

In standard American thinking, these components can only be stacked "normally" in two ways-either a male body with a sexual preference for females, a male gender identity, a male personality, male display, and male roles (which Americans call "a man") or a female body with a sexual preference for males, a female gender identity,

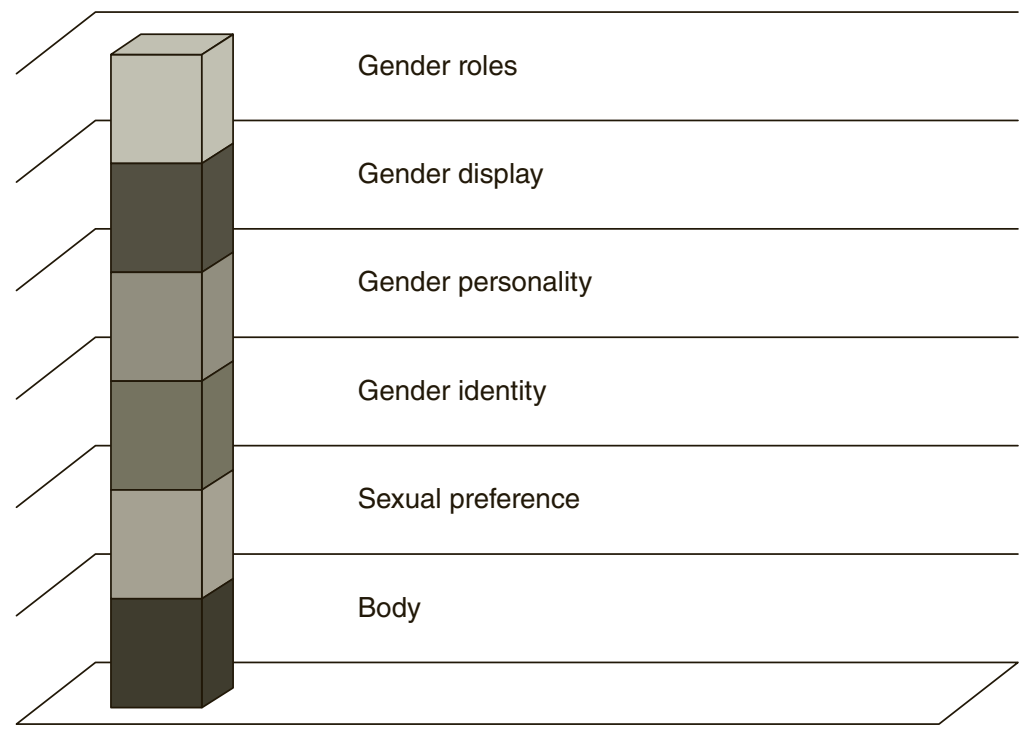

Figure 6.2 The components of sex/gender. 
etc. (which Americans call “a woman”). This produces the conventional normative gender binary in America. However, in actuality each of these components is itself multiple (there are more than two kinds of bodies, more than two sexual preferences, more than two gender identities, etc.), and they can be stacked in multiple ways, producing additional gender categories.

\section{The Social Construction of Sex/Gender}

Since the independent variables or elements of sex/gender can be combined in diverse ways, there is little in the way of "natural" or "universal" sex or gender across cultures, and different societies may actually name different combinations of elements as "third" genders, for which there is no equivalent in the American or Western gender system (for more on this topic, see Chapter 7). On the other hand, it is conceivable to observe the physical differences between males and females and to decide culturally that there is only one gender, as was sometimes done in ancient Greek society: given the cultural assumption that every kind of thing had its perfect form, and that the perfect form of humanity was the male form, then there was only one kind of human-male-and females were some sort of incomplete or imperfect version of humanity.

Early modern social thinkers did not pay much attention to sex/gender; the focus was predominantly on class or on race and ethnicity. Marx did not concern himself with sex/gender, although his colleague Friedrich Engels wrote a book on the evolution of the family (The Origin of the Family, Private Property, and the State) that described what he called the "world historic defeat of the female sex," which was ultimately based on class and economic relations, not sex/gender itself. The little work that touched on sex/gender at all tended, like Engels' book, to be interested in the family or in sexual behavior and to be highly normative. A good example is Johann Jakob Bachofen's 1861 Mütterrecht ("Mother Right”), in which he argued that human society was originally promiscuous and then developed through a stage of matriarchy or female-dominated family on the way to the modern and better patriarchal monogamy. As late as 1968 in a volume edited by Richard Lee and Irven DeVore called Man the Hunter, it was claimed that male advances like stone tools and hunting had been engines that drove human evolution.

One of the first researchers to take the cultural construction of sex and gender seriously was Margaret Mead, whose 1935 Sex and Temperament in Three Primitive Societies sought to test assumptions about the relationship between sex/gender and personality. Investigating three New Guinea societies, she claimed that sex differences in personality did not follow the American norm: among the Arapesh men and women alike felt and acted the way that Americans expect women to behave, while among the Mundugumor both sexes were aggressive like American men, and Tchambuli men seemed to display the personality traits that Americans associate with women while Tchambuli women did not. Therefore, she concluded, the "cultural assumptions that certain temperamental attitudes are 'naturally' masculine and others 'naturally' feminine" are not supported (xiii)—rather, "the personalities of the two sexes are socially produced" (310).

Subsequent cross-cultural studies on sex/gender have reported wide variations in gender behavior, roles, and relations. Hunter-gatherer or foraging societies have been described as comparatively gender-egalitarian: while a gender division of labor is virtually 


\section{Sex and Gender: Male and Female}

universal across culture, men and women in foraging societies both contributed to the group's food supply, and in many cases women actually contributed more. In some horticultural (simple farming) societies, women enjoyed unusually high status and power: according to Judith Brown, Iroquois women controlled most of the production and distribution of food, and in matrilineal Iroquois society the older women "had the power to raise and depose the ruling elders, the ability to influence the decisions of the Council, and occasional power over the conduct of war and the establishment of treaties" (1975: 238). On the other hand, pastoralists (animal herders) have been characterized with very patriarchal cultures, in which men controlled the productive resources (although women often did the actual work of animal tending) and exercised the political and religious power.

In some societies, the sexes were highly segregated, with women often restricted to the domestic or home space. At the extreme, men have sometimes feared the "polluting" effects of contact with women. In such societies, relations between the sexes have been avoidant, even hostile. At the other end of the spectrum, among hunter-gatherer peoples like the !Kung bushmen of southern Africa "the sexes mix freely and unselfconsciously without the diffidence one might expect to see if they thought they were in some way intruding” (Draper 1975: 93).

In Western societies, with their Greco-Roman and Christian heritage, men and women have historically been judged as somewhat or highly unequal, with women occupying a status of inferiority and dependence. Young unmarried women were generally under the authority of their fathers, and marriage transferred that authority to their husbands (reflected in the traditional American wedding practice of the father "giving" the bride to the groom). A woman had to have a male guardian to make legal and financial decisions for her. In medieval Church law like the Corpus Iuris Canonici, the situation was still more explicit and rigid:

Women should be subject to their men. The natural order for mankind is that women should serve men and children their parents, for it is just that the lesser serve the greater.

The image of God is in man and it is one. Women were drawn from man, who has God's jurisdiction as if he were God's vicar, because he has the image of the one God. Therefore woman is not made in God's image.

Woman's authority is nil; let her in all things be subject to the rule of man.... And neither can she teach, nor be a witness, nor give a guarantee, nor sit in judgment.

(quoted in O'Faolain and Martines 1973: 130)

Such attitudes persisted into the early modern period, as in Johann Gottlieb Fichte's 1795 The Science of Rights, where he demanded that a woman be subject either to her father or her husband. Even more, the power of a husband over his wife should not seem compulsory but completely voluntary on her part:

She is subjected through her own continuous necessary wish-a wish which is the condition of her morality - to be so subjected. She has the power to withdraw her freedom, if she could have the will to do so. But that is the very point: she cannot rationally will to be free. Her relation to her husband, being publicly known, she 
must, moreover, will to appear to all whom she knows as utterly subjected to, and utterly lost in, the man of her choice.

(quoted in O'Faolain and Martines 1973: 287)

Women were often regarded as literally physically unfit for independence. In some cases, it was argued that a woman's womb and her brain competed for her limited energy. Thus, a woman who received an education or who had a career would physically deplete her womanhood. Not surprisingly, women into the modern era-including in the United States-were frequently diagnosed with medical conditions if their behavior was judged to be "unladylike" or "immoral." In other words, the female body was frequently the subject of cultural evaluation and cultural intervention.

\section{Box 6.1 Women's Bodies and Morals in Early-Twentieth-Century America}

In the late 1800s and early 1900s, America was undergoing traumatic social change, and many opportunities opened for women to act more freely. Urbanization and industrialization gave young women access to money, the world outside the family, and an emerging youth culture (see Chapter 10). As Michael Rembis describes in Defining Deviance, special courts were established for juvenile offenders, especially girls, who were accused of moral delinquency, including staying out late, dancing, going to the movies, and illicit sexual activity. Some of these girls were taking advantage of the modern urban life that we enjoy today; others came from "broken homes" or poverty or were victims of physical abuse or rape. Yet their "deviance" was interpreted as a medical and mental fault. The proposed solution to this crisis of womanhood in turn-ofthe-century America was isolation, essentially incarceration, in institutions for "mentally defective" girls, like the State Training School for Girls in Geneva, Illinois. Inside these sex-segregated institutions, the girls were subjected to intelligence tests and other kinds of "scientific" measurements, as well as to instruction, religious services, physical exercise, and wholesome group activities like the Girl Scouts. In all of these ways, the system "sought to mold those individuals whom they deemed capable of reform to fit within dominant, middle-class notions of a moral, virtuous wife and mother" (2013: 97). Of course, not all were assessed to have the mental capacity to aspire to normal American life; many were expected to spend their entire lives in the school/ prison. Significantly, Rembis finds that boys actually comprised the majority of supposed delinquents brought before the courts but that the vast majority of institutionalizations involved girls.

It is important to realize that, while females are subject to intense social construction, males are no less socially constructed. In fact, in his study Manhood in the Making, David Gilmore concluded that masculinity across cultures is a social project and not a natural "fact" given by male body and genitalia alone. Around the world, maleness is arguably even more fragile and contested than femaleness: 


\section{Sex and Gender: Male and Female}

there is a constantly recurring notion that real manhood is not a natural condition that comes about spontaneously through biological maturation but rather is a precarious or artificial state that boys must win against powerful odds. This recurrent notion that manhood is problematic, a critical threshold that boys must pass through testing, is found at all levels of sociocultural development regardless of what other alternative roles are recognized.

(1990: 11)

This is why Gilmore insisted that manhood has a "stressed or embattled quality" (17) which requires repeated demonstration and display, in the form of bragging, fighting, drinking, womanizing, competing, supporting a family, and passing various tests and ordeals like initiation rituals. The key to manhood, Gilmore suggested, is not even so much a distancing from womanhood as a "revolt against boyishness" (29), in which the male-bodied person must prove that he is a man.

\section{Gender as Performance}

Based on such realizations, a number of scholars have argued that sex/gender should be understood not as a fact or a condition but as an act or a process. Instead of saying that someone "has" or "is" a sex/gender, these thinkers advocate treating sex/gender as a verb: the individual "genders" or is "gendering" or is "gendered." (Imagine what it would be like to treat race or class not as a fact/condition but as an act/process, in which we talked about "racing" or "classing.") Michel Foucault (1978) was one of the first to insist that sex and gender are a form of discourse, a way of talking about and thus inventing and then managing sex/gender categories. As the title of his influential book The History of Sexuality indicates, sex/gender is historical, a phenomenon with a history instead of an unchanging natural reality. Judith Butler extended this perspective on the performance of sex/gender, as in her 1990 Gender Trouble.

According to Rosalind Morris's survey of performance thinking in sex/gender, "The theory of performativity defines gender as the effect of discourse, and sex as the effect of gender" (1995: 567). That is to say, how we think about, how we talk about, and how we act on sex/gender makes manifest, makes real, the very things that we think/say/do. Rather than focusing on sexes or genders, we are urged to focus on how we gender people, spaces, institutions, and other aspects of society. The practices of gendering can be found, of course, in everything from language (like gendered pronouns) and clothing to media images in music, movies and television, and especially advertising. Society dictates what sexes/genders exist and how they should be performed. This viewpoint make sex/gender radically constructed and radically ambiguous; certainty about what sexes/genders exist and their "correct" performances is exploded. As a result, sex/gender becomes "not a fact or an essence, but a set of acts that produce the effect or appearance of a coherent substance" (572-3). Like other culturally defined and constructed category systems, "although gender is a set of acts, it works and derives its compulsive force from the fact that people mistake the acts for the essence and, in the process, come to believe that they are mandatory" (573). Written or "inscribed" onto and into our very bodies, sex/ gender seems real and becomes real: we have no choice but to perform our sex/gender roles and norms or be judged for refusing. 


\section{Sex/Gender in America}

The US Census is one of those instruments that embed the assumptions of binary and real sex/gender. By official Census definitions, in 2010 there were 156,964,212 females in the United States and 151,781,326 males; females outnumbered males 50.8 percent to 49.2 percent. For more granular detail on the sex/gender composition of the country, one device is the population pyramid, also known as an age-sex structure, which illustrates the number of people in each sex/gender and in each age increment (usually shown in 5- or 10-year increments; for more on age, see Chapter 10).

Two interesting facts stand out about the current sex composition of the United States. First, males outnumber females in the earliest years of life (10.3 million to 9.9 million), but females catch up to males around age 35-40 and then pass men, exceeding their numbers at every higher age level. In the 85-89 age range, there are almost twice as many women as men, in the 90-94 age range almost three times as many, and nearly five times as many women as men reach age 100 . The median age of women (38.5 years) in America is therefore higher than the median age of men (35.8).

Second, males and females are not distributed evenly across the country. The variation by major geographic region is fairly modest in terms of sex ratio or the ratio of men to women. Obviously, a perfectly equal ratio would be 100 men for every 100 women, but even in the West, the most equal region, the ratio is 99.3, while it is more unbalanced in the other parts of the country-96.8 in the Midwest, 96.1 in the South, and

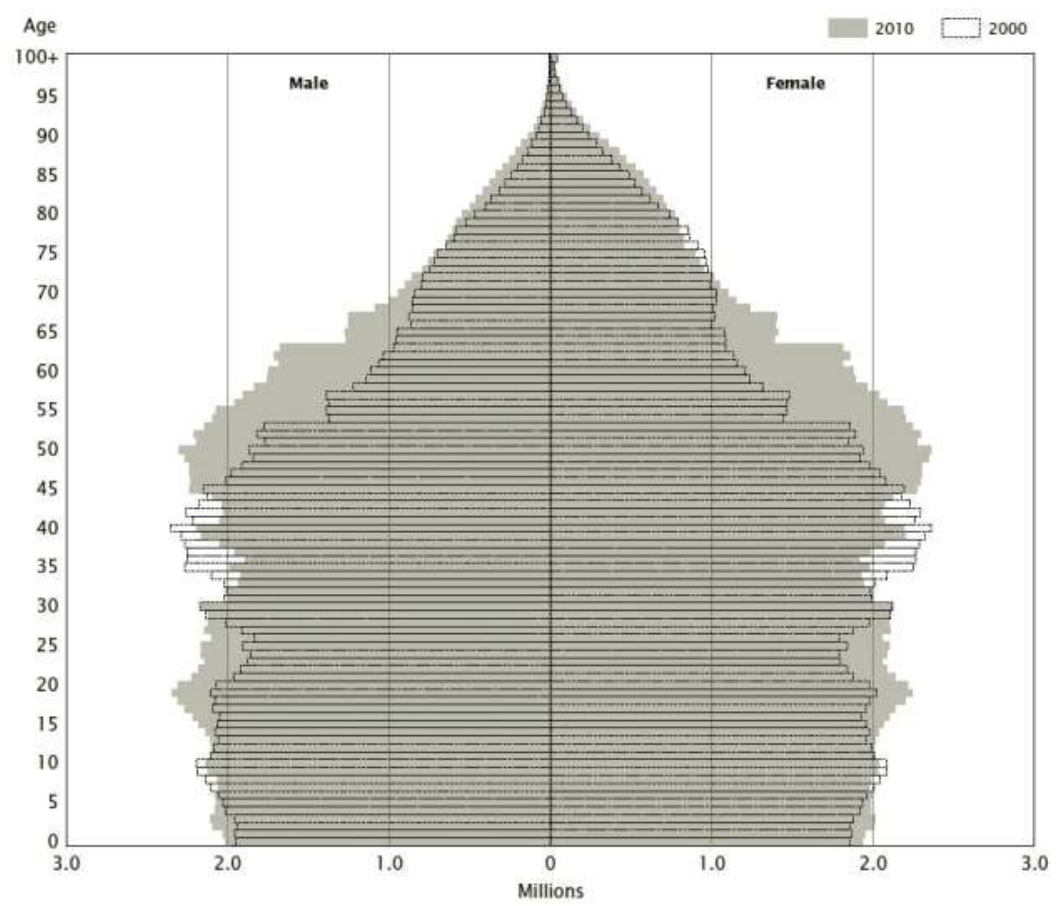

Figure 6.3 US population pyramid, 2000 and 2010.

Source: U.S. Census Bureau. 2010 Census Brief: Age and Sex Composition 


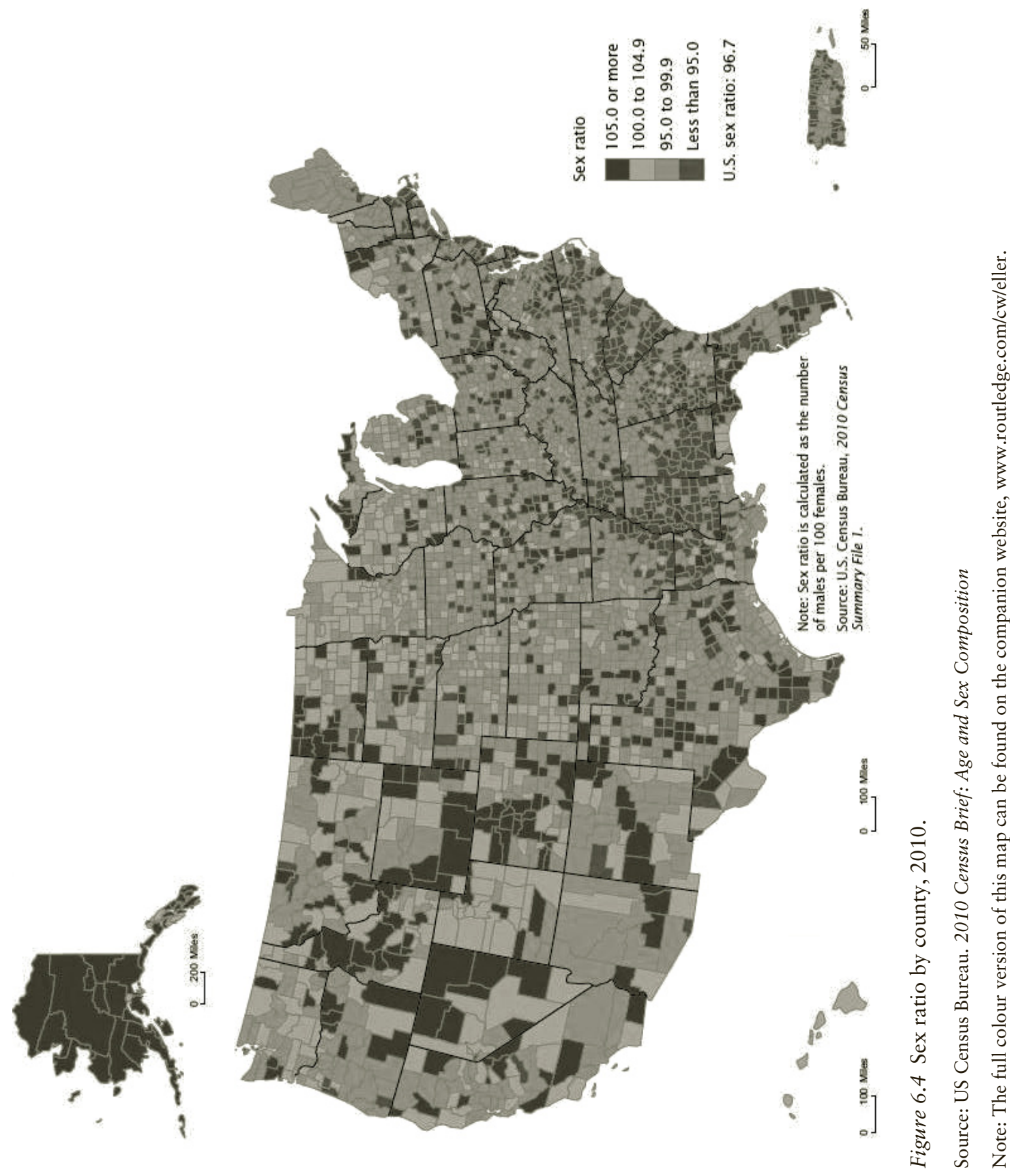


94.5 in the Northeast. At the state level, Alaska has the highest ratio of men to women (108.5), followed by Wyoming (104.1) and North Dakota (102.1). The lowest ratio of men to women is found in the District of Columbia (89.5), then Rhode Island (93.4), Maryland (93.6), and New York (93.8). The greatest variation occurred at the county level, from a high of 258.8 in Crowley County, Colorado (where men outnumber women 2.5 to one) to a low of 76.1 in Pulaski County, Georgia (the site of a state women's prison).

In 2005, the Census Bureau (Spraggin 2005) issued a report on sex/gender based on 2000 Census data (as of the time of writing this book, a similar report on 2010 has not been furnished), which contained some additional noteworthy information. For example, the sex ratio varied by race, with more Hispanic men (105.1) and more Native Hawaiian/Pacific Islander men (102.8) than women but more white (96.3), Asian (92.8), and Native American (98.7) women than men; the most extraordinary case was the disparity between black women and men (90.1). Also, marriage among women of every age had declined steadily from 1970 until 2000: in the age range 25-29 only 12.2 percent had never married in 1970 but 38.1 percent had never married in 2000, while in the age range of 30-34 a mere 7.4 had never married in 1970 but fully 21.9 percent had never married in 2000 . The percentage of both men and women currently married dropped over those decades (from 61.2 percent to 54.6 percent of women and from 65.7 percent to 58.6 percent of men). Perhaps most dramatically and tellingly, the number of either sex/gender living alone increased at all age levels; in the adult age range of $25-44$, the percentage of women living alone rose from 2.8 percent to 7.1 percent and the percentage of men living alone grew from 4.8 percent to 11.2 percent.

Finally, both sexes/genders improved their educational attainment, but women's achievement outpaced men's: while the percentage of males with a college degree or more doubled from 13.5 percent to 26.1 percent, the percentage of women attaining the same level nearly tripled from 8.1 percent to 22.8 percent (more on the issue of education below). Likewise, women's participation in the workforce rose from 37.8 percent of all workers in 1970 to 46.7 percent in 2000, with the greatest gains in management and business/administration (from 16.6 percent of workers to 41.9 percent). However, as has been much noted, men of every race out-earned women of the same race, with the biggest disparity among whites. Therefore, women were more likely to be poor than men at every age level but especially in old age.

\section{A Short History of Sex/Gender in the US}

The European settlers in North America necessarily brought with them their patriarchal sex/gender attitudes and institutions, including, of course, the family and the church, as summarized above. For instance, in 1645 John Winthrop of Massachusetts gave a speech "On Liberty," in which he stated that a woman's "own choice makes . . . a man her husband; yet, being so chosen, he is her lord, and she is to be subject to him, yet in a way of liberty, not of bondage; and a true wife accounts her subjection her honor and freedom and would not think her condition safe and free but in her subjection to her husband's authority." Then, comparing a husband to Christ and a wife to the church, he continued that 


\section{Sex and Gender: Male and Female}

his yoke is so easy and sweet to her as a bride's ornaments; and if through forwardness or wantonness, etc., she shake it off, at any time, she is at no rest in her spirit, until she take it up again; and whether her lord smiles upon her and embraceth her in his arms, or whether he frowns, or rebukes, or smites her, she apprehends the sweetness of his love in all, and is refreshed, supported, and instructed by every such dispensation of his authority over her.

(Winthrop 1645)

Such was the situation described almost two centuries later by Alexis de Tocqueville, who observed that young American girls were remarkably free but that this freedom ended suddenly at marriage. "While there is less constraint on girls there than anywhere else, a wife submits to stricter obligations. For the former, her father's house is a home of freedom and pleasure; for the latter, her husband's is almost a cloister," he reported (1969: 592). However, women were well aware of their marital fate, well prepared for it, and well adjusted to it, he believed. Hence, "the American woman never gets caught in the bonds of matrimony as in a snare set to catch her simplicity and ignorance. She knows beforehand what will be expected of her, and she herself has freely accepted the yoke. She suffers her new state bravely, for she has chosen it" (593). And he approvingly commented that Americans have resisted the temptation to make men and women equal, a temptation afflicting Europe in his day: Americans "have carefully separated the functions of man and woman so that the great work of society may be better performed" (601).

In America, more than anywhere else in the world, care has been taken constantly to trace clearly distinct spheres of action for the two sexes, and both are required to keep in step, but along paths that are never the same. You will never find American women in charge of the external relations of the family, managing a business, or interfering in politics; but they are also never obliged to undertake rough laborer's work or any task requiring hard physical exertion. No family is so poor that it makes an exception to this rule.

If that description was accurate in 1830 , it would not remain so for long.

Harriett Martineau, one of the unsung pioneers of early sociology, could not quite agree with de Tocqueville's assessment. In her Society in America (1837), written decades before Marx, Durkheim, or Weber would put pen to paper, she exclaimed,

If a test of civilization be sought, none can be so sure as the condition of that half of society over which the other half has power, from the exercise of the right of the strongest. Tried by this test, the American civilization appears to be of a lower order than might have been expected from some other symptoms of its social state. The Americans have, in the treatment of women, fallen below, not only their own democratic principles, but the practice of some parts of the Old World.

It is true that in the early years of the republic, women were not granted the full rights of citizens, and neither the authors of the Constitution nor many legal scholars since 
thought that the Constitution guaranteed women's rights. In fact, in 2011 Supreme Court Justice Antonin Scalia stated that the Constitution, even the 14th Amendment (see below), does not prohibit discrimination on the basis of sex: "Nobody ever thought that that's what it meant. Nobody ever voted for that," he explained. In fact, women actually lost rights immediately after American independence: women had previously been able to vote in most states but were stripped of that right in New York in 1777, in Massachusetts in 1780, and finally in the last of the existing states, New Jersey, in 1807.

In response, women began to agitate for fundamental rights, inspired by perhaps the opening shot of the so-called "first wave" of feminism, Englishwoman Mary Wollstonecraft's 1792 A Vindication of the Rights of Woman. Significantly, while they pursued their own rights, many female activists also championed the rights of African slaves in America, including the abolition of slavery altogether. Heroes of women's suffrage (the right to vote) such as Elizabeth Cady Stanton and Angelina Grimke were also vocal critics of slavery, although they were excluded from the World Anti-Slavery Convention in London in 1840 because they were women.

The first Women's Rights Convention was held in Seneca Falls, New York in 1848, at which the extreme idea of women voting was adopted. Unfortunately, male abolitionists, including prominent African American men like Frederick Douglass, declined to support the women's rights movement both before and after the end of slavery, as they saw this as an unnecessary distraction and controversy in the midst of fighting for black men's rights. Appropriately enough (and the reason for Scalia's comment above), the 14th Amendment to the Constitution, which officially granted citizenship and "equal protection under the law" to "all persons born or naturalized in the United States" including former slaves in 1868 , went on to specify that citizens were male. To test this interpretation of citizenship and equal rights, 172 women tried to vote in New Jersey that year but were turned away; in 1872, Susan B. Anthony was actually arrested for voting. Finally, as if to end the legal objection to the disenfranchisement of women, the Supreme Court ruled in its 1874 Myner $v$ Happerstett case that citizenship does not automatically confer the right to vote anyhow.

The right of women to vote began to gain political traction in the 1880 s, with a women's suffrage amendment debated but defeated in the US Senate in 1886. At the state level, women had some success, winning the right to vote in Colorado in 1893 and in Utah in 1896 (where they had lost the right only nine years earlier). Despite setbacks like a physical attack on a parade in 1913, in which many women were injured and no perpetrators were ever arrested, the 19th Amendment to the Constitution securing women's voting rights was ratified in 1920.

The 1920s were years of unprecedented gender and other social freedom, during which American women lived more liberated and public lives than at any previous time. These liberated women, often called "flappers," engaged in such shocking behaviors as drinking, smoking, and dancing (not to mention voting), and dressed and acted more provocatively than American women ever had (see below). The Depression of the 1930s ended much of this freedom, but World War II saw women recruited into factory work out of necessity. In the 1950s a new wave of conservatism hit the US, with women largely re-consigned to the home and its domestic functions. However, the civil rights movements of the 1960s inspired women to act again as well, in what is seen as the "second wave" of feminism. In 1966 the National Organization 


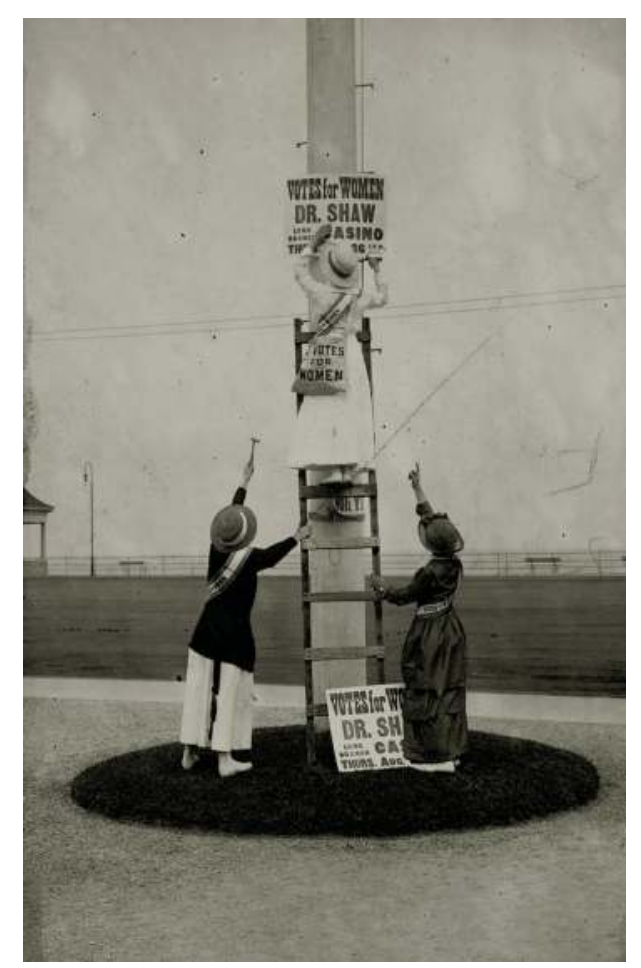

Image 6.1 Suffrage campaign in New Jersey c.1915.

(Courtesy of the Library of Congress, Prints and Photographs Division)

for Women was founded, expressing its key issues as legal and economic equality of women but also reproductive rights and the end of violence against women.

Three critical developments in the area of sex and gender occurred in the 1970s. First, a law known as Title IX was passed in 1972, which required federally funded schools and colleges to provide equal educational opportunities for women, including sports (see below). Also in 1972, Congress passed the Equal Rights Amendment (ERA), a very simple statement to the effect that "Equality of rights under the law shall not be denied or abridged by the United States or any state on account of sex." As innocuous as that language seems, the ERA was hugely controversial (for instance, there were fears that it would make sex-segregated bathrooms illegal), and after ten years it had not received the ratification of thirty-eight states needed to make it law (it was ratified by thirty-five states) and so expired. Third, in 1973 the Supreme Court decision Roe $v$ Wade made abortion legal in the United States, giving women more control over their sexuality and reproduction than they had ever known.

Women have continued to make strides, actually surpassing men in a number of measures (see below), and lesbian women, gay men, and people of other sexual orientations and identities have also begun to enjoy more rights and public acceptance. However, sex and gender continues to evolve in the US and to be the subject of formal social thinking and explicit social movements. Since the 1990s, some observers have 
identified a "third wave" of feminism, taking much more seriously the slogan attributed to Carol Hanisch that "the personal is political" (Hanisch 1970). In line with contemporary theory (indeed, highly influential on contemporary theory), third-wave feminism has criticized the traditional gender binary, stressed the social construction of sex/gender categories, linked gender issues to race and class, and reached beyond heterosexuality to raise questions of homosexuality, transgender, and queer theory (see Chapter 7).

\section{Womanhood in America}

A historical and social account of sex/gender demonstrates two key points-that sex/ gender categories, roles, and relations have changed over time and that sex/gender is diverse and plural today. This is true for womanhood, which we will discuss now, as much as for manhood, which we will discuss below. In other words, womanhood has a history in the United States, and there is more than one ideal for how to be a woman in the US today.

It has already been shown that women were viewed in early American society as weak, dependent, even incompetent creatures, not full citizens (or even full persons) and not entirely capable of being so. In her A Vindication of the Rights of Woman, Mary Wollstonecraft wrote in 1792 that women were not "thought to have enough strength of mind to acquire virtue properly so-called" (2010:12). To the contrary, the traits expected of and taught to a woman were "a little knowledge of human weakness (properly called 'cunning')," "softness of temperament," “outward obedience," and "scrupulous attention to a puerile kind of propriety"; in a word, women were advised "to turn ourselves into gentle domestic animals" (13).

Throughout early American history, women were repeatedly and adamantly told that this is what they should be, establishing what became known as the Cult of True Womanhood. The true American woman became a more overt object of concern, and of construction, in the $1800 \mathrm{~s}$, as attested by the volume of advice and guidance that women received on how to be a proper lady, wife, and mother. As the ideal of (middle- or upper-class and white) family and household evolved in the nineteenth century, women were valued in this "cult of domesticity" as the sources and protectors of purity and morality of the family. A veritable industry of instruction for women flowed in the form of books and magazines, including but hardly limited to Mrs. William Parkes' 1828 Domestic Duties: or, Instructions to Young Married Ladies, on the Management of their Households, and the Regulation of their Conduct in the Various Relations and Duties of Married Life, Sally Kirby Padelford Fales' 1834 Familiar Letters on Subjects Interesting to the Minds and Hearts of Females, Daniel D. Smith's 1837 Lectures on Domestic Duties, Eliza Leslie's 1840 The House Book, Catherine Beecher's 1841 A Treatise on Domestic Economy (and later with Harriet Beecher Stowe her 1869 The American Woman's Home), and so on. An 1880 pamphlet taught women "How to Get a Husband," and the venerable and still-published magazine Ladies' Home Journal began its life in 1883.

Of course, this class- and race-specific model of female domesticity was not appropriate for, and was not practiced by, all women in America. African women in America before and after the Civil War tended to have little opportunity to aspire to such domestic bliss, and new female immigrants often had to work outside the home as hard as or 


\section{Sex and Gender: Male and Female}

harder than men. Even for many white women, especially on the frontier, life was hardly as idyllic as the books and magazines portrayed it. Further, it was at this precise moment that the perfect middle-class home was both being invented and undermined. Industrialization was separating the spheres of home and work as never before, and the two spheres were cast as gender-specific domains (public/work for men, private/ home for women). However, even this imagined separation did not reflect reality, as many women, especially young ones, were recruited into the new factories (particularly textile factories) of early industrial America. Lowell, Massachusetts was one famous site for women's wage labor, where already by 1840 some 8,000 women provided the majority of the workforce in the textile mills. This brought women out of the home, put them in physically demanding positions, equipped them with cash, and gave them a taste of independence and the new emerging American way of life.

Consequently, womanhood was believed to be in crisis by many well-meaning defenders of American civilization. By the later 1800s, men and some women worried that women were losing their femininity. For instance, as gender historian Michael Kimmel reports, Edward Clarke in 1873 warned of the dire effects of educating women: "The result of college education, Clarke argued, was that women were losing their ability to breed, developing 'monstrous brains and puny bodies,' with 'flowing brains and constipated bowels"' (2012: 72). Edward Bok, editor of the Ladies' Home Journal, concurred, proclaiming that the "number of women in business who lose their gentleness and womanliness is far greater than those who retain what, after all, are woman's best and chief qualities" (72). We saw above (Box 6.1) how the freer style of women's behavior of the age caused many of them to be labeled and incarcerated as moral delinquents and mental defectives.

The new image of the "flapper" previously mentioned must surely have seemed like the end of civilization. The flapper of the 1920s who danced and drank and smoked and hung around with men

was not just a spunky rebellious young woman who strove to defy her mother's traditions and caused uproar in society (although she certainly did so along the way). Rather, the Flapper was, and still is, the key symbol of the loud, modern youth of the 1920s. Her frankness about sexuality created both a new emotional and sexual culture for women, and a new foundation for male and female courtship. She shook the social norms and rocked the traditional female roles. She showed women across the globe that being submissive could only harm the potentially remarkable female.

(New York University 2007)

These early paragons of women's liberation led Cole Porter to write the immortal song, "Anything Goes."

Women were redefined again in the 1940s as "Rosy the Riveter," strong capable beings who could assemble an airplane or tank for the war effort. However, the end of the war, and the Cold War against godless and anti-family communism, drove a renewed conservatism in gender roles, especially for women. As Stephanie Coontz explained in her 1992 The Way We Never Were: American Families and the Nostalgia Trap, the domestic sphere was once more idealized (this time, a suburban domestic sphere), with the woman again ensconced (some would say imprisoned) as a modern 


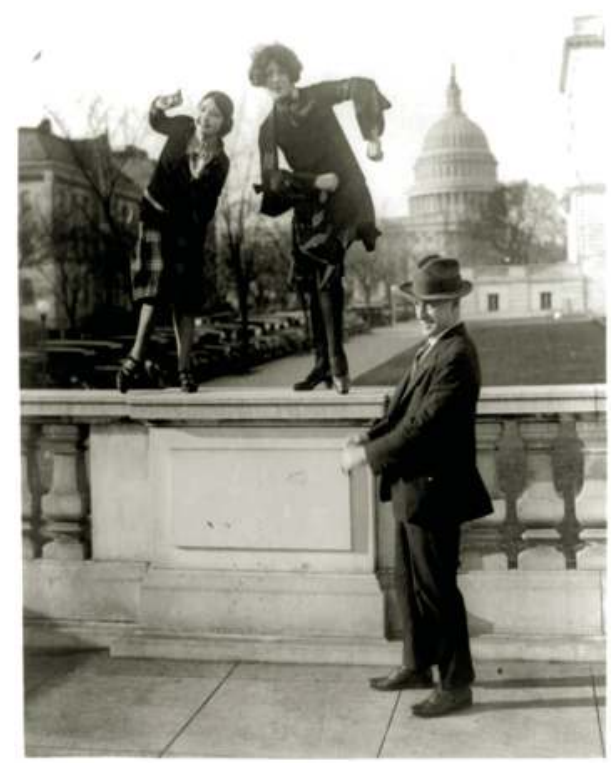

Image 6.2 Two flappers doing the Charleston with US Capitol in background, 1920s.

(Courtesy of the Library of Congress, Prints and Photographs Division)

wife and mother. Coontz found that women who rejected the wife/mother role were deemed physically or mentally ill; failure or lack of desire to have children was a "quasi-perversion," and a 1954 Esquire article called working women a "menace," just as the 1947 book The Modern Woman: The Lost Sex accused educated or professional women of castrating their men.

This was the era of valium (and sometimes electroshock) to adjust women into their ordained roles, but neither pills nor therapy nor the pressures of society could fit all women to this narrow definition of womanhood. Instead, in 1963 Betty Friedan announced women's unhappiness as "the problem that has no name" in her epochal The Feminine Mystique. Her analysis and complaint was precisely that women were being forced into restrictive roles that robbed them of the opportunity to develop their individual identities. (A generation earlier in 1929, Virginia Woolf had stressed that a woman needs A Room of One's Own-and her own money-to become a full person.) The women's liberation movement and the achievements of Roe $v$ Wade and Title IX only deepened the crisis, and the controversy, of gender and women's roles in the US. For instance, while most of us easily accept the idea of women's sports, defenders of traditional culture and gender saw the arrival of Title IX as yet another assault on both womanhood and manhood. In his aptly titled Gender Suicide, George Gilder argued that sport was "possibly the most important male rite in modern society," and the participation of women "reduces the game from a religious male rite to mere physical exercise, with some treacherous danger of psychic effect"; 


\section{Sex and Gender: Male and Female}

women athletes were a "disgusting perversion" of the "ideal of beauty and truth" of males athletics $(1973: 216,218)$. He actually added that men had the physique of the noble hunter, while the "female body, on the other hand, resembles the body of nonhunting primates" (221). (I am pained even to repeat these words and wonder how Gilder would react to the decorated female athletes and Olympians that his country has since produced.)

\section{The Gender Gap in Education}

As ignorant and hysterical as opinions like Gilder's are, they do illustrate the point that sexes/genders do not exist in isolation but comprise a sex/gender system, and changes in one category elicit changes in other categories and to the wider society. A crucial area of sex/gender change in contemporary American society is education. Females, of course, were largely excluded from higher education until the 1900s, and even then many were only allowed to attend sex-segregated schools and colleges. By 1992 the educational disparities between boys and girls had become so alarming that the American Association of University Women released a famous study called How Schools Shortchange Girls, asserting that schools were not meeting the needs of girls, who were trailing boys both academically and psychologically.

Fascinatingly, there is indeed in the twenty-first century a gender gap in education, but it is completely the reverse of those 1992 findings: females surpass males in almost every measure. According to Buchmann, DiPrete, and McDaniel, from the earliest years of schooling girls surge ahead. For instance, boys are more likely to have their entry into kindergarten delayed and are twice as likely to repeat kindergarten; they are also more likely to be held back by one or more grades in elementary school (2008: 321). Girls on average earn higher grades than boys in school and reportedly have been earning higher grades at least since the 1950s; they particularly outpace boys in reading (322). Girls have actually closed the gap in the male stronghold of math and now take the same advanced high school math classes and get better grades in them (323). At the same time, elementary and high school boys lead girls in the areas of "reading disabilities, antisocial behavior, mental retardation, attention disorders, dyslexia, stuttering, and delayed speech"; they struggle with "more developmental disabilities, more disruptive conduct in class and less positive orientations to learning activities” (322).

This early advantage continues for females as they progress through the education system. Young women are more likely to graduate from high school, to enroll in college, and to graduate from college. It was around 1980 that women caught up with and then passed men in college enrollment and graduation; women at present comprise more than half of all college students (at least 57 percent) and earn more than half of four-year degrees. Interestingly, the gap is widest for non-white students: women currently earn two-thirds of bachelor's degrees among African Americans, 61 percent among Hispanics, and 60 percent among Native Americans, compared to 57 percent among whites (326). And the female performance does not end there: women have become the majority in graduate school, earning 59 percent of all master's degrees and almost half of all doctoral degrees (49 percent), law degrees (49 percent), medical degrees (47 percent), and dental degrees (44 percent). Some observers worry now that males are experiencing an educational crisis. 


\section{Women in the Workplace}

The situation for women and work is more mixed. According to the US Department of Labor, the majority of women over age 16 (58.6 percent) are in the workforce, and women now constitute almost half (46.8 percent) of all workers in the country. The vast majority of those working women (73 percent) hold full-time jobs, and women weathered the recent economic recession better than men, since typically male-dominated jobs in manufacturing and construction were particularly hard hit. On average, a working woman brings in 42 percent of her family's household income, and 40 percent of working mothers are the primary or sole wage-earner in their family (Rosen 2010: 70).

Despite these facts, and the fact that most of the jobs projected to add employees in coming years are dominated by women, women still face two major problems in the work world. The first is the well-known wage gap: the median weekly wage for a fulltime working woman was $\$ 669$ in 2010, which was 81 percent of the median wage for men of $\$ 824$. Interestingly, among younger workers age 16 to 24 , the wage gap was much narrower, women earning 95 percent of men's wages. And women are still much less likely to reach the higher levels of business: less than 40 percent of managers are women, and a mere 4.2 percent of CEOs of large (Fortune 500) companies are women.

Observers have offered a number of explanations for the lag in and barriers to women's achievement at work. Blatant sexual discrimination is one undeniable factor. Women also tend to work fewer hours in their jobs and are more likely to work parttime. According to the US Census Bureau, in 200737 percent of men worked more than forty hours per week, compared to 20 percent of women, and 69.5 percent of women worked less than forty hours, compared to 49.7 percent of men. Women are also overrepresented in some traditionally lower-paying jobs such as secretaries and

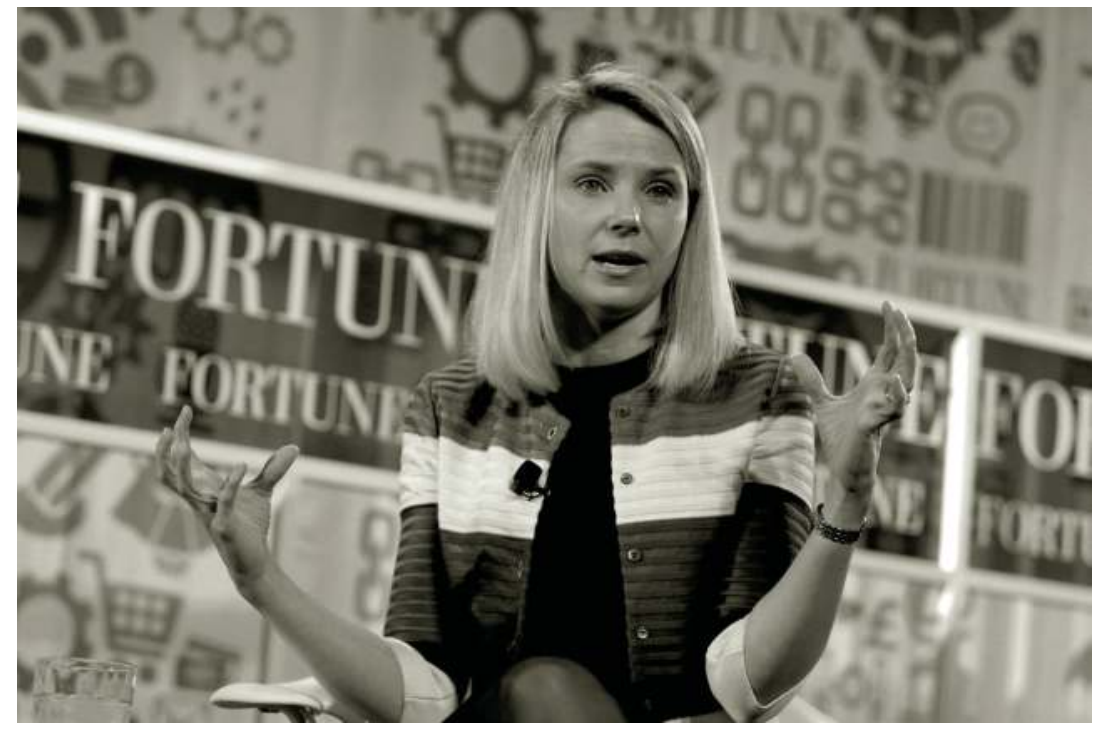

Image 6.3 Yahoo CEO Marissa Mayer speaks onstage at the FORTUNE Most Powerful Women Summit, 2013.

(Courtesy of Paul Morigi/Getty Images for FORTUNE) 
administrative assistants (fully 96.1 percent), elementary school teachers, cashiers, restaurant wait staff, maids and cleaning services ( 89 percent), and childcare workers (94.7 percent). Some pundits have stressed that women are more likely to interrupt their careers because of their children than men are. A quite controversial article by a professional woman in 2012 argued that women "still can't have it all" when it comes to work and parenting (Slaughter 2012). Of course, part of the problem here is that women still bear a disproportionate burden of childcare and housework duties. Finally, other observers have commented that the workplace does not reward female behavior and values as much as, say, the school environment does. Garance FrankeRuta finds that women in the work world "begin to fall behind the moment they leave school" because they bring behaviors that succeed in school, like "studying, careful preparation, patient climbing from one level to the next," to the "real world" where those skills and habits are not the path to promotion (2013: 28-9).

\section{The Wars Over Womanhood}

The diversity of women's roles, experiences, and choices has not always been a cause of celebration or even peaceful coexistence. Both men and women have argued openly in recent years about the "proper" choices for women and about the costs to themselves and to others for their decisions. Two particularly acrimonious arenas of social debate have been the so-called "mommy wars" and "nanny wars."

Some social scientists, commentators, and rank-and-file women have insisted, for example, that a woman needs to be at home, for her children if not for herself. That is, many people still maintain that the ideal and socially positive role for a woman is wife and stay-at-home mom, and a flurry of books has made claims ranging from working women miss the best moments of their children's lives to working women are selfish and socially destructive. On the other side, working women have responded that work gives them personal fulfillment and does not hurt but actually helps children; some have gone so far as to assert that mothering is mind-numbing and destructive of self and of the opportunities for other women. Both sides often ignore the facts that many women work not because they love it but because they must in order to support their families and that women are diverse and that neither full-time work nor full-time mothering is right for every individual.

More troubling are the "nanny wars," or the controversy over who is raising the children of working women. One aspect of the debate is the effect of young children growing up with a non-parent as primary caregiver. However, as Caitlin Flanagan and others have suggested, there is a much more ominous class and race dimension to the hired-childcare issue. They see the outsourcing of parenting as a case of "the tendency of white women to shape comfortable lives around the toil and suffering of black women" (2004: 112) or, more generally, of women of lower classes and non-white races. While not all working women are white and not all nannies are non-white, there is definitely an army of women of disadvantaged class and race providing domestic services that allow women of advantaged class and race to enjoy their lives. Many of the caregivers-providing what social scientists often call "emotional labor"—do not earn much money, have children of their own whom they must leave during the day (or in another country) to raise another woman's children, and work in conditions that Flanagan calls serf-like. More than a few of these caregivers are recent immigrants, 
some even illegal immigrants. Flanagan thus rightly worries about the irony of some women liberating themselves from the roles of wife and mother by imposing these roles on other women, or "how so many middle-class American women went from not wanting to oppress other women to viewing that oppression as a central part of their own liberation” (114).

\section{Box 6.2 Every Woman is Beautiful (or Better Be)}

Among the many issues that deserve attention, a crucial one for American women is beauty. Beauty was not an overriding concern in earlier American culture, but since the 1800s it has become increasingly important, and clearly American culture does not apply standards of beauty to men in any way near to the pressures it places on women. One controversial example is beauty pageants for women (and apparently now also for little girls). The preoccupation with female beauty can easily be seen in advertising and in movies and television, and the norms of female beauty are very specific and very burdensome; not many women can live up to the images of super-models and celebrities. Indeed, many super-models and celebrities cannot live up to those standards, as has been revealed in the extreme airbrushing of photographs that make these women more beautiful than humanly possible. The costs of beauty to women have been stressed. First, there is the financial cost of makeup and fashion. Second, there is the psychological cost, in terms of body image and self-esteem; one measure of this cost is the prevalence of eating disorders among young women. But Naomi Wolf, in her 1991 The Beauty Myth: How Images of Beauty are Used Against Women, argued forcefully that beauty standards have not only personal but political consequences. "The more legal and material hindrances women have broken through," she wrote, "the more strictly and heavily and cruelly images of female beauty have come to weigh upon us" (1991: 10). She regarded this beauty myth as "a violent backlash against feminism that uses images of female beauty as a political weapon against women's advancement" (10). If so, then developments like the "Campaign for Real Beauty" by the soap and cosmetic company Dove should be viewed with some suspicion: while the idea behind the campaign is that all women are beautiful and that there are different kinds of beauty, it still insists that women must preoccupy themselves with beauty (and buy products to achieve their "natural" beauty).

\section{Manbood in America}

Just as there is no such thing as womanhood in America but only womanhoods, so there is no such thing as American manhood but only manhoods. In fact, if we follow David Gilmore's line of thinking that manhood is at least as socially constructed and potentially even more embattled than womanhood (see above), then we may conclude that masculinity has been as problematic_and as much in crisis-as femininity in the United States, if not more so.

One of the most productive ideas for understanding men in the US is "hegemonic masculinity." Most commonly associated with R. W. Connell (1987), hegemonic masculinity 


\section{Sex and Gender: Male and Female}

is the dominant norm of manhood that reigns at any time in a society. Like ideals of female beauty, not all or even most men live up to the ideal of masculinity; in a later assessment of the concept, Connell and Messerschmidt accentuate that hegemonic masculinity

was not assumed to be normal in the statistical sense; only a minority of men might enact it. But it was certainly normative. It embodied the currently most honored way of being a man, it required all other men to position themselves in relation to it, and it ideologically legitimated the global subordination of women to men.

(2005: 832)

Connell also proposed the term "hegemonic femininity" to name the culturally dominant norm for women, but she changed that term to "emphasized femininity" to indicate that femininity was not hegemonic in society.

The significance of the idea of hegemonic masculinity can be summarized as follows:

1 A particular set of behaviors, attitudes, and traits (both physical and psychological/emotional) is held up as the standard for men, against which both men and women are judged.

2 It does not refer to some timeless essence of manhood but is rather a social construction of a certain time and place; therefore

a It can differ from one society to another;

b It can change over time within any one society;

c It can and usually does co-exist and even compete with other non-hegemonic masculinities.

3 It is institutionalized in various aspects of society (socialization, stories, media, family, religion, etc.) and taught to young men and women.

As historical research shows, masculinity was diverse, complex, and contested from the earliest days of European occupation of North America. Two critical facts shaped the experience of men in colonial America. First, from the initial wave of British settlers, men tended to substantially outnumber women: John Gilbert McCurdy writes of the Jamestown colony in 1607 that "it contained too many men. Too many men led to too much fighting and ultimately diverted the colonists from their original mission" (2011: 9), and this pattern was replicated by non-European immigrants of the 1800s and the westward expansion of the United States, where camps and towns that were often over 90 percent male engaged in the "bachelor vices" of drinking, gambling, and fighting. Second, the founding British settlers naturally brought their notions of manhood with them, including general patriarchy but also a more specifically classinformed masculinity. The hegemonic man of England was the gentleman, a man of high birth who also proved himself in combat. However, as McCurdy contends, Jamestown and other early American colonies were "divided between the well-born who came to profit from the labors of others, and the economically desperate who saw America as an overseas adventure" (16). These two styles of manhood often clashed, and each type of man questioned the other's manhood, although the rougher "common" version of masculinity was almost sure to win, given the large number of low-born men relative to gentlemen and the hardships of colonial life. 
Thus, in America (and other colonial settings like Canada and Australia) the new ideal of masculinity was the "self-made man," who was free and autonomous, selfsufficient, and mentally and physically equal to any other man who might cross his path. He was above all else masterful, in complete control of his emotions, his family, and his property. According to Jessica Choppin Roney, this image evolved into the "effective man" in urban settings like Philadelphia, where a true man took an interest in civil affairs and contributed his time and energy. A prime site for performing the role of the effective man was city volunteer organizations, which "came to be associated with service; public service became doubly associated with men and masculinity" (Roney 2011: 157). One good example then (and today) is the volunteer fireman, but other opportunities existed, from the militiaman to the humanitarian. The key point is these voluntary roles and institutions "were established for and by men"-women were not expected or allowed to participate- “and more specifically, mature white men of comfortable economic means" (168).

Accordingly, not only was there a class component to the capacity for manhood, but there was also a distinct racial component. Two contrasting and conflicting versions of manhood were found among Native Americans and African slaves, and both were riddled with ambiguities for white men. There was and is, of course, no single Native American culture but rather many and highly diverse cultures, but the European conquest of North America and its conception of masculinity as mastery made white men project "their power through masculine discourse. They did this by emphasizing their economic mastery over Indians, trumpeting their wartime successes, and proclaiming their invasions of Indian country as crowning military achievements" (Boulware 2011: 59). In the colonial era and later, whites disparaged Native American military tactics, gender roles, and especially institutions like the berdache (see Chapter 7) in which men were seen to dress and act like women. At the same time, whites could not help but admire Native toughness: contemporary white writers noted that peoples like the Cherokee "can always lift the hatchet: the snow does not freeze him; nor the sun make him faint" and that white men could not keep up with them in marching, running, or enduring hunger (51). Reciprocally, Native men were often not impressed with the soft hands and dandy ways of whites: one Cherokee leader condemned white men as "unfit for the chase, or for war. In the winter's snow you must burn a fire; and in the summer's heat you faint in the shade" (51).

The relationship between white and African masculinity was even more problematic, since the institution of slavery entailed the denial to black men of all of the privileges of manhood; white men were the master, black men were the mastered. Yet, the irony here was even more intense, as slave society depended on the physical strength of men, and it was undeniable that black men were men. So, during and after the slave era, white men had to systematically undermine the masculinity of black men, by calling them "boy," by committing violence against them, and by demonstrating their ineffectiveness by taking their women. But the ambivalence was clear here too: in his history of American masculinity, Michael Kimmel asserts that black men "were seen simultaneously as less manly than native-born whites and as more manly, especially as more sexually voracious and potent" (2012: 69). Indeed, the eternal sin of black men through the nineteenth and twentieth centuries was their alleged lust for white women and their alleged tendency to rape white women (this was the charge behind many lynchings). 


\section{Sex and Gender: Male and Female}

Predictably, the manliness of immigrant groups was also questioned and impugned. Kimmel quotes an 1890 source on the Chinese, which called them "wretched yellow under-fed coolies, with women's garments over their effeminate limbs, [who] will not have the courage or the desire or the capacity to make soldiers and defend their oppressors" (69). Men from the Middle East were often perceived as sensuous and feminine, and even Mexicans were thought to lack "all the manlier virtues"; the great scientist Louis Agassiz from his perch at Harvard University warned that "the manly populations" from Western Europe were imperiled by the "effeminate progeny of mixed races, half Indian, half Negro, sprinkled with white blood” (69).

If American manhood was under assault from foreign blood, it was also coming under assault from social change. The self-sufficient yeoman farmer of colonial days was being replaced by the wage laborer who owed his living to another man or to a faceless company in an anonymous city setting. Kimmel claims that "industrialization, technological transformation, capital concentration, urbanization, and immigrationall of these created a new sense of an oppressively crowded, depersonalized, and often emasculated life" (62). This was also the age of the assertive woman, as American women began to demand their rights to vote and to participate in society (see above). And the final threat to American manhood was the perceived emergence of the homosexual, who violated the core of hegemonic masculinity (see Chapter 7).

The day of the self-made man was passing, so a new image of masculinity was needed, one that valued the "stately and Protestant virtues, such as industry, usefulness, and thrift; to substitute virtues of personality for success and do a good job" (76). Thus employment and the factory floor or the office became the site for performing manhood, but this too was ambiguous, since the factory or office worker was not his own master. New enactments of masculinity had to be invented, and around the turn of the twentieth century these included both the profound (like war) and the absurd (like growing a beard: notice that all American presidents in the late 1800s wore beards). Men began to take tonics and potions to enhance their virility (Kimmel claims that both Post's Grape Nuts and Kellogg's flakes were initially promoted as foods for men's health). Men who were now trapped indoors during the day sought their manhood outdoors, and hunting became an important cultural act; new organizations like the Boy Scouts (founded in 1910) helped young men acquire the skills lost to the city and the workplace. But probably no venue of manliness was more crucial than sports, which moved to the center of American men's experience: professional sports for the elite athlete were combined with physical exercise for the amateur, as in the YMCA, founded in 1851, which director Luther Gulick understood as a means to create the "manly boy" (132).

Through the middle of the twentieth century, multiple versions of manhood vied for hegemony. The 1940s was the period of the noble soldier, the "greatest generation" who won World War II. The 1950s was the day of the "organization man," the man in the gray flannel suit who worked silently for his company and supported a wife in the suburbs. However, the same earlier anxiety arose from this male role: the eminent sociologist C. Wright Mills called the white-collar employee a "victim, the small creature who is acted upon but who does not act, who works along unnoticed in somebody's office or store, never talking aloud, never talking back, never taking a stand" (1953: ix, xii). And if middle-class white men living the American Dream (see Chapter 5) were unsatisfied, for disadvantaged classes and races the crisis of manhood was even more acute. Sociologists and anthropologists began to identify "protest 


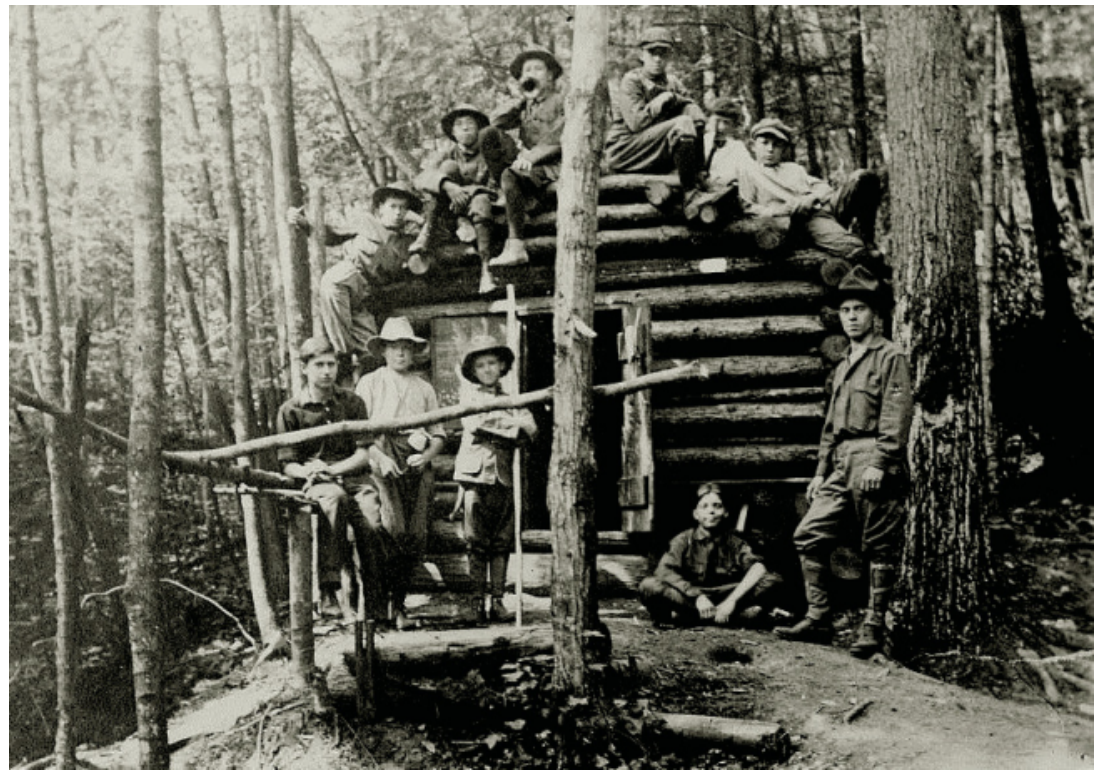

Image 6.4 Boy Scouts.

(Courtesy of the Bain Collection, Library of Congress, Prints and Photographs Division)

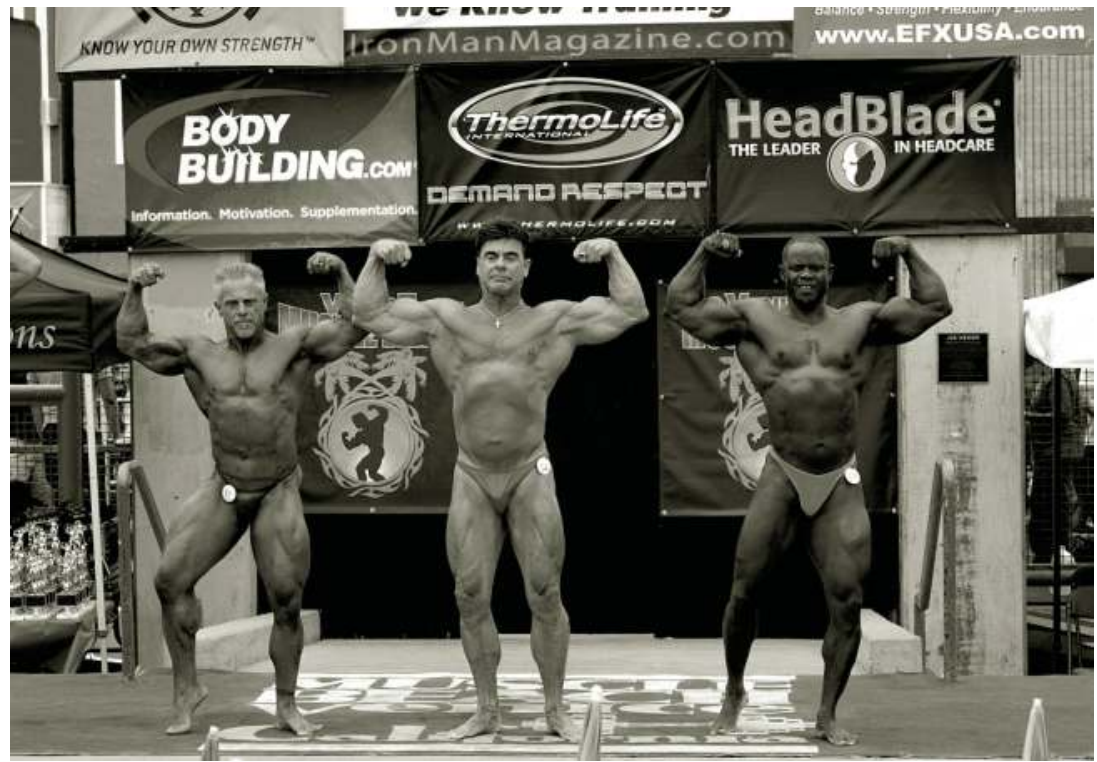

Image 6.5 Contest at Muscle Beach in California, which dates back to the 1930s.

(Courtesy of the Jon B. Lovelace Collection of California Photographs in Carol M. Highsmith's America Project, Library of Congress, Prints and Photographs Division) 


\section{Sex and Gender: Male and Female}

masculinity," a reaction against restrictions on manliness and the absence of positive ways to achieve and express manliness. Beatrice Whiting characterized protest masculinity as "a strong need to reject his underlying female identity. This may lead to an overdetermined attempt to prove his masculinity, manifested by a preoccupation with physical strength and athletic prowess, or attempts to demonstrate daring and valor, or behavior that is violent and aggressive" (1965: 126-7).

Simultaneously, a rival masculinity started to form in the 1960s and 1970s that embraced a man's "feminine side" and questioned the need to indulge in male bravado and violence. So, in contrast to the John Wayne image of men, an image of the Alan Alda (the actor who played sensitive, anti-war doctor Hawkeye Pierce on $M * A * S * H$ ) or the Phil Donahue (the liberal talk-show host) gave men new models to follow or fight about. Today in America, it is difficult to say which masculinity is hegemonic; more likely, there are different masculinities that are hegemonic for different races, classes, ages, and regions. The hard-partying, womanizing frat guy is a valued model of manhood for many young adult (especially college-age) males. The computer nerd enjoys a certain honor, after the achievements of Bill Gates and Steve Jobs. In the early 1990s figures like Robert Bly (1990) attempted to revive the "wild man" or "hairy man" who yearns to burst out of every sensitive suit-and-tie man, while religious leaders like Bill McCartney (Promise Keepers) and Louis Farrakhan (Nation of Islam's “Million Man March") tried to restore men to the center of their families. Meanwhile, poor men and non-white men struggled with the hegemonic masculinities that mostly represented middle-class white men. Alexander Lu and Joel Wong (2013) recently proposed the concept of "minority masculinity stress theory" to account for how Asian American (and presumably other non-white) males experience an American masculinity that does not include them and that actually produces symptoms like stress, substance abuse, and depression, not to mention macho overcompensation.

\section{Conclusion}

Like race and age, sex/gender is a set of cultural categories and norms based on certain physical differences. Even more than race and age, these cultural categories and norms are usually experienced as natural and real, and the sex/gender options (which are not considered "options" at all) are restricted to two and only two. However, American history, along with cross-cultural investigation, has shown conclusively that sex/gender is not an unchanging binary essence. Societies differ in the number of sexes/genders they recognized, the roles they assign, and the relations between the sexes/genders.

Finally, like physical differences of race and age, as well as social differences of ethnicity and class (and, as we will see in future chapters, of language, religion, and region), the culturally constructed categories of sex/gender have real consequences. How a society thinks about and treats men or women affects their livelihood, their bodies and emotions, and often their very lives. And often in American society, sometimes below people's perception but sometimes in plain view, sex/gender norms and relations are diverse and contested, occasionally erupting into heated controversy. In fact, sex/ gender may be more open in American society today to criticism and revision than any other dimension of diversity. It is simply not obvious at all what a man or a woman is supposed to be in contemporary America, which is a source of stress but also of freedom. 


\section{Sex and Gender \\ Beyond the Gender Binary}

On Wednesday, July 3, 2013, the California state legislature passed a law requiring public elementary and high schools to allow transgender students to decide which bathroom they use and which sports teams they join on the basis of their current gender identity rather than the sex/gender to which they were assigned at birth or their DNA. California thus became the first state to have a state-wide policy confirming the rights of people who have chosen a gender other than the one that society has chosen for them or which their body would seem to dictate. But California is hardly the first state to face the question: only days before, Colorado ruled that a transgender first-grader (born a boy and with a boy's body) was free to use the girls' bathroom at her grade school. Not everyone is happy about these outcomes, though: California state senator Jim Nielsen (Republican) complained that "Elementary and secondary students of California-our most impressionable, our most vulnerable-now may be subjected to some very difficult situations" (Don Thompson 2013).

What is a society to do when sex/gender-segregated facilities and opportunities do not conform to the sexes and genders of its citizens? Is it necessary to have sex/gendersegregated facilities and opportunities (the United States does not permit race-, ethnic-, or class-segregated social spaces)? Is recognizing and dealing with gender diversity and gender-nonconforming individuals a very difficult situation? And don't perhaps the gender-nonconforming individuals face some very difficult situations themselves?

In every human society there are males and females, although there is tremendous diversity within each sex/gender, and every society constructs the norms and expectations for each sex/gender and judges individuals by how well they perform their gendered roles. However, "male" and "female" hardly exhaust the issues and alternatives in sex/gender, sexuality, and sexual identity. In fact, it will be recalled from the previous chapter that sex/gender is a composite phenomenon, not based solely on physical traits like genitalia. Other elements of a person's sex/gender include sexual preference or desire, gender identity, gender personality, gender display, and gender roles (see Figure 7.1). Each of these elements can vary independently, resulting in combinations that do not fit within the simple gender dichotomy of male and female. In other words, a person may have a male body but desire other males sexually or self-identify as a woman-and that is only the beginning of a very long list of possible alternative sex/ gender constructions.

As already discussed, most Western societies, including the United States, traditionally operate with a binary notion of sex/gender: there are males/men and there are females/women. Western and American societies have, of course, recognized other 


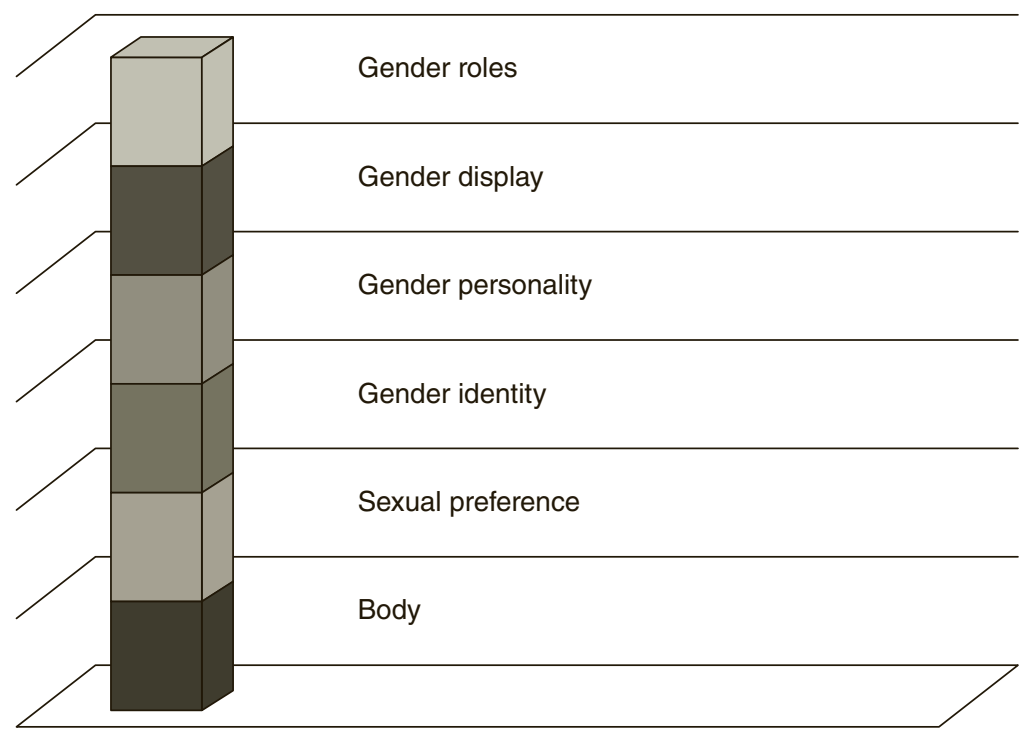

Figure 7.1 The components of sex/gender.

sexual activities and proclivities, but from the perspective of heteronormativity, these other sexualities and identities have usually been labeled as "deviant," sometimes actually pathological (i.e. illness) or even criminal. Heteronormativity might be thought of as the "hegemonic sexuality" in the United States and other Western societies, in which the normal and good sexuality is heterosexuality, the sexual desire for a member of the opposite sex. Any other option is devalued and stigmatized (abnormal).

The documented variation in sex/gender, as well as the organization and mobilization of people of non-heteronormative sex/gender, does not support a binary notion of either maleness/femaleness or heterosexuality/homosexuality. First, sexualities are much more numerous and complex than merely "same" or "other." Second, sexualities seem to be less "fixed" or settled and more "fluid" than we usually imagine: an individual's sexuality is not necessarily set once and for all at birth or even in adolescence or adulthood. Third, since non-normative sexualities are frequently disadvantaged or oppressed (sometimes literally punished), many social scientists as well as persons of non-normative sex/gender have stressed the "intersectionality" between sex/gender minority and other types of social exclusion such as race and class. Ultimately, perhaps more strongly than any other area of human diversity, sex/gender not only challenges but disrupts our taken-for-granted categories. In many ways, non-binary and nonnormative sexes, genders, sexualities, and identities are transgressive and subversive: they "move across" (trans-gress) and "turn under" (sub-vert) familiar and assumed ways of thinking, to which we can never return.

\section{The Social Construction of Sexual Diversity}

As we acknowledged at the outset of this chapter, human societies always include persons with male or female genitalia. Societies also always indulge in sexual activity, and most societies have had some (although often a quite different) notion of marriage. And 
humans in all times and places have experienced desires and attractions, pleasures, and love-all of which can be and have been independent of body form, sexual activity, and marriage. Within the heteronormative norms of American society, ideally all of these phenomena coincide: two individuals with opposing genitalia desire each other, love each other, marry each other, and have sex with each other. This is not the case in all times and places (and obviously not the case for all Americans). Accordingly, Judith Halberstam (1998) reminded us of the dangers of what she called "perverse presentism," which we might extend to "perverse ethnocentrism," meaning the presumption that the concepts and attitudes of present-day America on the subject of sex/gender, sexuality, and sexual identity have been shared by all societies around the world and throughout time. They have not been.

The very idea that there are two and only two sexes or genders is not a universal thing. Thomas Laqueur (1990) asserted that the idea of two exclusive sexes/genders is a fairly recent development in Western societies: before the eighteenth century, he argued, there was only one sex/gender, namely male, and as late as the early twentieth century Sigmund Freud's psychosexual theory seemed to pronounce male sexuality as the normal or basic one, with females being some mysterious version of males (suffering, for instance, from "penis envy"). On the other hand, Plato told a famous story in his dialogue Symposium about the original bisexuality of all humans in mythical time (some male/female, some male/male, others female/female) who were torn in half by the gods and thus spent their lives in search of their other half-making individuals "naturally" heterosexual, homosexual male, or homosexual female.

However, it is not as simple as that. For instance, in every society there have been individuals whose very sexual anatomy was non-normative, either by nature or by human intervention. The truth is that not every human being is born with clearly male or female genitalia; they may have genitalia of anomalous shape or size or of both sexes or neither. In prior times such persons might be called "androgynous" (literally male-female) or "hermaphrodite" (literally Hermes and Aphrodite, an ancient Greek male god and female god, respectively), and there was often great shame attached to the condition. Today, such persons tend to prefer to be called intersex and may be proud and organized: there is an Intersex Society of North America (http://www. isna.org/) "devoted to systemic change to end shame, secrecy, and unwanted genital surgeries for people born with an anatomy that someone decided is not standard for male or female."

There are a number of medical conditions that can produce intersex persons, including androgen insensitivity syndrome and Klinefelter's syndrome. In the former, a child has male chromosomes and testes, but because the body is resistant to the male hormones known as androgens, the testes do not descend and the child develops as a female; in the latter, a male child has two $\mathrm{X}$ (female) chromosomes in addition to the $\mathrm{Y}$ (male) chromosome, often resulting in feminine appearance, gynecomastia (enlarged breasts), and sterility. On other occasions, for various reasons, societies sometimes removed the genitalia of people, especially males, to produce a eunuch. Richard Joel Wassersug (2012) admits that he is a surgical eunuch, a genetic male who has had his testicles removed or destroyed, in his case as treatment for prostate cancer and "not out of any desire to transition to female." In parts of India, genetic males continue to have their genitalia ritually removed not to become women but precisely to become "neither men nor women," an identity or status known as hijra or aravani which is effectively a third gender (Nanda 1999). 
In the next sections, and throughout this chapter, we will thus see how American/ Western and other societies construct categories out of diverse bodies, desires, and behaviors. More importantly and powerfully, we will see how American/Western society has created identities and an ontology (a theory or system of being, or what kinds of beings, including human beings, actually exist) out of bodies, desires, and behaviors. In one of the most-quoted passages in Michel Foucault's history of sexuality, he taught that sexual acts have only recently been transformed and accepted as sexual identities. His comments on homosexuality are generalizable to other sexual classifications:

Sodomy was a category of forbidden acts; their perpetrator was nothing more than the juridical subject of them. The nineteenth-century homosexual became a personage, a past, a case history, and a childhood, in addition to being a type of life, a life form, and a morphology.... The sodomite had been a temporary aberration; the homosexual was now a species.

Kim Phillips and Barry Reay (2011) take this idea to mean that, while sex has been a universal and transhistorical part of human life, "sexual identity" and even "sexuality" are relatively new notions. Sex, in other words, existed long before "sexuality," the latter term introduced only in the late 1800s.

\section{Inventing Homosexuality}

In many, if not all societies, there have been individuals whose sexual and romantic desires included someone of their own sex/gender. These individuals did not always desire exclusively members of their own sex, and they often, if not usually did not think of themselves as "homosexual" or "gay."

Ancient Western cultures (Greek and Roman) had a place for accepted samesex relationships, both physical and emotional. John Boswell noted several types of ancient, mostly male-male, relationships, ranging from the sexual use of male slaves and servants to the maintenance of a male concubine to a more enduring and meaningful bond between male "lovers" or "admirers." In the latter relationship, an adult man chose a boy or young man and "played the role of educator and protector, comparable to that of the husband in a heterosexual marriage" (1994: 56). Known as pederasty, the motivation was sexual but also aesthetic (the appreciation of male beauty) and the central dynamic of the relationship was age difference rather than sex/gender sameness. Perhaps most famously, the Spartan army used male-male relationships to strengthen the bonds between soldiers. The Spartan warrior also married a woman, however, and ceased the same-sex activity when he left the military. None of these ancients would have called themselves "homosexuals."

In other societies there have also been occasions, sometimes institutions, for same-sex sexual activity that did not qualify in their eyes as "homosexual." Among a number of peoples in New Guinea, it was believed that a male baby will not inevitably grow into an adult man; as discussed in the previous chapter, manhood is not a natural condition but a ritual achievement. Groups like the Sambia felt it necessary to inject maleness into boys, and since maleness was contained in male substances like semen, then boys received semen from young men through performing acts of oral sex on the young men. Dubbed "ritual homosexuality" by Western scholars, no Sambia would have 
considered it homosexuality — and certainly not a "homosexual identity" — since men stopped participating in this oral sex in their twenties and married a woman, establishing their "heterosexual" identity (Herdt 1987). In modern Japan, Mark McClelland found men who desire and perform sex with men but "did not necessarily rule out marriage to a female partner" (2000: 464). Sexuality and marriage were widely regarded as two unrelated issues, and marriage was valued as a social institution, "a practical arrangement" to establish a household and family, rather than as a source of love and sexual satisfaction (465). McClelland concluded, "Same-sex desiring men and women who identify with Western models of being 'gay' or 'lesbian' are, however, a minority within a minority in Japan” (468). Similarly, among same-sex desiring Muslim men in Indonesia, many marry women and have children because that is the social expectation and because, more profoundly, homosexuality "is incomprehensible as a form of sexual selfhood" (Boellstorff 2005: 575). In fact, "it is only in the last thirty years that some Indonesians have started calling themselves gay, and only in particular, limited circumstances" (577).

Some might argue that Sambia, Japanese, and Indonesian gay men suffer from false consciousness and a denial of their true self. We might and should look at the matter in another way, that some societies in recent time have invented the very notion of a "true sexual self." The Western invention of sexual categories and identities largely occurred in the nineteenth century, as part of the project to subject every aspect of life to scientific examination and classification. A German physician named Karl Westphal in 1869 identified the "invert" who suffered from "contrary sexual feelings." This invert experienced sexual desires for the same sex and also manifested opposite-gender traits, the men acting effeminate and the women manly. The term "invert" was replaced almost immediately, though, by Karl Maria Benkert's (who wrote under the pseudonym Kertbeny) 1869 neologism of "homosexual." According to Benkert,

Nature in her sovereign mood has endowed at birth certain male and female individuals with the homosexual urge, thus placing them in a sexual bondage which renders them physically and psychically incapable-even with the best intention-of normal erection. This urge creates in advance a direct horror of the opposite sex, and the victim of this passion finds it impossible to suppress the feeling which individuals of his own sex exercise upon him.

(quoted in Money 1988: 9)

It will be appreciated that this emerging new field of "sexology" was completely misguided about homosexuality, starting with the fact that Benkert's description only fits males. Further, male homosexuals are not necessarily or ordinarily incapable of an erection, nor are they horrified by women. Finally, as John Money goes on to explain, Benkert focused exclusively on genitals and the sex act (homosexual) while ignoring love (homophile) or physical attraction (homogenic) (1988: 9). But Benkert's term, and its many unfortunate associations and assumptions, stuck. Another German, psychiatrist Richard von Krafft-Ebing, in his 1886 Psychopathia Sexualis, adopted the word "homosexual" to name a particular "sexual perversion" which he regarded as congenital or given at birth and which was characterized by "the want of sexual sensibility for the opposite sex, even to the extent of horror, while sexual inclination and impulse toward the same sex are present" (1906: 335). In a series of pamphlets 


\section{Sex and Gender: Beyond the Gender Binary}

called The Riddle of "Man-Manly" Love released between 1864 and 1880, Karl Heinrich Ulrichs separated homosexuals (whom he called Urnings) as a "third sex."

There was much more in this vein, culminating perhaps in Havelock Ellis' multi-volume Studies in the Psychology of Sex, the second volume of which was dedicated to "sexual inversion," which he defined more narrowly than homosexuality. Homosexuality included all sexual attractions to individuals of the same sex, while sexual inversion was more specifically an "inborn constitutional abnormality toward persons of the same sex" (1908: 1). Interestingly, Ellis stated that homosexuality was actually quite common across cultures and even in non-human animals; also, he disliked the word "homosexual" as "barbarously hybrid" and suggested the use of "homogenic" instead. At any rate, Ellis also acknowledged that sexual inversion occurred among women as well as among men. Finally, he recognized that sexuality as such was not the only arena of inversion. There were also inverts whose sexual desire was heterosexual but who "feel like a person of the opposite sex" and adopt "the tastes, habits, and dress of the opposite sex, while the direction of the sexual impulse remains normal."

\section{Diversity Fact:}

The earliest reference to gender ambiguity in the United States is the 1629 colonial Virginia case of Thomas (or Thomasine) Hall, who was declared to be both male and female and to wear the clothing of both sexes.

\section{Inventing LGBT}

In contemporary American discourse, other sexual identities have not only been invented but have been assembled into a supposed "community," including gay (for homosexual men), lesbian (for homosexual women), bisexual, and transgender, designated by the acronym GLBT or LGBT. As we will see below in more detail, the idea that there are four "sexualities," let alone that they comprise a single community of non-hegemonic sexes/genders, is both new and highly contested.

Like other scholars of sexuality, Boswell noted with some curiosity that there was "little written on female homoeroticism in Europe in antiquity or during the Middle Ages" (1994: xxix). This does not imply by any means that female-female sexual and/or emotional relationships were non-existent or unknown. There are a number of reasons for this apparent indifference or silence on women's same-sex behavior. One is the obvious and dramatic "phallocentrism" of Western thinking, in which men's sexuality is the basic concern and model for all human sexuality; phallocentric and patriarchal cultures are much more preoccupied with what males are doing than what females are doing. Second, since female same-sex behavior is not procreative, males found it less threatening to paternity. Third, it must be admitted that heterosexual male sexuality, as the hegemonic sexuality, finds female same-sex activity stimulating.

The term "lesbian" harkens back to ancient Greece, where a female poet named Sappho was born on the island of Lesbos around the sixth century BCE. Renowned for her love poems that were addressed to women as well as to men, she was often 
referred to as the Lesbian poet Sappho. Her own name became associated gradually with female-female eroticism (leading to the term "Sapphic," which is little used today) and "lesbian." The word "lesbian" appeared in this context before the technical term "homosexual," although it only settled into scientific usage around 1870 . It occurs several times in Krafft-Ebing's 1886 Psychopathia Sexualis, usually in the form of "lesbian love," including a short four-page section on lesbian love which claims that most "female urnings do not act in obedience to an innate impulse, but they are developed under conditions analogous to those which produce the urning by cultivation" (607). Krafft-Ebing attributed such "forbidden friendships" to experiences of prison or prostitution (or both).

Another potential reason why female homosexual relations were tolerated and more invisible than their male counterparts, according to Phillips and Reay, is that female homosocial (that is, women socializing with women) and homosexual behaviors were often construed as "manifestations of male impersonation" (2011: 93). The women frequently dressed like men, comported like men, and even performed their seductive and sexual acts like men. In some instances, homosocial or homosexual interactions between women were perceived as "practice" for being with men; in other cases, her desires or behaviors were explained by her being a "tribade," a woman with an enlarged clitoris who engaged in quasi-heterosexual (penetrative) sex.

In the West as elsewhere, women's intimate relationships with each other were not always or exclusively sexual. Close friendships might include a component of touching, hugging, or kissing. Elisabeth Kirtsoglou describes a community of homosocial women in Greece, some of whom are married with children, who meet at a public spot to talk, dine, dance, and (if they are so choose and are unmarried) "pursue erotic relationships" (2004: 5). Few if any of them consider themselves lesbians; some simply "prefer the friendship network" of the group "to heterosexual conjugality" (6), while all "resist the labels lesbian, homosexual and bisexual" and "claim that what ties them are 'sentiments' of 'elective affinity' and not a clear lesbian identity" (9). As a more distant example, Deborah Shamoon writes about the "passionate friendships" that formed between schoolgirls in early modern Japan. In the new social environment of the single-sex school, and fed by images in girls' magazines, an explicit practice evolved known as $S$ kankei ("S relationship," the S standing for shisu or the Japanization of "sister"), which Shamoon characterizes as homosociality, a strong, even romantic bond between two girls that could have "a homoerotic element" but that "should not be read as lesbian in the twenty-first century sense of a fixed sexual identity" (2012: 11). Not only was $S$ kankei not necessarily sexual and certainly not expected to be a lifetime "sexuality," it was also accepted as good and normal by Japanese society. Older girls would pursue and "court" younger ones in what was, once again, seen as a largely harmless anticipation of future heterosexual roles.

Havelock Ellis' mention of inverts and the distinction between sexual desire, sexual identity (those individuals who "feel like a person of the opposite sex"), and "the tastes, habits, and dress of the opposite sex" reminds us of the sexual performance and display features involved in practices like cross-dressing or transvestism. Magnus Hirschfeld is widely credited with coining the term transvestite (literally "acrossdress”) in a 1910 book, Die Transvestiten or The Transvestites, although some similar words were most likely already in circulation. Clothing, of course, is only one dimension of sexual display, and there are diverse reasons for engaging in the behavior, to 


\section{Sex and Gender: Beyond the Gender Binary}

which we will return below. The point is that not many people avow the identity of "a transvestite"; it is seldom, in Foucault's terms, a species.

Some individuals take their "crossing" further, actually identifying with what society holds to be the opposite sex/gender. Hirschfeld is usually awarded the credit for introducing the term transsexual for such people. In his 1910 work he used the word Geschlechtsübergänge which translates to "sexual over-going." Then in 1919 he founded the Institute for Sexology in Berlin, where male-to-female "sex change" or sex reassignment surgery was practiced from 1920. This experience led him to propose the term seelischer Transsexualismus, or "psychic transsexualism" for the person who identifies with the "opposite sex" (that is, the sex that is not socially ascribed to their body). The term "transsexual” became well established after Harry Benjamin's 1966 book The Transsexual Phenomenon, in which he characterized transsexualism as an extreme version of transvestism (that is, the individual wants to change more than his/her clothing). Individuals who go through the process of sex transition (and it is a process, one that can take years to complete) are sometimes known as MTF (male-tofemale or transwoman) or FTM (female-to-male or transman). Not all transsexuals undergo sex-reassignment operations or want to, though, and being a transsexual says nothing about a person's sexual preference.

\section{Box 7.1 The "Two-Spirit" in Native American Culture}

European Americans, with their Western/Christian binary gender categories, often found the gender practices of Native American cultures incomprehensible and sometimes abominable. One such practice was labeled berdache (a French word derived from Arabic or Persian implying homosexuality or male prostitution) because of the anomalous characteristics of the biological males who performed it. Specific tribes and societies had their local terms for such individuals, such as winkte in Lakota or nadleehi in Diné/Navajo, and the details of the category likewise varied across Native cultures. Most generally, these male individuals dressed like women, did women's work, and in numerous ways comported themselves like women. They were not necessarily homosexual, though; some married women, some married men, and some did not marry. They were also not despised in Native cultures but respected and often revered. They certainly did not modify their genitalia. In fact, the Native understanding of such individuals was that their gender depended not on the body but on the spirit-or rather, spirits. It was commonly held that they embodied two spirits, a male and a female, which made them doubly spiritual. Today, a preferred label by many such individuals is "two-spirit," and there are presently many two-spirit organizations around the country (for example, the NorthEast Two-Spirit Society, http:// www.ne2ss.org/) and an international convention. According to Carolyn Epple, the English language and American/Western categories fail to grasp the basis of Native "third genders" (and sometimes "fourth genders," like the North Piegan "manly-hearted woman") and of Native gender thinking as a whole. The Diné/Navajo do not share the American/Western assumption that "male" and "female" are mutually exclusive or that they are 
even constants. Among the Diné/Navajo, and other Native American and indigenous peoples, "everything exists as both male and female" (1998: 278), and gender may be situational rather than permanent or an "identity." This is why, as Will Roscoe (1998) titled his book, the local conception for such individuals amounts to "the changing ones," the people for whom gender is most fluid and mutable.

The " $\mathrm{t}$ " in LGBT ordinarily refers to a still more remarkable phenomenon, which has recently come to be called transgender. According to GLAAD (Gay and Lesbian Alliance Against Defamation, http://www.glaad.org/reference/transgender), transgender offers an

umbrella term for people whose gender identity and/or gender expression differs from the sex they were assigned at birth. The term may include but is not limited to: transsexuals, cross-dressers, and other gender-variant people. Transgender people may identify as female-to-male (FTM) or male-to-female (MTF). Use the descriptive term (transgender, transsexual, cross-dresser, FTM or MTF) preferred by the individual. Transgender people may or may not choose to alter their bodies hormonally and/or surgically.

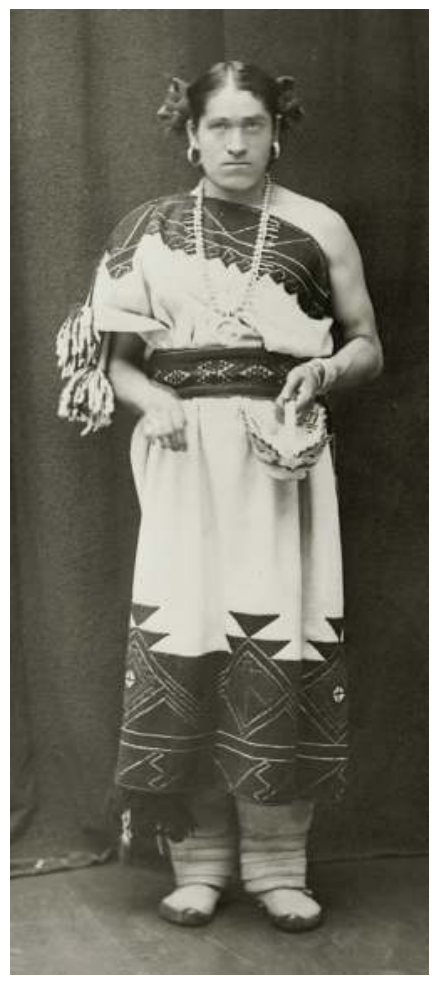

Image 7.1 We-Wa, a Zuni “two-spirit."

(Courtesy of the US National Archives and Records Administration, ID 523798) 
As such, it encompasses transsexuals and transvestites, although there is considerable dispute about the territory of these terms. Some individuals and organizations have added the term genderqueer for, according to GLAAD, "individuals who identify as between genders, or as neither man nor woman. Genderqueer identity may be seen as an identity under the gender non-conforming umbrella. Genderqueer individuals may or may not pursue any physical changes, such as hormonal or surgical intervention. Genderqueer individuals may or may not identify as trans.” In other words, genderqueer individuals may reject the entire notion of strict gender categories and identities and perform their gender in individualized ways-or even reject entirely the idea that they have or perform gender.

Finally, the "b" in LGBT refers to bisexual. Bisexuality commonly means sexual interest in either or both sexes/genders, but this is far too simple. Bisexuality does not imply that the individual desires both sexes/genders equally or at the same time; a bisexual person may have a preference or may alternate between preferences over time. Perhaps this is the reason why bisexuality has been so controversial. Some experts and activists have argued that all humans are naturally bisexual. Others have maintained that bisexuality is a distinct third sexuality: the International Classification of Diseases specifies the three human sexual orientations as heterosexual, homosexual, and bisexual (Gooß 2008). Some actually dismiss the idea of bisexuality altogether, seeing it as either temporary, transitional between one's "true" identity as gay or straight, or a kind of false consciousness or deception, as if trying to "pass" as straight or enjoy "heterosexual privilege" while really being gay.

One of the first studies of bisexuality was Fritz Klein's 1978 book The Bisexual Option, which drew on the Kinsey Scale of human sexuality (see below) to insist that not all people fall neatly into the heterosexual or homosexual category. For Marjorie Garber, bisexuality subverted the notion that sexuality was binary and stable; rather than "one more sexuality," Garber understood bisexuality to put "into question the very concept of sexual identity in the first place" (1996: 66). To make things maximally complicated, David Halperin suggests that bisexuality can describe thirteen different kinds of people and their sexual preferences and behaviors, including those who:

- $\quad$ are sexually attracted to males and females;

- $\quad$ are not prevented from being sexually attracted to anyone because that person is male or female;

- $\quad$ are sexually attracted to the individuals they are attracted to, whether those individuals are male or female;

- are sexually attracted to their own sex but have a sexual history that includes sex with persons of the other sex;

- $\quad$ are sexually attracted to the other sex but have a sexual history that includes sex with persons of their own sex;

- $\quad$ are in a stable, long-term, sexual and erotic relationship with someone of their own sex but are also sexually attracted to persons of the other sex;

- $\quad$ are in a stable, long-term, sexual and erotic relationship with someone of the other sex but are also sexually attracted to persons of their own sex;

- have sex only with persons of their own sex who are gay and persons of the other sex who are heterosexual;

- $\quad$ have sex only with other bisexuals (men or women); 
- have sex only with persons of their own sex but identify as bisexual;

- $\quad$ have sex only with persons of the other sex but identify as bisexual;

- have sex with males and females but identify as gay or lesbian; and

- have sex with males and females but identify as heterosexual.

(2009: 452-3)

\section{Sexual Diversity in the United States}

Sexual diversity is a problem in the United States, in more ways than one. First, the US Census does not collect data on sexuality, sexual preference, or sexual behavior (recall from the previous chapter that the Census simply asks individuals to identify by one of two sex/gender categories, male or female). There are, thankfully, other sources of research on sexuality. However and second, the stigma on non-heteronormative sexuality could lead some individuals to decline to provide information or could make them difficult to locate at all. Worse and third, because of the complexity and controversy over terminology, individuals might reject the terms and categories into which surveys and questionnaires attempt to place them. For example, a person who has only had fantasies about the same gender, or perhaps a single sexual encounter with the same gender, might not feel that the label "homosexual" applies to him/her. Finally, of course, non-heteronormative sexuality is a huge cultural and political problem in the United States, where the law has been and still is used to disadvantage or punish "deviant" acts and identities. Until a few decades ago, homosexuality was literally a crime in most parts of the US, and struggles for "gay rights" and same-sex marriage continue today. It was only in 2013 that the Boy Scouts agreed to admit gay boys, but it still bans gay Scout leaders.

One of the first and most radical works on American sexuality was done by Alfred Kinsey, whose large-scale research yielded two seminal books, Sexual Behavior in the Human Male in 1948 and Sexual Behavior in the Human Female in 1953. Kinsey not only reported that American sexual behavior was much more varied than most people thought or cared to admit (much of it conducted in secret) but that sexuality did not fall neatly into two discrete categories as either heterosexual or homosexual. From his investigations he arrived at a continuous range of sexuality, known as the Heterosexual-Homosexual Rating Scale (or simply the Kinsey Scale), in which there was a spectrum of seven positions from "exclusively heterosexual" to "exclusively homosexual" with five variations in between:

- $\quad$ predominantly heterosexual, only incidentally homosexual;

- $\quad$ predominantly heterosexual, but more than incidentally homosexual;

- $\quad$ equally heterosexual and homosexual;

- predominantly homosexual, but more than incidentally heterosexual;

- predominantly homosexual, only incidentally heterosexual.

Much more recent work by Robert Epstein (2012) has confirmed these findings. Studying almost 18,000 people from forty-eight countries including the US, Epstein and colleagues Paul McKinney, Shannon Fox, and Carlos Garcia developed a fourteen-point scale of sexuality on which many individuals occupy an intermediate position between totally straight and totally gay-and on which any 
MEAN SEXUAL ORIENTATION

ALL SUBJECTS $(n=17,785)$

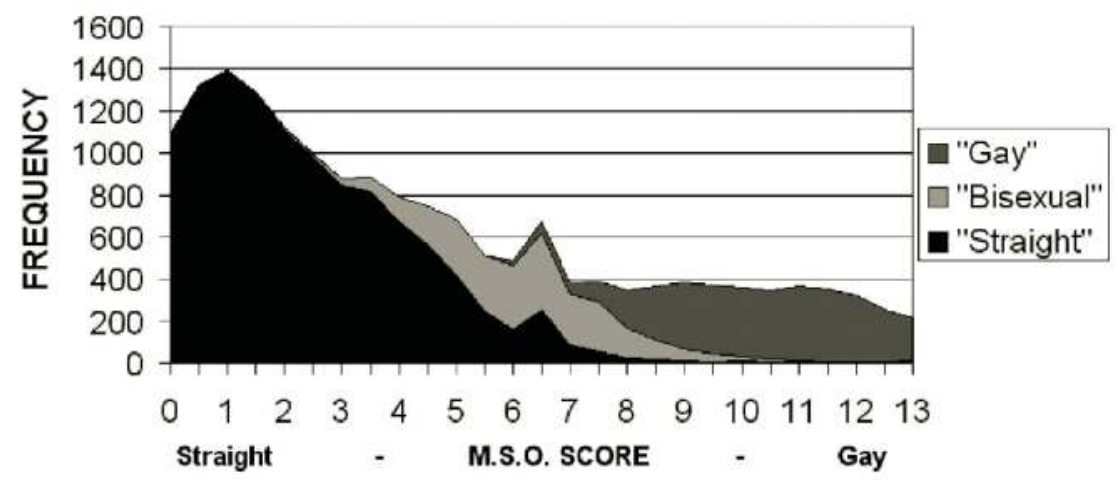

Figure 7.2 Fluid-continuum model of sexual orientation.

Source: Epstein, McKinney, Fox, and Garcia, 2012

single individual may demonstrate both straight and gay tendencies (see Figure 7.2). You can take the Epstein sexuality test and see your own results at http://mysexualorientation.com/.

Discoveries like these make any statistics on sexuality in the United States highly suspect. At any rate, for some time it has been commonly claimed that approximately 10 percent of the population was gay. New information from the Kinsey Institute in 1990 calculated that almost 14 percent of men and 4.25 percent of women admitted to having "extensive" or "more than incidental" homosexual experience, but that is not the same as identifying as a homosexual (McWhirter, Sanders, and Reinisch 1990). However, the American National Health Interview Survey conducted in 1990-91 found that only 2-3 percent of men affirmed that they had had sex with another man at least once, and the National Health and Social Life Survey in 1992 reported that 4.9 percent of men and 4.1 percent of women had had a homosexual experience since age 18. Reports of homosexual desire in the National Health and Social Life Survey suggested that almost twice as many people $(7.7$ percent of men and 7.5 percent of women) had felt the desire for same-sex contact.

Closer to the present, the 2010 National Survey of Sexual Health and Behavior, on the basis of a sample of Americans ages fourteen to ninety-four, estimated that 8 percent of men and 7 percent of women identify as gay, lesbian, or bisexual. A Gallup poll in 2012 asked Americans if they identify as lesbian, gay, bisexual, or transgender and got a 3.4 percent yes rate (although a larger number, 4.4 percent, refused to answer). Women (3.6 percent) were slightly more likely to accept a LGBT identity than men (3.3 percent), and the LGBT self-identification rate dropped dramatically by age: 6.4 percent of 18-29-year-olds identified as LGBT, 3.2 percent of 30-49-yearolds, 2.6 percent of 50-64-year-olds, and 1.9 percent of people over age 65. LGBT self-identification was much higher for lower-income people (5.1 percent for individuals earning less than $\$ 24,000$ and 2.8 percent for those earning more than $\$ 90,000$ ), 
probably indicating the job and wage discrimination against non-heteronormative persons. The differences between regions of the country were relatively small-3.7 percent in the East, 3.6 percent in the West, 3.4 percent in the Midwest, and 3.2 percent in the South (Gates and Newport 2012). The highest rate was recorded in the District of Columbia (10 percent), followed by Hawaii (5.1 percent). The lowest rates were in Tennessee, Mississippi, Montana (2.6 percent each), and North Dakota (1.7 percent).

Not surprisingly, LGBT individuals tend to be much more politically liberal: 45 percent called themselves liberal and 20 percent conservative. Some 44 percent identified as Democrats and only 13 percent as Republicans, and a full 71 percent supported Barack Obama during the 2012 presidential campaign. Finally, there was a race differential in LGBT self-identification: 3.2 percent of white Americans claimed to be gay, lesbian, bisexual, or transgender compared to 4.0 percent of Hispanics and 4.6 percent of African Americans.

It is obviously very difficult to determine exactly how many people of non-heteronormative sexuality reside in the United States, and the very attempt is unfortunately an exercise in the kind of category-construction and identity-imposition that we have seen throughout this chapter. Moreover, the numbers we get depend on what question we ask: having a "gay" or "lesbian" identity is different from having a same-sex sexual encounter, which is different from having same-sex desires or fantasies. At the extreme, the differences between heteronormative and non-heteronormative people are escalated by the differences and even antagonisms between and within the various non-heteronormative sexualities, as we will now examine.

\section{Gay in America}

It is fair to say the male experience has dominated discussions of sexuality in America (and beyond) in a number of ways. One essential element of this male domination is the preoccupation with, and condemnation of, male homosexuality as a violation of "hegemonic masculinity" (see Chapter 6) which is straight, married, and conventionally masculine (as opposed to effeminate). Another key element, as we will soon see, is the centrality of male homosexuality for the study of, and the mobilization of, the non-heteronormative "community." For a long time male homosexuality was taken (and sometimes still is taken) as the norm of non-heterosexuality, by which female homosexuality, bisexuality, and other sexualities were (mis)understood. In a word, male homosexuality functioned something like a begemonic non-heteronormative sexuality in research and activism.

American society has certainly never been terribly welcoming of male homosexuality, although it was often the behavior (commonly conceived as "sodomy") rather than the identity that was proscribed. Even so, numerous historians and other writers have commented on how the "problem of homosexuality" in the 1800s was part of the greater "crisis of masculinity" introduced in the previous chapter. As urban men were seen as losing their frontier toughness and their agrarian self-sufficiency, many Americans fretted about the softening and feminizing of men. One result, according to George Chauncey's major study of gay men in turn-of-the-century New York, was a "cult of muscularity" (1994: 113) and of virility in general. One of the signs of a manly man was overt heterosexuality (which was perhaps all the working man had to show of his diminished masculinity), and homosexual men posed an anxious alternative. 
Wrote Chauncey: "It was as if they had decided that no matter how much their gender comportment might be challenged as unmanly, they were normal men because they were heterosexual" (117).

Despite this anxiety, Chauncey pointed out two facts. First, there was a lively and overt "gay world" in New York City by the early 1900s which "took shape in the streets, cafeterias, saloons, and apartments of New York, and gay men played an integral role in the social life of certain neighborhoods. Fairies drank with sailors and other workingmen at waterfront dives and entertained them at Bowery resorts" (133). Gay men were not only visible in society but mixed freely with straight men in public places. Second, because the issue was effeminate display rather than sexual activity, the masculine man "who responded to his solicitation-no matter how often-was not considered abnormal, a 'homosexual,' so long as he abided by masculine gender conventions"; the emphasis on masculinity instead of sexuality allowed men "to engage in extensive sexual activity with other men without risking stigmatization and the loss of their status as 'normal men'" (13).

This openness to effeminate/homosexual men was not universally shared or permanent. For example, a Dr. Ferdinand Eugene Daniel in 1893 opined that "sexual perversion" in men should be prevented through castration. As late as 1953 Karl Bowman and Bernice Eagle shared the same opinion in their article "The Problem of Homosexuality" in the Journal of Social Hygiene. And the tolerant 1910s and 1920s gave way to the intolerant 1930s and 1940s, with their "pansy craze" (Kimmel 2012: 148 ) and the medicalization and exclusion of homosexuality. In Chauncey's words, "the state built a closet in the 1930s and forced gay people to hide in it" (1994: 9). It is well known that the American Psychiatric Association regarded homosexuality as a mental disorder until 1973.

From that time, male homosexuality took on some of the contours that contemporary Americans associate with it, including its supposedly illicit (sex in secret) and promiscuous nature. To the extent that this stereotype was true, it was largely because society provided no avenue for licit and monogamous male same-sex sexuality or relationship. While there were, of course, men who formed long-term intimate relationships with other men, male same-sex contact was mostly pushed into the shadows. Stephen Murray acknowledged that the gay bar "was the first gay institution, and for most members of the 'pre-liberation generation,' the only one" (1996: 69). Michael Bronski explained that "gay bars were not simply for cruising, but . . . they were community centers, public meeting places, town squares, clotheslines people could hang over to gossip, and bulletin boards. .. . The bar was where you found your information" (1993: 83). In addition, men could meet for more transient and often more anonymous sexual encounters in bath houses, parks, and public restrooms.

Laud Humphreys conducted a famous (and infamous) study of male sexual liaisons in public bathrooms during the late 1960s, which was published as Tearoom Trade: A Study of Homosexual Encounters in Public Places. Posing as a gay man at "tearooms" (the slang term for these restrooms) at public parks, Humphreys acted as a lookout (a "watchqueen") while men conducted their sexual affairs. Writing down their automobile license plate numbers, he interviewed several of these men a year later. His findings confirmed the earlier work of Kinsey and the entire thrust of this chapter, that men who engage in same-sex sexual contact do not necessarily identify as gay nor live a "gay lifestyle." More than half (54 percent) of the men in his survey 
were married and living with their wives. Humphreys concluded that 38 percent of the men were decidedly not homosexual or bisexual; of the other almost twothirds, 24 percent were bisexual and happily married, 24 percent were "closeted" homosexuals and single, and only 14 percent were openly gay and part of the "gay community." In 1990, Frederick Desroches replicated Humphrey's work in Canada, where his sample yielded 58.4 percent married men (and another almost 10 percent separated, divorced, or in common-law marriages), an average age for the whole sample of 41 years, and a very low percentage of individuals (as few as 10 percent) who regarded themselves as gay.

Meanwhile, the legal pressures against male homosexuality were beginning to build to a critical level. By the late 1960s only two states in the US (Illinois and Connecticut) had decriminalized homosexuality, and the police routinely raided gay hangouts and harassed or arrested gay men, sometimes spying on them in bathrooms. In response, the Mattachine Society was one of the first formal organizations to promote gay-or what they called "homophile" or same-love-rights. Central to the organization was Harry Hay, who, along with Rudi Geinreich, Dale Jennings, Bob Hull, and Chuck Rowland, convened the inaugural meeting of the Mattachine Society in Los Angeles, California in 1950. Seeking an "ethical homosexual culture," they advocated political action on behalf of gay men and were soon followed by other institutions, like the Council on Religion and the Homosexual in 1964.

\section{Diversity Fact:}

In 1952, the Congress prohibited gay (and lesbian) foreigners from entering the United States. The exclusionary law was only repealed in 1990.

The turning point in gay rights and gay activism, however, is generally considered to be the Stonewall riot in New York City which broke out on June 29, 1969 and lasted for three days. When police raided the Stonewall Inn that night, as they often did, the gay customers refused to flee and started a rebellion instead. This was a significant moment of self-empowerment, after which the poet Allen Ginsberg was quoted as saying, "You know, the guys there were so beautiful—they've lost that wounded look that fags all had ten years ago" (Carter 2004: 199). Many gay-rights organizations emerged subsequently, including the Gay Liberation Front, Gay Activists Alliance, and the Gay and Lesbian Alliance Against Defamation (GLAAD).

Another turning point for gay men was the appearance of AIDS in the early 1980s. By 1981 enough men in the gay community had contracted odd and rapidly progressing fatal illnesses that physicians and the media began to refer to "gay compromise syndrome" (Murray 1996: 104). For a time it was assumed that homosexuality was a primary cause of AIDS (and that AIDS was a punishment for gay ways), although it was soon discovered that the HIV virus was transmitted through blood and bodily fluid exchanges, as in shared hypodermic needles and blood transfusions. Nevertheless, AIDS devastated the gay community, with most gay men knowing or loving someone who died from the disease. 


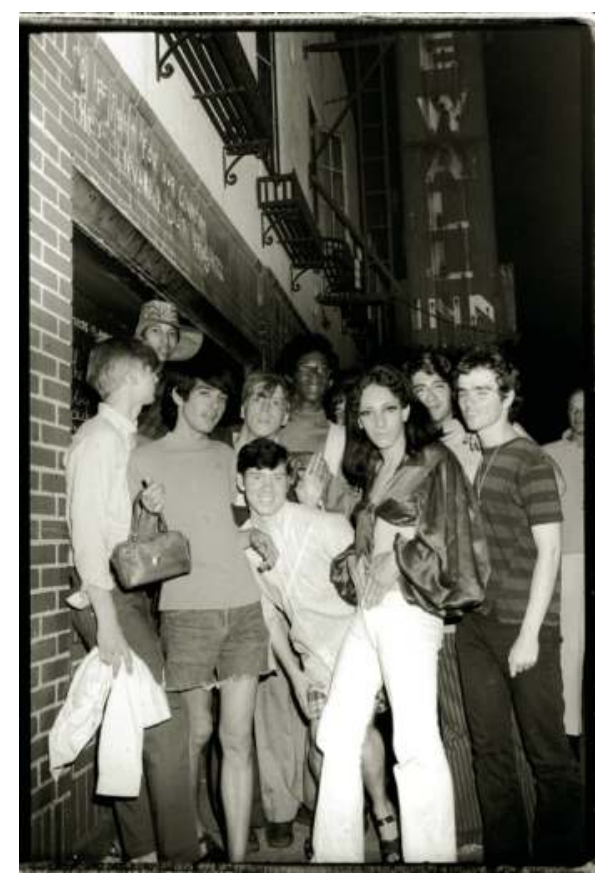

Image 7.2 A group outside the boarded-up Stonewall Inn, 1969.

(Courtesy of Fred W. McDarrah/Getty Images)

In the twenty-first century, despite the lingering stereotypes, homosexual men in the United States are very diverse. Not all are drag queens or wear seatless leather chaps. Not all are flamboyant in their sexuality at all. Many live quiet domestic lives in stable relationships. While there is a documented preoccupation with physical appearance (even "muscularity") among gay men, like all people their tastes vary, including the phenomenon of the "bear," or large, hairy man, that some find attractive.

\section{Lesbian in America}

Women who desire women have had similar and yet quite different experiences in the United States. For one thing, a masculine woman is on balance less troubling to American society than a feminine man (and not all lesbians are masculine anyhow). For another, male and female homosexuals, although tossed together in the same category ("homosexual"), have not always necessarily socialized in the same places or formed a functioning "community." For a third, female homosexuals bear a double burden of social disadvantage—as both homosexuals and women-and have not always found a welcoming home among either group.

The early twentieth century was a time of freedom and experimentation for women as much as (if not more than) for men, heterosexual and homosexual women alike (see Chapter 6). The age of "flappers" also saw explicit lesbian individuals and relationships. And as in the case of men, the 1930s and 1940s were less tolerant, and the 1950s, as mentioned previously, were years of hegemonic models of wife and mother 
for women. Out of this environment grew the first organization for lesbian women, the Daughters of Bilitis, formed by a lesbian couple named Del Martin and Phyllis Lyon in San Francisco, California in 1955 as a social venue for lesbians (not unlike the women of the Greek social group described above). Starting small, chapters sprang up in other major cities within a few years, and the organization even published a magazine called The Ladder, which explained the motivations of the group as public education, participation in research, changes in the law, and self-education for the lesbian woman "to enable her to understand herself and to make her adjustment to society." As those words imply, the message of the Daughters of Bilitis, not unlike the Mattachine Society, was to assimilate to the wider society in outward appearance while maintaining a healthy homosexual identity.

Despite their similarities and common causes, many lesbians viewed the emerging "gay rights" movement as overly male, focusing primarily on masculinity and male sex roles. Critics and activists like Tamsin Wilton complained that the gay movement has been dominated by middle-class white males. Fortunately, not long after the founding of the Daughters of Bilitis, the women's or feminist movement also appeared, and lesbian women felt at least as in need of liberation as other women. Unfortunately, as the first that we will see of what Judith Halberstam (1998) called "border wars" between various sex/gender constituencies, the relationship between feminists and lesbians was not always comfortable. Some mainstream feminists did not want to get involved in the politics of lesbianism (or actually disapproved of it), while some lesbians did not share identity with the middle-class white women who seemed to drive the feminist movement. In their 1970 manifesto "The Woman-Identified Woman," the Radicalesbians claimed for themselves the righteousness of womanhood as a whole: "A lesbian is the rage of all women condensed to the point of explosion." Such radical lesbian feminists might even declare that they were the true feminists,

that lesbianism is political and that women who withhold their sexual and emotional energies from men and share them with women are making a powerful feminist statement. They point out that heterosexual women, being emotionally and sexually dependent on men, can never commit themselves 100 percent to feminism, and that a lesbian-by definition as independent of men as it is possible to be-represents both a challenge to male power and a committed bedrock for the feminist struggle.

(Wilton 1995: 20)

Some went so far as to demonize not only heterosexuality (as women's self-subjugation to men) but also penetrative sex, deeming all sexual penetration as heterosexuality and all heterosexuality as "eroticized inequality" (104). In reaction, according to Tamsin Wilton, it was "not uncommon for non-lesbian feminists to accuse lesbians of oppressing them as heterosexual women" (87).

Within the lesbian community/category there is plenty of diversity too. For example, two recurring models of lesbian identity or performance have been the "butch" and the "femme." Esther Rothblum, a prolific researcher on sexualities, asserts that the terms "butch" (masculine, "mannish" presentation) and "femme" (feminine appearance and behavior) have been in use for more than a century. Yet during the 1970s these roles declined in favor of a "politically correct" androgyny; in this context, "old' culture lesbians who still identified as butch or femme roles were criticized" (2010: 29). In her 2010 study, Rothblum finds that butch and femme still exist and that in general 


\section{Sex and Gender: Beyond the Gender Binary}

butch lesbians do seek a femme partner and vice versa (34). However, not all of the women thought that the terms applied to them, and more than a few "identified as both or in between" (37)—dashing yet one more binary. Indeed, some explicitly "felt that the concepts were too binary and that they themselves were on a continuum, or in between, or that it depended on the situation or the identity of their lover" (39). Less than half of the women in her survey considered the labels important. Rothblum even finds some hostility toward femmes for trying to "pass" as heterosexual women.

Another notable variable in the lesbian experience is the timing and motivation for "coming out" with a lesbian identity. In their summary of lesbian coming-out literature, Morris et al. asserted that there is no absolutely universal progression of stages toward lesbianism but cited Paula Rust's research that girls felt their first same-sex attractions at an average age of 15.4 and first doubted their heterosexuality around age 17; the average age of self-identification as lesbian was 21.7 (1995: 38). They further determined that usually "romantic involvement or thoughts" preceded sexual contact and in fact led to sexual exploration. Specifically, they identified three patterns:

First were those women who described sexual exploration with other girls or women outside of any lesbian context-that is, they did not see themselves (or their partners) as lesbian; some did not even know there was such a thing. Some said that they felt more than they thought their partners did: It was more for them than just "practicing for boys." For a second group of women, sexual exploration coincided with their first labeling of themselves as lesbian. And a third group conceived of themselves as lesbians before having any sexual involvement with other women.

One other variable on which lesbian women differed (and also differed from gay men) was parenthood and the timing of their sexual self-identification. Using large-scale data from the 1994-5 Lesbian Wellness Survey, Jessica Morris, Kimberly Balsam, and Esther Rothblum discovered that lesbian (and bisexual) women often married men and had children before coming out and that this delayed their coming out. To be precise, more than 90 percent of women who had children before coming out had previously been married to a man, compared with 50 percent of women who had children after coming out and 12.6 percent of childless women. Married women with children came out, on average, five years later than their counterparts (2002: 147). Also, married women with children reported relatively fewer female partners, not surprising because of the years they spent with men. Interestingly, Hispanic women were more likely to have been married with children before avowing a lesbian identity, and African American women were the least likely to have been married (150). Finally, it is worth noting once more that these lesbian women manifested a less-than-perfectly lesbian identity: on a scale of 0 to 100 , with 0 indicating "exclusively lesbian," the average score was 13, with 26 percent of the women scoring between 21 and 50 and 3 percent actually over 50 (that is, more heterosexual than homosexual).

\section{Gay/Lesbian Couples and Families}

At least as interesting and important as the individual characteristics of gay men and lesbian women is the nature of their relationships. Less work has been done on this 
question, but it is a crucial question not only because homosexuals form relationships but because there is so much attention in the United States about the benefits and harms of gay/lesbian marriage and parenthood.

According to the American Community Survey based on data from 2005 to 2011, there were 650,000 same-sex couples, the slim majority of them (51 percent) female. (Of course, there were undoubtedly more same-sex individuals in relationships but not officially recognized as "couples.") One-fifth of these couples were raising children under the age of 18 (sometimes from previous heterosexual relationships). On average, same-sex couples were younger than opposite-sex couples by five years. By 2011 , individuals in same-sex relationships were more likely to have a college degree (46 percent) than individuals in opposite-sex couples (32 percent). By 2011, men in same-sex couples earned almost as much money as heterosexual men, while women in same-sex couples earned substantially more than their heterosexually-married counterparts.

What is really revealing is the dynamics of same-sex relationships and households. For example, according to the 2010 Census, same-sex couples were much more likely to be interracial than married heterosexual couples (it is important to note that the Census regarded all same-sex couples as "unmarried" whether they were married or not). In same-sex households, 14.5 percent were estimated to include an interracial couple, whereas only 6.9 percent of married heterosexual couples were interracial; interestingly, unmarried heterosexual couples were almost equally likely to be interracial as gay couples. If we include Hispanic origin to race, then 20.6 percent of gay partners were different in race or Hispanic origin, while only 9.5 percent of married straight couples differed; unmarried straight couples (18.3 percent) were closer to the same-sex pattern.

Social scientists have studied various aspects of the interactions between gay and lesbian partners and compared those interactions to straight partners. Gotta et al. (2011) measured couple behavior in seven areas-traditionally "feminine" housework, traditionally "masculine" housework, finances, support, communication, requesting/ refusing sex, and decision-making_and noticed differences between types of relationships as well as over time. Gay men and lesbians were more likely to divide so-called "feminine" housework equally than their straight peers (although all types of couples shared "women's" work more equally in 2000 than in 1975). Gays and lesbians also shared conventionally “men's” housework more equally. Gays and lesbians communicated more equally with their partners than straight couples did, and gay men and lesbians were more equally supportive of their relationship than heterosexuals. Finally, gays and lesbians divided their household finances more equally than straight partners.

As mentioned above, the stereotype of homosexual individuals portrays them as promiscuous and incapable of stable relationships. Gabrielle Gotta et al., in contrast, find that gay and lesbian couples also aspire to monogamy and have become less likely to have sex outside the relationship than twenty-five years ago. That being said, gay men especially often take a more liberal and unconventional attitude toward sex outside the relationship than either lesbians or straight partners. Judith Stacey (2011) comments that gay men are more likely to engage in and to tolerate "cruising" (seeking sex with another man) or friend-sex relations by their partners as well as to enter into polyamorous (multiple partner) relationships. In the case of lesbians, it is well 
documented that they engage in sex less frequently than straight married women and that sexual activity diminishes over time, something which has been dubbed "lesbian bed death." Solomon, Rothblum, and Balsam interpret this phenomenon to mean that lesbians "may spend more time on romance than on genital sex" and may engage in activities that are not defined in American culture as "real sex" (2005: 572).

Finally, John Gottman et al. studied how gay, lesbian, and heterosexual couples handled conflict, concluding that gay/lesbians in conflict were less belligerent, less domineering, less tense and afraid, and less whining than their straight counterparts, also displaying more affection, humor, and joy in the midst of conflict. The authors reasoned that "gay and lesbian relationships may operate on different principles than heterosexual relationships with respect to power and affect" (2003: 87). This leads to a very profound implication, made by a number of researchers: straight couples, even the modern and liberal ones, tend to enact relatively traditional gender roles and norms in their relationships in regard to chores, money, arguing, and power in general. However, because there are no traditional roles/norms for same-sex couples (and perhaps because of their individual unconventional natures), gay and lesbian partners not only are able to negotiate the dynamics of their relationship to their mutual satisfaction but are required to do so. In a cover article for The Atlantic, Liza Mundy goes so far as to suggest that "by providing a new model of how two people can live together equitably, same-sex marriage could help haul matrimony more fully into the 21st century" for straight folks too (2013: 58).

This applies to parenting as well, which is a particularly contentious issue in the political debates about homosexuality and same-sex marriage. As in other dimensions of their relationships, gay and lesbian couples tend to share child care and parenting duties more equally than straight couples (Farr and Patterson 2013). And as far as the impact on the children is concerned, there is no evidence that children raised in same-sex partner households turn out any worse than children with straight parents. Charlotte Patterson's research is typical of our knowledge of children with same-sex parents:

There were no significant differences between teenagers living with same-sex parents and those living with other-sex parents on self-reported assessments of psychological well-being, such as self-esteem and anxiety; measures of school outcomes, such as grade point averages and trouble in school; or measures of family relationships, such as parental warmth and care from adults and peers.... The only statistically reliable difference between the two groups-that those with same-sex parents felt a greater sense of connection to people at school-favored the youngsters living with same-sex couples.

(2006: 242)

\section{Bisexual in America}

Compared to homosexuality, bisexuality emerged comparatively late as a research topic and as a social identity. In one of the classics in the field, Bisexuality and the Challenge to Lesbian Politics, Paula Rust (1995) explained that bisexuality was basically invisible both in the mainstream and in the gay/lesbian media and culture, often dismissed by both as homosexuals temporarily engaging in heterosexual relations or as a kind of false consciousness for gays and lesbians who did not want to accept their homosexuality. In short, as Steven Angelides put it in his history of bisexuality, long 


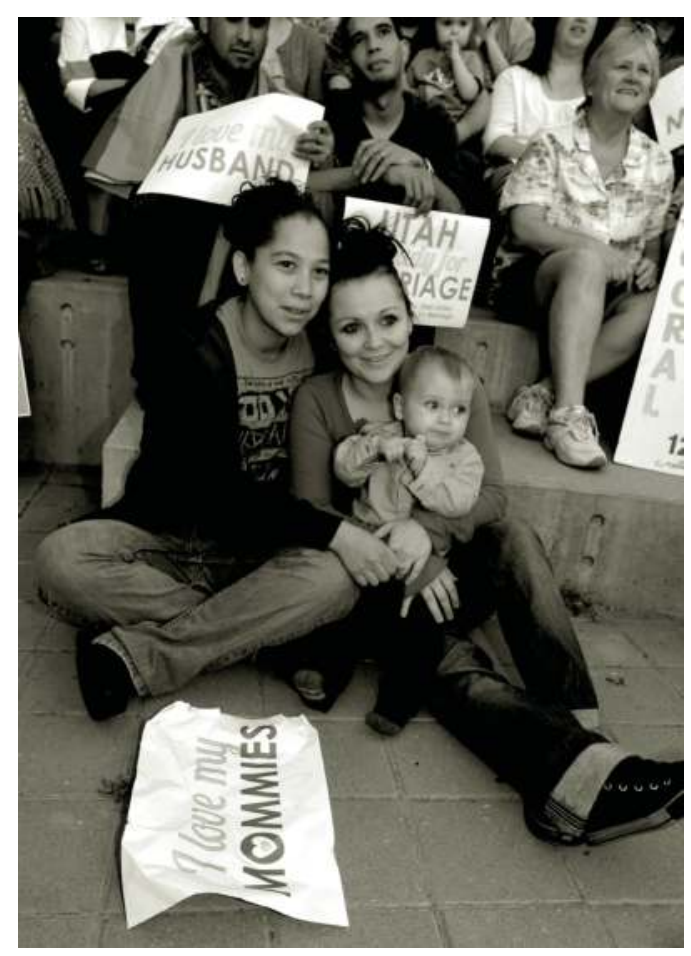

Image 7.3 Same-sex parents, Utah.

(Courtesy of George Frey/Getty Images)

after homosexuality had been declared a sexual species and "mapped, measured, and monitored" (2001: 1), bisexuality was still ignored and actively doubted. On the other hand, as mentioned above, Marjorie Garber used bisexuality to question the reality of heterosexuality and homosexuality.

Nevertheless, it is all too clear that not all individuals fall, during their entire lives, neatly into the hetero/homosexual categories, and as early as 1976 Philip Blumstein and Pepper Schwartz offered a pair of articles on the male and female bisexual. Launching from the earlier discoveries of Kinsey and Humphreys (see above) on the blurry lines between sexual identities and their lack of continuity with sexual activities, they identified a set of men who "were firmly committed to a bisexual identity even though their recent erotic histories (or in some cases their entire erotic histories) were almost exclusively homosexual or heterosexual" (1976a: 343). Some of the men felt that the label "bisexual" clarified their (sometimes unexpressed) sexual feelings or desires, while others believed that one or a few homosexual encounters in a heterosexual life made them bisexual. Significantly, Blumstein and Schwartz found "great readiness to disbelieve and denigrate a person's assertion of being bisexual" among gay men (347), partly as a political statement (that bisexuality threatened gay liberation) and partly as a rejection of a non-binary sexuality. A man who avowed bisexuality, had taken homosexual lovers, and who was or had been married had the "credentials" 


\section{Sex and Gender: Beyond the Gender Binary}

to be a bisexual. While the researchers described heterosexual men with homosexual experiences and homosexual men with heterosexual experiences, they recognized a set of men who "had more than simply sexual experience with both genders," who had substantial simultaneous relationships with men and women, and/or who engaged in mixed-gender group sex. They concluded that men "were more likely to maintain an uninterrupted bisexual self-definition once the label was adopted than were female bisexuals" (1976a: 351).

The picture they painted of bisexual women was somewhat different. Compared to men, homosexual behavior among supposedly heterosexual women was "discussed in terms of responses to different kinds of situational exigencies and the rationalizations used to deal with the experience while insulating the heterosexual self-identification" (1976b: 171). Discussing the same-sex encounters of supposedly straight women and the heterosexual encounters of supposed lesbians, they then analyzed self-identified bisexual women, some of whom declared the gender of their partner to be irrelevant (even that a monosexual preference was sexist) or who claimed that they had different "needs" that could only be met by male and female lovers. Many women described the role of an early homosocial/sexual relationship, with "a gradual transformation of a close friendship (with a girlfriend, a college roommate, etc.) through ever increasing levels of intimacy to a final level of overt sexuality and sometimes durable commitment" (174). Others, of course, "discovered" their bisexuality later in life, commonly after a heterosexual marriage. More than a few were introduced to bisexuality during three-way or group-sex encounters. As with the men, not all of the self-identified female bisexuals had much or any same-sex experience, and also as with the men, bisexual women "provoked a great deal of antipathy from the lesbian community because of what was seen as their 'false consciousness' and unwillingness to suffer the stigma attached to the term lesbian" (177).

Thus, bisexuals in the United States are in a particularly awkward position, their sexuality not only stigmatized and actually often discounted in what Mary Bradford (2004) has called a sexually "dichotomous culture." She claims that most people who eventually identify as bisexual go through a period of denying one or the other of their sexual attractions due to "the lack of models and to derogatory associations with the term 'bisexual'” (2004: 13). She quotes one woman who explained, "We really had no words for that experience or that concept." Worse, as we have already seen, there is what has been called biphobia in both the straight and the gay/lesbian world. One of Bradford's interviewees said it best: "Bi's are too straight for the gay community and they're too queer for the straight community" (15). This is one reason why bisexuals often feel driven to tell their stories and to make themselves visible, as in Robyn Ochs' edited collection Getting Bi: Voices of Bisexuals around the World (2005).

\section{Diversity Fact:}

American bisexuals have their own flag, designed by Michael Page in 1998. It features a wide pink stripe at the top to symbolize homosexuality, a wide blue stripe at the bottom to represent heterosexuality, and a narrow purple stripe inbetween to stand for those who combine the two colors and sexualities. 


\section{Trans in America}

If anyone has a hard time finding an established place in the American society and gender system, it is "trans" individuals, who occupy that wide territory of transvestite, transsexual, and transgender. Indeed, many trans people dispute the very notion that there are established "places" or categories or norms of gender, and many are quite happy with their gender exceptionality.

There have probably always been individuals who bent normative models of gender, and some societies have had names and places for such people. In American and Western systems, there has been less space and less tolerance for such exceptions, and an array of sexualities, identities, and displays have been tossed into classifications like "homosexual" or "invert" or "sexual deviant." As already told, terms like "transsexual" were invented only in the early twentieth century, along with medical operations that could transform a person into "the other" sex (which was often the sex that the person "really was"). At the same time, the psychologist Carl G. Jung proposed that every human being contained male (animus) and female (anima) psychological components. Literature like Virginia Woolf's 1928 novel Orlando: A Biography and Marlene Dietrich's 1930 movie Morocco also depicted gender-crossing characters.

Medical science continued to collapse transvestism and transsexualism, as in Dr. Felix Abraham's 1931 Genital Reassignment of Two Male Transvestites, but, of course, not all transvestites think they are or want to become "the other" sex. The world of transvestism is itself incredibly varied and surprisingly institutionalized, as described by David Valentine (see Box 7.2).

\section{Box 7.2 The Transvestite "Scenes" of New York}

An imagined community like LGBT or even "transgender" is really a loose assortment of gendered "scenes," according to David Valentine. Riding his bicycle between locations in New York City, he encounters three quite unique scenes in the transvestite sub-community of the transgender community. The Clubhouse, where the transgendered come to dance and compete, has its own (if not entirely consistent or mutually exclusive) categorization of people, for the purposes of dance and other (e.g. vogue and walk) contests. These formal and written categories include fem queen (including "runway diva," "performance," and "glamour"), butch (including "butch vogue," "butch face," and "butch street wear"), butch queen (including "butch queen bazaar," "butch queen vogue femme," and "butch queen runway"), butch queen up in drag, man, and woman. Further, some categories are judged on their "realness," but "everyone at the hall ... refer [sic] to themselves and each other as 'gay'" (2007: 80). Most disorienting, sometimes the attendees are not sure or consistent about assigning each other to their categories. The second location is an event for Crossdressers International (www.cdinyc.org), where the mostly male guests are dressed as women (in drag) but for very different reasons: "For them, cross-dressing is erotic [that is, it is sexual] and/or an expression of an inner self, not an opportunity to engage in explicit theatrical performance" (88). Moreover, the guests 


\section{(continued)}

tend to insist that they are not gay, even when they are attracted to each other or to non-cross-dressing men; they "do not experience that attraction as homosexuality and resist attempts to use that category to describe them" (88). The third location is a formal ball, the "Night of a Thousand Gowns," an upscale fundraiser hosted by the Imperial Court, "an organization whose membership is made up of mainly white self-identified gay men who do performative drag" (90). For these transvestites, dressing in women's clothing "is considered to be in the realm of art and performance and to have no implications for members' gender identity or sexual practice/desire/identity" (90).

Transsexualism came most clearly to American attention with the 1952 sex change of MTF transsexual Christine Jorgensen (born George William Jorgensen). In 1960 Transvestia magazine appeared, followed by the foundation of an organization called The Society for the Second Self, a support group for transgender individuals. In 1966 Harry Benjamin published The Transsexual Phenomenon, which was also the year of an event overshadowed by the later Stonewall riot. At the Compton's Cafeteria riot in San Francisco in 1966, transgender customers, male and female, stood up against police efforts to arrest them, a tale told in the 2005 documentary Screaming Queens: The Riot at Compton's Cafeteria. One immediate effect of this event was the formation of the National Transsexual Counseling Unit.

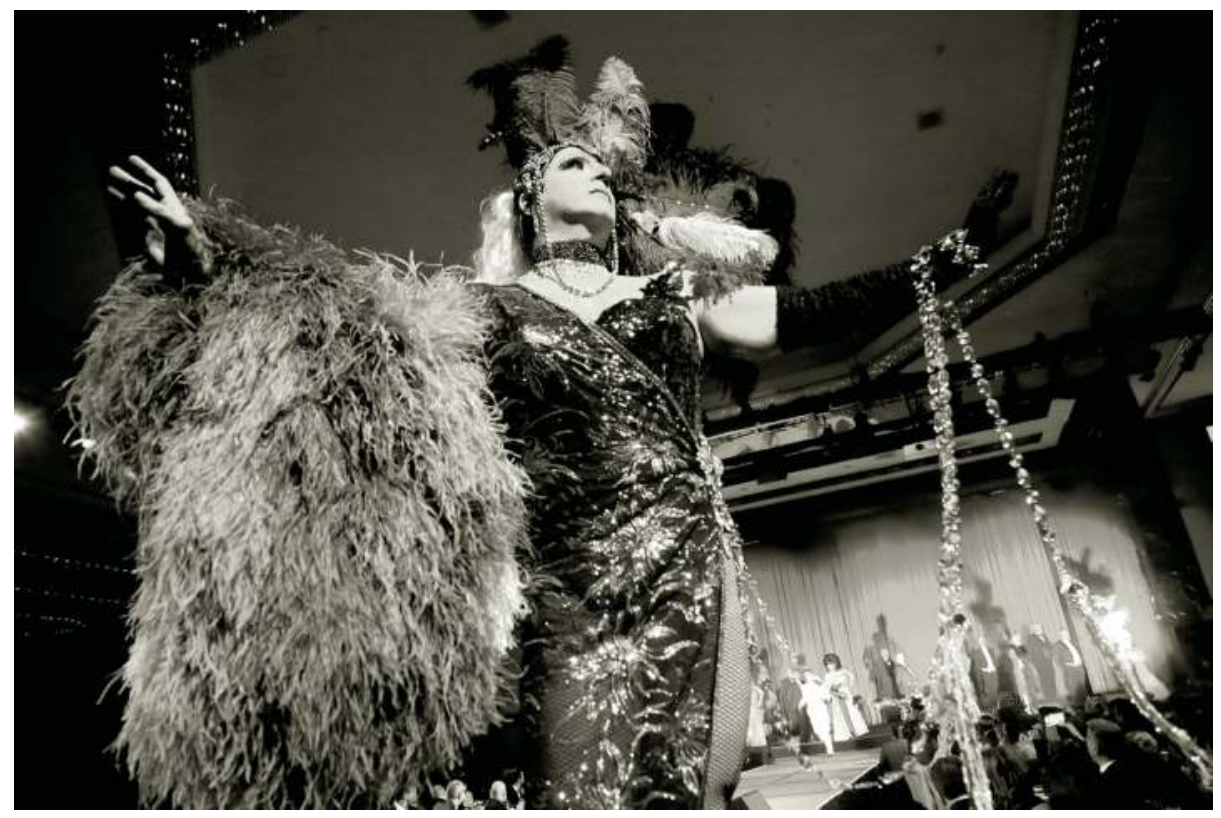

Image 7.4 Night of a Thousand Gowns, 2013.

(Courtesy of Astrid Stawiarz/Getty Images) 
However, symptomatic of the gender "border wars" alluded to previously, the gay/ lesbian movement often broke with the trans movement, as did the women's movement. A dramatic example of the mutually hostile and exclusionary thinking was Janice Raymond's 1979 The Transsexual Empire: The Making of a She-Male, which noted that transsexualism is "largely a male phenomenon. Female-to-constructed-male transsexuals are relatively rare" (1994: xiii). Raymond thus argued that sex reassignment was an exercise in men's relative freedom compared to women and a result of the lack of a men's liberation movement. Transsexual surgery, she maintained, "is the invention of men initially developed for men," and "it should not be surprising that men, who have literally and figuratively constructed women for centuries, are now 'perfecting' the man-made women out of their own flesh" (xiv-xv). It is surprising, nonetheless, that men should want to be women in a chauvinistic society, especially when men are not in general attracted to transwomen.

In short, trans Americans have faced arguments and dismissals about their identities from straight men, feminist women, and gays and lesbians. Fortunately a few researchers have studied trans people objectively and allowed them to speak for themselves. Rhonda Factor and Esther Rothblum, for example, sampled 166 transgender adults (including MTFs, FTMs, and genderqueers) and got some interesting results. All three trans groups were more highly educated than the general population. MTFs, they discovered, identified as different from their birth gender earlier than FTMs. Of the MTFs, 88 percent were on permanent hormone treatment, compared to 77 percent of FTMs and 34 percent of genderqueers. Around one-quarter of MTFs had undergone genital surgery but none of the FTMs (surgically constructing a male body out of a female remains a more complicated proposition than constructing a female body out of a male). And, contrary to popular opinion, 14 percent of MTFs and almost one-third of FTMs did not intend to do genital reassignment. But a change of gender identity did usually include a change of name: all of the MTFs, and almost all of the FTMs (92 percent) and genderqueers (83 percent), preferred a name other than the one they were given at birth. Contrary to Raymond's position, genderqueers were actually much more likely to be assigned female ( 70 percent) at birth than male (30 percent), and a small number ( 6 percent) of MTFs were actually born intersex rather than biologically male. In the final analysis, "More than one-third of MTFs and FTMs described their gender identity as fluid" (2008: 245).

Andrew Forshee looked specifically at transgender men (biological women reassigned to male), 93 percent from the US and 7 percent from Canada. They too were highly educated, almost half with some college education and more than 10 percent with graduate degrees. The largest single group simply called themselves "male," while 12 percent adopted the designation "FTM transsexual," 18 percent "FTM," and 9 percent genderqueer. 3 percent continued to call themselves female (2008: 228). They tended to be young: the largest number were between 18 and 25, and numbers steadily declined with age. Most were taking testosterone, but less than half had undergone a mastectomy (to remove their breasts) or a hysterectomy (to remove their uterus).

Naturally, it is not easy to be trans in America, where not only the gender categories but the attitudes, institutions and spaces, and laws are not kind to individuals of nonnormative gender. Arnold Grossman and Anthony D'augelli interviewed transgender youths who described a pattern of negative reactions to their gender and "confusion between their gender identity and sexual orientation” (2006: 111). For instance, while 


\section{Sex and Gender: Beyond the Gender Binary}

83 percent of the subjects were biological males, only 54 percent indicated that their preferred gender was male-to-female. Half of the biological males identified as gay, 35 percent as heterosexual, and 15 percent as unsure; of the females, 75 percent considered themselves bisexual and the rest lesbian. And the four kinds of problems they claimed to face in American society were "the lack of safe environments, poor access to physical health services, inadequate resources to address their mental health concerns, and a lack of continuity of caregiving by their families and communities" (112). One of these problematic spaces, as established at the beginning of this chapter, is the bathroom, as well as the locker room. At least, thankfully, as of 2012 "transgender" is no longer classified as a mental disorder by the American Psychiatric Association and its Diagnostic and Statistical Manual (DMS-5). However, people who are distressed by their gender identity can still be diagnosed as suffering "gender dysphoria."

\section{Conclusion}

As detailed and complicated as this chapter has been, it hardly exhausts the diversity of sexualities, sexual identities, sexual practices, and sexed/gendered displays and performances in the United States. This is partly because sexuality is itself a complex and multifaceted composite of body, desire, behavior, pleasure, and love. We have not even addressed polyamory (loving two or more people at the same time), partner-swapping or "swinging," group sex, pornography, or prostitution, not to mention celibacy and asexuality. The sexual activity of human beings is truly mind-bogglingly diverse.

What we have seen is that sex, gender, and sexuality are independent variables and that each is more than binary. These category-systems are also not "categorial" but continuous: there is no way to divide people into mutually exclusive groups or camps of "male" and "female" or "heterosexual" and "homosexual." Sexual identity is not digital nor is it stable, no matter how much society tries to declare, institutionalize, and legislate otherwise.

In fact, more than any other realm of diversity, sex/gender not only eludes but explodes our attempts to categorize. Our categories and beliefs of sex/gender dissolve in the face of the actual thoughts and actions of individuals, and the society we have built on the foundation of our sex/gender categories and beliefs is shaken by our knowledge of our own sex/gender diversity. 


\section{Language}

In 2006 the Voting Rights Act of 1965 was up for reauthorization, and people cannot vote if the ballot is in a language that they do not understand. For this reason, in 1975 a section (Section 203) had been added to the Act requiring multilingual ballots for nonEnglish speakers. The re-authorization, especially Section 203, was controversial and hotly debated, and while the debate on the floor of the US Congress was conducted in English, the two sides spoke interestingly different versions of English. Those who were opposed to the measure tended to repeat words like "Mexico," "foreign," "Hispanic," "immigrant," and "assimilation," while those who supported the measure preferred to use words like "citizens," "voters," "discrimination," "participation," and of course "rights" (Subtirelu 2013: 47). According to Subtirelu, each side was using a strategic version of their common language that conveyed attitudes toward language and its relation to American identity. The anti-Section 203 lawmakers presented English "as a neutral element that has some natural connection to the United States"; further, language (in this case, English) was seen as crucial "in uniting a collectivized image of the United States (often vaguely represented with we and our)" (49). English came across then as a necessary part of "civic nationalism": a person who does not speak English is excluded from full membership in the nation. The pro-Section 203 advocates to the contrary used "a discourse of inclusion that represents: (1) non-English speakers as having legitimate claims to the right to vote; and (2) S203 as a means of achieving the desirable purposes of promoting democracy and combating discrimination" (55). Non-English speakers too were voters and citizens, and English was not part of the definition of the American nation. In the end, Section 203 was re-enacted for another twenty-five years.

How can and should a society conduct its political and civil affairs when the population does not speak a single common language? Is it necessary to share a single common language in order to be a unified "nation"? And what does it mean when we notice, not only that people speak different languages in America, but that people deploy different versions and styles (like word choices) of English depending on their circumstances, their status, and their political agenda?

Language is a human universal, yet languages are social and vastly diverse. While language depends on evolved physical (anatomical and neural) traits, speaking any particular language is an effect of living in a particular society. 


\section{Diversity Fact:}

There are an estimated six thousand languages spoken in the world today. Many of these languages are seriously endangered, with only a few living speakers.

Although people tend to associate specific languages with specific societies, it is not quite true that the borders of a language correspond to the borders of a society, nation, or country. For example, while English is the predominant language of the United States, English is spoken neither by all Americans nor by only Americans. Obviously, English did not originate in the United States or in the Western hemisphere; it was transported there by migrants from England. And it was not transported exclusively to the United States; Canada, Australia, New Zealand, and many other British colonies received large numbers of English-speakers or administrative institutions in English (or both). As a result, at least forty-four countries recognized English as either the or an official language as of 2001, including African states such as Botswana, Ghana, Kenya, and South Africa, Asian states such as Sri Lanka, India, and the Philippines, and Caribbean states such as Barbados, Jamaica, and Trinidad and Tobago (Bhatt 2001). More, each of these countries potentially speaks its own variation of English, leading to what linguists have come to call "world Englishes": "There is now a growing consensus among scholars that there is not one English language anymore: rather there are many," with different "sociolinguistic histories, multicultural identities, multiple norms of use and acquisition, and distinct contexts of function" (Bhatt 2001: 527).

Just as a language may not be restricted to one society, a society may not be restricted to one language. Some countries, like Switzerland or Canada, are officially bilingual or multilingual. The United States, which is often touted as monolingual (in that English is the overwhelmingly dominant language and that most Americans speak only one language), is, of course, not a society that speaks a single language, and Terrence Wiley argued that the label "monolingual" is often misleading in any case. Instead, even the most monolingual society includes remarkable linguistic diversity, related to many social variables, and "persistence of the myth of monolingualism reflects the dominant relationship of one language over others. It is also perpetuated by attitudes toward dialect and register (i.e., the appropriate level of discourse), whereby one variety of language, the school-taught standard, is seen as being inherently superior to other varieties" (Wiley 1996: 22).

Finally, the diversity of American language hardly ends with the recognition that English does not hold a monopoly. In addition to variation between languages, there is extensive variation within any language, including English. In line with Wiley's observation, there are differences in American English pronunciation, vocabulary, and grammar, whether those differences are between regions, races, classes, genders, education levels, occupations, and so forth. Individuals even speak different versions of their language depending on what situation they are in or who they are talking to.

In short, there are many issues to consider when discussing American language diversity, far more than simply English versus Spanish. In a society as large and complex as the United States, languages inhabit what Bonnie Urciuoli (1995) has wisely called a "linguistic ecology," where, like different living beings in an ecosystem, 
different languages and linguistic forms comprise a dynamic system of practices and identities that interact, interpenetrate, and change over time.

As a note, in this chapter, if only due to lack of space, we will not be dealing with written language or literacy, which is an important subject in its own right. We will also not deal with "body language" or other forms of non-verbal communication, which are every bit as cultural and diverse as verbal language.

\section{Understanding the Diversity of Language}

Like all of the other subjects of this book, language is a category-system, such that people are classified as "English speakers" or "Spanish speakers," etc. And just as many individuals are multiracial, many individuals are multilingual, although they may be more proficient in one language than another or feel stronger attachment to one language than another. More like religion than perhaps any other categorysystem, people may alter their language by "converting to" or learning another language; indeed, non-English-speaking immigrants have customarily been encouraged and expected to convert to English and generally have done so.

However, language is unlike the other category-systems so far examined in this book in being a "nested system." A nested system is one in which several levels of diversity operate at the same time, the lower levels organized into next-level forms and practices, and those next-level forms organized into yet higher forms. Each level has its particular alternatives and variations and can be combined with alternatives and variations at higher levels. This is a perfect example of the "composite" nature of culture introduced previously. In the case of language, the lowest level consists of sounds, the next level of words and other "meaningful" utterances, a third level of orderly combinations of words (what we typically call "sentences"), and the highest level of socially appropriate speech performances-that is, saying the right thing to the right person in the right circumstances.

\section{The Building Blocks of Language}

A language is not a monolithic thing but a very complex and loose system of multi-level skills and abilities. As just mentioned, the most basic level of linguistic competence is sound, and the description and classification of speech sounds is phonology. From among all of the sounds that humans can make with their vocal tract, any particular language employs some and not others in its phonetic system. For example, English uses many sounds that other languages do not, such as th (actually, there are two different th sounds in English, as in "though" and "through"). French does not use th, and French-speakers tend to find it difficult to enunciate the sound. English also distinguishes between $r$ and $l$ in a way that Japanese does not, often making it hard for Japanese-speakers to pronounce (and sometimes spell) English words with those sounds. At the same time, English lacks sounds that occur in other languages, like the "click" sounds of some southern African languages or the rumbled $r$ of French as in words like roi (French for "king," which tends to get pronounced by English-speakers as wa). Most American English-speakers do not "roll" their $r$ and doing so does not change the meaning of a word, but rolling an $r$ in Spanish is common and elegant. 
Languages also vary in how they use and combine their sounds. English-speakers can make the sound $n g$ but only in the middle or at the end of words (as in "singer" or "sing”); no English words use $n g$ as an initial sound. Some Warlpiri words do, though, like ngapa (water), which most English-speakers cannot pronounce correctly (try saying "sing-apa," then say it without the "si"). English also permits "consonant clusters" of two or three consonants, like str, which is relatively rare across languages. Hawaiian and Tahitian require every consonant to be followed by a vowel, or vowels can occur alone, sometimes several in a row.

When speakers of one language use their sound system in speaking another language, we recognize an "accent." Accents occur because speaking a language is a physical skill, involving learned habits of moving the tongue, lips, and other vocal parts. When a person shifts to a different language, it is often a struggle to unlearn those habits and adopt the habits of the second language. But, of course, pronunciations vary even within a language, resulting in regional or national accents. Several vowels are enunciated differently in American than in Australian English: the $i$ of American English (as in "ripe") gets enunciated as $o i$ in Australian (sounding like "roip"), and the $a$ of American English (as in "tape") is spoken as $i$ in Australian (sounding like "tipe"). Hence, the Australian greeting "Good day" sounds like g'die to Americans. As we will see, even within the United States, the sound practices of English vary according to region, race, class, ethnicity, etc.

Whichever sounds a language includes and whatever its combination rules, all languages create bundles of sounds to make meaningful (that is, possessing a dictionarytype definition) words. The study of how a language builds words and other meaningful sound-combinations is known as morphology (from the Greek morph for "shape" or "form) or semantics (from the Greek semasia for "meaning"). This is the question of the vocabulary of a language, how speakers make and modify words. In English, the most fundamental rule is to start with a word root (often derived from Greek or Latin) and to add suffixes and prefixes to create new meanings (e.g. "happy" + "un-" + "-ness" = "unhappiness"). A single sound like $-s$ can change meaning, from singular to plural. German is notorious for its capacity to build long words by the process of agglutinization, attaching words to words. Arabic starts with three-consonant roots or radicals and varies them to arrive at a set of related meanings; for instance, the root $k-t-b$ referring to marking or writing yields katib (writer), kutub (books), kitaba (the act of writing), istiktab (dictation), and so forth.

All languages evolve, and English has a special facility for inventing new words, by the assembly of new roots and prefixes/suffixes, like "sociology" (from society + -ology) or "psychology" (from the Greek psyche for soul or breath). English can even spawn false roots and prefixes/suffixes, resulting in portmanteau words like "shopaholic" or "telethon" (-obolic is not a suffix that means "addicted to," nor is -thon, as in "marathon," one that means "long”). Additionally, no language's lexicon or list of words is closed, but English is especially open to borrowing from other languages. Many English words, including "coffee," "lemon," and "saffron," originate from Arabic, as do all sorts of words that start with al such as "alchemy," "alcohol," "algebra," and "algorithm" (the Arab world was far ahead of the West in math and science and added many words to the European math/science vocabulary). American English also likes to make acronyms, such as the very term "USA" or others like IRS or UN. 
But the vocabulary of a language is not the key issue of semantics. Much more significant are issues of "core vocabulary" and "semantic range." The core vocabulary of a language consists of the words that are used most commonly in a language and/ or which have the most salience for speakers. A language's core vocabulary says a lot about what is important to that society, and in American English, some of the core words would include "self," "change," "success," and, as seen in the opening vignette, "rights." The semantic range of a word refers to all of the meanings covered by the particular word. A good example is the English word "to know," which covers three quite distinct phenomena-to know a fact, to be acquainted with a person, and to possess a skill like riding a bicycle. The crucial point is that not all languages divide up their semantic ranges in the same way: in Spanish there are two words meaning "to know" (saber and conocer) depending on whether one "knows" a fact or a person. Because of this important issue of semantic range, translation between languages is often complicated and involves losing or adding meanings in the process. Finally, because word choices matter so intensely, as in the case of the Voting Rights Act debate, we should think of words are not merely names for things ("citizens" versus "immigrants") but as assessments about things. It is no exaggeration to say that words are mini-arguments, deployed to win discussions and influence people's thinking. Some words are particularly powerful (I call them "power words") because they can deliver a knock-out blow to the other person's ideas-or the other person him/herself. In English, words like "socialist" or "terrorist" or "Nazi" are not meant to be descriptive but are meant to be destructive. If you can paste such a term on another person, you have discredited their claims and actions and often discredited them as a person.

Words are further combined into utterances or "sentences" by rules of grammar or syntax. In English, the basic rule for making intelligible sentences is word order, with subject first, then verb, then object. Other languages depend on different word orders-or do not depend on word order at all. Much more important, again, than the nuts and bolts of grammar are the kinds of information that can be or must be encoded into a sentence, depending on the language. For instance, English pronouns demand that the speaker specify gender ("he/him/his," "she/her/hers"). French and Spanish, by contrast, require that every noun is given a gender, and adjectives and numbers must match the gender of the noun. Russian nouns take six different "case" forms based on their function in a sentence (subject, direct object, possessive, etc.); English nouns perform case functions but do not have case-specific forms. Languages also vary in the kinds of information conveyed in their verb "tenses": English speakers tend to think in terms of past/present/future, but the Native American language Shoshone includes tenses for actions that continue over time, for actions that occur repeatedly, for actions that result from other actions, and for actions that occurred in the past but the effects of which are felt in the present.

\section{Diversity and Change in Language}

As we have seen, languages vary widely in their sounds, their words, and their sentences. Languages also are not static but continually change, emerge, and disappear. English itself is a relatively new language, arising from a mixture of Greek and Latin, Germanic, Arabic, Celtic, and other sources.

Throughout history, but particularly in recent centuries, with the rise in international travel and colonialism, languages have come into contact with one another 
and produced new language variations. One of the first effects of language contact is usually a pidgin, which is a hybrid language, ordinarily with a reduced vocabulary and simplified grammar. Used to communicate between linguistic groups, a pidgin is not considered to be the first or main language of either group. However, when a new or hybrid language achieves a certain level of sophistication, and when it becomes the first or primary language of a group, we call it a creole. An example of an English-based creole is tok pisin ("talk pidgin") in Papua New Guinea, which is a widely-spoken and recognized official language of the country.

Socially significant variations can also be found within a language, as in the case of diglossia, or the coexistence of two forms of the same language in a society. For example, Arabic speakers may be fluent in or at least familiar with classical Arabic (the language of the Qur'an) and also in colloquial or vernacular Arabic. A vernacular form of language is one that ordinary speakers use on a day-to-day basis. One of the more controversial questions in American English is whether African Americans speak a distinct version of the language, variously dubbed "Ebonics" or "African American Vernacular English" or "Black Vernacular English" (see below). Some linguists use the term diglossia to refer to bilingualism as well, as when Spanish speakers in the US switch between Spanish and English.

In a geographically sprawling country like the United States, people in different regions or even in different cities many speak more or less different dialects of the same language. A dialect is a version of a language differentiated from other versions by phonology, vocabulary, and/or grammar (see below). Regions and cities are not the only sources or correlates of intra-language variation, though. Some linguists have proposed that men and women speak their common language differently, which Shannon McEwen (1996) among others has termed a "genderlect." Stretching the terminology, we might also think about the reality of "racelects," "classlects," "agelects," and even "occupationlects" (jargons and technical vocabularies, like the speech practices of doctors, lawyers, or computer programmers). Whatever the merit of all of these neologisms, linguists use the term lect to refer to any version of a language that has a distinct functional identity or "place" in the wider language community. At the lowest level, any single individual has a characteristic way of speaking, which has been called an "idiolect."

An individual tends to speak a certain dialect all of the time (although linguists understand that individuals have the capacity to know and switch between multiple dialects and other lects, in what is known as code-switching), but any masterful speaker of a language must be competent in a number of variations of a language depending on situational factors. One set of variations recognized by linguists is known as "registers." Susan Dicker defines register as a form of a language "used in a particular context (a courtroom, synagogue, or laboratory) by the people functioning in that context (judges and lawyers, rabbis, or scientists)" (2003: 12). Thus, as a speaker moves between different speech contexts or situations, s/he must perform the correct register to be deemed a fully competent participant in the society. Some linguists make a distinction between register and style, the latter defined by Dicker as "a situational variation of language. Speaking in front of a large audience in a formal setting requires a different style than that of speaking to an intimate group of friends" (12). For instance, a formal style of English tends to entail more careful pronunciation, a more sophisticated vocabulary, stricter observance of grammar, longer sentences, and 
a more serious tone (Obrecht 1999), while informal English style, used in casual and personal interactions, uses more contractions (e.g. isn't instead of is not), a simpler vocabulary, looser grammar, and a less serious tone.

Register is part of the topic that linguists refer to as sociolinguistics or pragmatics, that is, how people actually use language in social interaction. No language is simply a list of words, and language is not simply about transmitting information. Speaking is also social action, and "speech acts" serve other functions and have other effects than data transmission. A speech act conveys "social information" about the speakers, the situation, and the topic of speech, among others. One component of sociolinguistics is honorifics or specialized linguistic forms (words, grammar, tone, titles, etc.) that indicate the relative social status of speakers and thus convey respect or deference. In American English, saying "May I please have ..." rather than "Gimme" is polite and shows respect, as does calling someone "Mister" or "Doctor" rather than using their first name. In British English there are honorific forms for speaking to royalty (such as "Your Highness"), but lacking royalty Americans do not include these forms.

Finally, participating in a language community requires more than knowledge of definitions and grammar. It involves knowing the kinds of things that members of that community are likely to say and the kinds of background knowledge they possess and employing that knowledge at the right time. We might call this the "literature" of the society, except we do not limit the term to written literature. Another term might be "folklore," although we are not limiting the idea to traditional stories and songs. We mean conventional linguistic forms like proverbs, riddles, and jokes, as well as basic history (for Americans, the deeds of George Washington and Abraham Lincoln), famous speeches (the Gettysburg Address or Martin Luther King's "I have a dream" speech), and popular culture (baseball and football references-and knowing that "football" in American English does not mean soccer).

\section{Box 8.1 Basil Bernstein and the Two Codes of English}

There are many, many versions of a language like English, which linguists sometimes call "codes," and a competent member of society must master multiple codes and switch between them appropriately. Basil Bernstein described two contrasting codes in particular, namely, a restricted code and an elaborated code. Bernstein began by noting that while language is a system of abstract rules, speech "is constrained by the circumstances of the moment, by the dictate of a local social relation. ... Speech indicates which options at the structural and vocabulary level are taken up" (1964: 55). Since any particular society offers a finite range of possible relationships and situations, a number of more or less distinct codes will emerge. A restricted code is characterized by comparatively limited and rigid language options; freedom in speech variations is "severely reduced," and therefore speakers cannot interject much of their individual personality, perspective, or intent (58). Speech forms may have to conform closely if not perfectly to previous and conventional performances (for example, a fairy tale should ideally be told exactly the same way on each occasion). What is important in the 
(continued)

restricted code, then, is that the "status aspect of the social relation is salient" and the "code reinforces the form of the social relation by restricting the verbal signaling of differences" (60). More simply stated, in the restricted code individual characteristics are de-emphasized and social status characteristics are emphasized. While all members of a society understand and sometimes use a restricted code, it is especially suited for "closed communities like prisons, combat units of the armed service, criminal subcultures, and also in peer groups of children and adolescents and between married couples of long standing" (61). Bernstein also proposed that it is typical of the lower classes. The elaborated code, on the other hand, "is person rather than status oriented" (63). Speakers using the elaborated code may choose more freely from available linguistic forms and inject more individual personality, perspective, or intent. The elaborated code allows the speaker "to make explicit his discrete intent," precisely because "the discrete intent of the other person may not be taken for granted" (63). In other words, speakers are not engaging in highly conventional speech routines and cannot assume shared knowledge with each other. Persons interacting in the elaborated code are not simply occupants of a social status but are individuals, and Bernstein suggested that the "concept of self of a speaker" is limited in the restricted code but more fully realized in the elaborated code. Not surprisingly, Bernstein concluded that the elaborated code was suited for interactions between people who do not know each other well, are interacting in less structured circumstances, or are more highly educated and members of higher classes.

\section{Language Diversity and Identity}

An awareness of all of this diversity between and within languages leads us to ask, What is the language community? It is not flippant to go so far as to ask, What is a language? That is, when are the differences between/within linguistic forms sufficient to declare that a new or different language exists? And how does the line drawn between languages or language forms affect the attitudes and behaviors of their speakers toward each other?

Max Weinrich is usually credited with popularizing the slogan, "A language is a dialect with an army and navy." While that statement is hardly strictly true, there is some wisdom to it. The question is, When do we call something "a language" as opposed to a dialect or some other lect? Ultimately, we can only offer a social definition of "a language": a set of verbal practices (sound, lexicon, grammar, pragmatics) that is sufficiently different that non-members cannot understand it and that is regarded by members and non-members as a distinct language. This allows for some dispute over what is and is not "a language."

As already established, language boundaries do not map neatly onto political or social boundaries; there is, in short, no easy way to draw a line around all and only English speakers. Linguists often prefer the concept of "linguistic community" over others like "society” or "nation." According to John Gumperz, a linguistic community is 
a social group which may be either monolingual or multilingual, held together by frequency of social interaction patterns and set off from the surrounding areas by weaknesses in the lines of communication. Linguistic communities may consist of small groups bound together by face-to-face contact or may cover large regions, depending on the level of abstraction we wish to achieve.

(1962: 31)

Thus, a society or nation or country may be divided into several linguistic communities, and a linguistic community may straddle several societies or nations or countries (hypothetically, at least some Canadians probably belong to the same linguistic community as some Americans). As Gumperz also specified, a linguistic community need not be monolingual; indeed, complete "bi- or multi-lingualism is the rule rather than the exception in a wide variety of societies" (30). So language need not and often does not correspond one-to-one with society/country/nation.

Even so, modern nations and countries (especially the nation-state) often attempt to establish not only one language but one form of that language as the "right" one or the "standard" one. Benedict Anderson (1983) is renowned for discussing how shared language media like newspapers (and today television, movies, music, and electronic and social media) helped create nations and states as "imagined communities" in which all members or citizens could potentially talk to each other, even if in practice they do not. This entails the invention of a "standard language," which Gumperz defined, following Garvin and Mathiot, as "a codified form of a language accepted by and serving as a model to a larger speech community" (1962: 33). But, of course, the designation of one form (dialect, classlect, racelect, genderlect) of a language renders all of the others forms as non-standard and sometimes as stigmatized.

Bonnie Urciuoli therefore reminded us that when "languages take on sharp edges. . . . they are mapped onto people and therefore onto ethnic nationality" (1995: 533). This is another instance of the kind of "species invention" that Foucault identified in relation to gender (see Chapter 7). In the present case, the person who speaks a particular language (or languages) in a particular way is construed as a type of person, as a species of language speaker, even as a person who possesses a linguistic identity. Consequently, Urciuoli contended that speech differences like accents came to be seen "not simply as phonological variations but as indexes of stereotypic personality and character traits" (532), not unlike race. In this way of thinking, speaking a language constitutes an "act of identity," and in a later writing she made the provocative but not unjustified claim that linguistic variations have gotten "mapped onto" social differences of region, class, gender, and especially race and ethnicity (2001: 200). She paid particular attention to race, arguing that, "race has been remapped from biology onto language" in several ways: "in the idea of inherently superior or inferior varieties; in the way that intellectual traits are 'naturally' attributed to those varieties; in the way that, for example, Spanish is seen as 'invasive"” (201).

In the end, then, language is much more than a communication medium. As Wiley has succinctly expressed it, language

is a marker of status. Like race and ethnicity, language provides one of the important means by which individuals and groups identify and distinguish themselves from others. Prejudice on the basis of language is not unlike other forms of 
prejudice and may work in conjunction with them or serve as a surrogate for them. ... As a related, or surrogate, form of racism, discrimination on the basis of language may be called "linguicism."

(1996: 121)

That is to say, "language not only gives people a way of identifying with their cultures, but also constitutes a means by which they identify people and cultures different from their own" (Dicker 2003: 5)—with all of the positive and negative consequences of such differentiation.

\section{Language Diversity in the United States}

The diversity of race, ethnicity, class, and gender in the United States pales by comparison to the variety of language. Not only do literally hundreds of distinct languages share American soil-and always have, since before European invasionbut the dominant language of English is divided into an untold number of sublanguages, dialects and other lects, and situational linguistic specialties.

The difficulty of describing America's linguistic ecology begins with deciding how to determine what language a person speaks. In 1980 the American Community Survey of the US Census added three questions on language: "Does this person speak a language other than English at home?" if yes, then "What is this language?" and "How well does this person speak English?" (see Figure 8.1).

\section{4 a. Does this person speak a language other than English at home? \\ $\square$ Yes \\ $\square \quad$ No $\rightarrow$ SKIP to question 15a}

b. What is this language?

For example: Korean, Italian, Spanish, Vietnamese

c. How well does this person speak English?

$\square$ Very well

$\square$ Well

$\square \quad$ Not well

$\square \quad$ Not at all

Figure 8.1 2011 American Community Survey questions on language.

Source: US Census Bureau. American Community Survey Report: Language Use in the United States, 2011 
The total number of languages spoken in the United States is complicated by the problem, discussed above, of deciding what is a distinct language. For instance, the category of "French" includes French itself as well as Patois, Cajun, and French Creole; is that one language or four?

\section{Diversity Fact:}

Eight subcategories of Chinese are also distinguished in the ACS: Chinese, Hakka, Kan or Hsiang, Cantonese, Mandarin, Fuchow, Formosan, and Wu.

Consequently, the number of languages believed to be spoken in the US ranges between 226 and 332. At least eight of these languages included more than a million speakers, making them significant linguistic minorities. The largest non-English language groups in the US are listed in Table 8.1.

An additional 783,140 people were categorized as speaking "other Asian languages" (a classification including at least twenty languages, from Mongolian to Turkish, Tamil, and Burmese), while 688,596 more were listed as "other Indic languages" (containing a dozen languages like Bengali, Nepali, Sinhalese, and Romany).

Based on the premise that the language one speaks at home is one's primary language, the ACS calculated in 2007 that 80.3 percent of Americans were English speakers (i.e., spoke only English at home) and that 19.7 percent were non-English speakers (i.e., spoke a language other than English at home). Most of these nonEnglish speakers spoke Spanish, but vexing the notion of calling them "non-English speakers" is the fact that the majority of individuals in all non-English categories reported that they spoke English "very well" (see Table 8.2).

In other words, most non-English speakers are also English speakers, and very few speak no English at all.

Table 8.1 Most commonly spoken non-English languages in the US, 2009

\begin{tabular}{lr}
\hline Language & Speakers \\
\hline Spanish or Spanish Creole & $35,468,501$ \\
Chinese & $2,600,150$ \\
French, including Patois, Cajun, and French Creole & $1,964,556$ \\
Tagalog & $1,513,734$ \\
Vietnamese & $1,251,468$ \\
German & $1,109,219$ \\
Korean & $1,039,021$ \\
Russian & 881,723 \\
Arabic & 845,396 \\
African languages* & 777,553 \\
Italian & 753,992 \\
Portuguese or Portuguese Creole & 731,282 \\
\hline
\end{tabular}

Source: US Census Bureau, 2009 American Community Survey

"At least nineteen languages are bundled together in the category "African languages" 
174 Language

Table 8.2 Language spoken at home other than English and English-speaking ability, 2007

\begin{tabular}{llllll}
\hline Language & $\begin{array}{l}\text { Percent of total } \\
\text { non-English } \\
\text { speakers }\end{array}$ & \multicolumn{4}{l}{ English-speaking ability } \\
\cline { 2 - 6 } & Very well & Well & Not well & Not at all \\
\hline Spanish or Spanish Creole & 62.3 & 52.6 & 18.3 & 18.4 & 10.7 \\
Other Indo-European & 18.6 & 67.2 & 19.6 & 10.4 & 2.8 \\
Asian or Pacific Island & 15.0 & 70.1 & 19.7 & 8.1 & 2.1 \\
Other & 4.1 & 70.1 & 19.7 & 8.1 & 2.1 \\
\hline
\end{tabular}

Source: US Census Bureau, American Community Survey Report: Language Use in the United States, 2007

We can look at the distribution of languages in America from a variety of angles, including the race-and-ethnicity angle. In 2009 the US Census released information on the relationship between race/ethnicity and language spoken at home. Among Hispanics, 76.2 percent spoke a language other than English (LOTE) at home; Dominicans were the least likely to speak English (91.9 percent LOTE) and Puerto Ricans were the most likely (66.2 percent LOTE). African Americans had a very low rate (7.9 percent) of non-English at home, while Asians had a remarkably high rate of LOTE (77.1 percent), slightly higher even than Hispanics. Native Americans had a lower rate of LOTE (29 percent) than most non-white groups but still significant. Interestingly, individuals of mixed race also had a noticeable rate of LOTE at home (19.6 percent), with more than half (50.4 percent) of mixed white and "some other race" descendants speaking a LOTE.

Finally, there was also a geographic component to language diversity in the US. Not surprisingly, California documented the highest percentage of LOTE-speakers, at 43 percent. New Mexico (36 percent) and Texas (34 percent) were not far behind. More surprising was the fact that Rhode Island led all states in the percentage of Hispanics who spoke a LOTE at home ( 87 percent), followed immediately by Florida ( 86 percent). In terms of the sheer number of languages, according to the US English Foundation (http:// www.usefoundation.org/view/54) every state in the Union contained at least twenty-four languages, with sixty-nine or more languages spoken in forty states and more than one hundred in at least twenty states. California again led the country, with 207 languages spoken within its borders, followed by New York (169), Washington (163), and Texas (145). The least diverse states were Wyoming, South Dakota, Vermont, and North Dakota.

At a still more local level, the US English Foundation measured that of the 3,141 American counties, 5 percent contained more than fifty languages and more than onethird contained at least ten languages. Interestingly, while Spanish was the second most common language in over 80 percent of US counties (and the most common language in thirty-five counties, including twenty-six counties in Texas), other languages actually outnumbered Spanish in specific parts of the country. German was the second most common language in 195 counties, especially in North and South Dakota and Montana. French was the second most common language in seventy-six counties, predictably in Louisiana but also in Maine, Vermont, and New Hampshire (where the Acadians, whose name morphed into "Cajuns," once lived), and Norwegian was the second most common language in fourteen counties in the upper Midwest states of North Dakota, Minnesota, Montana, and Wisconsin. The Native American language of Dakota remained the second most common language in nineteen counties within that people's traditional territories of North and South Dakota, Montana, and Nebraska. 

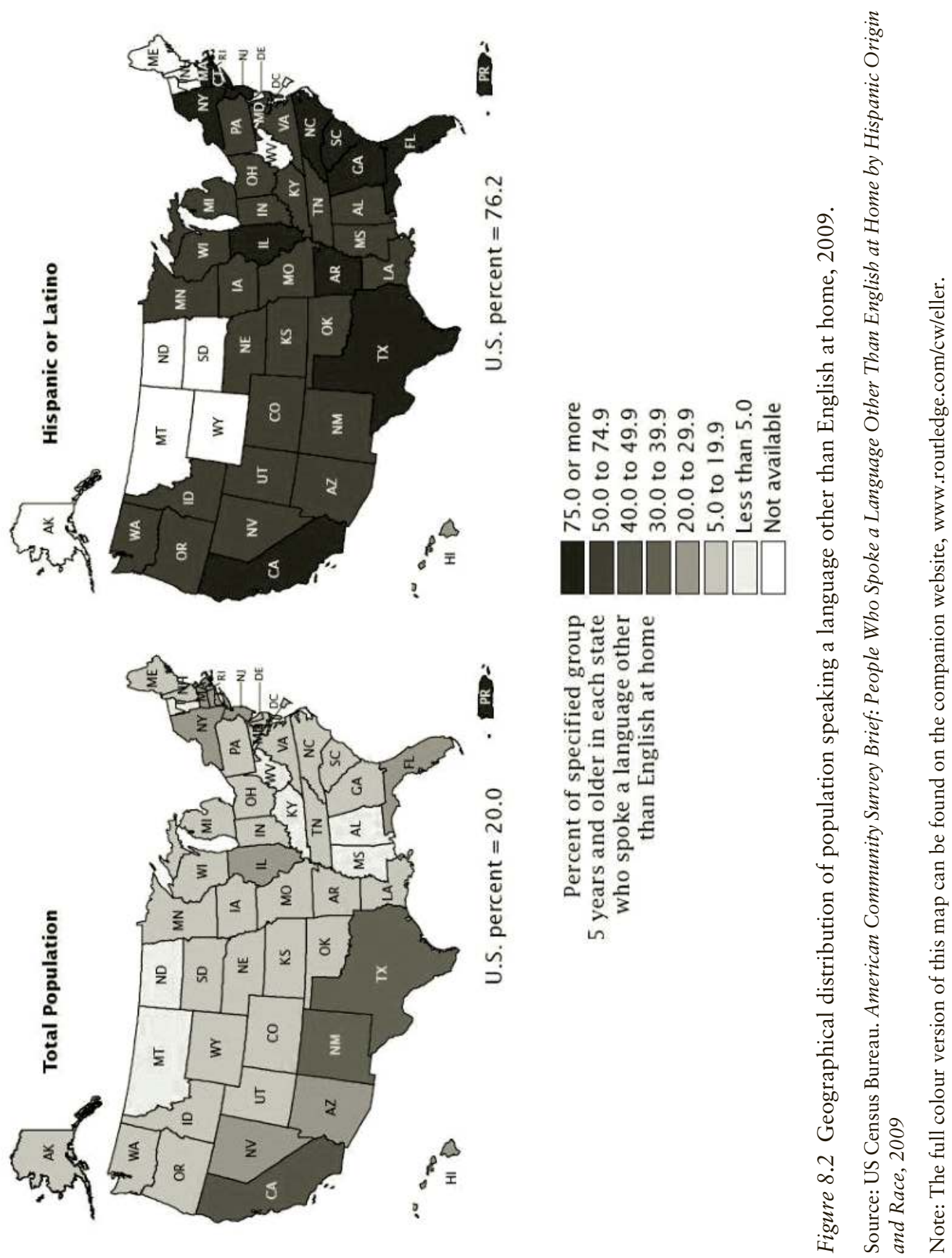


\section{Language}

\section{Native American Language Diversity}

Mention of the Dakota language urges us to begin the discussion of American languages with the first languages on the American continent. Although we cannot be completely sure (and because the designation of languages is fraught with problems, as already seen), there were probably some 250 to 300 indigenous languages spoken in the territory that would become the United States. In his 1891 Indian Linguistic Families of America North of Mexico, John Wesley Powell calculated that there were fifty-eight language families in native North America, including the Algonquian, the Athapascan, the Siouan, and the Zunian. Today most scholars organize the diversity of native languages into fewer families, some as few as eight or nine. Note that Native American languages, of course, did not conform to the political boundaries of the later countries of Canada, Mexico, and the US (see Companion Website for maps).

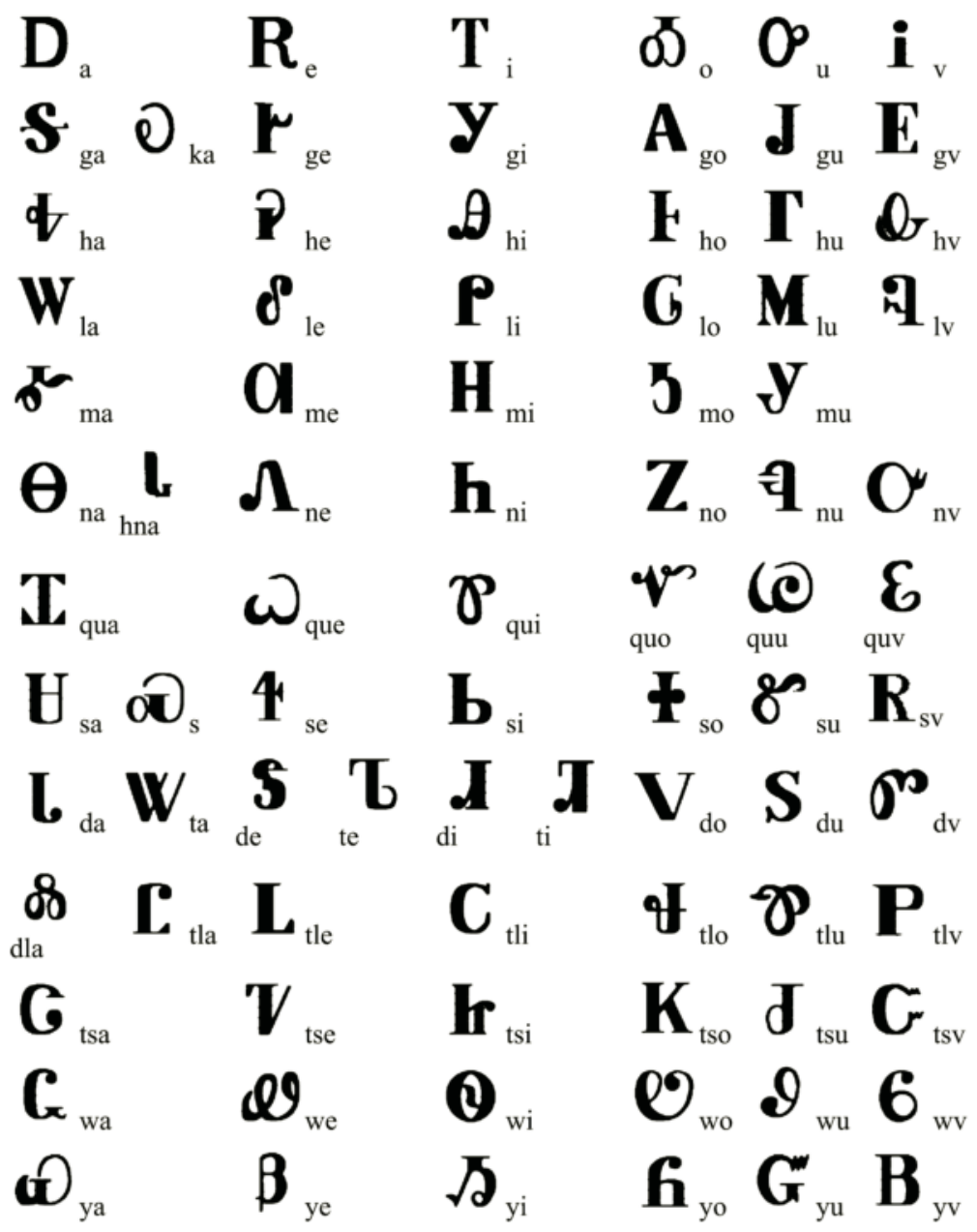

Figure 8.3 The Cherokee Syllabary. 
The effects of European immigration on Native American languages were complex and highly (but not thoroughly) negative. For example, many Native American languages were written down for the first time during British colonialism and later after American independence. As late as the latter 1800s, missionaries were busy studying indigenous languages, if only for the purpose of translating the Christian scriptures into local languages to facilitate religious conversion. In a recent history of mission work in the US and Canada, C. L. Higham quoted Samuel Francis Smith who in 1879 noted that Christian hymns "were printed in Shawnee, Delaware, Ottawa, Otoe, and Ojibwa, as well as in Cherokee so that these barbarous tongues were consecrated to the high praises of God" (2000: 62). Higham went on to explain that the "Church Missionary Society, the American Board of Commissioners of Foreign Missions, and the Baptist Missionary Union, among others, impressed upon their workers the importance of learning native languages and translating the Bible into that language" (62). While this policy was not necessarily respectful of native languages (and certainly not of native religion), it did contribute to the preservation of many languages and to the development of literacy in those languages.

The Cherokee are particularly renowned not only for acquiring literacy but also for inventing their own writing system. A bicultural Cherokee man named Sequoyah is credited with single-handedly introducing a syllabary (not an alphabet, but a set of symbols for syllables) in 1821. The tribe quickly adopted the system and by 1825 had rendered the Bible and other religious and legal documents in it. Soon they had their own printing press and began to produce their own newspaper, Tsa la gi Tsu lehisanunhi ("Cherokee Phoenix").

However, the story of the impact of British and American governments on Native American languages was not always so positive. From early in the contact, the dominant policy was to discourage the use of indigenous languages in favor of English. Some languages died out completely and only exist today, if at all, in books and other records. Perhaps the high point (or low point) of language assimilation occurred under the "Indian boarding school" regime, during which white administrators had more or less complete control over Native American children and their language acquisition.

\section{Box 8.2 Language Assimilation: The Indian Boarding School}

Colonial and American regimes had long used every tool at their disposal to achieve the cultural assimilation of Native peoples. Two of the main tools were violence or war and relocation. Native groups were routinely beaten down ("pacified" was a more polite term) or even decimated, some to extinction, while their remnants were often forcibly moved to distant or inhospitable lands. The most infamous, but hardly the only, case of relocation was the forced march of the Cherokee from their southeastern homeland to Oklahoma territory in what is remembered as the "Trail of Tears." A third tool, frequently applied after the other two had succeeded, was education. For maximal effectiveness, a boarding school approach was preferred in the late 1800s and early 1900s, keeping children under the supervision of school officials and away from their parents and society days, nights, and weekends. One of the first, and certainly the most 
(continued)

influential, Indian boarding schools was the Carlisle Indian Industrial School, established in Carlisle, Pennsylvania in 1879 by Captain Richard Henry Pratt. As his title suggests, Pratt had been a soldier and then a warden of Indian prisoners in the 1870s. These experiences inspired him to establish a school with some of the key qualities of an army or a prison, including barracks-like housing, military discipline, and strict control of every aspect of life. (Coincidentally, Pratt and others believed that this was the best approach for non-Native minorities like African Americans too.) At Carlisle, education focused on three main components which were felt to be the stuff of "civilization"-Christianity, manual or trade skills, and English. In imposing English, Native languages were banned; children's Indian names were taken away and replaced with American English names, and children were punished for speaking their native tongue. Their clothes and other traditional property were also confiscated and often destroyed, their hair was cut, and they were placed in military-type uniforms.

Carlisle became the model for a system of twenty-six publicly funded Indian boarding schools over the ensuing decades (many more Indian children were educated in Christian mission schools). Almost 12,000 Native American children from 140 different tribes passed through Carlisle before its closure in 1918, and other boarding schools operated into the 1930s. In the film Our Spirits Don't Speak English, graduates/survivors of these programs describe their experiences, including being captured and taken to school and being humiliated and beaten while there. A particularly moving moment in the film comes when an elder named Andrew Windy Boy recounts how he was repeatedly hit for speaking Cree: tearfully he says, "I was hit so much that I lost my tongue, I lost my native tongue."

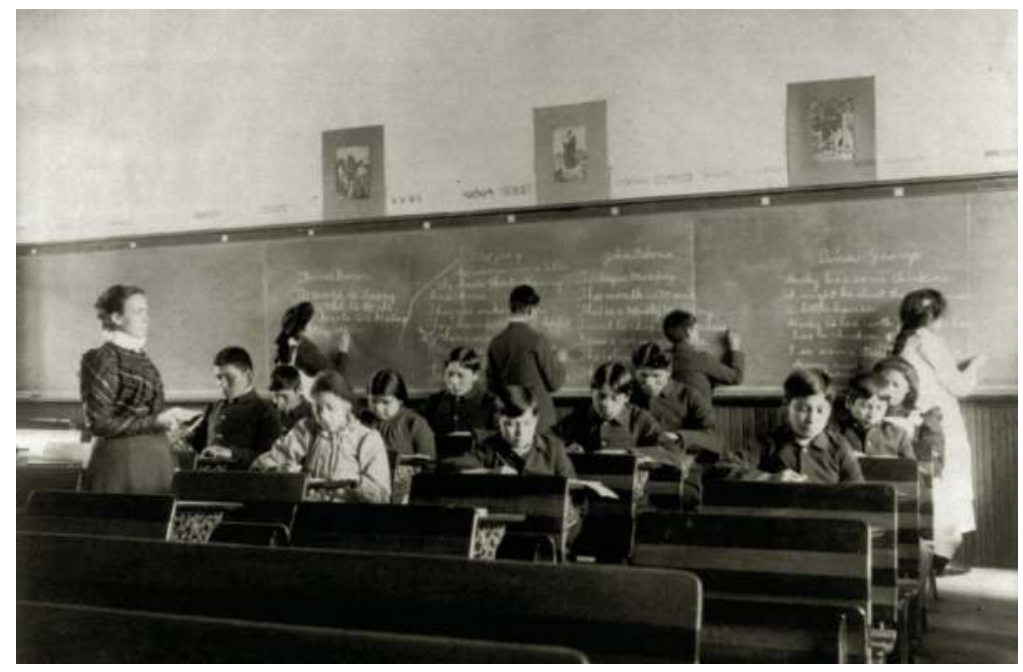

Image 8.1 Class at Carlisle Indian School, c.1901.

(Courtesy of the Frances Benjamin Johnston Collection, Library of Congress, Prints and Photographs Division) 
Table 8.3 Most commonly spoken Native North American languages

\begin{tabular}{lc}
\hline Language & Number of speakers \\
\hline Navajo & 169,471 \\
Yupik & 18,950 \\
Dakota & 18,616 \\
Apache & 13,063 \\
Keres & 12,945 \\
Cherokee & 11,610 \\
Choctaw & 10,343 \\
Zuni & 9,686 \\
Ojibwa & 8,371 \\
Pima & 7,270 \\
Inupik & 7,203 \\
Hopi & 6,634 \\
\hline
\end{tabular}

Source: US Census Bureau. American Community Survey Brief: Native North American Languages Spoken at Home in the United States and Puerto Rico, 2006-2010

In the present era, the American Community Survey includes 169 Native North American languages, with a total of 372,095 speakers in 2010. The largest Native language communities are listed in Table 8.3.

Older Native Americans (22.3 percent) are more likely to speak their indigenous language than younger people (11 percent among youths aged five to seventeen years). Even so, among all Native American age groups, English is more likely to be spoken at home than an indigenous language. Predictably, many Native languages that have survived into the twentieth century are in danger of dying; the organization Survival International (http://www.culturalsurvival.org/programs/elc/ program) estimated that by 1997 fifty-five Native North American languages had only between one and six living speakers. Some peoples, like the Wampanoag of Massachusetts, are actively trying to preserve or revive their languages. Significantly, the 1990 Native American Language Act committed the United States to "preserve, protect, and promote the rights and freedoms of Native Americans to use, practice, and develop Native American Languages."

Finally, it is worth noting that Native American words live on in English, which borrowed many indigenous terms and names. Such words as caribou, chipmunk, hickory, moccasin, moose, skunk, succotash, and totem derive from Native languages. Many place-names in America also originate from Native languages, including the Mississippi River, the Appalachian mountains, and the names of many states-Alabama, Alaska, Arizona, Arkansas, Connecticut, Hawaii, Illinois, Iowa, Kentucky, Massachusetts, Michigan, Minnesota, Mississippi, Missouri, Nebraska, New Mexico, North and South Dakota, Ohio, Oklahoma, Tennessee, Texas, Utah, Wisconsin, and Wyoming.

\section{Dialects of American English}

English came to replace the multiple Native languages as the dominant tongue on the American continent, but American English, as we have firmly established above and will describe more below, is hardly a single homogeneous speech form. Americans know full well that citizens in different regions and even specific cities have their 
unique variations of the common American language, variations which are sometimes nearly unintelligible to each other and which carry different amounts of prestige and stigma.

Based on available resources, "dialect collector” Rick Aschmann (http://aschmann. net/AmEng/) counts eight major dialects of English in North America with a number of sub-dialects, based on pronunciation differences:

1 Canada (not counting Francophone Quebec).

2 Northern New England.

3 The North (from southern New England and New York State to Michigan and Illinois).

4 Greater New York City.

5 The Midland (from New Jersey and Pennsylvania to Ohio, Indiana, and Missouri).

6 The South (from Virginia to Texas, not counting southern Florida, and a variety of local sub-dialects).

7 North Central (from Michigan's Upper Peninsula to eastern Montana).

8 The West (from the western Great Plains to the Pacific Coast and Alaska).

See Companion Website for map. Some of these dialects and their geographic areas can be further subdivided: Aschmann divides the North into western North, Inland North, the St. Louis corridor, Indiana North, Eastern North, Albany, and Providence.

Again, this classification is based on sound differences (like if and how $r$ or $l$ is pronounced). Dialects also vary in vocabulary, grammar, and pragmatic features. Very recently, Joshua Katz used dialect survey data in response to 122 questions on phonetics and semantics to create maps of speech variations across the country. The survey sought answers to questions like how people pronounce "aunt" or "caramel" or "coupon" or which words they use for "the long sandwich that contains cold cuts, lettuce, and so on" or "a sweetened carbonated beverage" (see http://www4.uwm.edu/ FLL/linguistics/dialect/maps.html for the entire list of questions).

\section{Language Policy and Bilingual Education}

Two things are true about the ecology of American language: America has always been a polyglot country, and English has always been the dominant language. Despite, or perhaps because of, the overwhelming dominance of English, the United States has never had a formal language policy. There is, for instance, no official language stipulated in the Constitution, and the US does not have an official language even today. English has been virtually taken for granted as the language of the Union. Harold Schiffman, for example, has stressed that the United States has neither an explicit national language nor an explicit language policy, although it does have a "linguistic culture" that "supports the use of English to the exclusion of almost all other languages, so that an explicit policy that would officialize English is not necessary, and probably never will be" (2005: 121).

This does not mean, of course, that Americans have lacked an awareness of the role of English in national life and identity. The case of Indian boarding schools makes the American concern for English quite apparent. Interestingly, Bonnie Urciuoli insisted that the "isomorphism between English-American and non-English-un-American has 
had a long gestation, although it was not ideologized in the earliest decades of U.S. history" (1995: 537). It was only in the second half of the nineteenth century, with the rising tide of non-English-speaking immigrants, that "the English border was being legally wrapped around potentially disruptive groups," and the naturalization of new citizens required them to speak English as of 1906.

By the twentieth century, many English-speaking Americans thus came to view "English-speaking" and "American" as synonymous and therefore language assimilation to be crucial to the survival of the American nation. Accordingly, there have been various calls to establish English as the official language of the United States and to implement a pro-English policy. Advocates of this position, like the organization US English (http://www.us-english.org/), argue that having an official language

is essential and beneficial for the U.S. government and its citizens. Official English unites Americans . . . by providing a common means of communication; it encourages immigrants to learn English in order to use government services and participate in the democratic process; and it defines a much-needed common sense language policy.

(The website for US English rejects the notion that "official English" means "English only.")

No less a light than Samuel Huntington in his Who Are We? The Challenges to America's National Identity, who identifies himself in his Foreword as "a patriot and a scholar" (2004: xvi), defends the "Anglo-Protestant" America that he knows and loves against the perceived forces that threaten to undermine it, among which he counts "the doctrines of multiculturalism," "the weakness or absence of the factors that previously promoted immigrant assimilation combined with the increased tendency of immigrants to maintain dual identities" (what we called the "unmeltable ethnics" in Chapter 4), "the denationalization of important segments of America's elites," and-most importantly for our purposes here- "the dominance among immigrants of speakers, largely Mexican, of a single non-English language (a phenomenon without precedent in American history), with the resulting tendencies toward Hispanization and the transformation of America into a bilingual, bicultural society" (138, emphasis added).

No doubt, defenders of America's true English (or even worse, Anglo-Protestant) identity would have mixed feelings about the 1968 Bilingual Education Act, which was adopted "as a supplemental grant program to assist local school districts to teach students who do not know English” (Osorio-O’Dea 2001: 5). In her twenty-year retrospective of the law, also known as Title VII of the Elementary and Secondary Education Act (ESEA), Gloria Stewner-Manzanares called it "the first federal recognition that LESA (limited English speaking ability) students have special educational needs and that in the interest of equal educational opportunity, bilingual programs that address those needs should be federally funded" (1988: 1). Specifically, the Bilingual Education Act (BEA) provided “(1) resources for educational programs, (2) training for teachers and teacher aides, (3) development and dissemination of materials," and (4) parent involvement projects" but "did not explicitly require bilingual instruction or the use of the students' native language for educational purposes" (1).

The focus on language, education, and opportunity became more acute after the 1974 Supreme Court decision in Lauv Nichols, in which the plaintiffs were not Spanish speakers but Chinese speakers. The Supreme Court ruled that such LESA students 


\section{Language}

were entitled to language accommodations (educational services of some sort in their own language) as a civil right. In the same year, the Equal Education Opportunity Act expressly named instructional programs as part of the remedy to language barriers in schools. A "bilingual education program" was thus defined as "one that provided instruction in English and in the native language of the student to allow the student to progress effectively through the educational system" (3).

Naturally, many controversies arose over the implementation and goals of bilingual education programs. Should such initiatives be intended as a transition to English or as a perpetuation of the native language? What are the most effective methods of bilingual education? Up to what grades should bilingual education be offered? And most problematically, since the US is hardly a bilingual country, how many different languages does a school have to provide non-English services in? According to James Crawford (2008), by 1994 teachers in California had been certified in seventeen different languages (although 96 percent of them were certified in Spanish), and recall that Californian schools could potentially have as many as 207 languages in their classrooms.

In 2002, the BEA was allowed to expire and was superseded by President George W. Bush's No Child Left Behind legislation. The old law was replaced by the English Language Acquisition Act, and the federal Office of Bilingual Education and Minority Language Affairs was renamed the Office of English Language Acquisition, signaling a clear change in America's language priorities. Kim Potowski writes that bilingual "has become almost a dirty word in educational circles, with more and more pressure to shift children to all-English classrooms as soon as possible. California, Arizona, and Massachusetts have eliminated bilingual education in favor of 'sheltered English immersion"' (2010: 20). The latest thinking seems to be to encourage English proficiency along with some amount of preservation of the native language, an idea called "English Plus."

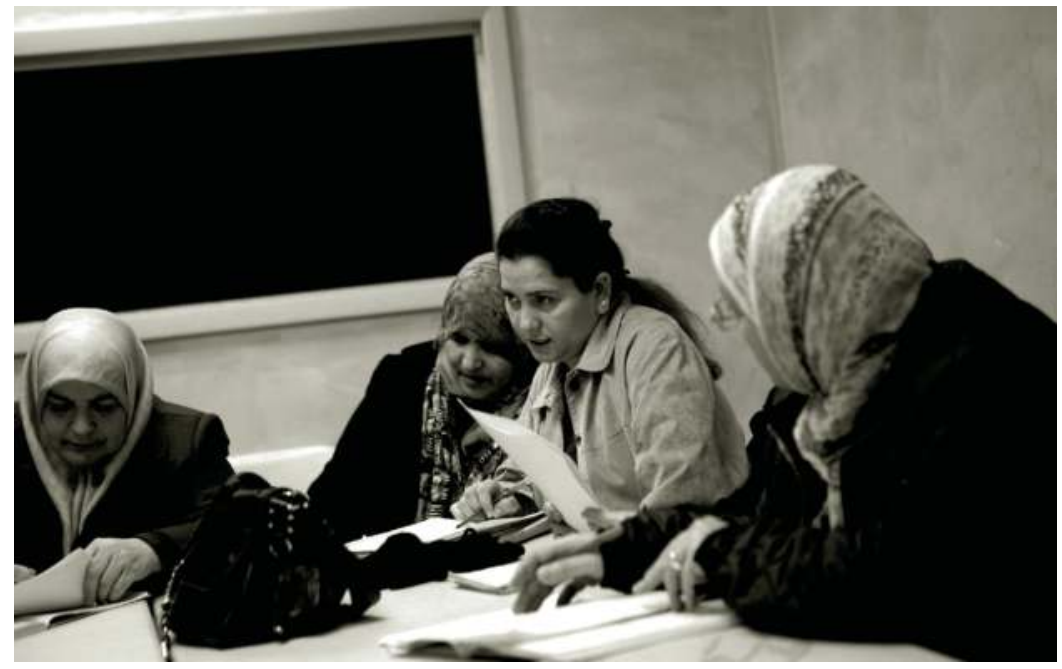

Image 8.2 Arab-American women sit in a classroom during a course in English as a Second Language at the Arab American Association of New York office in Bay Ridge, Brooklyn.

(Courtesy of Robert Nickelsberg/Getty Images) 
In the meantime, two other noteworthy facts about multilingualism in the United States bear mentioning. First, many non-English-speaking adults are enrolled in English as a Second Language (ESL) programs—as many as 1.2 million in 2005 (Potowski 2010: 8). At the same time, many English-speaking students and adults are learning second languages, especially Spanish and French, in formal classroom settings and in less formal ways (e.g. online and with language training software like Rosetta Stone). Many Americans feel the importance to understand at least some non-English languages. While most English-speaking Americans can hardly qualify as bi- or multilingual, even English-speaking America is not quite as monolingual as it once was, which is important in an increasingly globalized world.

\section{Diversity Fact:}

As discussed in Chapter 11, many deaf Americans consider American Sign Language to be their natural and "ethnic" language. Often traced back to the American School for the Deaf, founded by Thomas Hopkins Gallaudet in 1817, it was inspired by the even earlier development of sign language in France and first taught by Frenchman Laurent Clerc.

\section{Language Stratification in America: Class and Gender}

By now it should be perfectly clear that a "single standard English exists only in theory, in the pages of English grammar textbooks" (Dicker 2003: 10). To that assessment, however, Dicker quickly adds, "In actuality, various factors influence the way people of wealth and status express themselves." And these variations within the English language are not all equally valued, some serving as markers of status and conferring special prestige, leading to language stratification or socially unequal forms of a language.

Class is one of America's most enduring stratification systems, and one indicator of class is speech patterns. As already found in Basil Bernstein's analysis of speech "codes," individuals of different education levels and class tend to speak differently, most obviously because higher education and class tend to provide a more extensive vocabulary, a finer sense of grammar, and a wider range of conversational topics. Along with Bernstein, the other pioneer in class-based language was William Labov, who began research on speech patterns in New York City in the early 1960s. In the same year that Bernstein published his article on restricted and elaborated codesin fact, in the same issue of the same academic journal-Labov urged that variations in speech must be understood in terms of "their role in community life," particularly their relation to the social position of the speakers (1964: 164).

In that article, and in his subsequent book The Social Stratification of English in New York City (1966), Labov collected samples of spontaneous speech and analyzed five variables quantitatively: the presence or absence of $r$ as a final or pre-consonant sound, the pronunciation of the vowel $a$ in such words as "bad" or "cash" or "ask" and the vowel-sound ob as in "caught" or "dog" or "talk," and the initial consonantsounds th as in "thing" and $d h$ as in "then." He further divided speakers into ten class-levels, with $0-1$ as lower class, $2-5$ as working class, 6-8 as lower middle class, and 9 as upper middle class. In particular, he discovered strong correlations between 


\section{Language}

$r, t h$, and $d h$ and class. For example, upper-middle-class speakers were by far the most likely to pronounce their $r$, while most of the time middle-class and working-class speakers did not pronounce it. Likewise, he reported "sharp stratification" in the use of $t h$ and $d h$, "in that the population is divided into two radically different sections by their use of the (th) variable" and the related (dh) variable (1964: 170). Interestingly, Labov also tested different kinds of speech performances, from casual speech to careful speech to reading to word lists and found that the results were consistent for classes but also varied over performance type: all classes were more likely to enunciate $r$ in reading and word lists than in casual speech.

In his 1966 book, Labov also reported a study of language variation between employees of three department stores in New York City-the most prestigious Saks, the middle-level Macy's, and the comparatively low-status Kleins. Again he found a consistent relationship between class and pronunciation. Lastly, he carried his research to Martha's Vineyard, an area of upper-class residents which is regarded by linguists as "an island of $r$-pronouncers in a sea of $r$-lessness" (1972: 6). With speech patterns reflecting "a long record of resistance to Boston ways and manners," Labov studied the incidence of vowels ay and aw, known as dipthongs because they actually combine two vowel sounds, and reasoned that the unique phonetic pattern of the island was related to class and identity: "the immediate meaning of this phonetic feature is "Vineyarder," and when a resident pronounces ay or aw in the local way, s/he "is unconsciously establishing the fact that he belongs to the island: that he is one of the natives to whom the island really belongs" (1972: 36).

A more controversial question is the relationship between speech patterns and gender, if only because the research has yielded contradictory results. Part of the difficulty is distinguishing between gender stereotypes and actual gender differences, while part is related to different studies using different methods and variables. Also, presumed gender differences may be confounded with other social variables such as status and power, and gender speech patterns may have changed since the initial research in the 1970s. For instance, in 1977 Cheris Kramer tested perceptions of gendered speech and found that subjects considered certain traits to be more typical of male speech, such as "demanding voice, deep voice, boastful, use swear words, dominating speech, loud speech, show anger rather than concealing it, straight to the point, militant speech, use slang, authoritarian speech, forceful speech, lounge and lean back while talking, aggressive speech, blunt speech, [and] sense of humor in speech" (1977: 158). On the other hand, participants associated the following tendencies with female speech:

enunciate clearly, high pitch, use hands and face to express ideas, gossip, concern for listener, gentle speech, fast speech, talk about trivial topics, wide range in rate and pitch, friendly speech, talk a lot, emotional speech, use many details, smooth speech, open and self-revealing speech, enthusiastic speech, smile a lot when talking, good grammar, polite speech, gibberish.

Kramer was quick to point out that such stereotypes "do not, of course, necessarily correspond to actual differences in the speech of females and males" but that "the beliefs held by the participants about the speech of women and men have an importance of their own. The stereotypes are part of our social heritage" (159). 
Two other important observations arose from Kramer's work. First, women were actually more attentive to language differences than men were, suggesting that power relations were at play: individuals in subordinate positions tend to be more sensitive to verbal and social cues. Second, Kramer concluded that women's speech was not only perceived as different from men's but as inferior to men's, “a sort of 'counter language' to men's. ... Especially in the perception of the men, female speech can be summarized as friendly, gentle, enthusiastic, grammatically correct, but containing gibberish on trivial topics. Kind, correct-but unimportant” (159).

It bears keeping these two observations in mind as we consider the investigation of gendered speech, since power inequality and male perspective lurk in any attempt to explore it. The classic studies of women's language practices began with Robin Lakoff's 1973 article "Language and Woman's Place," followed in 1975 by a book of the same title. Lakoff contended that women's talk differed from men's in a number of distinct and informative ways: women used more "hedges" to soften their speech (e.g. "sort of" and "it seems like"), more polite or deferential forms (e.g. "would you mind”), more "tag questions" (e.g. “... aren't you?”), more direct quotation and proper grammar and pronunciation, a more extensive vocabulary in certain areas (e.g. colors), more interrogative relative to declarative intonation (i.e. asking questions rather than making statements), more qualifiers (e.g. "I think that") and apologies, and less inclination to interrupt and speak at all.

The other key figure in the debate is Deborah Tannen, whose 1990 You Just Don't Understand reiterated many of these claims. Men and women, she asserted, use language differently: men compete for status, strive for independence, solve problems, convey information and give orders, while women seek support, strive for intimacy, build relationships, convey feelings, and offer suggestions. Daniel Maltz and Ruth Borker went so far as to liken gender speech difference, especially in cross-sex talk (that is, when men and women talk to each other), as cultural difference. Accepting the basic premises of the gendered speech styles described above, they proposed the existence of "distinct male and female subcultures" (1982: 200).

While gender language differences seem intuitively appealing, the research has been divided. In 1980 William O’Barr and Bowman Atkins examined speech behavior in the courtroom setting and noted differences in what might be called "women's language" which, they concluded, "is neither characteristic of all women nor limited only to women" (1980: 102). While women used "women's language” more than men, this particular speech style had less to do with gender than with power; to be precise, it was a speech style associated with powerlessness. Therefore, they suggested that "the tendency for more women to speak powerless language and for men to speak less of it is due, at least in part, to the greater tendency of women to occupy relatively powerless social positions" (104). Presumably, then, as women rose to positions of social power, they would speak less of stereotypical "women's language."

In support of this judgment, Yaguchi, Iyeiri, and Okabe (2004) studied language behavior in formal settings like faculty meetings and White House briefings and learned that women do not use hedges like "sort of" and "kind of" more than men. In fact, in academic settings, women actually used hedges less often than men did, and female speakers were seen to be more assertive in their talk than men. Shannon McEwen, cited above, "failed to find much direct evidence of gendered language use either consciously or unconsciously" among young speakers and concluded that such gendered differences 
as do exist "only begin to solidify in late childhood or early adolescence and only for a small set of factors/variables" (1996: 457). Caroline Henton's data even showed that the presumed pitch range of women's speech, allegedly giving it a "swoopy" quality, is not real; rather, "female and male pitch ranges do not differ significantly" (1989: 307), and the stereotype that women's speech is "over-emotional and shrill" is a sign of an "androcentric society" that continues "to mark women as an 'outgroup"” (308).

Since male/female is not the only dimension of gender diversity in America, it makes sense that social scientists have also investigated "gay" speech practices. As with women's speech, homosexual speech stereotypes abound, and Valentina Cartei and David Reby explored gay speech stereotypes by studying how male actors play homosexual characters. Male actors do tend to make their voices more "feminine" when playing gay characters, using higher pitch and more "melodious" and less "baritone" voices (2012: 85), but this indicates more what an audience expects to hear than what gay males actually do.

In a major review of supposed gay speech, Don Kulick assessed that "gay and lesbian language does not and cannot exist in the way it is widely imagined to do" (2000: 243). He noted that the early days of homosexual-language research focused on purported gay-specific terminology, a sort of code that gays spoke in. The eminent sociologist Ernest Burgess opined in 1949 that the "homosexual world has its own language, incomprehensible to outsiders" (1949: 234), and Gershon Legman actually compiled an alleged glossary of "the language of homosexuality" in 1941. In 1972 Bruce Rodgers published another lexicon of gay-speak titled The Queen's Vernacular, and almost a decade later the edited volume titled Gayspeak (Chesebro 1981) appeared, in which, according to Kulick, gay language was "characterized by the use of argot, innuendo, categorizations, strategic evasions (such as omitting or changing gendered pronouns), and, in the case of activist language, conscious revaluation of formerly derogatory terms" (2000: 256). Kulick ultimately rejected this view, though, suggesting that we think in terms of "language and desire" rather than of language and homosexuality.

\section{Language Stratification in America: Race and Ethnicity}

In heavily English-speaking America, English naturally sits at the top of the hierarchy of languages in the country. Aside perhaps from the romantic associations of French or Italian, all other languages are ranked as less (and less American) than English. It goes without saying, then, that non-English speakers face practical disadvantages and social stigmas for their languages.

Indeed, as mentioned above, some observers like Bonnie Urciuoli have seen language differences serving the same functions are racial and ethnic differences in the United States. In her paper on Puerto Rican students in upstate New York, she argued that they "find themselves linguistically marked in crypto-racial ways, in both Spanish and English" (2003: 1). Spanish speakers in contemporary America particularly "experience race-marking mapped onto language behavior"-even when they speak in English, because the presence of a Spanish accent or of Spanish words is "conflated with notions of 'broken' languages" (6). In short, bilingualism (in this case, lingering Spanish) “is acceptable so long as the non-belonging language leaves no trace in English, the belonging language. Strict linguistic partition is taken as evidence of 
self-control and self-improvement, which are evidence of acting like a middle-class American" (16). But if "language becomes marked by an accent signaling a personal history outside the protection of class/race privilege, it becomes a 'problem' to be 'diagnosed' and 'fixed'" (21).

In her work, Urciuoli raised the issue of "monitoring" the speech of non-English speakers, and Jane Hill expanded on this idea in her 1998 article and 2008 book on language and racism. Hill explicitly credited Urciuoli for identifying the "ethnification" of accented English and the policing of standard-English practices. Hill's emphasis was on the irony that while Spanish-speaker "code switching is condemned as disorderly, Whites 'mix' their English with Spanish" routinely to produce what has been called Mock Spanish (1998: 682). Mock Spanish involves the use of random Spanish words, like amigo or hasta la vista, or Spanish accent, or worst of all, pseudoSpanish forms like "mucho trouble-o" (682) or corruptions of Spanish like "chili today and hot tamale."

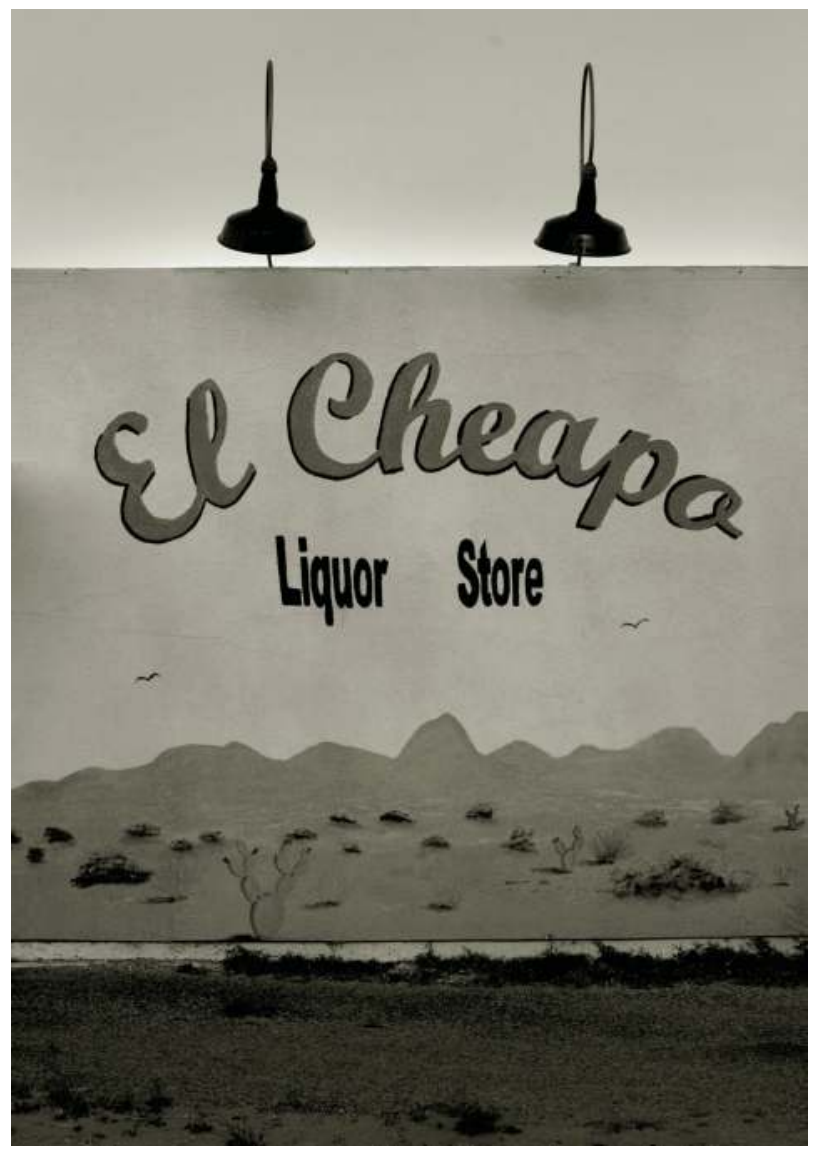

Image 8.3 Example of Mock Spanish.

(Courtesy of Jill Johnson/Fort Worth Star-Telegram/MCT via Getty Images) 
While many Mock Spanish speakers might find this harmlessly funny, even misguidedly respectful, Hill stressed that it conveyed two very important negative messages. The first was white/English privilege: whites and English speakers are free to play with Spanish (and other languages, giving us Mock French or Mock Italian or Mock Japanese, etc.), but Spanish speakers are not free to play with English. Second and much more serious, the ways that Mock Spanish is used convey powerful pejorative messages about Spanish speakers. Hill concluded that

in order to "make sense of" Mock Spanish, interlocutors require access to very negative racializing representations of Chicanos and Latinos as stupid, politically corrupt, sexually loose, lazy, dirty, and disorderly. It is impossible to "get" Mock Spanish - to find these expressions funny or colloquial or even intelligible-unless one has access to these negative images.

She called this "covert racist discourse" or, as the title of her book expresses it, "the everyday language of white racism."

White English speakers find themselves relatively free to mock Spanish diction, but most would not expect to get away with mocking African American speech styles. In his early research on New York City, Labov noted racial and ethnic as well as class language stratification. He commented that there exist "certain marginal phonemic differences in the speech of New Yorkers which serve as near-absolute differentiators of racial groups" (1964: 174). For instance, he determined that for most African American speakers of English in New York (and virtually all African Americans speak English, except for new immigrants from Africa, many of whom actually bring English skills with them) "there is no contrast between pin and pen, tin and ten, since and cents" (1964: 174). However, this phonetic habit "is a regular characteristic of Southern English" and therefore not racially specific.

The idea of whether or not familiar African American speech styles are merely perpetuations of Southern English has been subjected to considerable scrutiny. One of the most prolific scholars of African American English, Walt Wolfram, explained that two characteristics of African American English—sometimes called Black Vernacular English (BVE), Vernacular Black English (VBE), or African American Vernacular English (AAVE)-were the absence of the copula (i.e., words like "is" and "are") and the use of "an invariant form of be" as in "I be" and "He be." Copula deletion, he found, did occur in the South but usually among the rural and poor population; it was much less common among college-educated and professional people. On the other hand, the distinctive use of $b e$ "is typically NOT found in Southern white speech, though it is an integral aspect of all VBE varieties studied" (1974: 524).

If the BVE or AAVE use of be does not originate in Southern English, where does it come from? In a much more recent essay, Wolfram suggested that the characteristic be is "largely an innovation of the post-World War II era and that the change has spread from an urban locus outward" (2004: 114). That is, at least some of AAVE appears to be relatively new, predominantly urban, and highly associated with youth, related to "the developing oppositional identity that has developed in African American youth culture" (130). 
Wolfram and others have described other features of AAVE, including done as part of the past tense (e.g. "They done used all the good ones") or had plus the simple past tense (e.g. "They had went outside"), as well as be done in sequential/ resultative forms (e.g. "By the time we get there, my ice cream be done melted"). Sometimes mines is used as a personal pronoun (e.g. "The book is mines"), and the -s may be left off of plurals (e.g. "I got fifty cent"). (All examples here are derived from Wolfram 2004.)

A remarkable controversy broke out in 1996 when the Oakland, California school system recognized AAVE as a legitimate language, the speakers of which were at a disadvantage in English classrooms. As a non-standard form of English, Ebonics, as it was called, it was taken to be the dialect of African American students and therefore deserving of the same language accommodations as other languages under the Equal Education Opportunity Act. For instance, teachers could become certified in Ebonics and use it as a language of instruction. Critics of the policy attacked this decision for various reasons: some saw it as racist, while others thought that it would deter black students from learning standard English. Interestingly, the Linguistic Society of America issued a statement in 1997 endorsing Ebonics or AAVE as a "systematic and rule-governed" speech form rather than an inferior version of English and commending the Oakland district for accepting it as a stepping stone "to helping students master Standard English.”

\section{Diversity Fact:}

In the 1800 s and early 1900 s there was a lively American literature in Yiddish, a fusion language of German, Hebrew, Aramaic, and Slavic. At one time there were seven Yiddish newspapers in New York City, and famous authors like Saul Bellow and Isaac Bashevis Singer have written in or translated Yiddish. A number of English words are borrowed from Yiddish, including bagel, chutzpah, glitch, maven, putz, and schlep.

\section{Conclusion}

While most Americans confidently speak English, and some even fret about the future of English and of the American society and identity premised on English, the United States is and always has been-and looks to continue to be-a multilingual society. Many languages share the American space, but they are arranged in a hierarchy with English at the top. Speakers of a language other than English may face difficulties participating in the wider society, but the country has also taken steps to make American democracy accessible in other languages, while many language communities have established their own language-specific institutions.

Languages as composite systems are open to borrowing from each other. English itself is a language that evolved and continues to evolve by absorbing various linguistic influences. According to some commentators, though, English speakers may enjoy more freedom to adopt and play with other languages than non-English speakers do. 


\section{Language}

There are also great variations within a language like English, which exist at every level of linguistic skill from sound to vocabulary to grammar to practical use. Further, any language offers a number of registers and styles for different situations and relationships. No language is a monolithic or socially neutral or blind system; nonlinguistic information can be and must be coded into language along with "the facts." Finally, language variations exist in relation to other cogent social variables like class, race, ethnicity, region, and gender. Language may even be a marker of such social identities and may indicate the unequal power relations and status of these various categories within the larger English-speaking community. 


\section{Religion}

Americans hold contrasting views on the relationship between government and religion. The First Amendment to the US Constitution opens with the two clauses, "Congress shall make no law respecting an establishment of religion, or probibiting the free exercise thereof," known in constitutional law as the establishment clause and the free exercise clause. Another view is that American society, even American government, was originally and is continually based on Christian principles. Christian spokesman Pat Robertson has gone so far as to declare: "The Constitution of the United States, for instance, is a marvelous document for self-government by Christian people. But the minute you turn that document into the hands of non-Christian people they can use it to destroy the very foundations of our society. And that's what's happening" ("The 700 Club," December 20, 1981; cited in Pelletier 2004).

What is the role of religion in the founding and functioning of American society?

Either way, the United States contains many different religions and many different versions of the Christian religion. What is the religious status of America? If it does not have a single religion, does it have a dominant religion? And can a society survive without a single or a dominant religion-or without a religion at all?

It is more common - and more acceptable—to say that the United States is a Christian country than to say, for instance, that it is a white country or an English-speaking country (although there are those who make those claims as well). However, to assert that the US is a Christian country is equally problematic as asserting that it is a white or Anglophone country: there is certainly a majority in each case, but there are also many minorities as well as tremendous diversity within that not-all-monolithic majority.

There is no disputing that religion plays a notable role in American life. That keen observer Alexis de Tocqueville recognized that Americans were a religious people, as well as an optimistic, materialistic, egalitarian (at least in spirit), energetic, and frankly somewhat unsophisticated people: "The religious atmosphere of the country was the first thing that struck me on arrival in the United States" (de Tocqueville 1969: 295). Even so, he could not help but perceive almost two hundred years ago that American religiosity was divided into an "innumerable multitude of sects" (290). Many denominations of Christianity had arrived on American shores by 1830, and, of course, many other religions besides Christianity would arrive, such that virtually every religion in humanity would be represented within its borders. Furthermore, many new sects, denominations, and entire religions would grow out of American 


\section{Religion}

soil, some more eccentric and controversial than others. De Tocqueville himself commented that "From time to time strange sects arise which strive to open extraordinary roads to eternal happiness. Forms of religious madness are very common there" (574). Indeed, America has been so religiously creative and unorthodox that Philip Jenkins concludes: "Extreme and bizarre religious ideas are so commonplace in American history that it is difficult to speak of them as fringe at all. To speak of a fringe implies a mainstream" (2000: 5)—and there are so many streams and tributaries of American religion that it is difficult (and perhaps unnecessary) to attempt to identify one as the main stream. Rather, American religion is distinctly diverse-and distinctly American-like every other facet of the society.

\section{The Social Nature and Function of Religion}

Before we can speak sensibly of American religious diversity, we must understand what religion is. The starting point for this discussion is to understand what religion is not. We cannot, as social scientists, define religion in a way that admits only particular kinds of religions and excludes others. Thus, we cannot define religion as "the belief in God," since not all religions believe in one god, let alone the same god. We cannot even define religion as "the belief in gods," since some religions do not contain gods at all; at least some versions of Buddhism, for example, do not refer to gods, and many pre-modern religions lacked the concept in favor of other kinds of entities like nature spirits or ancestor spirits or non-personal supernatural forces (like Polynesian mana or Chinese chi).

So we are not permitted to take the position of the character of Parson Thwackum in the Henry Fielding novel The History of Tom Jones, who said, "When I mention religion I mean the Christian religion; and not only the Christian religion, but the Protestant religion; and not only the Protestant religion, but the Church of England" (1979: 105). In other words, when most people say "religion" they mean their own religion. Social theorists have made many attempts to define religion more inclusively, sometimes in terms of specific features or substance, sometimes in terms of general function. The early ethnologist E. B. Tylor in 1871 gave one of the simplest possible definitions: "the belief in spiritual beings." The psychologist William James naturally gave a more psychological definition, regarding religion as "the feelings, acts, and experiences of individual men in their solitude, so far as they apprehend themselves to stand in relation to whatever they may consider the divine" (1958: 34). Émile Durkheim, one of the founders of modern sociology, predictably approached religion from a more social perspective, defining it as "a unified system of beliefs and practices relative to sacred things, that is to say, things set aside and forbidden-beliefs and practices which unite into one single moral community called a Church, all those who adhere to them" (1965: 62). American anthropologist Clifford Geertz suggested one of the most-often quoted definitions in anthropology, namely: “(1) a system of symbols which act to (2) establish powerful, pervasive, and long-lasting moods and motivations in men by (3) formulating conceptions of a general order of existence and (4) clothing these conceptions with such an aura of factuality that (5) the moods and motivations seem uniquely realistic" (1973: 90).

All of these, and many others, have their merits, but for reasons that will become apparent shortly, we will adopt here the definition proposed by anthropologist Robin Horton, who wrote that 
in every situation commonly labeled religious we are dealing with action directed towards objects which are believed to respond in terms of certain categories-in our own culture those of purpose, intelligence, and emotion-which are also the distinctive categories for the description of human action. The application of these categories leads us to say that such objects are "personified." The relationship between human beings and religious objects can be further defined as governed by certain ideas of patterning and obligation such as characterize relationships among human beings. In short, Religion can be looked upon as an extension of the field of people's social relationships beyond the confines of purely human society.

(1960: 211)

The virtue of Horton's approach lies in several areas. First, religion is action, not just "belief" or "ideas," and even when it is belief or ideas those too are actions. Religion calls upon its members to behave and to live in certain ways, from how they wear their hair to the food they eat to the names they take to how they structure their time and their space. Second, religion involves a particular kind of entity (often called "spiritual"), which has many of the essential qualities of a human being, of a person, especially mind or will or personality. These entities are "agents" that act with intention. Therefore and third, human beings enter into the same kinds of relationships with them that we enter into with each other-relationships of communication, trust, authority, love, respect, fear, dependence, and so on. That is to say-and Horton says it-religion posits some set of non-human persons with whom humans interact in a social way. Non-human spiritual persons are a part of society-and more than just a part.

\section{The Modular Nature of Religion}

Members of religions and scholars of religions alike have been inclined to assume an essence, and a true essence, in religion. However, the plethora of new religions and a closer inspection of established religions show that a religion is not a categorial "thing" so much as a composite product. In fact, religion was one of the first areas to which compositional thinking was applied. Anthony Wallace noted in 1966 that the term religion is "a summative notion and cannot be taken uncritically to imply . . . one single unifying, internally coherent, carefully programmed set of rituals and beliefs" (78). More precisely, for Wallace religion starts from a unique "premise," that supernatural entities like "souls, supernatural beings, and supernatural forces exist" (52). From there, any particular religion is constructed out of a combination of "elementary particles," building blocks or bits, all of which have their non-religious counterparts, of which Wallace identified thirteen: (1) prayer (or talk more generally), (2) music and dancing and singing, (3) physiological exercises, including substance use and physical hardships and trials, (4) exhortation or orders, encouragements, and threats, (5) myth, (6) simulation/imitation such as magic, witchcraft, and ritual, (7) mana or the power one gets from contact with powerful objects, (8) taboo or the prohibition from contact with certain things, (9) feasts, (10) sacrifice, (11) congregation or group activity, (12) inspiration, such as hallucination and mysticism, and (13) symbols. Particular assemblages of these bits form "ritual complexes," and particular bundles of ritual complexes form a "cult institution," understood as "a set of rituals all having the same general goal, all explicitly rationalized by a set of similar or related beliefs, 
and all supported by the same social group" (1966: 75). A loosely integrated combination of cult institutions is, for Wallace, a religion.

Whether Wallace's thirteen elements are exhaustive (and they are probably not) is secondary. The point is that religion in general, and any specific religion, is seen as an amalgamation of items, no one of which is "essential." Religion is a product of (already existing) materials. For Pascal Boyer and Scott Atran, it is a by-product, picking up and integrating already existing psychological and social traits of humans, such as concept formation, attention to exception, reciprocity or social exchange, and, most basically, agency detection-the attribution of mind or will or intention to others. So Boyer concludes that religion arises from "mental systems and capacities that are there anyway ... . [T] he notion of religion as a special domain is not just unfounded but in fact rather ethnocentric" (2001: 311). Atran states still more strongly and clearly that "there is no such entity as "religion"” (2002: ix) but that religion as a phenomenon and any particular religion as an institution is a result of the conjunction of more basic, interchangeable, and ultimately human and social modules.

The further significance of this perspective is the appreciation that each actual religion is not a closed and discrete "type" (any more than a race or a gender is a closed and discrete "type") but instead a historically and culturally specific aggregation of more basic elements. These elements, like genes in biological populations, can move between religions, so that, for instance, Christianity can absorb a bit from another religion like Buddhism or Native American religion. Even more profoundly, a religion can absorb a bit from non-religious sources: some of the most common, and most consequential, sources in recent experience have been politics, economics or class (think of the contemporary version of Christianity known as the "prosperity gospel”), race, nationalism (both of which combine with religion in many varieties of the white supremacy movements as described in Chapter 3), psychology, technology, and even popular culture (music, movies, etc.). Religions are thus open, diverse, and evolving phenomena, and nowhere has this been more apparent than in the United States.

\section{The Social Functions of Religion}

For members of a religion, the most important question is usually whether the religion is true and what exactly the religion requires of them. For the social sciences, the most important question is how religion is related to society and what it does for that society. There have been many theories of why religions exist and what they contribute to individual and collective life, but for our purposes three functions of religion are key: explanation, control, and legitimation.

All religions answer certain questions, such as how the world began or why sickness or death exists. This is the explanatory function, which can provide explanations for origins, for reasons why things occur, and for basic descriptions of how the world works. One of the most common types of religious explanations is the origin story, often told in myth: the actions of spirits or of human ancestors brought particular conditions into being. These origin stories can explain the sources of natural facts like death or pain during childbirth and, more to our purposes in this book, the sources of social facts, like government or marriage or language. In its cosmology, a religion can explain how the very universe is organized-what kinds of dimensions and entities it contains. Finally, religion can also explain more specific problems, not just the cause of sickness and 
misfortune but the cause of $m y$ sickness or misfortune. Of course, not all religions answer all questions. Not all religions, for example, tell members how to get to heaven, since not all religions have a concept of heaven; likewise, not all religions tell members how to achieve a better rebirth, since not all religions have a concept of rebirth (like Hinduism does). As Sherry Ortner (1978) noted, a religion answers the questions that the religion poses in the first place. And sometimes the answer is that we don't know the answer.

Humans are not, though, idle speculators. We want knowledge for specific and practical purposes. If we are sick, we want to know how to get well. If there is a storm coming, we want to know how to turn it away. If there is a problem with our government or economy, we want to solve it. The second function of religion is (at least possible or putative) control-control of nature, control of supernature (i.e., influencing supernatural beings), and control of society. Again, our purposes focus on society. Religion provides social control by giving rules for behavior, rewards and punishments for obeying those rules, supernatural agents to administer the rules, and human agents (priests and prophets, diviners and witches) to manage the religious system. Religion is "political" in this sense, and when it functions well it "gets results."

Humans face an additional challenge, which is to understand why they should do these particular things, follow these particular rules, live this particular way. Why is this the good way, the right way, the legitimate way? Religion provides this legitimation as no other source can-by taking it out of human hands. The deep significance of religious explanations, whether of natural and of social facts, is that those facts were either ordained by or are the consequence of non-human and super-human action. A religious rule or reality is a "given" for humans, because it is given to humans, not a result of their own decision. A human-made rule or institution could, after all, change by human agreement or could be wrong. But rules and institutions created (by decree or precedent) by superior beings have superior authority because those superior beings are the author. Thus, the religious explanation and origin of a social fact makes that fact automatically righteous and obligatory. It gives the ultimate reason for practicing and preserving that way of life.

\section{Box 9.1 “Civil Religion” and Religious Legitimacy in the US}

According to Robert Bellah, "there actually exists alongside of and rather clearly differentiated from the [Christian] churches" another religion which is equally "elaborate and well-institutionalized" (1967: 1). Admittedly borrowing a term from Rousseau's The Social Contract, he called this second faith America's "civil religion." Central to this civil religion is the concept of "God," "a word that almost all Americans can accept but that means so many different things to so many different people that it is almost an empty sign" (3). The civil religion does not ordinarily make reference to Jesus or to specific beliefs and doctrines that might be divisive. As he admitted, the god of civil religion "is not only rather 'unitarian,' he is also on the austere side, much more related to order, law, and right than to salvation and love" (7). Neither the god nor the civil religion as a whole is "in any specific sense Christian," but the god is not a general god, and 
(continued)

the civil religion is not a "religion in general" (8). Why does the US have and need a civil religion in addition to Christianity? Bellah's answer was first that no sectarian religion, even Christianity, can or should be injected into civil affairs, yet there are occasions and circumstances in which a religious invocation seems appropriate, even essential. Bellah thus suggested that the civil religion provides a religious sanction that (most) Americans can accept. But why is a religious sanction required at all? His answer was that a society and its institutions require legitimation and transcendental goals. Religion not only explains but legitimates social arrangements; in the US, where the people are sovereign and their will law, the civil religion assures citizens that "the ultimate sovereignty" lies with God. This both ensures the goodness and value of the laws and institutions and also provides a ground for judging and criticizing them: "The will of the people is not itself the criterion of right and wrong. There is a higher criterion in terms of which this will can be judged; it is possible that the people may be wrong" (4). Further, the sense of transcendental goals means that American decisions and actions are "going somewhere," part of a greater plan and a greater good-literally, that Americans are doing God's work on earth. This makes their history and their policies virtuous and important by definition. Even this does not exhaust the efficacy of the civil religion. It is "ceremonial" but not merely ceremonial; the civil religion achieves "national solidarity" $(13)$ in a way that no other more sectarian religion can because it calls upon "God" as a national symbol-one that means whatever the hearer wants it to mean. In other words, the very fact that "the meaning of God is by no means so clear or obvious" allows listeners and participants to hear and feel and believe whatever they are so inclined. It does not ask them to believe anything in particular but merely to believe something (3).

\section{American Religion(s), or Religion American-Style}

The need for a unifying civil religion may become more obvious when we consider the extraordinary religious diversity in the United States: while there may be five or six or seven distinguishable race-categories, with dozens of possible combinations (see Chapter 3), there are literally thousands of religions, sects, and denominations of religion in the country and even more in the world. Incredibly, by one estimate (Barrett, Kurian, and Johnson 2001) there are 34,000 Christian sects in the world alone, not counting all of the non-Christian groups and, of course, the new religions that are being invented every day-as many as two or three a day by some accounts (e.g. Lester 2002: 38).

In the US, religion is equally fecund. According to the American Religious Identification Survey (ARIS) conducted by Barry Kosmin and Ariela Keysar in 2008, while 76 percent of the American population identified as Christian, the diversity within this designation was great, and no single church enjoyed a majority. Catholicism actually represented the largest single constituency, at around 25 percent, and the "Protestant" category was, as it has always been, subdivided into numerous denominations. Then, obviously, some 25 percent of Americans identify as non-Christian, including up to 15 percent who identify as "no religion" (more on them below). 
Table 9.1 The Christian population of the US

\begin{tabular}{lrrrr}
\hline & $\begin{array}{l}\text { Number } \\
1990\end{array}$ & $\begin{array}{l}\text { Percent } \\
1990\end{array}$ & $\begin{array}{l}\text { Number } \\
2008\end{array}$ & $\begin{array}{c}\text { Percent } \\
2008\end{array}$ \\
\hline Total US adult population & $175,440,000$ & 100 & $303,203,000$ & 100 \\
Total Christian groups & $151,225,000$ & 86.2 & $173,402,000$ & 76.0 \\
Catholic & $46,004,000$ & 26.3 & $57,199,000$ & 25.1 \\
Baptist & $33,964,000$ & 19.4 & $36,148,000$ & 15.8 \\
Protestant-no denomination & $17,214,000$ & 9.8 & $5,187,000$ & 2.3 \\
Methodist/Wesleyan & $14,174,000$ & 8.0 & $11,366,000$ & 5.0 \\
Lutheran & $9,110,000$ & 5.1 & $8,674,000$ & 3.8 \\
Christian-no denomination & $8,073,000$ & 4.6 & $16,834,000$ & 7.4 \\
Presbyterian & $4,985,000$ & 2.9 & $4,723,000$ & 2.1 \\
Pentecostal/Charismatic & $5,647,000$ & 3.2 & $7,948,000$ & 3.5 \\
Episcopal/Anglican & $3,043,000$ & 1.7 & $2,405,000$ & 1.1 \\
Mormon & $2,487,000$ & 1.4 & $3,158,000$ & 1.4 \\
Churches of Christ & $1,769,000$ & 1.0 & $1,921,000$ & 0.8 \\
Jehovah's Witness & $1,381,000$ & 0.8 & $1,914,000$ & 0.8 \\
Seventh-Day Adventist & 668,000 & 0.4 & 938,000 & 0.4 \\
\hline
\end{tabular}

Source: Institute for the Study of Secularism in Society \& Culture. American Religious Identification Survey 2008: Summary Report

Table 9.2 The non-Christian population of the US

\begin{tabular}{lclcc}
\hline & Number 1990 & Percent 1990 & Number 2008 & Percent 2008 \\
\hline Total other religions & $5,853,000$ & 3.3 & $8,796,000$ & 3.9 \\
Jewish & $3,137,000$ & 1.8 & $2,680,000$ & 1.2 \\
Muslim & 527,000 & 0.3 & $1,349,000$ & 0.6 \\
Buddhist & 404,000 & 0.2 & $1,189,000$ & 0.5 \\
Hindu & 227,000 & 0.1 & $934,000^{*}$ & 0.4 \\
New religious movements & $1,296,000$ & 0.8 & $2,804,000$ & 1.2 \\
$\quad$ and other religions & & & & \\
Total no religion & $14,331,000$ & 8.2 & $34,169,000$ & 15.0 \\
Atheist & N/A & & $1,621,000$ & 0.7 \\
Agnostic & $1,186,000$ & 0.7 & $1,985,000$ & 0.9 \\
Humanist & N/A & & 49,000 & $<0.1$ \\
Don't know/refused & 4,031,000 & 2.2 & $11,815,000$ & 5.2 \\
\hline
\end{tabular}

Source: Institute for the Study of Secularism in Society \& Culture. American Religious Identification Survey 2008: Summary Report

"estimated (not included in 2008 survey)

The Pew Forum's US Religious Landscape Survey, the numbers of which vary slightly from the ARIS report, added that 0.6 percent of Americans were Orthodox/ Eastern Christians and that less than 0.3 percent were Quakers.

Not to mention the tens of thousands of Unitarians, Baha'i, Sikhs, Taoists, Wiccans, Scientologists, Rastafarians, Santerians, Druids, and so on, ad infinitum. 


\section{Diversity Fact:}

Identification with a religion does not necessarily entail active participation in that religion. The ARIS study finds that only 59 percent of Catholic households actually maintain membership in a church, whereas 69 percent of Baptist households do, 55 percent of Jehovah's Witnesses, 68 percent of Lutherans, 66 percent of Methodists, 75 percent of Mormons, and 83 percent of Evangelicals/Born Agains. The national average for active membership in one's stated religion is 54 percent.

The diversity within religions must not be overlooked. For instance, within Christianity there are the three main divisions of Catholic, Protestant, and Orthodox, each not only holding different religious views but also different forms of organization. American Catholicism is part of a unified worldwide institution headed by the Pope. Orthodox Christianity has no international organization but is subdivided into multiple "national churches," such as Russian Orthodox, Greek Orthodox, and so on. Protestant is more a type or category of church than an ecclesiastic organization; there is no centralized Protestant organization. Within the Protestant category are many churches such as Baptist, Methodist, Presbyterian, Lutheran, Episcopal (the American version of Anglican), and innumerable others. However, even "Baptist" or "Methodist" is not a single unified identity or ideology: according to Albert Wardin, writing for the Baptist History and Heritage Society, there are at least 54 distinct "groups and subgroups" under the Baptist umbrella, ranging "from the Southern Baptist Convention with millions of members and tens of thousands of churches to the General Six Principle Baptists which today have only one remaining small church" (2001: 1), not to mention the American Baptist Churches, the Cooperative Baptist Fellowship, the Swedish Baptist, the Baptist Missionary Association, the Free Will Baptist, the Baptist Bible Fellowship, the Primitive Baptist, the Seventh-Day Baptist, the Slavic Evangelical Baptist, the United Baptist, the Full Gospel Baptist, and various "historically Black" Baptist churches. Similarly, Methodism is more a movement than a specific church, comprising over 40 Methodist/Wesleyan groups. To be sure, not all Jews or Muslims or Hindus, etc. in the US believe the same things or are organized into a single institution either, as we will see below.

\section{The American Style of Religion}

One of the reasons why religions are so diverse is that they, like but even more so than other aspects of culture, have an uncanny ability to adapt to local social circumstances. General American society and values differ from other societies and affect the way that Americans practice their religions. Even de Tocqueville perceived that early Americans had "brought to the New World a Christianity which I can only describe as democratic and republican” (1969: 288). Since his observations, many other students of American religion have commented on the unique qualities of American religion, including populism, religious searching and revivalism, emotionalism, moralism, and syncretism and innovation.

American religions have tended to be religions "of the people, by the people, and for the people" and to disdain the high theology of "learned men" and formal institutions. 
Especially in its Protestant forms, American religions have often even foregone formal training in favor of non-ordained, self-appointed preachers who claim as much authority in religious matters, and often have as much or more effect on religious matters, as "official" religious leaders and trained theologians. Since Americans privilege the rights and feelings of the individual and resist the authority of "experts," they are often attracted to the self-made religious man (the Billy Grahams and Benny Hinns) and struggle against the structured religion that would dictate to them. Most dramatically, many American Catholics do not accept the mandates of the Pope and the Church. Beyond issues of leadership, populist religion must speak to the interests, values, and practices of the masses, the ordinary folk, whether this is the middle class, the urban poor, young people, or punks and Goths. Hence, religions morph to suit the audience they address.

American religion is also remarkably dynamic and unsettled. In fact, the great scholar of American religion, Martin Marty (1984), insisted that Americans are on a "constant pilgrimage," looking for something to fulfill them. Even de Tocqueville noticed that Americans are a restless people, always on the move, including in their religious identity. Much more recently, Richard Madsen has insisted that what Americans value more than faith is the "faith journey," and he regards "the most typical religious act in America" to be "seeking/finding" (2009: 1283). One expression of this attitude is the "tent revival," the circulation of peripatetic preachers who try to stir up religious fervor; in former days, this involved a literal tent, although today it can exploit the media of television and the internet. Another expression is the historical cycle of religious enthusiasm, like the "Great Awakenings" to be discussed below. A third, as we will mention shortly, is the continual tinkering with or even invention of religions.

Americans, as pragmatists and individualists, want their religion to be personally meaningful and effective, which largely means affective, that is, emotional. For many Americans, religion is less of something to believe or even to do than of something to feel. Americans tend to embrace religions with heart, seeking ones that make them laugh and cry. Since, as Madsen stresses, Americans actively choose their religion, then Americans tend to base that choice on which "faith gave them satisfaction" (2009: 1278). He notes in particular that some of the fastest-growing religions in the country are those that "place strong demands on their members, intellectually, emotionally, and morally" (1269). Some forms of American religion, like Pentecostalism, include (to many people) extreme outbursts of emotion or enthusiasm (from the root en-theos literally meaning "God within") such as jumping and clapping, weeping, falling down and rolling, speaking in tongues, and the like.

American religions tend to be preoccupied with "moral" issues and to place "morals" and "values" high on their agendas. Americans often think that theirs is a uniquely moral country, which they see as a guarantor and protector of good and right in the world (a "shining city on the hill," one leader said, a "beacon to the world"). The revivalism in American religions has frequently consisted of an effort to renew the "moral character" of individuals and society, and practically and even legally, American religions often mobilize over "moral" (which tends to be a code-word for "sexual") problems like abortion, marriage, homosexuality, pre-marital sex, contraception, pornography, and more recently stem-cell research, etc.

Americans, as individualists and inventors, invent not only their individual religious identities but also entirely new religions. Accordingly, America has been the scene for a 


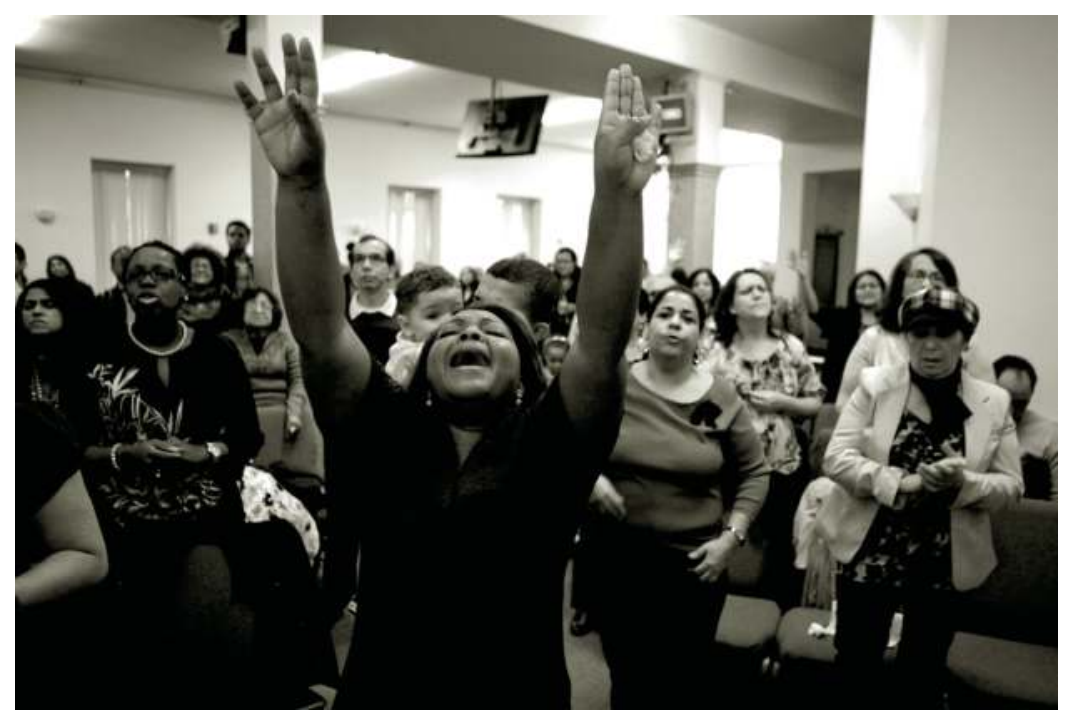

Image 9.1 Evangelical congregation in Boston.

(Courtesy of Melanie Stetson Freeman/The Christian Science Monitor via Getty Images)

remarkable amount of religious innovation, creating previously unknown religions like Mormonism (Latter Day Saints), Christian Science, Jehovah's Witnesses, Shakerism, and, more recently, Scientology and The Evolutionary Level Above Human (TELAH, better known as "Heaven's Gate"). Certain themes recur in these systems (which are widely held to be "cults" in their initial phases but usually become respectable denominations and churches if they survive long enough) such as apocalyptic expectations, the notion of sin, and a sense of being the special or chosen people. As in TELAH and Scientology, the tendency toward religious syncretism has allowed Americans to blend familiar Christian themes with aspects of other religions and even of non-religion like psychology, technology, and popular culture, including science fiction/UFO ideas.

Again, to be sure, not all American religions evince these general tendencies, nor do the members of any one religion agree on all the correct doctrines and activities. This fact makes for still greater diversity and individual interpretation.

\section{A Brief History of American Religions}

As mentioned, it is a widely stated opinion (at least among the Christian majority) that the US is a Christian country or was founded by Christians or on Christian principles or was founded on the principle of religious freedom. Notwithstanding that the last claims are contradictory, it is true that European settlers brought with them their Christianity but that they settled the continent for multiple reasons-one of which was religion-and with multiple attitudes toward and outcomes for religion.

Jamestown (founded 1607: see Chapter 3), the first English settlement in America, was actually a business venture, not a religious colony, and as an official outpost 
of English society it was officially not just Christian but Anglican; failing to be an Anglican, or failing to attend Anglican church services, was punishable. The England that populated the American colonies was, in fact, a singularly intolerant society, with laws like the 1648 Ordinance for the Punishing of Blasphemies and Heresies which specified the death penalty for rejecting Christ's divine nature (e.g. for all nonChristians as well as certain heretical Christians), for Unitarianism, for questioning the authenticity of the Christian scriptures, and, of course, for atheism. The 1662 Act of Uniformity established Anglicanism as the sole religion of the state, and the Test Act of 1673 required all state office holders to take an oath against Catholicism.

Coming from such an environment, it is unlikely that most English immigrants would have a noticeably liberal attitude toward religion-especially the "Puritans" of Massachusetts, a fundamentalist sect that rejected and was rejected by the mainstream Anglican community. They came to North America for their own religious freedom but not to promote freedom and equality of all religions: as Samuel Willard wrote of his recent ancestors in 1681, "I perceive they are mistaken in the design of our first Planters, whose business was not toleration; but were professed Enemies of it, and could leave the World professing they died not Libertines. Their business was to settle, and (as much as in them lay) secure Religion and Posterity, according to that way which they believed was of God" (quoted in Feldman 1997: 331). Anyone who disagreed with the Puritan belief "shall have free Liberty to keep away from us, and such as will come to be gone as fast as they can, the sooner the better" (quoted in Feldman: 125). Quakers were officially banned, Jews was forbidden from residing in the colony, and blasphemy was a capital offense. Colonial Maryland's much-vaunted 1649 Toleration Act provided fairly little toleration, ordering

That whatsoever person or persons ... shall from henceforth blaspheme God, that is Curse him, or deny our Saviour Jesus Christ to be the son of God, or shall deny the holy Trinity the father, son, and holy Ghost, or the Godhead of any of the said Three persons of the Trinity or the Unity of the Godhead, or shall use or utter any reproachful Speeches, words or language concerning the said Holy Trinity, or any of the said three persons thereof, shall be punished with death and confiscation or forfeiture of all his or her lands and goods to the Lord Proprietary and his heirs.

In other words, the first century of American settlement was the age of religious establishment, with each colony typically promoting its own particular denomination and using political power to suppress heterodoxy, to enforce church membership and attendance, to collect obligatory taxes to support the established church, and to punish all who violated religious regulations. To be sure, religions other than Christianity-and often other than Protestant Christianity-were not even acknowledged, let alone tolerated.

By the early 1700s, the settlers were outgrowing the original coastal colonies and drifting westward to the interior of the continent. Individuals and families were slipping from the direct control of centralized churches, and in many instances their perceived moral character was declining. Hence arose the First Great Awakening, during the decades from 1720 to 1750 , the first peak in a cycle of rising and falling American religious enthusiasm. According to Marty (1984), the key to the first awakening, as perhaps to every subsequent one, was choice, in the sense that individuals had many 


\section{Religion}

churches and denominations to choose between and in the sense that commitment to a particular church or denomination was a personal choice, a voluntary commitment. All of the old churches were available to choose from, as well as several new ones, including Baptism and Methodism. And religion was carried to the masses, especially the rural western masses, by men of religious conviction, "circuit-riders" who traveled from town to town with the fire of religion in their bellies-men like Jonathan Edwards and George Whitefield and James Davenport and Charles Woodmason, who left indelible marks on American religion with their tent meetings and their energetic evangelism. By the early 1880s Methodism had exploded from less than 5,000 members to more than 200,000.

The American Revolutionary War distracted attention from religion for a few decades, bringing with it the founding of the modern state known as the United States of America, the US Constitution (written 1787), and the era of disestablishment, that is, the severing of the official relationship between government and churches. The effort took many years and many legal battles, but by the early to mid-1800s most states had separated themselves from religion. Many scholars regard this end to official support of one or more favored religions as one of the principal factors in the burst of religious energy that came to be known as the Second Great Awakening (1820-50), during which several now-famous directions in or denominations of religion emerged.

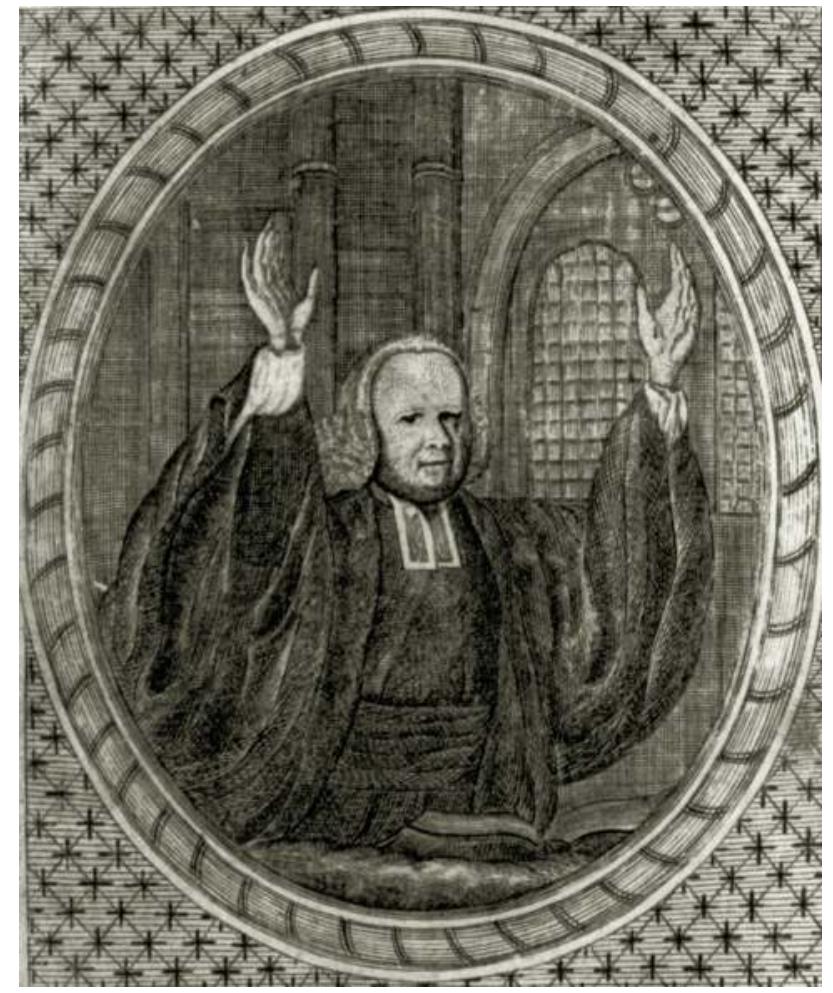

Image 9.2 George Whitefield, eighteenth-century illustration.

(Courtesy of the Library of Congress, Prints and Photographs Division) 
One aspect of the Second Great Awakening was the appearance of the "primitive Christianity" movement, an attempt to find a simpler and more authentic Christianity, more in tune with what was perceived as the original teachings of Jesus and the structure of the early church. Groups that called themselves merely "Christian" or "Disciples of Christ" appeared, led by men like Barton Stone and Alexander Campbell. One hot-bed of religious enthusiasm was upstate New York, which was nicknamed the "burned-over district" for the movements that sprang up and spread there. The most successful of these was the Church of Jesus Christ of Latter Day Saints, also known as the Mormons, originated by Joseph Smith in western New York: it was perhaps the first truly "American" Christianity since it taught of a Judeo-Christian society in pre-Columbian America with its own advent of Christ. Mormonism, or LDS, was not well-received outside the new church, and its members fled further west, eventually reaching the Great Salt Lake where they settled in what would become Utah.

Another aspect of the Second Great Awakening was apocalyptic thinking. This was a time of expectation of the end of the world, as seen in William Miller's predictions of Jesus' second coming. Following what is remembered as "the great disappointment" (i.e., the failure of the world to end), Miller's movement evolved into Seventh-Day Adventism. Yet another trend of the early nineteenth century was utopian communitarianism, the belief that people could create ideal and perfect communities. Some of these were non-religious (like the Oneida Community), but others were religious, like the United Society of Believers, also called Shakers, founded by "Mother Ann" Lee. A final quality of this period was a fascination with mentalism or spiritualism, sometimes referred to as transcendentalism, which emphasized the power of mind or spirit over body or matter. In some ways this notion was compatible with Christianity; in many other ways it was distinct from and in some instances opposed to Christianity.

Two important sources of transcendentalism were the hypnosis of Franz Anton Mesmer (from whose name we get the term "mesmerism" for hypnosis) and the spiritualism of Emanuel Swedenborg. In writings like The Worship and the Love of God and his eight-volume Arcana Coelestia, Swedenborg championed a view of mind/spirit and body/matter existing on different planes, of which humans could become more aware and more in control. Enlightenment of this sort was not dependent on knowledge of any specific religion or scripture but on the achievement of a higher consciousness that could be known directly from nature or experience. This attitude was influential outside of religion as well, including in the literature of Ralph Waldo Emerson, who rejected "religion" in favor of spiritual intuition: religion as known in its conventional (including Christian) guises was little more than "the dead forms of our forefathers" (quoted in Marty 1984: 210). Spiritual growth did not require a religion or church. Out of such ideas, often mingling with more traditional Christian ones, came mindcure movements like Christian Science (formally, the Church of Christ, Scientist) and, of course, much later Scientology, the Unification Church of Reverend Sun Myung Moon, and teachers like Norman Vincent Peale and Deepak Chopra.

In the late 1800s, what we can rightly call the first "New Age" came, with exposure to Eastern, ancient, tribal, and pagan religions as they syncretized with Christianity and mentalism/spiritualism. Helena Blavatsky and Henry Olcott, working in the 1870s, were instrumental in introducing Hinduism and Buddhism to America through their Theosophical Society. Blavatsky and other group founders conveyed yoga, meditation, and concepts of "the occult" into mainstream US society. The World's Parliament of 


\section{Religion}

Religions, held in Chicago in 1893, was also highly significant for bringing nonChristian religions to American attention, as was the visit of Zen Buddhist master Daisetz Taitaro Suzuki in 1897.

The cross-breeding of Western/Christian religions (already, as we have seen, quite diverse) with non-Western/non-Christian religions was very fertile, producing a plethora of new religious experiences (often marketed as old religious experiences) of an "esoteric" nature. For instance, in 1907 Levi Dowling published The Aquarian Gospel of Jesus the Christ, long before the better-known "Age of Aquarius" in the 1960s. The year 1911 saw Rudolf Steiner's account of The Submerged Continents of Atlantis and Lemuria, while Ian Ferguson wrote on The Philosophy of Witchcraft in 1924 and Gerald Gardner essentially launched the modern pagan/witchcraft movement with his 1954 Witchcraft Today and 1959 The Meaning of Witchcraft.

Christianity too responded to changing times, first with the "social gospel" focused on addressing poverty and injustice and later with "fundamentalism," "Pentecostalism," and "evangelicalism," all intended to restore the true and personal experience of the religion to their followers. Fundamentalism emerged in the years between 1910 and 1915 to meet the challenge of evolutionism specifically and modernism more generally. Based on a series of publications called The Fundamentals: A Testimony to the Truth, it endorsed a set of principles familiar to Christianity, particularly Protestant Christianity, namely the infallible truth of the Bible, the virgin birth and divinity of Jesus, the atonement for sin through his crucifixion, and his bodily resurrection and inevitable return. This led to the formation of the World's Christian Fundamentals Association in 1919, following in the tradition of the Niagara Bible Conference (1883) and the Bible Institute of Los Angeles (1909). Mostly apoliticalintent on saving souls, not winning votes-fundamentalism and evangelicalism turned political in the late 1970 s, as we will see below.

\section{Diversity Fact:}

The Scopes "monkey trial" was a dividing line between the old fundamentalism and the new. Technically known as The State of Tennessee $v$ John Thomas Scopes, the 1925 case involved Scopes, a teacher who intentionally violated Tennessee's law against teaching evolution. A show trial throughout, each side hired a high-profile lawyer-William Jennings Bryan for the state and Clarence Darrow for the defense. Contrary to common knowledge, Scopes actually lost the case and paid a $\$ 100$ fine, but fundamentalism was so discredited in the process that it did not re-emerge until the 1950s. In the meantime, Mississippi and Arkansas added their own anti-evolution laws.

\section{Religion in Contemporary American Society}

At the opening of the twenty-first century, religion was more prominent in American society than at any time in recent decades, yet it was also vastly more diverse. The simultaneous prominence and pluralism of religion make for a curious and complicated American religious scene. 


\section{Competing Styles in Christianity}

It is more than apparent that "Christian" is not a single monolithic identity or ideology, any more than "white" or "male" is. Not only are there multiple churches, denominations, and sects of Christianity (and some disagreement as to who precisely is a Christian: there are those who deny that Mormons are Christians and even those who deny that Catholics are Christians), but within each church/denomination/sect there are differences in style and approach. For instance, it is often claimed that all religious people are conservative, either politically or theologically, but this is not true. There is a liberal Christian stream that accepts and embraces various aspects of modern and secular culture; many Christians either do not hold conventional conservative beliefs and values or actually use their religion to promote "liberal" causes like the equality of women, the rights of gays and lesbians, or, as in the case of Martin Luther King, Jr., civil rights. Some liberal Christians go so far as to reject the notion that only Christianity has religious truth, believing all religions have (at least some) validity.

In recent years, the evangelical stream of Christianity has become a major cultural force. According to the Barna Group, an organization that conducts religious surveys, an evangelical is first a "born-again Christian," a person who has made a personal commitment to Jesus and embarked upon a new religious existence; additionally, they take "a personal responsibility to share their religious beliefs about Christ with nonChristians," which beliefs include the existence of the devil, salvation through grace, the perfection of the Bible, and the sinless nature of Jesus. By some measures, as much as 40 percent of the US population applies the label to themselves. However, the Barna Group also finds extreme diversity within this group: not all accept the Bible as absolutely accurate, less than half believe that the devil is real, and over one-quarter are not even born-again (2007).

The term Pentecostalism refers to a particular brand of Christianity that stresses "the gifts of the spirit" through a direct personal contact with divinity. It was born around the same time as the official fundamentalist movement; the General Council of the Assemblies of God, established by three hundred Pentecostal leaders in 1914, was the first large and organized Pentecostal body, and ARIS recorded almost 1 million members of the Assemblies of God in 2008, with 663,000 more in the Church of God. Pentecostalism most fully develops the American personal-emotional approach to religion, stressing intense emotional and ecstatic experiences and "signs" of the Holy Spirit like speaking in tongues, clapping and singing and jumping, and "laying on of hands" for miraculous healing.

Fundamentalism, as already indicated, originally referred to a specific, and specifically theological, movement in early twentieth-century America. Since then, it has taken on two important characteristics. First, it no longer applies exclusively to that movement but has become a general religious style; the point is that the "fundamentals" of a religion depend on precisely what that religion teaches. For instance, Americans may be familiar with the Fundamentalist Church of Jesus Christ of Latter Saints, or FLDS, which came to media attention for its closed polygamous communities. Obviously, not all Christian fundamentalists practice or defend polygamy. At the same time, fundamentalism is no longer exclusively Protestant or even Christian: there is a fundamentalist Catholic trend, as well as fundamentalist Judaism(s) and Islam(s), not to mention Hinduism and other religions. 
Second, Protestant-Christian fundamentalism has divided into an intriguing, if not disturbing array of distinct movements. Many fundamentalists simply want to conduct religious lives detached from the modern society that they disdain; in this sense, the Amish would qualify as fundamentalists, who keep true to their fundamentals. Most familiar is the political fundamentalism of the Moral Majority, the Christian Coalition, and Focus on the Family. Already mentioned is the racist fundamentalism of the Ku Klux Klan (see Chapter 3), the Christian Identity movement, and other such groups. At the far end of fundamentalism, unknown to most Americans, are the Christian Reconstructionists, also known as Dominionists. Christian Reconstructionism seeks to reshape ("reconstruct") American law and society in accordance with biblical, specifically Torah/Old Testament standards, including the death penalty for adultery, blasphemy, heresy, homosexuality, idolatry, and witchcraft; the banning of any congregation or religion that does not accept Mosaic law, including, of course, all non-Christian religions; the return of women's status to ancient conditions; the criminalization of abortion, punishable by death; and the elimination of income taxes and the prison system (the death penalty presumably rendering jail mostly unnecessary). Their rationale was expressed clearly by the late R. J. Rushdoony and his Chalcedon Foundation (www.chalcedon.org): “The law is therefore the law for Christian man and Christian society. Nothing is more deadly or more derelict than the notion that the Christian is at liberty with respect to the kind of law he can have" (1973: 8-9). And by law, they mean ancient Hebrew law.

\section{Non-Christians: Jews in America}

Jews represent the largest non-Christian religious group in the US, reckoned at 1.2 percent in 2008 by ARIS or 1.7 percent in 2008 by the Pew Foundation. They are a predominantly urban population, mainly located in East Coast cities (Boston, New York/Long Island, Philadelphia, Washington, DC) as well as Detroit, southern Florida,

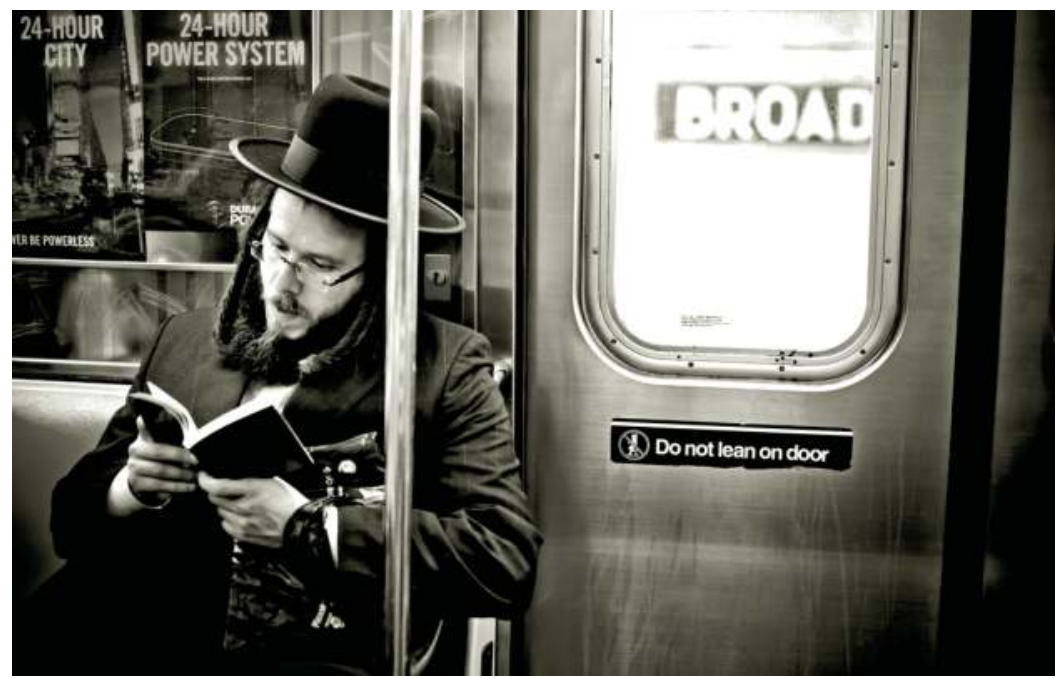

Image 9.3 A Jewish man on the subway in New York City.

(Courtesy of Andrey Bayda/Shutterstock.com) 
St. Louis, Las Vegas, Los Angeles, and San Francisco (see Figure 9.1). The Jewish group is further distinguished by sectarian differences, including Reform (43 percent of American Jews), Conservative (31 percent), and Orthodox (10 percent).

Jews have been in (although not always welcome in) the US from early in its history; by the outbreak of the Revolutionary War, there were some two thousand residing in the colonies. The increase in immigration from central and southern Europe during the middle and late 1800s brought many more Jews from countries like Germany, Poland, and Russia. As early as 1843 a national American Jewish organization, the B'nai B'rith, was founded. By 1900 approximately 1 million Jews lived in the United States, a full half of them in New York City. By 1924 that number has risen to 2 million but was substantially cut off by the National Origins Act (see Chapter 2)

Despite the presence of Jews in the republic from its inception, attitudes toward Jews were not (and often still are not) entirely positive. Anti-Semitism, prejudice against and discrimination specifically toward Jews, has been a perennial problem in the country. As noted above, Jews were banned from some pre-independence colonies, and during the Civil War General Ulysses Grant even tried to expel them from the areas of the South under his control (a decree rejected by President Lincoln). The last state to grant Jews political equality was New Hampshire in 1871. The later nineteenth and the twentieth centuries were a period of organized, even institutionalized, anti-Semitism, just as it was a period of institutionalized, even scientific, racism (see Chapter 3). The large numbers of immigrants were altering the face of some American cities; Jews were often distrusted for their alleged disproportionate control of wealth and power; and, of course, they were non-Christians. A poll conducted in 1939 indicated that only 39 percent of Americans believed that Jews should be treated equally to other Americans, that more than half thought they should be restricted in some way, and 10 percent wanted them out of the country altogether.

Meanwhile, the revived Ku Klux Klan of the 1920s and beyond added anti-Jewish propaganda and even violence to its agenda, and prominent Americans like Henry Ford spoke and wrote in openly anti-Semitic ways. A group of workers and police attacked a Jewish funeral procession in New York City in 1902, a Jewish man named Leo Frank was lynched in 1915, and race riots in Detroit in 1943 spilled over to Jewish businesses. In response to such dangers, the Anti-Defamation League was founded in 1913 in order, as its website (www.adl.org) states, "to stop the defamation of the Jewish people and to secure justice and fair treatment to all."

Sadly but not surprisingly, other minorities in the US, especially African Americans, and especially African American members of the Nation of Islam, have been particularly anti-Semitic, claiming that Jews are responsible for many of the woes of the black community. A study in 1998 by the Anti-Defamation League showed that blacks were almost four times as likely to be highly anti-Semitic (34 percent) as whites (9 percent). A subsequent study by the same organization (2005) found that overall anti-Semitism had actually increased slightly (from 12 percent to 14 percent), that older and less educated people held the most negative views toward Jews, and that Hispanics were also more likely to hold extremely anti-Semitic opinions (29 percent) than the general population. As noted in Chapter 3, many of the white nationalist and Christian Identity organizations also disdain Jews, and certain "militia" groups have come to claim a conspiracy by Jews to take over the American government as establish the "ZOG" or Zionist-occupied government, if, they say, it has not happened already. 


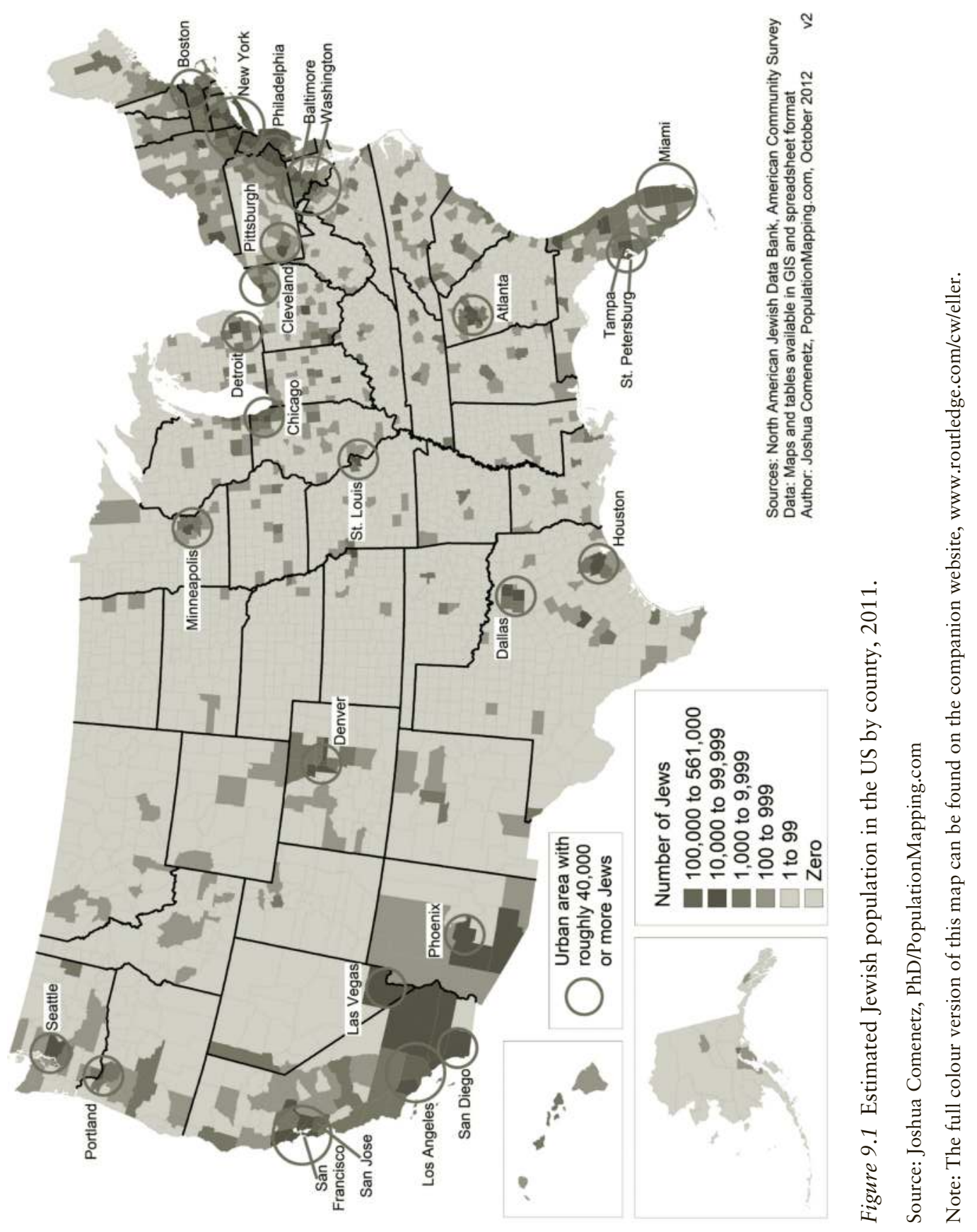




\section{Non-Christians: Muslims in America}

Muslims have come to the recent attention of Americans, unfortunately, because of the September 11, 2001 attacks. Few Americans realized that Muslims have been on the North American shores as long as Europeans/Christians have, traveling with Columbus' expedition in 1492. Many Muslims were brought to America as African slaves-as many as 15-20 percent of the entire transported population-although few of their names are known, other than Selim the Algerian (died 1825).

The chronicle of Islam in America resumes after slavery with the arrival of southern European, Middle Eastern, and Asian immigrants in the latter half of the nineteenth century. Muslims in the US then and since have hailed from many different countries and continents, adding a racial, linguistic, and ethnic dimension to the religious diversity: Muslims came and continue to come from Arab countries as well as South Asia (especially India, Pakistan, and Afghanistan), Southeast Asia (such as Malaysia and Indonesia), Iran (where the majority is Persian, not Arab), Turkey (where the majority is Turkish, not Arab), Europe (particularly Albania and Bosnia), and Africa. However, as Numan (1992) rightly observes, the complexity of Muslim identity in America is greater yet, since the community contains not only immigrants who brought their religion with them as well as their offspring born in the US but converts among the already existing population, of all races and ethnic groups but predominantly African American.

Hence the story of Islam in America cannot be completely divorced from the story of Africans in America. A Sudanese immigrant named Satti Majid founded the Muslim Union Society in New York around 1904, which led to other organizations like Sheik Daoud Ahmed Faisal's Islamic Mission of America in 1924. However, American-born blacks also appropriated Islam as early as the Moorish Science Temple of Noble Drew Ali, opened in 1913 in Newark, New Jersey. Marcus Garvey of the "back to Africa" movement (see Chapter 3) was also influenced by Dusé Muhammad Ali, who started the Universal Islamic Society in Detroit around 1926. The main event, however, was the formation of the Nation of Islam sometime in 1930 or 1933, depending on the source. The key figures were Wallace Ford, renamed Fard Muhammad, and Elijah Muhammad. Under Elijah Muhammad and later Malcolm X (Al Hajj Malik al-Shabazz), the Nation of Islam evolved into a black-nationalist movement rejecting Eurocentric, Christian-centric culture and identity and tying the African American community to its home continent of Africa and its "true" religion of Islam. Louis Farrakhan eventually achieved leadership in the Nation of Islam.

After 1960 and the loosening of immigration restrictions, the Muslim population began to grow, through both immigration and conversion, and to organize. The Muslim Students Association (1963), the Islamic Circle of North America, United Muslims of America (1982), and the Council on American Islamic Relations (1994) are among such groups. Muslims currently comprise 0.6 percent of the American population, with African Americans making up the bulk of this number. Many immigrants and their ancestors from other countries, including Lebanon, Syria, Iran, Pakistan, Turkey, and Albania (under 114,000), have brought Islam to the US, although we cannot assume that all of these people were or remained Muslim. 


\section{Non-Christians: Eastern and Native American Religions}

Christianity, Judaism, and Islam are regularly regarded as the "Abrahamic" religions for their common doctrines and histories. However, the United States also hosts many religions with no ties to these traditions. Among the "Eastern" religions mentioned by the Harvard Pluralism Project (www.pluralism.org) are Hinduism, Buddhism, Jainism, Sikhism, Baha'i, Shinto, Taoism, Zoroastrianism, Native American religions, and paganism. The ARIS 2001 study, for example, counted over 1 million Buddhists and 766,000 Hindus in 2001, with 84,000 Baha'i, 40,000 Taoists, 57,000 Sikhs, and 140,000 pagans, not to mention Wiccans and Druids (not all of these groups were counted in the 2008 study). The 2008 Pew study gives the Buddhist total at 0.7 percent of the US population, larger than the Muslim population and further subdivided into Zen, Theravada, Tibetan, and other Buddhists; Hindus are estimated at 0.4 percent distinguished by many different beliefs and practices.

Hinduism, a religion associated with India, first came to American attention during the World Parliament of Religions of 1893, mentioned above. Swami Vivekananda, a disciple of Sri Ramakrishna, came to the event as a representative of the Ramakrishna Mission to promote the Vedanta teachings of Hinduism; he was also highly educated and familiar with Western and American ways and offered a form of Hinduism comprehensible and palatable to Americans. He established the first Vedanta Society in New York in 1894, and within half a century there were thirteen Vedanta centers in the US. Converts among Americans, many due to the efforts of the Maharishi Mahesh Yogi who was embraced by the Beatles in the 1960s, were supplemented by an influx of immigrants from India after 1965: the 2010 Census tallied more than 2.8 million Asian Indian Americans, although there are certainly Buddhists, Muslims, and even Christians among them. Hinduism is known in America today through many of its teachings (like reincarnation) and practices (like meditation and yoga), as well as organizations such as the International Society for Krishna Consciousness (ISKCON), better known as the "Hare Krishnas." The Hindu American Foundation (www.hinduamericanfoundation. org) was formed in 2003 to represent the Hindu American community.

\section{Diversity Fact:}

Four institutions in the vicinity of Washington, DC illustrate the diversity of American Hinduism. The Hindu American Religious Institute is a "non-sectarian temple" that includes elements from many parts of India, making it "a microcosm of the global Hindu community" (Long 2013: 20-1). The Washington Kali Temple is a specifically Bengali institution, while the Vedanta Center of Greater Washington, DC attracts "non-Indians raised in a North American, primarily Protestant Christian, religious milieu" (27). Meanwhile, parents who want their children exposed to the Hindu version of fundamentalism, Hindutva or "Hindu-ness," can send those youngsters to the Shantiniketan Summer Camp to become fundamentalists through "games, lectures, and events" including "a set of drills and formation" featuring "militant yoga" and "loud nationalist chants for Hindu solidarity” (Falcone 2012: 170-1). 
Buddhism in America is perhaps personified by the Dalai Lama, the exiled leader of Tibetan Buddhists, but Tibetan Buddhism is merely one school in a lively and diverse religion, centered in South and Southeast Asia. Buddhism arrived in the US with the first major wave of Asian, especially Chinese, immigrants in the early-to-mid-1800s. The first Buddhist temple was constructed in San Francisco in 1853. When Chinese migration was curtailed in 1882 (see Chapters 2 and 4), Japanese and Koreans became the carriers of the religion, at first to Hawaii and eventually the American mainland; in fact, Japanese missionaries formed the Young Men's Buddhist Association in 1898 to support Buddhist work on Hawaii. Buddhism also filtered to America through its literature, read by the "transcendentalist" thinkers like Thoreau, Emerson, and Whitman. The two critical developments, though, were the formation of the Theosophical Society by Helena Blavatsky and Henry Steel Olcott (mentioned above) in 1875 and the World Parliament of Religions, which featured such Buddhist luminaries as Japanese Zen monk Soyen Shaku and Sri Lankan activist Anagarika Dharmapala. Soyen Shaku and other Zen teachers like Nyogen Senzaki and Sokatsu Shaku built a lasting presence in California, from which Buddhism, particularly its Zen form, took root. While Hinduism is largely an immigrant religion, Buddhism has won many American converts, due to its perceived spiritual and ethical qualities. Estimates calculate that one-quarter to onethird of American Buddhists are non-Asian converts, including many celebrities like Richard Gere. More than a few Americans practice various Buddhist techniques, like meditation and vegetarianism, without adopting or even knowing Buddhist doctrines.

Finally for present purposes, long before there were Europeans and Christians on American soil there were many, perhaps hundreds, of distinct Native American religions. Or, if Michael McNally (2005), writing for Harvard's Pluralism Project, is correct, "religion" is not quite the right term for pre-contact spiritual/cultural practices, since the two hundred to three hundred distinct groups had "no word for religion" and a different approach to spiritual/cultural matters than that associated with familiar religions like Christianity. They were certainly not "other-worldly," even if they entertained beliefs in spiritual beings—or spiritual persons—who also inhabited other realms. Although Native American "religions" were strikingly diverse, they tended to emphasize a spiritual relationship between humans, other living species, and the land, often connected to superhuman spirits and the spirits of the ancestors. The situation is also complicated by the political uniqueness of native peoples, who have rights and powers not granted to other minorities in the US (see Chapter 4). Because native religions were so totally foreign to European settlers, and so clearly non-Christian, the newcomers often did not recognize them as religion at all—or recognized them as demonic. As Reverend Samuel Purchas wrote in the early 1600s, the Indians were

so bad people, having little Humanitie but shape, ignorant of Civilitie, of Arts, of Religion; more brutish then the beasts they hunt, more wild and unmanly then that unmanned wild Countrey, which they range rather than inhabite; captivated also to Satans tyranny in foolish pieties, mad impieties, wicked idlenesse, busie and bloudy wickedness; hence have wee fit objects of zeale and pitie.

(quoted in Pearce 1965: 7-8)

Accordingly, native religions, like every other aspect of their societies, came under unrelenting attack. As the Spanish did in their territories, the British prohibited various 


\section{Religion}

indigenous religious practices in their colonies. After independence, the US continued to suppress native religion officially and institutionally. Boarding schools, often run by Christian denominations, were effective tools to curb Indian culture and religion and replace it with American "civilization" and Christianity. In 1883 Henry Teller, in his role as Secretary of the Interior, established "courts of Indian offenses" in order to punish and thereby "to eliminate 'heathenish practices' among the Indians" (Utter 1993: 89). Indian religious activity was often associated with resistance to white rule, as in the case of the Ghost Dance, and was met with force, as in the case of the 1890 Wounded Knee massacre. In 1921 the Bureau of Indian Affairs ordered its agents to employ force and even jail to stop Indian religion. Interference with native spirituality has also been indirect, as in the laws banning peyote use (which is central to the new Native American Church) and protecting endangered species like eagles (whose feathers are often crucial to traditional rituals), as well as the seizure and exploitation of lands with religious significance to native peoples. Since the 1970s, however, a series of legislation has reaffirmed some native religious rights. For instance, the 1978 American Indian Religious Freedom Act extended First Amendment rights to the Native American Church and other indigenous religious expressions. The 1990 Native American Graves Protection and Repatriation Act (NAGPRA) gave tribes access to human remains and cultural artifacts removed from burial sites, as well as some control over future excavations of those sites. The Religious Freedom Restoration Act of 1993 made it more difficult for the government to interrupt religious practices, and Bill Clinton's 1996 Executive Order 13006/7 advanced Native American claims to their sacred sites. Finally, the 2000 Religious Land Use and Prison Act (RLUIPA), while not focusing on Indian religion, granted religions in America full use of their land and property along with the right of members to observe their practices in prisons-in the case of Native Americans, including wearing their hair long or having access to sweat-lodges.

\section{Religion, Race, and Politics}

As with other dimensions of diversity, religion in the US has implications for other, seemingly unrelated social behaviors and groupings, including, for example, race: the Pew survey reports that 78 percent of African Americans identify as Protestant while only 23 percent of Hispanics do. Mormons were found to be 86 percent white and 3 percent black, while Muslims were 37 percent white and 24 percent black. Hindus were 88 percent Asian.

One rather obvious and important implication is politics, including party affiliation, stands on particular issues, and voting behavior, as well as larger public legislative and systemic matters. The Pew Foundation study determined that, as recent elections have highlighted, religious affiliation often relates strongly to political style (conservative/ liberal/moderate) and to party affiliation. Evangelical Protestants considered themselves more conservative (52 percent) than liberal (11 percent), while Jews were more typically liberal (38 percent) than conservative ( 21 percent).

It will be noted that political style does not always translate directly into party affiliation. Also, Jehovah's Witnesses tend to disavow political participation altogether.

The 2004 presidential election, in particular, emphasized the relation between religion and voting, both in terms of specific issues and in terms of the degree of religiosity. Exit polls suggested that, more than usual, "values" informed people's choices, 
Table 9.3 Political style and party identification by religion

\begin{tabular}{llllll}
\hline Religion & $\begin{array}{l}\text { Conservative } \\
\text { (percent) }\end{array}$ & $\begin{array}{l}\text { Moderate } \\
\text { (percent) }\end{array}$ & $\begin{array}{l}\text { Liberal } \\
\text { (percent) }\end{array}$ & $\begin{array}{l}\text { Republican } \\
\text { (percent) }\end{array}$ & $\begin{array}{l}\text { Democrat } \\
\text { (percent) }\end{array}$ \\
\hline Total & 37 & 36 & 20 & 35 & 47 \\
Evangelical & 52 & 30 & 11 & 50 & 34 \\
Mainline Protestant & 36 & 41 & 18 & 41 & 43 \\
Historically black & 35 & 36 & 21 & 10 & 77 \\
Catholic & 36 & 38 & 18 & 33 & 48 \\
Mormon & 60 & 27 & 10 & 65 & 22 \\
Orthodox & 30 & 45 & 20 & 35 & 50 \\
Jehovah's Witness & 21 & 12 & 17 & 10 & 15 \\
Other Christian & 20 & 35 & 40 & 26 & 55 \\
Jewish & 21 & 39 & 38 & 24 & 66 \\
Muslim & 19 & 38 & 24 & 11 & 63 \\
Buddhist & 12 & 32 & 24 & 18 & 66 \\
Hindu & 12 & 44 & 35 & 13 & 63 \\
Other & 12 & 33 & 47 & 13 & 66 \\
Unaffiliated & 20 & 39 & 34 & 23 & 55 \\
\hline
\end{tabular}

Source: Pew Research Center 2008

with hot issues like gay rights and abortion having great salience. Also, what has been dubbed the "God gap" seemed to emerge, with people who attend church more regularly voting more Republican and people who attend church less often or not at all voting more Democrat.

\section{Box 9.2 The Twelve Religious Tribes of America}

In an attempt to make some sense of America's religious diversity and the association between religion and politics, John Green and Steven Waldman (2006) have proposed to classify Americans into twelve "religious tribes" based on their religious styles and their social/cultural attitudes. These include:

1 the religious right, who are mostly evangelical Protestants (12.6 percent);

2 "heartland cultural warriors," not as conservative as but usually in consonance with the religious right (11.4 percent);

3 moderate evangelicals, who are culturally conservative but economically moderate (10.8 percent);

4 the religious left, who hold progressive/liberal religious and political views (12.6 percent);

5 those who are spiritual but not religious ( 5.3 percent);

6 Black Protestants, who are traditional in their religion but liberal in their politics (9.6 percent);

7 Jews and 8. Other Religions, who tend to be liberal politically, whatever their religious orientation (4.6 percent);

9 seculars, who are mostly socially and politically liberal (10.7 percent); 


\section{Religion}

(continued)

10 "white-bread Protestants," members of the (often declining) mainline denominations (8.1 percent);

11 "convertible Catholics," the moderate wing of the Catholic constituency (7 percent);

12 Latino-Christians, usually Catholic and typically religiously conservative but politically liberal.

Green and Waldman note that the first three categories are solidly Republican in their affiliation and voting behavior, while \#4 through \#9 are dependably Democrat. Categories \#10, 11, and 12 are swing voters who can vote Democrat or Republican depending on the candidate and issue.

The other political angle on religious diversity is the relation between government and religion, between belief and law, or more generally the problem of "religion in the public square." A society as diverse as the United States is likely to run into legal conflicts over religious belief and practice, many of which end up at the ultimate arbiter of law in the country, the Supreme Court. The struggle, which might surprise some, has not mostly pitted the religious and the non-religious but rather one religious group against another. For instance, in its formative years the Church of Latter-Day Saints practiced polygamy, which was illegal in the US. Although the First Amendment guarantees that the government will not interfere with the free exercise of religion, when that exercise violates a civil law, there is a problem. In 1879 the Supreme Court (Reynolds $v$ United States) ruled that a religion was not exempt from civil law and that it was therefore acceptable to punish Mormon polygamy. Other minority religions also used the courts to press for their rights. In West Virginia State Board of Education v Barnette (1943), Jehovah's Witnesses won the right to defer from reciting the Pledge of Allegiance in school, based on their non-involvement in mundane politics. In 1972 Amish parents also sued to exempt their children from mandatory public education (Wisconsin $v$ Yoder) and won. Observant Jews, whose sabbath is Saturday, were disadvantaged by "blue laws" that called for business closure on Sunday, the Christian sabbath; in Braunv Brown (1961) Jewish business owners in Pennsylvania challenged this practice but lost. Other cases have involved religion in the workplace, such as Sherbert $v$ Verner (1963) which involved a Seventh-Day Adventist who was fired for refusing to work on Saturday, and Oregon Employment Division v Smith (1990) in which two Native American men sued an employer who fired them for use of peyote as members of the Native American Church.

Most people think first, however, of the cases concerning mainstream Christian practices in the public sphere, especially the public schools. For instance, in 1948 the use of school facilities during school hours to teach religion was ruled unconstitutional. The 1961 Torasco $v$ Watkins case declared an oath of belief in God unconstitutional. And most famously, Engel $v$ Vitale (1962) struck down an official prayer in a New York school, and two related cases-School District of Abington Township $v$ Schempp and Murray $v$ Curlett (1963)_blocked religious exercises like school prayer and Bible readings, on the grounds, as the ruling stated, that the free exercise of religion "never meant that a majority could use the machinery of the State to practice its beliefs." 
Religion has continued to be and will continue to be a divisive political issue, as the US becomes increasingly more religiously diverse. Whether the question is prayer in school, Christmas displays on public property, laws against gay marriage or abortion, or "In God We Trust" on the currency, it can no longer be assumed that everyone shares these sentiments and it can be fairly assumed that they do not. As the Ninth Circuit Court of Appeals argued in its ruling of the unconstitutionality of references to God in the Pledge of Allegiance, "A profession that we are a nation 'under God' is identical, for Establishment Clause purposes, to a profession that we are a nation 'under Jesus,' a nation 'under Vishnu,' a nation 'under Zeus,' or a nation 'under no god,' because none of these professions can be neutral with respect to religion” (US Court of Appeals for the Ninth Circuit 2002: 9123). Indeed, every one of these beliefs has been held by someone, and many are held by someone in America today.

\section{Irreligion in America}

As just noted, there is a sizeable percentage of Americans who avow no god. The ARIS study counted 15 percent identifying themselves with no religion, while the Pew Foundation survey places the number of unaffiliated at 16.1 percent. Either way, that makes the non-religious, the secular, the "unchurched," or however we should refer to them the third-largest constituency in the US, after Catholics and Baptists. And like these and all other religious groups, the unaffiliated or irreligious are remarkably diverse.

For instance, while the non-religious category contains a number of avowed atheists (0.7 percent ARIS, 1.6 percent Pew) and agnostics (0.9 percent ARIS, 2.4 percent Pew), it also contains a more substantial number of people who simply identify with "no religion" or "no particular religion." According to the Pew survey, almost half of the "no particular religion" group still considers themselves religious, and the ARIS report states that 20 percent of adult atheists or agnostics or someone in their household still belong to a religious organization while almost 40 percent of religious people or someone in their household do not belong to one.

Among those who reject religion from their lives, there is still great variety. The names they adopt for themselves include atheist, agnostic, humanist, secularist, secular humanist, skeptic, rationalist, and freethinker; recently, attempts have been made to introduce new and hopefully less prejudicial names like "bright" or "universist." One reason for the confusion, and for the generally low profile of a large constituency, is the persisting negative attitudes toward people without religion. In fact, a recent survey found that 50 percent of respondents held "mostly" or "very" unfavorable views about atheists, compared to 31 percent about Muslims, 17 percent about evangelicals, and 10 percent about Jews. An equal number (50 percent) said they would be unwilling to vote for an otherwise well-qualified candidate of their own party who was an atheist, versus 38 percent if a Muslim, 37 percent if gay, or 6 percent if black (Somin 2006). Part of this prejudice stems from fundamental misunderstandings, like that secularists lack moral values; other parts flow from the secularist disagreements with and even actions against religion, as well as the legal gains that the category has made in regard to religion in the public square, like the religious display or school prayer cases mentioned above.

Despite (or perhaps because of) their minority and marginal status, the atheist/ secular constituency is also organized, if loosely so. There are national-level associations 


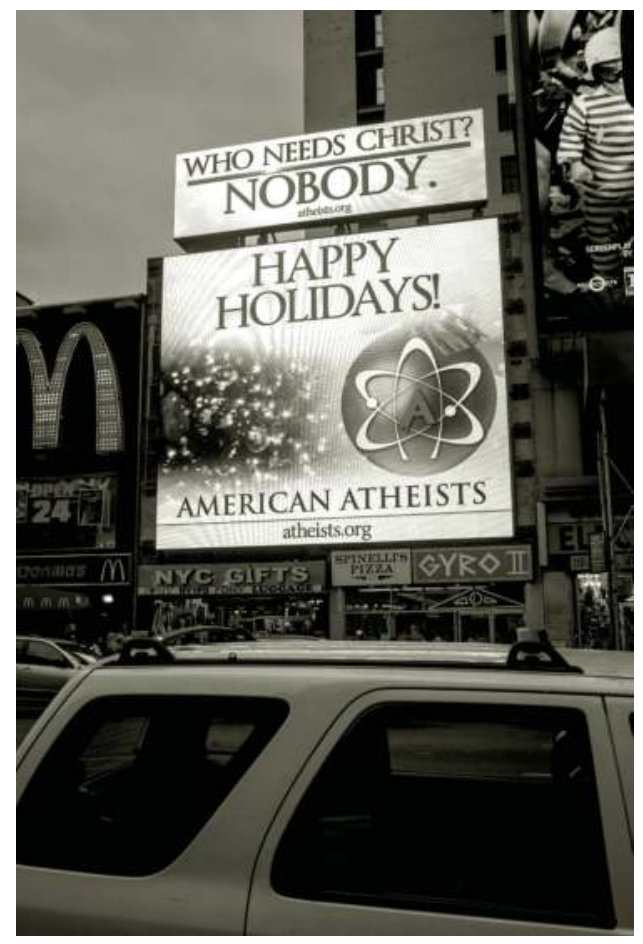

Image 9.4 Atheist billboard, New York City.

(Courtesy of Richard Levine/Alamy)

like American Atheists, the Council for Secular Humanism, the Freedom from Religion Foundation, and even Atheist Alliance International. Most publish newsletters and magazines and hold at least annual conferences; a political action committee (essentially a lobbying institution) called GAMPAC or Godless Americans Political Action Committee has been formed recently. There are any number of local groups and online communities and resources, and atheism/secularism has enjoyed a surprisingly popular moment in print of late, with such bestselling books as Sam Harris' The End of Faith, Richard Dawkins' The God Delusion, Daniel Dennett's Breaking the Spell, and Christopher Hitchens' God is Not Great.

\section{Conclusion}

Religion is an important factor in almost all societies, providing explanations, control mechanisms, and social legitimation. In the United States, Christianity has historically been the dominant religious system, but it has by no means monopolized the American religious landscape.

American religion, like every other aspect of American society, is diverse, composite, and constantly evolving. Christianity contains many distinct and often fractious churches, denominations, and sects. American Christianity, like every other religion 
in America, is also practiced "the American way," with populist, emotionalist, and syncretic tendencies. Meanwhile, Christianity shares the field with many-in fact, virtually all imaginable-religions, Western, Eastern, traditional, and new. Therefore, religion, ideally functioning to unify a society in belief and practice and value, inevitably raises social and political conflicts, which, in the American case, are often fought out in the court system as well as the ballot box and the media. It is highly unlikely that religion will diminish seriously in significance in American society, and at the same time it is highly unlikely that it will decrease in diversity. Quite the opposite: American religion is bound to become yet more diverse in coming years, making religious pluralism a perennial fact and challenge. 


\section{Age}

According to the US Census Bureau, in 201026.6 percent of Americans were under the age of 18 and 12.7 percent were over the age of 65. By some estimates, the percentage of older Americans will double by 2050, to approximately 25 percent. This is part of an international trend of what has been called "the graying globe," with the elderly population increasing in virtually all countries. The United Nations "State of World Population" report from 2005 projected that Europe would be nearly one-third elderly by 2050, Asia and Latin America almost 20 percent, with even Sub-Saharan Africa approaching 5 percent. There are already profound differences between the age compositions of different countries, related to income, access to food and health care, and fertility and birth rates: the 2008 "World Population Data Sheet" of the Population Reference Bureau estimated that Japan's population in 2007 was 13 percent under age 15 and 22 percent over age 65, while Liberia was 47 percent under 15 and 2 percent over 65. At the same time, Americans (and other country's citizens) are not aging the same way their parents did. People strive to be youthful and active much later into life than ever before. Former President George $H$.W. Bush sky-dived on his eighty-fifth birthday, something that I cannot imagine my father or his father doing.

How will the changing age structure of America affect its society and culture? Some answers are already emerging, in terms of retirement age, medical spending, institutions like Social Security and Medicare, and even products and images in advertising. And how will other aspects of society, including advancing technology and the media, affect how long we live and what we do with those extra years?

In every society there are people at different stages in the life cycle; more, much of society is organized by age, from privileges of driving, voting, and marrying to institutions from kindergarten to assisted living. It is truly odd then that discussions of diversity "commonly focus on class, gender, and ethnicity and often treat age as an unimportant background variable" (Scherger 2009: 23). Actually, age is one of the most universal human differences (along with gender) and is critical in all societies for structuring social categories and interpersonal interactions.

Age, like race and gender, is based on a physical fact: an individual really has lived for a certain number of years and attained a certain level of physical maturation. Yet, also like race and gender, every society "culturizes" the natural facts, giving them organization, meaning, value, and function. In other words, everyone who is 15 years old or 50 years old shares the same facts of age, but what it means to be 15 or 50 
varies from one society to another and changes over time in any particular society. The meanings and forms of aging have most definitely changed, and quite profoundly, in the United States.

Age is different from race and gender in two important ways, though. First, where an individual is (usually) assigned to a specific race or gender category (for example, "male" or "black") at birth and remains in that category throughout life, an individual moves through age categories, occupying all of them if s/he lives long enough. In sociological parlance, this means that every person will experience a number of age-related role exits and role entries in a lifetime, shedding the norms and values of a particular age-category and adopting those of a new category (say, moving from "adolescent" to "adult"). We call this "growing up."

Second, there are actually two parallel age-category systems at work in the United States, and a person always belongs to two kinds of age-categories at the same time. One age-category system is the "life-cycle" or developmental system, consisting of a series of statuses such as "new born," "child," "adolescent," "adult," and so on. Individuals pass through each category, occupying it temporarily. The other system is the "generation" system, consisting of a set of age cohorts, each individual assigned permanently to one on the basis of when s/he and the cohort were born. These cohort categories are not "real" but designated by arbitrary chronological cut-offs, like "Baby Boomer" or "Gen-Xer." But then, life-cycle/developmental categories are also arbitrary cut-offs of a continuous aging process.

\section{The Social Study of Age}

Scholars interested in the aging process have a number of tools at their disposal. Demography (from demos for "people" and graph for "write") is the name given to the description and analysis of population characteristics, forces, and trends. Some of the data collected and scrutinized by demographers and the social scientists who use their information include:

- Birth rate, the number of childbirths per 1,000 people in the society in a given year. According to the CIA World Factbook, in 2013 the global birth rate was 18.9 , but the variation between countries was dramatic-from a high of 46.8 in Niger to a low of 6.79 in Monaco. The United States stood at 13.7.

- Death or mortality rate, the number of deaths per 1,000 population per year. The CIA World Factbook calculated the global death rate for 2013 to be 7.9. Again, the range varies from 17.4 for South Africa to 1.5 for Qatar; the United States came in at 8.4. The sum of world birth and death rates, of course, means that the global population is still increasing.

- Fertility or fertility rate, the average number of children born to a woman during her lifetime (whether or not those babies live to adulthood). Globally, the rate in 2012 was 2.47 , with a range from Niger's 7.0 to Singapore's 0.8 ; the fertility rate of the US was 2.1 .

- Infant mortality, the death rate among babies under one year of age per 1,000 live births. The global infant mortality rate in 2013 was 37.6, with male babies outnumbering females (39.4 to 35.7). Rates by country range from two to over one hundred (see below). 
- Life expectancy, the average length of life span in a particular society. Global life expectancy for a child born in 2013 was 68 years, with women living on average about two years longer and men living two years less. The range of life expectancies varies from over 89 to around 49 (see below).

For comparison purposes, Tables 10.1 and 10.2 present the highest and lowest infant mortality rates and life expectancies around the world.

In order to visually represent the age distribution of a society at any given moment and over time, demographers use the population pyramid (or age-sex structure), previously introduced in Chapter 6. The contemporary US population pyramid is less than perfectly pyramidal because of the large cohort of Baby Boomers passing through the middle and later increments of the age structure. Comparing the 2000 and 2010 age structure (Figure 10.1), it is possible to see the Baby Boomers moving through their life-cycle as the large swelling in their 40s in 2000 and in their 50s in 2010. Other societies deviate from the "normal" or ideal age structure for specific reasons.

Table 10.1 Infant mortality, 2013 estimated

\begin{tabular}{lccr}
\hline $\begin{array}{l}10 \text { countries with lowest rates } \\
\text { (deaths per 1,000 live births) }\end{array}$ & $\begin{array}{l}\text { 10 countries with highest rates } \\
\text { (deaths per 1,000 live births) }\end{array}$ & \\
\hline 1 Monaco & 1.8 & 1 Afghanistan & 119.4 \\
2 Japan & 2.2 & 2 Mali & 106.7 \\
3 Singapore & 2.6 & 3 Somalia & 101.9 \\
4 Sweden & 2.7 & 4 Central African Republic & 95.0 \\
5 Hong Kong & 2.9 & 5 Guinea-Bissau & 92.7 \\
6 Iceland & 3.2 & 6 Chad & 88.0 \\
7 Italy & 3.33 & 7 Niger & 81.7 \\
8 France & 3.34 & 8 Angola & 78.3 \\
9 Spain & 3.35 & 9 Burkina Faso & 77.0 \\
10 Finland & 3.38 & 10 Malawi & \\
\hline
\end{tabular}

Source: The World Factbook. Central Intelligence Agency, 2013

The United States infant mortality rate was 5.9.

Table 10.2 Life expectancy, 2013 estimated

\begin{tabular}{lccc}
\hline $\begin{array}{l}10 \text { countries with highest expectancy } \\
\text { (in years) }\end{array}$ & $\begin{array}{l}\text { 10 countries with lowest expectancy } \\
\text { (in years) }\end{array}$ & \\
\hline 1 Monaco & 89.6 & 1 Chad & 49.0 \\
2 Japan & 84.2 & 2 South Africa & 49.5 \\
3 Singapore & 84.1 & 3 Guinea-Bissau & 49.5 \\
4 Switzerland & 82.3 & 4 Swaziland & 50.0 \\
5 Hong Kong & 82.2 & 5 Afghanistan & 50.1 \\
6 Australia & 82.0 & 6 Central African Republic & 50.9 \\
7 Italy & 81.9 & 7 Somalia & 51.2 \\
8 Liechtenstein & 81.59 & 8 Zambia & 52.5 \\
9 Canada & 81.57 & 9 Namibia & 52.1 \\
10 France & 81.56 & 10 Gabon & \\
\hline
\end{tabular}

Source: The World Factbook. Central Intelligence Agency, 2013

The US, at 78.6 years, holds the unimpressive fifty-first place. 


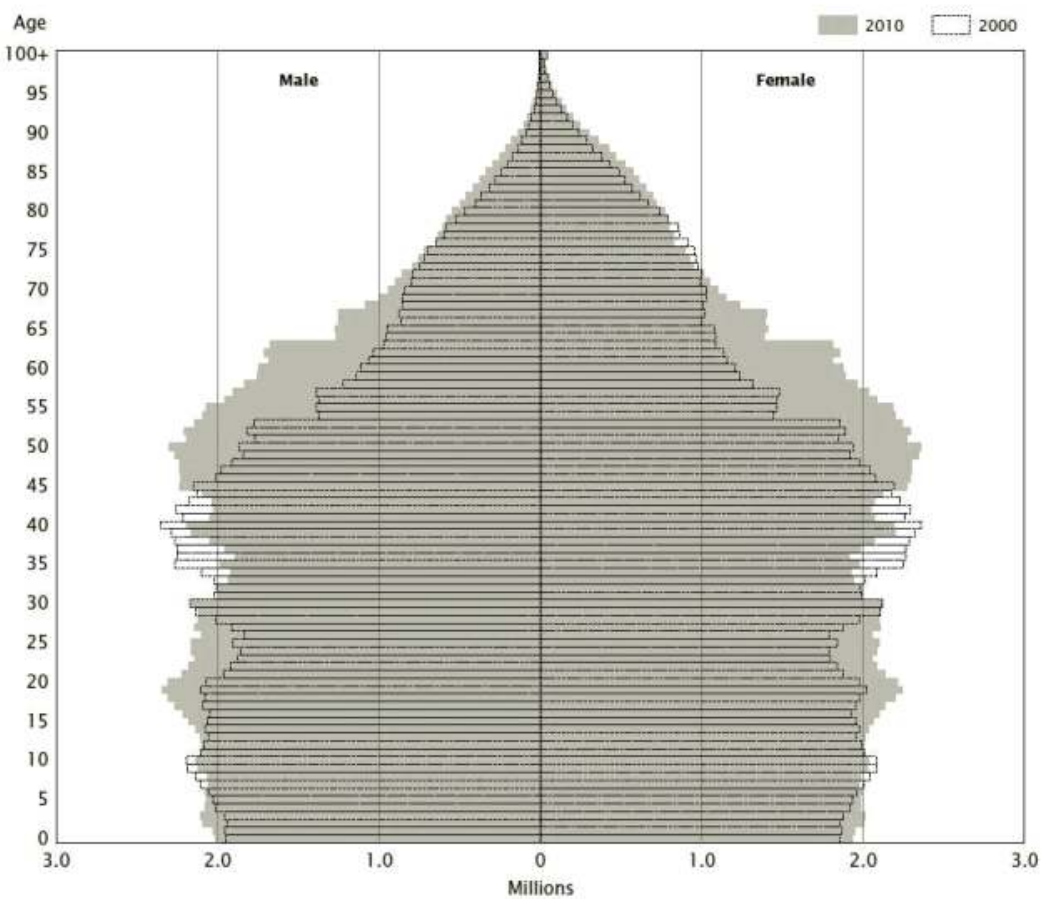

Figure 10.1 US population pyramid: 2010 and 2000.

Source: US Census Bureau. 2010 Census Brief: Age and Sex Composition

A society's age structure will also vary over time, as a large generation moves through the system or when a large or small next generation is born. This allows us to predict the future distribution of age in a society, as well as the increase or decrease of population in the future. Population pyramids that are "top-heavy" portray aging societies with likely declining future populations, while "bottomheavy” pyramids indicate young societies with likely rapidly growing populations in the future.

Many parts of Europe have recently experienced very low fertility rates coupled with high life expectancy, making their pyramids noticeably top-heavy. Italy is a good example (Figure 10.3)

On the other hand, some parts of the world are experiencing explosive birth rates and fast population growth, both presently and probably for years to come. Mexico is one example (Figure 10.4), with a very bottom-heavy pyramid as many children are born today, who will have more children when they reach maturity.

\section{The Social Construction of Age}

In all places and times, humans start out small and get bigger; if they live long enough, their hair turns gray and their skin gets wrinkled. Eventually they die. Aging therefore seems imminently natural. This may explain why early social thinkers paid 


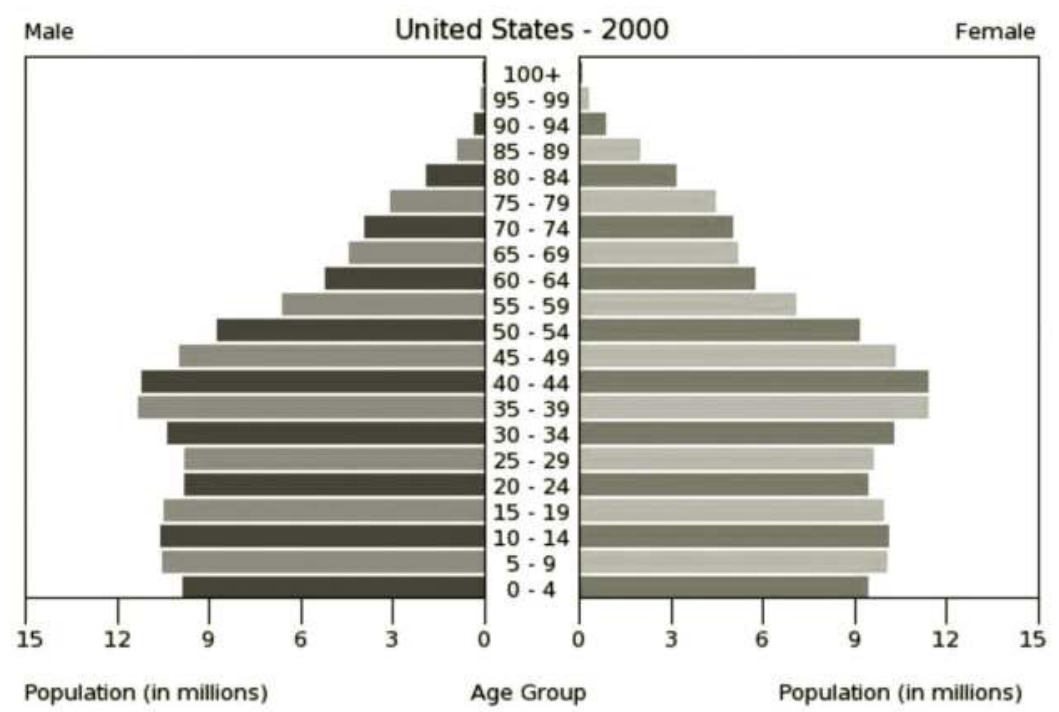

Figure 10.2a US population pyramid: 2000 (actual).

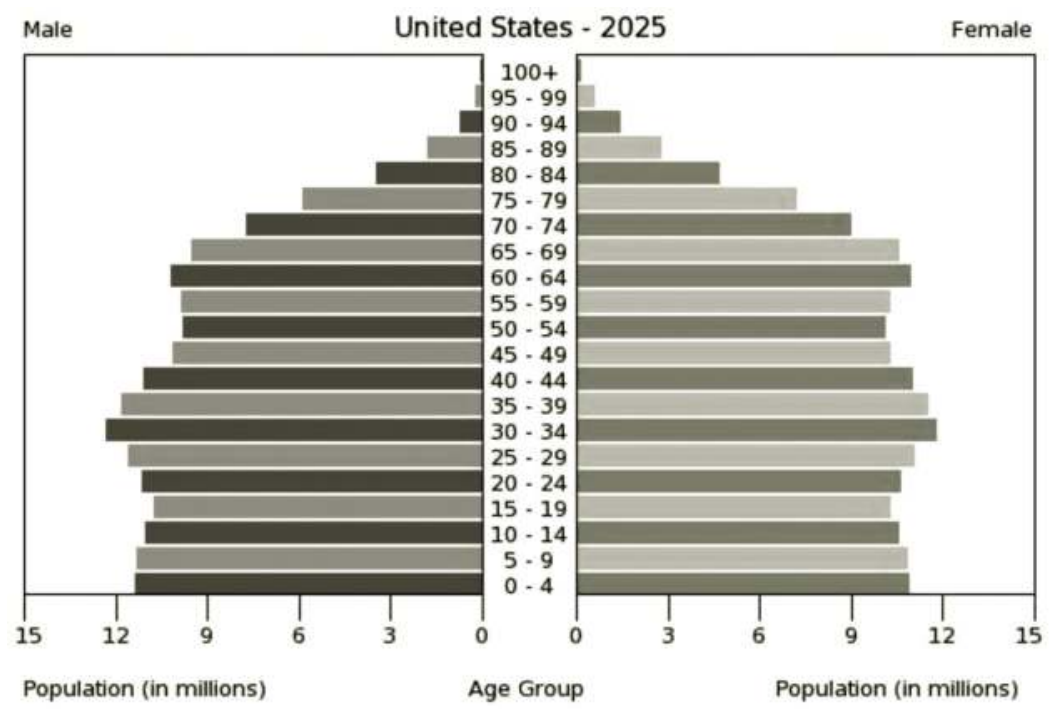

Figure 10.2b US population pyramid: 2025 (projected).

little attention to age as a social issue. However, age is socially constructed at least as much as sex/gender and easily as much as race; in fact, there are more (and more vague) age categories than sex/gender or race categories.

One of the first issues to consider is the division and labeling of the life span. In American English, the typical life span is roughly subdivided into named phases like "infancy," "childhood," "adolescence," "adulthood," "middle age," and so on. Additionally, each phase or stage is associated with particular activities, roles, and 


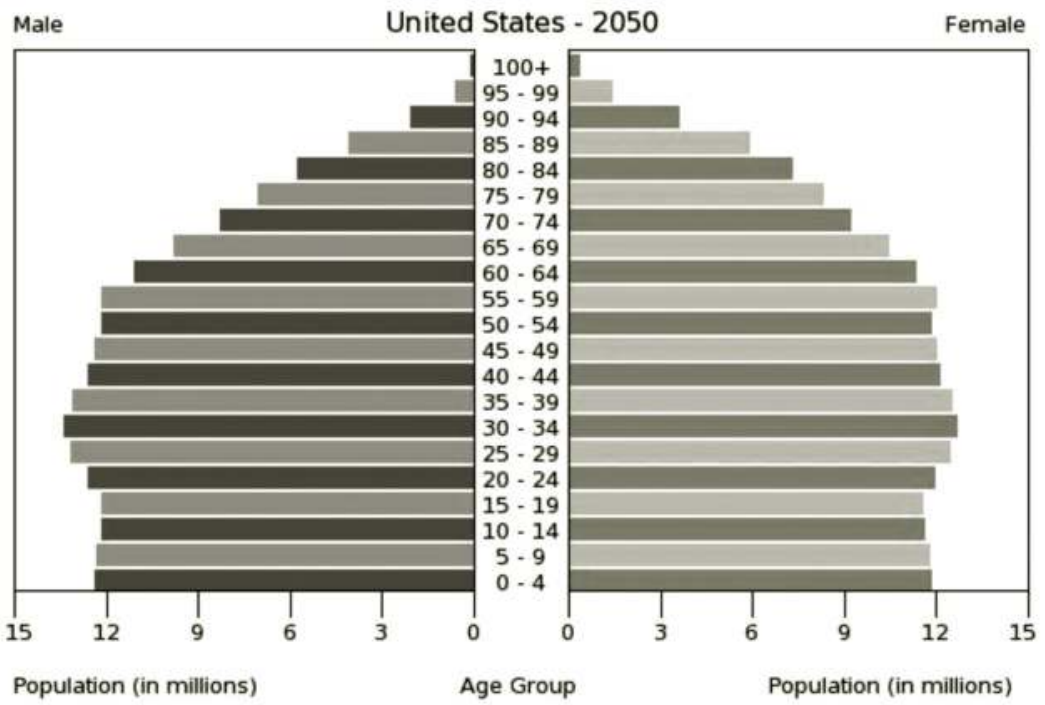

Figure 10.2c US population pyramid: 2050 (projected).

Source: US Census Bureau, International Data Base

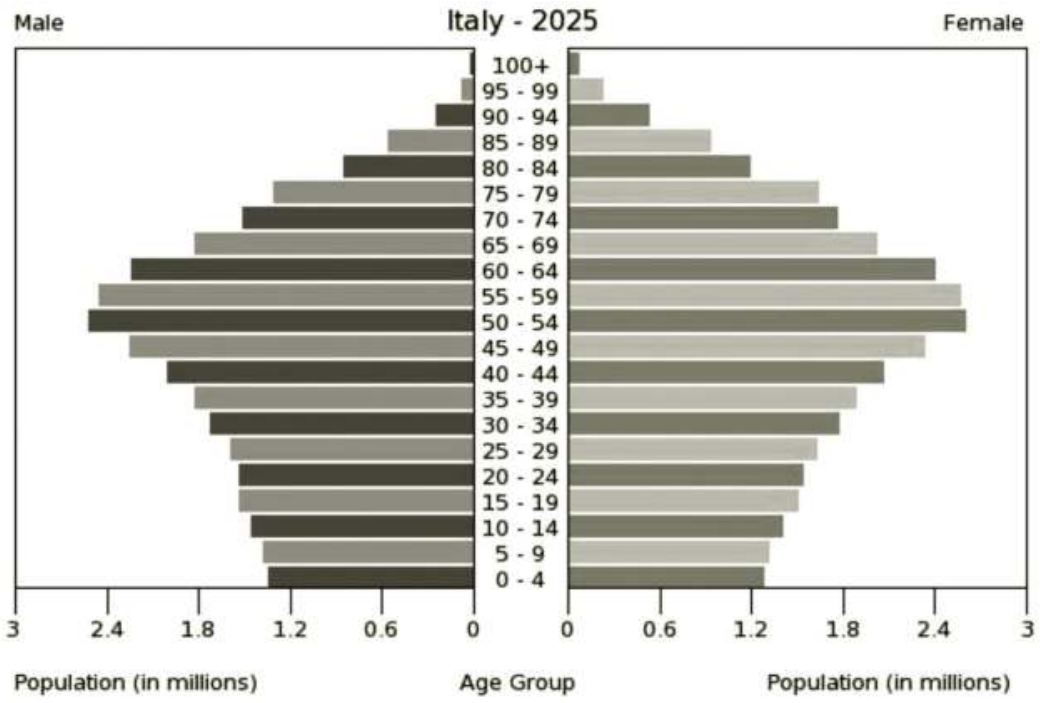

Figure 10.3 Population pyramid for Italy: 2025 (projected).

Source: US Census Bureau, International Data Base

institutions-childhood and adolescence with school, for instance, or adulthood with marriage and work, or old age with retirement and perhaps relocating to Florida or Arizona. Each phase/stage is also ordinarily associated with particular habits and 


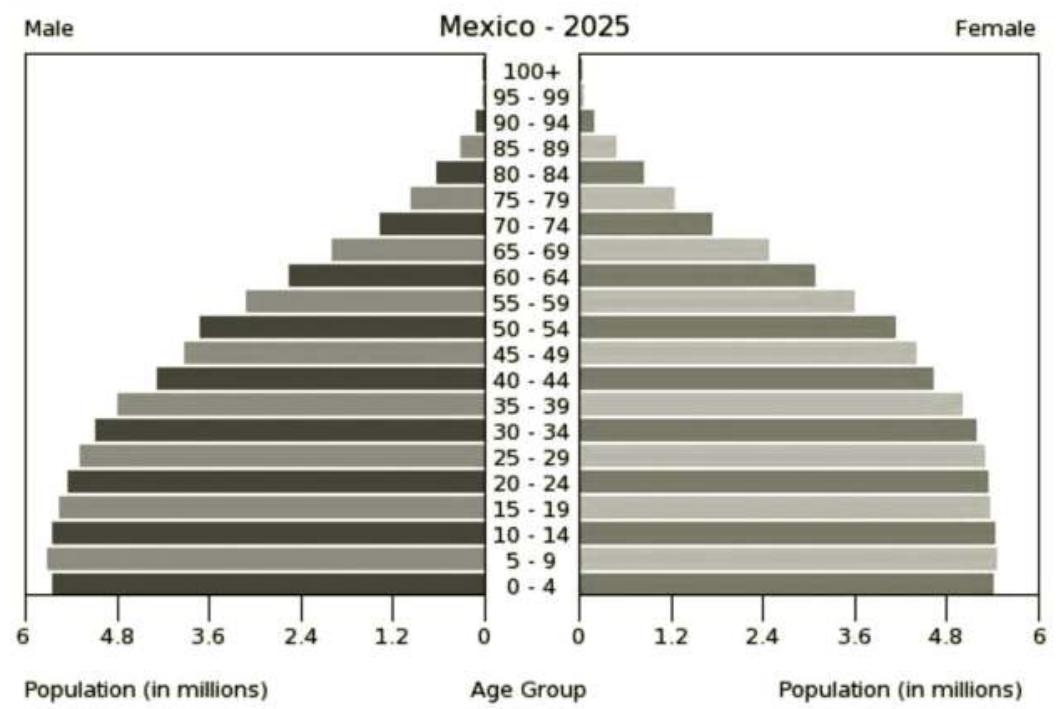

Figure 10.4 Population pyramid for Mexico: 2025 (projected).

Source: US Census Bureau, International Data Base.

personality traits-innocence and play for children, rebelliousness for teenagers, perhaps a "crisis" for middle age.

\section{Age Categories in Cross-Cultural Perspective}

While American age-related notions seem familiar and even natural, there is reason to think that they are not shared by all societies and cultures. For example, anthropologists have discovered that some societies have much different, and often much more precise and demanding, age categories. In what is known as the "age-grade system," a society may assign a cohort of young males (or in some societies, females) to the common status of "youth" or some such term. At late adolescence or early adulthood, the group would then be moved collectively into the "adult" (sometimes more accurately, "warrior") status, which they would occupy for ten or fifteen years. At the end of that period, they would be moved collectively again into a category like "elder," with different rights and responsibilities.

Classical Hinduism, by contrast, divided life into four stages or ashramas. The first stage, Brahmacharya, was the (celibate) student phase: lasting until age 25 , the occupant focused on his education and future profession. The second stage, Grihastha, was the time of marriage and family life, oriented toward the production of wealth and the reproduction of children. Not all men (as these stages are mostly intended for men) aspired to the final two stages. Vanaprashta, or the life of a hermit, began around age 50 and involved the renunciation of home and family (although he could bring his wife with him); ideally, the man lived in a modest hut in the forest, engaging 
in solitary prayer. The man who lived long enough became a Sannyasi, or wandering ascetic with no worldly attachments, devoted himself wholly to his eventual death and hopeful release from reincarnation.

Transition from one age status to another often involves some kind of ceremony, an "initiation" of some sort. With the transition comes a new role and new social expectations. For the African pastoral Maasai, graduation from "youth" to moran or "warrior" required a ritual, and successful completion earned the man a new name and the right to carry weapons. In Jewish tradition, boys under the age of 13 and girls under the age of 12 were not expected to observe all of the religious laws or commandments, but upon reaching that age they became obliged to obey them; hence, at age 13 a boy is feted as a bar mitzvah, or "son of the commandment" (although the familiar party or celebration for the bar mitzvah-or bat mitzvah for girls-is a modern innovation). Similarly, Catholicism contains a sort of comingof-age ritual in the "confirmation" which does more than acknowledge a change of age: according to the New Advent Catholic encyclopedia, confirmation "makes the recipient a "perfect Christian," confers "the seven gifts of the Holy Ghost" on the confirmee, and leaves "an indelible character" on him/her such that no person can undergo the rite twice.

Clearly not all societies ceremonialize transitions of age-status at the same time, for the same reason, or in the same way. In the United States, there is no standard coming-of-age moment or celebration, although such events as high school graduation, getting one's first driver's license, going on one's first date, or turning eighteen have some cultural significance. More profoundly, there is argument to support the idea that not all societies understand or experience the life cycle and its changes as Westerners and Americans do. One of the first researchers to question whether a lifestage was universal was Margaret Mead, who studied the coming-of-age process in Samoa and New Guinea. Her work has become somewhat controversial since it was first done in the 1920s, but her initial findings indicated that Samoan children (especially girls, who were the focus of her investigation) did not go through a tumultuous and rebellious "adolescence." As she wrote on page one of her book Coming of Age in Samoa, adolescence in the West is "characterized as the period in which idealism flowered and rebellion against authority waxed strong, a period during which difficulties and conflicts were absolutely inevitable" (1928: 1). Her observations led her to conclude that Samoan girls experienced no adolescent trauma but rather (for the most part) made a smooth and gradual transition from childhood to adulthood without the upheavals found-and expected-in the West.

\section{The Social Construction of Childhood}

The concept or category of "childhood" has been subjected to extensive historical and cultural analysis. For example, Philippe Ariès, in his Centuries of Childhood: A Social History of the Family (1962), asserted that childhood did not exist as a social concept in Western culture prior to some five hundred years ago and that it assumed its current form only much more recently. As late as the 1700s, he maintained, ideas about and attitudes toward children were quite different from those of today. In fact, children were not even regarded entirely as persons: since infant mortality rates were so high, 
young children were not necessarily believed to be complete human beings nor were they treated as such. If that sounds strange and archaic, Nancy Scheper-Hughes found something akin to this attitude among twentieth-century poor Brazilians, who suffered through so many losses that they believed that many babies simply do not even want to live. "Our babies [are] born already wanting to die," one mother stated (1992: 315). "They come into the world with an aversion to life ... food doesn't interest them; it doesn't hold their attention. You see, they are neither here nor there" (386). In this "Doomed Baby Syndrome," mothers allowed babies to starve and die because that is what the mothers thought the babies wanted: "It is better to let the weak ones die," a mother claimed, because the babies are "little angels" who come into the world solely for the purpose of dying (368).

According to Ariès, once the concept of childhood appeared, it took some time to reach its modern contours. In the sixteenth century there was still no idea of "childhood innocence," and young people were exposed to the coarseness of everyday adult life. Only in the seventeenth century did the notion of modesty and decency in front of children emerge. And the categories "child" and "childhood" were in part the products of two new social institutions, the nuclear/conjugal family and the school. He asserted that the "concept of the [conjugal] family, which thus emerges in the sixteenth and seventeenth centuries, is inseparable from the concept of childhood. The interest taken in childhood . . . is only one form, one particular expression of this more general concept-that of the family" (1962: 353). This new family style created a bi-generational household and directed great intensity at this new social species, the "child." The school further established a formal classification for childhood, what Ariès called a "specialization of the ages," such that "an age group ranging from five-to-seven to ten-to-eleven would be marked out" (301) and assigned age-specific expectations and exemptions by society.

Furthermore, societies even in the West have not always shared our modern sensibility about the nature and preciousness of the child. As we will see below, the early American Puritans believed that children were inherently sinful, almost evil. In his quite shocking The History of Childhood, Lloyd deMauss pronounced, "The history of childhood is a nightmare from which we have only recently begun to awaken. The further back in history one goes, the lower the level of child care, and the more likely children are to be killed, abandoned, terrorized, and sexually abused" (2006: 1). John Boswell likewise found that well into the 1700s and even 1800s the ancient practice of child abandonment was thriving in Western civilization. His examination of records from France and Italy indicated that child abandonment rates regularly hovered in the 10-15 percent range and sometimes reached one-third or more (as high as 43 percent in early-nineteenth-century Florence) in poor neighborhoods or in times of social and political unrest (1988: 16-17). In parts of the world child abandonment is still routinely practiced: UNICEF reported that 9,000 babies were left in hospitals and pediatric wards in Romania in 2004 (Lozinski 2006). In the contemporary world, children remain far from protected from abuses and are often among the chief victims, whether it is the child sex trade or the "recruitment" of child soldiers: the United Nations High Commissioner for Refugees (UNHCR) estimated that 300,000 underage persons served as soldiers and sex slaves around the globe in the early twenty-first century (UNHCR 2003). An unknown number of minors are also exploited as child labor, many trafficked into the United States from poorer countries. 


\section{Diversity Fact:}

According to the US Department of Health and Human Services, in 2011 there were some 681,000 unique reports of child abuse. Children under the age of 1 year suffered the highest rates of abuse $(21.2$ per 1,000$)$. Of all maltreated children, 75 percent were exposed to neglect, 15 percent to physical abuse, and almost 10 percent to sexual abuse. More than three-quarters of child deaths due to abuse or neglect were caused by one or both parents.

\section{The Social Construction of Adolescence and Beyond}

The cultural construction of age hardly stops with childhood. As we saw above, Hindu and Maasai cultures specify clear roles for all of the age categories recognized by those societies. In all societies, certain rights, responsibilities, and restrictions come with age: in Western societies, minors (usually under 16-18 years of age) are not supposed to drive or drink. At age 18 an American receives the right to vote and at age 21 the right to drink alcohol. Adulthood, like every other life-stage, carries expectations such as marriage, childrearing, employment, and, ideally, home ownership. But the expectations go much further: some kinds of jobs are "normal" adult jobs, while others are more typically associated with youth. Even clothing styles, eating habits, and musical tastes have age-appropriate standards (although these norms constantly change and have never been honored by every single individual).

Adolescence has been a particularly controversial age-category and life-stage. As already mentioned, Margaret Mead claimed that she found no distinct concept of adolescence in Samoa and none of the familiar marks of adolescence (emotional turmoil, suddenly raging hormones, conflict with parents, etc.). While all societies probably recognize some period of transition from childhood to adulthood, not all recognize the same period in the same way. For instance, Margaret Booth recently reported that the African Swazi have no indigenous word for adolescence. They do have many local terms for age-categories that divide life differently than America-for males, roughly age 8-17 is called lijele and age 17-27 is called lijaha or libungu, while for females the categories are different again and more articulate, with age 8-15 dubbed litshitshane, 15-17 lichikiza, 17-21 ingcugce, 21-4 makoti or umlobokati, and 24-55 umfati (2003: 225). Significantly, under the impact of Western contact, Christian missionization, and modern schooling Swazi people are being introduced to the idea of adolescence, although not all yet accept the notion. One additional informative example comes from the Arctic, where Inuit people also did not traditionally set apart an adolescent phase. However, wider social changes, including "population concentration, population growth, increased economic security, and increased exposure to southern (i.e., Canadian and American) value systems have resulted in the creation of a prolonged adolescent life-stage which was non-existent in the precontact period" (Condon 1990: 266). Crucial to the emergence of adolescence among the Inuit, and probably in America and the West, has been the rise of "a large adolescent peer group which now dominates the social/recreational activities of young people" (271), partly because of the social reorganization that follows from modern school systems and partly because of the separation of young people from the 
daily activities and productive work of adults. In Inuit society as in America, "teenagers spend most of their time interacting with friends and peers, both in and out of school, and very little time in the company of parents and other adults" (273).

Finally, old age is highly diverse and socially constructed too. Americans today (see below) try to postpone old age (and sometimes even adulthood) and extend the freedom and playfulness of youth as long as possible. In other traditions, like Hinduism, old age is a time of spiritual seriousness and renunciation of normal life. One of the strongest concepts of elderhood comes from Zafimaniry society, on the island of Madagascar. There, adults of marrying age find play "inappropriate" (Bloch 1998: 182). Even more, as they approach "elderhood" they are believed to "settle down" quite literally: they become "fixed" and "hardened," eventually becoming as still and immovable as their houses_indeed, actually turning into their houses. With this transition comes an entire way of life:

Being an elder is a status but it is also a style of behavior which the person adopts when he is being an elder. This is marked by posture and linguistic code. He tends to speak very quietly, using formalized and fixed language which is highly decorated and full of quotations and proverbs. When an elder speaks he addresses nobody, apparently not caring if he is heard or not, ignoring the fact that others may be speaking at the same time since a specific linguistic exchange would negate the almost other-worldly character of what he is saying.

(Bloch 1998: 183)

Gradually, the elder becomes "an inanimate object" (184), whose value is not practical "wisdom" but a concrete (again, quite literally) continuity between the past and the present, the living and the dead.

\section{The Invention of Life-Stages and Generations}

Thinking in terms of specific concrete life-stages is not a universal practice across cultures and is arguably quite recent even in America and the West, as we will see below. As in the case of sex/gender and race, the invention of life-stages was part of the general project of nineteenth-century science to establish firm and clear categories for types of people and to assign each person to his/her proper place and task. One of the pioneers of life-stage thinking was, of course, Sigmund Freud, whose preoccupation with childhood had a profound effect on Western experience. Freud's psychosexual stages from "oral" to "anal" to "phallic" to "latency" to "genital" only concerned sexual development and stopped with adulthood. Erik Erikson subsequently developed this stage mentality much further, carving the entire life cycle into eight "psychosocial" levels, each with its own special problem or project:

1 Age up to $12-18$ months: trust versus mistrust.

2 Age 12-18 months to three years: autonomy versus shame/doubt.

3 Age 3 to 6 years: initiative versus guilt.

4 Age 6 to 12 years: industry versus inferiority.

5 Age 12 to 18 years: identity versus role confusion.

6 Age 19 to 40: intimacy versus isolation.

7 Age 40 to 65: generativity verses stagnation.

8 Age 65 and over (which Erikson regarded as "maturity"), ego integrity versus despair. 
When it comes to the modern Western concept of adolescence in particular, no one had more influence than the psychologist G. Stanley Hall. Hall's magisterial 1904 twovolume Adolescence: Its Psychology and Its Relation to Physiology, Anthropology, Sociology, Sex, Crime, Religion, and Education essentially brought adolescence as we know it into the English vocabulary. It was proposed famously as a time of "storm and stress" characterized by conflict with parents, emotional mood swings, and indulgence in dangerous or even antisocial behavior. Adolescence-which, significantly, he identified as the age between 14 and 24 (and no contemporary 24-year-old would like to be called an adolescent) — was first the phase during which "the wisdom and advice of parents and teachers is overtopped, and in ruder natures may be met by blank contradiction" (1904, v.2: 79). Adolescents also suffered from "rapid fluctuation of moods" (v.1: xv), and these two factors combined to produce "a period of semicriminality" in otherwise normal youths (v.1: 404). According to Jeffrey Arnett, Hall's conception of adolescence and our own share "the prevalence of depressed mood in adolescence; adolescence as a time when crime rates peak; adolescence as a time of high sensation seeking; susceptibility to media influences in adolescence; characteristics of peer relations in adolescence; and biological [e.g. brain] development during puberty" (2000: 469).

Finally, the first major theorist to put the question of generation on the socialscientific agenda was Karl Mannheim, who in 1923, before Mead's seminal work on age in Samoa, acknowledged "the problem of generations." Not necessarily "a concrete group in the sense of a community" (1952: 288), what is important about a generation is sharing "a common location in the social and historical process" and therefore "a specific range of potential experience" (292). Individuals of the same generation have in common what we have come to call a social memory, having lived through the same events and thus become a category of similar "possible modes of thought, experience, feeling, and action" which "restricts the range of self-expression open to the individual to certain circumscribed possibilities" (292). Mannheim referred to this phenomenon as "the 'stratification' of experience" (297), guaranteeing that members of a society would not and could not all have the same perspective, knowledge, and attitudes.

However, at any given moment in a society, some people are old and some are young. A generation, or what Mannheim called more accurately a "generation unit," only emerges when the social experiences of people of different ages are different. That is, if society is the same as it was fifty years ago, then today's children and today's 50-year-olds would share the same basic experience; when society is diverse and changing rapidly, not only will today's children and today's 50-year-olds grow up in very different worlds, but it is possible that within any one generation there would be diverse experiences. Then "within any generation there can exist a number of differentiated, antagonistic generation units" (306). To summarize, "Not every generation location [i.e., growing up at a certain time in history] - not even every age group — creates new collective impulses and formative principles original to itself" (309). When it does, we can speak of a "generation" in the modern sense (or a "generation unit" in Mannheim's sense), with its own unique "generational style." Of course, the faster society changes, the more different each age cohort will be from all others-and the more internal differences there will be within any single age cohort, complicating the notion that there are discrete and unified "generations" in society. 


\section{Age Diversity in the United States}

The United States has the age profile of an advanced industrial society, with a relatively high median age and a large older population. The number of people in each age increment not only varies absolutely but also varies by sex and race/ethnicity, as shown in Tables 10.3 and 10.4 .

As mentioned in Chapter 6, women outnumber men substantially at later ages, while men outnumber women in the early decades of life (that is, more males are born than females, but females live longer than males).

The median age of the total American population was 36.9 in 2010, but this varied significantly by race. The median age for whites was 38.4, for African Americans 31.7, for Native Americans 29.9, for Asians 36.0, for Hispanics 27.5, and for people of two or more races only 19.9 .

These discrepancies mean that age is distributed differently within each of these race/ethnic categories. For instance, among non-Hispanic whites, the largest five-year increment is $50-54$ year olds $(15,800,000)$, while only $11,375,000$ are under age five. Among African Americans, the largest five-year increment is 15-19 year olds $(3,410,000)$, with almost as many under age five $(3,034,000)$ and one-quarter less in the 50-54 range $(2,650,000)$. Among Hispanics $(5,053,000)$, Native Americans $(286,000)$, and people of two or more races $(840,000)$, the single largest five-year increment is actually children under age 5 .

Table 10.3 American population by various age increments and sex

\begin{tabular}{lrrr}
\hline Age increment & \multicolumn{1}{l}{ Total } & \multicolumn{1}{c}{ Male } & \multicolumn{1}{c}{ Female } \\
\hline All ages & $304,280,000$ & $149,485,000$ & $154,795,000$ \\
Under 5 & $21,434,000$ & $10,955,000$ & $10,479,000$ \\
Under 15 & $62,112,000$ & $31,757,000$ & $30,355,000$ \\
$15-20$ & $25,470,000$ & $12,931,000$ & $12,538,000$ \\
$21-44$ & $98,303,000$ & $49,236,000$ & $49,068,000$ \\
$45-64$ & $79,782,000$ & $38,768,000$ & $41,014,000$ \\
65 and over & $38,613,000$ & $16,793,000$ & $21,820,000$ \\
85 and over & $4,693,000$ & $1,631,000$ & $3,062,000$ \\
\hline
\end{tabular}

Source: US Census Bureau. Current Population Survey, Annual Social and Economic Supplement, 2010

Table 10.4 American population by various age increments and race/ethnicity, in thousands

\begin{tabular}{lrrrrrr}
\hline $\begin{array}{l}\text { Age } \\
\text { increment }\end{array}$ & White & $\begin{array}{l}\text { African } \\
\text { American }\end{array}$ & $\begin{array}{l}\text { Native } \\
\text { American }\end{array}$ & Asian & Hispanic & $\begin{array}{l}\text { Two or } \\
\text { more races }\end{array}$ \\
\hline Total & 246,630 & 39,909 & 3,188 & 14,415 & 49,726 & 5,499 \\
Under 5 & 15,944 & 3,034 & 286 & 943 & 5,053 & 840 \\
5 to 13 & 28,273 & 5,412 & 459 & 1,636 & 8,501 & 1,259 \\
14 to 17 & 12,941 & 2,619 & 205 & 741 & 3,595 & 450 \\
18 to 24 & 23,536 & 4,741 & 387 & 1,315 & 5,788 & 668 \\
16 to 64 & 161,100 & 26,783 & 2,108 & 10,132 & 31,515 & 2,890 \\
65 and over & 34,926 & 3,418 & 235 & 1,333 & 2,858 & 278 \\
85 and over & 5,189 & 397 & 20 & 113 & 305 & 29 \\
\hline
\end{tabular}

Source: US Census Bureau. Population Division 


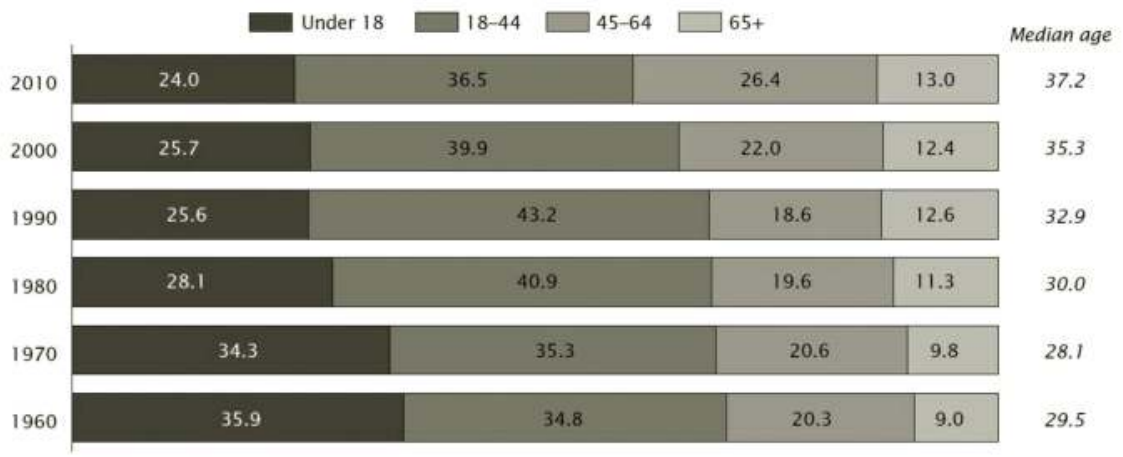

Figure 10.5 Age distribution and median age in US, 1960-2010.

Source: US Census Bureau. 2010 Census Brief: Age and Sex Composition

Age groups are also distributed unevenly across the American landscape. In 2010, the Northeast was the oldest region, with only 15.3 percent of the population under age 5 but 21.2 percent of the Americans over age 85. The Midwest was not quite as old, with 21 percent of those under age 5 and 23.1 percent of those age 85 or more. The West was relatively young, where 25.3 percent of Americans under age five and 22.5 percent of those over age 85 resided. The South had the highest percentage of very young people, with 38.4 percent of children under age 5 and only 33.2 percent of seniors over age 85 . The median ages in the four regions were:

- Northeast-39.2 years

- Midwest-37.7 years

- South-37.0 years

- West-35.6 years

Seven states had a median age of 40 or more: Maine (42.7 years), Vermont (41.5 years), West Virginia (41.3 years), New Hampshire (41.1 years), Florida (40.7 years), Pennsylvania (40.1 years), and Connecticut (40.0). Note that Florida, commonly regarded as the retirement capital of the United States, did not have the highest median age in 2010, although it shared the honor of the highest median age with West Virginia in 1990 and 2000.

Finally, the state with the lowest median age was Utah, which at 29.2 years was the only state with a median age under 30 . Utah was followed by Texas (33.6 years), Alaska (33.8 years), and Idaho (34.6 years). Even so, all states saw a rise in their median age between 2000 and 2010, indicating the nationwide aging of the population. Only the District of Columbia decreased in median age, since nearly half (48.6 percent) of the population of America's capital region was between the ages of 18 and 44 .

At the city level, median age ranged from a high of 45.4 in Scottsdale, Arizona to a low of 23.3 in Provo, Utah. Of the ten cities with the highest median age, five were in Florida (Clearwater, Cape Coral, Fort Lauderdale, Hialeah, and St. Petersburg), while three of the cities with the lower median age were in Texas (Killeen, Denton, and Laredo). Interestingly, Arizona with the oldest city of Scottsdale also had one of 


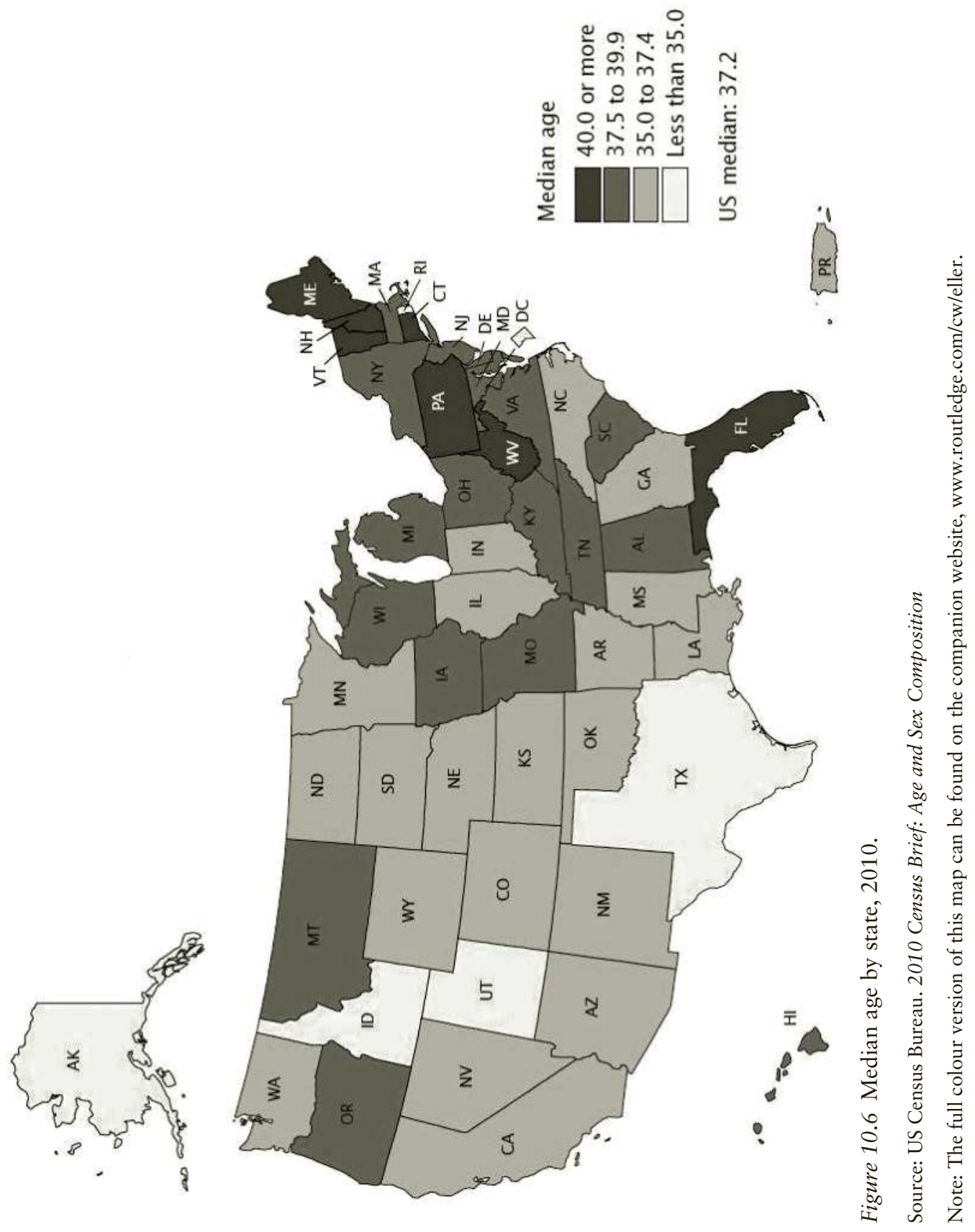


the youngest cities (Tempe), and Florida, with several of the oldest cities, also had one of the youngest cities in Gainesville. Both Tempe and Gainesville are major college towns, illustrating how local factors can account for substantial variations.

\section{Inventing American Childhood}

Although all Americans begin life as babies and slowly grow toward maturity, American society has not had one universal unchanging concept of, or experience of, "childhood." In fact, Americans have not always been as age-conscious as they are today, with formal named age categories and highly elaborated age-appropriate roles and norms. Joseph Kett explained that in the America of the 1700s "someone's age was one of the least important correlatives of his or her experience" but that by the twentieth century "life experiences increasingly clustered around age norms" (2003: 370). Further, Harvey Graff (1995) reminded us that Americans take multiple, even conflicting, paths from birth to adulthood, depending on races, class, gender, sexual identity, religion, (dis)ability, and many other factors.

That childhood in the US as elsewhere is "a social and cultural construct that has changed radically over time" (2004: viii) is amply illustrated in Steven Mintz's study of American childhood. Americans have not even always agreed on what age range constitutes childhood, let alone on the specific freedoms and responsibilities of the category or on the very nature of the child. From the earliest days of European settlement, attitudes and practices regarding children have varied. The Puritans of New England, for instance, did not share the modern idea that childhood was a time for play and parental indulgence; instead, children were born sinners characterized by "intransigence, willfulness, and obstinacy" (19) which had to be overcome quickly and sternly. Mintz wrote that Puritan parents "considered crawling bestial and play as frivolous and trifling" (10), and children were introduced to the adult world early, including knowledge of death and damnation. Additionally, children under age 12 were not always raised in their parents' home but were fostered out to other households.

In contrast, in Maryland and Virginia, where death rates were high and families were unstable (life expectancy was forty-some years and marriages lasted on average seven years), children were freer-or at least English children. "Indentured servitude was the defining experience" for children of other nationalities and races, including European immigrants and, of course, African slaves (38). Much of the labor of these colonies was performed by Africans, who did not enjoy the leisure of white children but rather actually did much of the work of raising those white children. Mintz argued that it was in the Middle Colonies, from New York to Delaware, that the more familiar pattern of parenting and childhood first emerged, the "intense emotional bonding between parents and children, indulgent childrearing, and an acceptance by parents of early youthful independence" (48).

However, even this more "modern" approach to childhood was largely by and for the middle class, who "sheltered their children from the workplace and economic struggles and kept them in school and the family home longer than in the past" (76). Poor families, rural families, immigrant families, and slave families had no such luxuries. Nevertheless, Mintz concluded that by the early 1800s Americans "viewed children in much more positive terms ... as special beings with their own distinct needs and nature" (80). The concept of "girlhood" arose within the developing concept of childhood, allowing the 


\section{Age}

young girl some freedom before her entrance into the world of womanhood and motherhood, but this also signaled a new discontinuity between the childhood experiences of boys and girls.

Despite the fact that an urban middle-class notion of sheltered childhood existed and expanded in the nineteenth century, for many American children the reality was adult-like responsibilities such as wage labor. Few children attended school, where childhood was most clearly defined. Consequently, two ideas and tracks of childhood emerged-the "protected child," who was spared the harsh realities of life, and the "useful child," who shared the responsibility for providing for the family (152). But the "protected child" view was to prevail, as public opinion (and the needs for adult employment) turned against child labor and as the government began to assume new powers "to protect children from abuse, exploitation, and neglect" (156). This required new laws and new institutions, such as child-protection and adoption legislation and orphanages, places for delinquent or homeless children, and, most importantly, a separate juvenile justice system (first implemented in Chicago in 1899).

The construction of modern childhood also depended on two other streams of culture. One was literature, specifically children's fiction and magazines, which offered popular images of children, from Louisa May Alcott's 1868 Little Women to Mark

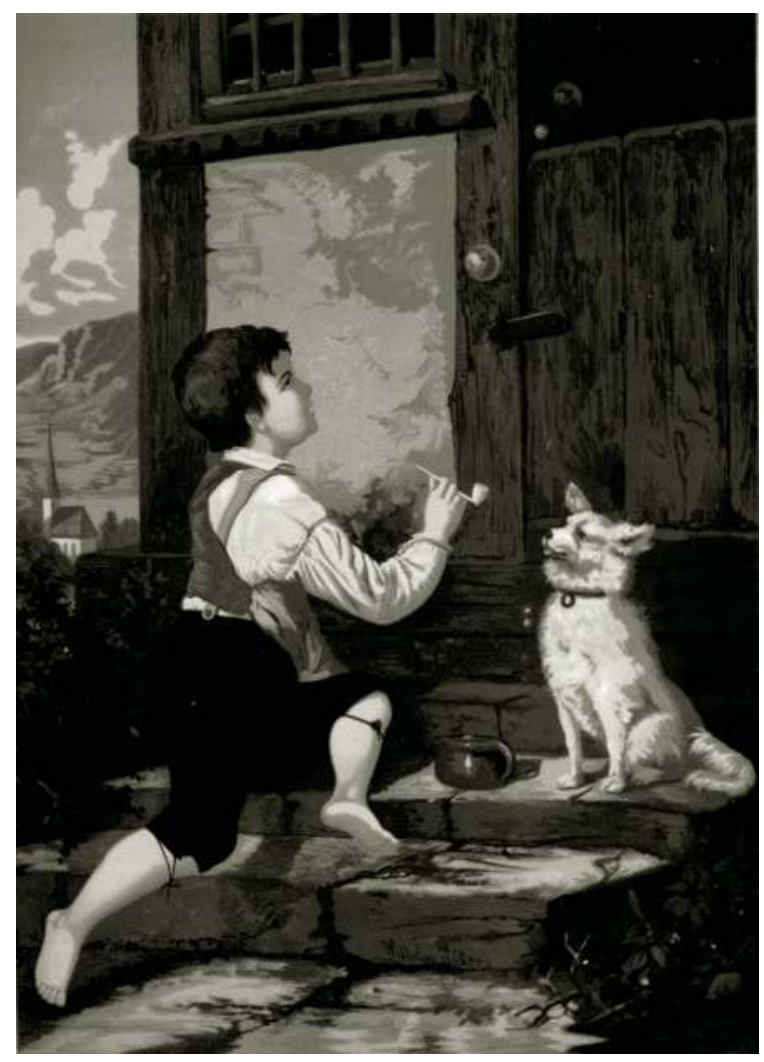

Image 10.1 “Childhood's Happy Hours," illustration c.1873.

(Courtesy of the Library of Congress, Prints and Photographs Division) 
Twain's 1876 Tom Sawyer, Johanna Spyri's 1880 Heidi, Thomas Hughes' 1857 Tom Brown's School Days, Lewis Carroll's 1865 Alice's Adventures in Wonderland, and Rudyard Kipling's 1894 The Jungle Book. The early 1900s added Kate Douglas Wiggin's 1903 Rebecca of Sunnybrook Farm and Eleanor H. Porter's 1913 Pollyanna, the archetype of the sheltered child. The second stream was the scientific study of the child, which followed from the general nineteenth- and twentieth-century scientific investigation and classification of humans, including their race (see Chapter 3), gender (see Chapter 6), and sexuality (see Chapter 7). In 1889 the Society for the Study of Child Nature was formed, and, of course, around 1900 Sigmund Freud began to move the child front and center in psychological theory. (We have already seen how G. Stanley Hall introduced the notion of adolescence in 1904.) By the 1920s, childexperts were offering their advice to anxious parents, who turned increasingly to them "for help in dealing with such problems as sibling rivalry, bedwetting, moodiness, rebelliousness, and sleeping problems" (Mintz 2004: 219).

Meanwhile, childhood was beginning to take on a life of its own. Sequestered in schools and entertained by new media like movies and comic books, a distinct "youth culture" began to take shape that would reach its fullest extent among adolescents (see below). Perceiving a crisis (related to the crises of masculinity and femininity discussed in Chapter 6), parents in the 1950s were warned that childrearing practices had become too permissive and indulgent-and I am sure they felt that their dire predictions were realized in the rebellious youth movement of the 1960s. Since the 1960s and 1970s two more developments have contributed to the stress around childhood. The first is the growing commercialization of children, the intentional selling of products to the child market demographic. The second is the increasing sexualization of childhood, with children exposed to sexually provocative images and even encouraged to dress and act in ways that were formerly only appropriate for adults (if even for them).

\section{Box 10.1 Is Childhood Disappearing?}

The familiar concept of childhood as a time of innocence and freedom to "be a kid" is a recent one, not a universal or natural one, but some observers have noted this concept is already changing. David Elkind's 1981 The Hurried Child: Growing Up Too Fast Too Soon, Marie Winn's 1983 Children without Childhood, and Kay Hymowitz' 1999 Ready or Not: Why Treating Children as Small Adults Endangers Their Future-and Ours are only a few examples of this worried literature. In 1982 culture critic Neil Postman first published The Disappearance of Childhood in which he acknowledged that "childhood" was a recent invention but one whose time had just about run out. Postman considered the century from 1850 to 1950 as the classic era of the child, with school as the key institution in shaping the age-category. Indeed, he insisted that classic childhood "was an outgrowth of an environment in which a particular form of information, exclusively controlled by adults, was made available in stages to children in what was judged to be psychologically assimilable ways" (1994: 72) in age-appropriate versions and doses. But the beginning of the end of classic childhood, he opined, was 
(continued)

television, which opened up the adult world to the youngster; adults could no longer hide adult realities, from war to sexuality, from children. Television, he wrote, "erodes the dividing line between childhood and adulthood" (80). And this was all before the Internet, cell phones, texting, Facebook, Twitter, and other democratizing information technologies with which young people can access the adult world and interact beyond the control or even glimpse of adults. As a result, many adults feel that children are growing up far too fast, perhaps not having a classic childhood at all. Instead, they are precociously sexually aware-and sometimes sexually active or at least influenced by sexy styles of dress and behavior-in ways that contradict the deepest notion of the innocent pure child.

Mintz thus points out the fundamental paradox or contradiction of contemporary childhood:

Young people mature physiologically earlier than ever before. The media prey on children and adolescents with wiles of persuasion and sexual innuendo once reserved for adult consumers. The young have become more knowledgeable sexually and in many other ways. They face adultlike choices earlier. Yet contemporary American society isolates and juvenilizes young people more than ever before.

Worse, there are actually more contradictions within contemporary childhood, including the non-innocent, non-sheltered experience of many of America's juveniles. Too many are subjected to violence and abuse, and too many live in poverty: the child poverty rate is higher than the national poverty rate and is highly unequal across races/ ethnicities, with 12.4 percent of white non-Hispanic children living in poverty in 2010 as opposed to 39 percent of black children, 35 percent of Hispanic children, and 14 percent of Asian American children. As many as 1.6 million children are homeless. And perhaps some Americans perceive a danger from the sheer shortage of children: through the 1960s and 1970s children (age less than 17) represented between 31 percent and 36 percent of the American population. In 1978 that percentage dropped to 29 percent and has only declined from there; in 2011 the number fell to 23.7 percent and is predicted to remain in the low-twenties for years to come.

\section{Inventing American Adolescence/Young Adulthood}

If there is a quintessentially American age category, it is adolescence; our very image of the adolescent is the iconic American teenager of the 1950s. Perhaps it is the midtwentieth-century adolescent who captures our imagination because s/he had just been “discovered." Joseph Kett (2003) contended that adolescence was first invented in the United States in the years between 1890 and 1920. Kenneth Keniston, writing thirty years earlier, argued that prior to 1900 , "adolescence was rarely included as a stage in the life cycle"; instead, infancy "was followed by a period of childhood that lasted until around puberty, which occurred several years later than it does today. After puberty, most young men and women simply entered some form of apprenticeship 
for the adult world" (1970: 631). As noted several times already, it was only in 1904 that G. Stanley Hall made the idea of adolescence scientifically and socially significant.

Although adolescence was not a brand new idea (the word derives from the Latin for "to grow" and "to feed or nourish"), American society became especially interested in these transitional years between childhood and adulthood not simply because they were there but because, according to Keniston, they had become a problem. The 1800 s, with urbanization, industrialization, the rise of universal education, and the associated changes in the family and gender roles just described above, produced a contingent of restless, often troublesome young people (mostly males) who seemed to be involved in crime, gangs, and general social nonconformity. In particular, the much-discussed "youth culture" was emerging, characterized by "wanting to be with and for [their own] kind" (1901:20) as William Forbush put it in his early-twentieth-century The Boy Problem.

Keniston attributed the socially disturbing quality of the lifestyle of young people to the fact that the years of the teens and early twenties had become not "transitional" to adulthood but "more like a waiting period" in which the individual was neither child nor adult (1962: 161). In fact, it was becoming the opposite of transitional but rather a separate and awkward life-stage: "it has roles, values, and ways of behaving all its own; it emphasizes disengagement from adult values, sexual attractiveness, daring, immediate pleasure, and comradeship in a way that is true neither of childhood nor of adulthood" (161). He added, "The youth culture is not always or explicitly anti-adult, but it is belligerently non-adult."

As adolescence became increasingly what Erik Erikson (1968: 157) called a psychosocial moratorium, almost a break in or cessation of maturation, it necessarily found its own subculture, its own role models, and its own institutions. By the late 1930s adolescent movie stars like Mickey Rooney "served as the model for the modern middle-class Kleen Teen" (Mintz 2004: 251), and by 1941 at the latest the word "teenager" had made its appearance in the American language. Interestingly, Mintz claims that the 1940s saw the lowest proportion of teen-aged people in American history, and yet (or therefore) it was the 1940s and 1950s teenager who "created the script of modern teenage life" (285). And the script is all too familiar, characterized by pleasing and romantic notions of "letterman jackets, juke joints, malt shops, driveins, sock hops, double dates, and 'parking' at secluded spots" (Mintz 2004: 285), as commemorated in the television series Happy Days with Richie and the Fonz.

However, all was not sunshine in the halcyon days of adolescence, as adults often perceived a crisis of youth as portrayed in books and movies like 1953's Blackboard Jungle and 1955's Rebel Without a Cause, not to mention (anti-)heroes like James Dean, Marlon Brando, and Elvis Presley. And, of course, the site for performing adolescence was and still largely is high school, the purpose of which, according to Thomas Hine in The Rise and Fall of the American Teenager, was "to indoctrinate youth with middle-class standards. But by segregating young people with many others their own age, universal high school education gave teenagers the chance to set standards of their own" (1999: 243). The same year, Patricia Hersch's A Tribe Apart: A Journey into the Heart of American Adolescence took readers into the world of high school, this "gathering up of young people, the leaving of adults to separate worlds, not to be brought back together again until evening" (1999: 11). In fact, in an institutional setting relatively free not only of adults but also of younger children, adolescents "have built their own community. The adolescent community is a creation by default, an amorphous 


\section{Age}

grouping of young people that constitutes the world in which adolescents spend their time" (21). This is why, Hersch concluded, "America's own adolescents have become strangers. They are a tribe apart, remote, mysterious, vaguely threatening" (14).

The aggressive youth movement of the 1960s, together with the "generation gap" felt between idealistic young people and their jaded elders, was only the logical outcome of Hall's storm-and-stress view of adolescence. Oddly, before the moment that it exploded, Edgar Friedenberg in 1959 prophesied in his The Vanishing Adolescent that it was disappearing, and perhaps the classic innocent adolescent of the 1950s was vanishing, replaced by what cultural conservatives like Spiro Agnew and Norman Vincent Peale called "demanding little tyrants" who had grown into "unkempt, irresponsible, destructive, anarchical, drug-oriented" hippies" (quoted in Mintz 2004: 318). By the end of the century Hine could summarize that

America created the teenager in its own image-brash, unfinished, ebullient, idealistic, crude, energetic, innocent, greedy, changing in all sorts of unsettling ways. A messy, sometimes loutish character who is nonetheless capable of performing heroically when necessary, the teenager embodies endless potential not yet hobbled by the defeats and compromises of life. The American teenager is the noble savage in blue jeans, the future in your face.

(1999: 9)

However, this merely loutish character seemed to have turned into a genuine societal threat by then, with deadly adolescent gangs, "superpredators" who appeared to harm and kill without conscience, rings of sexually active teens in middle-class suburbs, and eventually "sexting."

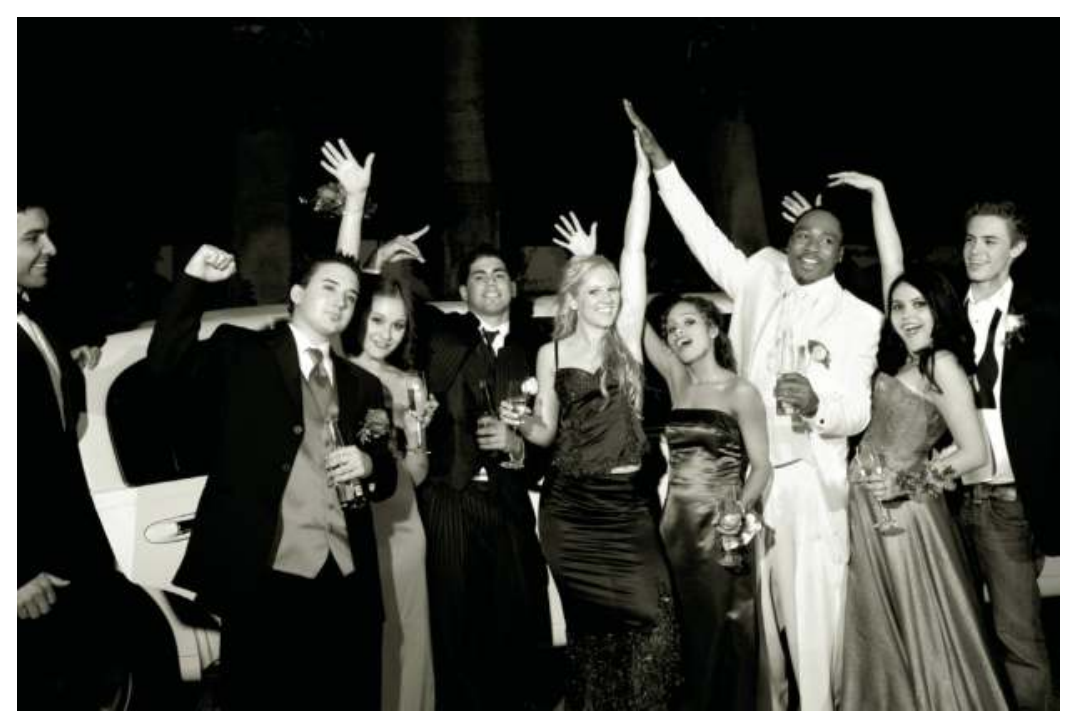

Image 10.2 Teenagers dressed for their high school prom.

(Courtesy of Digital Vision/Thinkstock by Getty Images) 


\section{Diversity Fact:}

According to the US Department of Health and Human Services, Office of Adolescent Health, the psychological health of America's adolescents declined slightly between 2009 and 2011. A total of 28 percent of high school students reported feelings of sadness or hopelessness in 2011, compared to 26 percent in 2009, including 21 percent of males and 36 percent of females. In 2011, 13 percent of males and 19 percent of females seriously considered suicide, and 6 percent and 10 percent, respectively, attempted suicide.

Finally, the volatility of American age-categories like "adolescence" is evinced in the attempts to invent more age-categories by parsing the post-childhood years ever more finely. A perfect example is the creation of the "tween." No one born before about 2000 was ever a tween, even if they were at one time eleven or twelve years old. "Tween" is a new term for the immediate pre-teen years, recognizing (or creating) that group as a distinct market with its own tastes and preferences (for example, for Justin Bieber or Hannah Montana). At the other end of the age range, theorists have proposed that the transitional period to adulthood extends beyond the teen years to perhaps the early- or mid-twenties. Keniston suggested the non-specific term "youth" to refer to that time between the late teens and approximately 24 years of age when an individual is no longer a child or adolescent but has "not settled the questions whose answers once defined adulthood: questions of relationship to the existing society, questions of vocation, questions of social role and life-style" (1970: 634), particularly with regard to questions of marriage and childbearing.

Likewise, identifying "a previously unrecognized stage of life" (Keniston 1970: 635), Jeffrey Arnett has coined the term "emerging adulthood" for the period between age 18 and 25, which is actually more consistent with Hall's original definition of adolescence. An age classification specific to industrial or post-industrial societies that postpone adulthood, it is distinguished by "identity explorations," "instability," "self-focus," the overt experience of "feeling in-between," and a sense of "possibilities, when hopes flourish, when people have an unparalleled opportunity to transform their lives" (2004: 8). Not only is this period defined by the lack of full adult responsibilities and lifestyles, but it is characterized also by the presence of certain behaviors, such as the peak of "unprotected sex, most types of substance abuse, and risky driving behaviors such as driving at high speeds or while intoxicated" (2000: 475).

What Keniston's and Arnett's offerings have in common, along with other coinages like "postadolescence" or "prolonged adolescence," is a perception that young people are increasingly delaying, voluntarily or involuntarily, the acceptance of conventional adult roles and responsibilities, like jobs, marriages, and families. A general trend in America seems to be to postpone growing up as long as possible-and certainly not growing up in the old familiar way. Susan Littwin noticed this fact in her 1986 The Postponed Generation: Why American Youth Are Growing Up Later, and it has only become more acute in recent years. Ironically, the same complaint was lodged against 
"twentysomethings" in 2012, who would be the generation born almost immediately after the publication of Littwin's book. Robin Marantz Henig and Samantha Henig (2012) pondered why young adults "seem stuck" and refuse to grow up, noting that the Baby Boomers suffered from precisely the same affliction. Hence we see the rise of youthful, even "belligerently non-adult," forms of adulthood conveyed in new terms like "rejuvenile" (Noxon 2006) and "grup"-the kind of adults who still play children's games, wear youthful clothing, and carry on the habits of their youth.

\section{Inventing American Middle Age and Elderhood}

As with race, class, gender, or any other social variable, categories do not exist in isolation but only as part of a more or less comprehensive category system. Thus, as the stages and norms of early life were being elaborated, so later life underwent a similar elaboration. We should be able to anticipate now, for instance, that before the midto late-1800s "the concept of middle age did not exist; it had not been invented yet. Middle age may seem like a Universal Truth, a fundamental law of nature . . . but it is as much a man-made creation as polyester or the rules of chess" (Cohen 2012: 5). The same naturally goes for elderhood or senior citizenship or whatever label one applies to the final years of life.

There has long been more attention directed to old age than to youth, perhaps because old age seems more like a problem than youth. In fact, most sociological discussions of "age diversity" focus primarily if not exclusively on old age, as if childhood, youth, adulthood, etc. are not ages too. Adulthood has received the least attention although it is the longest stage, lasting officially or statistically for over forty years (from 18 to 65). Erik Erikson identified only two stages during those decades (dividing adulthood into "young adulthood" from 19 to 40 and "middle adulthood" from 40 to 65). Yet during those forty-plus years, people go through many changesmarriage(s) and divorce(s), children and an "empty nest," fluctuations in job, in residence, and in health. Adulthood is hardly monolithic.

Concepts like middle age and elderhood have a quite different meaning when the average life expectancy is not much more than 40 years, as it was in the US from the 1600s until the 1800s; life expectancy did not top 50 years for both men and women until the early 1900s and did not exceed 60 until the 1920s. Perhaps because there was so little old age available, American society did not formulate distinct categories and norms for it. According to Patricia Cohen, in nineteenth-century rural America, "a sweet sixteen and a sedate sixty-year-old could wear the same style without embarrassment. By the end of the century, expectations had altered as each age developed its own dress code" (43). As people began to live longer, later life began to garner more interest and more celebration: Cohen quotes a 1910 item from the San Francisco Call which stated that the woman of that era "is just beginning to live at thirty ... and she absolutely refuses to consider herself old until she is seventy" (49).

At the same time, though, later life came to be seen as a time of declining health, energy, and beauty, which was important in a society that increasingly valued youth. The first recorded "face lift" occurred in 1901, and G. Stanley Hall returned with a new book in 1922 on Senescence: The Last Half of Life, in which he declared ages 30 to 45 to be midlife and warned that adults were wearing themselves out trying to look and act young past age 40 . That even adulthood had become a psychological 
and social problem was evinced by the invention of the term "mid-life crisis" in 1965 by Elliott Jaques, who placed this crisis around age 35. Softening the blow, the magazine Psychology Today refers to the "midlife transition" which, it assures us on its website, "is a natural stage that happens to many of us at some point (usually at about age 40 , give or take 20 years)." So midlife can apparently occur anywhere between age 20 and age 60. Multiplying the moments of age-based crisis, Oliver Robinson and Jonathan Smith (2010) have recently suggested a quarterlife crisis that strikes Americans between the ages of 25 and 40. Such crisis thinking persists, despite the fact that researchers like Elaine Wethington (2000) find that midlife is not always and equally stressful and that a small minority of people experience a "crisis."

Two interesting manifestations of the social category "middle age" are the MIDUS project and what Cohen calls the "Midlife Industrial Complex." MIDUS, or Midlife in the United States (http://midus.wisc.edu), describes itself as "a national longitudinal study of health and well-being" established in 1995 because "the wide terrain known as midlife-the longest segment of the life course-remains largely uncharted." In a scientific-categorial society, nothing can remain uncharted. The Midlife Industrial Complex, in Cohen's estimation, is “a massive industrial network that manufactures and sells products and procedures to combat supposed afflictions associated with middle age; and a mental syndrome that exaggerates angst about waning powers, failure, and uselessness in one's middle years" (165).

Officially and culturally in the United States, old age begins at age 65, which has been the customary age for retirement. The officially elderly have been studied much more thoroughly than adults in general or the middle-aged specifically, including in the Census. In a Census report on older Americans called "The Older Population

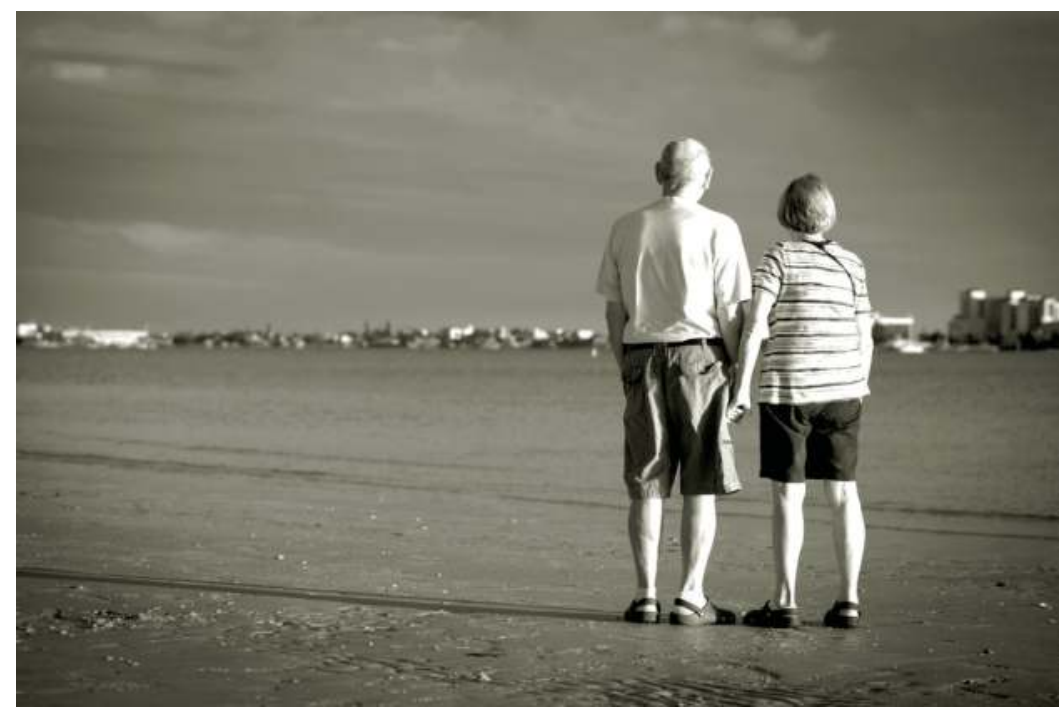

Image 10.3 Retired couple, Florida.

(Courtesy of Edward Fielding/Shutterstock.com) 
2010," 13 percent of the population was identified as being 65 years of age older; 0.1 percent of Americans or 424,608 people, were 95 years old or older. Since some Americans live to or past age 100, the "older American" or senior citizen category covers almost as many years as the "adult" category.

As in the rest of the world, the elder population is growing relative to the entire population: in 1900 only 4.1 percent of Americans were aged 65 or more, and this trend is expected to continue, with the most dramatic growth in the 95 -and-over range. As previously mentioned, a larger share of the population of the Northeast is over 65 (14.1 percent) and over 85 (2.2 percent) than in any other region of the country; the smallest share is in the West (11.9 percent and 1.6 percent, respectively). Elder Americans are unevenly distributed geographically, as depicted in Figure 10.7.

\section{Diversity Fact:}

Old age in the US is significantly related to race and ethnicity. For instance, although non-white minorities compose much more than 20 percent of the general population, they compose only 20 percent of the elder population; a mere 7.2 percent of Hispanics were 65 or older, 8.9 percent of African Americans, 8 percent of Native Americans, and 9.4 percent of Asian Americans, compared to 16.3 percent of non-Hispanic whites. These differences speak to some combination of immigration of younger people and the negative effects of racial inequality and health disparities (see Chapter 11).

Contrary to some assumptions, older Americans are not disproportionately poor. Indeed, the poverty rate among the elderly in 2010 was 9 percent, lower than the general poverty rate. Poverty was more common for older women (10.7 percent) than men (6.7 percent) and much more common for African Americans (18 percent) and Hispanics (18 percent) than for whites (6.8 percent). Also contrary to stereotypes, very few (1.5 million or 4.1 percent) of Americans aged 65 and above lived in institutions for the elderly, and more than half of older Americans lived with their spouses, while more than one-quarter lived alone. Not surprisingly, residence in an elder facility increased with age, from 1.1 percent for 65-75-year-olds to 13.2 percent for 85 and above.

Elderhood has a history in America too, particularly since it was comparatively rare until recently. As Margaret Morganroth Gullette (2004) puts it, we are not only aged by time but we are also "aged by culture." That is, culture not only plays a major role in how long we live-whether we make it to old age-but also in defining the roles, norms, and institutions of old age. For example, retirement at age 65 (which was not an option in previous centuries of self-sufficient farm work) became feasible when people began to do modern industrial or office work and when the life expectancy was not much more than 65 . Today, many elders want to, need to, and are able to work much longer. American society in the twentieth century created new institutions to provide a "safety net" for older people, from Social Security in the 1930s to Medicare in the 1960s (see Chapter 11). But most of all, people do not age the way they used 


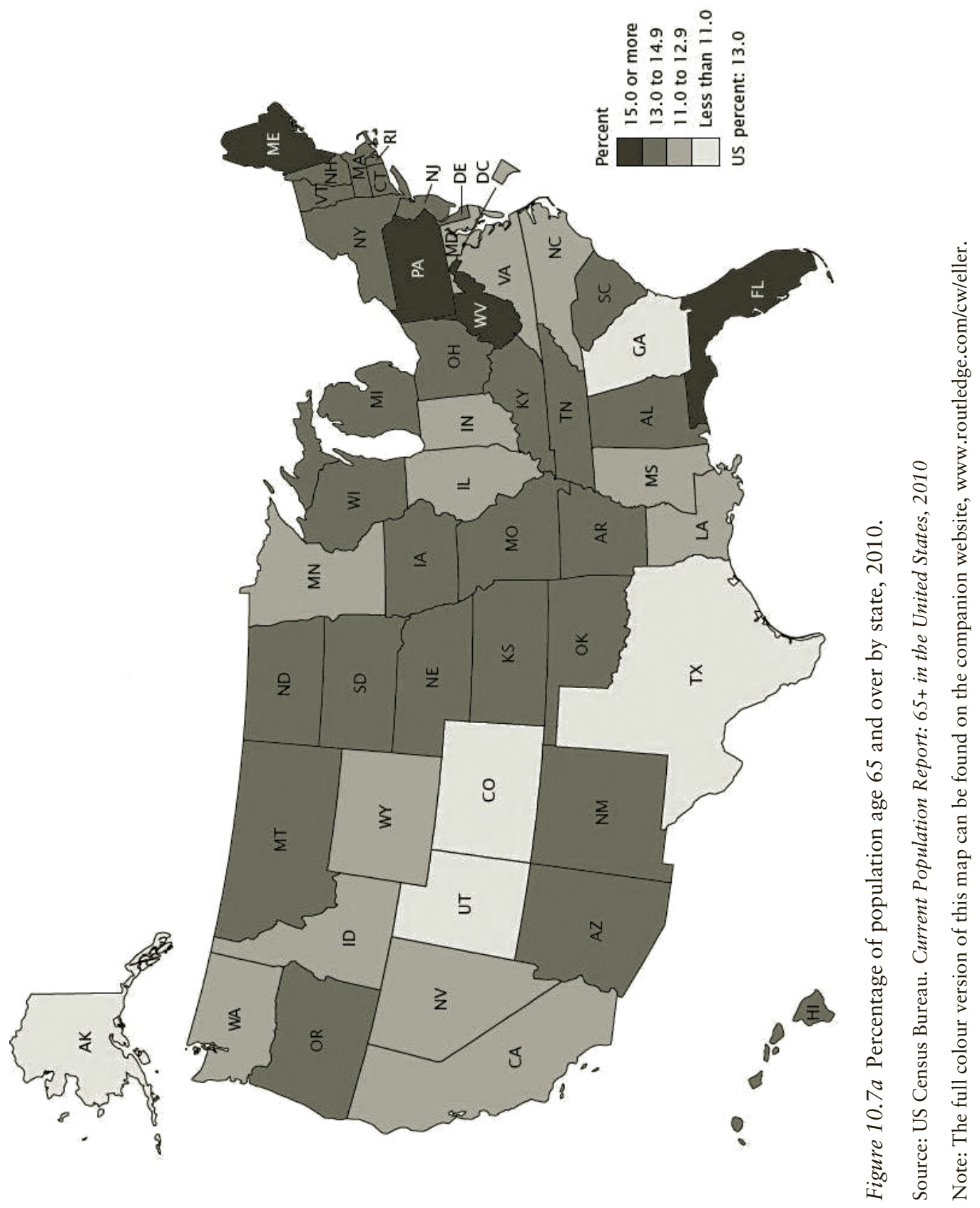




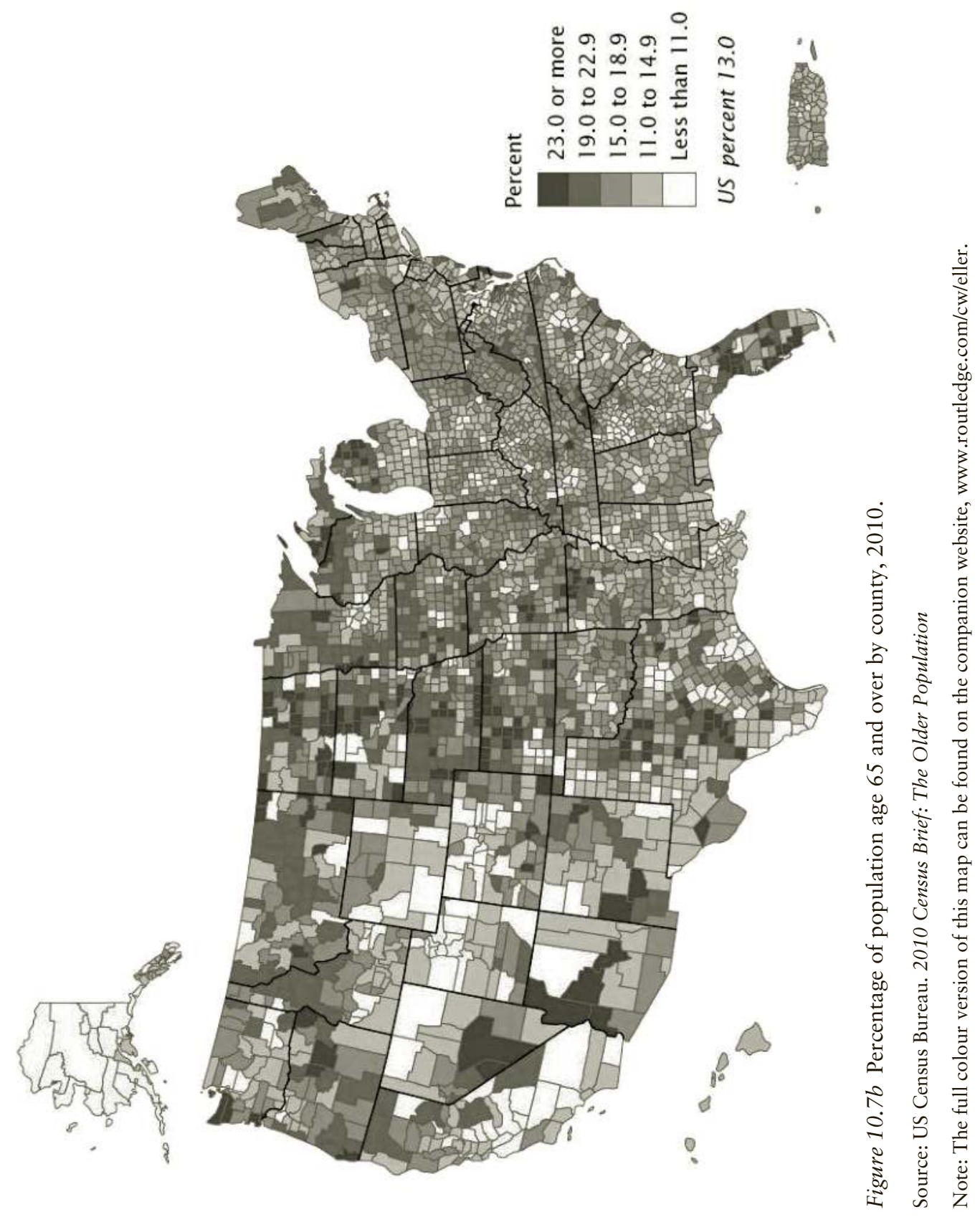


to; like middle age or even adulthood, modern Americans can and do try to postpone elderhood, desiring to remain active and independent much longer than people of previous eras. Gone are the days of what sociologists used to call "disengagement theory" in which it was believed that older people withdrew from society and waited to die.

\section{Box 10.2 Numbering the Days in an Elderly Community}

Elderhood is not a single community or experience in the United States; rather, the category of "elder" contains much diversity, of age, of gender, of ethnicity, of health, and so forth. In a classic study (also made into a movie by the same title, Number Our Days), Barbara Myerhoff described a group of elder Jewish Americans living in southern California. Having mostly immigrated from Eastern Europe years before, the focus of their life at the time of research (late 1970s) was the Aliyah Senior Citizens' Center. The four thousand elderly Jews in the neighborhood used the Center "all day, every day" for everything from "hot meals" to "cultural events, discussions, classes of all kinds, along with social affairs, religious ceremonies, celebrations of life crises, anniversaries, birthdays, memorials, and occasional weddings" (1978: 8). Living near the beach with the Center literally at the center of their lives, they formed a "small, stable, cohesive, delimited, and homogeneous" community which Myerhoff characterized as "an entire, though miniature, society" (8). And despite the "sense of doom" over the fact that their community was inevitably dying out, she found life at the Center to be "passionate, almost melodramatic. Inside, ordinary concerns and mundane interchanges are strangely intense, quickly heating to outburst" (7). Further, there was internal diversity even in this little world, as well as differences between the Center faction and other elderly Jews in the area. For instance, much of the day was spent on benches at the beach which were "segregated by sex and conversation topic. The men's benches are devoted to abstract, ideological concerns-philosophical debate, politics, religion, and economics. The women's benches are given more to talk about immediate, personal matters - children, food, health, neighbors, love affairs, scandals, and 'managing"' (4). And the Center folk shared the beach with other Jews, like the people who simply came to picnic or play games (who considered the Center people to be "too political or religious") or the socialist activists who handed out literature and collected donations (and who considered the Center people "too politically conservative") (5). Even among elderly southern California Jews, there were many ways to be old.

\section{American Generations}

One of the formative facts of human life and society is that all of the age categories are occupied simultaneously: although individuals move through the life cycle and its socially constructed categories, at any given moment some individuals are in the "child" category while others are in the "elder" category (having occupied the "child" category themselves decades earlier). We refer to these simultaneous age cohorts as generations because, as Mannheim explained above, each shares a 
particular position in the social process, having lived through certain experiences (World War II, Vietnam, disco, 9/11, etc.) and thus sharing certain memories and the personalities that are shaped by social experience.

People are being born constantly, so there is no obvious or natural way to divide the generations. We tend to assume that a generation refers roughly to the period of time that it takes for a birth cohort (people who are born within a few years of each other) to grow to reproductive age and have their own children, which is generally 20 years or so. Where to open and close such a birth cohort is a social question, usually answered by relating it to some major historical event, like a war. Thus, the so-called "Baby Boomer" generation consists of the people who were born in the years after World War II and who matured through the era of economic plenty, suburbanization, cultural conservatism, and the "Cold War" with its immanent threat of nuclear annihilation. That generation had children around the same time, who constituted the next birth cohort, and so forth.

As in the case of life-cycle categories discussed above, Americans have not always thought in terms of generations, and it is a uniquely modern habit to name generations and attribute distinct traits to them. Furthermore, since the ancient era, adults have tended to feel that the young generation lacks knowledge and respect, so doomspeaking pronouncements about the young generation are nothing new.

At any rate, the cut-offs and names of supposed generations are entirely arbitrary and socially defined. For instance, according to Elwood Carlson (2009) in a study for the Population Reference Bureau, seven generations have lived into or through the twentieth century, which he defines as:

1 The New Worlders (born 1871 through 1889), who mostly lived on farms; onequarter were immigrants.

2 The Hard Timers (born 1890 through 1908), who fought in World War I and lived through the Great Depression and World War II.

3 The Good Warriors (born 1909 through 1928), who fought in World War II and have been lovingly dubbed "the greatest generation."

4 The Lucky Few (born 1929 through 1945), who were too young to fight in World War II but enjoyed the economic boom of the 1950s.

5 The Baby Boomers (born 1946 through 1964), the largest generation of the century born after World War II and the first generation to receive a formal nickname.

6 Generation X (born 1965 through 1982), who entered the workforce shortly before the turn of the twenty-first century.

7 The New Boomers (born 1983 through 2001), a generation almost as large as the Baby Boomers and who, together with new immigrants, will comprise the largest generation living in the twentieth century.

According to this data-packed study, the seven generations differ along many dimensions from family structures to education levels to political attitudes, as summarized in Table 10.5 .

Politically, the most consequential developments were the increase in moderate independents (from 9 percent of Hard Timers and 5 percent of Good Warriors to 16 percent of Baby Boomers and 19 percent of Generation Xs) and the decline in moderates in both parties, reflecting the greater political polarization of America today. 
Table 10.5 Comparison between seven twentieth-century generations

\begin{tabular}{|c|c|c|c|c|c|c|c|}
\hline & $\begin{array}{l}\text { New } \\
\text { Worlders }\end{array}$ & $\begin{array}{l}\text { Hard } \\
\text { Timers }\end{array}$ & $\begin{array}{l}\text { Good } \\
\text { Warriors }\end{array}$ & $\begin{array}{l}\text { Lucky } \\
\text { Few }\end{array}$ & $\begin{array}{l}\text { Baby } \\
\text { Boomers }\end{array}$ & Gen $X$ & $\begin{array}{l}\text { New } \\
\text { Boomers }\end{array}$ \\
\hline $\begin{array}{l}\text { Percent with both parents at } \\
\text { home during childhood }\end{array}$ & n.d. & 81 & 89 & 85 & 86 & 79 & 69 \\
\hline $\begin{array}{l}\text { Percent with less than } \\
\text { high school }\end{array}$ & 83 & 75 & 52 & 25 & 12.5 & 12.5 & n.d. \\
\hline $\begin{array}{l}\text { Percent with four years of } \\
\text { college }\end{array}$ & 3.5 & 5 & 8.5 & 18 & 27 & 32 & n.d. \\
\hline $\begin{array}{l}\text { Percent men ever married } \\
\text { by age } 29\end{array}$ & 66 & 69.9 & 78.8 & 84.9 & 70.6 & 60.7 & n.d. \\
\hline $\begin{array}{l}\text { Percent women ever } \\
\text { married by age } 29\end{array}$ & 80.5 & 82.5 & 86.3 & 90.8 & 79.7 & 70.3 & n.d. \\
\hline Percent men farmers & 22 & 13 & 5 & 2 & 1 & n.d. & n.d. \\
\hline Percent men professionals & 4 & 6 & 10 & 17 & 21 & n.d. & n.d. \\
\hline Percent liberal Democrat & n.d. & 12 & 12 & 14 & 15 & 13 & n.d. \\
\hline $\begin{array}{l}\text { Percent conservative } \\
\text { Republican }\end{array}$ & n.d. & 19 & 15 & 16 & 14 & 14 & n.d. \\
\hline
\end{tabular}

Source: Compiled from Carlson, 2009

Generational differences came to a crescendo in the 1960s with the "generation gap" mentioned above. Baby Boomers coming of age in the 1960s were liberal and critical to an unprecedented extent, giving America its hippie and peace movements. At no time before did the generations seem farther apart in experience and attitudes. The Baby Boomers went on to become parents and employees (and managers and politicians) themselves, in many ways maintaining their generational values while in other ways conforming more closely to conventional norms.

This raises the point that a generation can be a social force in its own right, as with the Baby Boomers who were unique not only in values but also in sheer numbers. That generation dominated the youth culture of the 1960s, the business culture of the 1980s, and they are set to dominate the retirement culture of the twenty-first century. However, as a reminder of Mannheim's distinction between an age cohort and a true "generation unit," some observers have suggested that the Baby Boomer generation be subdivided into early/older or Alpha Boomers (born 1946-54) and later/younger Boomers (1955-64), whose experiences and circumstances are relatively disparate.

At present, one of the most important sites in society where generational differences show up is the workplace. According to a report on generational differences at work prepared for the University of Minnesota, Anick Tolbize concluded that the pre-Baby Boomer generation (here called the Traditionals) was loyal, "highly dedicated, averse to risk and strongly committed toward teamwork and collaboration" (2008: 2). They "believe in paying their dues ... , prefer formality, have a great deal of respect for authority, like social order, and . . . love their things and tend to hoard stuff." Baby Boomers, who were raised by the Traditionals but rebelled against much of their world, "believe that hard work and sacrifice are the price to pay for success" (3). They "are confident task completers," "more process- than result-oriented," and they have "a sense of entitlement . . . reluctant to go against peers and judgments of others who do not see things their way." Generation Xs "aspire more than previous generations to achieve a balance between work and life," are "more independent, 
autonomous, and self-reliant," and "are not overly loyal to their employers" (3). They are technologically skilled, tolerant of diversity, and not motivated primarily by money. Finally, the New Boomers (called here Generation Y or Millennials), still fairly new to the workplace, have great facility with technology and are comfortable with diversity. They are sometimes perceived as "demanding" and "confident" as well as "entrepreneurial" and "less process focused" (4).

The Millennials, according to a Pew Research Center survey, are far and away the most socially networked and attached to their technology. They are also the most ethnically diverse generation, only 61 percent white (compared to 80 percent of the pre-Baby Boomers, here called the "Silent Generation") and 19 percent Hispanic, 13 percent African American, and 4 percent Asian American. Being highly diverse and highly educated ( 34 percent with some college and 15 percent with a four-year degree or more), they are tolerant and liberal. In fact, their top three answers to the question of what makes their generation unique are technology use, popular culture, and being liberal or tolerant. (For the other four working generations, traits like "work ethic" or "respect" or "morals" showed up on their list, but not for the Millennials.) The Millennials are much more likely to lean toward the Democratic Party (54 percent) and much less likely to lean Republican (40 percent, and only 30 percent in 2008). They are more open than any previous generation on a variety of social issues such as gay couples and parenting, single motherhood, cohabitation without marriage, and interracial marriage. They also less religious.

One troubling trend, according to Jean Twenge, is that Millennials appear to be at least as, if not more, materialistic than previous generations (Twenge and Kasser 2013) and, even more problematically, more narcissistic (Twenge et al. 2008). They have incredibly high self-esteem, extroversion, and assertiveness, which is not necessarily bad, but it is the continuation of a decades-long trend and could make it more difficult for the generations to get along at work and in America's other institutions.

\section{Conclusion}

As Patricia Cohen concluded, "Prior to 1850 , age was rarely used to measure status or grant entitlements, endowing someone with the right to drink, live independently, or drive a carriage. There were no legal standards for becoming an adult, no clear demarcation between a juvenile and a full-grown criminal. Age was not an essential ingredient of one's identity" (2012: 28). However, over the past century and a half in America, people have come to be categorized more finely and firmly on the basis of their age characteristics, as they have on their racial or sex/gender or other characteristics.

Like race and sex/gender, age is a natural fact, but how societies organize and utilize the fact of age varies across cultures and over time. America does not have the same age categories today that it had a century ago, at the moment when many of these categories were invented or given their modern form. Individuals also age differently today than they did in the past, and they will age differently in the future. This sets age cohorts further apart as "generations" with unique and sometimes incommensurable attitudes and values. Finally, within each age category and generation we find additional diversity, in relation to race, sex/gender, class, religion, religion, and so on. Age may have been dismissed as unimportant background variable in the past, but it cannot be dismissed so easily today. 


\section{Health and (Dis)ability}

The epidemic of obesity in the United States is both remarkable and alarming. According to the Organization for Economic Cooperation and Development (OECD), 68 percent of Americans were overweight in 2008 and 34 percent were obese, making the US the fattest country in the world. Mexico actually had more overweight citizens ( 70 percent) but not quite as many obese (30 percent), and both were well over the troubling average of 50 percent overweight and 16 percent obese in the thirty-four countries of the OECD, including the US, European states, Japan, Israel, Mexico, and Turkey. There are many reasons for this weight gain, some related to what has been called "diseases of development" or the kinds of health habits and problems that rich industrialized societies face. Developed countries can simply afford to eat more, and they tend to eat more fatty and sugary foods. Their residents also tend to get less physical activity, between sedentary jobs and screen-based entertainment on televisions, computers, and handheld devices. Some scientists have even tied weight gain to chemicals in

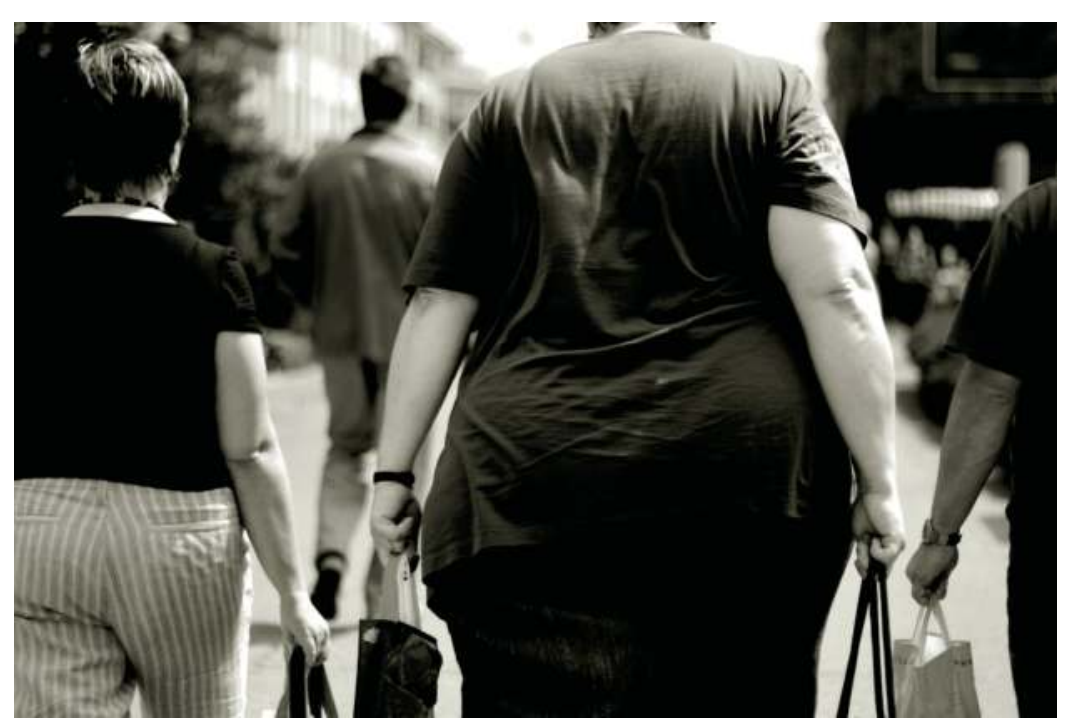

Image 11.1 Obesity is on the rise in the United States.

(Courtesy of Jakub Cejpek/Shutterstock.com) 
the environment, like bisphenol $A$ and other "endocrine disruptors" that appear to signal the body to store fat; bisphenol $A$ is used in many modern products from plastics to the linings of cans, making it almost impossible to avoid. But modern lifestyles do not explain the recent and unequal spread of obesity. The Centers for Disease Control report that in 1990 no state in the US had an obesity rate above 15 percent and ten states had a rate under 10 percent; by 2007, every state except Colorado had a rate above 20 percent, most states had a rate over 25 percent, and three southern states (Alabama, Mississippi, and Tennessee) suffered an obesity rate over 30 percent. Obesity is also more common among African Americans and Mexican Americans than among whites (see discussion and table below).

Why has a basic physical characteristic like weight suddenly and dramatically changed in the United States? How is it related to other social statuses, and how is it related to other health conditions? And how does it affect other aspects of society, from conceptions of beauty to the design and marketing of products?

Like race, gender, and age, health and ability/disability have a physical basis; they are about the body in some way (even mental and psychological health and disability is about the brain to some extent). However, like those phenomena, health and (dis)ability are also social. They are social in origin, social in organization, and social in consequence. How we live, the choices we make, and the statuses we occupy all shape our health and (dis)ability, which in a feedback fashion then shapes how we live and our subsequent options and statuses.

Health and (dis)ability cover a wide range of physical states, from illness to injury to conditions that many or most people merely find undesirable. Not all of these conditions necessarily constitute "sickness," but they are unified in being perceived as problems-problems which, in conventional American thinking, should if possible be solved, usually by modern medical means. Thus, unlike any of the other categorysystems discussed in this book, health and (dis)ability categories are paralleled by a set of categories and institutions intended to intervene in health and (dis)ability conditions, such as medical professionals of many kinds, hospitals and other care facilities, insurance companies, pharmaceutical companies, research institutes, and many more. While those professions and institutions will not be a subject of this chapter, they are essential to any understanding of contemporary health systems and outcomes.

Even more, health and (dis)ability are not a simple and objective matter of being "healthy" or "sick." Social concepts and attitudes in regard to what constitutes health or sickness vary between societies and change over time. Conditions that were once regarded as "illness" may be redefined as not-illness; the classic example, presented in Chapter 7 , is homosexuality. At the same time, new categories of illness may be identified, or existing categories may be expanded. A controversial example today is autism. Along with attitudes, treatment approaches change over time. And, most interestingly, some people who "have" a condition that is medically diagnosable and generally felt to be negative may actually embrace that condition not as an imperfection but as an identity, like many hearing-impaired and deaf individuals in the United States (see below). This is why we choose in this chapter to complicate the assumption that every non-normative physical state is a disability, preferring to use the term "(dis)ability."

Finally, unlike most other physical category-systems, but more like age, most of us will occupy more than one health and (dis)ability status in our lives, sometimes briefly, 
sometimes permanently. And our bodily conditions will affect everything from our ability to navigate the social environment (e.g. enter buildings or climb stairs) to our relationships with other people (who may feel sorry for us or uncomfortable around us-or even fear and avoid us).

\section{Diversity Fact:}

People who used to be pejoratively called "dwarves" or "midgets" today tend to prefer to be called "little people," signaling that they are not so much defective as different. Some 50,000 Americans have reduced body size due to hundreds of different genetic and biochemical conditions, and many choose to associate and socialize with other little people in organizations like Little People of America.

\section{The Social Construction of Health and (Dis)ability}

By now, the idea that even physical states and differences are socially constructed should be familiar. While there are sometimes non-social causes of health and (dis)ability (such as genetic ones in the case of little people), even genetic abnormalities can often be linked to environmental and behavioral factors like smoking, substance use, and chemicals. A classic and tragic example is the generation of "thalidomide babies" who were born in the 1950s and 1960s with missing or malformed limbs because their mothers took the chemical called thalidomide. Some people believe today that the surge in autism is related to vaccinations, but there is no evidence to suggest such a link.

Many health and (dis)ability statuses are much more directly and obviously linked to social and institutional factors, such as:

- Individual behaviors, such as smoking, drinking alcohol, using or abusing prescription or illegal drugs, unsafe sexual practices, and risk-taking activity (like driving too fast or texting while driving).

- Beliefs and values, such as religious objections to certain medical procedures like blood transfusion or attitudes that subject women to unnecessary harm and/or inadequate care.

- Social inequalities, such as racial and ethnic discrimination, income and education disparities, or even marital status.

- The physical environment, including residential neighborhood, the quality of housing (e.g. the presence of lead-based paint or asbestos), crowding, pollution, and what have been called "food deserts" or areas where fresh nutritious inexpensive food is unavailable.

- Healthcare systems, both in terms of the quality and in their availability, as affected by cost, access to insurance, and the location of healthcare providers and facilities.

Further, health and (dis)ability states can be the basis of social organization, that is, individuals in particular statuses of health and (dis)ability can organize or be organized formally to interact with and support each other and/or to influence the attitudes or policies of the wider society. The Little People of America just mentioned is one 


\section{Health and (Dis)ability}

example, as are organizations from ACT UP (AIDS Coalition to Unleash Power) to the Special Olympics, or even the American Association of Retired Persons (if we presume that "old age" is a health condition). Finally, physical and social factors combine to determine differences in health outcomes or what are frequently called health disparities, that is, the unequal health effects on different kinds of people (by race, gender, class, age, etc.) in terms of quality of life, incidence of particular illnesses or disabilities, or rate of death. As we will see below, there are some quite consistent relationships between social statuses and health/(dis)ability conditions, such that the "intersectionality" found between gender and other social variables (see Chapter 7) is also found between those social variables and health disparities.

\section{Cultural Conceptions of Health and (Dis)ability}

Culture and society can make us unhealthy, but they also define in the first place what it means to be "sick" or "disabled" as well as offering explanations for why a person is sick/disabled and proposing solutions or cures for it. Societies have diverse notions of the meaning and standard of health. For instance, while Americans fret about obesity, plumpness or fat has been a sign of wealth or status in other societies; likewise, a tan is a marker of health and beauty in contemporary America, while in the past it signaled inferior status (i.e. of a person who was compelled to labor outdoors).

Traditional Chinese medicine is based on the concept of chi, which refers to energy within the body. This energy is believed to flow through the human body, as well as through all of nature, along specific channels; when chi is blocked or out of balance, illness can occur. Chi is also in food, and so diet is an important aspect of Chinese healing practices. But since chi comes in two modes-yin or slow/dark/moist/feminine, and yang or fast/bright/dry/masculine-males and females need different amounts of these two forms of chi and should therefore eat different diets. Finally, health can be enhanced or restored through the manipulation of chi not only in diet but also in exercise (like tai chi), treatments like acupuncture and acupressure which improve the flow of $c h i$, and even the arrangement of one's living space (feng shui).

In many societies, physical health and spiritual condition are enmeshed. Most societies over history have believed that some, if not most of human illness (and other misfortune) is caused by spirits or humans using spiritual power for evil purposes. One cross-culturally common explanation of illness is spirit attack or spirit possession. The !Kung or Ju/hoansi bushmen of southern Africa claimed that their dead ancestors were responsible for most of the sickness in society, because the ancestors were lonely and desired to pull their loved ones closer to them (that is, to death). Angry or malicious spirits could cause harm in many societies, and "soul loss" was also a common reason for illness. On the island of Mayotte between Mozambique and Madagascar, people recognized both "natural disease" and spirit possession, or menziky lulu, in which a spirit entered a victim's body, rose into the head, and took control of the body, displacing the victim's own soul (Lambek 1981).

On the other hand, spirit possession was sometimes seen as a therapy for physical and/or social problems. According to Janice Boddy, almost half of the women of the Sudanese village of Hofriyat were afflicted by the zar spirits, beings that almost exclusively assaulted married women. Significantly, the symptoms of spirit possession were refusal or inability to perform normal wifely duties-that is, failure in their 
expected role as wife and mother-and "once possessed, a women is always possessed thereafter" (1988: 4). Therefore, since a woman could not escape spirit possession, she instead made peace with it, undergoing therapeutic trance, which cemented the spiritual paradox of "a woman who is not who she is-not human, not Hofriyat, not even in most cases, female" (22). She thus became internally diverse, part human and part zar, which made her behavioral abnormality tolerable (see the discussion of the "sick role" below).

Researchers have reported a number of culturally specific syndromes around the world, including amok in Malaysia and Indonesia. Based on a Malaysian word for "to engage furiously in battle," amok has been characterized "by sudden unprovoked outbursts of uncontrollable rage and aggressive behavior, often leading to indiscriminate injury or death to others" (Hempel, Levine, Meloy, and Westermeyer 2000: 582). Obviously, English has picked up this word to describe equally unexplainable violent behavior. Certain northern Native American societies, like the Chippewa, Ojibwa, and Cree, recognized an affliction that has been called windigo disease, since victims suffered from a belief that they had become a windigo, that is, a cannibalistic monster. Individuals with windigo disease displayed high anxiety and even attempted suicide to prevent their transformation.

A curious syndrome has appeared around the world, in which male victims believe that their genitals are being attacked or shrunken by evil intent. Known as koro in China, it has been described as "a kind of panic disorder with the leading symptom of fear projected to the genitals" (Garlipp 2008: 25), specifically that the genitals are shrinking or retracting into the body, often combined with a fear of death. Similar phenomena have been reported in Africa, where the shrinkage is widely held to be a matter of "criminal tampering," a "form of penis-napping" in which the organ is stolen "and held for ransom" or used for purposes of magic, witchcraft, or sorcery (Adams and Dzokoto 2007: 89).

In Western societies too, health and (dis)ability are tightly entangled with culture. More than a few Europeans and Americans continue to believe in spiritual disease (and thus spiritual cures). Over history, various notions of health and sickness have prevailed, such as the theory of four "humors" (blood, phlegm, black bile, and yellow bile) that composed the body. Witchcraft was taken seriously enough to warrant witch hunts and witch trials. Western treatments of disease have also varied greatly, including bloodletting and the application of poultices or soft moist substances spread on cloth and placed on the skin. The mentally ill were often subjected to all manner of handling, from confinement and chaining to spinning, dousing with cold water, and lobotomy (removal of part of the brain).

If physical illness and disability in the West has been an area of cultural definition (see the discussion of deafness below), mental illness and disability has been even more sensitive to culture, precisely because mental illness shows itself in behavioral and attitudinal abnormality. In fact, the very notion of "mental illness" is a relatively recent one; in the past, the same conditions have been labeled as crime or sin or other non-medical failures (see the discussion of medicalization below). We have already seen how homosexuality or "gender identity disorder" have been added to and deleted from rosters of mental illness. Because mental illness is so intimately tied to social norms, some critics have gone so far as to assert that the very idea of "mental illness" is a cultural concept. Two famous representatives of this position are R. D. Laing with 


\section{Health and (Dis)ability}

his The Politics of Experience (1967) and Thomas Szasz with his The Myth of Mental Illness (1961). Both essentially contended that psychiatry, as Szasz phrased it, is "the study of personal conduct" (1961: 7) and as such is necessarily socially and culturally bound: some person, group, institution, or society must define "normal conduct" and then impose that normality on others, thus creating the categories "abnormal," "mentally ill," "sick," or "disabled."

\section{The "Sick Role"}

Generally we think of being sick as a purely physical condition: if you have a bad cold or flu, then you have a hard time getting out of bed, or if you have a broken leg, then you need crutches to walk. But sickness or disability is also a social category, as just suggested, and specifically it is a category or set of categories under the more general category of "abnormality." American sociologist Talcott Parsons extended this idea still further, arguing that sickness is socially labeled and socially organized in yet another way-that there is such a thing as a sick role that we are allowed and expected to play when we are ill. It is easy to see how doctors and nurses play a "healing" role, but it was an important (and controversial) step to think of the patient as playing a social role too. Parsons identified four aspects of the "institutionalized expectation system relative to the sick role" (1951: 436):

- “exemption from normal social responsibilities, which ... requires legitimation by and to the various alters involved and the physician often serves as a court of appeal as well as a direct legitimatizing agent."

- "the sick person cannot be expected by 'pulling himself together' to get well by an act of decision or will. In this sense also he is exempted from responsibility-he is in a condition that must 'be taken care of'” (437).

- " "the state of being ill as itself undesirable with its obligation to want to 'get well."”

- "the obligation ... to seek technically competent help, namely, in the most usual case, that of a physician and to cooperate with him in the process of trying to get well."

In other words, the person who plays—or has been assigned—the sick role does not have to perform his/her usual social activities; s/he can stay home from work or take a day off from school. Further, s/he is not responsible for his/her actions: if it is the illness or injury that causes certain behavior, then the individual cannot be held accountable for it. The sick person also submits him/herself to the authority of a medical specialist and should do his/her part to get well, including following the doctor's orders, taking the medicine, observing the diet, or what have you. In short, the sick role is a kind of freedom from social norms as well as a kind of surrender to a different set of norms: "the sick person is helpless" (440).

As a functionalist, Parsons rightly recognized that "being sick" is part of the social system of statuses, practices, and values that comprise health and medicine and not a mere physical fact. He also in some ways likened the "sick role" to social deviance, in the sense that the sick person is, and is expected to identify and comport as, an individual who is not quite right. This means submitting oneself to the medical regime, in its many cultural and historical forms, as discussed above. It also means accepting a certain stigma, in the sense elaborated by Erving Goffman (see Chapter 1). Two 
of Goffman's markers of stigma were "abominations of the body" (what we could roughly call physical illness, injury, or deformity) and "blemishes of individual character" (which would fall roughly into the category of psychological disorder or mental illness) (1963: 4). Goffman concurs with Parsons that such a stigmatized person tends to "fall outside the ordinary, natural, and desirable" (Goffman 1963: 3) and to require a course of treatment or intervention, often involving seclusion from "we normal" (5) in a specialized facility like a hospital or asylum. It also involves, perhaps gradually, the acceptance of a new, usually diminished, identity and a new set of social relations, as reported by Robert Murphy in Box 11.1.

\section{Box 11.1 A Social Scientist Learns the Sick Role: Robert Murphy's Body Goes Silent}

Researchers often describe norms, roles, and institutions from outside, that is, without actually occupying the status they study. In the case of sickness, all of us, even social scientists, eventually succumb to some disease, and Robert Murphy courageously reported on the decline of his own health with the sober objectivity of scholar. In The Body Silent he told how he was diagnosed with a tumor on his spinal column that led to progressive weakness and dependence; he also kept up a dialog with the health concepts and practices of an indigenous people, the Mundurucu of the Amazon rainforest. He first experienced his illness as a "breach of order, an assault upon both flesh and thought"; his tumor "infringed upon both symbolic coherence and real systems of motor control" (1990: 33). After the awareness of the breach of the order of his personal and social life came the experience of losing a part of himself. A critical aspect of the deviance of illness is the diminution of the self, resulting in a reduced self or "damaged self." Murphy the sick person, the wheelchair-ridden person, the dependent person, could not do what Murphy the healthy person formerly did. Especially as a man, Murphy found this threatening to "the cultural values of masculinity: strength, activeness, speed, virility, stamina, and fortitude" (94-5). Worse yet, he discovered that illness carries a sort of stigma, a judgment of inferiority: wellness, he said, is "an unmarked category" (103), largely taken for granted, while sickness or disability is a negative status, a kind of "embattled identity" similar to all other undervalued categories. The social experience of other people changed for him too. He felt resented by healthy people, as if he were a traitor to the ideal of good health-and perhaps a reminder to healthy people of their own fragility. Old friends did not know how to relate to him; some stopped relating at all. He made new friends and contacts in the disabled community. He also found himself asked (and forced) to submit to the handling of doctors, nurses, and physical therapists and to make their lives easier by not showing too much emotion and by being passively obedient. Finally, he felt the effect on his wife and family, who now had to rearrange their lives to accommodate his. "Such shifts within the family structure often create strains so deep that it self-destructs .... When [marriages] are additionally freighted with the problems of the handicapped, they frequently dissolve” (207). 


\section{Medicalization}

As we have seen in previous chapters, the creation of categories (particularly gender and age categories, but also to an extent race/ethnic and even class and language categories) escalated dramatically in the nineteenth and early twentieth centuries with the advent of modern science and medicine. Great efforts ensued to identify and name the "types" of individuals that existed as well as the "stages" through which individuals progressed. The implication is that science and medicine have not always been, and have only recently become, the arbiters of normality, whether in terms of gender, age, race, or indeed of health and (dis)ability.

Before many conditions were "diagnosed" as medical conditions, they were understood-and responded to-in other ways. Some examples would include drunkenness, vagrancy, perhaps poverty, and as we have mentioned numerous times homosexuality or transvestism/transsexuality. Such behaviors (and sometimes organic diseases like leprosy or epilepsy) were viewed before the arrival of modern science and medicine as perhaps spiritual problems or punishments. Then these conditions (and what counts as a "condition" in the first place depends on culture) would not and could not have been labeled as "medical problems" but as matters of sin, crime, or character flaw and were treated as such. Poor people were often placed in the care of jailers, and homosexuals were often placed in the care of religious authorities (and jailers too).

In the past century, we have seen a remarkable transition from a sin/crime model of health and (dis)ability (and of abnormality and deviance in general) to a medical model, which has been called medicalization. Irving Zola defined medicalization as the "process whereby more and more of everyday life has come under medical dominion, influence and supervision" (1983: 295), and Peter Conrad added that it "consists of defining a problem in medical terms, using medical language to describe a problem, adopting a medical framework to understand a problem, or using a medical intervention to 'treat' it" (1992: 210). As Conrad reminded us, many behaviors have been medicalized lately, and many new medical conditions have been proposed to name and describe them. Among the forms of medicalized deviance, he listed

madness, alcoholism, homosexuality, opiate addiction, hyperactivity and learning disabilities in children, eating problems from overeating (obesity) to undereating (anorexia), child abuse, compulsive gambling, infertility, and transexualism, among others. Natural life processes that have become medicalized include sexuality, childbirth, child development, menstrual discomfort (PMS), menopause, aging, and death.

A number of consequences flow from the phenomenon of medicalization. One is the increasing scope of medicine: if obesity or alcoholism or homosexuality is a medical condition, then there are more areas for medical professionals to intervene-and more medical services to offer (that is, sell) to clients or patients. Another is the extension of the features of the sick role to more people and their behaviors: if alcoholism is an illness rather than a choice or a character flaw, then the alcoholic is not entirely responsible and is to some degree "out of control." Third and related to this, medicalization often means moving a behavior from the category "moral failure" to "medical condition," now not to be punished or condemned but to be medicated and cured. 
In another essay, Conrad and co-author Valerie Leiter (2004) described four cases of medicalization and their specific medical interventions: male impotence or "erectile dysfunction" and Viagra, "social anxiety" and Paxil, shortness and human growth hormone, and infertility and in-vitro fertilization. Harvey Molloy and Latika Vasil discussed the more contentious question of Asperger's Syndrome and by implication autism and argued that Asperger's Syndrome-a psychological "condition" characterized by lack of empathy, poor verbal skills, repetitive speech, and general inability to form social relationships-may not be a "medical problem" so much as a personality difference. They further warned of the dangers of viewing differences as disabilities (see below for a discussion of deafness as a "culture") and the attempt of medicine "to help to rehabilitate or 'normalize' the child" (2002: 659).

Medicalization, whether of health/(dis)ability, gender, age, or any other difference, is an interesting illustration not just of the social construction of categories and conditions, but also of social control and social jurisdiction. That is, medicalization gives "medicine jurisdiction over virtually anything to which the label 'health' or 'illness' could be attached" (Conrad and Leiter 2004: 159). In other words, medicalization gives the medical profession control over more aspects of social life. Michel Foucault stressed what he called "techniques of self" that impose institutional control over persons, and some of his main examples were medical, as in his famous The Birth of the Clinic, subtitled An Archaeology of Medical Perception (first published in French in 1963) and Madness and Civilization: A History of Insanity in the Age of Reason (first published in French in 1965). He described the evolution of medical thinking and institutions, or regimes, especially the power of the medical professional. This power is exercised initially through the "medical gaze," or the right to look at us in indiscrete and impersonal ways, but embodied in many deep practices from taking our clothes away to slapping a label (diagnosis) on us to keeping records on us to strapping us down to a bed. Indeed, Rodney Coe's (1978) discussion of hospital practices mentioned three specific kinds of control: control over resources (like clothes and medicines, as well as information), restriction of mobility, and what he called "stripping" or the removal of the markers of the patient's pre-medical self and the imposition of a new self in the form of hospital gowns and wrist bracelets.

Two last words on medicalization are in order. First, medicalization is never entirely complete and is always contestable; members may resist the encroachment of the medical worldview into their lives. Second, there is always the possibility of "demedicalization," such that conditions that were previously thought to be medical are reconceived in some other way. For instance, Conrad and Foucault both mention the preoccupation in nineteenth-century Western society with masturbation, as if it would cause any number of medical conditions; for a time, professional psychology also categorized homosexuality as a medical disorder but has since taken it out of that category.

\section{Health and (Dis)ability Diversity in the United States}

Like age, Americans span the entire gamut of statuses of health and (dis)ability, and individual Americans will occupy many different health/(dis)ability statuses during their lifetime. The United States also has an elaborate healthcare industry and legal system, with some of the most advanced technology — and the highest spending-of any country in the world. In 2011, the United States spent more on healthcare per 
capita $(\$ 8,508)$ than any other country, according to the OECD; the second-highest per capita healthcare spending was in Norway $(\$ 5,669)$, and Japan spent less than half as much per person as the United States $(\$ 3,213)$. The average per capita spending in OECD member-countries was $\$ 3,322$.

\section{Diversity Fact:}

The infant mortality rate in the United States was estimated to be 5.9, much worse than the rates in Monaco (1.8) and Japan (2.2). The life expectancy of an American in 2013 was 78.6 years, fifty-first in the world and far behind number one Monaco (89.6) or number two Japan (84.2).

Despite spending more per person on healthcare than any other country, the United States does not have the best health outcomes, as measured by infant mortality and life expectancy. Health conditions and health outcomes also diverge widely between Americans along all of the expected variables of race, ethnicity, class, gender, and age.

According to the US Department of Health and Human Services' annual "Health, United States" report for 2012, 10.4 percent of Americans were regarded as in fair or poor health, an increase from 2010 (10.1 percent) and 2000 (8.9 percent). Obesity, as mentioned at the outset of the chapter, had also increased, to 35.9 percent of Americans age 20 or over, up from 33.9 percent in 2007-8 and 30.3 percent in 19992000. The percentage of Americans under age 65 without health insurance stood at 17.2 percent in 2011, an improvement from 2010 (18.2 percent) but worse than 2000

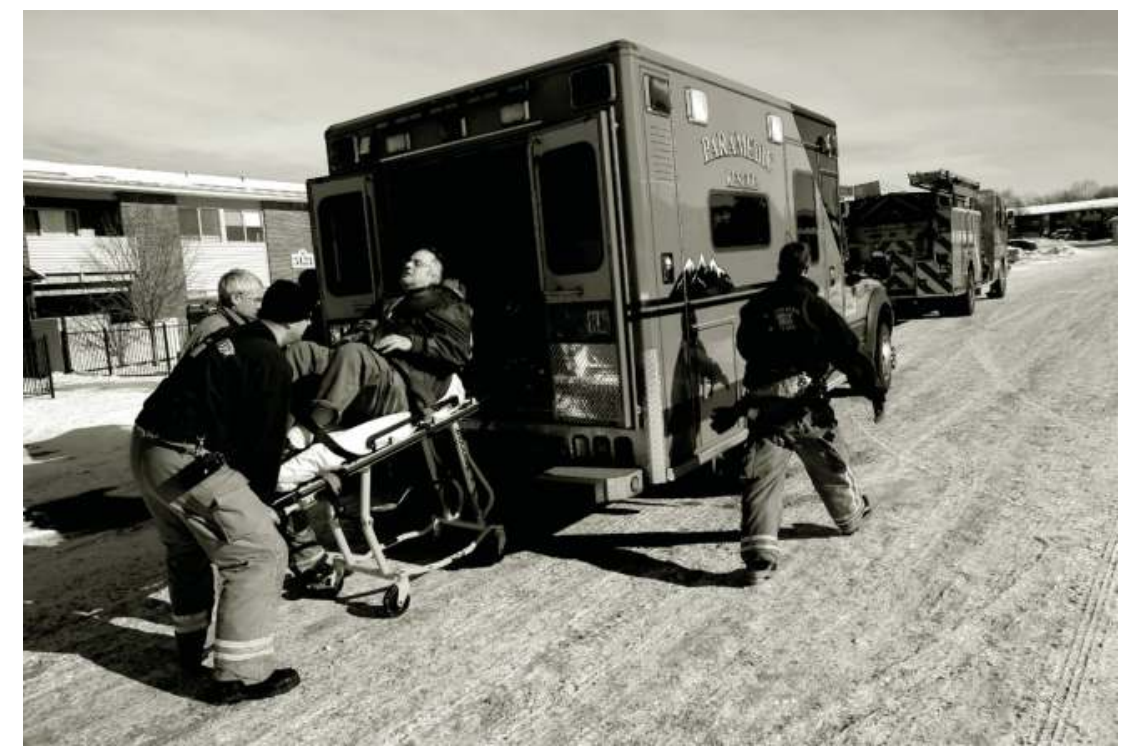

Image 11.2 Paramedics attend to a man in Colorado.

(Courtesy of John Moore/Thinkstock by Getty Images) 
(17.0 percent). Cigarette smoking was in decline, to 19 percent of Americans in 2011 from 19.3 percent in 2010 and 23.2 percent in 2000 . The death rate or morbidity rate from all causes dropped to 747.0 in 2010, compared to 949.6 in 2009 and 869.0 in 2000, but heart disease remained the primary killer of Americans, with cancer second. Among the other key indicators of American health were the following:

- Motor vehicle-related injuries were responsible for a death rate of 11.3 per 100,000 of population.

- The suicide rate was 12.1 per 1000,000 of population, more than twice the homicide rate (5.3).

- The suicide rate was much higher for men (19.8) than for women (5.0), as was the homicide rate (8.4 for men, 2.3 for women).

- Almost one-third (31.9 percent) of Americans had high blood pressure and 13.6 percent had high cholesterol.

- Only 20.6 percent of Americans engaged in aerobic and muscle-strengthening activity, and a full 48 percent of adults did not meet federal physical activity guidelines.

- Approximately 6 percent of children under the age of 18 had had an asthma attack in the past year, and 5 percent had a food allergy.

- Attention deficit hyperactivity disorder (ADHD) was diagnosed in 9.6 percent of all American children between the ages of 5 and 17, with as many as 11.7 percent of 10-17-year-olds diagnosed. Males (13.1 percent) were more than twice as likely to be labeled ADHD than females (5.9 percent), African Americans (10.8 percent) more than whites (9.8 percent), and the poor (12.5 percent) more likely than the non-poor (the higher the income, the lower the rate of ADHD).

- Americans made 1.2 billion visits to medical offices in 2010-1.0 billion visits to a doctor's office, 101 million to hospital outpatient departments, and 130 million to a hospital emergency room. As many as one-fifth of all Americans made at least one visit to an emergency room.

As much of these data suggest, there is not only diversity of health and (dis)ability in the United States but disparity in these matters in relation to basic social categories and statuses. For instance, a study released in 2011 concludes that American life expectancy in 2007 differed widely by county, from a high of 81.1 years for men and 86 years for women to a low of 65.9 years for men and 73.5 years for women. For African

Table 11.1 Top five causes of death by age, 2010

\begin{tabular}{|c|c|c|c|}
\hline Age 1-24 & Age 25-44 & Age 45-64 & Age 65 and over \\
\hline $\begin{array}{l}\text { Unintentional } \\
\text { injuries }\end{array}$ & $\begin{array}{l}\text { Unintentional } \\
\text { injuries }\end{array}$ & Cancer & Heart disease \\
\hline Homicide & Cancer & Heart disease & Cancer \\
\hline Suicide & Heart disease & Unintentional injuries & $\begin{array}{l}\text { Chronic lower } \\
\text { respiratory } \\
\text { disease }\end{array}$ \\
\hline Cancer & Suicide & $\begin{array}{l}\text { Chronic lower } \\
\text { respiratory disease }\end{array}$ & Stroke \\
\hline Heart disease & Homicide & Chronic liver disease & Alzheimer's disease \\
\hline
\end{tabular}

Source: National Vital Statistics Report, 62 (6). Deaths: Leading Causes for 2010 


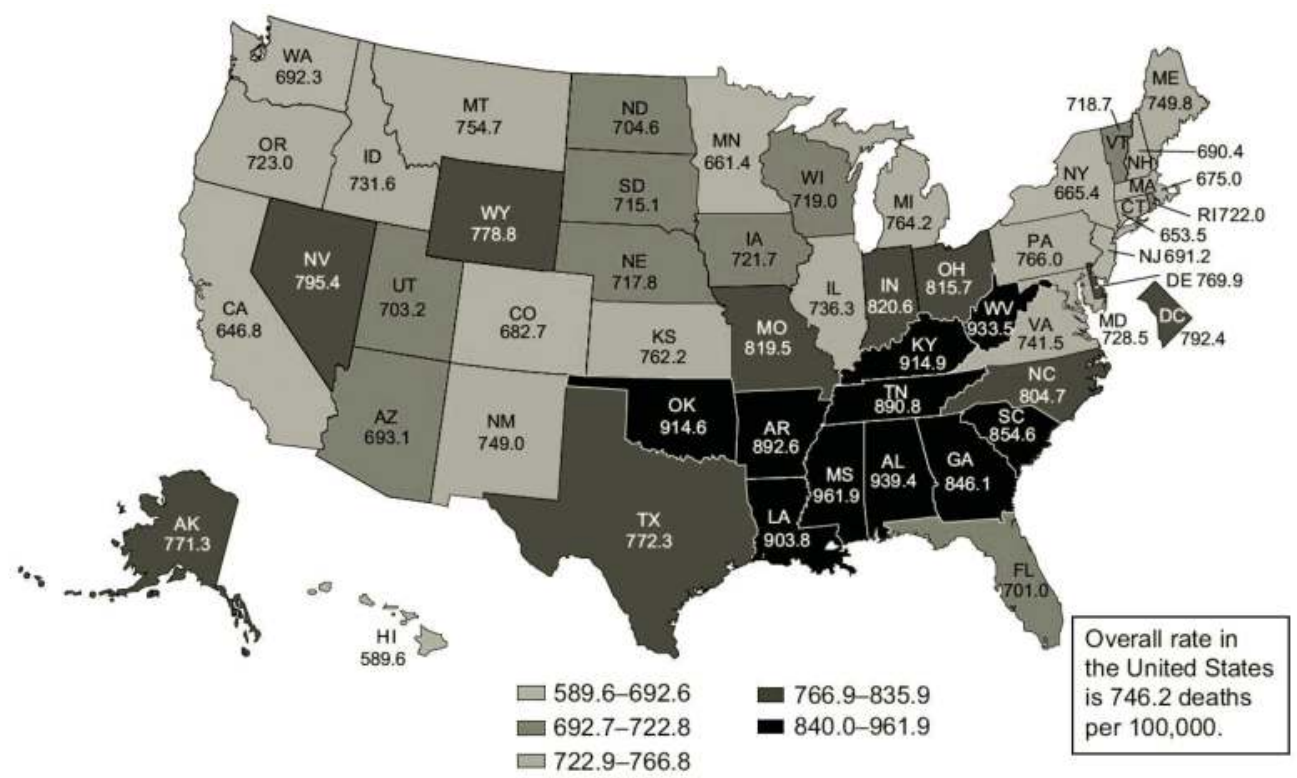

Figure 11.1 Age-adjusted death rate by state, 2010.

Source: National Center for Health Statistics Data Brief no. 99. Death in the United States, 2010

Note: The full colour version of this map can be found on the companion website, www.routledge.com/cw/eller.

Americans the numbers were worse, with a range from 59.4 to 77.2 years for men and from 69.6 to 82.6 years for women. More disturbingly, the vast majority of counties actually fell further behind the international standard for life expectancy in developed countries. The counties with the lowest life expectancies are heavily concentrated in the South, and the report warns that the US "has extremely large geographic and racial disparities, with some communities having life expectancies already well behind those of the best-performing nations. At the same time, relative performance for most communities continues to drop" (Kulkarni, Levin-Rector, Ezzati, and Murray 2011: 3).

\section{Health Disparities and Class}

Sociologists have drawn a strong connection between health disparities and socioeconomic inequalities. Bruce Link and Jo Phelan have gone so far as to call socioeconomic conditions the "fundamental causes" of the differences in health conditions and outcomes (Link and Phelan 1995; Phelan, Link, and Tehranifar 2010). In their (widely held) view, the difference in "money, knowledge, prestige, power, and beneficial social connections" (2010: S28) impacts health in a number of ways:

First, it influences multiple disease outcomes, meaning that it is not limited to only one or a few diseases or health problems. Second, it affects these disease outcomes through multiple risk factors. Third, it involves access to resources that can be used to avoid risks or to minimize the consequences of disease once it occurs. 
Finally, the association between a fundamental cause and health is reproduced over time via the replacement of intervening mechanisms.

Fred Pampel, Patrick Krueger, and Justin Denney analyze the relation between socioeconomic variables and health still further. First, they note that socioeconomic status means more than using income "to purchase good health" (2010: 349). Rather, social and economic differences appear to affect the odds of engaging in unhealthy habits like smoking, poor diet, and less physical exercise. They then specify nine means by which socioeconomic status can shape health-related behavior (353-60):

1 most directly, deprivation, inequality, and stress;

2 fewer benefits of healthy behaviors, that is, the fact or perception that healthy behavior does not really make a difference in one's life or are not worth the extra cost and effort;

3 other latent traits, such as the effects of family structures or schools;

4 "distinctions" in the style or taste of different classes, such as cultural preferences for thinness or a smoke-free life;

5 lack of knowledge and of access to information about health risks;

6 efficacy and agency, that is, the ability to gather and process information and to solve problems, giving the person a sense of control over his/her life, behavior, and medical treatment;

7 aids for healthy behavior, such as the capacity to afford quit-smoking products, gym memberships and weight loss programs, and healthier foods;

8 community opportunities, like access in the neighborhood to gyms and fitness centers, health-food stores, and parks, bicycle trails, and recreation centers, as opposed to cigarette and liquor stores and fast-food restaurants;

9 social support, social cohesion, and peer influence.

Socioeconomic status is, of course, a complex concept, including many particular subvariables. Of all of them, Pampel, Krueger, and Denney (2010) hold out education as the most influential: for instance, "high school dropouts have odds of smoking and not exercising that are, respectively, 3.7 and 4.9 times larger than for college graduates" (351). Irma Elo, in her analysis of social class and health, concurs:

educational attainment is perhaps the single SES indicator that most consistently exhibits a significant association with various measures of health and all-cause and cause-specific mortality in a wide variety of settings: Those with higher levels of schooling have better health and longer lives. In the United States, life expectancy at age 25 in 2000, for example, was estimated to be seven years higher for individuals who had attended at least some college (56.6 years) than for those with a high school education or less (49.6 years).

(2009: 557)

The reasons for the strong correlation to education and health are manifold: knowledge and decision-making skills, typically higher income, safer occupation, better access to medical technology (not to mention medical insurance), a healthy middle- and upperclass lifestyle, freedom from financial stress including the financial resources to handle a medical crisis, and better housing conditions and neighborhoods. Interestingly, since 


\section{Health and (Dis)ability}

the health of children is related to the education of their mothers, and since health during childhood can affect health throughout life, higher-educated women set the terms of health not only for themselves but for the next generation of middle- and upper-income citizens.

\section{Health Disparities and Race/Ethnicity}

Disparities in health and (dis)ability are related to race and ethnicity in a number of ways. The first and most obvious is the association of race/ethnicity with class and income in the United States: most non-white categories suffer lower incomes and less prestigious occupations. The fact that health insurance is connected to employment thus becomes another indirect variable in the health conditions and outcomes of different race and ethnic groups.

In addition to the class/income variable, Jason Schnittker and Jane McLeod (2005: 86) also list other aspects of race/ethnic experience in the US that impact health. One is differential exposure to toxic and other hazardous conditions, related to poor neighborhoods being located next to major highways or waste sites, not to mention the prevalence of violence and drugs. Furthermore, they mention "targeted marketing of commodities that harm health" like alcohol and cigarettes, combined with insufficient available medical care, in the form of lack of doctors and clinics. Finally there is the experience of racial and ethnic discrimination, which contributes to stress as well as to "health-damaging self-perceptions."

The most glaring measure of health disparities is life expectancy, and African Americans live shorter lives on average than white Americans, as seen in Figure 11.2.
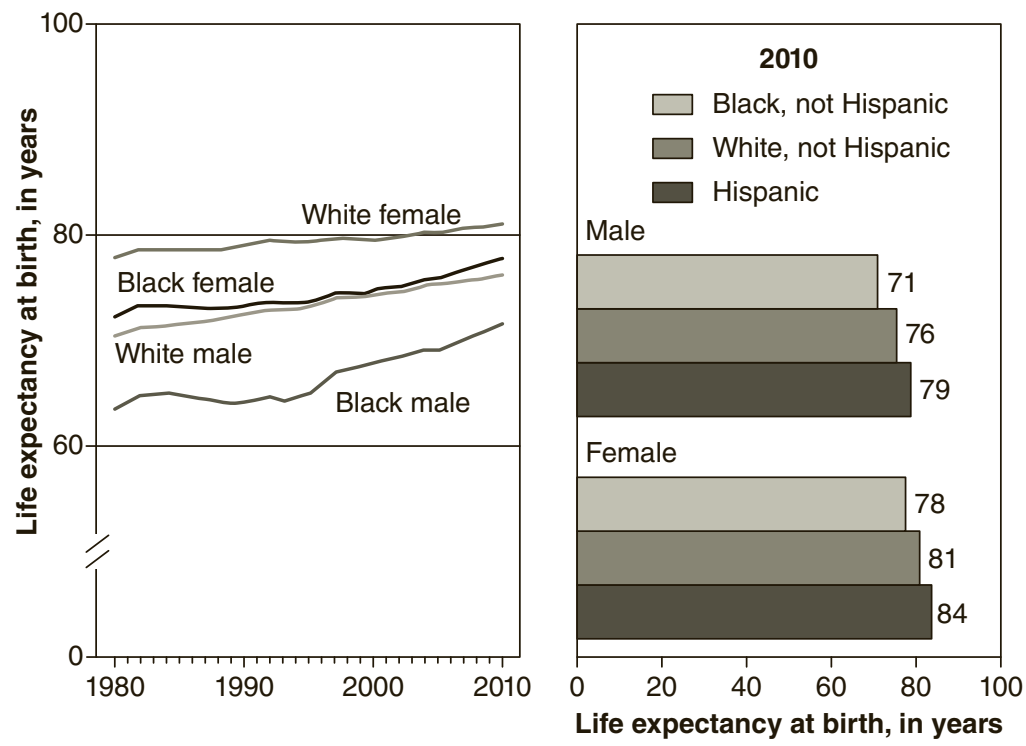

Figure 11.2 Life expectancy at birth by race and Hispanic origin.

Source: National Center for Health Statistics. Health, United States, 2012 
Surprisingly, though, Hispanics actually live longer on average than both blacks and whites. (Note that women of all races live longer than men.)

The American races and ethnic groups also die from different causes, which is very telling about American society. Table 11.2 illustrates that all races die most often from heart disease or cancer, which are largely diseases of aging. However, a cause of death that does not appear in the top ten for any racial or ethnic group other than African Americans is homicide: homicide is in fact the number seven killer of African Americans (especially men). White Americans are much more likely to die from suicide than from homicide, and suicide also shows up in the top ten causes for Native American and Asian American deaths.

The infant mortality rate varies dramatically by race and ethnicity as well. According to the US Department of Health and Human Services' Office of Minority Health, the infant mortality rate in 2009 among non-Hispanic whites was 5.3 while among nonHispanic blacks it was more than twice as high at 12.4. The Native American infant mortality rate was also higher than white (8.47). The general Hispanic rate was 5.29, although for Puerto Ricans specifically the rate was unusually high (7.18). Asian Americans enjoyed the lowest rate, of 4.4. One leading cause of death for African American infants was low birth weight: more black babies $(1,734)$ died from low birth weight than white babies $(1,629)$, despite the fact that the African American population is a fraction of the white population.

Table 11.2 Top ten causes of death by race and ethnicity, 2010

\begin{tabular}{|c|c|c|c|c|}
\hline White & $\begin{array}{l}\text { African } \\
\text { American }\end{array}$ & Hispanic & $\begin{array}{l}\text { Asian } \\
\text { American }\end{array}$ & $\begin{array}{l}\text { Native } \\
\text { American }\end{array}$ \\
\hline Heart disease & Heart disease & Cancer & Cancer & Cancer \\
\hline Cancer & Cancer & Heart disease & Heart disease & Heart disease \\
\hline $\begin{array}{l}\text { Chronic lower } \\
\text { respiratory } \\
\text { disease }\end{array}$ & Stroke & $\begin{array}{l}\text { Unintentional } \\
\text { injuries }\end{array}$ & Stroke & $\begin{array}{l}\text { Unintentional } \\
\text { injuries }\end{array}$ \\
\hline Stroke & Diabetes & Stroke & $\begin{array}{l}\text { Unintentional } \\
\text { injuries }\end{array}$ & Diabetes \\
\hline $\begin{array}{l}\text { Unintentional } \\
\text { injuries }\end{array}$ & $\begin{array}{l}\text { Unintentional } \\
\text { injuries }\end{array}$ & Diabetes & Diabetes & $\begin{array}{l}\text { Chronic liver } \\
\text { disease }\end{array}$ \\
\hline $\begin{array}{l}\text { Alzheimer's } \\
\text { disease }\end{array}$ & Kidney disease & $\begin{array}{l}\text { Chronic liver } \\
\text { disease }\end{array}$ & $\begin{array}{l}\text { Influenza and } \\
\text { pneumonia }\end{array}$ & $\begin{array}{l}\text { Chronic lower } \\
\text { respiratory } \\
\text { disease }\end{array}$ \\
\hline Diabetes & Homicide & $\begin{array}{l}\text { Chronic lower } \\
\text { respiratory } \\
\text { disease }\end{array}$ & $\begin{array}{l}\text { Chronic lower } \\
\text { respiratory } \\
\text { disease }\end{array}$ & Stroke \\
\hline $\begin{array}{l}\text { Influenza and } \\
\text { pneumonia }\end{array}$ & Septicimia & Alzheimer's disease & Kidney disease & Suicide \\
\hline Kidney disease & $\begin{array}{l}\text { Alzheimer's } \\
\text { disease }\end{array}$ & Kidney disease & $\begin{array}{c}\text { Alzheimer's } \\
\text { disease }\end{array}$ & Kidney disease \\
\hline Suicide & Septicemia & $\begin{array}{l}\text { Influenza and } \\
\text { pneumonia }\end{array}$ & Suicide & $\begin{array}{l}\text { Influenza and } \\
\text { pneumonia }\end{array}$ \\
\hline
\end{tabular}

Source: National Vital Statistics Report, 62 (6). Deaths: Leading Causes for 2010 


\section{Diversity Fact:}

In black neighborhoods of Memphis, Tennessee the infant mortality rate reaches 17-roughly three times the national average. A special neonatal intensive-care unit was created at the Regional Medical Center in 1968 to deal with the problem, but it persists today. Among the contributors to high infant mortality are premature birth, poor maternal nutrition, lack of prenatal healthcare, high blood pressure, and accidents. Up to 80 percent of babies are born to unwed mothers. So many black babies are buried in the potter's field graveyard that it is nicknamed Babyland.

Short of death, the health circumstances of American race and ethnic groups vary in other significant ways. Schnittker and McLeod report that African Americans, for example, are less healthy, with higher incidences of hypertension, diabetes, asthma, and AIDS, as well as some cancers (2005: 78). Hispanics, as is often the case, are intermediate: they suffer equal or lower rates of heart disease and cancer as non-Hispanic whites but higher rates of diabetes, tuberculosis, and homicide. The Office of Minority Health featured the following health data in 2013:

- Native Americans are 50 percent more likely than non-Hispanic whites to be diagnosed with asthma, and African Americans are 2.7 times as likely to die from asthma.

- African Americans and Native Americans are twice as likely to be diagnosed with diabetes as whites, while Mexican Americans were 1.8 times as likely. Native Hawaiians and Pacific Islanders had three times the rate of diabetes of whites.

- Native Americans are 70 percent more likely than whites to be obese; Native Hawaiians and Pacific Islanders are 2.7 times as likely to be obese.

- In terms of dental health, African Americans are more likely to have cavities, missing teeth, and gingivitis than whites. Mexican American children are more likely to have cavities than white children, and Hispanic adults are twice as likely as whites to have untreated cavities. Native American young children (age two to four) have five times the national rate of dental decay, and Native American adults have 2.5 times the national rate of periodontal disease.

- Native American women have three times the AIDS rate of white women, and Hispanic women have four times the white rate. African American men have 7.6 times the rate of AIDS as white men, and African American women have an astounding twenty times the rate of white women.

\section{Health Disparities and Gender}

Despite the fact that American women and men die from many of the same causes (primarily heart disease, cancer, stroke, and lung disease), sociologists and epidemiologists have identified some important health differences between the genders. According to the Society for Women's Health Research (http://swhr.org): 


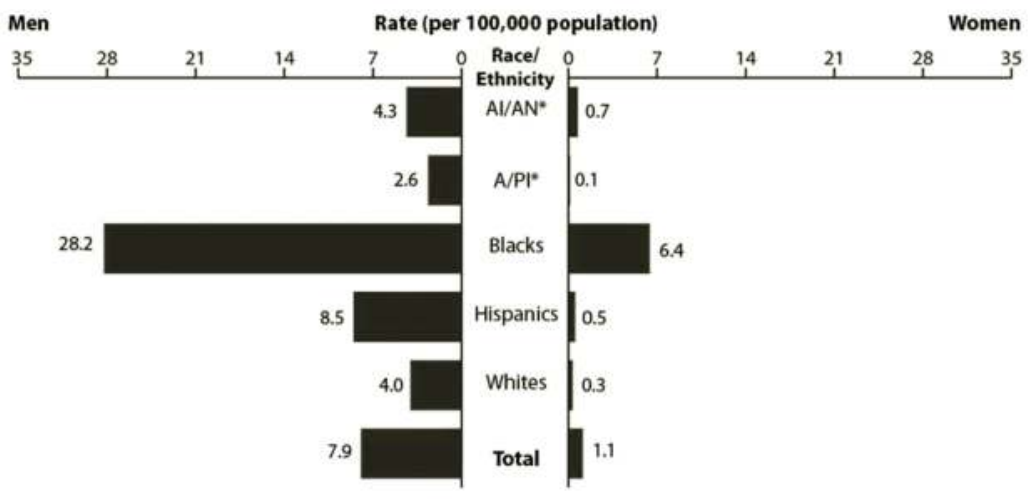

Figure 11.3 Rates of primary and secondary syphilis by race/ethnicity and sex, 2010.

Source: Centers for Disease Control and Prevention. Sexually Transmitted Disease Surveillance 2010

*AI/AN refers to American Indian and Alaska Native

*A/PI refers to Asian and Pacific Islander

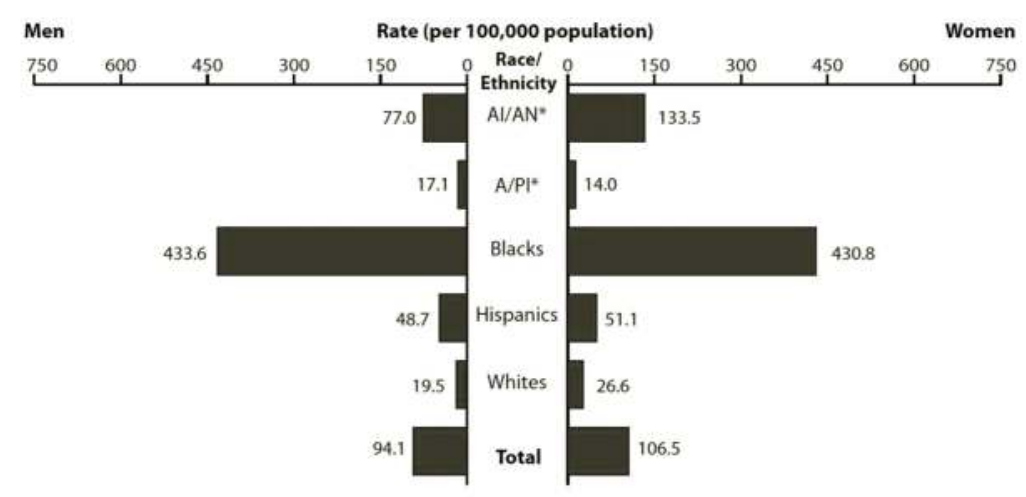

Figure 11.4 Rates of gonorrhea by race/ethnicity and sex, 2010.

Source: Centers for Disease Control and Prevention. Sexually Transmitted Disease Surveillance 2010

*AI/AN refers to American Indian and Alaska Native

*A/PI refers to Asian and Pacific Islander

- chronic pain conditions like rheumatoid arthritis, migraine, and fibromyalgia are more common in women;

- more women die from strokes and heart disease each year than men;

- women are two or three times more likely to experience depression than men;

- women are twice as likely to catch a sexually transmitted disease as men, and HIV is one of the top ten killers of women aged 25-54; among African American women aged 24-34, it is the number one killer.

Also as an apparent contradiction, women on average live several years longer than men yet appear to suffer from more illness than men. In assessing the literature on 
gender and health, Jen'nan Read and Bridget Gorman suggest that much of the difference in gender mortality relates to lifestyle:

At younger ages men tend to engage in more health-damaging behaviors than women (like heavy drinking, illegal drug use, and until recently smoking) that adversely affect their well-being and increase their risk of death via accidental injuries and homicide. These behaviors also have a cumulative impact that negatively affects men's health at later stages of life by elevating their likelihood of premature death from life-threatening conditions (e.g., heart disease, cancer). In contrast, women are more likely to suffer from nonfatal, chronic conditions such as arthritis and disability that do not necessarily result in their death but do depress their quality of life.

(2010: 373)

In addition, "across a wide array of risky behaviors (including illegal drug use, drunk driving, and lack of seatbelt and helmet use), men participate at higher levels than women. As a result, they experience more unintentional injuries than women, contributing to their elevated rate of premature mortality" (374-5).

At the same time, statistics indicate that women are less healthy than men. Some of the difference is attributable to women's longer lives: since they outlive men, they suffer more long-term degenerative disease like heart disease and cancer. Women's historically lower socioeconomic status, including (until recently) education, could mitigate some of the behavioral advantages affecting female health. But some social scientists like Constance Nathanson have seen more at work than this. She argued that cultural norms impacted women's health in unique ways, including “(1) women report more illness than men because it is culturally more acceptable for them to be ill; (2) the sick role is more compatible with women's other role responsibilities; and (3) women have more illness than men because their assigned social roles are more stressful" (1975: 57). Juanne Clark went further to mention a number of more pestilent cultural attitudes that plague women, such as the "myth of female frailty" which holds that women are weaker and more in need of professional intervention than men. Even more, many aspects of women's lives and bodies have been especially medicalized, like pregnancy, childbirth, and the menstrual cycle; at its worst, this has led to the "belief that female reproductive organs are expendable equipment, dangerous and dysfunctional outside of childbearing" (1983: 64).

Unlike men, women are under singular pressure in American society to conform to certain standards of beauty, which negatively impact their health. Naomi Wolf described in her book The Beauty Myth (1991) how cultural images and ideals damage the physical and mental health of women. One of the main effects of this social pressure, other than unnecessary and often unhealthy cosmetic surgery, is eating disorders and body dysmorphic disorder, in which women perceive non-existent imperfections in their body and appearance (i.e. their own body-image is inaccurate). According to the National Eating Disorders Association, up to 10 million females have a life-threatening eating disorder like anorexia or bulimia, while 25 million struggle with binge eating. Almost half of the cases of anorexia occur in teenage girls, and more than half of all teenage girls engage in unhealthy weight-loss activities like fasting, skipping meals, vomiting, or taking laxatives. At the same time, obesity actually is more common among women than among men of all races, as seen in Table 11.3. 
Table 11.3 Healthy weight, obesity, and Grade 3 obesity by gender, race/ethnicity, and poverty level (age 20 to 74 ) as percentage of population, 1988 to 2010

\begin{tabular}{|c|c|c|c|c|c|c|c|c|c|}
\hline \multirow[t]{2}{*}{ Category } & \multicolumn{3}{|c|}{ Healthy weight } & \multicolumn{3}{|c|}{ Obese } & \multicolumn{3}{|c|}{ Grade 3 obese* } \\
\hline & 1988 & 1999 & 2010 & 1988 & 1999 & 2010 & 1988 & 1999 & 2010 \\
\hline Male & 37.9 & 30.2 & 29.8 & 20.6 & 31.1 & 34.4 & 1.9 & 5.2 & 6.3 \\
\hline Female & 45.3 & 35.6 & 33.6 & 26.0 & 34.0 & 35.1 & 4.3 & 6.8 & 8.0 \\
\hline White male & 37.4 & 29.5 & 25.6 & 20.7 & 28.7 & 34.7 & 2.0 & 3.6 & 4.3 \\
\hline White female & 49.2 & 39.7 & 36.9 & 23.3 & 31.3 & 32.9 & 3.7 & 5.9 & 7.0 \\
\hline Black male & 40.0 & 35.5 & 28.3 & 21.3 & 27.9 & 38.7 & 2.6 & 3.6 & 7.6 \\
\hline Black female & 28.9 & 21.2 & 17.7 & 39.1 & 49.4 & 54.4 & 8.3 & 13.7 & 16.7 \\
\hline Mexican male & 29.8 & 25.6 & 18.0 & 24.4 & 29.0 & 36.5 & n.d. & 3.1 & 4.4 \\
\hline Mexican female & 29.0 & 27.6 & 20.2 & 36.1 & 38.9 & 45.8 & 5.0 & 5.9 & 7.0 \\
\hline Below poverty level & 37.3 & 32.4 & 27.5 & 29.2 & 35.9 & 37.9 & 5.0 & 8.4 & 7.9 \\
\hline
\end{tabular}

Source: National Center for Health Statistics. Health, United States, 2011

*Grade 3 obesity is defined as a body mass index (BMI) of 40 or more

Finally, women's health in the United States is uniquely impacted by violence. "Sexual violence, stalking, and intimate partner violence are major public health problems in the United States," concluded the National Intimate Partner and Sexual Violence Survey, conducted by the National Center for Injury Prevention and Control of the CDC (Black et al. 2011: 1).

Many survivors of these forms of violence can experience physical injury, mental health consequences such as depression, anxiety, low self-esteem, and suicide attempts, and other health consequences such as gastrointestinal disorders, substance abuse, sexually transmitted diseases, and gynecological or pregnancy complications. These consequences can lead to hospitalization, disability, or death.

Among the findings of the survey was that 18.3 percent of women had been raped at some time during their lives (and 1.4 percent of men). As we have come to understand, rape is most often perpetrated by someone that the victim knows: 51.1 percent of rapists were intimate partners of the victim, and 40.8 percent were male acquaintances. Rape and sexual violence in general tend to affect younger women disproportionately: 79.6 percent of women reported that their first rape occurred before age 25, and 42.2 percent claimed that it occurred before age 18 . Overall, almost 30 percent of women and 10 percent of men had been the victims of rape, physical violence, and/or stalking, and 35.6 percent of women and 28.5 percent of men experienced rape, physical violence, or stalking at the hands of an intimate partner. Native American women reported a higher incidence of rape (26.9 percent) than Hispanic (14.6 percent), white (18.8 percent), or African American (22 percent) women; multiracial women claimed the highest rate (33.5 percent).

Of course, the worst health outcome is death, and the Violence Policy Center announced in 2012 that 1,800 women were murdered by men in 2010. Of the cases in which the relationship of the murderer to his victim could be determined, 94 percent 
of the women were killed by an acquaintance, and 65 percent were killed by a husband or other intimate partner. The average age of the victim was 40 . Race was also a factor in female homicides: 87 percent of murders were intra-racial (victim and perpetrator were the same race), and homicide rates for women varied from 2.59 per 100,000 for black women, 1.06 for white women, and 1.0 for Native American women to 0.6 for Asian and Pacific Islander women.

\section{Disability Disparities in the US}

Human beings have long had a problematic and often intolerant attitude toward individuals with "abnormal" or "imperfect" bodies. The ancient philosopher Aristotle, in the seventh book of his Politics, wrote, "let there be a law that no deformed child shall live," and the Greeks of ancient Sparta were reputed to destroy "defective" infants by throwing them off a cliff. Romans apparently also abandoned or persecuted the disabled, including the blind, deaf, and mentally disabled. Sometimes, deformed persons were kept for entertainment, as in the circuses that would become part of modern Western and American culture. The medieval Catholic Church even taught that the deaf could not get to heaven, since they could not hear or speak the holy words and sacraments (Higgins 1980). Whether the "idiot cages" in which disabled people were kept in early modern European towns were for the protection, punishment, or exploitation of those people is unclear.

Jean-Marc Gaspard Itard around the turn of the nineteenth century was one of the first to work constructively with disabled individuals, specifically deaf-mutes. Before his time, the prevailing sentiment was expressed by John Bulwer in 1648, who believed that "deaf children were the result of their parents' sinfulness and little better than 'Dumbe Animals'” (Wrigley 1996: 2). Itard disproved the dominant assumption that individuals who could not hear or speak were automatically mentally deficient, helping to design teaching methods appropriate for them. Sign or hand language for the hearingimpaired first appeared in France, from where it later spread to the United States.

As early as 1798 the US had a law providing for assistance to disabled sailors, and the Connecticut Asylum for the Education and Instruction of Deaf and Dumb Persons was founded in 1817. In 1848 Dr. Samuel Gridley Howe, previously the director of the Perkins School for the Blind, opened the Massachusetts School for Idiotic and Feeble-Minded Youth to teach mentally disabled children, and soon other institutions for the "feeble-minded" followed in Albany, New York and Columbus, Ohio. However, such pejorative language illustrates that attitudes toward the disabled were still not very positive. Indeed, Paul Higgins found that deaf-mutes were not permitted to vote in New York in the early 1800s and that the deaf (along with the insane) were prohibited from taking civil service exams (1980: 25). Owen Wrigley added that the deaf were classified in the US Census from 1830 until 1900 among the "defectives."

The eugenics period of American history, from the mid-1800s to the early 1900s, was especially difficult for the disabled (see below). "Defective genes" were to be culled from the population, and Dr. Harry Haiselden portrayed a eugenics physician in his 1917 film The Black Stork in which he advocated a kindly death for deformed newborns. Fortunately, intelligent and articulate disabled individuals like Helen Keller, born in 1880, were available to advocate for themselves and for their remarkable abilities, given cultural opportunities and assistance. In 1919 the Ohio Society for Crippled Children was established, which eventually became Easter Seals (www.easterseals. com), providing charitable services for physically disabled youths. But a key moment 


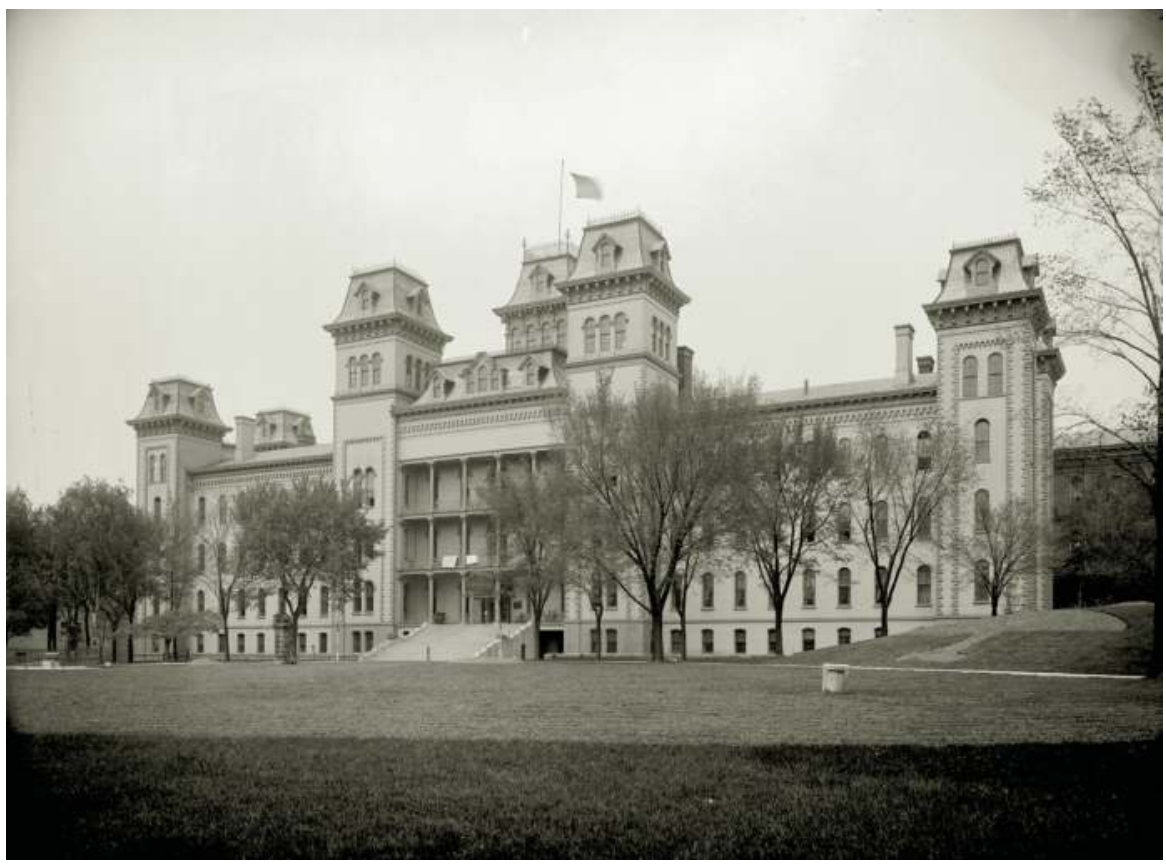

Image 11.3 The Deaf and Dumb Institute in Columbus, Ohio, c.1904.

(Courtesy of the Library of Congress, Prints and Photographs Division)

in the recognition of social obligation to the disabled came in 1935 , with the Social Security Act and its permanent programs for Americans with disabilities.

Many organizations appeared from mid-century on, including the Association for Retarded Citizens (ARC) and the Muscular Dystrophy Association (MDA), both in 1950. Since 1966, MDA has broadcast a yearly fundraising telethon on Labor Day, hosted for years by Jerry Lewis. In 1962 Eunice Kennedy Shriver established the Special Olympics for disabled athletes, but it was the 1963 Mental Retardation Facilities and Community Mental Health Centers Construction Act that opened the contemporary era of accommodation for the disabled, with provisions for disabilities councils and protection and advocacy systems. In 1984 the law was renamed the Developmental Disabilities Assistance and Bill of Rights Act. Three other key steps toward accommodation of the disabled were the 1968 Architecture Barriers Act which required that the physical design of buildings not present an obstacle to people with disabilities; Section 504 of the Rehabilitation Act of 1973, which outlawed discrimination on the basis of disability; and of course the 1990 Americans with Disabilities Act or ADA (www.ada. gov), described on the US government's official website as

one of America's most comprehensive pieces of civil rights legislation that prohibits discrimination and guarantees that people with disabilities have the same opportunities as everyone else to participate in the mainstream of American life-to enjoy employment opportunities, to purchase goods and services, and to participate in State and local government programs and services. 
Notice that the ADA is formally and explicitly modeled on previous civil rights legislation aimed at remedying inequalities based on race, ethnicity, gender, and language.

\section{Box 11.2 Is Deafness a Disability or a Culture?}

Many people would no doubt regard deafness as a medical condition, indeed a disability, and it is true that most people acquire deafness or hearing loss as a result of accident or injury. Nevertheless, a significant number of hearingimpaired people do not consider themselves "disabled" at all but rather as members of a deaf minority, even of a distinct community or subculture that has been called Deafworld. Harlan Lane (2005), one of the preeminent scholars of deafness, insists that Deafworld qualifies as a social identity and community-even as an "ethnicity"- because it possesses a shared name and sense of community, as well as a culture (norms, values, knowledge, arts, and customs) the most important item of which is its language of American Sign Language, a social structure and set of institutions like schools for the deaf (the leading one being Gallaudet University), and history. Owen Wrigley, in his aptly named The Politics of Deafness, for instance, reminded us that deafness is part of biopolitics or how we think about and organize bodies; "it involves the politics of being 'normal,' the politics of difference and deviance, the politics of identity" (1996: 220). Accordingly, the deaf founded their own American organization, the National Association of the Deaf, in 1880, and in 1924 they held the first World Games for the Deaf, followed by the establishment of the American Athletic Association of the Deaf in 1945. Since that time they have opened a National Theater for the Deaf in 1967, as well as many schools, clubs, and other social groups, including an international network of websites (www.deafwebsites.com). Harlan Lane, Robert Hoffmeister, and Ben Bahan concluded in their major study of Deafworld that "Deaf people themselves, who surely should know whether they have a disability or not, typically find they do not have a disability" (1996: 410). Instead, they often find themselves disadvantaged in a majority-Hearing world, one that excludes and "medicalizes" them. This is why many inhabitants of Deafworld reject medical "cures" for deafness like cochlear implants—and even "assimilation" practices like lip-reading-since they feel that such "treatments" are an assault on their deaf identity and culture.

Both the Census and the Centers for Disease Control (CDC) collect data on disabilities in America. According to the 2010 Census, 18.7 percent of Americans or 56.7 million people were identified with a disability, 12.6 percent or 38.3 million with a severe disability. Specific details are provided in Table 11.4.

The Census further divides disability into three major categories-communicative, mental, and physical-and finds that of more than 50 million disabled Americans, 30.3 million were disabled in one of these categories, 15.8 million were disabled in two categories, and 4 million were disabled in all three. Most disabilities fell in the physical domain (41.5 million), while mental disabilities (16.8 million) and communicative 
Table 11.4 Disabled Americans by type and severity of disability, 2010

\begin{tabular}{lc}
\hline Type of disability & Percent \\
\hline Vision impairment & 3.3 \\
Severe vision impairment & 0.8 \\
Hearing impairment & 3.1 \\
Use of hearing aid & 2.3 \\
Severe hearing impairment & 0.5 \\
Speech impairment & 1.2 \\
Movement impairment-lower body & 12.6 \\
Difficulty climbing stairs & 9.2 \\
Use of wheelchair & 1.5 \\
Use of cane, crutches, or walker & 4.8 \\
Movement impairment-upper body & 8.2 \\
Difficulty with at least one "activity of daily living” & 3.9 \\
Cognitive or mental impairment & 6.3 \\
Learning disability & 1.6 \\
Alzheimer's disease, senility, or dementia & 1.0 \\
Intellectual disability & 0.5 \\
Developmental disability, i.e. cerebral palsy or autism & 0.4 \\
\hline
\end{tabular}

Source: US Census Bureau. Current Population Report: Americans With Disabilities, 2010

disabilities (15.7 million) were similar in number but far behind. Not surprisingly, the incidence of disability increases with age and is positively correlated with poverty and negatively correlated with employment.

The CDC adds information about the relationship between disability and other social variables. For instance, in 2011 for adults age 18 to 64, women (13.1 percent) were more likely to be disabled than men (11.8 percent). African Americans (16.1 percent) and Native Americans (13.6 percent) were more likely to be disabled than whites (12.2 percent), but Asian Americans were the least likely to be disabled (5.4 percent). The disability rate for Hispanic Americans was 8.6 percent. As mentioned, disability was closely associated with poverty: 25.1 percent of the poor were disabled, and the rate steadily declined with increase in income. Finally, more people living outside cities (18.1 percent) than living inside cities (11.5) were disabled.

Perhaps more important than the amount of disability in the United States is the amount of ability among the disabled. With assistive technologies, training programs, and sympathetic laws, disabled Americans have proven themselves capable of living ordinary or even extraordinary lives. In fact, as evinced in the case of the deaf or of "little people," many disabled Americans do not accept the label "disabled" but rather consider themselves "differently abled" or just fine the way they are.

\section{Mental Illness in the US}

Americans, like other people, struggle with not only their physical but also their mental and emotional health. This is highly significant for two reasons. First, as Laing and Szasz argued above, mental illness is even more prone to social construction and social control than physical illness. Second, and related to the first, vague and changing definitions and categories can render a large chunk of the population with the label 


\section{Health and (Dis)ability}

"mentally ill." And indeed, in 2010 the Substance Abuse and Mental Health Services Administration reported that one-fifth of Americans faced some kind of mental illness. One in twenty ( 5 percent) had such severe mental illness as to interfere with school, work, or family. Women (23 percent) were more likely to have a diagnosed mental illness than men (16.8 percent), and young adults (29.9 percent) had twice the rate of older adults (14.3 percent).

America's history with mental illness is a very checkered one. No such concept even existed until the modern era, abnormal behavior rather attributed to spiritual affliction, a sinful nature, a criminal tendency, or a character flaw. Englishman Thomas Willis, living in the 1600 s, is often credited with founding modern clinical neuroscience (Williams 2007), but, according to Robert Whitaker in Mad in America: Bad Science, Bad Medicine, and the Enduring Mistreatment of the Mentally Ill (2002), Willis' 1684 book described the insane as animal-like, insensitive to cold and heat and pain, and almost immune to exhaustion. Treatment of the insane thus required "breaking" their wild stubborn nature through discipline, bleeding, and near-starvation. In addition to Willis' prescription, treatment of mentally ill people often involved physical ordeals like swinging or spinning, or restraint and immobilization, as well as near-drowning and the application of caustic substances to the skin.

Whitaker considers Pennsylvania Hospital, a Quaker facility, to be the first mental hospital in America. Opened in 1756, it practiced the mental healthcare regimen of the day, with "patients" held in underground cells where they were chained and beaten, watched over by "keepers" with whips, and open to public view. Frenchman Philippe Pinel was among the first to suggest that mental illness was psychological and social and to call for "moral therapy" which allowed the patients some freedom and dignity, including access to fresh air and daily activities. The first moral-therapy institution in the United States was established in Philadelphia in 1817.

In the 1840s Dorothea Dix championed improved conditions for mental patients and was instrumental in the eventual creation of thirty-two public psychiatric hospitals in the United States. The second half of the nineteenth century, unfortunately, was the era of eugenics (see Chapter 3), during which both physical and mental health became connected with ideas of race and race hygiene. For example, Francis Galton's 1869 Hereditary Genius argued for the fundamental inequality of human types, and eugenicists generally believed that "mental defectives" of all races were a drag on the species and should be eliminated. In 1891 Victoria Woodhull declared that "imbeciles" as well as criminals and the poor should not be allowed to procreate (Whitaker 2002: 46), and Charles Davenport called for the sterilization and castration of the mentally ill and "other misfits" (48).

Since mental illness was regarded as an inherited (and often a racial) trait, institutionalization of the mentally ill—who were usually labeled as "mentally defective" or "feeble-minded" and considered to be incapable of independent living-was a natural recourse. Between 1880 and 1929 the population in mental institutions quadrupled (57), and Whitaker maintains that 40 percent of these patients were immigrants. (Recall Michael Rembis' research, discussed in Chapter 6, on the institutionalization of young white women for being sexually precocious and therefore "deviant.") As noted, sterilization was a more final solution, and in the early 1900s thirty states adopted sterilization laws, starting with Indiana in 1907; Iowa specified the targets for sterilization in its legislation of 1913 as "criminals, rapists, idiots, feeble-minded, 
imbeciles, lunatics, drunkards, drug fiends, epileptics, syphilitics, moral and sexual perverts, and diseased and degenerate persons" (quoted in Whitaker 2002: 58). A few experts even recommended euthanasia for the insane.

Treatments, and categories, for mental illness branched in many directions in the twentieth century. Sigmund Freud's psychoanalysis and its "talking cure" emphasized the role of traumatic experiences as well as unconscious drives and instincts. Medical techniques, both in the areas of chemicals and operations, revolutionized mental healthcare, introducing methods such as electro-convulsive therapy (ECT or "electroshock"), chemically-induced comas and seizures, and lobotomy. In 1954 Thorazin was hailed as a wonder-drug to treat psychosis, followed soon after by Prolixin and Haldol. In the meantime, government was beginning to pay attention to mental health: the 1946 National Mental Health Act created the National Institute of Mental Health (www.nimh.nih.gov), and under President John F. Kennedy the Mental Retardation Facilities and Community Health Centers Construction Act was passed in 1963, reforming the mental health system by replacing mental hospitals with neighborhood clinics and aiming to deinstitutionalize the mentally ill.

\section{Diversity Fact:}

The population of mental institutions has dropped precipitously since 1970, from an institutionalization rate of more than 600 per 100,000 Americans to well under 100 by 2001 . At the same time, the prison population has skyrocketed, from a rate of 150 to 600 per 100,000. Many individuals with psychological problems end up in jail today; in fact, a recent column in The Economist (August 3-9, 2013) contends that prisons and jails "are the main mental-health facilities in the country," and they are not really designed for that purpose.

Today and for the past several decades, mental health has been largely defined by the Diagnostic and Statistical Manual of Mental Disorders of the American Psychiatric Association, first published in 1952 and currently in its fifth edition. Multiple agencies track mental health in America, such as the National Institute of Mental Health (NIMH) (see above) and the Substance Abuse and Mental Health Services Administration (www.samhsa.gov). As mentioned, depending on how mental illness is defined, as many as 20 percent of Americans suffered from some version of it and 5 percent from a serious version. Of those who experienced mental illness, 39.2 percent received some kind of treatment.

America's mental health complaints are numerous and diverse. Approximately 8.7 million people had serious suicidal thoughts, with 1.1 million actually attempting suicide. The NIMH calculates that anxiety disorders strike 40 million or 18 percent of American adults each year, including panic disorder (6 million), obsessive-compulsive disorder or OCD (2.2 million), post-traumatic stress disorder or PTSD (7.7 million), and social phobia (15 million), to name a few. Another 2.4 million people are considered schizophrenic, a condition that typically manifests in late adolescence or early adulthood for men but later (20s-30s) for women. Bipolar disorder strikes 


\section{Health and (Dis)ability}

5.7 million Americans, with 25 as the median age of first occurrence. Attention deficit hyperactivity disorder (ADHD) is harder to estimate, but numbers range from 3 percent to 9 percent of children, with a median onset of age 7 and a much higher incidence among boys than girls; 4.1 percent of adults have also been diagnosed as ADHD. Americans suffer from a variety of eating disorders, including 0.6 percent with anorexia during their lifetimes, 1 percent with bulimia, and 2.8 percent with binge eating; as mentioned, eating disorders are much more common among women. Finally, a very prevalent mental health complaint is depression, which affects 14.8 million Americans and is considered by the NIMH to be the leading cause of disability for adults. Major depression is more common among women than men.

There are also differences in mental health across race and ethnic groups. African Americans report 20 percent more psychological problems than whites, including higher levels of sadness, hopelessness, and worthlessness. Native Americans suffer from 1.7 times the psychological distress of whites, especially feelings of nervousness and restlessness, and suicide is the second leading cause of death among Native Americans ages 10 to 34. The rate of psychological distress among Hispanic Americans is only 10 percent higher than among white non-Hispanics, but Hispanics are much less likely to commit suicide.

\section{Conclusion}

Health and (dis)ability can vary in almost infinite ways, and by injury or infection, accident or aging, an American can expect to occupy many health and (dis)ability statuses in a lifetime. More, while health and (dis)ability is largely about real physical (and mental) differences, it is also socially constructed. Their causes, correlations, and consequences are deeply connected to culture, as defined, classified, and organized by society.

Since health and (dis)ability differences are literally matters of life and death, we tend to talk not just of diversity but of disparity. Further, these disparities are distributed unevenly across, and intimately related to, other social variables discussed in this book, from race and ethnicity to class, gender, age, and even language and religion. Perhaps nowhere else in American society is the intersectionality between social statuses more apparent and more urgent.

Health and (dis)ability also have a history, both in terms of attitudes and policies and in terms of actual specific health conditions and outcomes. Fewer Americans suffer and die today from infectious diseases because of advances in medical knowledge, but at the same time more Americans suffer and die from diseases of longevity, like heart disease and cancer, and diseases of development, like diabetes and obesity. Our society and way of life can make us well, and it can also make us sick. 


\section{Region and Geography The Spatial Distribution of Diversity}

In political discussions, Americans have become accustomed to speaking of "red states" and "blue states," that is, states that dependably vote Republican or Democrat, respectively. As can be seen in Figure 12.1, red or Republican states tend to be located in the South and Great Plains, while blue or Democrat states tend to be situated in the Northeast and the West. These differences have been very consistent over time (although decades ago the party associations were flipped, with Republicans being the liberal Northern party and Democrats the conservative Southern party) and are so strong that, in most elections, it can be assumed with great confidence that California will go Democrat and Texas will go Republican. As presidential election watchers know, the outcome usually depends on a few "swing states" where the result is not a foregone conclusion. Interestingly, when the election returns are examined at a more local level, it is clear that there are many red counties in blue states and many blue counties in red states. For example, while coastal (and more urban) California is solidly

WINNER:

$\square$ Barack Obama, Democratic Running Mate: Joe Biden Popular Vote: 62,346,445 Electoral Votes: 332

$\square$ Mitt Romney, Republican Running Mate: Paul Ryan Popular Vote: $58,976,480$ Electoral Votes: 206

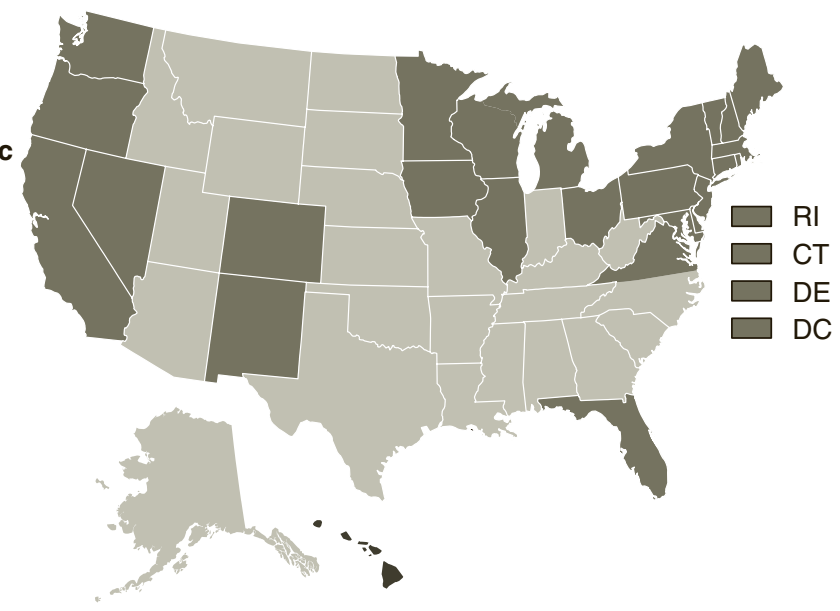

Figure 12.1 Electoral College results for 2012 Presidential Election by state.

Source: US National Archives and Records Administration

Note: The full colour version of this map can be found on the companion website, www.routledge.com/cw/ eller. 


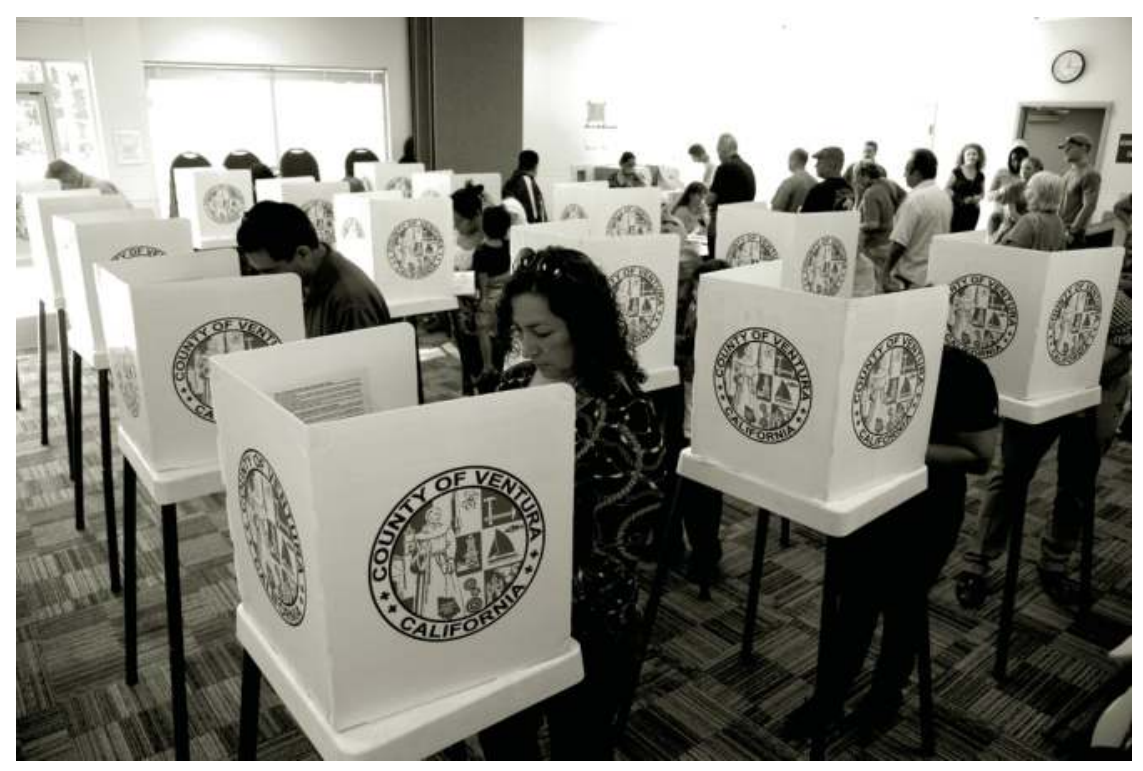

Image 12.1 2012 Presidential Election: Voters at polling station in Ventura County, California.

(Courtesy of American Spirit/Shutterstock.com)

blue, inland (and more rural) California is largely red; likewise, New York City is blue but much of upstate New York is red, and most of Texas is red although southern Texas is blue. While most of the surface area of the country is colored red, the most populous regions (again, the cities) are strongly blue. A clear example is Illinois: most of the state is red, but Chicago's overwhelming blue population handed the state to the Democrats.

Why are there strong, persistent, and socially and politically important differences between people in different places? How do places shape our social experiences, attitudes, and opportunities, and how do social differences shape places?

As we have seen indirectly throughout this book, not only are Americans incredibly diverse, but their diversity is not randomly distributed. In many regards, from speech patterns to ethnic residence to religious affiliation and religiosity, Americans are distributed unevenly yet systematically across the land that is the United States. Some of these spatial distributions are new or changing, but others are old and stable; for example, Southern and rural areas have long and dependably been conservative in their politics and their religion, while Northern and urban areas have been equally consistently liberal.

It is also apparent that diversity exists within spaces as well as between them. Within American states, there are differences between counties and between rural and urban areas. Within urban areas, there are differences between neighborhoods or what the US Census calls "census tracts." A census tract is one of the "small, relatively permanent statistical subdivisions of a county. Census tracts nest within 
the county and are given a numeric code that is unique within the county. The minimum population for a census tract is 1,200 and the maximum is 8,000 . Most census tracts average about 4,000 people." There are even differences between and within households. So not only are there differences within differences across space, but the results that we get from studying these differences depend on what resolution we use to acquire our data, that is, what level (national, state, county, census tract, etc.) we focus on.

The other thing that we have seen throughout this book is that even natural or physical qualities are socially constructed-given social meaning, social organization, and social use. It is unlikely that there is anything about the South that makes it "naturally conservative." Rather, the history of the people who occupy places (i.e. the first and later settlers in the region, the events that occurred there, etc.), the relations and boundaries between groups and categories of people, the institutions and economic/political conditions that occur there (i.e. the industries or job opportunities that exist there, as well as forms of local government, family, religion, and so on), and of course the physical environment itself (i.e. hills, rivers, deserts, etc.) and the built environment (the roads, the housing stock, the infrastructure, and such) all influence who lives where and what kinds of beliefs, attitudes, and other cultural characteristics those people have. Further, as we will argue below, the traits of places are not just passive effects but active constituents of society. For example, the very size of a place or whether it is densely or thinly populated or whether it is near to or remote from other places contributes to the social experience of the people who live there. Finally, places have meaning and value to people; a place is, at least potentially, home to someone, and people fill places with memory and significance. Some places are, indeed, "sacred" to at least some people. In a word, places are not all alike nor are they are equal.

\section{The Spatial Dimension of Social Diversity}

Given the obvious evidence that places make a difference in social life, it is odd, according to Frank Lechner writing just over twenty years ago, that "space has never been central to sociological thought" (1991: 195). In fact, Lechner contended that most of the founding scholars of social science paid little attention to the spatial distribution of social difference, with the exception of Georg Simmel. In 1903 Simmel published an essay titled "The Sociology of Space," in which he argued, in Lechner's words, for the "practically inevitable spatial embeddedness of social configurations" (196). Some social theorists have gone so far as to identify a "geometry of society" based on the fact that "sociation becomes spatially real" (196) as social groups and categories sort themselves across space.

Simmel proposed five "fundamental qualities" or variables of space as a social phenomenon, beginning with exclusivity, or the extent to which one group/category or institution monopolizes a space or shares it with others. For example, some neighborhoods may be exclusively upper-class or lower-class or exclusively white or black, while other neighborhoods are economically or racially mixed. The second and obvious issue for spaces is boundaries, of which the most familiar are political boundaries like the borders of New York City, Texas, or the US. However, Simmel stressed that such a boundary "is not a spatial fact with sociological consequences, but a sociological 
fact that forms itself spatially" (1997: 143). All social boundaries are human-made, even when they coincide with natural features like rivers and coastlines. Further, some spaces have no visible boundaries, such as neighborhoods or regions (e.g. what is the boundary of "the Northeast" or of "Europe"?). Finally, social diversity is not only contained within boundaries but spills across boundaries; a good example is Hispanic American culture, which straddles (and to some extent ignores) the US/Mexico border. So we cannot presume that social boundaries and formal political boundaries coincide, as we will discuss more below.

Third, Simmel asserted that space works to fix or freeze, to objectify and reify, social differences and relations. For instance, establishing separate spaces for different races, classes, religions, or languages serves to construct and perpetuate their difference and their inequality. Also, once something like a slum or a gated upper-class community is built, it becomes a social fact and shapes subsequent social action (residence, policing, school quality, and much more). Simmel's fourth variable was "the sensory proximity or distance between people who stand in some relationship or other to one another" (1997: 151), referring to the ease or even the possibility of people based in different places interacting with and experiencing each other. Obviously, people who live near each other will interact more, and, communication technology notwithstanding, people in remote or segregated places will interact with outsiders less than those in neighboring or integrated places. The fifth variable, not to be overlooked, was mobility, since people may occupy a certain place at any given moment but migrate to another place permanently or shuttle between places (like the city and the suburbs) routinely. This is a particularly important point for Americans, who are all products of past migrations, and it also reminds us that mobility is every bit as important for understanding the social use of space as location is. People move from place to place as their social circumstances change, and places change their nature as different kinds of people move in or out of them.

In short, as Lechner put it, "many forms of sociation cannot be understood without taking into account both their spatial context and their use of space" (1991: 198). Picking up this thought, in his contribution to the ground-breaking anthropological work Senses of Place Edward Casey stated that humans “are ineluctably place-bound. More even than earthlings, we are placelings, and our very perceptual apparatus, our sensing body, reflects the kinds of places we inhabit" (1997: 19). Thomas Gieryn, citing Casey, extended this perspective, insisting that "everything we study is emplaced; it happens somewhere and involves material stuff" (2000: 466). Thus, "sociologists have a stake in place no matter what we analyze, or how," including standard social topics like "inequality, difference, power, politics, interaction, community, social movements, deviance, crime, life course, science, identity, memory, history" (463). He added that "place" is a relative term, since a place "could be your favorite armchair, a room, building, neighborhood, district, village, city, county, metropolitan area, region" (464), or an entire country, continent, or planet. Perhaps most profoundly, Gieryn claimed that a place can have social effects of its own: a place "is not merely a setting or backdrop, but an agentic player in the game-a force with detectable and independent effects on social life" (466). Stated again and more forcefully, "Places have power sui generis, all apart from powerful people or organizations who occupy them: the capacity to dominate and control people or things comes through the geographic location, built-form, and symbolic meanings of a place" (475). 


\section{Diversity Fact:}

According to a recent University of Vermont study (Mitchell et al. 2013) using Twitter messages as data, the happiest states in the US are Hawaii (at number one), Idaho, Nevada, Utah, Colorado, Maine, and Vermont. The unhappiest states are Michigan and several Deep South states, including Louisiana (dead last), Alabama, Mississippi, and Georgia.

\section{Human Ecology and Human Geography}

Writing in 2002, the eminent urban sociologist Herbert Gans advocated for a "spatial sociology" which examines "how society, i.e., individuals and collectivities, transform natural into social spaces, how they use and exchange it, what social, economic, and other processes and forces come into place in these uses and exchanges, and how both kinds of space affect individuals, collectivities, and social processes and forces" (2002: 329). Among the variables calling for attention were location, density and crowding, "propinquity and neighboring" (333), and the types and uses of public space. Speaking of propinquity, only one year earlier Miller McPherson, Lynn Smith-Lovin, and James M. Cook reminded us that the most basic social process is homophily, or the association of people who share social characteristics and that "the most basic source of homophily is space: We are more likely to have contact with those who are closer to us in geographic location than those who are distant" (2001: 430). For this reason, John Logan very recently urged the study of

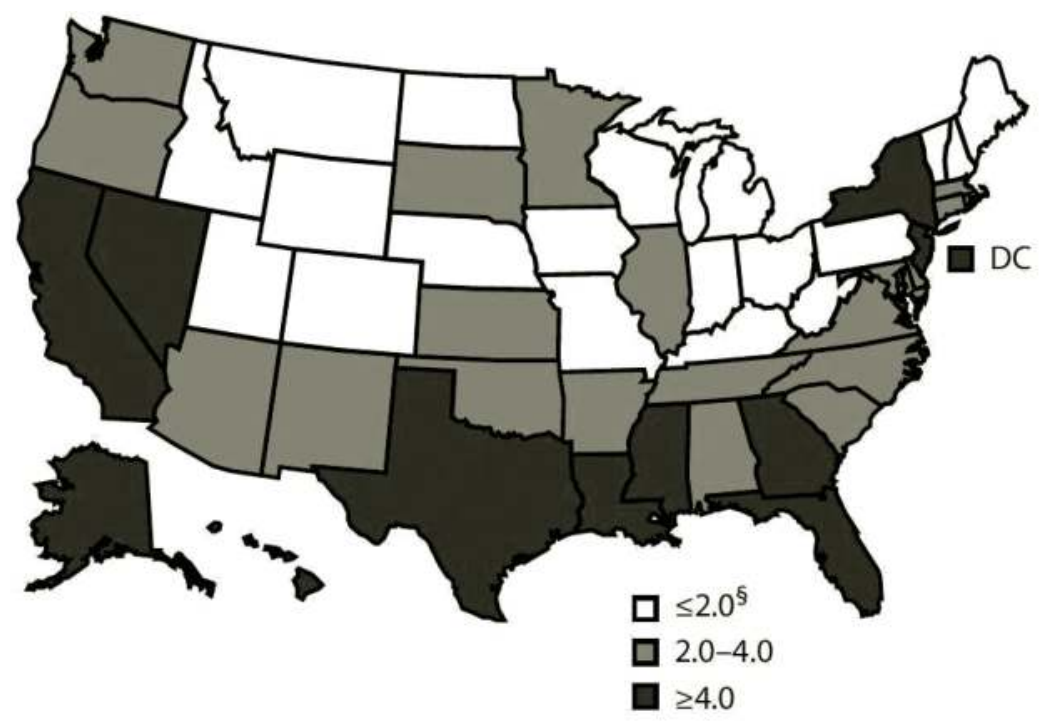

Figure 12.2 The spatial distribution of health: Tuberculosis rate (per 100,000 population) by state, 2009.

Source: Centers for Disease Control and Prevention. Morbidity and Mortality Weekly Report 59, 2010

Note: The full colour version of this map can be found on the companion website, www.routledge.com/ cw/eller. 
spatial clustering or "the tendency for similar things to be near one another" (2012: 518), which, as we have already noticed, lends itself to mapping and to Gans' spatial sociology. We will discuss many additional examples later in the chapter.

Interestingly, in relation to Lechner's complaint about the lack of spatial interest in sociology, there is in fact a spatially informed tradition in the social sciences, going back to the human ecology approach of Robert Park and others in the 1930s. Human ecology starts from the premise that humans do not simply occupy territory but modify that territory, and by modifying their territory they create human-made spaces in which they must live and work. Cities are such human-made spaces, but so are small towns and farms; indeed, there is no space inhabited by humans that is not profoundly transformed by human habitation. Human ecology takes quite seriously some basic naturalistic concepts such as the environment, adaptation, competition, and symbiosis (i.e. living together for mutual benefit). As Park understood, all species, humans included, form functional interrelations with other members, with other species, and with the environment itself. Humans, though, add a layer of culture or shared meanings, values, and communicative and behavioral norms.

Park defined "community" as "a population, territorially organized," that is "more or less completely rooted in the soil it occupies" with "its individual units living in a relationship of mutual interdependence that is symbiotic" —and in the case of humans specifically, "societal" (1936: 4). The societal aspect of human community, of course, includes groups and institutions, along with technology and "custom and beliefs." Any specific historical society was seen as a particular arrangement and equilibrium of individual, environmental, and social/cultural forces. So human ecology was offered by Park as a means "to investigate the processes by which the biotic balance and the social equilibrium (1) are maintained once they are achieved and (2) the processes by which, when the biotic balance and the social equilibrium are disturbed, the transition is made from one relatively stable order to another" (15).

Two of the ecological processes highlighted by Park were dominance and succession. Dominance occurs when one "type" achieves spatial advantage over another; this could be one species over another or one social group or category over another. In the human context, dominance would be the condition in which one class, race/ethnicity, sex, religion, language group, age group, etc. enjoys superiority by dominating the space and its resources (housing, jobs, healthcare, or what have you). Succession, by contrast, happens when one species/group displaces another and occupies its position. Park explicitly applied this model to urban structure and urban change, but it applies equally well to any environment: rural areas become cities, cities are abandoned and become rural, and neighborhoods in rural or urban areas are infiltrated by new groups, displacing former residents. As he wrote, "The so-called natural or functional areas of a metropolitan community-for example, the slum, the rooming-house area, the central shopping section and the banking center-each and all owe their existence directly to the factor of dominance, and indirectly to competition" (8). The terms of dominance and succession in modern America are first and foremost land values: "It is these land values that determine the location of social institutions and business enterprises. Both the one and the other are bound up in a kind of territorial complex within which they are at once competing and interdependent units" (8). Ultimately, as land values change and as various groups grow or shrink and jostle for power and space, some groups abandon—or are pushed out of-locations and are supplanted by others. 
In short, a city is a dynamic ecological system, and we would not expect its current distribution and use of land to be its permanent distribution and use.

\section{Box 12.1 A Case Study in Domination and Succession: Downtown Lofts}

Until 1970, urban sociologist Sharon Zukin (1982) found, no one particularly wanted to live in a downtown loft. Lofts were spaces where light industry such as textile manufacturing or printing was done or sometimes where poor bohemian artists resided. However, by a convergence of factors, lofts began to become places to live rather than places to produce, resulting in the succession of these spaces from production to habitation. But if you think about it, the reassignment of productive space as residential space reduces production and eliminates jobs: "Factory space that is subdivided into apartments, with kitchens and bathrooms, is dead as far as productive activity is concerned. Thus the most fundamental part of a mode of production-the space where products are actually produced-is shifted to another use" (19). This does not happen spontaneously, of course; rather, she saw this process as part-and an intentional part-of the general deindustrialization of New York City and of the US as a whole. Between 1950 and 1970, the number of manufacturing jobs in New York City shrank by almost one-third and in the garment industry specifically by almost half (24).

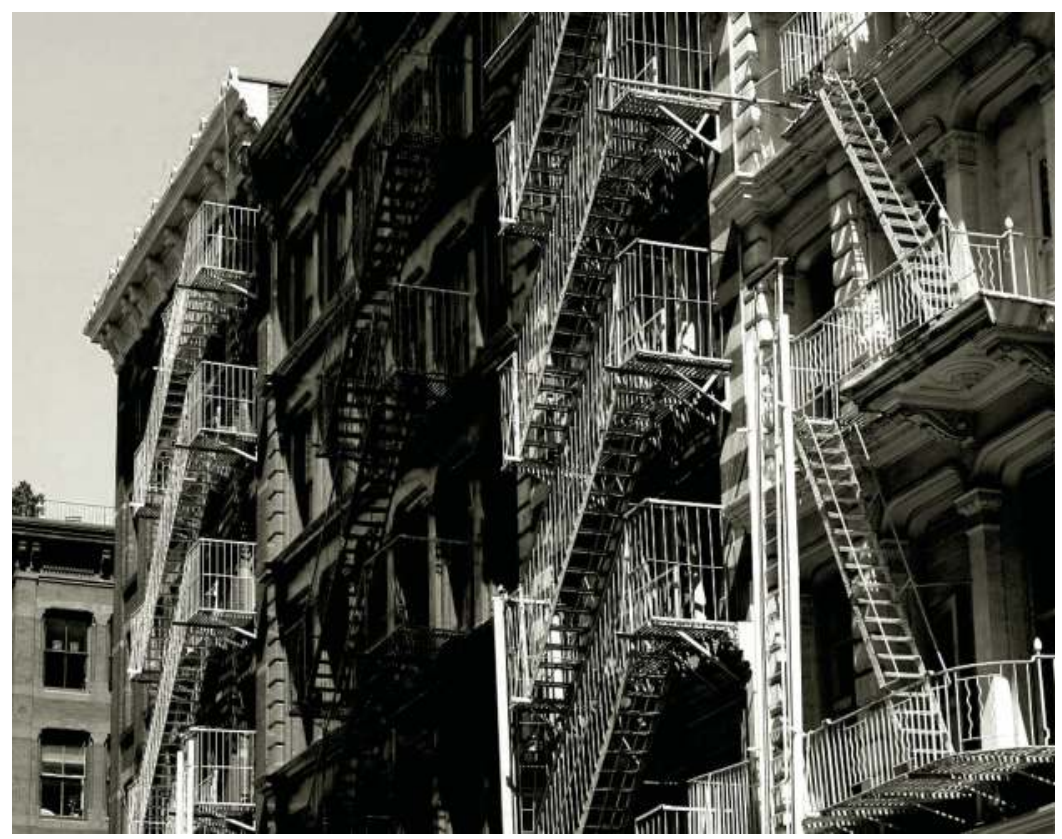

Image 12.2 SoHo lofts.

(Courtesy of the Carol M. Highsmith Archive, Library of Congress, Prints and Photographs Division) 
(continued)

Further, the city's "patrician elite," including its bankers, lawyers, and "civicminded industrialists," had developed "hostility toward manufacturers," especially in Manhattan (25). They used such tactics as zoning, building codes, tax laws, and even condemnation and eminent domain (seizing real estate in the name of public interest) to drive out loft-based downtown industries and to free those spaces for white-collar uses like offices and apartments. But professional offices and upperclass residents would not immediately replace factories; the intermediate colonists were artists who found lofts suitable as combined living spaces and studio spaces. By the late 1960s the city government had rezoned the neighborhoods to allow artists to live and work in lofts in the SoHo district; later that access was extended to Greenwich Village, both of which became synonymous with funky downtown culture. The next step was therefore cultural, the creation of a "loft lifestyle."

In the 1970s lofts became sought after as middle- and upper-class living sites, with their historical significance and their rough picturesque qualities and new sense of openness. Because lofts are often one large undivided space (not separate rooms), "Living in a loft is a little like living in a showcase" (69), and for upwardly-mobile individuals and couples (often childless) interested in conspicuous consumption, they were just the thing. As trend-setting people began to occupy them, they became more socially desirable-and more financially valuable. And all of this change converged in a new definition of the urban person or urban self, as well as a new relationship with space and with industry: industry became almost nostalgic and the lofts "a kind of tourist attraction" (69). Zukin concluded that loft living was both a rejection and an embrace of modernity: "Living in a loft is an attempt to replace modernism's mass production of the individual with an individualization of mass production" (68).

Eventually the confluence of physical space and social organization gave rise to a new discipline or subdiscipline, human geography. According to Christopher Gibson, writing in the International Encyclopedia of Human Geography, while geography tends to pursue the study of the earth's physical features, human geography addresses the question of the relation between physical features and people, including "cultural identities, political territories, and societies. .. . Human geographers analyze population trends, theorize social and cultural change, interpret geopolitical conflict, and seek to explain the geography of human economic activities around the world" (2009: 213). In their major textbook on the subject, The Human Mosaic, Mona Domosh, Roderick Neumann, Patricia Price, and Terry Jordon-Bychkov identify five key themes in the discipline. The first is "region," which can specify:

- a formal region, or one inhabited by individuals who share one or more cultural characteristics, like a language or religion (e.g. "the Muslim world");

- a functional region, or a political or economic unit (e.g. the United States or the European Union);

- a vernacular region, or a region that exists for its residents based on a shared perception or social experience (e.g. the "Rocky Mountain region" or "the Middle East"). 
The second theme, also mentioned by Simmel, is mobility. The third, closely related to mobility, is globalization or "the binding together of all the lands and peoples of the world into an integrated system driven by capitalistic free markets, in which cultural diffusion is rapid, independent states are weakened, and cultural homogenization is encouraged" (2012: 13). The fourth is "nature-culture" or "the complex relationships between people and the physical environment, including how culture, politics, and economies affect people's ecological situation and resource use" (16). The natureculture complex refers not only to what natural features and resources actually exist but people's knowledge and perception of them. Finally, the authors mention "cultural landscape," or what we have called the built environment, that is, "all the built forms that cultural groups create in inhabiting the earth-roads, agricultural fields, cities, houses, parks, gardens, commercial buildings, and so on" (23). They add that the cultural landscape reflects and realizes "a culture's needs, values, and attitudes toward the earth" (23), including the symbolic value that people attach to places.

\section{The City as a Social Place}

For good reason, very much of the attention of social science has been aimed at the city, as a very special kind of place. The city is not a uniquely modern phenomenon (there were ancient cities too), but it is the distinctive social form of modern society, and it shapes and is shaped by other crucial aspects of modernity. The key motor of

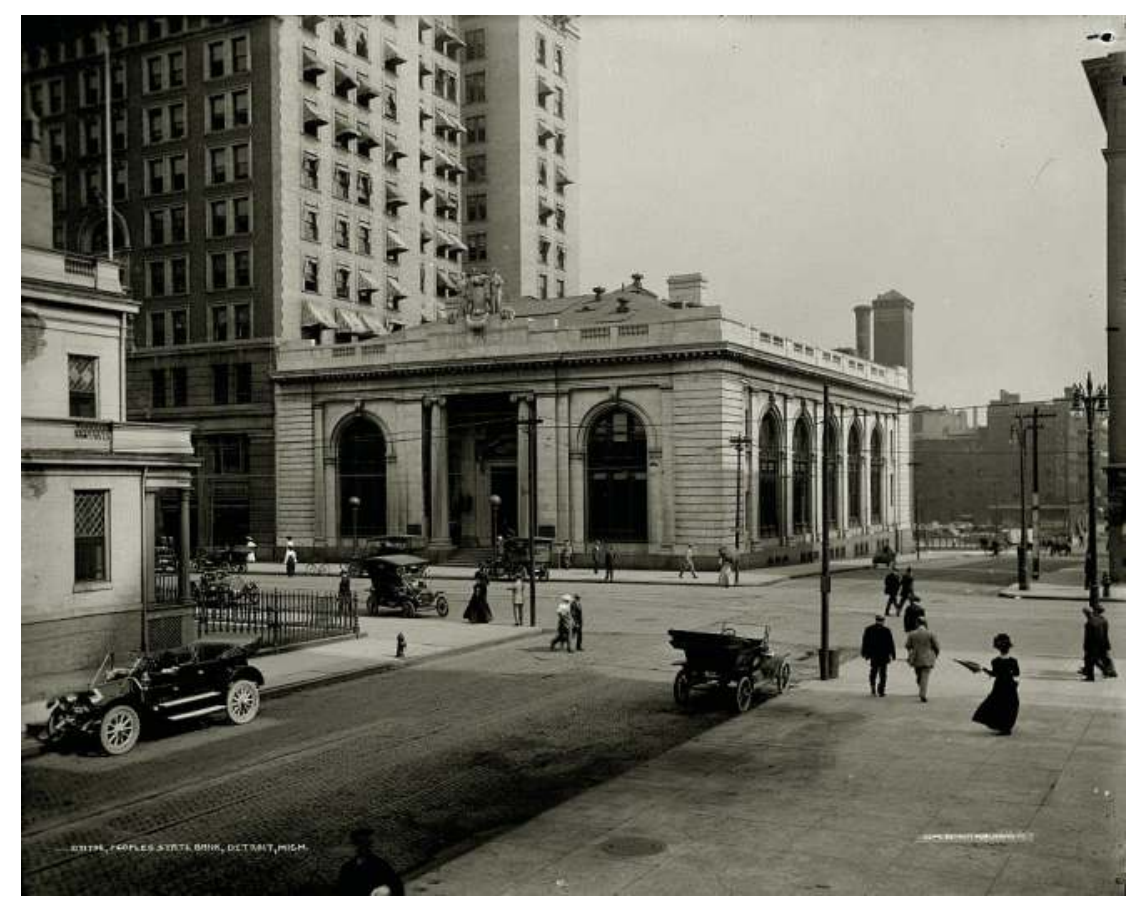

Image 12.3 Detroit, c.1910.

(Courtesy of the Library of Congress, Prints and Photographs Division) 
the modern city, arising during the Industrial Revolution, was the factory: because the factory was a center of labor and production, and because transportation technologies were limited, people had to migrate to and pack into a dense space around the factory, hence the city. The consequence, according to many observers and critics including Karl Marx and Friedrich Engels, was a foul space, characterized by pollution, inadequate and cramped housing, poverty, and illness.

More important to social scientists than the physical conditions of the industrial city were the social experiences and effects. Émile Durkheim, one of the founders of sociology and a leading theorist of modern society, is not generally credited with much spatial concern, but Leo Schnore, in a 1958 analysis of Durkheim's work, argued that he was indeed concerned with "the environmental basis of social organization" as well as the role "of population phenomena, especially size, density, and spatial distribution” (1958: 620). Central to Durkheim's view of the nature of modern/urban life was his notion of "moral density" or dynamic density, meaning the amount of interaction or the rate at which particular individuals come into contact with each other, which was certainly affected by population size, population concentration, and technology. Since cities are, by definition, dense human settlements, the moral density of urban life had necessarily to be different from the moral density of rural/village/mechanical life.

Central too to Durkheim's understanding of modern urban society was the division of labor, which meant that human groups could and would differentiate economically (do different work) and virtually "speciate" in a human-ecology sense and so occupy different social and spatial niches in the society. In short, modern urban society was not merely more people crowded into the same space but more different kinds of people created by and adjusting to the new human-made terrain of the city.

However, or perhaps because of this change, many social theorists were quite critical of the new society and lifestyle that was forming in the city. Durkheim himself contrasted the mutually dependent, legalistic, and formalistic ("organic" in his terminology) nature of modern urban social life to the more idyllic, family-based premodern society based on shared sentiments and interpersonal relationships. Other thinkers were more hostile. In 1903 Georg Simmel wrote The Metropolis and Mental Life, in which he listed some of the ills of the city. Living in a city exposed people to intense, fast, and constantly shifting sensory stimulation, upsetting and intensifying their emotions. More, the city produced an "intellectualistic" person who was selfconscious, self-interested, matter-of-fact, and calculating. Such people were driven by time and money, and their relationships in general were more impersonal-at best "reserved," at worst avoidant. And mentally, they became "blasé," indifferent, detached, and accustomed to a world that was "homogeneous, flat and grey."

Louis Wirth's evaluation was equally negative but more specific. In his memorable 1938 essay "Urbanism as a Way of Life," he first characterized the city as consisting of three interconnected facets: "a physical structure comprising a population base, a technology, and an ecological order"; "a system of social organization involving a characteristic social structure, a series of social institutions, and a typical pattern of social relationships"; and "a set of attitudes and ideas, and a constellation of personalities engaging in typical forms of collective behavior and subject to characteristic mechanisms of social control" (1938: 18-19). Within this physical/social context arose a distinct way of life that he called urbanism. The ethos or quality of living in a large dense throng of humans was clear and bad: 
Large numbers account for individual variability, the relative absence of intimate personal acquaintanceship, the segmentalization of human relations which are largely anonymous, superficial, and transitory, and associated characteristics. Density involves diversification and specialization, the coincidence of close physical contact and distant social relations, glaring contrasts, a complex pattern of segregation, the predominance of formal social control, and accentuated friction, among other phenomena. Heterogeneity tends to break down rigid social structures and to produce increased mobility, instability, and insecurity, and the affiliation of the individuals with a variety of intersecting and tangential social groups with a high rate of membership turnover. The pecuniary nexus tends to displace personal relations, and institutions tend to cater to mass rather than to individual requirements. The individual thus becomes effective only as he acts through organized groups.

In short, the nature of urban existence breeds "superficiality," "anonymity," and a "transitory character," not to mention "sophistication" and "rationality" (12). Interpersonal relations are "segmented" or incomplete as well as "utilitarian" (13). The city-dweller has "no sentimental and emotional ties" with other human beings, and personal relationships are substituted with formal political controls. Everything about the city is inhumane: not people and their identities and needs but rather the "clock and the traffic signal are symbolic of the basis of our social order in the urban world" (16). Just as we are regulated from the outside, so we are divided across many different but partial groups; our social participation is accordingly voluntary, trivial, and fragmented. "Personal disorganization, mental breakdown, suicide, delinquency, crime, corruption, and disorder might be expected under these circumstances to be more prevalent in the urban than in the rural community" (23).

\section{Diversity Fact:}

According to an item in The Atlantic Monthly (March 2006, page 50), more residents of downtown areas (45 percent) held bachelor's degrees in 2000 than residents of suburbs (around 30 percent) or of urban but not downtown areas (under 30 percent). Not all downtowns were equal, though: 65 percent of Boston's downtown residents had four-year degrees but only 15 percent of Phoenix's downtowners.

\section{Places and Non-Places: Space in Modernity and Supermodernity}

A house is not a home, and a space is not a place. Most social scientists agree that "space" is an abstract and impersonal concept, not yet socialized. A "place," on the other hand, is socially constructed and socially inhabited; it is somebody's place, with a history and a meaning and a "set of relations by which a given site can be defined" (Foucault and Miskowiec 1986: 23). A place is not just a physical entity but an imagined territory-as Gieryn explained, "interpreted, narrated, perceived, felt, understood, and imagined" (2000: 464). It is "filled up" by the people who inhabit it, named and remembered and storied. 
But not all physical spaces and social spaces quite have all of these qualities, and Michel Foucault was one of the first to comment on them. Originally introduced in an interview in 1966, Foucault applied the term heterotopia ("other-place") to real physical locations (as opposed to the unreality of utopia) "which are something like counter-sites, a kind of effectively enacted utopia in which the real sites, all the other real sites that can be found within the culture, are simultaneously represented, contested, and inverted" (Foucault and Miscowiec 1986: 24). He suggested two social purposes of such "other places," either "to create a space of illusion that exposes every real space" or "to create a space that is other, another real space, as perfect, as meticulous, as well arranged as ours is messy, ill constructed, and jumbled" (27). Two examples he offered of heterotopias were brothels and colonies. Here in modern America, better and more familiar examples might be Disneyland or a cruise ship-or that epitome of otherness, Las Vegas, where the regular rules of society do not apply (what happens there stays there, they say).

Later, Marc Augé proposed the term non-place to designate many of the key sites of modern society, or what he chose to call supermodernity. Supermodernity, associated with globalization and late capitalism, is characterized by the contraction, almost the overthrow, of space and time, and most contemporary readers will understand that notion. Electronic technology allows instantaneous connection with anyone anywhere, rendering space and place relatively irrelevant; it actually creates non-spatial "places" like online discussion and shopping "sites." Even people and objects are in rapid and continuous motion, and mobility and travel become formative experiences. This supermodernity creates places to facilitate mobility, like airports and railroad stations, highways and hotels, that occupy physical space but that are home to no one. Augé makes the following distinction between places and non-places: "If a place can be defined as relational, historical, and concerned with identity, then a space which cannot be defined as relational, or historical, or concerned with identity will be a non-place" (1995: 77-8). Supermodernity or even modernity, of course, did not invent the nonplace; there have been roads and transit stations for a long time. But in supermodernity such non-places are super-abundant, essential for the function of society, and we spend more and more time in/on them. And anyone who has spent hours in airports, for example, knows that they really do feel simultaneously both "anywhere" (all airports are largely alike) and "nowhere" (an airport is a way-station, never a destination).

Finally, one does not have to be a globe-hopping traveler to experience the placelessness of contemporary society. Even before Augé, Americans were noticing and complaining about the loss of place, as illustrated by James Howard Kunstler's The Geography of Nowhere (1993). The first major "nowheres" in America, by many estimations, were suburbs, which were originally conceived and used as "bedroom communities" for people who worked and played in the city. Most suburbs had no history, and most lacked real community. However, nowhere has been infiltrating more and more American space, most notably the interchangeable shopping malls with their interchangeable stores and restaurant chains. A chorus of scholars as well as ordinary Americans have expressed alarm at "the consequences of placelessness, inauthenticity, sameness and the standardization of landscapes" (Arefi 1999: 184), using negative terms like "plastic" or "sterile" or "unliveable" or "soulless" to describe these empty places (187). The effects on the people who live in or pass through such non-places may be destructive, according to Gieryn: "The loss of place ... must have 
devastating implications for individual and collective identity, memory, and history and for psychological well-being" (2000: 482). Consequently, observers like Robert Putnam in Bowling Alone: The Collapse and Revival of American Community (2000) have pondered the isolation and rootlessness of modern America.

\section{The Spatial Diversity of American Society}

Virtually every aspect of American diversity has its spatial component. The United States, more than most countries, is a conglomerate of parts with their own histories, subcultures, traditions, and dialects; it is, after all, a "union" of states, many of which began as separate colonies and the rest of which joined the federation at different times in different ways. The northeastern region was the first populated by English settlers, of varying religion depending on the colony (Anglicans in Virginia, Catholics in Maryland, Quakers in Pennsylvania, Congregationalists in New England). Southern colonies developed a slave-based economy and culture, which would mark the future developments in that region. Parts of the south and mid-west, like New Orleans and Michigan, had French legacies, while most of the western region had a significant Spanish history, and all of the territory had a rich Native American heritage. Many more immigrants brought their cultures and institutions, settling unevenly throughout the country. Today, as Figure 12.3 depicts, the American population is still distributed unevenly across the landscape, with important social, economic, and political implications.

Even social variables that would seem to have little to do with geography, such as sex, are spatially distributed in interesting and informative ways, as seen in Figure 12.4. Other variables, as already discussed in previous chapters and as described in more detail below, also have their geographic array, with social/historical causes and effects. Surely, American society cannot be understood apart from its spatial dimension.

In fact, American diversity itself is spatially diverse, as John Sullivan calculated in 1973. Using an index of variables, including education, income, occupation, housing, ethnicity, and religion, he determined that northeastern states like New York, Connecticut, Massachusetts, and New Jersey were the most diverse, while southern states, including Mississippi, Arkansas, and North and South Carolina, were the least diverse. More importantly, he found support for the prediction that diversity itself "should increase party competition, decrease discrimination, and increase policies aimed at the more unfortunate members of society" (1973: 84). Almost twenty years later, David Morgan and Laura Ann Wilson recomputed the so-called Sullivan Index using 1980 data and found that the northern and southern states were "now much more alike than they were in 1960," but that "while the South has changed considerably over time, it still remains significantly different (statistically) from the rest of the country on the diversity index" (1990: 75). Specifically, socio-economic differences had declined, but regional differences in culture persisted. Finally, New York still led the country in diversity, followed by New Jersey, Massachusetts, and California, while the South still languished behind in diversity, Arkansas being the least diverse state, then North Carolina, West Virginia, and Tennessee.

\section{What is an American Place?}

As just seen, scholars and the general public are very accustomed to distinguishing between the "North" and the "South" of the United States, and to be sure measurable 


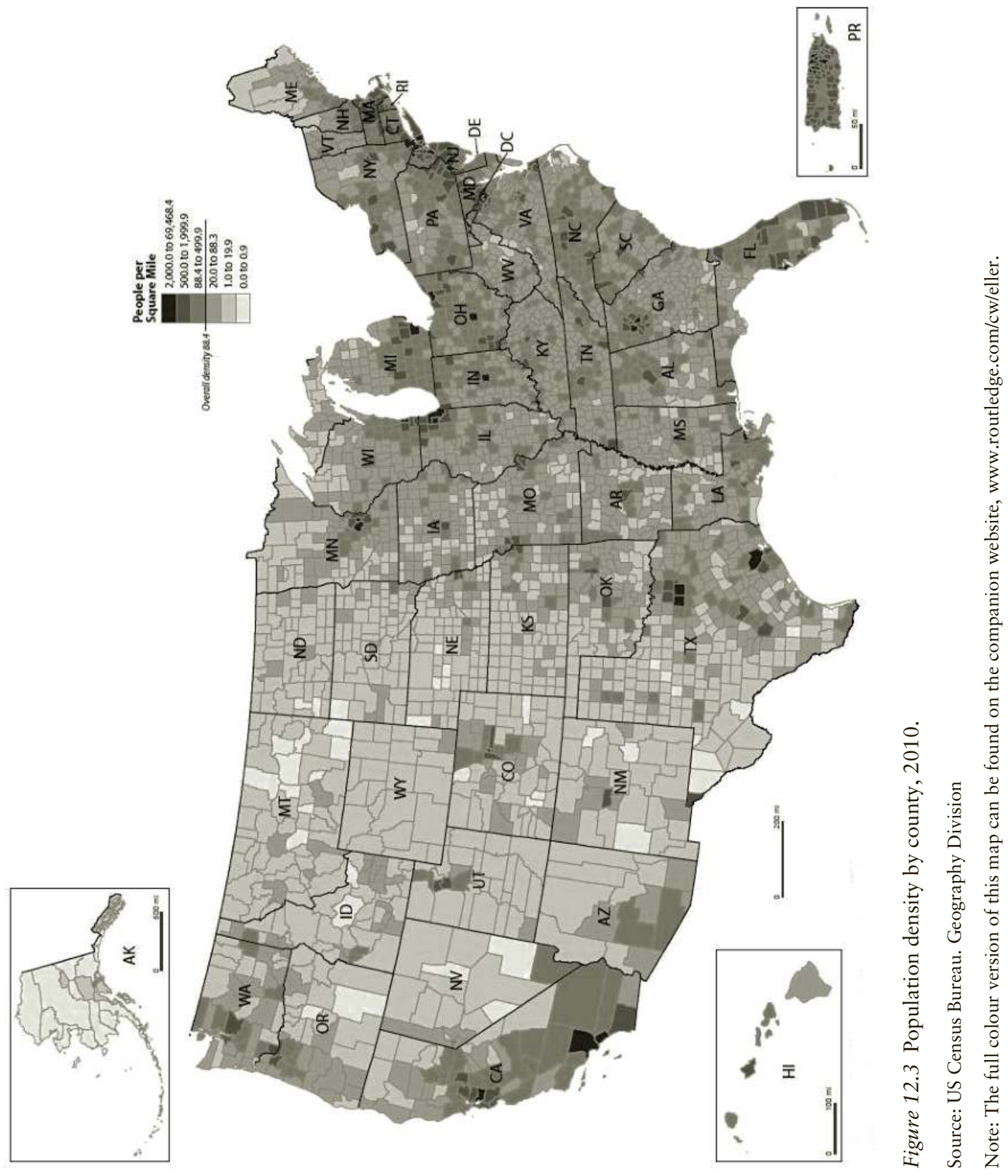




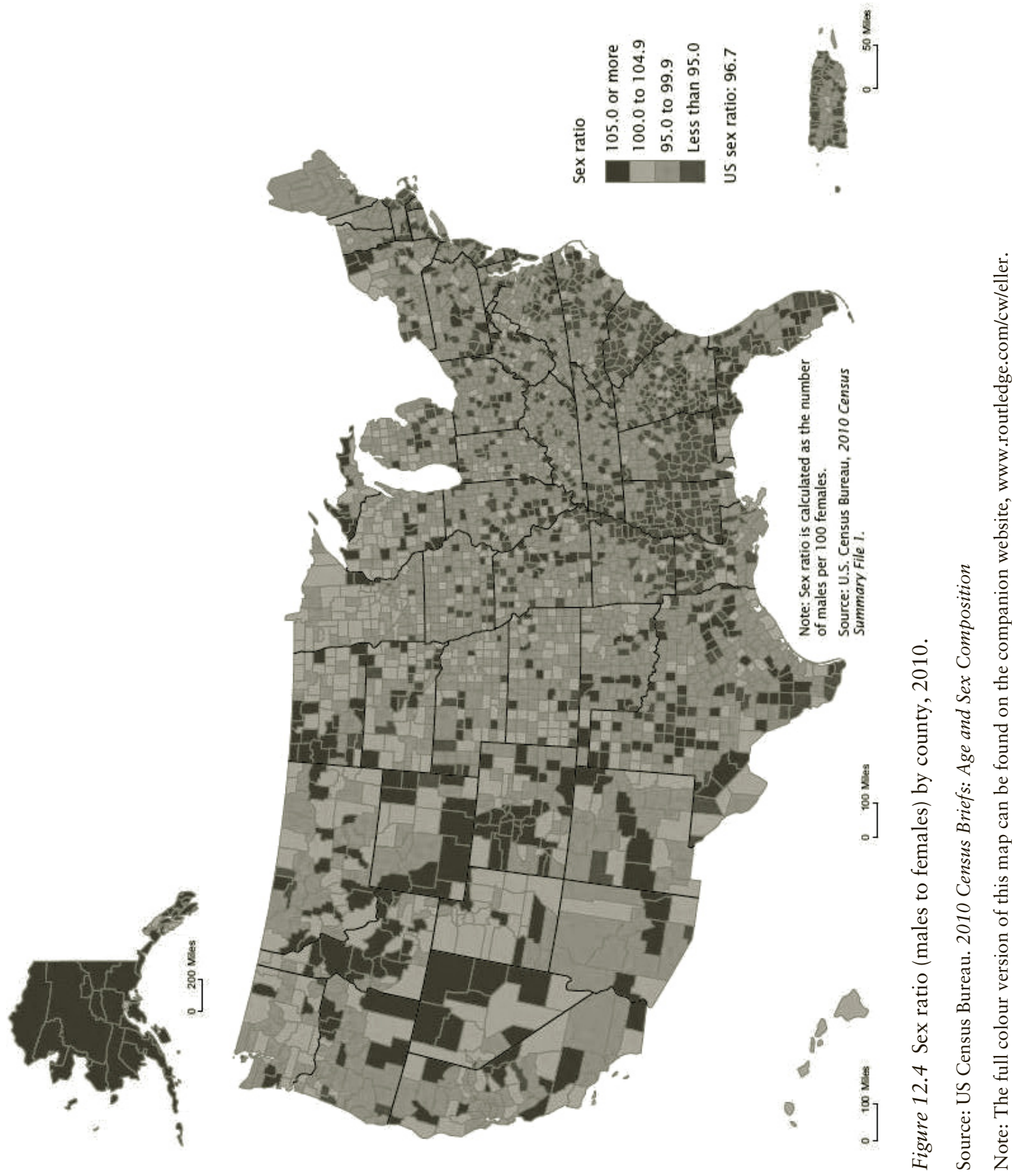


differences persist between them. But is that the only or most relevant way to sort American diversity regionally? What exactly are the "American places" to study? In fact, if the question does not sound insane, where exactly is America? Obviously, three hundred years ago there was no such place as the United States; then, there were only a few British colonies clinging to the eastern coastline, along with Spanish territories in the south and west, French colonies on the fringe of British ones, and vast expanses of Native American land.

It has already been noted that the units that we use to examine a geographic region have an influence on the results we get from our examination. At the national level, a certain statistical distribution of categories can be identified; however, at the regional or state or county or census tract level, other patterns appear. Further, as researchers agree, differences exist within areas (states, regions, etc.) just as commonalities link places across areas, and certainly the official or formal (e.g. political) boundaries on maps do not necessarily correspond to the contours of diversity across space.

Probably the most common way to organize macro-level diversity within the United States is in terms of four geographical regions-Northeast, Midwest, South, and West. We have used this system in previous chapters. This is a very blunt division, though, and the US Energy Information Administration has suggested a subtler division with two or more subregions within each region, as portrayed in Figure 12.5.

But social and cultural variables cross-cut these geographic areas too, as the electoral map at the outset of the chapter illustrates, and these social/cultural characteristics do

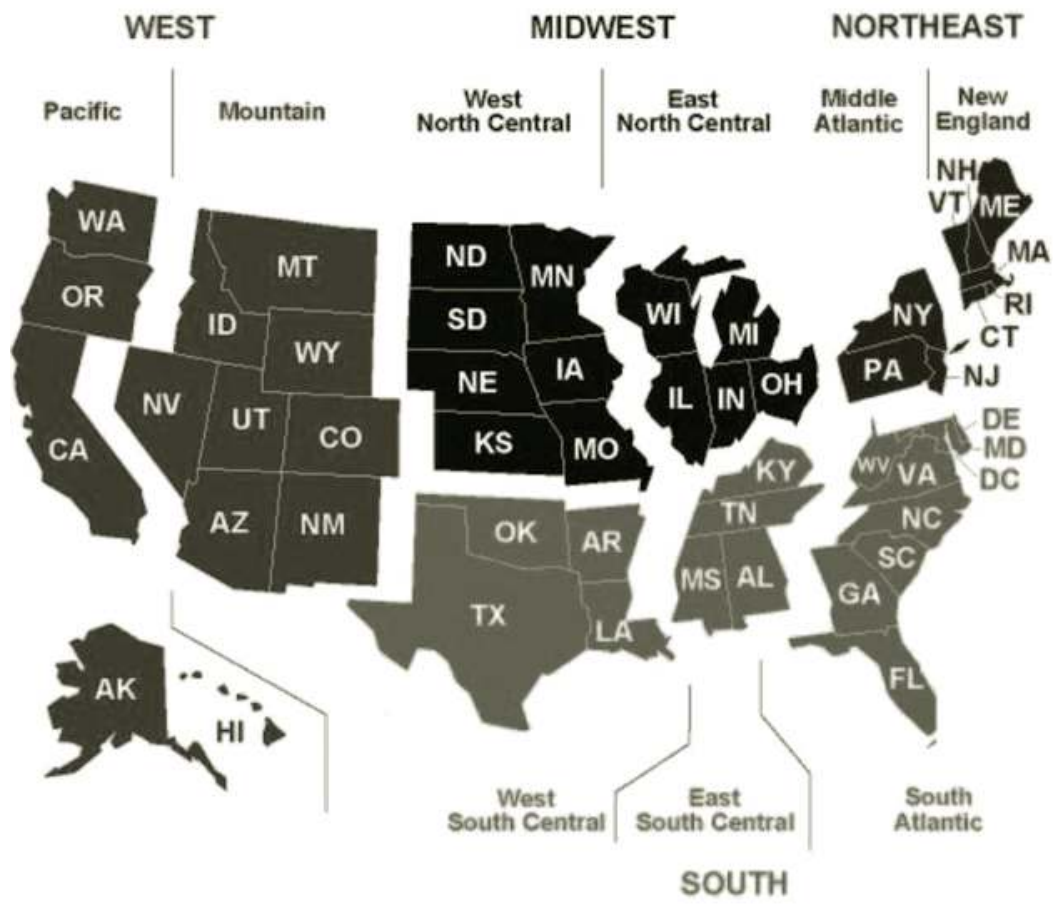

Figure 12.5 Regions and sub-regions in the United States.

Source: US Energy Information Administration

Note: The full colour version of this map can be found on the companion website, www. routledge.com/cw/eller. 
not necessarily respect international borders. This is why Joel Garreau proposed a model of regional diversity that treated all of North America as one great diversity system. "Forget about the borders dividing the United States, Canada, and Mexico, those pale barriers so thoroughly porous to money, immigrants, and ideas," he wrote (1981: 1). Additionally, forget about "East and West, North and South, faint echoes of glorious pasts that never really existed save in sanitized textbooks" and about "the maze of state and provincial boundaries, those historical accidents and surveyor's mistakes" (1). Instead, he offered a model of nine "nations" spread across three countries on one continent (see Figure 12.6), specifically:

1 New England, or the Yankee region of far northeastern US as well as northeastern Canada.

2 The Foundry, or the old industrial region of the US and Canada, from New York City and Philadelphia through Pittsburgh and Cleveland to Detroit and Chicago. More recently, this area has been dubbed the Rust Belt because of the decline of its factories and the abandonment of its cities.

3 Dixie, or most of the original Confederate South, comparatively rural and sharing the troubled history of slavery.

4 The Islands, or the Caribbean area including Cuba, Haiti, and parts of southern Florida.

5 Mexamerica, or the southwestern part of the US as well as, obviously, Mexico, with its strong Hispanic culture and its significant proportion (in some counties, majority) of Hispanic and Spanish-speaking people.

6 Ecotopia, or the strip of West and Northwest coast from southern California to Portland, Seattle, Vancouver, and south-coastal Alaska, renowned for its liberal and environmentally conscious culture.

7 The Empty Quarter, or the great swath of North America from the western Great Plains through the Rocky Mountains and the southwestern desert, up through Canada and Alaska. The quarter is hardly empty, though, as major cities such as Denver, Salt Lake City, and Las Vegas sit there.

8 The Breadbasket, or the fertile plains of the US and southern Canada that produce much of the countries' corn and wheat.

9 Quebec, or that North American anomaly of French-speakers on a predominantly English- and Spanish-speaking continent.

More recently, Joel Lieske constructed a model of "regional subcultures" based on the valid premise that "the peoples who settled the United States came with distinctive ethnoreligious identities, cultural preferences, and ways of life" and generally "settled in clusters, not as randomly dispersed individuals" (1993: 890). On the basis of dozens of categories over variables of race/ethnicity, religion, and social structure (urbanization, industrialization, mobility, education, occupation, income, and so on), he separated thirteen "factors" that accounted for most (68 percent) of the variation in the country. These factors, as described in his even more recent reassessment of the study (2010), include

1 Global, or the multiracial and multiethnic subculture associated with large cities.

2 Blackbelt, or African American subculture. 


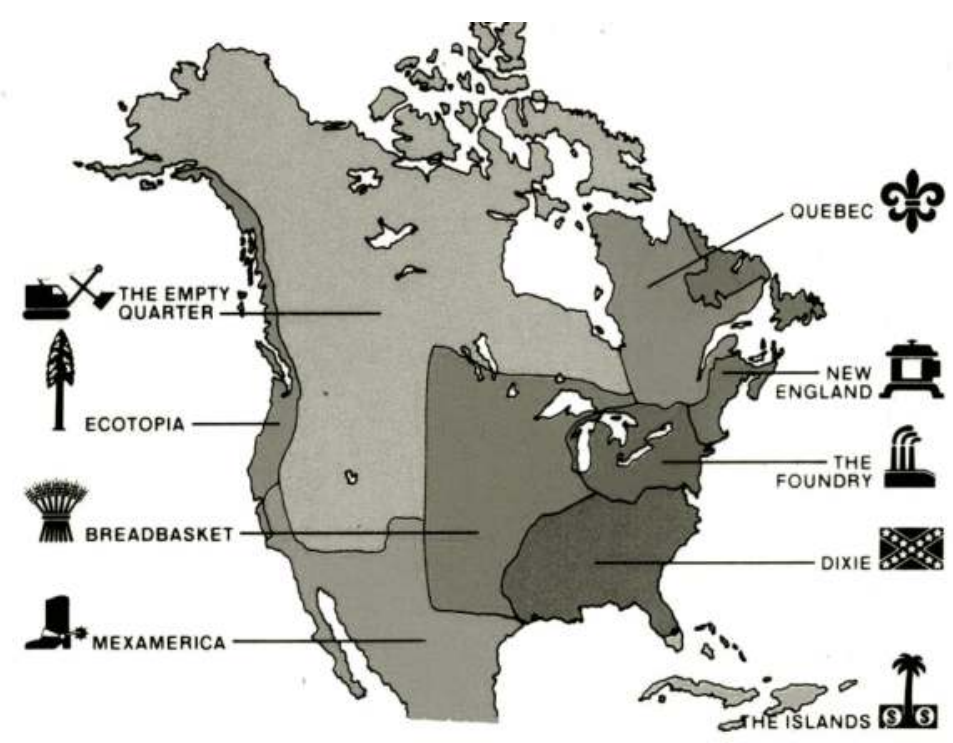

Figure 12.6 Garreau's nine nations of North America.

Courtesy of The Garreau Group

3 Rurban, or the newly emerging subculture of rural-urban places, where young educated (often high-tech employed) people or, alternatively, retired people settle.

4 Nordic, or the subculture of Germanic and Scandinavian settlers.

5 Nonethnic, or the subculture of white Americans who do not identify with an ethnic ancestry (see Chapter 4).

6 Germanic, or the subculture of Prussian Lutherans.

7 Latino.

8 Border, or the subculture of Southern Baptists and Churches of Christ, notably conservative.

9 Anglo-French.

10 Heartland, or the subculture of Northern mainstream Baptists, Methodists, and nondenominational Christians.

11 Native American.

12 Dutch, or the subculture of New York and Pennsylvania Dutch, including Amish.

13 Mormon.

Lieske argues that 3,000 of America's counties can be classified into eleven "relatively homogeneous clusters or subcultures." Notice that these subcultures somewhat overlap Garreau's nine nations but are intermixed in more complicated ways.

\section{Geographic Mobility in the United States}

Sociologists, demographers, and human geographers also agree that, in addition to emplacement, we must consider mobility as one of the key characteristics of the social 


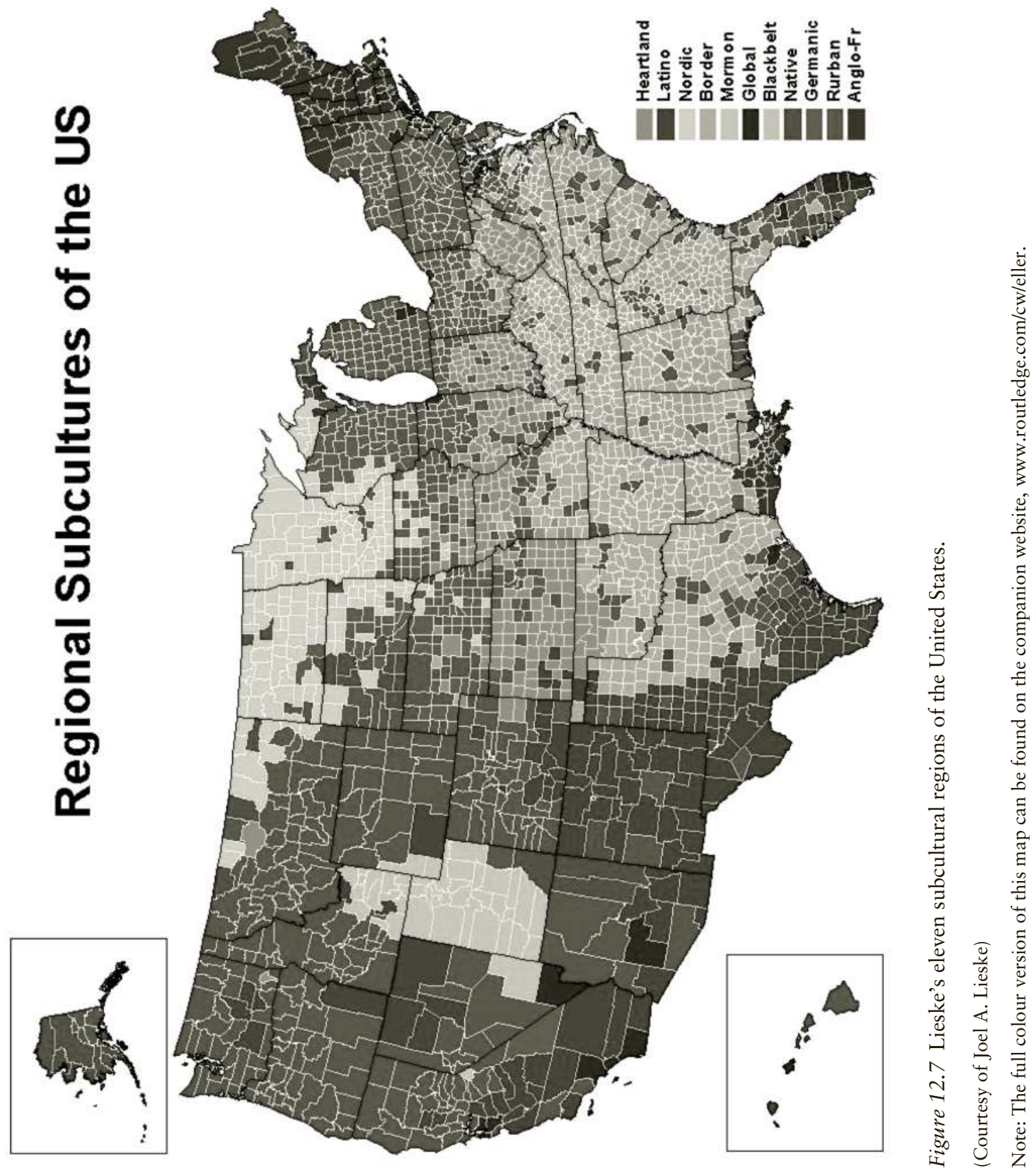




\section{4}

The Spatial Distribution of Diversity

use of space. Americans have always been a mobile people; the first non-Native settlers had to travel great distances to arrive on American soil, and Americans trekked over centuries across the continent to occupy its every corner. One of the most formative modern migrations, as discussed in Chapter 3, was the so-called Great Migration of African Americans from the South to the Northeast and Midwest, providing a classic case of Park's succession: places formerly occupied by whites or other ethnic groups were taken over by blacks, completely changing the racial and institutional nature of those places. In tandem with African American in-migration to Northern and Midwestern cities was an out-migration of middle-class whites to that new place called "the suburbs," again reshaping American space.

Throughout the twentieth century, Americans continued to be geographically mobile, often reflecting their social mobility: as people achieved economic success, they moved to new neighborhoods. On the other hand, in bad economic times, people either moved to survive or, as in the latest recession, lost much of their mobility because they were unable to sell their homes or find jobs. Accordingly, fewer people moved in 2007-8 than at any time since 1962, when, of course, the population was much smaller. The US Census reported that the mobility rate in 2008 was 11.9 percent, the lowest since World War II, and longer-distance moves (i.e. out of state) dropped to half the rate of the year 2000.

In the second decade of the twenty-first century, as the economy and the housing market recover, Americans are mobile, although most residential moves are short-distance (within the same county), with many fewer moving to a different county within the same state, to a different state, or even out of the country altogether (see Table 12.1).

According to the US Census the Americans most likely to move between 2011 and 2012 were young people, in their twenties, and they were also the most likely to move out of their original region. In terms of education, high school graduates and those with some college education were most likely to move but mostly within the same county. Never-married individuals were by far the most likely to move and to leave the country. Not surprisingly, renters were almost three times as likely to move as homeowners, and people below the poverty line were only half as likely to move as those with incomes more than 150 percent of the poverty line.

Despite the fact that Americans in general are on the move, Americans do not move equally between all American places. Figure 12.8 illustrates that some places enjoy greater in-migration than others, particularly parts of the South and West, while other places have actually seen a net loss of population, especially the Northeast and Midwest, Garreau's old "Foundry" or the declining Rust Belt.

Table 12.1 Mobility of American population by distance moved, 2012 to 2013

\begin{tabular}{lc}
\hline Distance of move & Number of people \\
\hline Within same county & $23,150,000$ \\
Within same state & $6,961,000$ \\
Within same region & $1,311,000$ \\
To different region & $2,447,000$ \\
Out of country & $1,036,000$ \\
No move & $271,325,000$ \\
\hline
\end{tabular}

Source: US Census Bureau. Geographical Mobility: 2012 to 2013 


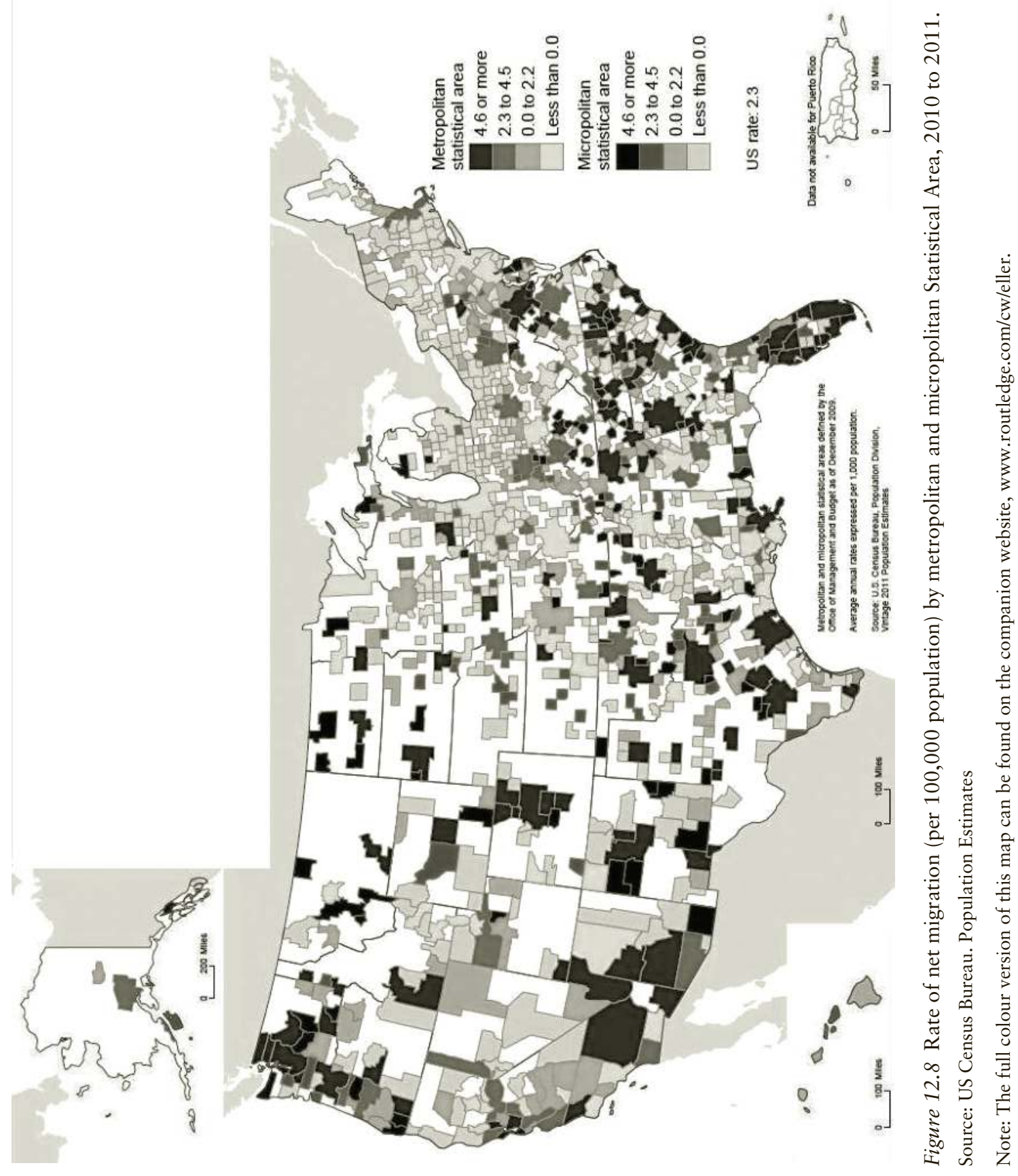


Finally, Figure 12.9 shows that Americans' reasons for geographical mobility have varied somewhat over the past decade but have remained relatively stable. Housing issues have long been a main motivator, especially in 2011-12, and job-related issues became a bigger reason for moving between 2006 and 2008.

Another interesting and revealing way to think about American mobility is in terms of immigration. Immigrants continue to stream into the United States, but their places of origin have shifted, from mostly European countries to mostly Hispanic and Asian countries. More fascinating, and perhaps troubling, is the news about Chinese immigration. America has long been a magnet to Chinese immigrants, who often settled in ethnic enclaves or "Chinatowns," some of which are particularly historic, like San Francisco's Chinatown. However, with the economic problems in the United States, and the economic growth of China, there is less attraction in America for Chinese citizens. We mentioned in Chapter 4 the decline in Chinese immigration. Even more dramatically, more than a few long-time Chinese residents of the United States have decided to return to China. This dwindling of Chinese immigration, together with the reversal of immigration flow, "all but ensures the end of Chinatowns" (Tsui 2011: 18). Hence we see another case of spatial succession.

\section{Spatial Dimension of Race and Ethnicity Diversity}

Chapters 3 and 4 discussed America's racial and ethnic composition, but for the most part the spatial distribution of race and ethnic groups was not considered. That is,

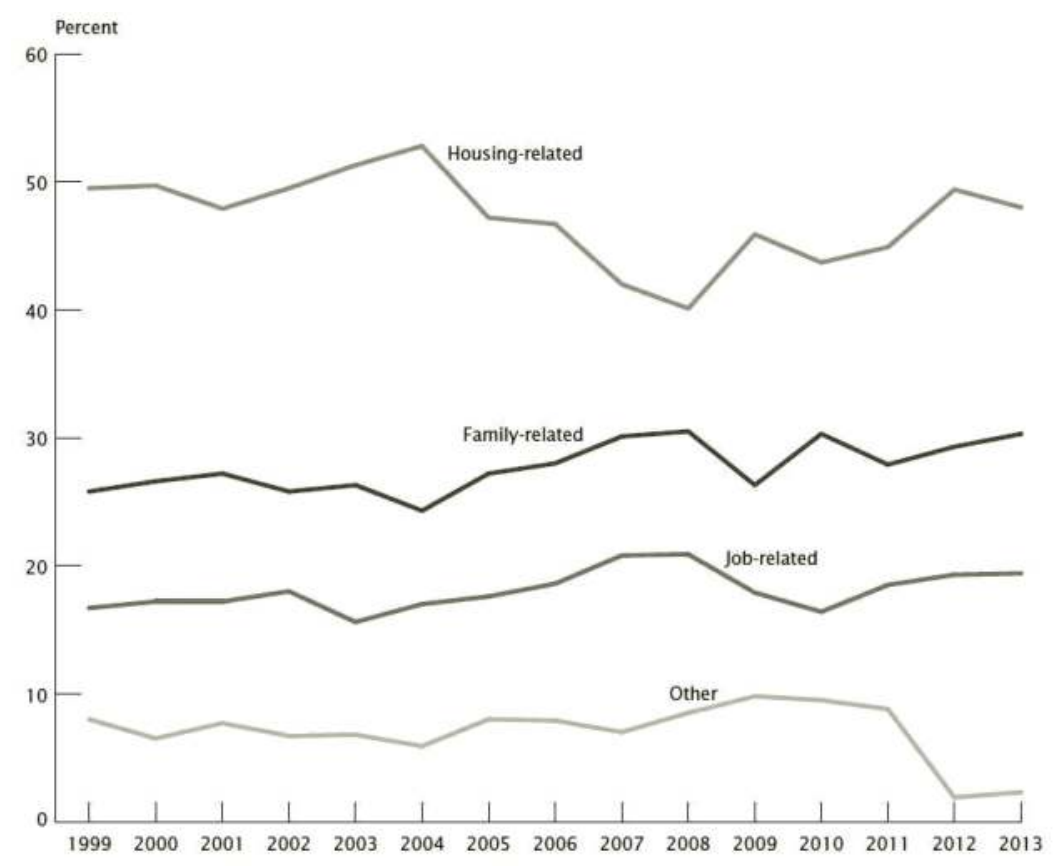

Figure 12.9 Reasons for moving, 1999 to 2013.

Source: US Census Bureau. Population Characteristics: Reasons for Moving, 2012 to 2013 
the American population as a whole may be 12.6 percent African American and 16.3 percent Hispanic, but this hardly means that every place in the country has precisely those percentages of black or Latino citizens. In some places the percentages are much higher, in others much lower, and we can see the racial clustering in America quite clearly on maps like Figures 12.10 and 12.11.

The distribution of race and ethnic groups in the United States naturally corresponds to historical and contemporary forces. For example, the high proportion of African Americans in the South and in specific urban locations is an effect of Southern slavery and then the already mentioned migration north beginning around the turn of the twentieth century. Because of slavery, the black population of southern colonies was much greater than that of northern colonies. According to a 1970 publication of "Historical Statistics of the United States," on the eve of the Civil War in 1860 , the population of the South included 8 million white people, almost 4 million black slaves, and a quarter-million free non-whites, making the region approximately one-third black. The enslaved and free black population of Georgia $(465,000)$ almost equaled the white population $(592,000)$. However, Marian Borg made an apt observation about this population concentration: "in the South, close physical interaction between Blacks and Whites has not been unusual" and indeed has been quite common, while the very scarcity of African Americans in the North until recently means that white Northerners "have been more averse to interacting closely with Black people in private spheres," which is evinced in "neighborhood segregation in urban areas" (1997: 40).

As Southern blacks migrated north, they increasingly found themselves in predominantly black (and poor) neighborhoods of cities. By the mid-1900s African Americans, especially in urban centers, "faced a near-apartheid situation of persistent high segregation, barely responsive to improvements in black socioeconomic standing" (Logan 2013: 160). In fact, rather than permitting spatial integration, American laws and practices virtually guaranteed residential segregation, from "redlining" or discouraging blacks from buying houses in certain neighborhoods, to policies of clearing ethnic slums and relocating people in high-concentration racially-segregated public housing (see the case of Pruitt-Igoe in Box 12.2 below).

John Logan finds that black/white segregation reached a high point in the $1960 \mathrm{~s}$ and that, despite improvement in the ensuing decades, racial spaces still show enduring separation. For instance, the fifty-nine census tracts with the largest percentage of African Americans are home to over one-third (36.2 percent) of the entire black American population but only 1 percent of the white population. On the other hand, there are forty-eight census tracts with 99 percent white population (163). Hispanics and Asian Americans suffer from much less segregation, yet Logan concludes that as each of these groups increases in number "it becomes more isolated (that is, group members are more likely to live in a residential enclave) and group members live in census tracts with much smaller shares of white neighbors" (163). The good news is the emergence of "global neighborhoods" or multiracial and multiethnic spaces: half of Asians, almost half (44 percent) of whites, and over one-third (35-6 percent) of blacks and Hispanics lived in such mixed places in 2010 (164).

In a 2012 study for the Manhattan Institute, Edward Glaesner and Jacob Vigdor found that racial segregation had declined in many major cities such as New York, 


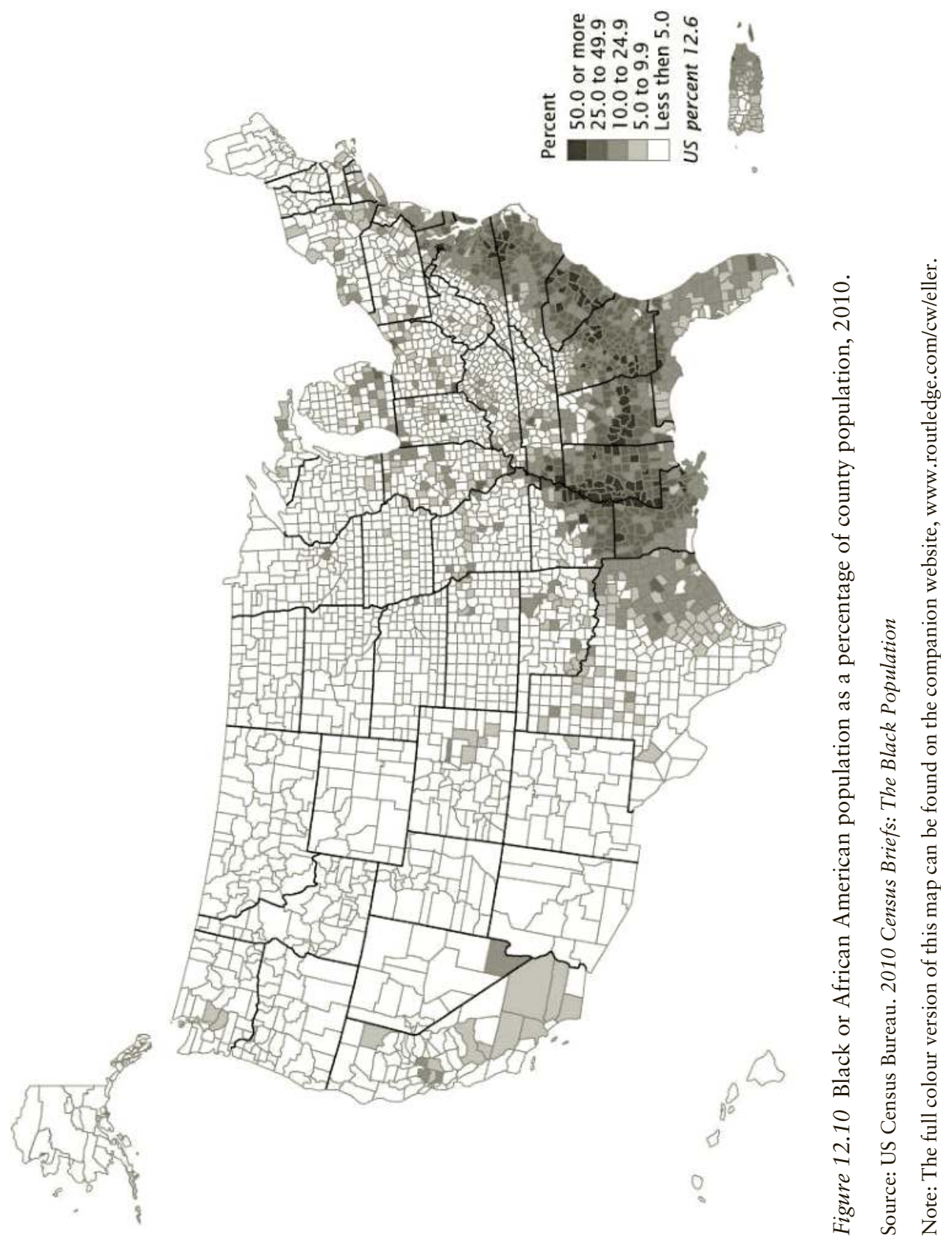




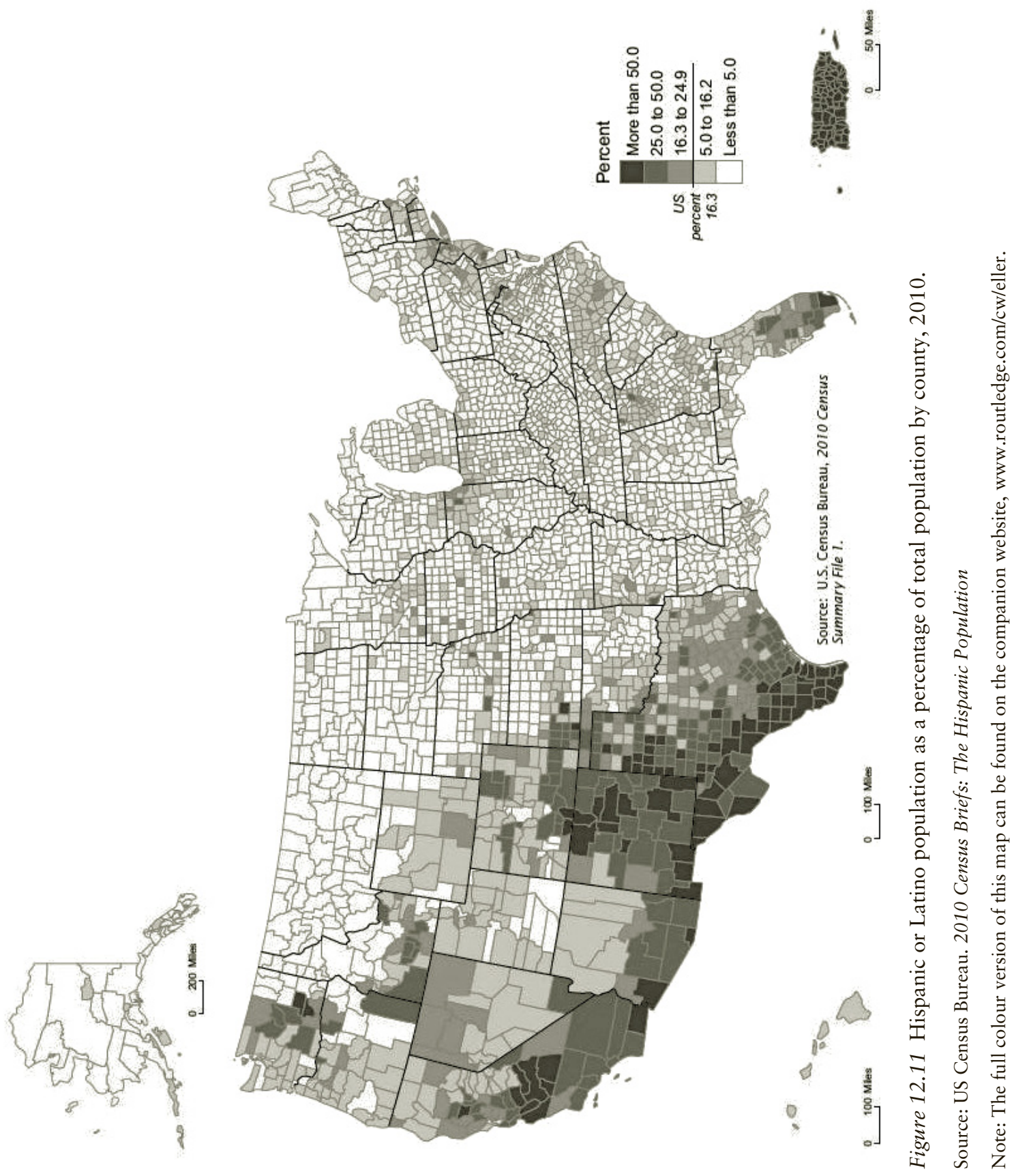


Los Angeles, Chicago, Philadelphia, and Boston. Disappointingly, it had actually increased in some locations, including Boise, Portland (Maine), Ann Arbor (Michigan), and Greeley (Colorado). And while there were few (424 to be precise) census tracts with no black residents, yet the "average African American lives in a neighborhood where the share of population that is black exceeds the metropolitan average by roughly 30 percentage points" (2012: 4). The problem is highlighted by a closer inspection of Chicago, where, according to the 2009 American Community Survey, the community of Edison Park registered 93.6 percent white, 3.7 percent Hispanic, 1.7 percent Asian, and an unbelievable 0.0 percent black, whereas West Garfield Park was 95.6 percent black, Hermosa was 85 percent Hispanic, and Armour Square was 67.9 percent Asian.

Finally, one of the most interesting spatial changes has been the growth of nonwhite populations in rural America. Daniel Lichter reminds us that, although Americans often imagine rural America as overwhelmingly white, in actuality it "has been home throughout its history to large numbers of racial and ethnic minorities" who "are often geographically and socially isolated from mainstream America and easily forgotten or ignored" (2012: 4). Hispanics, he calculates, provided more than half (56 percent) of non-urban population growth between 2000 and 2010, and Hispanics are often highly concentrated even in non-metropolitan locations: in both the Midwest and the South, half of all Hispanic population growth occurred in only a small handful of counties, often where employers in agriculture or meatpacking seek immigrant laborers. Two last points are worth mentioning. First, the demographic shift in rural America is a result of a combination of non-white in-migration and white out-migration, as younger whites leave rural areas. Second, contrary to the assumption that this ethnic transformation is destroying rural America, Lichter argues that most studies have shown "few large negative effects on local communities overall" (18) and actually highly positive effects in some cases, reversing population declines and bringing economic vibrancy to stagnant economies. Indeed, Lichter indicates that "white elderly and young Hispanic workers are entering into a new synergetic relationship that is driving economic development and community change" (21).

\section{Spatial Dimension of Class Diversity}

America's income, jobs, and poverty are distributed unevenly through the population, both in terms of key social variables such as race, ethnicity, language, and gender and in terms of space. In ways, these two factors interact, as many key social variables are themselves spatially distributed (as just acknowledged, racial and ethnic groups are often concentrated spatially and disadvantaged economically. Figures 12.12 and 12.13 illustrate this geographical diversity of income and poverty.

Naturally, these two maps are almost mirror images of one another: the areas of high income (especially the Northeast urban corridor and parts of the Rocky Mountain region) are also the areas of the lowest poverty. However, at a finer level of analysis, we would find pockets of poverty inside otherwise rich and highincome cities. 

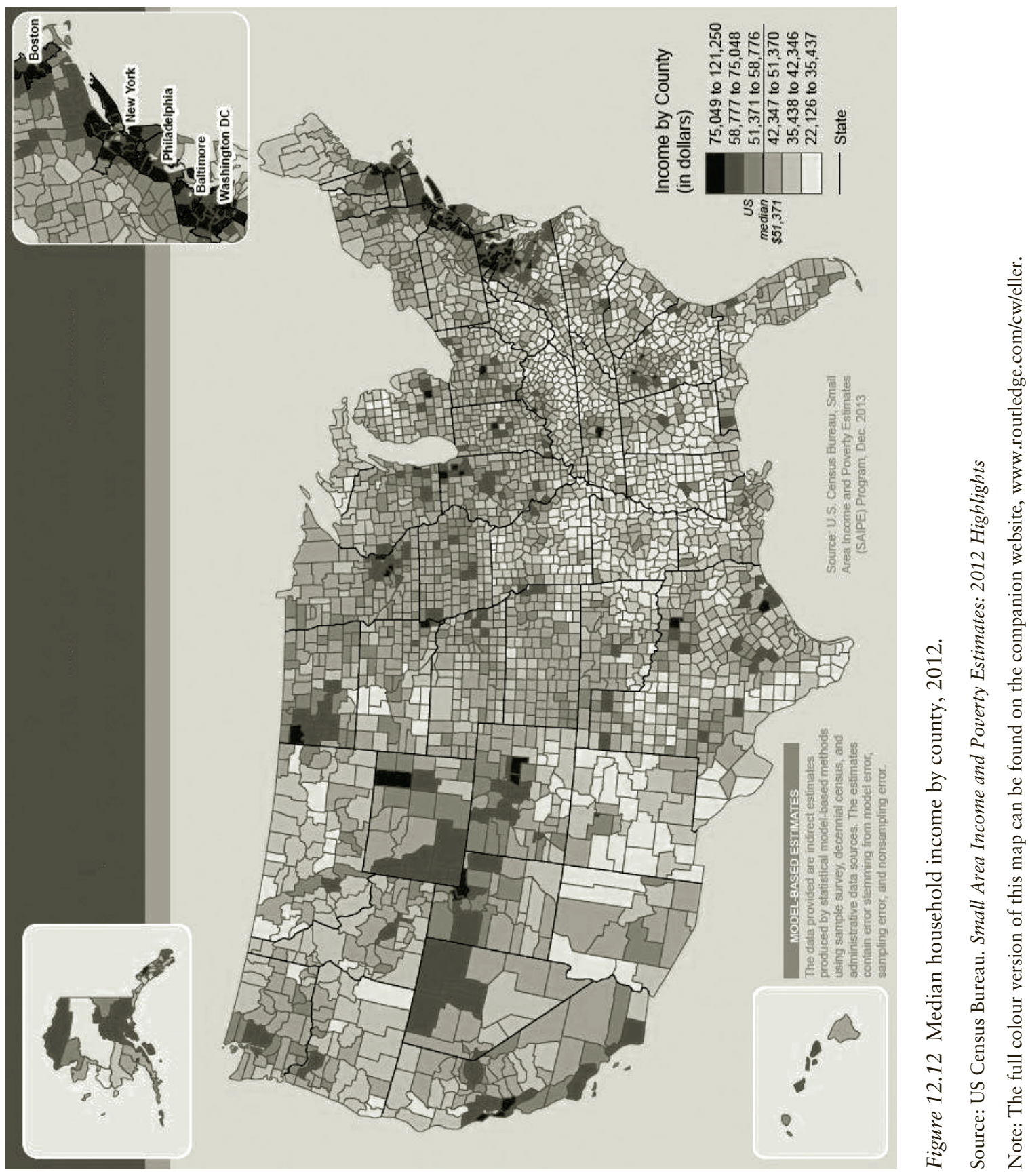


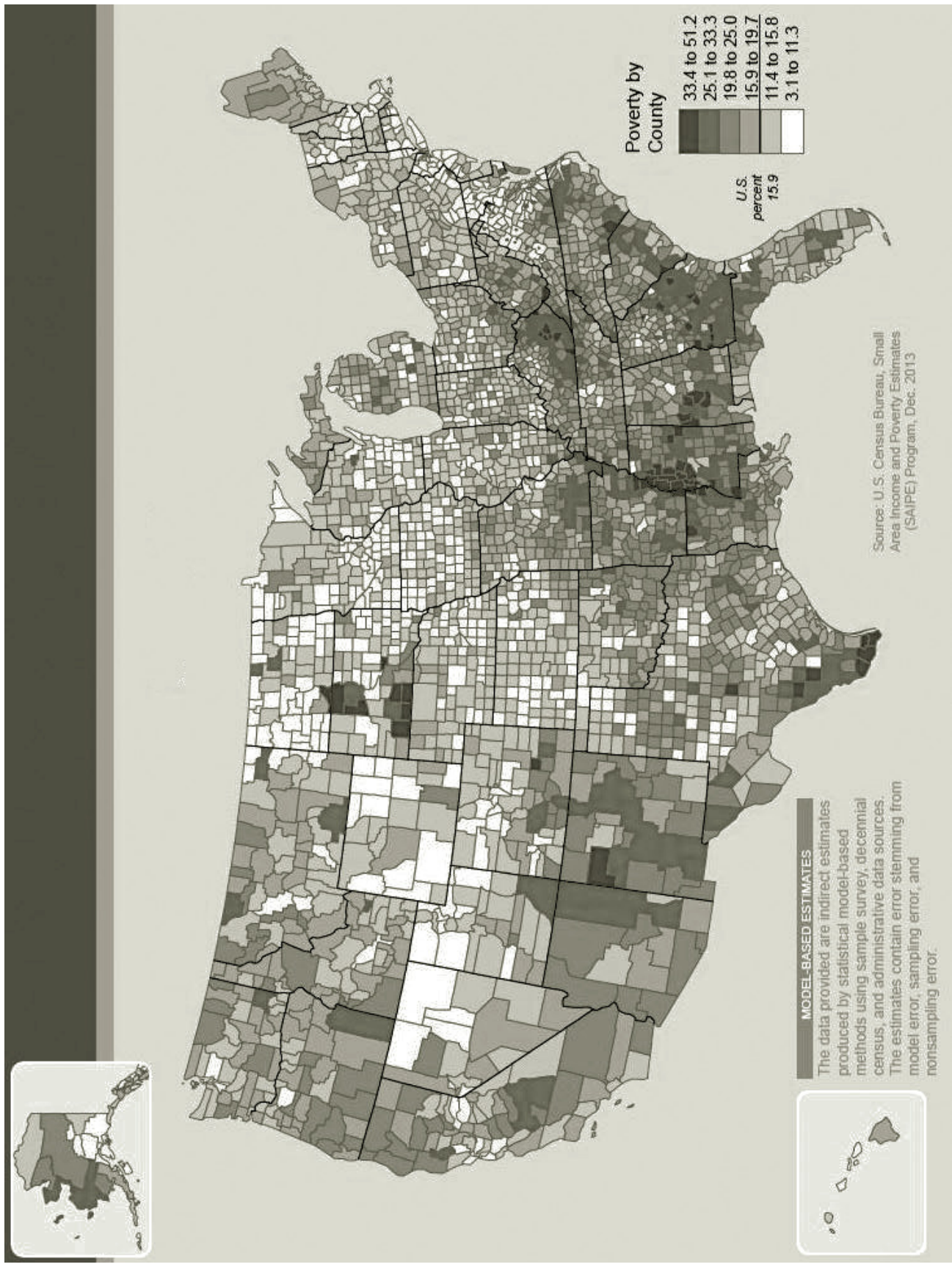

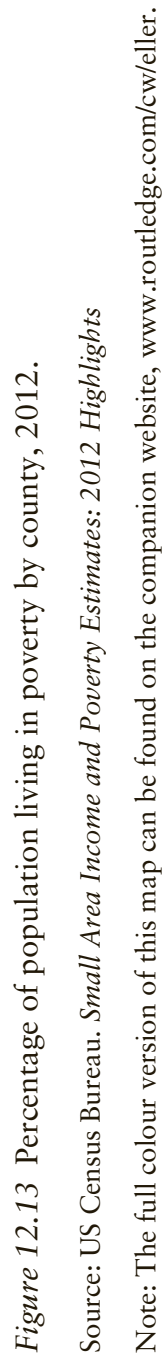




\section{Diversity Fact:}

According to Forbes.com, the richest county in America (as measured by median household income) is Loudoun County, Virginia $(\$ 117,481)$, followed by Falls Church City, Virginia; Los Alamos County, New Mexico; Fairfax County, Virginia; Hunterdon County, New Jersey; Howard County, Maryland; Arlington County, Virginia; and Douglas County, Colorado. Note that several of these places are in the environs of Washington, DC. The poorest counties (as measured by poverty rate) are located in quite other parts of the country, with Ziebach County, South Dakota sitting at 50.1 percent poverty. Close behind are Todd County, South Dakota; Shannon County, South Dakota; Issaquena County, Mississippi; Humphreys County, Mississippi; and Washington County, Mississippi. The remaining bottom fifteen counties are all in the South, except for one in North Dakota and one in South Dakota. The poor South Dakota counties are mostly on or near Native American reservations.

Daniel Lichter and Kenneth Johnson have made not only the obvious observation that poverty in America "tends to be spatially concentrated" but also noted that "concentrated and persistent poverty has historically been highest in America's most remote rural areas" (2007: 333). Like other researchers, they have identified a "double disadvantage" for the rural poor, combining low incomes with physical remoteness and isolation, inadequate infrastructure (housing, drinking water, roads, electricity, and such), and a lack of social services like education and health care. The rural poor, they add, "are more likely to be exposed to environmental toxins (e.g. agricultural chemicals) and work-place injuries" (333). Paul Voss et al. call this latter problem "place poverty" as opposed to "people poverty," that is, the sources of poverty are not in the poor people themselves but in the nature and structure of their living environment, with "urban economic dislocations, faltering regional economies, high unemployment, poor and often disorganized local employment opportunity structures-all forces over which the individual has little or no control" (2006: 371).

Not surprisingly, Lichter and Johnson find that almost 20 percent of non-metropolitan counties in 2000 had a poverty rate of 20 percent or more, far ahead of the national average; worse, the twelve counties with poverty rates over 40 percent were all nonmetropolitan. The overall poverty rate in 2000 for metropolitan places was 11.9 percent, compared to 14.8 percent for non-metropolitan places. They also make the interesting comment that poverty may be exacerbated less by the sheer physical concentration of poor people and more by the spatial separation of the poor from the non-poor.

Despite the fact that it is easy to relate poverty to the urban/rural dichotomy, such terms as "rural" and "urban" are blunt tools for representing the details of class today, since the simple urban/rural distinction "may have been appropriate in the era of industrialization, but it fails to capture contemporary urban-rural structure" (Wang et al. 2012: 564). It is crucial to realize that economic and residential patterns have blurred the lines between urban and rural places (564), calling for new ways of thinking about American space. Wang et al. mention emerging concepts for describing places. One is the Rural Urban Density Code (RUDC), which classifies places as rural, mixed rural, mixed 
urban, or urban. Another is the Rural Urban Continuum Code (RUCC), which offers a gradient of nine categories of metropolitan and non-metropolitan sites. The results of these alternate categorizations are significant. First, using the RUDC gives us a less urban America than we usually think. Second, the RUCC allows us to make finer associations between poverty and place, indicating that small metropolitan counties have higher poverty rates than large or medium metropolitan counties. Likewise, the RUDC shows that mixed rural counties have less poverty than rural ones but higher poverty than urban ones. Finally, the RUDC suggests that poverty disparities are influenced by a few counties with atypical poverty rates. On this analysis, some of the mixed rural counties with high poverty rates are actually not in the South but in upstate New York, in the vicinity of Buffalo, Rochester, Syracuse, and Utica-Rome (Wang et al. 2012: 578).

One last point is worth our attention. David Peters distinguishes between poverty and inequality, with surprising results. Places with high or extreme inequality, he argues, are found in large cities and regions of the Great Plains and Rocky Mountains. Unexpectedly, places of inequality "have better socioeconomic outcomes, with fewer at-risk populations, higher incomes, lower poverty, and greater economic participation" (2013: 1490). It is places characterized by equality that "are associated with low-skill services, education, and health services, manufacturing, and stable farm economies" (1490). We may interpret this data as the presence of high-income households in the unequal places, compared to the absence of such households in the equal places; in other words, equal places must be places where everyone is equally poor. Peters further explains that extreme inequality is highly clustered in a few (45) counties, with high inequality only somewhat less concentrated (to 358 counties). The places of persistent equality are also clustered (502 counties). This means that "national inequality rates in the United States may be driven by these few counties" (1496). In closing, he also mentions that places of inequality are found in both rural and urban environments but relatively not in the South (again, indicating widespread poverty) and that unequal places tend to have more non-white populations.

\section{Box 12.2 The Rise and Fall of an American Place: Pruitt-Igoe}

Race, class, crime, and the long-term history of American place, especially urban place, converge in the St. Louis housing project known as Pruitt-Igoe. The 1940s and 1950s were a boom time for the American economy and American cities; at the same time, urban residents and city politicians and planners were troubled about the concentration of poverty and blighted neighborhoods in the country's great cities. With the 1949 Housing Act, the federal government began to provide funds for the redevelopment of rundown areas ("urban renewal"), based on a vision of engineering place by demolishing poor neighborhoods and replacing them with modern (usually dense high-rise) public housing. St. Louis was one of many targets for such planning, and in 1952 the Pruitt-Igoe project was seen as the path to a bright future for the city. Unfortunately, many factors interacted to doom the project. For one, St. Louis, like other once-booming cities, reached its population zenith in the 1950 s (at over 850,000 people) and then began to decline. This decline was totally unexpected. By 1990, St. Louis had less than half of its peak population. Also, while poor people of all races were welcome 
at Pruitt-Igoe, it was African Americans who made up the bulk of its residents, and for some people Pruitt-Igoe and other similar projects around the country were seen as ways to concentrate and isolate blacks in specific neighborhoods and keep them out of suburbs and the newly gentrifying downtown. Critics went so far as to condemn public housing as a means of hypersegregation. But these were not the only problems. The decline of the city's population meant that more low-cost private housing became available, so those with the means departed Pruitt-Igoe, leaving behind only the poorest of the poor. Perverse welfare policies required men to stay away from their families in order for those families to qualify for aid and reduced rent; a subculture of mothers and children without men developed in the projects. Then there was the problem of maintenance: the city and the federal government did not allocate money for upkeep and security, so the buildings began to deteriorate. Soon, youths were vandalizing their own buildings, and drug dealers arrived. Crime and violence became rampant, and a once-happy neighborhood became a place of danger and fear. In a way, the entire neighborhood of Pruitt-Igoe became a non-place, even a Foucauldian heterotopia, holding up a mirror to society. In 1972, only twenty years after their construction, three of the original towers of Pruitt-Igoe were imploded, and by 1976 the entire site had been cleared. Today, what was once a hopeful place is an abandoned field, part of the emptying of American urban space.

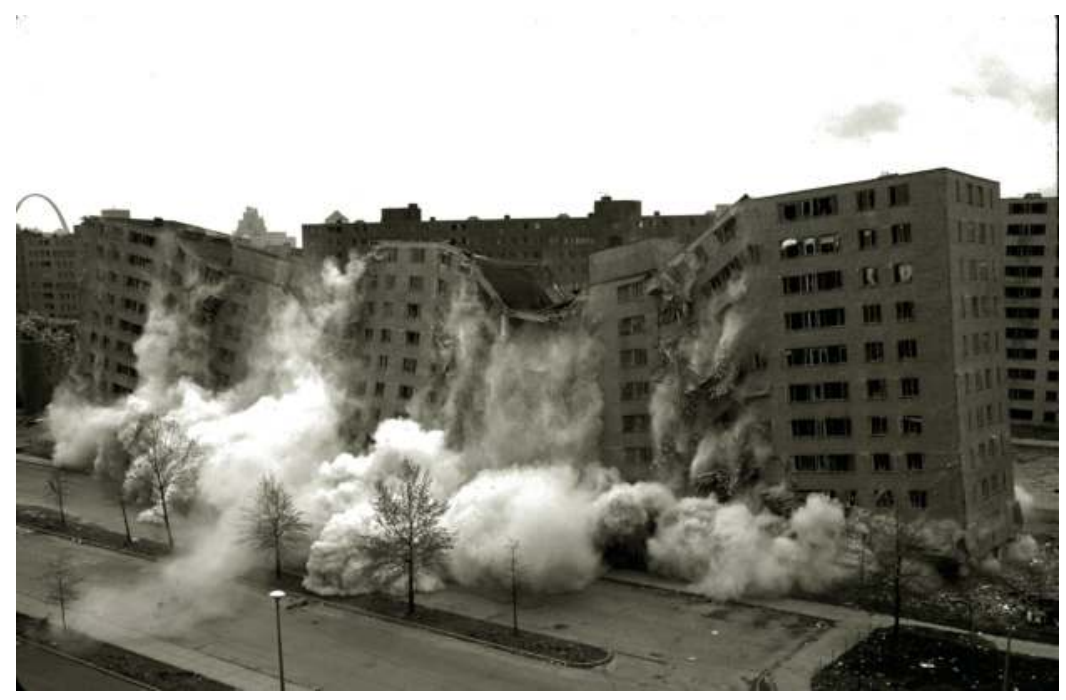

Image 12.4 Pruitt-Igoe housing project being demolished, 1972.

(Courtesy of Lee Balterman/The LIFE Images Collection/Getty Images)

\section{Spatial Dimension of Crime Disparities}

One of the social issues to which the spatial perspective has been applied most consistently and most profitably is crime. Law enforcement officials have long known that crime is spatially concentrated and closely related to place; one example is broken 
windows theory, which holds that crime is attracted to areas that are already experiencing general physical decay-literally, where the windows have been broken out, where houses have been abandoned or allowed to deteriorate, and where physical and social order is evident.

In a word, "Crime is not random" (Brantingham et al. 2005: 3667), and criminologists can and do take the same kind of ecological approach as urban sociologists like Robert Park have taken. Brantingham et al. assert that the ecology of crime "consists of four dimensions-the law, the offender, the target, and the place," so "there is a definite patterning in the temporal and spatial characteristics of crime," not the least of which is that offenders and victims understandably meet in the places where both spend most of their time (3667), including the "activity spaces" of "home, work, and recreation" and the "pathways" that connect them (3668).

In 1954 Lyle Shannon documented the fact that crime rates vary by region of the country. Murder rates, for instance, were highest in the Southeast and lowest in the Northeast and Midwest. Assault too was correlated with the South. The property crime of larceny or theft was concentrated in the West and Rocky Mountain regions, with "lower rates extending eastward to another moderately high rate area, an area running from the South Atlantic states up to Michigan in the East North Central section"; the lower incidence of larceny was found in the Northeast (1954: 270-1). These crime profiles have been very steady over time, up to the latest data, for the year 2011, as presented in Table 12.2.

The persistent violence, and apparent toleration of violence, in the South has been attributed by many scholars and historians to the history of slavery and race relations in the South, as well as to a "culture of honor" that makes self-defense and violent retaliation normal — what has sometimes been called the "Southern subculture of punitiveness." To test this notion, Larry Baron, Murray Straus, and David Jaffee devised a couple of scales-the Legitimate Violence Index and the Violence Approval Index-both of which were "intended to measure cultural support for legitimate violence" (1988: 84). Based on their measures, support for violence was highest in the South and the northern Rocky Mountains, with Wyoming and Montana scoring highest, followed by Mississippi, Utah, Idaho, Georgia, Nevada, and Arkansas, in that order. The lowest support for legitimate violence was found in Rhode Island, followed by Massachusetts, New Jersey, Maryland, and New York.

As with the other topics discussed in this chapter, we desire a finer-grained analysis than the state or regional level. FBI statistics, for instance, indicate that violent crime is more common in metropolitan areas $(428.3$ per 100,000$)$ than in cities outside

Table 12.2 Crime rates by region, 2011

\begin{tabular}{lll}
\hline Region & $\begin{array}{l}\text { Violent crimes per } \\
100,000 \text { inhabitants }\end{array}$ & $\begin{array}{l}\text { Property crimes per } \\
100,000 \text { inhabitants }\end{array}$ \\
\hline South & 428.8 & $3,370.8$ \\
Midwest & 349.9 & $2,844.3$ \\
West & 378.0 & $2,831.5$ \\
Northeast & 352.1 & $2,121.8$ \\
\hline
\end{tabular}

Source: Criminal Justice Information Services Division, Federal Bureau of Investigation 
metropolitan areas (399.7) or in non-urban counties (195.1). That is predictable and almost stereotypical. On the other hand, if we consider specific crimes like rape, the rate is actually higher in cities outside metropolitan areas (41.6) than in metropolitan areas themselves (27.0), and the latter is only a bit higher than in rural counties (22.0). Property crimes like burglary showed the same pattern-high in metropolitan cities but highest in non-metropolitan cities and lowest in rural counties.

At an even more local level of analysis, the American Community Survey calculated homicide rates for specific neighborhoods in Chicago, finding that some communities, like Lincoln Park and Hyde Park, enjoyed very low murder rates (Hyde Park experiences less than one homicide per year), while areas such as Austin (with 450 murders in one year), Garfield Park, and Greater Grand Crossing had disturbingly high murder rates. Homicide rate was closely correlated with race-very low in white neighborhoods, very high in black ones-as well as with education and income. All of these social variables converged in a deadly way.

Determining exactly what it is about certain places that encourages or deters crime has been a main concern of criminologists and law enforcement authorities. Yves Zenou, in a paper explicitly titled "The Spatial Aspects of Crime," likens crime to a disease with transmission vectors, two of which are peer models and local access to jobs. In a word, people commit crimes if others around them are doing so, and the absence of jobs in a place makes crime more likely. He contends that the facts show that "modest improvements in the job accessibility of male youth . . cause marked reductions in crime” (2003: 466). Gregory DeAngelo (2012) applies an ecological approach to an unnamed Northeastern city, describing how criminals compete for limited resources and target certain victims or neighborhoods, particularly high-density residential areas like communities near a college. Further, considering suburban crime, Marilyn Brown stressed the "friction of distance" (1982: 249) that underlies the location of crimes. Interestingly, violent crimes are less likely to occur far from the offender's home area than property crimes. Violent crimes like murder or assault tend to happen within the perpetrator's community, whereas perpetrators are willing to travel to other communities to commit theft or burglary, and "the higher the value of the potential booty, the longer the journey is likely to be" (249).

Finally, in understanding the disparity between crime rates in urban and rural places, Steven Deller and Melissa Deller declare that motivators of crime function differently in different places. For example, concentrated poverty is correlated with violent crime in urban places, "but poverty concentration plays no role in helping explain rural violent crime" (2012: 226). The fact is that poverty matters, "but how it matters varies across geographic locations" (227).

\section{Diversity Fact:}

According to the FBI, the ten most violent cities in America, based on violent crime rate, were: 10. Cleveland, Ohio, 9. Baltimore, Maryland, 8. New Haven, Connecticut, 7. Birmingham, Alabama, 6. Stockton, California, 5. Memphis, Tennessee, 4. St. Louis, Missouri, 3. Oakland, California, 2. Detroit, Michigan, and 1. Flint, Michigan. 


\section{Spatial Dimension of Religious Diversity}

One last topic for consideration in this chapter is religion, which is not only dazzlingly diverse in the United States (see Chapter 9) but also spatially distributed. Americans are accustomed, for instance, to speaking of the South as the "Bible Belt," where religious adherence is strong and where religion affects culture and politics overtly. For clear historical reasons, Mormonism is especially prominent in the western Rocky Mountain region, and Nordic Lutherans disproportionately settled in the upper Midwest. In fact, it will be noted that most of Lieske's eleven regional subcultures (see above) are based on religious characteristics.

Danièle Hervieu-Léger is one recent scholar who has insisted that we take seriously the territoriality of religion. Far from being indifferent to the material world, religion is intimately concerned with space, in fact adding a new dimension not encountered in other categories of society-the dimension of sacred space. All religions have places that are more significant, more powerful, because of events that transpired there (like Jesus' mission in Jerusalem or Muhammad's in Mecca) and/or supernatural powers that are seated there (like Mount Olympus to the ancient Greeks). Religions also sacralize space, establishing consecrated ground for churches, cemeteries, or ritual sites. Last but not least, religions participate in the naming of ordinary space: Spanish Catholics planted saint-cities throughout North America, many of which remain today (such as San Diego and San Francisco), and even Anglo-Protestants recreated sacred spaces in their wake, including Bethlehem, Pennsylvania; New Canaan, Connecticut; and Corpus Christi, Texas.

As immigrant groups arrived in the United States bearing their native religions, or as new religions like Mormonism sprang up on American soil, religions began to evince a geographic distribution. Wilbur Zelinsky in 1961 maintained, for example, that the spatial distribution of Catholicism was already set by the mid-1800s, with high concentrations in the Northeast and West as well as coastal strips of Texas and Louisiana (the latter reflecting a unique French Catholicism). Much more recently, Lisa Marie Jordan (2007) emphasized that the geographical distribution of religious diversity had not changed much over the past thirty years or longer, with the twenty-first-century geography of Catholic adherence basically the same as in Zelinksy's time. Not only do certain religions dominate in certain places, but the amount of religious diversity varies from place to place. The least diverse places, once again, are the South as well as Utah and southern Idaho (the latter being strongholds of Mormonism) and New England. Religious diversity is comparatively high in the Midwest, the Northwest, and the mid-Atlantic region.

Showing that the ecological perspective is applicable to religion too, Peter Vincent, Morton Winsberg, and Barney Wharf portray different religions as occupying different "niches" in society, "consisting of varying social and demographic groups" (2006: 83). Turning this light on the South, they find that the Southern Baptist Church does not have the monopoly there that we often presume. Rather, Methodists were actually present in more counties $(1,085)$ than Southern Baptists $(1,083)$, and other denominations and religions were widely present, from Catholicism (970 counties), Presbyterianism (812 counties), and even Baha'i (834 counties). Their data suggest that "there is not one South, but many Souths in terms of religious beliefs" (85-7). Even so, religious change is slow in the South: it is uncommon for a new church 
or denomination to penetrate the region and even more uncommon for an existing church or denomination to disappear (91).

Religion predictably intersects with other aspects of diversity, including class and race. Religious attitudes and affiliations significantly influence politics, the family, and other social institutions, although not always in the expected ways. For instance, the Census Bureau determined that divorce is more common in the South, that alleged bastion of Christian family values, than in other parts of the country. The divorce rate in 2009 was 10.2 per 1,000 for men and 11.1 per 1,000 for women in the South, higher than the national average (9.2 for men and 9.7 for women) and much higher than the relatively liberal Northeast (7.2 for men and 7.5 for women). Anil Rupasingha and John Chilton actually find that religion is bad for economic growth at the county level, with a "statistically significant negative association between church adherence in general and county income growth between 1990 and 2000" (2009: 446-7)—but a positive correlation between education and income growth. Joel Porter also reports the negative effect of church membership on the diversity of an individual's friends, compared to other kinds of group memberships; while all group-formation increases a person's connections, "religious-group membership has the most inhibiting effect" (2010: 143), and full-time employment has a much more positive impact on friendship diversity than religious affiliation. Members of conservative Protestants churches had "the least diverse friendship networks" (143), most likely reflecting the lack of diversity in their congregations.

One final religious development worth noting is the phenomenon of the "megachurch," with many observers recognizing the connection between such churches and urban and suburban places. In their "Geography of Megachurches in the United States," Barney Warf and Morton Winsberg assert that "the distribution of megachurches by county population reflects the profoundly urban locational bias of this institution": 36 percent of such churches sit in counties of 1 million residents or more (2010: 39). In a way this is self-evident, as only large population centers could sustain a congregation of thousands. Still, the fact that megachurches "are a predominantly suburban and exurban phenomenon, locating in places accessible mostly (or only) by automobile, with ample parking, often near highway intersections" (41) says a lot about contemporary American religion, space, and society. Justin Wilford's (2012) recent study of Rick Warrens' well-known Saddleback Church in Orange County, California explores how such churches have evolved specifically to take advantage of the space (and placelessness) of the modern suburb.

\section{Conclusion}

The United States is diverse in many variables, and these variables interact with each other in important ways. However, scholars and policymakers have tended to overlook the variable along which all other variables are distributed-the spatial/geographic variable. For historical reasons as well as on the basis of homophily, people do not settle randomly but rather tend to cluster among others like themselves. This makes American diversity measurable, even visible, across space.

Space, like skin and genitals and years of age, is a physical thing, but humans organize it, give it meaning, value it, and put it to social use. In a word, like the natural 
aspects of their bodies, they live in it socially and culturally. Social life and cultural systems turn spaces into places, and places have a social force all of their own.

While mobility is part of emplacement, just as change is part of being, the persistence of American spatial diversity is profound. Places can remain and have remained spatially organized by race, ethnicity, class, and religion for decades, in some cases longer. Succession occurs, as groups that formerly dominated a space surrender that domination, willingly or not, to newly arriving groups. But we cannot understand American diversity, or how that diversity influences economic, political, and cultural conditions, without an awareness of the distribution of Americans over American space. 


\section{Glossary}

Achieved status-a social position or role that a person acquires through some effort or accomplishment of his or her own.

Achievement gap — the difference in educational performance and attainment, especially between white and black Americans.

Age cohort—a set of people born at roughly the same time and presumably sharing a historical experience.

Anglo-Israelism - a branch of the Christian Identity movement that asserts that the English peoples of the world, including Anglo-Americans, are the true Christian nation.

Anthropometry - the measurement of human bodies to determine individual and group ("racial") physical characteristics.

Annexation - the integration of new territory (usually some other society's or country's territory) into an already existing society or country.

Anti-Semitism-discrimination against and/or animosity toward Jews.

Ascribed status—a social characteristic that it attributed to a person without any effort on their part, either innate (like sex or race) or acquired in the normal course of development (like age).

Assimilation-the social process by which individuals and groups are absorbed into another, usually dominant, cultural group.

Bilingual Education Act-a 1968 law (officially Title VII of the Elementary and Secondary Education Act of 1968) aimed at meeting the educational needs of students with limited English-speaking ability by providing grants for creative educational programs for non-English-speaking students.

Biphobia-a fear or rejection of bisexuals or the idea of bisexuality.

Birth rate- the number of childbirths per 1,000 people in the society in a given year.

Bisexual-a person who experiences sexual interest in or attraction to either or both sexes/genders.

Body dysmorphic disorder-a medical condition in which sufferers (often women) perceive non-existent imperfections in their body and appearance (i.e. their own body-image is inaccurate).

Broken windows theory - a policing theory that holds that neighborhoods that show signs of deterioration and disregard (like broken windows) are more subject to crime.

Built environment-the physical structures and changes to the natural environment (e.g. houses, roads, farms, canals, etc.) made by humans and constituting part of the material world in which they must live. 


\section{Glossary}

Categorial thinking - the idea is that humans (or anything else) can be divided into a finite set of discrete and non-overlapping categories, sometimes as few as two, without exception or with nothing in between.

Category-in sociology, a set of humans who share some specified physical or social characteristic, whether or not they identify or interact as such; more generally, any supposedly discrete location in a classification system that distinguishes people or things on the basis of shared traits.

Census tract-according to the US Census, one of the small, relatively permanent statistical subdivisions of a county. Census tracts nest within the county and are given a numeric code that is unique within the county. The minimum population for a census tract is 1,200 and the maximum is 8,000 . Most census tracts average about 4,000 people.

Christian Identity - a social movement that insists that the white race is the true Christian nation.

Christian Reconstructionism - a social movement aiming to change or "reconstruct" American society in conformity with Christian (often Old Testament) laws and values.

Civil disobedience-deliberately breaking a law that the violator believes is unjust and illegal.

Civil religion-based on Rousseau's work and re-stated by Robert Bellah, a form of religion that identifies with a specific society and political system and serves to integrate and legitimate that social/political system.

Code-switching - the ability and practice of knowing and switching between multiple dialects and other lects depending on social circumstances.

Confederation - a loose alliance between political units, such that each constituent unit retains some of its political independence and cultural distinctiveness.

Conspicuous consumption-as formulated by Thorstein Veblen, the notion that the upper class consumes specific kinds and quantities of goods and services in order to display its superior social status.

Core vocabulary-the set of most commonly used words in a language.

Counterculture-a group or subset within a society that more or less intentionally adopts behaviors, beliefs, or practices that are at odds with or opposed to the mainstream of society.

Creole-a hybrid language that has become the first or primary language of a society.

Critical Race Theory-also known as CRT and associated primarily with Derrick Bell, a movement and body of research that maintains that race and racism is a "normal" part of American society, supported by majoritarian ideas, perceptions, and discourses; that therefore racism cannot be eradicated by official legal means alone; and that the experiences and disadvantages of African Americans cannot be conveyed through standard categories or "isms" or conventional academic writing styles.

Cultural assimilation-a type of assimilation which refers specifically to the loss of distinctive cultural traits, such as language or religion.

Cultural pluralism - the toleration or encouragement of cultural difference in a society, that is, the acceptance of individuals or groups within a society without requiring or expecting them to surrender their cultural uniqueness.

Culture - the learned and shared ways of behaving, thinking, and feeling in a social group. 
Culture of poverty-most associated with Oscar Lewis, the alleged social characteristics and common behaviors that are descriptive of the poor (whether or not these characteristics and behaviors actually create poverty).

Deafworld-the term used by some deaf people to refer to a distinct community and culture of the deaf.

Death rate-the number of deaths per 1,000 population per year; see also mortality rate.

Dialect-a variant of a language distinguished by its phonology, vocabulary, and/or grammar.

Diaspora-the dispersion of a social group from its historical homeland (often applied specifically to the Jewish community).

Diglossia - the use of two varieties of a language by members of a society for distinct functions or by distinct groups or classes of people.

Discrimination-according to Gordon Allport, any conduct based on a distinction made on grounds of natural or social categories, which have no relation either to individual capacities or merits, or to the concrete behavior of the individual person; more generally, unequal treatment of individuals on the basis of their physical or cultural traits and memberships.

Disestablishment — the elimination of official or "established" religion at the state or federal level.

Division of labor-the differentiation of the economy into a set of distinct production tasks, which are assigned to different individuals, groups, or classes, usually creating economic and political inequalities.

Ebonics-a version of English controversially associated with African Americans.

Elaborated code-according to Basil Bernstein, a form of speech featuring more freedom of linguistic forms and more opportunity for individual expression (person-oriented rather than status-oriented).

Enculturation-the process by which a person learns or acquires his or her culture, usually as a child. Also known as socialization.

Essentialism - the notion that each "kind" of person or thing is distinguished by an inherent and unchanging "essence" or nature.

Establishment - the promotion of a particular religious denomination as the official "established" religion of a society, province, or country, perhaps requiring membership, attendance, and/or financial support by all residents.

Ethnic conflict-violence between groups on the basis of (real or putative) cultural or identity differences.

Ethnicity-the phenomenon of organizing around some aspect of shared culture to integrate an identity group, differentiate it from other groups, and compete in a multiethnic context for resources.

Ethnocide-the destruction of a group's culture, without necessarily killing any of the members of the culture.

Eunuch - a gender category involving non-sexual individuals (usually men), who may be castrated or merely celibate, sterile, or lacking sexual desire.

Evangelical - a style of Christianity associated with individual conversion (being "born again"), a belief in the accuracy of the Bible, and the commitment to spread Christianity throughout society. 


\section{Glossary}

Fertility rate-the average number of children born to a woman during her lifetime.

Fundamentalism - a type of cultural/revitalization movement in which members attempt to address perceived social problems or disadvantages by restoring the perceived "fundamentals," or oldest, most important, and most "genuine" elements of culture; in Christianity, a style of religion that promotes the "original" or "fundamental" beliefs and practices of Christianity and often aims to instill those beliefs and practices on society and/or to separate itself from non-fundamentalist society.

Genderqueer-an individual who identifies as between genders or as neither man nor woman, rejecting conventional sexual/gender categories.

Genocide-the destruction of a group or society by harming, killing, or preventing the birth of its members.

Gini index-a single coefficient that represents income inequality: the Gini index number ranges from zero to one, with zero meaning perfect income equality and one meaning perfect inequality (a single individual or household owns all wealth).

Grammar-the linguistic rules for combining words and producing intelligible utterances of different kinds (e.g. statements, questions, commands, etc.); see also syntax.

Gross national product - the total value of all the goods and services produced in a country (the gross domestic product) plus the income earned by citizens from investments in other countries.

Health disparities-differences in health conditions and outcomes (e.g. the incidence of disease or the age of death) relative to social variables such as gender, race, income, education, etc.

Hegemonic masculinity-the cultural ideal of masculinity, against which women and even non-normally masculine men are judged.

Heteronormativity-the view that heterosexuality is the only normal, even real, sexual preference or identity.

Heterotopia-according to Michel Foucault, a real place where the normal rules and expectations of society do not quite apply, or where the norms of society are simultaneously represented, contested, and inverted.

Homophily - the tendency of people to associate with others who share their social characteristics and thus commonly to form physical areas or communities with shared social characteristics.

Honorifics-modes of speech that indicate relative social status and convey respect or deference.

Human ecology — as formulated by sociologist Robert Park, the application of scientificl ecological principles to humans, who are seen as a species that occupies, modifies, and competes for territory.

Human geography-also known as cultural geography, the subdiscipline of geography that studies the relationship between humans and their physical environment, or the social and cultural division and use of space.

Identity politics-the notion and project that culture or culture-based identity is or should be political and that groups should strive for recognition or power on the basis of their cultural or identity differences.

Infant mortality rate - the death rate among babies under one year of age per 1,000 live births.

Intersectionality — as formulated by Kimberlé Crenshaw, the combined effect of multiple statuses (specifically in her analysis, race and gender) on the individual, 
creating unique experiences and social/legal issues that are not fully appreciated from the perspective of any single status or status-domain.

Intersex-a term for individuals with culturally ambiguous genitalia, some of whom claim it as a normal status and as a sexual identity.

Islamophobia - a recently introduced term for the fear and hatred that some Westerners feel toward Islam and Muslims.

Language stratification-the division of society into unequal groups or layers on the basis of socially unequal forms of language, or the association of different linguistic practices and styles with different strata of society.

Lect-a technical term for a version of a language that has a distinct functional identity or "place" in the wider language community (based on region, age, gender, race, etc.).

Legitimation - the social justification for a particular practice, institution, or way of life; that is, the reasons (often based in religion) why social life should be a particular way.

Life expectancy - the number of years of age which a person can expect to live in any particular society.

Linguistic community-according to John Gumperz, a social group integrated by shared communicative practices, which may be monolingual or multilingual, whose members could at least potentially talk to each other.

Master status - the most important or defining of all of the statuses occupied by an individual.

Medicalization - the social process of categorizing a physical state or condition as a "medical" problem and thereby subjecting it to the power and interventions of medical experts.

Meritocracy - a system in which people ideally have what they deserve. In a true meritocracy, those individuals with talent who make an effort are justified in earning the greatest rewards.

Miscegenation-a negative term for the genetic mixing of races.

Mock Spanish-the use of random Spanish words, a Spanish accent, or pseudoSpanish forms in English.

Model minority - a term often applied to Asian Americans, who have been particularly successful in the US in terms of income, education, employment, family stability, and other characteristics valued by American society.

Morphology — the area of language dealing with how meaningful bits (usually but not exclusively words) are created and manipulated by the combination of language sounds; see also semantics.

Mortality rate-see also death rate.

Multiculturalism - a variety of movements and initiatives that demand an acknowledgement of, a respect for, sometimes even a celebration of the multiple cultural streams that comprise American culture and society.

Naturalization-the process by which immigrants to a country become citizens of that country.

Nativists-those people who claim to be the "native" and true citizens of a country and pursue policies to protect their power and interests against recent immigrants to the country.

Non-place-as proposed by Marc Augé, a physical space that it is not particularly a site of human relationships and history, especially transportation nodes like airports and hotels. 


\section{Glossary}

Partition-the political division of the territory of a country between two or more ethnic or racial groups, creating two or more countries.

Pentecostalism - a style of Christianity associated with direct personal contact with divinity and "gifts of the spirit" such as speaking in tongues or spiritual healing.

Phonology - the description and classification of sounds in language.

Physical/racial assimilation - the absorption of groups or races into a society through intermarriage and the reduction of physical differences between the groups/races.

Pidgin - a simplified version of a language that is usually used for limited purposes, such as trade and economic interactions, by non-native speakers of the language (as in Melanesian pidgin versions of English). Usually an incomplete language that is not the "first" language of any group.

Pluralism-the coexistence of multiple social/cultural groups in the same society or state.

Population pyramid-a graphical representation of the distribution of population into age categories (typically five- or ten-year increments) in a society, often also showing the population differences between the sexes at each age; also known as age-sex structure.

Poverty line-the official measure of income below which an individual or family is considered poor.

Pragmatics - the rules or practices regarding how language is used in particular social situations to convey particular social information, such as the relative status or power of the speakers, and to achieve desired linguistic effects; see also sociolinguistics.

Prejudice-negative ideas about or attitudes toward persons because of the categories or groups to which they belong.

Protest masculinity - a form of masculine identity and behavior, often associated with aggression and violence, that is related to efforts to prove that the person is a "man" and not feminine or childish.

Quintile-one-fifth or 20 percent of the population of a country.

Refugee-a person who leaves his/her home country due to political danger or natural disaster.

Register-a form of speech used in specific social contexts, such as court, church, classroom, etc.

Restricted code-according to Basil Bernstein, a form of speech with comparatively limited and rigid language option, in which individuality is restricted and social status emphasized.

Role-a "part to play" or the behavioral norms and expectations associated with a particular status or "place" in society.

Role entry-the process by which individuals commence playing a particular role, temporarily or permanently.

Role exit - the process by which individuals cease playing a particular role, temporarily or permanently.

Semantic range-the set of meanings conveyed by a particular word, that is, the "range" of its referents or the variety of phenomena or conceptions that it names.

Semantics-see also morphology.

Sex ratio-the relative number of males and females in a society.

Shari'a-the legal code of Islam.

Sick role-as defined by sociologist Talcott Parsons, the social expectations that are placed on individuals who identify or are identified as sick. 
Social distance - a sociological measure of the degree to which groups are willing or unwilling to mingle and interact.

Social memory - the shared and transmitted memories of a society, whether or not these memories are "personal" or biographical memories (i.e. things that actually happened in the individual's lifetime)—or whether or not they are true.

Social mobility - the possibility or ease of changing one's position in the social stratification system.

Social movement-a more or less organized and intentional effort to change some aspect of society.

Social stratification-the division of society into different and unequal "layers" on the basis of wealth, status, or prestige.

Society-a group of people who share a common culture, live near each other and interact with one another, and tend to intermarry.

Sociolinguistics-see also pragmatics.

Sovereignty - the power of self-rule; the highest level of political authority and independence.

Status-a "position" in the structure of a society; a "kind of person" to be in a society. Stereotype-a simplistic view of individuals who belong to a particular category or group. Stigma-according to sociologist Erving Goffman, an attribute that is socially discrediting, that makes the possessor of the trait different from and less desirable than others-sometimes literally bad, weak, or dangerous.

Structural assimilation - $\mathrm{a}$ form of assimilation in which groups are integrated into the society (for instance, sharing the same jobs or the same neighborhoods), whether or not they share the same culture.

Structural pluralism - the exist of multiple groups within a society, when those groups occupy different sites in the social structure-different classes, occupations, neighborhoods, and institutions-on the basis of their cultural differences or even in the absence of any appreciable cultural differences.

Style-a situational variant of language, such as formal or informal style, characterized by differences in pronunciation, vocabulary, grammar, and tone of voice.

Subculture - a group or subset within a society that is distinguished by some unique aspects of its behavior (such as clothing styles, linguistic usages, or beliefs and values).

Supermodernity—as proposed by Marc Augé, the present era characterized by extreme mobility and detachment from place.

Symbol—anything (word, object, image, gesture, etc.) that "stands for" or "represents" something else, in a culturally conventional and arbitrary way.

Syncretism - the blending or superimposing of elements from two different cultures, or a social movement based on such blending.

Syntax-see also grammar.

Termination - a federal policy in the 1950s and 1960s to remove government recognition of Native tribes and to reduce the members of those tribes to "individuals" in the conventional American sense.

Title IX - part of the Education Amendments of 1972, guaranteeing fair access on the basis of sex to educational programs and activities (including sports) in educational institutions receiving federal financial assistance.

Transgender-an umbrella term for individuals whose gender identity and/or gender expression differs from the sex they were assigned at birth. 


\section{Glossary}

Translocal—crossing local/national borders, occurring in more than one place or country.

Transman-a person who has been sexually reassigned from female to male.

Transsexual - a person whose gender/sexual identity does not match his/her body, whether or not that person has begun or completed a physical (surgical) reassignment into another or "the opposite" gender.

Transvestite-literally "across-dress," a person who wears the clothing associated with another or "the opposite" gender.

Transwoman-a person who has been sexually reassigned from male to female.

Vernacular-a form of a language used by ordinary speakers in their day-to-day lives. 


\section{Bibliography}

Adams, Glenn and Vivian Afi Dzokoto. 2007. "Genital-Shrinking Panic in Ghana: A Cultural Psychological Analysis." Culture and Psychology 13 (1): 83-104.

Alba, Richard. 1990. Ethnic Identity: The Transformation of White America. New Haven: Yale University Press.

Alexie, Sherman. 1994. The Lone Ranger and Tonto Fistfight in Heaven. New York: HarperPerennial.

Allegretto, Sylvia A. 2011. “The State of Working America's Wealth, 2011.” Washington, DC: Economic Policy Institute.

Allport, Gordon. 1979. The Nature of Prejudice. Reading, MA: Addison-Wesley Publishing Company.

American Association of University Women. 1992. How Schools Shortchange Girls: A Study of Major Findings on Girls and Education. Annapolis, MD: American Association of University Women.

Anderson, Benedict. 1983. Imagined Communities: Reflections of the Origin and Spread of Nationalism. London: Verso.

Angelides, Steven. 2001. A History of Bisexuality. Chicago: The University of Chicago Press.

Anspach, RR. 1979. "From Stigma to Identity Politics: Political Activism Among the Physically Disabled and Former Mental Patients." Social Science and Medicine 13A: 765-73.

Anti-Defamation League. 1998. "How Prevalent is Anti-Semitism in America?” http://www.adl. org/antisemitism_survey/survey_print.asp, accessed January 15, 2009.

_. 2005. "American Attitudes Towards Jews in America.” http://www.adl.org/anti_semitism/ anti_semitic_attitudes.pdf, accessed January 15, 2009.

Appiah, Kwame Anthony. 2006. Cosmopolitanism: Ethics in a World of Strangers. New York: W. W. Norton.

Arab American National Museum. n.d. Arab Americans: An Integral Part of American Society. Dearborn, MI: Arab American National Museum.

Arefi, Mahyar. 1999. "Non-Place and Placelessness as Narratives of Loss: Rethinking the Notion of Place." Journal of Urban Design 4 (2): 179-93.

Ariès, Philippe. 1962 [1960]. Centuries of Childhood: A Social History of the Family. Robert Baldick, trans. New York: Alfred A. Knopf.

Arnett, Jeffrey Jensen. 2000. "Emerging Adulthood: A Theory of Development from the Late Teens through the Twenties." American Psychologist 55 (5): 469-80.

- 2004. Emerging Adulthood: The Winding Road from the Late Teens Through the Twenties. Oxford and New York: Oxford University Press.

Atran, Scott. 2002. In Gods We Trust: The Evolutionary Landscape of Religion. Oxford: Oxford University Press.

Augé, Marc. 1995 [1992]. Non-Places: Introduction to an Anthropology of Supermodernity. John Howe, trans. London and New York: Verso. 
Auster, Lawrence. 1994. "The US Must Restrict Immigration to Prevent Cultural Disintegration.” In Fred Whitehead, ed. Culture Wars: Opposing Viewpoints. San Diego: Greenhaven Press, 56-62.

Barna Group, The. 2007. “Survey Explores Who Qualifies as an Evangelical.” http://www.barna. org/barna-update/article/13-culture/111-survey-explores-who-qualifies-as-an-evangelical, accessed June 6, 2013.

Baron, Larry, Murray A. Straus, and David Jaffee. 1988. "Legitimate Violence, Violent Attitudes, and Rape: A Test of the Cultural Spillover Theory." Annals of the New York Academy of Sciences 528: 79-110.

Barrett, David B., George T. Kurian, and Todd M. Johnson. 2001. World Christian Encyclopedia: A Comparative Survey of Churches and Religions in the Modern World. Oxford: Oxford University Press.

Barth, Fredrik, ed. 1969. Ethnic Groups and Boundaries. Boston: Little, Brown \& Co.

Bell, Derrick. 1987. And We Are Not Saved: The Elusive Quest for Racial Justice. New York: Basic Books.

- 1992. Faces at the Bottom of the Well: The Permanence of Racism. New York: Basic Books.

Bellah, Robert N. 1967. "Civil Religion in America.” Daedalus 96 (1): 1-21.

Bernstein, Basil. 1964. "Elaborated and Restricted Codes: Their Social Origins and Some Consequences.” American Anthropologist 66 (6, part 2): 55-69.

Bhatt, Rakesh M. 2001. "World Englishes." Annual Review of Anthropology 30: 527-50.

Black, Michele C., Kathleen C. Basile, Matthew J. Breiding, Sharon G. Smith, Mikel L. Walters, Melissa T. Merrick, Jieru Chen, and Mark R. Stevens. 2011. "The National Intimate Partner and Sexual Violence Survey: 2010 Summary Report.” Atlanta, GA: National Center for Injury Prevention and Control, Centers for Disease Control and Prevention.

Bloch, Maurice E. F. 1998. How We Think They Think: Anthropological Approaches to Cognition, Memory, and Literacy. Boulder, CO: Westview Press.

Bloom, Howard. 1995. The Lucifer Principle: A Scientific Expedition into the Forces of History. New York: The Atlantic Monthly Press.

Bloom, Paul. 2008. "First Person Plural." The Atlantic 304 (4): 90-8.

Blumstein, Philip W. and Pepper Schwartz. 1976a. "Bisexuality in Men." Journal of Contemporary Ethnography 5 (3): 339-58.

Blumstein, Philip W. and Pepper Schwartz. 1976b. "Bisexuality in Women." Archives of Sexual Behavior 5 (2): 171-81.

Bly, Robert. 1990. Iron John: A Book about Men. New York: Addison-Wesley.

Boas, Franz. 1928. Anthropology and Modern Life. New York: W. W. Norton.

Boddy, Janice. 1988. "Spirits and Selves in Northern Sudan: The Cultural Therapeutics of Possession and Trance." American Ethnologist 15 (1): 4-27.

Boellstorff, Tom. 2005. "Between Religion and Desire: Being Muslim and Gay in Indonesia." American Anthropologist 107 (4): 575-85.

Bogardus, Emory. 1933. "A Social Distance Scale.” Sociology and Social Research 17: 65-71.

Booth, Margaret Zoller. 2003. "You Learn and Learn and Learn. ... And Then You are an Adult': Parental Perceptions of Adolescence in Contemporary Swaziland." Adolescence 38 (150): 221-37.

Borg, Marian J. 1997. "The Southern Subculture of Punitiveness? Regional Variation in Support of Capital Punishment." Journal of Research in Crime and Delinquency 34 (1): 25-45.

Boswell, John. 1988. The Kindness of Strangers: The Abandonment of Children in Western Europe from Late Antiquity to the Renaissance. Chicago: The University of Chicago Press.

- 1994. Same-Sex Unions in Premodern Europe. New York: Villard Books.

Boulware, Tyler. 2011. “We Are Men': Native American and Euroamerican Projections of Masculinity During the Seven Years' War.” In Thomas A. Foster, ed. New Men: Manliness in Early America. New York and London: New York University Press, 51-70. 
Bowman, Karl M. and Bernice Eagle. 1953. "The Problem of Homosexuality." Journal of Social Hygiene 39 (1): 2-16.

Boyer, Pascal. 2001. Religion Explained: The Evolutionary Origins of Religious Thought. New York: Basic Books.

Boyer, Richard O. and Herbert M. Morais. 1975 [1955]. Labor's Untold Story. New York: United Electrical, Radio, and Machine Workers of America.

Bradford, Mary. 2004. "The Bisexual Experience.” Journal of Bisexuality 4 (1/2): 7-23.

Brantingham, P. L., U. Glässer, B. Kinney, K. Singh, and M. Vajihollahi. 2005. "Computational Model for Simulating Spatial Aspects of Crime in Urban Environments.” IEEE International Conference on Systems, Man and Cybernetics 4: 3667-74.

Bronski, Michael. 1993. "How Sweet (And Sticky) It Was." In John Preston, ed. Flesh and the Word 2. New York: Plume, 73-84.

Brooks, David. 2000. Bobos in Paradise: The New Upper Class and How They Got There. New York: Simon \& Schuster.

Brown, Judith. 1975. "Iroquois Women: An Ethnohistoric Note.” In Reiter, Rayna, ed. Toward an Anthropology of Women. New York and London: Monthly Review Press, 235-51.

Brown, Marilyn A. 1982. "Modelling the Spatial Distribution of Suburban Crime." Economic Geography 58 (3): 247-61.

Brubaker, Rogers and David D. Laitin. 1998. "Ethnic and Nationalist Violence." Annual Review of Sociology 24: 423-52.

Buchmann, Claudia, Thomas A. DiPrete, and Anne McDaniel. 2008. "Gender Inequalities in Education." Annual Review of Sociology 34: 319-37.

Burgess, Ernest W. 1949. "The Sociological Theory of Psychosexual Behavior.” In P. H. Hoch and J. Zubin, eds. Psychosexual Development in Health and Disease. New York: Grune, Stratton, 227-43.

Butler, Judith. 1990. Gender Trouble: Feminism and the Subversion of Identity. New York and London: Routledge.

Canetti, Elias. 1963 [1960]. Crowds and Power. Carol Steward, trans. New York: The Viking Press.

Capps, Randy, Kristen McCabe, and Michael Fix. 2011. “New Streams: Black African Migration to the United States." Washington, DC: Migration Policy Institute.

Carlson, Elwood. 2009. “20th-Century US Generations.” Population Bulletin 64 (1).

Cartei, Valentina and David Reby. 2012. "Acting Gay: Male Actors Shift the Frequency Components of their Voices towards Female Values when Playing Homosexual Characters.” Journal of Nonverbal Behavior 36: 79-93.

Carter, David. 2004. Stonewall: The Riots that Sparked the Gay Revolution. New York: St. Martin's Press.

Casey, Edward S. 1997. "How to Get from Space to Place in a Fairly Short Stretch of Time: Phenomenological Prolegomena.” In Steven Feld and Keith H. Basso, eds. Senses of Place. Santa Fe, NM: School of American Research Press, 13-52.

Centers, Richard. 1949. The Psychology of Social Classes: A Study of Class Consciousness. Princeton, NJ: Princeton University Press.

Chauncey, George. 1994. Gay New York: Gender, Urban Culture, and the Making of the Gay Male World, 1890-1940. New York: Basic Books.

Chesebro, J. W., ed. 1981. Gayspeak: Gay Male and Lesbian Communication. New York: Pilgrim.

Clark, Juanne N. 1983. "Sexism, Feminism, and Medicalism: A Decade Review of Literature on Gender and Illness." Sociology of Health and Illness 5 (1): 62-82.

Coe, Rodney M. 1978. Sociology of Medicine, 2nd ed. New York: McGraw-Hill.

Cohen, Patricia. 2012. In Our Prime: The Invention of Middle Age. New York: Scribner.

Condon, Richard G. 1990. "The Rise of Adolescence: Social Change and Life Stage Dilemmas in the Central Canadian Arctic." Human Organization 49 (3): 266-79. 


\section{Bibliography}

Connell, R. W. 1987. Gender and Power. Sydney, Australia: Allen and Unwin.

Connell, R. W. and James W. Messerschmidt. 2005. "Hegemonic Masculinity: Rethinking the Concept." Gender \& Society 19 (6): 829-59.

Conrad, Peter. 1992. "Medicalization and Social Control." Annual Review of Sociology 18: 209-32.

Conrad, Peter, and Valerie Leiter. 2004. "Medicalization, Markets, and Consumers.” Journal of Health and Social Behavior 45 (extra issue): 158-76.

Coontz, Stephanie. 1992. The Way We Never Were: American Families and the Nostalgia Trap. New York: Basic Books.

Crawford, James. 2008. Advocating for English Learners: Selected Essays. Clevedon, UK: Multilingual Matters.

Creese, Gillian. 2011. The New African Diaspora in Vancouver: Migration, Exclusion, and Belonging. Toronto: University of Toronto Press.

Crenshaw, Kimberlé. 1989. "Demarginalizing the Intersection of Race and Sex: A Black Feminist Critique of Antidiscrimination Doctrine, Feminist Theory and Antiracist Politics." The University of Chicago Legal Forum 140: 139-67.

—. 1991. "Mapping the Margins: Intersectionality, Identity Politics, and Violence Against Women of Color.” Stanford Law Review 43 (6): 1241-99.

Crowley, Sara L., Lara J. Foley, and Constance L. Shehan. 2008. Gendering Bodies. Lanham, MD: Rowman \& Littlefield Publishers.

cummings, andré douglas pond. 2012. "Derrick Bell: Godfather Provocateur." Harvard Journal on Racial \& Ethnic Justice 28: 51-66.

Daniel, G. Reginald. 2005. "White into Black: Race and National Identity in Contemporary Brazil.” In Paul Spickard, ed. Race and Nation: Ethnic Systems in the Modern World. New York and London: Routledge, 87-113.

Davies, Sharyn Graham. 2007. Challenging Gender Norms: Five Genders among the Bugis in Indonesia. Belmont, CA: Wadsworth Publishing Company.

DeAngelo, Gregory. 2012. "Making Space for Crime: A Spatial Analysis of Criminal Competition." Regional Science and Urban Economics 42: 42-51.

Deller, Steven and Melissa Deller. 2012. "Spatial Heterogeneity, Social Capital, and Rural Larceny and Burglary." Rural Sociology 77 (2): 225-53.

deMauss, Lloyd, ed. 2006 [1974]. The History of Childhood. Lanham, MD: Rowman \& Littlefield.

Desroches, Frederick J. 1990. “Tearoom Trade: A Research Update.” Qualitative Sociology 13 (1): 39-61.

de Tocqueville, Alexis. 1969 [1830]. Democracy in America. George Lawrence, trans. J.P Mayer, ed. Garden City, NY: Anchor Books/Doubleday \& Company, Inc.

DeVos, George. 1975. "Ethnic Pluralism: Conflict and Accommodation.” In George DeVos and Lola Romanucci-Ross, eds. Ethnic Identity: Cultural Continuities and Change. Palo Alto, CA: Mayfield Publishing, 5-41.

Dicker, Susan. 2003. Languages in America: A Pluralist View, 2nd ed. Clevedon, UK: Multilingual Matters.

Dollard, John. 1937. Caste and Class in a Southern Town. New York: Doubleday Anchor Books.

Domosh, Mona, Roderick Neumann, Patricia Price, and Terry Jordan-Bychkov. 2012. The Human Mosaic, 12th ed. New York: W. H. Freeman.

Draper, Patricia. 1975. "!Kung Women: Contrasts in Sexual Egalitarianism in Foraging and Sedentary Contexts.” In Reiter, Rayna, ed. Toward an Anthropology of Women. New York and London: Monthly Review Press, 77-109.

Drug Policy Alliance Network. 2009. "Race and the Criminal Justice System." http://www. drugpolicy.org/communities/race/criminaljust/, accessed January 5, 2009.

Du Bois, W. E. B. 2006 [1903] The Souls of Black Folk. Philadelphia: University of Pennsylvania Press. 
Duneier, Mitchell. 1999. Sidewalk. New York: Farrar, Straus, \& Giroux.

Durkheim, Émile. 1965 [1915]. The Elementary Forms of the Religious Life. New York: The Free Press.

Dye, Thomas. 2002. Who's Running America? The Bush Restoration, 7th ed. New York: Longman.

Ehrenreich, Barbara. 2002. Nickle and Dimed: On (Not) Getting By in America. New York: Henry Holt.

Ellis, Havelock. 1908. Studies in the Psychology of Sex, Volume II: Sexual Inversion, 2nd ed. Philadelphia: F. A. Davis Company.

Elo, Irma. 2009. "Social Class Differentials in Health and Mortality: Patterns and Explanations in Comparative Perspective.” Annual Review of Sociology 35: 553-72.

Epple, Carolyn. 1998. “Coming to Terms with Navajo 'Nadleehi': A Critique of 'Berdache,' Gay,' 'Alternate Gender,' and 'Two-Spirit.'” American Ethnologist 25 (2): 267-90.

Epstein, Robert, Paul McKinney, Shannon Fox, and Carlos Garcia. 2012. "Support for a Fluid-Continuum Model of Sexual Orientation: A Large-Scale Internet Study.” Journal of Homosexuality 59: 1356-81.

Erikson, Erik H. 1968. Identity, Youth and Crisis. New York: W. W. Norton.

Factor, Rhonda and Esther Rothblum. 2008. "Exploring Gender Identity and Community among Three Groups of Transgender Individuals in the United States: MTFs, FTMs, and Genderqueers." Health Sociology Review 17 (3): 241-59.

Falcone, Jessica Marie. 2012. "Putting the 'Fun' in Fundamentalism: Religious Nationalism and the Split Self at Hindutva Summer Camps in the United States." Ethos 40 (2): 164-95.

Farr, Rachel H. and Charlotte J. Patterson. 2013. "Coparenting Among Lesbian, Gay, and Heterosexual Couples: Associations with Adopted Children's Outcomes." Child Development 84 (4): 1-15.

Feldman, Stephen M. 1997. Please Don't Wish Me a Merry Christmas: A Critical History of the Separation of Church and State. New York: New York University Press.

Fielding, Henry. 1979 [1749]. The History of Tom Jones. New York: Penguin Books.

Flanagan, Caitlin. 2004. "How Serfdom Saved the Women's Movement.” The Atlantic (March): $109-28$.

Forbush, William B. 1901. The Boy Problem. Chicago: The Pilgrim Press.

Forshee, Andrew S. 2008. “Transgender Men: A Demographic Snapshot.” Journal of Gay \& Lesbian Social Services 20 (3): 221-36.

Foucault, Michel. 1978 [1976]. The History of Sexuality, Volume I: An Introduction. Robert Hurley, trans. New York: Pantheon Books.

- 1988 [1965]. Madness and Civilization: A History of Insanity in the Age of Reason. New York: Vintage Books.

— 2003 [1963]. The Birth of the Clinic: An Archaeology of Medical Perception. A. M. Sheridan, trans. London: Routledge.

Foucault, Michel and Jay Miskowiec. 1986. "Of Other Spaces.” Diacritics 16 (1): 22-7.

Francis, David. 2012. "Where Do You Fall in the American Economic Class System?" http:// money.usnews.com/money/personal-finance/articles/2012/09/13/where-do-you-fall-in-theamerican-economic-class-system, accessed June 19, 2013.

Franke-Ruta, Garance. 2013. "Miss Education: Why Women's Success in Higher Education Hasn't Led to More Female Leaders.” The Atlantic (April): 28-9.

Fredrickson, George M. 2001. "Models of American Ethnic Relations: A Historical Perspective." In Deborah A. Prentice and Dale T. Miller, eds. Cultural Divides: Understanding Group Conflict. New York: Russell Sage Foundation, 23-34.

Freeland, Chrystia. 2011. "The Rise of the Global Elite.” The Atlantic (January/February). http:// www.theatlantic.com/magazine/archive/2011/01/the-rise-of-the-new-global-elite/8343/, accessed May 1, 2011. 


\section{Bibliography}

Freud, Sigmund. 1960 [1921]. Group Psychology and the Analysis of the Ego. James Strachey, trans. New York: Bantam Books.

Frevele, Jamie. 2011. "Tracing the Origins of Gender-Specific Clothing for Children.” http:// www.themarysue.com/gender-specific-clothing-for-children/, accessed June 24, 2013.

Furnivall, J. S. 1956. Colonial Policy and Practice: A Comparative Study of Burma and Netherlands India. New York: New York University Press.

Fussell, Paul. 1983. Class: A Guide through the American Status System. New York: Touchstone.

Gans, Herbert. 1962. The Urban Villagers: Group and Class in the Life of Italian-Americans. New York: The Free Press.

—. 2002. "The Sociology of Space: A Use-Centered View." City \& Community 1 (4): 329-39.

Garber, Marjorie. 1996. Vice Versa: Bisexuality and the Eroticism of Everyday Life. New York: Simon \& Schuster.

Gardner, Howard. 1983. Frames of Mind: The Theory of Multiple Intelligences. New York: Basic Books.

Garlipp, Petra. 2008. "Koro-A Culture-Bound Phenomenon: Intercultural Psychiatric Implications." German Journal of Psychiatry 11: 21-8.

Garreau, Joel. 1981. The Nine Nations of North America. New York: Avon Books.

Gates, Gary J. and Frank Newport. 2012. "Special Report: 3.4\% of US Adults Identify as LGBT.” http://www.gallup.com/poll/158066/special-report-adults-identify-lgbt.aspx, accessed July 10, 2013.

Geertz, Clifford. 1973. The Interpretation of Cultures. New York: Basic Books.

Gibson, Christopher. 2009. "Human Geography." In Rob Kitchin and Nigel Thrift, eds. International Encyclopedia of Human Geography. Amsterdam, Netherlands: Elsevier, 218-31.

Gieryn, Thomas F. 2000. "A Space for Place in Sociology.” Annual Review of Sociology 26: 463-96.

Gilder, George. 1973. Sexual Suicide. New York: Bantam Books.

Gilmore, David. 1990. Manhood in the Making: Cultural Concepts of Masculinity. New Haven, CT: Yale University Press.

Gitlin, T. 1995. The Twilight of Common Dreams: Why America Is Wracked by Culture Wars. New York: Metropolitan.

Glaeser, Edward and Jacob Vigdor. 2012. "The End of the Segregated Century: Racial Separation in America's Neighborhoods, 1890-2010.” New York: Center for State and Local Leadership at the Manhattan Institute.

Glazer, Nathan and Daniel Patrick Moynihan. 1963. Beyond the Melting Pot: The Negroes, Puerto Ricans, Jews, Italians, and Irish of New York City. Cambridge, MA: The Massachusetts Institute of Technology Press.

Goffman, Erving. 1963. Stigma: Notes on the Management of Spoiled Identity. Englewood Cliffs, NJ: Prentice-Hall.

Goldschmidt, Walter. 1950. "Social Class in America: A Critical Review." American Anthropologist 52 (4): 483-98.

Gooß, Ulrich. 2008. "Concepts of Bisexuality.” Journal of Bisexuality 8: 9-23.

Gotta, Gabrielle, Robert-Jay Green, Esther Rothblum, Sondra Solomon, Kimberly Balsam, and Pepper Schwartz. 2011. "Heterosexual, Lesbian, and Gay Male Relationships: A Comparison of Couples in 1975 and 2000." Family Process 50 (3): 353-76.

Gottman, John Mordechai, Catherine Swanson, Kristin Swanson, Rebecca Tyson, and Dan Yoshimoto. 2003. "Observing Gay, Lesbian and Heterosexual Couples' Relationships: Mathematical Modeling of Conflict Interaction.” Journal of Homosexuality 45 (1): 65-91.

Graff, Harvey J. 1995. Conflicting Paths: Growing Up in America. Cambridge, MA: Harvard University Press.

Greeley, Andrew M. 1971. Why Can't They Be Like Us? America's White Ethnic Groups. New York: E. P. Dutton \& Co. 
Green, John and Steven Waldman. 2006. "Tribal Relations: How Americans Really Sort out on Cultural and Religious Issues—and What it Means for our Politics." The Atlantic (Jan/ Feb 2006). http://www.theatlantic.com/magazine/archive/2006/01/tribal-relations/304503/, accessed June 6, 2013.

Grossman, Arnold H. and Anthony R. D'augelli. 2006. "Transgender Youth.” Journal of Homosexuality 51 (1): 111-28.

Gullette, Margaret Morganroth. 2004. Aged by Culture. Chicago and London: The University of Chicago Press.

Gumperz, John J. 1962. “Types of Linguistic Communities.” Anthropological Linguistics 4 (1): 28-40.

Halberstam, Judith. 1998. Female Masculinity. Durham, NC: Duke University Press.

- 2005. In a Queer Time and Place: Transgender Bodies, Subcultural Lives. New York: New York University Press.

Hall, G. Stanley. 1904. Adolescence: Its Psychology and Its Relation to Physiology, Anthropology, Sociology, Sex, Crime, Religion, and Education, vol. I and II. Englewood Cliffs, NJ: Prentice-Hall.

Haller, John S., Jr. 1971. Outcasts from Evolution: Scientific Attitudes of Racial Inferiority, 1859-1900. Carbondale and Edwardsville: Southern Illinois University Press.

Halperin, David M. 2009. "Thirteen Ways of Looking at a Bisexual." Journal of Bisexuality 9: 451-5.

Hanisch, Carol. 1970. "The Personal is Political." In Shulamith Firestone and Anned Koedt, eds. Notes from the Second Year: Women's Liberation. New York: Radical Feminist.

Hanshaw, Mark E. 2010. Muslim and American? Straddling Islamic Law and US Justice. El Paso, TX: LFB Scholarly Publishing.

Hempel, Anthony G., Ruth E. Levine, J. Reid Meloy, and Joseph Westermeyer. 2000. “A Cross-Cultural Review of Sudden Mass Assault by a Single Individual in the Oriental and Occidental Cultures.” Journal of Forensic Sciences 45 (3): 582-8.

Henig, Robin Marantz and Samantha Henig. 2012. Twentysomething: Why Do Young Adults Seem Stuck? New York: Hudson Street Press.

Henton, Caroline G. 1989. "Fact and Fiction in the Description of Female and Male Pitch." Language \& Communication 9 (4): 299-311.

Herdt, Gilbert. 1987 [1981]. Guardians of the Flutes: Idioms of Masculinity. New York: Columbia University Press.

Hersch, Patricia. 1999. A Tribe Apart: A Journey into the Heart of American Adolescence. New York: Ballantine Books.

Hervieu-Léger, Danièle. 2002. "Space and Religion: New Approaches to Religious Spatiality in Modernity." International Journal of Urban and Regional Research 26 (1): 99-105.

Higginbotham, A. Leon, Jr. 1978. In the Matter of Color: Race and the American Legal Process: The Colonial Period. New York: Oxford University Press.

Higgins, Paul C. 1980. Outsiders in a Hearing World: A Sociology of Deafness. Beverly Hills, CA and London: Sage Publications.

Higham, C. L. 2000. Noble, Wretched, and Redeemable: Protestant Missionaries to the Indians in Canada and the United States, 1820-1900. Albuquerque, NM: University of New Mexico Press.

Hill, Jane H. 1998. "Language, Race, and White Public Space.” American Anthropologist 100 (3): 680-9.

- 2008. The Everyday Language of White Racism. Malden, MA and Oxford: Blackwell.

Hine, Thomas. 1999. The Rise and Fall of the American Teenager: A New History of the American Adolescent Experience. New York: HarperCollins.

Holtzman, Jon D. 2000. Nuer Journeys, Nuer Lives: Sudanese Refugees in Minnesota. Boston and London: Allyn and Bacon. 
Holzman, M. 2006. Public Education and Black Male Students: The 2006 State Report Card. Schott Educational Inequity Index, Cambridge, MA: The Schott Foundation for Public Education.

Homelessness Research Institute. 2012. "The State of Homelessness in American 2012." Washington, DC: National Alliance to End Homelessness.

Horton, Robin. 1960. “A Definition of Religion, and its Uses." The Journal of the Royal Anthropological Institute of Great Britain and Ireland, 90 (2): 201-26.

Humphreys, Laud. 1970. Tearoom Trade: A Study of Homosexual Encounters in Public Places. Chicago: Aldine Publishing Company.

Huntington, Samuel P. 2004. Who Are We? The Challenges to America's National Identity. New York: Simon \& Schuster.

Huxley, Julian and A. C. Haddon. 1935. We Europeans: A Survey of "Racial" Problems. London: Jonathan Cape.

Ibish, Hussein. 2003. Report on Hate Crimes and Discrimination against Arab Americans: The Post-September 11 Backlash, September 11, 2001-October 11, 2002. Washington, DC: American-Arab Anti-Discrimination Committee.

Ignatiev, Noel. 1995. How the Irish Became White. London and New York: Routledge.

James, William. 1958 [1902]. The Varieties of Religious Experience: A Study in Human Nature. New York: Mentor Books.

Jaques, Elliott. 1965. "Death and the Mid-Life Crisis." International Journal of Psychoanalysis 46: 502-14.

Jenkins, Philip. 2000. Mystics and Messiahs: Cults and New Religions in American History. Oxford and New York: Oxford University Press.

Johnson, Lyndon B. 1966. Public Papers of the Presidents of the United States: Lyndon B. Johnson, 1965, vol. 2. Washington, DC: Government Printing Office.

Jordan, Lisa Marie. 2007. "Religious Adherence and Diversity in the United States: A Geographic Analysis.” Geography of Religion and Belief Systems 2: 3-20.

Kauffman, L. A. 1990. “The Anti-Politics of Identity.” Social Review 90 (1): 67-80.

Keniston, Kenneth. 1962. "Social Change and Youth in America." Daedalus 91 (1): 145-71.

—. 1970. "Youth: A 'New' Stage of Life.” The American Scholar 39 (4): 631-54.

Kett, Joseph F. 2003. "Reflections on the History of Adolescence in America." History of the Family 8: 355-73.

Kimmel, Michael. 2012. Manhood in America: A Cultural History, 3rd ed. New York and Oxford: Oxford University Press.

Kincheloe, Joe L. and Shirley R. Steinberg. 2001 [1997]. Changing Multiculturalism. Buckingham and Philadelphia: Open University Press.

Kirtsoglou, Elisabeth. 2004. For the Love of Women: Gender, Identity, and Same-Sex Relations in a Greek Provincial Town. London and New York: Routledge.

Kosmin, Barry A. and Ariela Keysar. 2009. American Religious Identification Survey 2008. Hartford, CT: Trinity College.

Kowalski, Kathiann M. 2003. Poverty in America: Causes and Issues. Berkeley Heights, NJ: Enslow Publishers, Inc.

Krafft-Ebing, Richard von. 1906 [1886]. Psychopathia Sexualis with Especial Reference to the Antipathic Sexual Instinct: A Medico-Forensic Study, 12th ed. F. J. Rebman, trans. New York: Rebman Company.

Kramer, Cheris. 1977. "Perceptions of Female and Male Speech." Language and Speech 20: 151-61.

Kulick, Don. 2000. “Gay and Lesbian Language.” Annual Review of Anthropology 29: 243-85.

Kulkarni, Sandeep C., Alison Levin-Rector, Majid Ezzati, and Christopher J. L. Murray. 2011. "Falling Behind: Life Expectancy in US Counties from 2000 to 2007 in an International Context." Population Health Metrics 9 (16): 1-33. 
Kunstler, James Howard. 1993. The Geography of Nowhere: The Rise and Decline of America's Man-Made Landscape. New York: Free Press.

Kwong, Peter. 1994. "China's Human Traffickers.” The Nation (October 17): 422-5.

Labov, William. 1964. "Phonological Correlates of Social Stratification." American Anthropologist 66 (6, part 2): 164-76.

-1966. The Social Stratification of English in New York City. Washington, DC: Center for Applied Linguistics.

- 1972. Sociolinguistic Patterns. Philadelphia, PA: University of Pennsylvania Press.

Laing, R. D. 1967. The Politics of Experience. New York: Ballantine Books.

Lakoff, Robin. 1973. "Language and Woman's Place." Language in Society 2 (1): 45-80.

- 1975. Language and Woman's Place. New York: Harper \& Row.

Lambek, Michael. 1981. Human Spirits: A Cultural Account of Trance in Mayotte. Cambridge: Cambridge University Press.

Lane, Harlan. 2005. "Ethnicity, Ethics, and the Deaf-World." Journal of Deaf Studies and Deaf Education 10 (3): 291-310.

Lane, Harlan, Robert Hoffmeister, and Ben Bahan. 1996. A Journey into the Deaf World. San Diego: Dawn Sign Press.

Laqueur, Thomas. 1990. Making Sex: Body and Gender from the Greeks to Freud. Cambridge, MA: Harvard University Press.

Le Bon, Gustave. 1896. The Crowd: A Study of the Popular Mind. New York: The Macmillan Company.

Lechner, Frank J. 1991. "Simmel on Social Space." Theory Culture Society 8: 195-201.

Lee, Richard B. and Irven DeVore, eds. 1968. Man the Hunter. Chicago: Aldine Publishing Company.

Lester, Tory. 2002. "Oh, Gods!" The Atlantic Monthly (February): 37-45.

Lewis, Hylan Garnet. 1955. Blackways of Kent. Chapel Hill, NC: University of North Carolina Press.

Lewis, Oscar. 1959. Five Families: Mexican Case Studies in the Culture of Poverty. New York: New American Library.

- 1961. The Children of Sanchez: Autobiography of a Mexican Family. New York: Random House.

Lichter, Daniel T. 2012. "Immigration and the New Racial Diversity in Rural America." Rural Sociology 77 (1): 3-35.

Lichter, Daniel T. and Kenneth M. Johnson. 2007. "The Changing Spatial Concentration of America's Rural Poor Population.” Rural Sociology 72 (3): 331-58.

Lieske, Joel. 1993. "Regional Subcultures of the United States.” Journal of Politics 55 (4): $888-913$.

- 2010. "The Changing Regional Subcultures of the American States and the Utility of a New Cultural Measure.” Political Research Quarterly 63 (3): 538-52.

Link, Bruce G., and Jo C. Phelan. 1995. "Social Conditions as Fundamental Causes of Disease." Journal of Health and Social Behavior 35 (extra issue): 80-94.

Logan, John R. 2012. "Making a Place for Space: Spatial Thinking in Social Science.” Annual Review of Sociology 38: 507-24.

—. 2013. "The Persistence of Segregation in the 21st Century Metropolis." City \& Community 12 (2): $160-8$.

Long, Jeffery D. 2013. "Diasporic and Indigenous Hinduism in North America.” In P. Pratap Kumar, ed. Contemporary Hinduism. Durham, UK and Bristol, CT: Acumen, 17-31.

Lozinski, Vladimir. 2006. "Ending Child Abandonment in Romania.” http://www.unicef.org/ infobycountry/romania_37375.html, accessed June 22, 2009.

Lu, Alexander and Y. Joel Wong. 2013. "Stressful Experiences of Masculinity among US-Born Immigrant Asian American Men.” Gender \& Society 27 (3): 345-71. 


\section{Bibliography}

Madsen. Richard. 2009. "The Archipelago of Faith: Religious Individualism and Faith Community in America Today.” American Journal of Sociology 114 (5): 1263-301.

Maltz, Daniel N. and Ruth A. Borker. 1982. "A Cultural Approach to Male-Female Miscommunication.” In John J. Gumperz, ed. Language and Social Identity. Cambridge: Cambridge University Press, 196-216.

Mannheim, Karl. 1952. "The Problem of Generations.” In Paul Keckemeti, ed. Essays on the Sociology of Knowledge. London: Routledge \& Kegan Paul, 276-322.

Martineau, Harriet. 1837. Society in America, Volume III. London: Saunders and Otley.

Marty, Martin E. 1984. Pilgrims in Their Own Land: 500 Years of Religion in America. New York: Penguin Books.

McCall, Leslie. 2005. “The Complexity of Intersectionality.” Signs 30 (3): 1771-1800.

McCurdy, John Gilbert. 2011. "Gentlemen and Soldiers: Competing Visions of Manhood in Early Jamestown." In Thomas A. Foster, ed. New Men: Manliness in Early America. New York and London: New York University Press, 9-30.

McEwen, Shannon. 1996. "Learning to Speak Like Girls and Boys: A Developmental Study in Gender and Narrative Style." In Byung-Soo Park and Jong-Bok Kim, eds. Language, Information, and Computation. Seoul, South Korea: Language Education and Research Institute, Kyung Hee University, 449-58.

McLelland, Mark. 2000. "Is There a Japanese 'Gay Identity'?” Culture, Health, \& Sexuality 2 (4): 459-72.

McNally, Michael D. 2005. "Native American Religious and Cultural Freedom: An Introductory Essay.” Harvard Pluralism Project. http://www.pluralism.org/reports/ view/176, accessed January 14, 2009.

McPherson, Miller, Lynn Smith-Lovin, and James M. Cook. 2001. "Birds of a Feather: Homophily in Social Networks." Annual Review of Sociology 27: 415-44.

McWhirter, David P., Stephanie A. Sanders, and June Machover Reinisch, eds. 1990. Homosexuality/Heterosexuality: Concepts of Sexual Orientation. The Kinsey Institute Series. New York: Oxford University Press.

Mead, Margaret. 1928. Coming of Age in Samoa: A Psychological Study of Primitive Youth for Western Civilization. New York: W. W. Morrow.

- 1935. Sex and Temperament in Three Primitive Societies. London: Routledge \& Kegan Paul.

Mills, C. Wright. 1953. White Collar. New York: Oxford University Press.

- 1956. The Power Elite. New York: Oxford University Press.

Mintz, Steven. 2004. Huck's Raft: A History of American Childhood. Cambridge, MA and London: The Belknap Press of Harvard University Press.

Mitchell, Lewis, Morgan R. Frank, Kameron Decker Harris, Peter Sheridan Dodds, and Christopher M. Danforth. 2013. "The Geography of Happiness: Connecting Twitter Sentiment and Expression, Demographics, and Objective Characteristics of Place.” PLoS ONE 8 (5): 1-15.

Molloy, Harvey, and Latika Vasil. 2002. "The Social Construction of Asperger Syndrome: The Pathologizing of Difference?" Disability and Society 17 (6): 659-69.

Money, John. 1988. Gay, Straight, and In-Between: The Sexology of Erotic Orientation. Oxford and New York: Oxford University Press.

Montagu, M. F. Ashley. 1945. Man's Most Dangerous Myth: The Fallacy of Race, 2nd ed. New York: Columbia University Press.

Morgan, David R. and Laura Ann Wilson. 1990. "Diversity in the American States: Updating the Sullivan Index.” Publius 20 (1): 71-81.

Morin, Richard. 2012. "Rising Share of Americans See Conflict Between Rich and Poor." Washington, DC: Pew Research Center.

Morris, Jessica F., Kimberly F. Balsam, and Esther D. Rothblum. 2002. "Lesbian and Bisexual Mothers and Nonmothers: Demographics and the Coming-Out Process." Journal of Family Psychology 16 (2): 144-56. 
Morris, Jessica F., Amy J. Ojerholm, Teri M. Brooks, Dana M. Osowiecki, and Esther D. Rothblum. 1995. "Finding a 'Word for Myself': Themes in Lesbian Coming-Out Stories.” In Karla Jay, ed. Dyke Life: From Growing Up to Growing Old. A Celebration of the Lesbian Experience. New York: Basic Books, 36-44.

Morris, Rosalind (1995) "All Made Up: Performance Theory and the New Anthropology of Sex and Gender." Annual Review of Anthropology 24: 567-92.

Moynihan, Daniel Patrick. 1965. The Negro Family: The Case For National Action. Office of Policy Planning and Research United States Department of Labor

Mundy, Liza. 2013. "The Gay Guide to Wedded Bliss.” The Atlantic (June): 56-70.

Murphy, Robert F. 1990 [1987]. The Body Silent. New York and London: W. W. Norton.

Murray, Stephen O. 1996. American Gay. Chicago and London: The University of Chicago Press.

Myerhoff, Barbara. 1978. Number Our Days. New York: Touchstone/Simon \& Schuster.

Nader, Laura. 1972. "Up the Anthropologist: Perspectives Gained From Studying Up.” In Dell Hymes, ed. Reinventing Anthropology. New York: Pantheon Books, 284-311.

Nanda, Serena. 1999. Neither Man nor Woman: The Hijras of India, 2nd ed. Belmont, CA: Wadsworth Publishing Company.

- 2000. Gender Diversity: Crosscultural Variations. Long Grove, IL: Waveland Press.

Nash, Manning. 1962. "Race and the Ideology of Race." Current Anthropology 3 (3): 285-8.

- 1989. The Cauldron of Ethnicity in the Modern World. Chicago: The University of Chicago Press.

Nathanson, Constance A. 1975. "Illness and the Feminine Role: A Theoretical Review." Social Science and Medicine 9 (2): 57-62.

National Association for the Advancement of Colored People. 1919. Thirty Years of Lynching in the United States 1889-1918. New York: Negro Universities Press.

New York University. 2007. "The Flapper: The Heroine or Antagonist of the 1920s.” https:// wikis.nyu.edu/ek6/modernamerica/index.php/AmericanPowerAmpCulturalHegemony/1920 sNewWoman, accessed June 28, 2013.

Newman, Katherine S. 1988. Falling from Grace: The Experience of Downward Mobility in the American Middle Class. New York: The Free Press.

Novak, Michael. 1972. The Rise of the Unmeltable Ethnics: Politics and Culture in the Seventies. New York: Macmillan.

Noxon, Christopher. 2006. Rejuvenile: Kickball, Cartoons, Cupcakes, and the Reinvention of the American Grown-up. New York: Crown Publishers.

Numan, Fareed. H. 1992. "The Muslim Population in the United States.” http://www.islam101. com/history/population2_usa.html, accessed January 15, 2009.

O'Barr, William, and Bowman Atkins. 1980. "'Women's Language' or 'Powerless Language.'” In Sally McConnell-Ginet, Ruth Borker, and Nelly Furman, eds. Women and Language in Literature and Society. New York: Praeger, 93-110.

O'Faolain, Julia and Lauro Martines, eds. 1973. Not in God's Image: Women in History from the Greeks to the Victorians. New York: Harper Torchbooks.

Obrecht, Fred. 1999. Minimum Essentials of English, 2nd ed. Hauppauge, NY: Barron's Educational Series.

Ochs, Robyn, ed. 2005. Getting Bi: Voices of Bisexuals around the World. Boston: Bisexual Resource Center.

Ortner, Sherry. 1978. Sherpas through their Rituals. Cambridge: Cambridge University Press.

- 1998. "Identities: The Hidden Life of Class." Journal of Anthropological Research 54 (1): $1-17$.

Osorio-O’Dea, Patricia. 2001. "Bilingual Education: An Overview.” Washington, DC: Congressional Research Service/The Library of Congress.

Pampel, Fred C., Patrick M. Krueger, and Justin T. Denney. 2010. "Socioeconomic Disparities in Health Behaviors.” Annual Review of Sociology 36: 349-70. 
Paoletti, Jo B. 1987. “Clothing and Gender in America: Children's Fashions, 1890-1920." Signs 13 (1): 136-43.

Parens, Joshua. 1994. "Multiculturalism and the Problem of Particularism." American Political Science Review 88 (1): 169-81.

Park, Robert E. 1936. "Human Ecology.” American Journal of Sociology 42 (1): 1-15.

Parker, Kim. 2012. "Yes, the Rich are Different." http://www.pewsocialtrends.org/2012/08/27/ yes-the-rich-are-different/, accessed June 23, 2013.

Parsons, Talcott. 1942. "Age and Sex in the Social Structure of the United States." American Sociological Review 7 (5): 604-16.

- 1951. The Social System. Glencoe, IL: The Free Press of Glencoe.

Patterson, Charlotte J. 2006. "Children of Lesbian and Gay Parents." Current Directions in Psychological Science 15 (5): 241-4.

Patterson, Orlando. 1975. "Context and Choice in Ethnic Allegiance: A Theoretical Framework and Caribbean Case Study.” In Nathan Glazer and Daniel Patrick Moynihan, eds. Ethnicity: Theory and Experience. Cambridge, MA: Harvard University Press, 305-49.

Pearce, Roy Harvey. 1965 [1953]. Savagism and Civilization: A Study of the Indian and the American Mind. Baltimore and London: The Johns Hopkins Press.

Pelletier, Joel. 2004. "American Fundamentalists.” http://www.americanfundamentalists.com/ cast/robertson.html, accessed February 17, 2007.

Peters, David J. 2013. “American Income Inequality across Economic and Geographic Space, 1970-2010.” Social Science Research 42: 1490-1504.

Pew Charitable Trusts. 2012. "Pursuing the American Dream: Economic Mobility across Generations." Washington, DC: Pew Charitable Trusts.

Pew Research Center. 2008. "US Religious Landscape Survey-Religious Affiliation: Diverse and Dynamic." Washington, DC: Pew Forum on Religion and Public Life.

—. 2010a. "Millennials: A Portrait of Generation Next." Washington, DC: Pew Research Center.

—. 2010b. "The Rise of Asian Americans." Washington, DC: Pew Research Center.

Pew Social \& Demographic Trends. 2012. "The Lost Decades of the Middle Class." Washington, DC: Pew Research Center.

Phelan, Jo C., Bruce G. Link, and Parisa Tehranifar. 2010. "Social Conditions as Fundamental Causes of Health Inequalities: Theory, Evidence, and Policy Implications.” Journal of Health and Social Behavior 51 (S): S28-40.

Phillips, Kim M. and Barry Reay. 2011. Sex Before Sexuality: A Premodern History. Cambridge, UK and Malden, MA: Polity.

Porter, Jeremy R. 2010. "Diversity, Macrosociology, and Religious Belonging: Using MixedLevel Models in Examining Spatial Variation and the Closed Community Thesis." Sociological Focus 43 (2): 128-49.

Postman, Neil. 1994 [1982]. The Disappearance of Childhood. New York: Vintage Books.

Potowski, Kim. 2010. "Language Diversity in the United States: Dispelling Common Myths and Appreciating Advantages.” In Kim Potowski, ed. Language Diversity in the United States. Cambridge: Cambridge University Press, 1-24.

Putnam, Robert D. 2000. Bowling Alone: The Collapse and Revival of American Community. New York: Simon \& Schuster.

Raymond, Janice G. 1994 [1979]. The Transsexual Empire: The Making of a She-Male. New York: Teachers College Press.

Read, Jen'nan Ghazal, and Bridget K. Gorman. 2010. "Gender and Health Inequality.” Annual Review of Sociology 36: 371-86.

Reagan, Bernice Johnson. 1993. “'Battle Stancing': To Do Cultural Work in America.” In Marta Moreno Vega and Cheryll Greene, eds. Voices from the Battlefront: Achieving Cultural Equity. Trenton, NJ: Africa World Press, 69-82. 
Rembis, Michael A. 2013. Defining Deviance: Sex, Science, and Delinquent Girls, 1890-1960. Urbana, Chicago, and Springfield: University of Illinois Press.

Republic of Lakotah. 2007. "Lakotah Unilateral Withdrawal.” http://www.republicoflakotah. com/2009/2007-lakotah-unilateral-withdrawal/, accessed June 10, 2013.

Rich, Chip and Steven R. Heape. 2008. Our Spirits Don't Speak English: Indian Boarding School. Dallas, TX: Rich-Heape Films.

Ripley, William Z. 1899. The Races of Europe: A Sociological Study. New York: D. Appleton and Company.

Roberts, Sam. 2006. "Out of Africa: More Africans are Now Coming to the United States as Immigrants than in the Days of Slavery." New York Times Upfront, November 27, 2006. http://teacher.scholastic.com/scholasticnews/indepth/upfront/features/index.asp?article= f112706_out_of_africa, accessed January 5, 2009.

Robinson, Marcus, Charles Pfeffer, and Joan Buccigrossi. 2003. "Business Case for Inclusion an Engagement.” Rochester, NY: wetWare, Inc.

Robinson, Oliver C. and Jonathan A. Smith. 2010. "Investigating the Form and Dynamics of Crisis Episodes in Early Adulthood: The Application of a Composite Qualitative Method.” Qualitative Research in Psychology 7 (2): 170-91.

Rodgers, Bruce. 1972. The Queen's Vernacular: A Gay Lexicon. San Francisco: Straight Arrow Books.

Roediger, David. 2005. Working Toward Whiteness: How America's Immigrants Became White-The Strange Journey from Ellis Island to the Suburbs. New York: Basic Books.

Rollock, N. and Gillborn, D. 2011. Critical Race Theory (CRT). British Educational Research Association. http://www.bera.ac.uk/files/2011/10/Critical-Race-Theory.pdf, accessed July 18, 2014.

Roney, Jessica Choppin. 2011. “Effective Men' and Early Voluntary Associations in Philadelphia, 1725-1775." In Thomas A. Foster, ed. New Men: Manliness in Early America. New York and London: New York University Press, 155-71.

Roscoe, Will. 1998. Changing Ones: Third and Fourth Genders in Native North America. New York: St. Martin's Press.

Rosen, Hanna. 2010. “The End of Men.” The Atlantic(July/August): 56-72.

Rothblum, Esther D. 2010. "The Complexity of Butch and Femme among Sexual Minority Women in the 21st Century." Psychology of Sexualities Review 1 (1): 29-42.

Rothstein, Richard. 2004. "A Wider Lens on the Black-White Achievement Gap." Phi Delta Kappan 86 (2): 104-10.

Rupasingha, Anil and John Chilton. 2009. "Religious Adherence and County Economic Growth in the US." Journal of Economic Behavior \& Organization 72: 438-50.

Rushdoony, R. J. 1973. The Institutes of Biblical Law. Nutley, NJ: Craig Press.

Rust, Paula C. 1995. Bisexuality and the Challenge to Lesbian Politics: Sex, Loyalty, and Revolution. New York and London: New York University Press.

Sahlins, Marshall. 1976. The Use and Abuse of Biology: An Anthropological Critique of Sociobiology. Ann Arbor: University of Michigan Press.

Samuel, Lawrence R. 2012. The American Dream: A Cultural History. Syracuse, NY: Syracuse University Press.

Scheper-Hughes, Nancy. 1992. Death without Weeping: The Violence of Everyday Life in Brazil. Berkeley: University of California Press.

Scherger, Simone. 2009. "Cultural Practices, Age, and the Life Course." Cultural Trends 18 (1): 23-45.

Schermerhorn, R.A. 1970. Comparative Ethnic Relations. New York: Random House.

Schiffman, Harold F. 2005. "Language Policy and Linguistic Culture." In Thomas Ricento, ed. An Introduction to Language Policy: Theory and Method. Malden, MA: Blackwell, 111-24. 


\section{Bibliography}

Schlesinger, Arthur. 1992. The Disuniting of America. New York: W. W. Norton.

Schnittker, Jason, and Jane D. McLeod. 2005. "The Social Psychology of Health Disparities." Annual Review of Sociology 31: 75-103.

Schnore, Leo F. 1958. "Social Morphology and Human Ecology." American Journal of Sociology 63 (6): 620-34.

Sentencing Project, The. 2000. "Reducing Racial Disparity in the Criminal Justice System: A Manual for Practitioners and Policymakers." Washington, DC: The Sentencing Project.

Shamoon, Deborah. 2012. Passionate Friendship: The Aesthetics of Girls' Culture in Japan. Honolulu: University of Hawaii Press.

Shannon, Lyle W. 1954. "The Spatial Distribution of Criminal Offenses by States." Journal of Criminal Law and Criminology 45 (3): 264-73.

Shipler, David K. 2004. The Working Poor: Invisible in America. New York: Alfred A. Knopf. Simmel, Georg. 1997. "The Sociology of Space." In David Frisby and Mike Featherstone, eds. Simmel on Culture. Mark Ritter, trans. London: Sage, 137-70.

Simpson, George E. and J. Milton Yinger. 1972. Racial and Cultural Minorities, 4th ed. New York: Harper \& Row.

Slaughter, Anne-Marie. 2012. "Why Women Still Can't Have It All.” The Atlantic (July/ August): 85-102.

Smedley, Audrey. 1999. Race in North America: Origin and Evolution of a Worldview, 2nd ed. Boulder, CO: Westview Press

Smith, Anthony Smith. 1991. National Identity. Reno, NV: University of Nevada Press.

Snow, Robert L. 1999. The Militia Threat: Terrorists Among Us. New York: Plenum.

Solomon, Sondra E. Solomon, Esther D. Rothblum, and Kimberly F. Balsam. 2005. "Money, Housework, Sex, and Conflict: Same-Sex Couples in Civil Unions, Those Not in Civil Unions, and Heterosexual Married Siblings.” Sex Roles 52 (9/10): 561-75.

Somin, Ilya. 2006. "The Final Prejudice: Atheists May be the Most Unpopular Minority, but Law Offers Few Answers." Legal Times 29 (16).

Spraggins, Renée. 2005. "We the People: Women and Men in the United States." Washington, DC: US Department of Commerce and US Census Bureau.

Stacey, Judith. 2011. Unhitched: Love, Marriage, and Family Values from West Hollywood to Western China. New York and London: New York University Press.

Stack, Carol. 1974. All Our Kin: Strategies for Survival in a Black Community. New York: Harper \& Row.

Stern, Kenneth. 1996. A Force upon the Plain: The American Militia Movement and the Politics of Hate. New York: Simon \& Schuster, Inc.

Stewner-Manzanares, Gloria. 1988. "The Bilingual Education Act: Twenty Years Later." Washington, DC: Office of Bilingual Education on Minority Languages Affairs, US Department of Education.

Subtirelu, Nicholas Close. 2013. "'English ... It's Part of Our Blood': Ideologies of Language and Nation in United States Congressional Discourse.” Journal of Sociolinguistics 17 (1): 37-65.

Sullivan, John L. 1973. "Political Correlates of Social, Economic, and Religious Diversity in the American States." The Journal of Politics 35 (1): 70-84.

Szasz, Thomas S. 1961. The Myth of Mental Illness: Foundations of a Theory of Personal Conduct. New York: Dell.

Takim, Liyakat Nathani. 2009. Shi'ism in America. New York and London: New York University Press.

Tannen, Deborah. 1990. You Just Don't Understand: Women and Men in Conversation. New York: Ballantine Books.

Terrazas, Aaron. 2010. "Mexican Immigrants in the United States." Migration Policy Institute. http://www.migrationinformation.org/usfocus/display.cfm?ID=767, accessed June 12, 2013.

Thompson, Derek. 2013. "Death of the Salesmen." The Atlantic (June): 18-20. 
Thompson, Don. 2013. “Transgender Bathroom Rights Bill Passed by California Lawmakers.” http://www.huffingtonpost.com/2013/07/03/transgender-bathroom-rights_n_3543601. html, accessed July 4, 2013.

Thorpe, Francis Newton. 1909. The Federal and State Constitutions, Colonial Charters, and Other Organic Laws of the States, Territories, and Colonies Now and Heretofore Forming the United States. Washington, DC: Government Printing Office.

Tolbize, Anick. 2008. "Generational Differences in the Workplace." Minneapolis, MN: University of Minnesota Research and Training Center on Community Living.

Toro, Luis Angel. 1995. “A People Distinct from Others': Race and Identity in Federal Indian Law and the Hispanic Classification of OMB Directive No. 15." Texas Tech Law Review 26 (4): 1219-421.

Tsui, Bonnie. 2011. “The End of Chinatown.” The Atlantic (December): 17-18.

Twenge, Jean M. and Tim Kasser. 2013. "Generational Changes in Materialism and Work Centrality, 1976-2007: Associations with Temporal Changes in Societal Insecurity and Materialistic Role Modeling.” Personality and Social Psychology Bulletin 39 (7): 883-97.

Twenge, Jean M., Sara Konrath, Joshua D. Foster, W. Keith Campbell, and Brad Bushman. 2008. "Egos Inflating Over Time: A Cross-Temporal Meta-Analysis of the Narcissistic Personality Inventory." Journal of Personality 76 (4): 875-901.

United Nations High Commissioner for Refugees (UNHCR). 2003. "Child Soldiers: Turning Refugees into Gunmen.” Refugees Magazine 131 (June 2003). http://www.unhcr.org/ 41372a294.html, accessed June 22, 2009.

United States Court of Appeals for the Ninth Circuit. 2002. Michael A. Newdowv US Congress et al. http://caselaw.findlaw.com/us-9th-circuit/1262890.html, accessed April 13, 2015.

Urciuoli, Bonnie. 1995. "Languages and Borders." Annual Review of Anthropology 24: 525-46.

—. 2001. "Complex Diversity of Language in the United States." In Ida Susser and Thomas C. Patterson, eds. Cultural Diversity in the United States. Malden, MA and Oxford: Blackwell, 190-205.

—. 2003. "Stealth Prejudice: Puerto Rican College Students' Experiences of Race-Marking Mapped onto Language." Paper delivered at Language and Im(migration) in France, Latin America and the United States: Sociolinguistic Perspectives, University of Texas, Austin.

US Census Bureau. 2001. "Overview of Race and Hispanic Origin 2000.” Washington, DC: US Census Bureau.

US Department of Health and Human Services. 2012. "Health, United States, 2012: With Special Feature on Emergency Care." Hyattsville, MD: National Center for Health Statistics.

Utter, Jack. 1993. American Indians: Answers to Today's Questions. Lake Ann, MI: National Woodlands Publishing Company.

Valentine, David. 2007. Imagining Transgender: An Ethnography of a Category. Durham, NC and London: Duke University Press.

Veblen, Thorstein. 1934 [1899]. Theory of the Leisure Class: An Economic Study of Institutions. New York: Modern Library.

Vincent, Peter, Morton D. Winsberg, and Barney Wharf. 2006. "Religious Diversity in the Southeastern US.” Southeastern Geographer 46 (1): 79-96.

Violence Policy Center. 2012. "When Men Murder Women: An Analysis of 2010 Homicide Data." Washington, DC: Violence Policy Center.

Voss, Paul R. David D. Long, Roger B. Hammer, and Samantha Friedman. 2006. "County Child Poverty Rates in the US: A Spatial Regression Approach.” Population Research and Policy Review 25 (4): 369-91.

Wade, Wyn Craig. 1987. The Fiery Cross: The Ku Klux Klan in America. New York: Simon \& Schuster, Inc.

Waldrep, Christopher and Michael Bellesiles, eds. 2006. Documenting American Violence: A Sourcebook. Oxford and New York: Oxford University Press. 


\section{Bibliography}

Wallace, Anthony F. C. 1966. Religion: An Anthropological View. New York: Random House. Wang, Man, Rachel Garshick Kleit, Jane Cover, and Christopher S. Fowler. 2012. "Spatial Variations in US Poverty: Beyond Metropolitan and Non-Metropolitan.” Urban Studies 49 (3): 563-85.

Wardin, Albert W, Jr. 2001. "Doing Diversity Baptist Style: Major Variations.” Brentwood, TN: The Baptist History and Heritage Society.

Warf, Barney and Morton Winsberg. 2010. "Geographies of Megachurches in the United States." Journal of Cultural Geography 27 (1): 33-51.

Warner, W. Lloyd, Marchia Mekker, and Kenneth Eells. 1949. Social Class in America: A Manual of Procedure for the Measurement of Social Status. Chicago: Social Research Associates, Inc.

Washington, Jesse. 2008. “Obama's True Colors: Black, White . . or Neither?” http://www. newsweek.com/id/174404, accessed December 16, 2008.

Wassersug, Richard Joel. 2012. "Embracing a Eunuch Identity.” http://www.tikkun.org/nextgen/embracing-a-eunuch-identity, accessed July 8, 2013.

Weber, Max. 1968. Economy and Society, Vol.1. Guenther Roth and Claus Wittich, eds. New York: Bedminster Press.

Wethington, Elaine. 2000. "Expecting Stress: Americans and the 'Midlife Crisis." Motivation and Emotion 24 (2): 85-103.

Whitaker, Robert. 2002. Mad in America: Bad Science, Bad Medicine, and the Enduring Mistreatment of the Mentally Ill. Cambridge, MA: Perseus Publishing.

Whiting, Beatrice B. 1965. "Sex Identity and Physical Violence: A Comparative Study." American Anthropologist 67 (6, pt. 2): 123-40.

Wiley, Terrence G. 1996. Literacy and Language Diversity in the United States. McHenry, IL: Center for Applied Linguistics and Delta Systems Co.

Wilford, Justin G. 2012. Sacred Subdivisions: The Postsuburban Transformation of American Evangelicalism. New York and London: New York University Press.

Williams, A. N. 2007. “Thomas Willis' Paediatric General Practice.” The British Journal of General Practice 57 (534): 70-3.

Williams, Gary L. 2011. "Special Issue: Critical Race Theory." Myriad: 2-6.

Wilton, Tamsin. 1995. Lesbian Studies: Setting an Agenda. London and New York: Routledge.

Winthrop, John. 1645. “On Liberty.” http://www.constitution.org/bcp/winthlib.htm, accessed July 7, 2014.

Wirth, Louis. 1938. "Urbanism as a Way of Life." The American Journal of Sociology 44 (1): $1-24$.

Wolf, Naomi. 1991. The Beauty Myth: How Images of Beauty are Used Against Women. New York: Morrow.

Wolfram, Walt. 1974. "The Relationship of White Southern Speech to Vernacular Black English.” Language 50 (3): 498-527.

- 2004. "The Grammar of Urban African American Vernacular English." In Bernd Kortmann and Edgar Schneider, eds. Handbook of Varieties of English. Berlin: Mouton de Gruyter, 111-32.

Wollstonecraft, Mary. 2010 [1792]. A Vindication of the Rights of Woman with Strictures on Political and Moral Subjects. http://www.earlymoderntexts.com/pdf/wollvind.pdf, accessed June 28, 2013.

Wrigley, Owen. 1996. The Politics of Deafness. Washington, DC: Gallaudet University Press.

Yaguchi, Michiko, Yoko Iyeiri, and Hirolko Okabe. 2004. "Style and Gender Differences in Formal Contexts: An Analysis of Sort of and Kind of in the Corpus of Spoken Professional American English." English Corpus Studies 11: 63-79.

Yinger, J. Milton. 1994. Ethnicity: Source of Strength? Source of Conflict? Albany, NY: State University of New York Press. 
Zelinsky, Wilbur. 1961. “An Approach to the Religious Geography of the United States: Patterns of Church Membership in 1952." Annals of the Association of American Geographers 51 (2): 139-93.

Zenou, Yves. 2003. "The Spatial Aspects of Crime." Journal of the European Economic Association 1 (2/3): 459-67.

Zola, Irving Kenneth. 1983. Socio-Medical Inquiries. Philadelphia: Temple University Press.

Zukin, Sharon. 1982. Loft Living: Culture and Capital in Urban Change. Baltimore and London: The Johns Hopkins Press. 


\section{Index}

achievement gap 52-3

Addams, Jane 99

adolescence 7, 138, 186, 222-5, 227-9, $235-9,273$

affirmative action 50-2

Affordable Care Act of 2010 (Obamacare) 100

African American 13, 17, 39-56, 84; age and 230, 242, 248; Census and 48-50, 65; double consciousness among 45; family among 102; gender and 128, 149, 154; geography and 291, 294, 297, 300, 305; health and 250, 259-60, 262-5, 267, 271, 274; income and 94, 96, 102; language and $168,174,178,188-9$; new immigrants 56-8; religion and 84, 207, 209, 212; violence and 71, 74; see also Black

Afrocentrism 34

Aid to Families with Dependent Children (AFCD) 100

AIDS 151, 264; AIDS Coalition to Unleash Power (ACT UP) 16, 252

Alamo, Battle of the 29, 74

Alexie, Sherman 71

Allport, Gordon 18-20

American Association of Retired Persons (AARP) 15, 252

“American dream" 89, 99, 110, 134

American Indian Movement 16, 68-9

Americans with Disabilities Act 269

Anderson, Benedict 171

anorexia 256, 266, 274

Anthony, Susan B. 123

Anti-Defamation League 207

apartheid 24, 297

Arab 24, 48, 57, 64, 66, 81-4, 166, 209

Arabic 64, 82, 144, 166-8, 173

Ariès, Phillipe 225-6

Arnett, Jeffrey 229, 239
Aryan Nations 60

Aschmann, Rick 180

Asian American 1, 28-30,77-81; age and 230, 236, 242, 248; biracial and 7, 50, 58; Census and 48-9; education among 32, 53; gender and 121, 136; geography and 297, 300 ; health and 263, 268, 271; income and 52, 94, 98; language and 81, 173-4; religion and 210-12

assimilation 21-2, 24-5, 34, 47, 66, 68, 86, 91, 163, 181, 270; Indian boarding school and $177-8$

atheists 197, 215-16

Atran, Scott 194

attention deficit hyperactivity disorder 259 , 274

Augé, Mark 286

autism 250-1, 257, 271, 274

Baby Boomer 7, 219-20, 240, 246-8

Babyland 264

Bachofen, Johann Jakob 115

Baptist 177, 197-8, 215, 292, 308

bar mitzvah 225

Barth, Fredrik 65

Bell, Derrick 53-4

Bellah, Robert 195-6

Benkert, Karl Maria 141

berdache 14, 133, 144

Bernstein, Basil 169-70, 183

bilingual education 180-3; Bilingual Education Act 77, 181

biracial 7-8, 57

birth rate $218-19,221$

bisexual(ity) 7, 139, 142-3, 146-9, 151, 154, $156-8,162$

Black 1, 12-13, 16, 23-4, 33, 36-61, 86; age and Barack Obama and 8; biracial and 7; 
family 102-3; gender and 112, 121, 123, 133; geography and 277, 291, 294, 297, $300,305,307$; health and 236, 262-4, 268; Hispanics 65, 73; income and 94, 98, 105, 109; language and 168, 189; religion 198, 207, 209, 212-13, 215; women 10, 130; see also African American

Black Panthers 47

Black Vernacular English (BVE) 168, 188

Blavatsky, Helena 203, 211

Bloom, Allan 35

Bloom, Howard 18

Bloom, Paul 6

Blumenbach, Johann Friedrich 8

Boas, Franz 37

bobos 107-8

Boston 30, 51, 85, 184, 200, 206, 285, 300

Boswell, John 140, 142, 226

Boy Scouts 134-5, 147

Boyer, Pascal 194

Brooks, David 107-8

Brown v Board of Education of Topeka, Kansas 46

Buddhism/Buddhist 1, 10, 192, 194, 197, 203-4, 210-11, 213

Bush, George H. W. 80, 218

Bush, George W. 182

busing 51

Butler, Judith 118

California 28, 30, 52, 57, 68-9, 73-4, 78, 291,307 ; diversity in 287 ; gender in 137 , 151, 153; Jewish elderly in 245; language in $174,182,189$; politics in 275 ; religion in 211,309 ; University of 51

Canada 24, 26, 57, 67, 75, 78, 133, 151, $161,164,176-7,180,220,291$

Canetti, Elias 18, 20

Carlisle Indian Industrial School 66, 178

caste system 90

Castro, Fidel 76

Catholic 27, 59, 63-4, 66, 73, 85, 196-9, 201, 205, 213-5, 225, 268, 287, 308

Caucasian 2, 7-8, 48, 73, 80, 82

census tract 276-7, 290, 297, 300

Chalcedon Foundation 206

Chauncey, George 149-50

Cherokee 66-7, 71, 133, 176-7, 179

Chicago 30, 43-4, 99, 204, 234, 276, 291, 300, 307

China 30, 48, 77-9, 253
Chinatown 79, 296

Chinese 1, 12, 24, 28, 30, 48-9, 65, 77-8, 296; Census categories of 173; Chinese Exclusion Act 30, 79; gender and 134; language and 181; religion and 211; traditional medicine of 252

Christian(ity) 1-3, 10-11, 21, 33, 35, 46, 191-2, 194; age and 225, 227; Arabs and 82, 84; civil religion and 195-6; colonialism and 66, 178, 212; gender and 114, 116, 144; geography and 292, 309; history of 201-4; Korean 81; Ku Klux Klan and 58-60; language and 177; intolerance and 201-2; politics and 213-4; statistics on 197-8; styles of 205-6; subjugation and 24; Supreme Court rulings on 214-5

Christian Coalition 206

Christian Identity 60, 206-7

Christian Reconstructionism 206

Christian Science 200, 203

civil religion 195-6

Civil Rights Act (1964) 23, 46, 50; Civil Rights Act (1875) 42; American Indian Civil Rights Act (1968) 68

Civil War 40-3, 58, 67-8, 99, 125, 207, 297

Compton's Cafeteria riot 160

Connell, R. W. 131-2

Conrad, Peter, 256-7

Constitution 23, 28, 41, 122-3, 180, 191, 202

Coontz, Stephanie 126-7

Crenshaw, Kimberlé 10, 53

critical race theory 53-4

Cuba(n) 30, 49, 73-4, 76-81, 291

Darwin, Charles 2

Daughters of Bilitis 153

Dawes Act 68; see also General Allotment Act

de Tocqueville, Alexis 36, 38, 62, 84, 94, 105, 122, 191-2, 198-9

deaf 15, 183, 250, 253, 257, 268-9, 271; Deafworld 270

deMauss, Lloyd 226

Democrat 97, 149, 213-14, 247-8, 275-6

depression (mental illness) 104, 136, 265 , 267, 274

desegregation 46, 50-1

"deserving poor" 98

Diagnostic and Statistical Manual 162, 273

dialect 164, 168, 170-2, 179-80, 189, 287 


\section{Index}

Dollard, John 99

double consciousness 45-6

Dred Scott 41

D'Souza, Dinesh 35

Du Bois, W. E. B. 44-5

Duneier, Mitchell 105

Durkheim, Émile 91-2, 122, 192, 284

Ebonics 168, 189; see also Black Vernacular English

Ehrenreich, Barbara 104-5

elaborated code 169-70, 183

Ellis, Havelock 142-3

Emancipation Proclamation 41

Engels, Friedrich 115, 284

English (language) 1, 3, 6, 10-11, 13-14, 21, $29,33,35,46,53,57,77,80-2,111,144$, 163-70, 173-5, 177-89, 191, 222, 229, 253, 291; English (people) 27, 30, 37-8, 60, 62, 66, 85, 200-1, 233, 287

Epstein, Robert 147-8

Equal Education Opportunity Act 182, 189

Equal Rights Amendment (ERA) 124

Erikson, Erik 228, 237, 240

evangelical(ism) 198, 200, 204-5, 212-3, 215

Farrakhan, Louis 46, 136, 209

fertility rate $31,219,221$

Filipino 49, 80; see also Philippines

Fifteenth Amendment 23

flapper 123, 126-7, 152

Florida 28, 30, 52, 57, 291; age in 223, 231, 233; Hispanics in 73-7; language in 174 , 180; religion in 206

Focus on the Family 206

Foucault, Michel 118, 140, 144, 171, 257, 285-6, 305

Fourteenth Amendment 23, 41, 123

friction of distance 307

Friedan, Betty 127

Freud, Sigmund 18-19, 139, 228, 235, 273

fundamentalism 4, 204-6, 210

Fundamentalist Church of Jesus Christ of Latter Day Saints (FLDS) 205

Furnivall, J. S. 20-1

Fussell, Paul 96

Gallaudet University 15, 183, 270

Gans, Herbert 85, 279-80

Gardner, Gerald 204

Gardner, Howard 9
Garreau, Joel 291-2, 294

Garvey, Marcus 45, 47, 209

gay $4,16,33,35,124,140-2,145-62,186$, 205, 213, 215, 248

Gay and Lesbian Alliance Against

Discrimination (GLAAD) 16, 145-6, 151

Geertz, Clifford 4, 192

genderqueer 146, 161

General Allotment Act 68 see also Dawes Act

Generation X 7, 219, 246-7

genocide 25

"Gentleman's Agreement" 80

Georgia 39, 98, 121, 279, 297, 306

Gieryn, Thomas 278, 285-6

Gilmore, David 117-18, 131

Gini index 93-4

Goffman, Erving 14, 254-5

Goldschmidt, Walter 95, 105

Graham, Billy 199

Grant, Ulysses 58, 207

Great Awakening 199, 201-3

Great Depression 75, 89, 99, 123, 246

Great Migration 43, 294

gross national product 93

Gumperz, John 170-1

Hall, G. Stanley 229, 235, 237-40, 268

Hawaii 78-80, 149, 166, 179, 211, 279; see also Native Hawaiian

hegemonic masculinity 131-2, 134, 136, 149

heteronormativity 138-9, 147-9

heterotopia 286, 305

Hill, Jane 187

Hindu(ism) 1, 90, 195, 197-8, 203, 205, 210-13, 224, 227-8

Hindutva 210

Hirsch, Patricia 237

Hirschfeld, Magnus 143-4

Hispanic 1, 11, 28, 30, 33, 73-7;

achievement gap among 53; affirmative action and 52; age and 230, 236, 242, 248; anti-Semitism among 207; Census and 48-50, 65; gender and 121, 149, 154-5; geography and 278, 291, 296-7, 300; health and 263-4, 267, 271, 274; income and 52, 94, 98; language and 174; prison and 55-6; religion and 212; Voting Rights Act and 163

Hofriyat 252-3

homelessness 96, 104-5, 234, 236

homicide 259, 263-4, 266, 268, 307 
homosexual(ity) 9, 11, 14, 115, 134, 138-44, 146-60, 162, 186, 199, 206, 250, 253, 256-7

Horton, Robin 192-3

Hull House 99

human geography 279,282

human ecology 279-80, 284

Humphreys, Laud 150-1, 157

Huntington, Samuel 181

identity politics 33,35

Immigration Act 30, 80, 83

Indian (American) 23, 36, 58, 66-73, 75, 133-4; boarding school 66, 177-8, 180, 212; Census and 48-50, 65; health and 265; language and 176-9, 180; religion and 211-12; see also Native American

India(n) (Asian) 24, 65, 80-1, 83-4, 210

infant morality rate 219-20, 225, 258, 263-4

integrationist 45-6

International Society for Krishna

Consciousness (ISKCON) 210

intersectionality $10-11,13,15,54,138,252$, 274

intersex 139, 161

Inuit 227

Iroquois 23, 67, 116

Islam 10, 46, 82, 205, 209; Islamophobia 83

Jamestown 27, 38, 132, 200

Japanese 12, 28-9, 49, 65, 73, 79-80, 141, $143,165,188,211$

Jew(ish) 1, 24-5, 29, 57, 60, 84-6, 197-8, 201, 206-8, 212-15, 225, 245

Jim Crow laws 23, 42, 46, 61

Johnson, Lyndon B. 50

Judaism 205, 210

Keniston, Kenneth 236-7, 239

Kennedy, John F. 50, 273

Kennewick Man 73

Kett, Joseph 233, 236

Kimmel, Michael 126, 133-4, 150

King, Jr., Martin Luther 45-7, 169, 205

Kinsey, Alfred 147-8, 150, 157; Kinsey Scale 146

Klein, Fritz 146

Korea(n) 24, 48-9, 77-8, 80-1, 173, 211

koro 253

Ku Klux Klan 20, 58-9, 206-7
Kulick, Don 186

Kunstler, James Howard 286

Labov, William 183-4, 188

Laing, R. D. 253-4, 271

Lakoff, Robin 185

Lakota 62, 144

Lau $v$ Nichols 181

Le Bon, Gustave 18, 20

Lechner, Frank 277-8, 280

Legitimate Violence Index 306

lesbian 4, 9, 16, 33, 35, 124, 141-3, 145, 147-9, 151-6, 158, 161-2, 186, 205

Lewis, Oscar 101-3

Lichter, Daniel 300, 303

Lieske, Joel 291-3, 308

life expectancy 62, 71, 90, 220-1, 233, 240, $242,258,260-2$

Lincoln, Abraham 41, 44, 169, 207

Little People of America 251

lofts 281-2

Logan, John 279, 297

lynching 42-3, 74, 133, 207

Maasai 225, 227

Madsen, Richard 199

Mannheim, Karl 229, 245, 247

Martineau, Harriett 122

Marty, Martin 199, 201, 203

Marx, Karl 91-2, 95, 105, 108, 115, 122, 284

Massachusetts 27, 66, 121, 123, 126, 179, 182, 201, 268, 287, 306

Mattachine Society 151, 153

Mead, Margaret 115, 225, 227, 229

Medicaid 100

medicalization 253, 256-7, 266, 270

Medicare 100, 218, 242

megachurch 309

mental illness 1, 14, 85, 103, 117, 126-8, $150,250,253,255,268,270-4$;

homosexuality as $150,250,253$; social construction of 254; transgender as 162

Methodist 197-8, 202, 292, 308

Mexico/an 3, 10, 28-30, 32, 49, 73-8, 85, 134, 163, 176, 181, 221, 224, 249-50, 264, 267, 278, 291

middle class $34,76,91-2,94-6,102,105$, 107-10, 117, 126, 131, 134, 136, 153, 183-4, 187, 199, 233-4, 237-8, 294

mid-life crisis 241 
Midwest 1, 9, 290, 294; African Americans in 294; age in 231; crime in 306; gender in 119, 149; Hispanics in 300; income and poverty in 94, 97-8; language in 174; Native Americans in 69; religion in 308 Millennials 248

Miller, William 203

Mills, C. Wright 106, 134

minimum wage 100,103

Mintz, Steven 233, 235-8

Mock Spanish 187-8

mommy wars 130

Moorish Science Temple 209

Moral Majority 206

Mormon(ism) 57, 197-8, 200, 203, 205, 212-4, 292, 303

morphology 166; see also semantics

Montague, Ashley 37

mortality rate 219

Moynihan, Daniel Patrick 86, 102

Muhammad 308

Muhammad, Elijah 46, 209

multiculturalism 20, 33-5, 181

Murphy, Robert 255

Muslim 1, 2, 17, 29, 82-4, 197-8, 209-10, 212, 215, 282; gender and 141; politics and 213; see also Islam

Myerhoff, Barbara 245

Nader, Laura 105

Nanda, Serena 13, 113, 140

nanny wars $130-1$

Nash, Manning 37-8, 64

Nation of Islam 46, 136, 207

National Association for the Advancement of Colored People (NAACP) 15, 42, 44-6

National Crime Victimization Survey 56

National Organization for Women 123-4

National Origins Act 30, 207

Native American 1, 8, 10-11, 13, 23, 25, 33, $36,38,62,66-73,84$; affirmative action and 51; age and 230, 242; biracial and 7; Census and 48; crime and 56; education and 53, 128; gender and 121, 133, 144-5; geography and 287, 290, 292, 303; health and 253, 263-4, 267-8, 271, 274; language and 167, 174, 176-9; religion and 194, 210-12, 214; see also Indian (American)

Native American Graves Protection and Repatriation Act (NAGPRA) 68, 73, 212
Native American Church 212, 214

Native Hawaiian 1, 48-50, 65, 121, 264; see also Hawaii

Nazi(sm) 20, 25, 60, 167

new African immigrants 56-7

Northeast 1, 290-1, 294; age in 231, 242; colonial settlement of 287; crime in 306-7; gender in 121; income and poverty in 97-8, 300; Native Americans in 67, 69; politics in 275; religion in 308-9; slavery in 41

New York (state) 27, 30, 57, 121, 123, 174, 180, 186, 203, 214, 233, 264, 268, 276, 287, 291-2, 304, 306; New York (city) 43-4, 57, 76, 79, 86, 105, 107, 149-51, 159, 183-4, 188-9, 206-7, 209-10, 275, 277, 281, 297

Nineteenth Amendment 123

No Child Left Behind 182

Obama, Barack 8, 149, 275

obesity 13, 249-50, 252, 256, 258, 266-7, 274

Oriental Exclusion Act 80

Orthodox 197-8, 207, 213

Ortner, Sherry 95, 111, 195

Park, Robert 280, 294, 306

Parks, Rosa 46

Parsons, Talcott 254-5

Pentecostalism 199, 204-5

Personal Responsibility and Work

Opportunity Reconciliation Act 100

Peters, David 304

Philippines 30, 75, 77-8, 80, 164; see also

Filipino

phonology 165, 168, 171

Pine Ridge 68

Plessy $v$ Ferguson 42

pluralism 20-1, 65, 204, 217; Harvard

Pluralism Project 210-11

population pyramid 119, 220-4

Postman, Neil 235

poverty $1,15,32,52,62,71,76,80-1,92$, 94, 97-105, 109, 117, 204, 236, 242, 256, 267, 271, 284, 294, 300-4, 307; culture of poverty 101-3; poverty line 97-8, 103, 294; "war on poverty" 100

power elite 106-7

pragmatics 169-70; see also sociolinguistics

Pratt, Richard Henry 66, 178

protest masculinity 135-6 
Protestant 27, 29, 33, 63-4, 85, 98, 134, $181,192,196-9,201,204-6,210,212-$ 14, 308-9

Pruitt-Igoe 304-5

Puerto Rico/ans 49, 73-6, 80, 86, 174, 186, 263

Putnam, Robert 287

rape $56,117,133,267,307$

Reconstruction 42

Rembis, Michael 117, 272

Republican 97, 107, 137, 149, 213-4, 247-8, 275

restricted code 169-70

Revolutionary War 27, 40, 67, 202, 207

riot 25, 42-3, 47, 78, 151, 160, 207

Roe $v$ Wade 124

Roosevelt, Franklin 100

Rothblum, Esther 153-4, 156, 161

Rural Urban Continuum Code (RUCC) 304

Rural Urban Density Code (RUDC) 303-4

Rust, Paula 154, 156

Sambia 13, 140-1

Sannyasi 225

Sappho 142-3

Scheper-Hughes, Nancy 226

Scientology 200, 203

Scopes trial 204

semantics 166-7, 180; see also morphology

Shakers (United Society of Believers) 203

Shamoon, Deborah 143

Shi'ite 64,84

sick role 254-6, 266

Simmel, Georg 277-8, 283-4

slavery $4,6,15,23-5,36,39-41,43,46,56$, 61, 98-9, 102, 123, 133, 209, 291, 297, 306

Smedley, Audrey 37

social distance $25-6,86$

Social Security 218, 242; Social Security Act 100, 269

sociolinguistics 164, 169; see also pragmatics South 1, 9, 40, 290-1; age in 231; crime in 306-7; diversity in 287; gender in 119, 149; health in 250, 260; Hispanics in 300; income and poverty in 94, 97-8, 100, 102, 300,304 ; language in 180, 188; migration from 294; Native Americans in 69; politics in 275-7; religion in 207, 308-9; segregation in 41-3; slavery in 41, 287 , 297; unhappiness in 279
South Africa 24-5, 164, 219-20

South Carolina 27, 39-43, 287

South Dakota 62, 67-9; poverty in 71, 303; diversity in 174; language in 179

Southern Christian Leadership Council 46

Southern Poverty Law Center 60, 84

Spanish (language) 1, 3, 16, 77-8, 164-5, 167-8, 171, 173-4, 181-3, 186-8; Spanish (people) 26-8, 39, 48-9, 66, 73, 77-8, 211, 287, 290-1, 308

Spanish-American War 75-6, 80

Sparta 140, 268

Stack, Carol 102-3

Stonewall Inn 151-2, 160

Student Nonviolent Coordinating Committee 47

Subtirelu, Nicholas 163

suicide 239, 253, 259, 263, 267, 273-4, 285

Sullivan, John 287

supermodernity 285-6

Supreme Court 24, 41-2, 46, 51, 78, 80, $123-4,181,214$

Swazi 227

Swedenborg, Emanuel 203

syntax 167

Szasz,Thomas 254, 271

Tannen, Deborah 185

termination 68

Texas 28-30, 52, 57, 179, 180, 277; age in 231; Hispanics in 73-5; language in 174; politics in 275-6; race and criminal justice in 56; religion in 308; riots in 43

Theosophical Society 203, 211

Thirteenth Amendment 23, 41

Title IX 124, 127

"Trail of Broken Treaties" 68

"Trail of Tears" 67, 177

transgender 125, 137, 142, 145, 148-9, 158-62

transsexual 144-6, 159-61, 256

transvestite 143-4, 146, 159-60, 256

twelve religious tribes of America 213-14

"two-spirit" 144-5

"undeserving poor" 98

United Muslims of America 209

Urciuoli, Bonnie 164, 171, 180, 186-7

Valentine, David 159-60

Veblen, Thorstein 105, 107 


\section{Index}

Vietnam(ese) 1, 24, 30, 49, 65, 77-8, 81, 173

Violence Approval Index 306

Virginia 27, 38-41, 51, 66, 142, 180, 233, 287,303

visa $32-3$

von Krafft-Ebing, Richard 141, 143

Voting Rights Act 77, 163, 167

Wallace, Anthony 193-4

Wallace, George 46

Weber, Max 63, 92, 122

West 1, 9, 290-1, 294; lynching in 43; age in 231, 242; colonial settlement of 287 ; crime in 306-7; gender in 121, 149; income and poverty in 94, 97-8, 119; language in 180; Native Americans in 67,69; politics in 275; religion in 308-9

Westphal, Karl 141

Whitaker, Robert, 272

White Aryan Resistance 60

white ethnics 84-8 white supremacist movement 58-61

Wiccans 197, 210

Wiley, Terrence 164, 171

Wirth, Louis 284

Wolf, Naomi131,266

Wolfram, Walt 188-9

Wollstonecraft, Mary 123, 125

Women'sRights Convention 123

Woods, Tiger 7

Woolf, Virginia 127, 159

World Parliament of Religions 210-11

World War I 29-30, 43, 53, 246

World War II 76, 79-80, 123, 134, 188, 246, 294

X, Malcolm 46-7, 209

Yiddish 189

Yinger, Milton 20, 63

Zafimaniry 228

Zukin, Sharon 281-2 